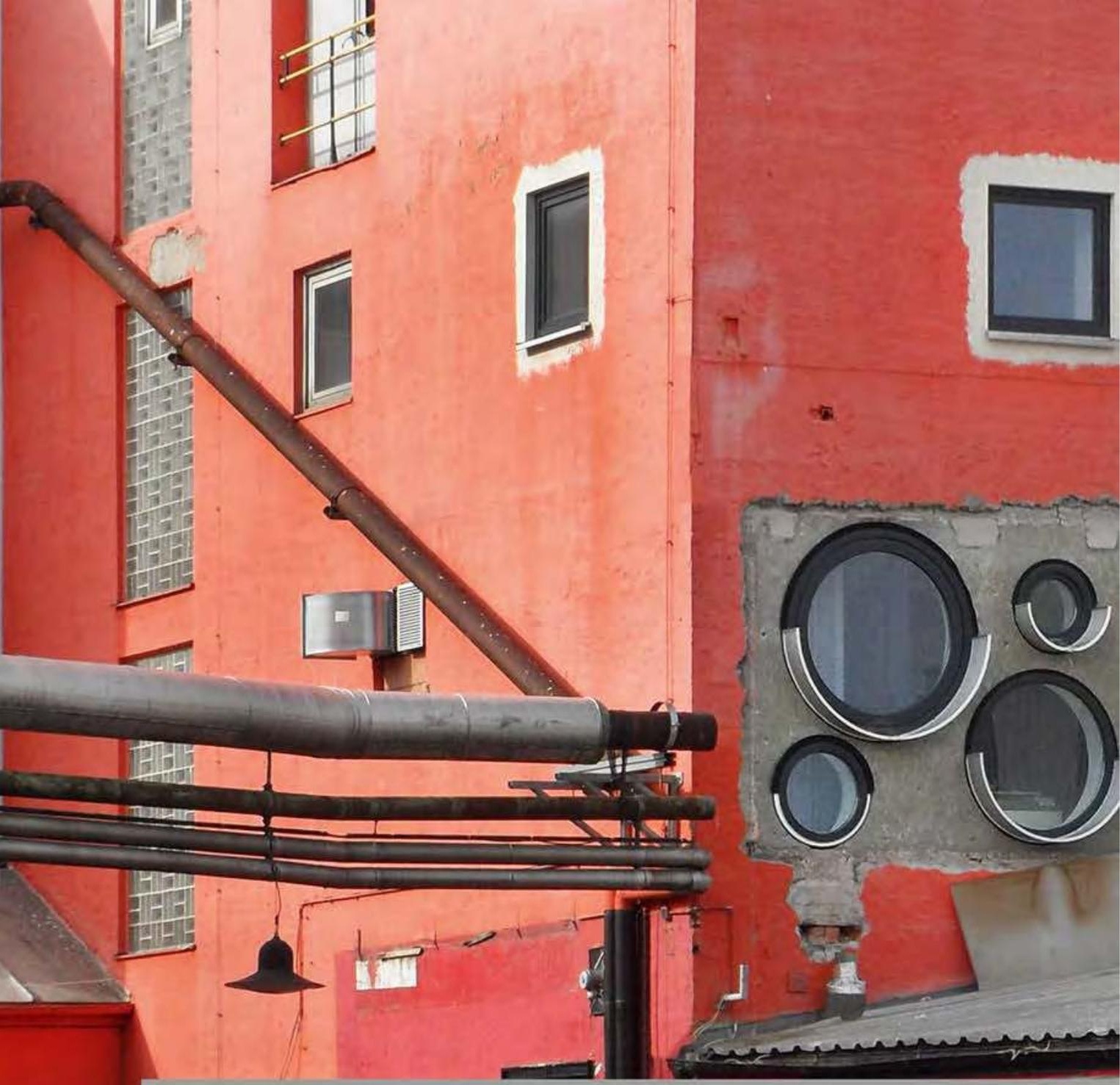

Norbert Kling

\title{
The Redundant City
}

\section{A Multi-Site Enquiry into Urban Narratives of Conflict and Change}

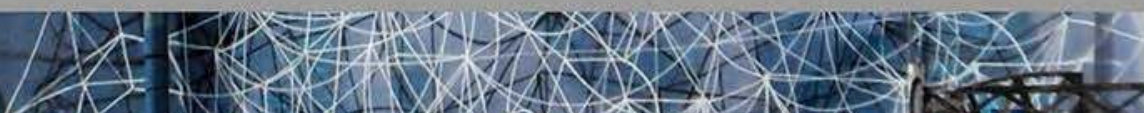

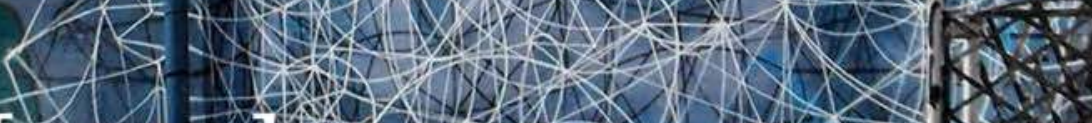
transcript troban stu d és,

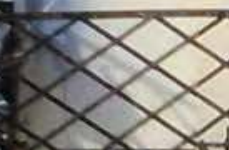

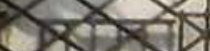

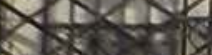

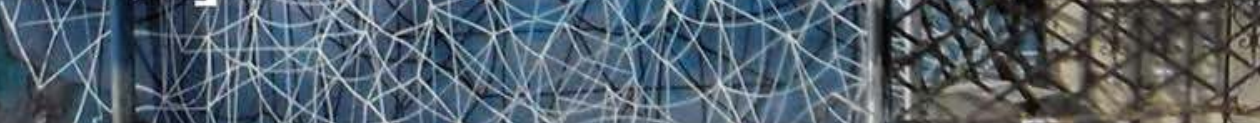
: 1 - 
Norbert Kling

The Redundant City

\section{Urban Studies}


Norbert Kling is an architect, researcher, and urbanist. He currently teaches architectural and urban design at the Technical University of Munich, where he received a Dr.-Ing. in Architecture. His research interests include conditions of asymmetric urban change and alternative spatial practices, as well as questions of concept formation, method and process in the spatial disciplines. He is partner at the award winning practice zectorarchitects London/Munich. 
Norbert Kling

The Redundant City

A Multi-Site Enquiry into Urban Narratives of Conflict and Change 


\section{Bibliographic information published by the Deutsche Nationalbibliothek}

The Deutsche Nationalbibliothek lists this publication in the Deutsche Nationalbibliografie; detailed bibliographic data are available in the Internet at http://dnb.d-nb.de

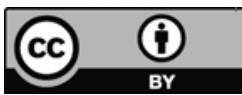

This work is licensed under the Creative Commons Attribution 4.0 (BY) license, which means that the text may be be remixed, transformed and built upon and be copied and redistributed in any medium or format even commercially, provided credit is given to the author. For details go to http://creativecommons.org/licenses/by/4.0/

Creative Commons license terms for re-use do not apply to any content (such as graphs, figures, photos, excerpts, etc.) not original to the Open Access publication and further permission may be required from the rights holder. The obligation to research and clear permission lies solely with the party re-using the material.

\section{First published in 2020 by transcript Verlag, Bielefeld (c) Norbert Kling}

All rights reserved. No part of this book may be reprinted or reproduced or utilized in any form or by any electronic, mechanical, or other means, now known or hereafter invented, including photocopying and recording, or in any information storage or retrieval system, without permission in writing from the publisher.

Cover layout: Maria Arndt, Bielefeld

Cover illustration and layout: Norbert Kling

Proofread and copy edited by Karl Detering, Munich

Typeset by Francisco Bragança, Bielefeld

Printed by Majuskel Medienproduktion $\mathrm{GmbH}$, Wetzlar

Print-ISBN 978-3-8376-5114-0

PDF-ISBN 978-3-8394-5114-4

https://doi.org/10.14361/9783839451144

Printed on permanent acid-free text paper. 
"To think about the city is to hold and maintain its conflictual aspects: constraints and possibilities, peacefulness and violence, meetings and solitude, gatherings and separation, the trivial and the poetic, brutal functionalism and surprising improvization."

Lefebvre, Henri (1985) Qu'est-que penser?, translated in: Kofman, Eleonore and Lebas, Elizabeth (1996) Lost in Transposition, $p .53$ 



\section{Content}

\section{Introduction}

Contributing Towards a Broader Understanding of Urban Transformation ................... 11

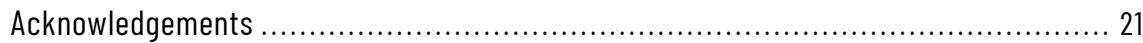

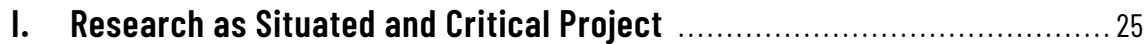

1. Problems of Research in Architecture and Urbanism ..................................... 26

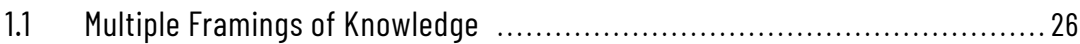

1.2 Separation of Macro and Micro Scales of Conceptualisation ......................2 29

1.3 Institutionalised Dominance of Static Space ........................................ 31

1.4 Positioning of Theory in Relation to Material and Social Worlds .................. 32

2. Learning from Criticisms of Scientific Knowledge Production ............................34

2.1 Shared Histories of an 'Aesthetics of Matters of Fact'? .............................34

2.2 About Raising New Questions and Taking a Risk .................................... 37

2.3 Instability of Scientific Knowledge and its Movement 'Away From' ............... 40

2.4 From 'Matters of Fact' to 'Matters of Concern' ...................................... 42

3. Assembling Architectural and Urban Research Perspectives .............................4 44

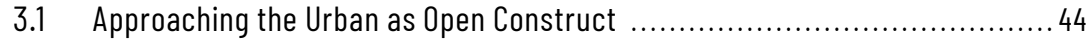

3.2 Reframing Critical Theory as Critical Urban Theory …….......................... 45

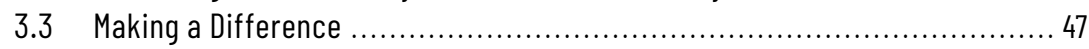

3.4 Adding Urban Action: Pushing the Limits of What We Can 'See' in the City ..... 49

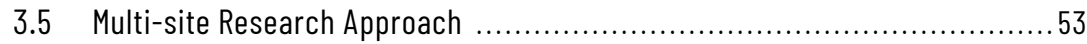

4. Grounding the Project: Situational Analysis and Grounded

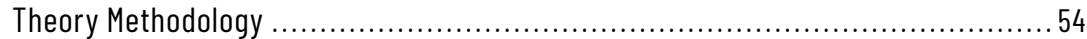

4.1 Turning to Social Science Methodologies: Situatedness of

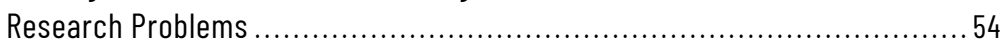

4.2 Social Worlds/Arenas Theory, Grounded Theory Methodology and

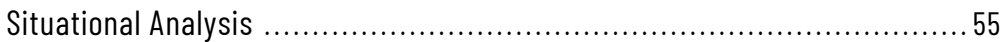

4.3 Approaching Research Questions from within the Situation ..................... 59

4.4 Discourse Theory and Situational Analysis ........................................... 61

4.5 Mapping and Drawing as Tools of Empirical Enquiry and Concept-Building ......65

5. Adapting the Iterative-Cyclical Research Model of Grounded Theory Methodology ... 67

5.1 Theoretical Sampling and GTM's Iterative-Cyclical Research Model .............67 67

5.2 Analytical Process A: Discursive-interpretative Analysis of Narratives ........ 71

5.3 Analytical Process B: Case Study Element. Working with Empirical Data ....... 74

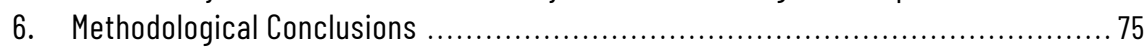


1. Introducing a Narrative-Based Analysis of Conflict and Change ......................... 82

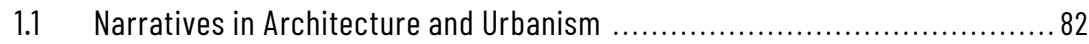

1.2 Starting and Ending the Iterative-Cyclical Process of Analysis ................... 86

2. Conflict as Category of Disciplinary Self-Affirmation ........................................ 88

2.1 Integrative Capacity of Pre-Modern Spaces of Emplacement

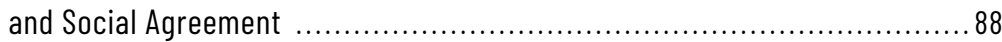

2.2 Cities as Sites of Rupture and Self-Referential Architectural Intervention ......89

3. Ambivalent Tactics of Conflict in Modernist Urbanism ................................... 93

3.1 The 'Lone Actor' and the Modernist 'Envelope' ..................................... 93

3.2 Narratives of Urban Simplification and Externalisation of Conflict .............. 95

3.3 Dialectic Process: Conflict and Change in Socialist Modernism .................. 99

3.4 Complex Reductionism in Present-day Modernisms ............................... 102

3.5 Planned Obsolescence and Creative Destruction ................................. 103

4. Political Spaces of Urban and Architectural Conflict ..................................... 107

4.1 Challenging Regimes of Truth and Professionalised Design Authority .......... 107

4.2 The Everyday as Site of Resistance and Emancipatory Practice ............... 110

4.3 Forensic Work and Commoning in Contested Spaces ............................. 115

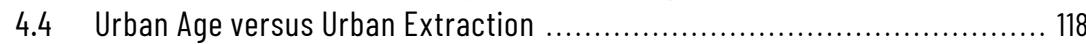

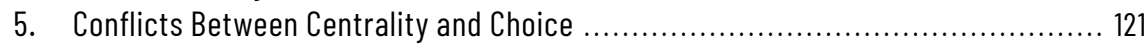

5.1 Contested Urban Centralities ...................................................... 121

5.2 Capitalism's Contradictory Movement between Fixation and Expansion ....... 124

5.3 Fringe Belt Collisions and Shrinking along the Logics of Choice ................. 125

5.4 Space Syntax and the Paradox of Centrality ...................................... 128

5.5 Capsularisation and Connectivity in Cities Without Cities ....................... 129

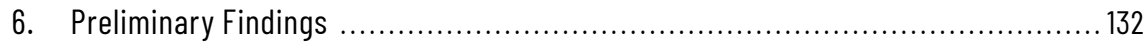

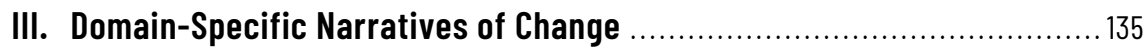

1. Dialectics, Evolution and Autopoiesis in Meta-Narratives of Change .................... 136

1.1 Framing Architectural and Urban Theory through Meta-Narratives

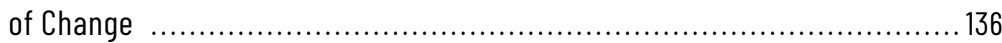

1.2 Dialectic Movements and the Urban as Contingent Process ..................... 136

1.3 Evolution through Unfolding, Deep Invariants and Repetitive Process ......... 139

1.4 Architecture as Self-Referential Autopoietic System ........................... 143

2. Narratives of Change as Critical Response to Modernism ............................... 145

2.1 Bye-Bye Utopia, or Utopia as Agent of Change? .................................. 145

2.2 Typomorphology - Built Form as Process .......................................... 148

2.3 Alexander - Conflict and Change in the Synthesis of Form ....................... 150

2.4 Rossi - Urban Permanence and Change .............................................. 153

2.5 Lynch - The Environmental Image of Time ......................................... 156

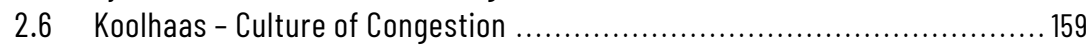

2.7 Failure as Agent of Change. The Myth of Pruitt-Igoe ……...................... 161

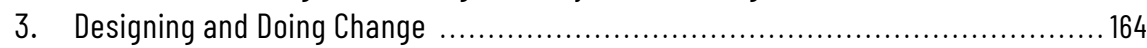

3.1 Deterministic and Non-Deterministic Models of Change ......................... 164

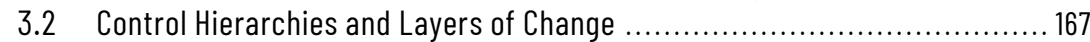

3.3 Admitting Uncertainty and Imperfection to Design ............................... 169

3.4 Performative Production of Liminal Situations and In-Between Spaces ....... 171 


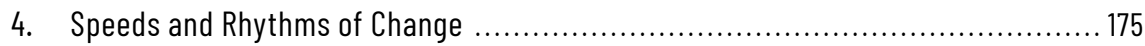

4.1 Gradual Change and Cataclysmic Change ................................... 175

4.2 Incrementalism and the Speed of Learning ...................................... 178

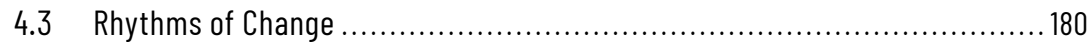

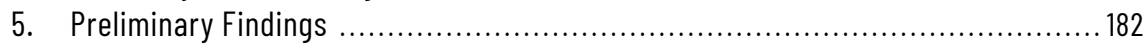

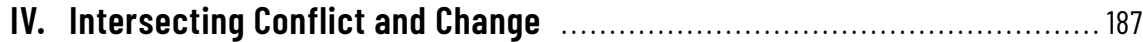

1. Positional Maps as Analytical and Heuristic Device ...................................... 188

1.1 Intersecting Conflict and Change: Approach and Methodological Framing .... 188

1.2 Setting up the Positional Map .............................................. 189

1.3 Approach to Interpretative Issues and Difficulties in the Positioning ......... 191

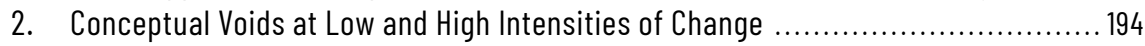

2.1 Observing the Overall Pattern of Positions ........................................ 194

2.2 Why There Should be More Concepts For Low and High Intensities

of Change .................................................................. 198

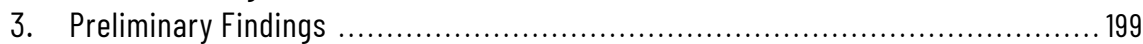

V. Constructing a New Concept of Change ............................................ 203

1. Zooming in: The Parkstadt Bogenhausen Housing Estate in Munich ................ 204

1.1 Justifying Empirical In-Depth Analysis ....................................... 204

1.2 Housing Estates as Sites of Urban Enquiry .................................... 206

1.3 Divided Biography of the Parkstadt Bogenhausen Housing Estate ........... 208

1.4 Commonhold-Type Ownership According to the WEG .......................... 213

1.5 Housing Estates Beyond 'Mass Housing' ....................................... 214

2. Empirical Grounding: Mapping Transformative Interactions ........................... 216

2.1 Combining Different Mapping Perspectives .................................... 216

2.2 Mapping the Parkstadt Arena: Social Worlds/Arenas Perspective .............. 218

2.3 Mapping the Overall Situational Process: Timeline and

Structural Conditions .................................................... 222

2.4 Mapping Recorded Decisions: Categorising and Open Coding of

Meeting Minutes ......................................................... 224

2.5 Mapping Negotiated Concerns: Thematic Coding and Detailed Sequences ... 227

2.6 Triangulating by Adding a Quantitative Perspective ........................... 236

2.7 Triangulating by Adding Contextual Data from the Field ...................... 241

3. Comparative View of Other Situations of Change in Munich ........................... 244

3.1 Munich's Housing Crisis and Long-Term Residential Development Plan ...... 244

3.2 Spatial and Structural Transformations in the Local Area ...................... 246

3.3 Observing Change in other Housing Estates in Munich ......................... 249

3.4 Placing the Changes in the Parkstadt Bogenhausen Estate in Context ........ 251

3.5 Heritage Preservation as Enabling Framework for Change ................... 253

4. Constructing the Redundant City Concept .................................... 257

4.1 Working towards a Synthesis: Assembling Empirical and Theory-Based Findings ............................................ 257

4.2 Empirically Grounded Characteristics of the Housing Estate's Process

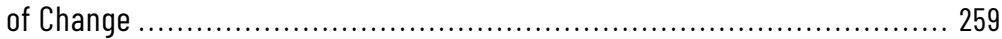

4.3 Dual Position: Discursive Movements in the Positional Map ..................... 271

4.4 Introducing the Ambivalent and Controversial Notion of Redundancy ........ 278 


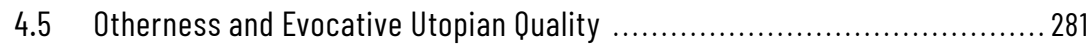

4.6 The Redundant City. A New Concept in Sixteen Theses ....................... 285

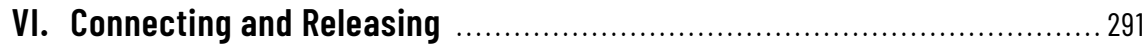

1. Making Multiple Connections ........................................................ 292

1.1 Multiplicity of Possible Connections in Multi-site Research ................... 292

1.2 Making Research Outcomes Available for Practical Uses ...................... 293

2. Working with the Redundant City Concept ............................................. 294

2.1 Towards a Broader Understanding of Change in Housing Estates ............. 294

2.2 Challenging the Selectivity in Munich's Densification Programme ............ 295

2.3 Questioning Structural Conditions in Arenas of Change ...................... 298

2.4 Appropriation and Redundancy in Buildings ................................. 302

3. Working with the Mapping Tools ................................................... 304

3.1 Community Mapping as Means of Empowerment and Agent of Change ....... 304

3.2 Extending the Repertoires of Mapping in Different Fields

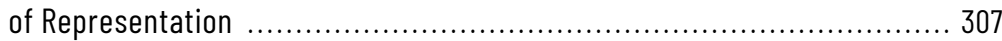

4. Working with Concepts and Narratives of Conflict and Change ....................... 309

4.1 Challenging Dominant Modes of Space Production ............................ 309

4.2 Positioning Design Interventions In the Urban Field ........................... 312

5. Concluding Remarks: Architectural and Urban Work as 'Matters of Concern' ......... 319

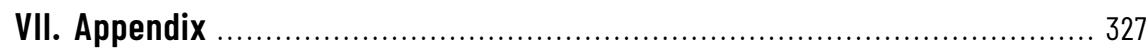

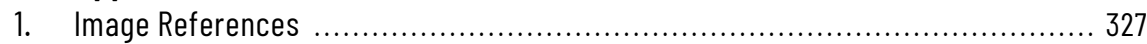

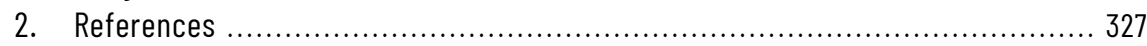




\section{Introduction}

\section{Contributing Towards a Broader Understanding of Urban Transformation}

Urban theory emphasises the dynamic nature of cities. Processes like restructuring, densification, segregation, gentrification and the contesting of urban centralities are core issues in current discourses on cities. Social, environmental, economic or political questions are broadly studied in their connectedness to urbanisation and urban transformation. Change is an ever present urban condition. Change is also related to conflict. People negotiate and fight over change. Materialities and fixations of different kinds exert resistances towards change. Institutions are challenged by and seek to control change. Urban conflict and change are more than anything the products of collective human action and of the processes humans conceive to structure their lives and the world.

Against the background of continuously shifting conditions of conflict and change, descriptions of and assumptions about spatial transformations have to be constantly re-examined and revised. Researchers and theorists from different backgrounds devise concepts to develop a better understanding of urban phenomena and to share their ideas with others. However, the complexity and recursive nature of urban processes raise major difficulties in representation, analysis and conceptualisation, not without consequences for their conceptual integration into architectural and urban theory and operational integration into urban practice. If change is an omnipresent aspect of urban reality, and if conflict is connected to change in multiple ways, to what extent, and in which ways, are they addressed in architectural and urban theory?

Although a significant number of concepts in architecture and urbanism are related to change in one way or the other, it seems that conceptualisations of conflict are underdeveloped. This is even more the case with joint conceptualisations of conflict and change. If they are studied in combination, change is often established as the main topic, whereas conflict is relegated to a supporting or subsidiary function. The reason for this might be twofold: change is such an evident phenomenon in the built environment that assigning it a key role in research does not require much justification $^{1}$; at the same time, change is closely related to what architects and urbanists do in practice. The actions which they employ in their work, such as designing, communicat-

1 Speaking for the social sciences, Hans Haferkamp suggests that "change is such an evident feature of social reality that any social-scientific theory, whatever its conceptual starting point, must sooner or later address it." (Haferkamp and Smelser 1992, p.2) 
ing, mediating, and the outcomes of their actions, such as a transformative process, a development plan, a design proposal, are all related to - and subject to - change. There is a long list of practically and instrumentally informed questions that may be raised as part of an architectural or urban enquiry into change. At the same time we may speak of a general tendency in architectural and urban conceptualisations to couple the problem of conflict exclusively with that of conflict resolution. Architects and urbanists are frequently seen as experts who handle and solve complex problems. Their professional identities are tightly related to the idea of the problem solver who describes and eliminates conflicts through spatial planning and 'design solutions'. If we look at the history of architecture and urbanism as institutionalised professions, we realise how they have over time, and under the surveillance of legislative and economic actors, adopted an extensive legal and administrative framework to avoid, manage, mitigate and resolve conflict. The framework is geared towards economic optimisation, smooth integration of workflows and the distribution of risk. The conceptualisations of conflict based on this identity are of limited theoretical range. Where contractual dependencies and the implicit agreement about problem solving define the framework of action, normative questions about the broader implications are not raised. As a rule, this is also the case in statutory planning consultations and institutionalised community involvement as part of building projects. Issues that are not considered material to the case are bracketed out and not admitted to the process. In applied and demanddriven forms of research funded by the building industry, development agencies or housing corporations, researchers are frequently commissioned to produce practical recommendations for conflict resolution, for maintaining efficiency despite conflict, and for the analysis and discussion of best-practice projects.

However, if conflict is predominantly perceived as something that interferes with established norms, working routines, administrative processes and added-value chains, without questioning the larger frameworks that enable and sustain them in the first place, and without questioning the full depth of the motives and interests of the parties involved, research perspectives are severely narrowed down and outcomes pre-defined. Here, macro-scale perspectives on conflict are excluded, together with the many different ways of 'doing' conflict and change at the micro scale.

In "La révolution urbaine" Henri Lefebvre challenges the dominant forms of space production, complete with the concepts, institutions and processes that are related to them (Lefebvre 2003 [1970]). Written in the midst of the late 1960s social unrest that emanated from Paris and other large cities, he criticised the implicit anti-urban intentionality inherent to the capitalist restructuring of space, together with its stabilising mechanisms of conflict mitigation and resolution. For Lefebvre, "[...] there is nothing harmonious about the urban as form and reality [...]" (ibid., p.175). In strict opposition to the modernist approach in architecture and planning, in particular in respect of practices of segregation that attempt to "[...] resolve conflicts by separating the elements in space" [ibid.), Lefebvre proposed that the urban must be conceptualised "[...] as a place of conflict and confrontation, a unity of contradictions [...]" (ibid., p.175f). He emphasised the dynamic and integrating power of the urban condition, as well as the potential of conflict to act as a driver of positive change. Today, almost fifty years after Lefebvre and other contemporaries formulated their criticisms of what they perceived as an anti-urbanity, we may claim that over-simplified perspectives on conflict continue to dominate our concepts of urban change. This influences the way public 
debates about urban conflict and change are conducted. It also contributes to the formation of blind spots in urban analysis and fails to provide incentives for developing new concepts.

If we look at other theoretical fields, beyond architecture and urbanism, we notice the diversity in joint conceptualisations of conflict and change. They range from grand social theory to situations of the everyday. Perhaps the most extensive and prominent example is the Marxist perspective, in which conflict and change are connected to class struggle, revolutionary process, accumulation and restructuring (Harvey 1975; 1982). Lefebvre's notion of conflict and change relates to this tradition, foregrounding and extending the socio-spatial implications of the theory (Lefebvre 1991 [1974]; 2003 [1970]). Karl Popper's anti-totalitarian theory of the open society emphasises pragmatic action as a driver of change, and utopianism as a source of conflict and violence (Popper 1947). Ralf Dahrendorf, who draws on Max Weber, Karl Popper and others, speaks of contested shifts in the balancing of "entitlements and provisions, [...] rights and opportunities" (Dahrendorf 2008 [1988], p.ix), whereby "the battles for more life chances provide the theme of the modern social conflict." (ibid.) Political theorist Chantal Mouffe understands conflict as constituent of modern society, and proposes "agonistics" as a vehicle of change within a multipolar world (Mouffe 2013). In social systems theory, Niklas Luhmann conceptualises autopoiesis as a fundamental form of change, in which communications that contradict each other may establish a conflict (Luhmann 1995 [1984], p.288). Symbolic interactionism assumes that meanings are produced through intersubjective interaction, which in itself defines a condition of continuous change. And if the collective production of meaning is disturbed, it is the participants' "commitment to stability" that activates mechanisms of conflict resolution so that interaction is "realigned" (Dellwing and Prus 2012, pp.33f) ${ }^{2}$. Joint conceptualisations of concept and change have also informed the urban sociology perspectives on space and the city. Georg Simmel suggests in "The Sociology of Conflict" and other writings that conflict is a fundamental principle of socialisation and in this sense of collective life in large cities (Simmel 1904, p.493f; Simmel 1950 [1903]). The history of urban sociology, since its various beginnings at the turn of the $19^{\text {th }}$ to the $20^{\text {th }}$ century, could be reconstructed on the basis of its conceptual approach to conflict and change. Manuel Castells suggests its general orientation has shifted "from the discipline studying social integration to the discipline specializing in the new social conflicts of postindustrialism." (Castells 2002, p.11). Both fields of research in urban sociology, the production and integration of differences, and the contradictory and conflictual aspects of the urban, continue to be of relevance for the research on the mutual relationship of urban environments and social processes, as well as the conceptualisations of urbanity (Siebel 1994). The editors of the volume "Negotiating Urban Conflicts. Interaction, Space and Control" suggest in the introduction that

"Cities have always been arenas of social and symbolic conflict. As places of gender, class, ethnicity, and the myriad variations of identity-related differences, one of the major roles they are predestined to play is that of a powerful integrator; yet on the other

2 Here, Dellwing and Prus refer to the writings of Gary Alan Fine, Erving Goffman, Randall Stokes and John Hewitt, and Anselm Strauss. 
hand urban contexts are, as it were, the ideal setting for marginalization and violence." (Berking et al. 2006, p.9)

Joint conceptualisations of conflict and change are characterised by their multiplicity different theories and research perspectives emphasise different aspects in their relationship. In some theories, conflict is the key driver of change, in others it is change or the absence of change - that are seen as the sources of conflict; some concepts are based on asserted causalities between conflict and change; some concepts infer practical, and therefore normative consequences from the relationship, others remain on the level of theory. Despite the fundamental differences in approach and conclusions, what these theories and concepts have in common is the view that conflict and change cannot be conceived as isolated objects. They suggest that conflict and change are mutually related to each other.

Taking both conflict and change into consideration holds the promise of a fuller understanding of phenomena of urban transformation, as opposed to considering change alone. The first part of this book, therefore, sets out to explore the rich yet dispersed body of narrative knowledge about conflict and change in the field of architecture and urbanism. With reference to the writings of Catherine Riessman (Riessman 2008), Willy Viehöver (Viehöver 2011) and others, narratives are defined as instruments used to conceptualise, communicate, integrate, memorise, instrumentalise, or politicise issues for an audience, that is, issues that are of broader concern. Accordingly, the analysis is focussed on the narratives produced and used in architecture and urbanism to conceptualise, communicate, integrate, memorise, instrumentalise, or politicise the phenomena, practices and situations of conflict and change that are relevant to their disciplinary fields. Some of these narratives maintain an abstract and theoretical level, while others are more focussed on the interactions of change and design, or the practical aspects of professional work. The exploration aims at identifying and assembling the concepts and positions they contain about conflict and change.

Research in architecture and urbanism cannot be considered a routine or pre-given process. Architectural and urban knowledge serves different and at times contradictory ends. It is spread across different "cultures of knowledge" (Biggs and Büchler 2011, pp.68f), or "knowledge landscapes" (Dunin-Woyseth and Nilsson 2011, p.80). Rather than perceiving this as an impediment to research, I take multiplicity as a resource to work with, based on the understanding that the urban is an open construct that defies closure (Lefebvre 2003 [1970], p.174). Urban issues cannot be grasped in isolation or from a single perspective. Reductionist research approaches which tailor research problems in such a way that they become rigorously demarcated objects are of limited range in urban research contexts.

In view of these epistemological and methodological difficulties, research perspectives are required that can handle openness and conditions in which the researcher does not have previous knowledge of the phenomena under study. In our case, this is provided by the social science research perspectives of grounded theory methodology (GTM) (Glaser and Strauss 1967; Strauss 1987) and situational analysis (SA) (Clarke 2005; Clarke, Friese and Washburn 2018). SA itself draws on social worlds/arenas theory (Strauss 1978b) and discourse theory (Foucault 1981 [1970]; Keller 2011a and 2011b). For the purpose of this research project, I combine GTM and SA with a critical urban perspective and add different analytical and interpretative instruments of 
architectural and urban research, to form a multi-site/multiple-methods approach. In the research design, critical-interpretative enquiry is conjoined with the scrutiny of empirically-driven research. The project engages with different bodies of knowledge, research materials and questions, without resorting to demarcation, categorisation, and closure.

The research project evolves along two connected iterative-cyclical processes based on the GTM model. In the discursive-interpretative process, urban narratives of conflict and change are assembled and discussed in essay-like units. The selection of narratives is based on the GTM principle of theoretical sampling. The exploration does not work with definitive fixations, nor does it seek to establish a comprehensive systematics based on categories. It follows an open mode of enquiry in line with the project's overall methodology. The first iterative-cyclical process leads to the production of a positional map, which is based on the SA repertoire of analytical mappings.

The positional map presented in this book assembles, for the first time, a broad range of concepts to do with conflict and change in a single visualisation. It evolved step-by-step in the explorative process. The map is conceived as an intersection, or analytical space of convergence, in which the concepts contained in some of the most influential narratives in architecture and urbanism, as well as the lesser known narratives, are condensed into individual positions. The intensity of change and the corresponding foregrounding of conflict in each concept are devised as ordering principles for the setting out of the positions on the map. The pattern produced in this way is not homogenous. It reveals a proportionalising tendency, or bias, in the conceptualisations, as a large number of concepts equate the intensity of change with the intensity of conflict. The pattern also shows densely populated areas circumscribing two voids. They occur, firstly, in the region of low intensities of change in combination with high levels of foregrounding of conflict, and, secondly, in the region of high intensities of change in combination with medium levels of foregrounding of conflict. Areas which have been treated only marginally by architectural and urban theory are in this way made visible. The voids could be understood as conceptual vacuums. They indicate that the theorisation of conflict has remained almost unexplored for conditions of low and high intensities of change. For these positional regions, the narratives of conflict and change are strangely silent.

The findings and discussion in the first part of the book point to four main issues:

Firstly, since the dissolution of the modernist paradigm of unlimited growth and rapid change led to the insight that urban problems cannot be approached through growth-based scenarios alone, conceptual alternatives to high intensities of change have gained in significance. The map shows that the region of low intensities of change is to a large extent occupied by depoliticised positions that do not pay much conceptual attention to controversies and urban conflict. However, concepts of change with high levels of foregrounding of conflict beyond the proportionalising bias seem to be of particular relevance if the urban condition is understood to define a highly contested field.

Secondly, some concepts in the narratives are developed and theorised in such a way that they do not easily transgress disciplinary boundaries. Issues that are not considered 'architectural' or related to design problems are regularly excluded. The keeping separate of material and social worlds and the anxious maintenance of disciplinary boundaries makes it difficult for concepts to travel and connect. This imposes limits 
for architecture and urbanism's ability to contribute their spatial and other specialist knowledge to broader discourses and public debates.

Thirdly, the growing significance of process-led urbanism and the steady formation of contested spaces in which conflicting interests intersect demand new conceptual approaches to conflict in architecture and urbanism. Understandings are required which go beyond the idea of conflict as a temporary condition that disappears with conflict resolution. In this situation, rather than insisting on the disciplines' expertise in 'problem solving' according to their own narrowly defined terms - which all too often has resulted in disappointment and frustration - the disciplines must put greater emphasis on detection, spatio-temporal analysis, communication, and actively working with conflictual conditions of change. The knowledge produced in this way should be shared and debated with others in the sense of urban "matters of concern" (Latour 2005).

Fourthly, the concepts represented in the positional map do not seem to adequately address certain observations of asymmetric urban change I made at the outset of my enquiries. In particular, the contrast between the outward inactivity in the Parkstadt Bogenhausen housing estate in Munich in comparison to the substantial transformations in the surrounding area could not be explained and raises new questions. Further and different research is required to engage with this phenomenon. This is the task of the case study which I present in the second part of the book.

How, then, can we conceptualise the pattern of change in the Parkstadt Bogenhausen housing estate if we consider dynamic processes and conflicts to be at the core of the urban condition? How, in doing so, can we challenge the voids and the proportionalising bias in the narratives of conflict and change, connect material and social worlds with each other, and conceptually move beyond problem solving?

In the course of pursuing these questions in the second part of the book, I engage with different sites of analysis, in particular the collectively negotiated process of change itself. Methodologically, I continue to work with SA and GTM and expand them with additional research steps. In terms of analysis, SA assumes that all elements constitutive "of the situation are in the situation" (emphasis in original, Clarke 2005, p.71). The situation to which I refer in the case study is thus both a conceptual representation of social and material reality, as well as a site and unit of analysis - the transformative process of the Parkstadt Bogenhausen housing estate. Engaging with urban issues means engaging with different processes simultaneously and across different scales. The meso level is of prime research significance if the urban is understood as collective process and not as mere aggregate level of individuals. Social worlds/arenas theory and SA offer a unique perspective on collective processes, and therefore also, as I set out to demonstrate in this book, on the collective processes through which spaces are co-produced and changed. SA itself integrates social worlds/arenas theory, to form an explicit theory of conflict. It has the capacity, among other things, to represent and analyse controversies, negotiations, commitment and collective action. It assumes that issues of broader concern are negotiated between and through social worlds that partially and temporally participate in arenas. The research approach which I follow in this book understands architecture and human actors as mutually co-producing spatial situations. Architecture and the built environment, equipped as they are with a multitude of institutionally, culturally, economically and otherwise produced proper- 
ties, reflect back on situations, as do human actors with their presence and underlying intentions in those situations.

Theorising on the constitution of space through the establishing of spatial relations in action, Martina Löw proposes that this "[...] is not as a rule done in isolation, but takes place in processes of negotiation with other actors. Negotiation of power structures is an immanent aspect of this process." (Löw 2016 [2001], p.191) Consequently, the case study combines actor-centred perspectives with the analysis of structural and material conditions. It traces collective processes together with the estate's trajectory of spatial transformation, based on a set of interrelated questions: Which internal and external factors influence a housing estate's process of change? How do human and non-human actors interact in order to produce the observed condition? What are the structural conditions in the process? What can we learn from the housing estate's changing, or non-changing, spatial characteristics? If SA highlights the usefulness of 'sensitising concepts' in empirical research, how could we use all the data and findings to arrive at a new concept of urban change?

Housing estates have an ambivalent relation to the city. They relate to the intrinsic web of social interactions and spatial practices of the everyday, as well as to the more abstract levels of planning thought, institutions, urban organisation, and socioeconomic processes. Research into housing estates is as diverse as the estates themselves. Public authorities, planners, architects, economists, social scientists and others have at all times sought to develop a better understanding of housing estates, be it because of professional or academic interest, or because of statutory, fiscal or other responsibilities. Research agendas have changed considerably over previous decades. They typically address technical problems, questions of design, management, funding, or social issues. However, modes of analysis that apply a very narrow frame to their research object have to carefully assess the theoretical range of their analysis, together with their assumptions about the "context of context" (Brenner 2013, p.92) that acts upon their particular research situation. Likewise, if conditions of change in housing estates are predominantly observed from macrostructural levels, researchers may lose sight of the processes that co-produce change 'on the ground'. The steep rise in rents and property prices in many metropolitan regions has brought housing-related issues back to the centre of public debates, together with fundamental questions like urban justice, inequality, and the right to the city (Brenner, Marcuse and Mayer 2012; Harvey 2012; Trapp 2018; Vogel 2019). Housing estates are directly connected to the political domain, as well as the research about them.

Completed more than sixty years ago, the Parkstadt Bogenhausen housing estate has been organised as a commonhold-type entity according to the 'Wohnungseigentumsgesetz' (WEG) since 1984. With almost 2000 units under a single commonhold declaration, it is the largest of its kind in Germany and forms a contiguous legal and spatial construct in the city, covering an area of 15 ha. Like other housing estates dating from the second half of the $20^{\text {th }}$ century, it is located within modernist frameworks of conflict evasion, simplification, tight-fit-functionalism, and static models of space. The homogenising tendency of the welfare state is inscribed in its spatial layouts. At the same time, it is connected to many different actors, institutional arrangements, and interests. It is characterised by its own ownership constellation, its unique decision-making process, and its contingent future(s). It is connected to the city in which it is located in its own ways. 
Munich is currently experiencing a phase of outward and inward expansion. Large scale restructuring and a myriad of small scale interventions transform the appearance and the functioning of the city. This includes the modification of housing estates, which is currently underway on an unprecedented scale, ranging from substantial densification programmes, to upgrading and typological diversification. The Parkstadt Bogenhausen housing estate, by contrast, does not seem to participate in the urban dynamic and clearly deviates from the general pattern of change. However, tight-fit functionalism and other readily available concepts do not provide satisfactory explanations for the observed difference. Assuming that the same overall economic and political frameworks apply in the situation, what kinds of actors, structures and processes have to interact in order to produce a residential environment that resists change and that produces such a stark contrast, or asymmetry? And what, if we consider permanence not as a quality in itself which offers stability and orientation in an ever-changing world, but as a rigidifying restriction to the inhabiting and appropriation of space?

The case study assembles and integrates data from archived meeting minutes and historical material, interviews, participant observation, surveys, and site photography to engage with the above questions. The main body of material, consisting of the minutes of the annual meeting of the housing estate's co-owners according to the WEG, is analysed in the second iterative-cyclical process. This time, the process is based on the standard GTM mode of analysis, which includes the classic tools of theoretical sampling, coding, and memoing. The complementary mappings show the structural conditions and relations in the 'Parkstadt Arena', as well as the overall situational process and the negotiating of common concerns, or 'themes', along a timeline. In the synthesising steps leading towards the construction of the concept, I bring together the conclusions of the GTM process, the SA mappings, the comparative analysis, and the quantitative data; and I exploit the heuristic capacity of the positional map by establishing a dual position and drawing new interpretative connections. The new concept is named 'Redundant City'. It describes the housing estate's unique condition and pattern of change.

The Redundant City has, on the one hand, the legally granted capacity to initiate and develop processes of change, based on the relative autonomy of a collectively exercised, ownership-based authority. On the other hand, collective self-regulation, structural and institutional frameworks, investment-driven accumulation and "dynamic conservatism" (Schön 1971) produce conditions which allow transformations to occur on the micro level, albeit in a very regulated and limited way, while inhibiting changes and interactions on the urban level. Hence, we see empowerment through ownership alongside rigidity, restriction, and stagnation. In the Redundant City processes of change are oriented towards the inside, while interactions with the city are reactive and reduced to a minimum. In the Redundant City, potential spaces of individual appropriation and change are related to potential spaces of stagnation. The Redundant City's pattern of change is fundamentally different to the pattern of other areas in the city and makes it in this sense a space of 'otherness'. It prompts us to think about difference and otherness, through being different and through co-producing a unique condition of asymmetric urban change. The Redundant City conveys the promise of a lasting space of possibilities, because its potential is unlikely to be ever fully realised and used. As the urban level of the Redundant City is likely to remain inactivated, 
it increasingly may generate desires and 'What if?' scenarios, outside and within the housing estate. The space conceptualised in this way is of broader relevance and has a political dimension. There is an evocative utopian quality to the Redundant City.

I have chosen redundancy to name the concept because it embodies the key aspects of the observed process - ambivalence, conflict, and change. Whereas the notion of redundancy is neither native to, nor common in architectural and urban discourse at the present moment, it is both widely used and well established in science and technology studies (STS), computer science, engineering, system theory, linguistics, communication theory, and genetics. In these contexts, it is, broadly defined, a surplus considered either as benefit or waste. Sometimes it is understood as creating positive, desirable effects, sometimes it represents the useless, excessive, the ignored. Redundancy is used to pursue different, almost opposing ends. It is often associated with questions about whether we should have more or less of something. I consider it in the context of this critique as surplus in the positive and negative senses together. Part of my purpose in choosing it, therefore, is to maintain the ambivalence inherent in the term. It is intended to make us aware of the Redundant City problematic, its simultaneously enabling and inhibiting characteristics, and the various implications this may have. By explicitly emphasising its different connotations, I seek to establish a conceptual position that is not fixed in a single place and that defies closure in the style of Latour's "matter of concern" (Latour 2005). The term 'Redundant City' functions as a signifier both for the new concept and its socio-spatial referent, the Parkstadt - 'Park City' - Bogenhausen housing estate. Hence, the controversial notion of redundancy is an invitation to critically engage with the Redundant City concept as well as the Parkstadt Bogenhausen housing estate and to connect them to current urban debates.

The observations made in the housing estate seem to confirm Martina Löw's proposition that "spaces, places, and boundaries are enduring precisely because they are socially constructed." (Löw 2016 [2001], p.xviii) At the same time they seem to confirm that resistances in spatial arrangements do not inevitably and irrevocably result in permanent conditions of inactivity and stagnation. For Löw also suggests that if habits and routines are replaced with new ones "[...] regularly, collectively, and with reference to relevant rules and resources, institutionalized spaces and spatial structures can be changed." (ibid., p.191) Hence, one of the underlying assumptions in the Redundant City concept is that changes can be initiated if action is assumed collectively and from within the political arena of urban change.

How, then, can the concept and the different methodological components that helped to produce it be used? Clearly, multiple connections can be made in a multi-site enquiry to answer this question. In order to provide an idea of the scope of uses, in the final chapter of the book I discuss potential applications for the mapping tools, the concept itself, and the assembled body of narrative knowledge of conflict and change.

The mapping instruments introduced in this research project helped to reveal the structural conditions, resistances, competing desires, conflicts, and the web of social relations that influence the situational process of the Parkstadt Bogenhausen housing estate. The mapping instruments could be further developed and applied to the analysis of other housing estates and situations of change. Conceived as community mappings, they could become means of empowerment, collective learning, and catalysts of change. The knowledge thus produced could put communities in a position from which they may more easily raise issues and engage in debates about their built envi- 
ronment and the aspects that intersect there. They could enable members of a specific social world in participative processes to better understand their situation in relation to other social worlds in the arena. The mappings may give actors a better idea about how and in which constellations decisions are made over time. They make visible the effects of pre-structured processes, the distribution of power, "compartmentalization" and "dynamic conservatism" (Schön 1971, pp.31-60), exclusion, or the establishing of a dominant maintenance project. Actors may in this way analyse how resistances influence participatory processes, or prevent change from occurring. This may facilitate connecting with the macro-level, the realm of WEG legislation, urban discourses on densification, accumulation, asymmetric urban change, or urban inequality, calling into question the structural conditions of change. Empowered through mapping, users, owner and non-owner residents may find new ways of extending their effective range of action to higher levels of control, of renegotiating power relations in the arena, and ultimately of changing the spatial arrangements and their housing estates. Commonhold-type entities according to the WEG as well as housing estates owned by housing associations or housing cooperatives could make use of the mapping tools. For there seems to be a growing awareness of the need to strengthen, establish, and open up arenas. The formerly widespread practice of managing change in housing estates as top-down process, as had been common practice in the Neue Heimat group and other large housing providers, is gradually giving way to more inclusive approaches. Different levels of participation are understood as one of the means of generating and including new qualities in housing.

At the same time, we see that research in housing, along with programmes of urban restructuring and densification, continue to be based on narrowly defined conceptualisations and dominant concepts of change. Categories of conflict that do not lend themselves to 'solutions', as well as sites of greater complexity that offer resistances, do not easily lend themselves to research projects. Researchers tend to concentrate on, or otherwise establish, problems that are sufficiently structured and clear, hoping that in this way existing instruments can be used, best practice approaches applied, and faster solutions provided. As a result, housing estates as well as smaller scale housing in dispersed ownership according to the WEG are often left aside in current research on densification and urban restructuring despite their overall relevance. In growing cities, this selective approach may lead to the concentration of densification and restructuring programmes in areas that already have to cope with issues of inequality. This raises questions about who in the urban population has to adapt to transformations, and in which ways, but also about the overall capacity of cities to absorb growth and accommodate change. Here, the concept could contribute towards a better understanding of dispersed ownership constellations and improve the basis of decision-making for urban policies on the spatial distribution of growth.

The prevailing phase of low interest rates in the European Union for both savings and mortgages has made residential property an attractive alternative to other forms of investment for private investors. In Germany, this has led to a rising demand for building land and residential units, in particular in metropolitan regions of cities like Hamburg, Munich, and Berlin. As expectations about valorisation and future returns are high, housing prices and rents are rising steadily. The construction of new commonhold-type property according to the WEG, as well as the subdivision of single ownership residential blocks into multiple private units continues to thrive in this 
condition. Subsidised affordable housing that has reached the end of the public funding period is often subdivided and sold on in the private market, which causes rents to rise and accelerates processes of displacement and gentrification. In a move to slow down the effects of subdivision on local neighbourhoods, municipal administrations have set regulations in place that control and restrict the conversions in designated areas ('Erhaltungssatzung', respectively 'Milieuschutz') (Landeshauptstadt München 2016b, pp.36, 133ff). This and other measures, like the capping of rents according to an approved local rent index ('Qualifizierter Mietspiegel'), mirror the difficult relationship between the individual's interests in private property and the common interest in the provision of affordable housing. Since the early 1970s, reformers have demanded property owners assume their social responsibility as required by constitutional law ('Grundgesetz'), and to contribute in an appropriate way to the common good (Hertweck 2018a, p.154; Vogel 2019). The problems and questions related to this basic conflict, as well as the selective approach outlined above, suggest that a better understanding of the characteristics of and dynamics in commonhold-type property according to the WEG is also in these fields urgently required.

At the time of writing, there are very few, if any cases which use the combination of SA, social worlds/arenas theory and GTM for spatial issues and problems raised from within the architectural and urban disciplines. Accordingly, an intended outcome of this project is to show that they provide a set of useful tools and new perspectives for engaging with urban and architectural research questions.

Summing up, this book explores the rich body of narrative knowledge in architecture and urbanism and confronts this knowledge with an empirically grounded situational analysis of a large housing estate. The outcome of this twofold research approach comprises a new perspective on urban narratives of conflict and change, an extension of SA mapping tools and their application to spatial issues, and the Redundant City concept, which describes a specific form of collectively negotiated urban change.

The research project is based on the assumption that dynamic processes and conflicts are at the core of the urban condition. It does not provide a solution to a problem, nor does it provide an exhaustive analysis of a demarcated and therefore closed research object. The goal is to contribute to the understanding of dynamic processes in and of spaces and cities. The project engages with processes and structural conditions that drive or inhibit change. It exemplifies how the urban could be conceived of as an open construct, both conceptually and in terms of methodology. It raises the question whether more emphasis should be given to conflict-oriented perspectives. It stresses multiplicity and questions the dominance of single narratives of conflict and change by presenting the many other positions we can relate them to and work with in urban theory and practice.

\section{Acknowledgements}

The idea for the research presented in this book evolved during my design teaching and research assignments at the Chair of Design and Building Science at Brandenburg University of Technology and at the Chair of Urban Design and Regional Planning at Technical University of Munich. My initial interest in the adaptability of buildings and in problems of density led me to the level of urban processes and the broad theoretical 
field of conflict and change. During this time, our architectural practice, zectorarchitects, started to be involved with the activation of a rooftop space in Dalston in East London and with the restructuring of the high street in the Bauhaus city of Dessau in Germany. I also became interested in the pattern of asymmetric urban change I was observing in the Parkstadt Bogenhausen housing estate in Munich as a resident. Together, these factors contributed to the formation of this project and the combination of issues it seeks to address.

The prolonged work on and completion of The Redundant City would not have been possible without the sympathetic support of many individuals and institutions to whom I am greatly indebted. Most of all, I would like to thank Professor Sophie Wolfrum at TUM and Professor Dr. h.c. Jörg J. Kühn at BTU for their unwavering encouragement, for the motivating criticism and conversations, as well as for the generous support during all stages of the research process and beyond. They provided me with inspiring academic homes where I could connect to different fields of urban and architectural enquiry, develop ideas, engage in joint research and teaching, and work with wonderful people. Thanks to all of them.

I wish to thank the Dr. Marschall Stiftung at Technical University of Munich for the generous contribution towards the book and open access publication. I also wish to thank the staff at the Graduate Center and Dean's Office of the TUM Faculty of Architecture for their administrative assistance and accompanying support.

Special thanks are due to Professor Dr. Ulrike Sturm, who throughout has provided practical advice in research matters. She kindly took on the tedious task of reviewing the conference paper on the case study. Her expert knowledge made me attentive to issues of argumentation as well as to current research in the field of commonhold-type housing. I am also grateful to Julia Zillich, who helped me to establish a focus for the research process at an early and critical stage of the project. I would like to thank Professor Dr. Maren Harnack for her encouragement and comments on the occasion of the Porous City conference, Tak Hoshino for a series of insightful conversations about conflict and urban process at the University of East London, Professor Dr. h.c. Thomas Sieverts for the perspicacious discussions of the term redundancy and the findings of the research, and Professor Dr. Sören Schöbel-Rutschmann for the support during and after the completion of the project.

I would like to thank all participants in Oikodomos and the Oikonet, the global network on housing research and learning, in particular Professor Dr. Leandro Madrazo, for the hospitality at the Brussels conference and the opportunity to discuss key aspects of the empirical research within a multidisciplinary setting at the Manchester conference. Thanks are also due to Professor Dr. Jenny Stenberg and Professor Lasse Fryk for sharing their experience with co-design processes and community empowering research on housing estates. Finally, I wish to mention in memory of Professor Dr. Johan Verbeke that the inspiring debates he and his colleagues initiated have enriched my work in various ways, for which I am very grateful.

The notions of conflict and change have recurrently informed my teaching in seminars and design studios. I would like to thank the students at BTU and TUM for their interest, contributions and projects. I would also like to thank the members of the PhD group as well as the many friends of the Chair of Urban Design and Regional Planning at TUM for sharing their ideas about design, research, and cities, which was made 
possible not least because Sophie Wolfrum and Alban Janson provided a regular and comfortable platform for socialising and debating.

Special thanks are due to Karl Detering and Simon Beesley for their valuable comments, the copy editing of the manuscript, and of two research papers that are related to this project. The team at transcript provided excellent support in all matters related to the publication and guided me smoothly through the publishing process. Thanks to them also.

The collective process of the Parkstadt Bogenhausen housing estate is at the core of the case study element. I am indebted to the residents of the housing estate, not only for the research opportunities and the observations I was able to make over the years of living on the estate, but also for their kindness as neighbours. I wish to thank the participants in the interviews, the members of the advisory board of the estate, as well as the teams in the administration's local branch and head offices for kindly providing material for the empirical study, as well as for the valuable information they divulged in conversations and interviews. I also wish to thank Werner Wittemer and the authors of the $50^{\text {th }}$ anniversary catalogue for sharing their expert knowledge about the history of and life on the housing estate.

Special thanks are due to Carsten Jungfer, for the many years of joint designing and theorising at zectorarchitects. Carsten's appreciative attitude made it possible for me to spend time on academic research while working on live projects in architectural practice, and in this way being able to test ideas against both practically and theoretically informed backgrounds. His work with the students at Oxford Brookes University and the University of East London provided a continuous source of inspiration. I thank him and Paola Mollica for their exceptionally generous hospitality in London. Thanks are also due to Moritz Hauser, who has kept the Munich office busy with architectural work and real hands-on change, as well as for his interest and sympathetic understanding.

Finally, I cannot say how much I owe to Myriam, Julian and Christopher, for their sustained support, sympathy, and attentive care throughout the project. Not only did they actively contribute to my photographic journeys, or make possible extended periods of working, teaching and researching, but through sharing their personal experiences they made me more sensitive to the richness of everyday life on the Parkstadt Bogenhausen housing estate. They encouraged me to see things from ever-changing and fresh perspectives. 
Figure 1: Barbican Estate by Chamberlin, Powell and

Bon 1965-1976, sheltered resident playground below

Seddon House, London 2017

\section{Research as Situated and Critical Project}

"The urban is defined as the place where people [...] find themselves standing before and inside piles of objects, experience the intertwining of the threads of their activities until they become unrecognizable, entangle situations in such a way that they engender unexpected situations."

Lefebvre, Henri (2003 [1970]) The Urban Revolution, Minneapolis, p.39

"[...] the spatial turn stands for the insight that all spaces (architectural spaces, urban spaces, regions, nation states, bedrooms, recreation parks, river landscapes, etc.) are always also results of social production: not only in the sense that there are professions that plan and design these spaces, but also in terms of the challenging insight that spaces only become spaces for people inasmuch as they areagain and again and again-produced socially. In other words: the constitution of space is a performative act.

[...] How we perform the synthesis between objects, how we span the space between things and people is a highly conventionalized, objectified practice, one that is pre-structured by professions such as planning and architecture."

Löw, Martina (2016 [2001]) The Sociology of Space: Materiality, Social Structures, and Action. New York, p.vii 


\section{Problems of Research in Architecture and Urbanism}

\subsection{Multiple Framings of Knowledge}

The framing of knowledge influences the modes and methods used to produce new knowledge and the way knowledge is justified. It influences the systematics of knowledge organisation and maintenance, as well as the teaching, dissemination, and the possible relations between different bodies and forms of knowledge.

This research project is closely connected to the disciplines of architecture and urbanism. Research in these disciplines occupies different epistemological dimensions and produces and uses knowledge that is framed in different ways. Interpretative, critical and discursively generated forms of knowledge prevail in criticism, history and architectural theory; quantifiable and empirically tested forms of knowledge define the basis for technology-driven applications in architecture and urbanism; design knowledge is produced extensively, but not exclusively, in the design studio. The difference in the framing of knowledge is mirrored by the different meanings assigned to research terminology. If we speak of an experiment in a materials research laboratory, we mean something different than the experiment of developing a curriculum (Knoll et al. 2008; 2011) or the experiment in designing (Schön 1987, p.70), which again is different from the experimental implementation of a transdisciplinary realworld project (Hirsch Hadorn and Pohl 2008, p.117). Similarly, statements of 'truth' make sense in the programming of building construction software, but are of limited reach in the architectural design studio, for "a theory is never proven or legitimised in an architectural design, only tested or extended." (Spuybroek 2008, p.287). The iterative, non-linear and contingent process of designing represents a mode of knowledge production that is very different to the systematic routines of the scientific method (Cross 2001). Its outcomes are often temporary, fragile and therefore unstable. Conversely, architectural and urban practice involves, among other things, the integration of systematic technical and production-orientated knowledge. This knowledge is produced by specialists of various disciplines and the teams who work on the realisation of architectural and urban projects. As part of this process different technologies are developed and used, workflows and budgets are scheduled, monitored and organised, or compliance with standards and regulations is ensured.

Architecture departments typically accommodate different framings of knowledge, "cultures of knowledge" (Biggs and Büchler 2011, pp.68f), or "knowledge landscapes" (Dunin-Woyseth and Nilsson 2011, p.80). In this academic space, the rationality of technology meets discursive analysis and the reflection-in-action of design (Schön 1987). The different framings of knowledge do not occur in isolation and co-exist with each other. Priority might be given to one framing over the other, depending on the perspective, research problem and discipline/sub-discipline involved, but we usually find them entangled. The general research outline issued by the Architecture Department at TU Darmstadt in 2009 and reprinted as an editorial in the architectural theory magazine "Generalist" suggests that research in architecture, to which I propose to add research in urban and landscape design, has to integrate different framings of knowledge, methods, and actors, without the reassurance - and the constraints - of working within the scientific system (Fachbereich 15 TU Darmstadt 2009): 


\begin{abstract}
"Architecture is a design discipline. Designing is a methodology for solving complex problems, which [...] requires empirical and theoretical analysis of the design constraints, but which cannot itself assert a claim to being a scientific method. [...] The questions raised in architecture come from neither a single discipline of knowledge nor do they permit themselves to be defined as purely interdisciplinary problems. [Hence it] [...] needs the interaction of various methods and instruments, and it seeks, with a view to the specifics of the project, interdependencies among technical, economic, ecological, and societal developments. Whereas the process of traditional research takes place exclusively within the scientific system (either within a discipline or between disciplines), this (transdisciplinary) approach to research decidedly integrates participants from social, non-university, and project-specific practice, and it aims to produce use-oriented solutions and effects with social relevance." (ibid., p. 4).
\end{abstract}

The complex non-linear and creative activity of design has been the subject of theoretical and self-reflexive enquiries since architecture and urbanism were established as disciplines, yet it is only recently and gradually that a research-by-design approach has been recognised by institutions as a form of research in its own right, and more specifically, as an academic form of research (Dunin-Woyseth 2005; Verbeke and Jakimowicz 2009). However, while design-led research is gaining in significance, which includes the spreading of "design thinking" into other fields and disciplines (Wolfrum and Janson 2016, p.10), there seem to be growing doubts as to whether the integrative capacity of design still holds. In "The Mutual Limits of Architecture and Science", Kenneth Frampton criticises the analytical fragmentation of architectural questions and asserts that "[...] comprehensive synthesis [...] remains the field's ultimate mandate." (Frampton 2000, p.368) John Fernandez observes that "clear and strong divisions between design and technology (and by the way, criticism, history and visual studies and others) have resulted in both productive and debilitating shifts away from the generalist center of design." (Fernandez 2006, p.16) The discipline's technical rationality is itself subjected to a continuous process of transformation. On the one hand, it has benefited from new technologies and ever growing capacities in the processing of data. On the other hand, research problems have increased in scale and complexity. Empirical-scientific methods deployed in other disciplines continue to feed into architectural and urban research, in particular from engineering and from fields concerned with the physicality of architectural and urban production, such as materials sciences, energy and environmental control, traffic modelling, robotics in construction, surveying, but also from the social sciences, or from economics for the managing of budgets and workflows. Processes of differentiation require architecture and urbanism to integrate a growing number of sub-disciplines and growing amounts of specialist knowledge. Like other disciplines, they seek to respond to the demand for 'verified'

1 Some of the positions on research in architecture that emerged in the Architecture Department at TU Darmstadt were debated in the panel discussion "Forschung in der Baukunst", which was held at BTU Cottbus on 03.02.2010, with Adeline Seidl, co-editor of the Ceneralist magazine, being part of the panel. Other guests included: Rainer W. Ernst (Muthesius University of Fine Arts and Design, Kiel), Karen Eisenloffel, Heinz Nagler, Wolfgang Schuster (all BTU). The session was moderated by Dagmar Jaeger (BTU). 
information from the private sector, local authorities, policy agencies and the political domain.

Where different framings of knowledge interact with each other, fundamental questions about ontology, epistemology, methods, and possible conflicts between them have to be addressed for each research situation anew. Architectural and urban knowledge serves different and at times contradictory ends. Its presuppositions, applicability and theoretical range need to be assessed and communicated by those who produce and use the knowledge. With reference to social theorist Andrew Sayer's concept of "naive objectivism" (Sayer 1992, cited in Brenner, Madden and Wachsmuth 2011, p.233), Neil Brenner et al. point to the potential fallacies of uncritical modes of analysis, in which researchers "[...] presuppose that the 'facts' [...] speak for themselves rather than requiring mediation or at least animation through theoretical assumptions and interpretive schemata." (ibid.) ${ }^{2}$. Research is related to and influenced by its supporting institutional frameworks. The multiple framings of knowledge in architectural and urban research raise difficulties, not only in terms of methodological and epistemological complexity, naive objectivism, the practical challenges of working with and managing different forms of knowledge, or the frequent problem of making choices, but also in terms of how research is evaluated by institutional bodies ${ }^{3}$. Research expert Halina Dunin-Woyseth suggests in her paper presented at the colloquium "The Unthinkable Doctorate" held in Brussels in $2005^{4}$, that

"[...] architectural research does not fit naturally into the classification of the traditional academic disciplines even if faculties of architecture are incorporated as separate disciplines in the institutions of higher education. One of the prime reasons for this is the issue of assessing the quality of architectural research." (Dunin-Woyseth 2005, p.86)

From outside the discipline, and on a more general level, the Bologna reform has started a process of critical repositioning of research in the design disciplines (ibid, p.91) $)^{5}$, which not only encompasses the level of doctorates, but the entire system of academic architectural education (Knoll et al. 2008; 2011). Given the dynamic environment in which architectural and urban knowledge is produced and applied, new configurations for research and further diversification will occur. Their critical reflection and the positioning of research in relation to them is a continuous process. Hence, research in architecture and urbanism cannot be considered a routine or pre-given

2 I return to this problem at a later stage when I connect to Bruno Latour's proposition of a paradigmatic shift away from "matters of fact" towards "matters of concern" (Latour 2005, p.39). For the rejection of naive objectivism in Reiner Keller's "The Sociology of Knowledge Approach to Discourse" see (Keller 2011a, p.271).

3 Non-university agencies that allocate funding and coordinate research projects, for example the DFC (Deutsche Forschungsgesellschaft) in Germany, are challenged by the different framings of knowledge and modes of knowledge production in similar ways as the university department.

4 Professor Dr. Johan Verbeke, then head of the research department at Sint-Lucas School of Architecture in Brussels, kindly provided me with the proceedings of the colloquium during a conference held at Sint-Lucas in 2011. Very sadly, Johan Verbeke unexpectedly passed away in 2018.

5 Halina Dunin-Woyseth assumes a dual perspective based on the situation in the doctoral programme at Oslo School of Architecture, and the recommendations as formulated in the Bologna-Berlin Process for future doctoral research in Europe (Dunin-Woyseth 2005). 
process. The presence of different kinds and framings of knowledge needs to be addressed if naïve objectivism and compartmentalised discourses are to be avoided. However, rather than perceiving this as an impediment to research, I share the view of the critics and researchers who take multiplicity as a resource to work with, in particular if we understand urban issues as something that cannot be grasped in isolation and from a single perspective.

\subsection{Separation of Macro and Micro Scales of Conceptualisation}

Regional development plans, zoning plans, urban design and architectural detailing establish a hierarchy of control levels, which are distributed across different scales. Each scale is controlled by different actors and authorities. Each scale deals with different aspects of the built environment. The process of specialisation and compartmentalisation - in the political domain, in social and economic organisation, in the professions and universities - further contributes to the establishment of hierarchies and affects the way actors work with each other. Henri Lefebvre observed in the 1970s that the problem of separation between the architectural, urban and regional levels in the professions produce conditions where "[...] neither common projects nor theoretical continuity are possible." (Lefebvre 1991 [1974], p.12) Kenneth Frampton reaffirms a decade later that "[...] the split between architecture and urban development has led to a situation in which the possibility of the former contributing to the latter and vice versa [...] has suddenly become extremely limited." (Frampton 2007 [1980], p.9) Differentiations within the professions, increasing levels of complexity and a drifting apart of methodologies between disciplines continue to contribute towards the widening of the gaps. Formalised representations of spatial organisation are part of this process. Here, the political dimension of scales becomes visible. As reductive abstractions of spatial reality, plans represent a limited number of aspects - and exclude others. Large scale plans have the tendency to smooth over differences and contradictions, and, by means of their integrative capacity, pass on this tendency to smaller scales, that is, to different levels of power. The hierarchy of scales enables institutions that work on large scale plans to exert control over lower scales. Institutionalised representations of space, which are produced within dominant practices and discourses, might thus appear as pre-givens on the lower scales. A reverse directionality is initiated whenever this process is made explicit and power relations are called into question. The exclusion of either large or small scales creates blind spots pertaining to the instrumental continuity between scales, as well as the potential conflicts within the system.

Neil Brenner argues that the detachment of research focussed on small scale phenomena from research concerned with large-scale sociospatial processes, geopolitics and geoeconomics, has contributed towards a crisis in urban theory and urban sociology (Brenner 2013, pp.90-94 and p.97). Brenner identifies the "analytical black-boxing" (ibid., p.93) ${ }^{6}$ of what he refers to as "context of context" (ibid., p.92) within the realms of (micro-)contextual and place-based practice as being symptomatic of this tendency (ibid.) ${ }^{7}$. According to Brenner, insufficiently defined concepts and "[...] the

6 Brenner uses the expression "analytically "black-boxed" (ibid.).

7 Neil Brenner explicitly refers to research activities based on actor-network concepts as pioneered by Bruno Latour, and research drawing on the notion of "assemblage" as conceptualised by Gilles Deleuze. 
fragmentation of urban realities in everyday political-economic and cultural practice is being replicated relatively uncritically within the discursive terrain of urban theory." (ibid.) With reference to Kenneth Frampton's (2000, p. 368) criticism of architectural research, I suggest that the problem of rejecting "macrostructural forms of argumentation" (Brenner 2013, p.92) has to also be dealt with in architecture. The jumping over or ignoring of intermediate scales, and the assuming of an 'external' position represent two variations of the bracketing out problematic. Confronting the phenomenon of Parisian banlieues and suburbanisation, Henri Lefebvre observed in 1968 that "[...] sociological thinking and political strategy, and so-called planning thought, tend to jump from the level of habitat and to inhabit (ecological level, housing, buildings, neighbourhood and thus the domain of the architect), to the general level (scale of land use planning, planned industrial production, global urbanization), passing over the city and the urban." (Lefebvre 1996 [1968], p.123) The possibility of empirically reconstructing and following interactions across different scales is at the base of Lefebvre's proposition to move analytically, in urban analysis, "[...] from the most general knowledge to [...] the city and conversely, particular and specific knowledge of urban reality to its global context" (ibid., p.105). Lefebvre's analytical focus embraces micro and macro, specific and global, in a double movement through different scales and times. His notion of movement suggests that, complementary to rupture, there is the possibility of continuity. Arguing along similar lines, Edward Soja asserts that "the appropriate response to the micro vs. macro choice is thus an assertive and creative rejection of the either/or for the more open-ended both/and also... ." (Soja 2000 [1996], p.310) Venturini, Jensen and Latour argue that the micro-macro perspective, if it is used in models that assume agents at the local level to be incapable of understanding processes at the macro level, may result in the privileging of positions external to both levels (Venturini, Jensen and Latour 2015, para. 1.5). It gives power and control to those who observe and analyse collective phenomena from the outside - scholars, modellers and external public officials - and it raises expectations that the initiatives for change and propositions for the restructuring of patterns of interaction should be brought forward by the neutral, observing outside, rather than by individuals or groups that act in the situation (ibid.). We see such dynamics operating in mediated planning processes in which external agents are expected to provide the larger picture, adjust the rulesin-use for better outcomes, or assist in the production of a consensus that is then supposedly more appropriate to the situation than if it was developed through the creative and self-reflective, but prejudiced, capacity of the participants themselves. Criticising reductionist simulations based on "thin concepts" (ibid., para.1.9), Venturini, Jensen and Latour assert that "[...] contrarily to what most social simulations assume, collective action does not originate at the micro level of individual atoms and does not end up in a macro level of stable structures." (ibid.) They emphasise the two-way continuity between scales and the intricate and heterogeneous nature of the network through which actions are distributed (ibid., para. 1.11). Yet whatever complexity the tools or models we apply to our analysis may assume, there are limits to what we can know about the city. In view of this problematic, Edward Soja suggests that "understanding the city must involve both views, the micro and the macro, with neither privileged, but only with the accompanying recognition that no city - indeed, no lived space - is ever completely knowable no matter what perspective we take" (Soja 2000 [1996], p.310). 
In multi-scalar thinking problems are related to each other across different scales. Conceiving a perspective that emphasises the analytical continuity between the extremes, and that neither privileges the micro, nor the macro, nor assumes an external position, may help us to develop a deeper understanding of urban processes. I readdress these issues upon assembling the methodological assumptions of situational analysis further below, as well as in my discussion of control levels in the field of change.

\subsection{Institutionalised Dominance of Static Space}

Architects, urbanists and the planning professions work with multiple ideas of space and integrate new perspectives on space into their concepts. However, their work is situated within institutionalised frameworks that have at their base an understanding of space as neutral and static entity. Hence, it seems that despite the efforts being made to revise and further develop ideas of space, we are confronted with the tendency in architecture, and maybe to a lesser degree in urbanism, to engage with the problems of space in over-simplified ways.

In the introduction to this thesis, I have argued that change is an ever present condition in the urban environment; that change is influenced by collective human action and of the processes humans conceive to structure their lives and the world; and that urban practice, as well as theory, are challenged by the dynamic nature of cities. Outlining an urban sociology for the twenty-first century, Manuel Castells asserts that "spatial transformation must be understood in the broader context of social transformation" (Castells 2002, p.11). According to Castells, "space does not reflect society, [...] it is a fundamental dimension of society, inseparable from the overall process of social organization and social change." (ibid.) To what extent, then, do established instruments and frameworks accommodate social and transformative dimensions in their conceptualisations of space? While the reality of post-industrial and post-growth restructuring projects as well as the spatial turn in the social sciences led to a rethinking of the urban condition as dynamic and open process (Selle 1994; Fezer and Heyden 2004; Ministerium für Landesentwicklung und Verkehr des Landes Sachsen-Anhalt 2010), we could argue that participants in institutionalised forms of architectural and urban practice continue to work with the all-pervasive model of Euclidean space, which defines space as an empty container into which objects and subjects may be placed and related to each other through measurement. Within this space, the Cartesian coordinate system is fixed to an assumed origin of space, which rests on itself and controls what is around it. Movements are described by means of vectors that are locked in position and follow the Euclidian operations of translation, rotation or reflection. The space thus defined is coherent, static and neutral. Like time, it is understood to be free of ideology and of subjective bias.

Static space can easily and accurately be reproduced in plans and physical models. It is used for quantifying space, for establishing property rights, for controlling the distribution of uses, for eliminating conflicts, in short, for conventional zoning and planning. It has shaped the instruments through which institutions and professions control and organise space today. The practicability of working with static space, along with the routines established around it, including our learnt perception, reinforces the claims of the model to represent space 'as it is'. 
Henri Lefebvre argues this kind of reduction and abstraction of reality is directly related to the commodification of space and the requirements of exchangeability (Lefebvre 1991 [1974], pp.337f, p.341). He highlights the contradictions in the resulting urban environments, which embody multiform fragmentation on the one hand and the striving towards homogeneity on the other (ibid., p.287). Lefebvre seeks to sensitise us to the far reaching effects of leaving aside the temporal and unstable dimension of space, of eliding the differences that contribute towards the production of space, of ignoring human agency and intentionality, of defining political problems of space as problems of engineering, of ignoring the hegemonic and stabilising structural effects which are reproduced with abstract space, of leaving aside the dimension of the everyday and the close-knit web of interactions and human relations that unfold in space and that co-produce space. He argues for a reconceptualisation of space as an extension of human agency, as site and means of intervention, action and change. He proposes an analytic "[...] shift from things in space to the actual production of space [...]" (emphasis in original, ibid., p.37) wherein actors combine their critical conceptualisations of space with the realisation of "counter spaces" and the development of alternative urban practices (Lefebvre 1991 [1974], pp.381f, p.419).

Since Lefebvre formulated his ideas in the 1970s, many critical projects have been conceived that approach space differently. Concepts of spatio-temporality have informed new ways of thinking about the built environment (Harvey 2000, pp.182ff). Process-oriented framings of spatial interventions have been proposed and tested (Heinemann and Schmidt 2004; raumlaborberlin, Maier and Heidelberger Kunstverein 2008; Wolfrum and Brandis 2015). Institutionalised frameworks and models of space are increasingly challenged by groups and actors who see the opportunity to (re-) connect their spatial agendas to the social and political, and in this way to strengthen the impact and relevance of their work. They demand established processes be opened up to accommodate different ways of 'doing' urbanism and architecture (Awan, Schneider and Till 2011).

\subsection{Positioning of Theory in Relation to Material and Social Worlds}

Jane Jacobs suggests that "When we deal with cities we are dealing with life at its most complex and intense." (Jacobs 2011 [1961], p.372) The work of architects and urbanists routinely engages with material and social issues. If their work exceeds certain levels of complexity, they cooperate with specialist consultants, sometimes with engineers, who advise on structural stability and the physicality of materials, and sometimes with sociologists, who advise on questions of the social. Based on the institutionalised division of labour they reproduce - unintentionally - what Latour criticises as the "bifurcation" of reality (Latour 2005, p.38), in particular if the specialists emphasise the incommensurability of their domains. This bifurcation separates "the social, or the mind" from "the material, or the natural" (ibid., p.34). Latour argues that the sciences are caught up in modes of enquiry that fail to add to what is given in experience as a result of this condition, and further, that they tend to disqualify what is given in experience (ibid., p.24f). In view of the reductionist perspectives produced in this way, Latour suggests that "what is important to remember is that bifurcation is unfair to both sides: to the human and social side as well as to the non-human or 'natural' side [...]" (ibid., pp.15f). Theorising about the epistemological relationship of architecture and soci- 
ety, sociologist and architectural theorist, Albena Yaneva observes similar reductionist effects in cases where one side is used to explain the other (Yaneva 2012, p.37). We could further claim that reductionisms in architecture are connected to the tradition of generating systematising bodies of knowledge, as for example in typology studies, or more recently, in parametrically defined urban models. These approaches seek to control complexity on the basis of predefined categorisations, which often results in the exclusion of issues that do not fit the methodology and the systematics of categories.

However, the growing sensitivity for the mutual relationship of the spatial and the social, in combination with the availability of digital means of analysis and representation, has helped to establish a series of new research perspectives. The emphasising of relational aspects in all things produced by humans has influenced actor-network theory, assemblage or situational analysis. In the recent past, we have seen the emergence of a series of architectural and urban research projects that seek to overcome, implicitly or explicitly, the division between the material and social worlds, by means of raising questions that transgress traditional disciplinary boundaries (Harnack 2012; Hebert 2012; Heiler 2013; Wolfrum and Brandis 2015). Similar tendencies are at work in the social sciences, where the sociocentric perspective, with its exclusive focus on interaction or communication, gives way to perspectives that put more weight on materiality, space or the human body (Delitz 2009; Stenberg and Fryk 2012; 2014; Löw 2016 [2001]). In choosing to leave the safety of compartmentalised thinking, they open up new trajectories for architectural and urban analysis. Theorising about the constitution of space, sociologist Martina Löw suggests that

\begin{abstract}
"The observable processes of space constitution in modern society can only be explained when space and society are not defined as two separate realities. If space is defined as uniformly given, then change seems to involve dissolution and destruction; if space is conceived as territory, then society is lost from sight; if space is equated with the actual place, the macrosociological perspectives are inconceivable. It is only when the systematic division between space and action is overcome and space (or spaces) are recognized as social products that it will be possible to understand the various dimensions of constitution." (Löw 2016 [2001], p.103)
\end{abstract}

It seems that a new generation of research is reemphasising the connectedness of the spatial, the social and the material in different fields. Not only has the spatial turn in the social sciences established new perspectives on the spatiality of the social, it has also opened up new ways for architectural and urban theory to (re-)connect to the social sciences. Perspectives based on relational concepts of space share the understanding that materialities are consequential. In doing so, they connect to the constructivist paradigm in sociology which offers a theoretical framework for the relationship between the material and social worlds. Peter L. Berger and Thomas Luckmann argue in the conclusion to their 1966 classic "The Social Construction of Reality. A Treatise In the Sociology of Knowledge", that humans, or in the words of Berger and Luckmann, "man" is

"[...] predestined to construct and to inhabit a world with others. This world becomes for him the dominant and definitive reality. Its limits are set by nature, but once constructed, this world acts back upon nature. In the dialectic between nature and the 
socially constructed world the human organism itself is transformed. In this same dialectic man produces reality and thereby produces himself." (Berger and Luckmann 1966, p.183)

If we understand "reality", or rather, "realities" as a contingent product of collectively sustained processes, we acknowledge that they are in constant transition. This means that architecture, as one aspect of reality produced by humans, cannot be assumed to be static. An understanding of architecture that takes into account the consequential aspects of materiality, as well as the effects of social action on space and on the material world, is not trapped in the opposition of architecture and society. In doing so, it gains access to a whole set of new questions, through which it may challenge reductionist approaches to space and the ontological bifurcation of the world. ${ }^{9}$

\section{Learning from Criticisms of Scientific Knowledge Production}

\subsection{Shared Histories of an 'Aesthetics of Matters of Fact'?}

At the outset of this chapter, I addressed the co-existence of different framings of knowledge in architectural and urban research, together with the implications, problems and possibilities this may raise. I concluded that research in architecture and urbanism is not a pre-given site, routine or process. Based on the understanding that the way the sciences are perceived in general also affects the understanding of research in architecture and other design-led disciplines, I propose to include in my methodological outline the criticisms of the production of scientific knowledge by Karl Popper, Thomas Kuhn and Bruno Latour, among others. Rather than restating their arguments, I concentrate on the concepts which I believe are related to the kind of research I intend to pursue and that are in this sense of relevance for the epistemological and methodological positioning of this research project. I also establish parallels between architecture's and urban sociology's shifting claims to scientificity.

There is a long tradition of relating architecture to art, and a more recent tradition of relating architecture to science. What seems to be a contradiction in classification gives expression to the shared epistemological foundations of the two fields. Enquiring into the nature of empiricism and its origins, Bruno Latour suggests that the mimetic relation of copy and model, as a concept, migrated from the arts to the sciences (Latour 2005, p.41f). According to Latour, art and science jointly contributed to an "aesthetics of matter of fact" as it emerged during the $16^{\text {th }}$ century in parallel with the growing interest in the representation of nature (ibid., p.15). Alan Colquhoun observes that "in the Renaissance both the aesthetic and the constructional codes became subject to systematic theory, and art and science were harmonized through the epistemology of a geometric universe." (Colquhoun 1971, p.87) With the formation and separation of engineering as a new academic discipline during the $19^{\text {th }}$ century, architecture

\footnotetext{
8 Upon arguing the everyday to represent the "dominant" form of reality (Berger and Luckmann 1966, p.21), Berger and Luckmann propose humans have the capacity to distinguish between "multiple realities" (ibid.).

9 I take up this argument in the section "From Matters of Fact to Matters of Concern" below.
} 
effectively lost a core component of its research base - the 'firmitas' as conceptualised by Vitruvius. It responded either by re-emphasising its status as a form of art or by institutionalising research in the newly created polytechnics alongside the faculty of engineering. In building practice, architecture claimed a role that integrates and coordinates other disciplines. During this period we see architectural and urban observations and systematisations in the discipline improve in precision and evolve in parallel to debates on style, aesthetics and social issues. Further reorientations occur during the 1920 s with the modernist movement's call to introduce technological and scientific principles to the design process. The Bauhaus contributes to this agenda, in particular during the directorship of Walter Gropius and Hannes Meyer (Droste 1991, pp.60f and p.193) ${ }^{10}$. In 1926, Walter Gropius asserted that "the Bauhaus workshops are essentially laboratories in which prototypes of products suitable for mass production and typical of our time are carefully developed and constantly improved." (Gropius 1926, p.96) ${ }^{11}$ The architects who signed the $1928 \mathrm{La}$ Serraz founding declaration of the Congrès Internationaux d'Architecture (CIAM), including Hannes Meyer and Ernst May, claim that "through educational work carried out in schools, a body of fundamental truths could be established forming the basis for a domestic science (for example: the general economy of the dwelling, the principles of property and its moral significance, the effects of sunlight, the ill effects of darkness, essential hygiene, rationalization of household economics, the use of mechanical devices in domestic life. etc.)" (CIAM 1928, p.111). The advocates of this perspective declared architecture to have finally become scientific and the design studio a laboratory. In 1929, on the occasion of the CIAM 2 congress in Frankfurt, which was dedicated to the problem of the 'Minimum Dwelling', Le Corbusier and Pierre Jeanneret demanded customs and traditions in architecture be left behind "[...] to seal new pacts in the scientific world and in that of large-scale contemporary production." (Le Corbusier and Jeanneret 1929, p.33)

"Everywhere, in everything, in our daily research, we lack scientific certainty. Physics and chemistry are the territories which we must prospect in the search for sufficient truths." (emphasis in original, ibid.)

During this period we see similar tendencies in the social sciences and urban sociology, which sought to improve on their epistemology by aligning themselves with the scientific-positivist paradigm by "[...] developing an elaborate set of assumptions about the making of sociology as a science parallel to the natural sciences" (Clarke 2005, p.28). At the beginning of the $20^{\text {th }}$ century, the many different practices and local cultures emerging in rapidly growing cities shifted into the focus of social research. Urban eth-

10 Magdalena Droste observes that during the fourteen years of its existence, the thematic and pedagogic orientation of the Bauhaus had shifted from the dualism of art/craft towards art/technology under Cropius and Moholy-Nagy (Droste 1991, p.60), before the art component gave way to social, economic, political and scientific concerns under Hannes Meyer. By then, architecture was considered a product of collaborative effort and scientific analysis (ibid., p.193). Within this general development, parallelisms seem to have existed. For example, upon reflecting on his teaching at the Bauhaus, Moholy-Nagy explicitly states that the material studies conducted in his course were non-scientific in nature, aiming at reconciling art and technology (Moholy-Nagy 2001 [1929], p.21) .

11 The curriculum of 1925 speaks of "praktische Versuchsabteilungen" (Droste 1991, p.136) 
nographers studied these social phenomena on their doorsteps, most prominently the loose network of researchers around Robert Park in Chicago, a city which was then one of the busiest places in the United States and a generator of social, technological and economical change (Häussermann and Siebel 2004, p.45; Gieryn 2006). Thomas Gieryn suggests that the Chicago School ${ }^{12}$ pursued a dual epistemological approach based on the concepts of "field-site" and "laboratory" (Gieryn 2006, p.7ff). On the one hand, the concept of field-site enabled researchers to define the phenomena under study as "naturally occurring - not made up in the course of inquiry" (emphasis in original, ibid., p. 13). On the other hand, the concept of laboratory meant that the findings could be assigned a degree of universality through which they could be transferred to other cities (ibid., p.10). The dual perspective established an epistemological framework that oscillated between field and lab, found and made, here and anywhere, immersed and detached (ibid., p.11). Gieryn observes that "untroubled by relativism or ideological distortions of Truth, Chicago School members took for granted that the city of Chicago possessed an a priori, external and objective reality discoverable and describable by systematic scientific methods." (ibid., p.7) ${ }^{13}$

In Europe, modernist building and planning principles - rationalised and scientifically legitimised - were applied at unprecedented scale with the onset of postwar [re-]construction and urban restructuring. The state of crisis that was to follow ${ }^{14}$ produced different, to some extent opposing reactions, which in turn influenced the choices available for architecture's relations to science. In some responses, architects exploited newly developed or hypothetical technologies in combination with elements of pop culture. Buckminster Fuller, Archigram, the Metabolists or Yona Friedman, among others, worked with this approach. Others assembled around the Design Methodology Movement during the late 1950s through to the 1970s, which sought to

12 Häussermann and Siebel speak of a network of researchers sharing similar views rather than of a narrowly defined "school" (Häussermann and Siebel 2004, p.45). Thomas Gieryn acknowledges the major influence Robert Park and Ernest Burgess had on the school during its heyday, but points to the different stages of the school's development and the resulting difficulties of speaking of "the" Chicago School (Gieryn 2006, p.8). It is not to be confused with the Chicago School of architecture, which is usually associated with Mies van der Rohe at the IIT.

It is now well understood that the different strands of urban sociology and ethnography did not develop in isolation. Robert Park, when already an experienced urban journalist and holding a degree in philosophy, attended some of Simmel's lectures on sociology in winter term 1899/1900. Häussermann and Siebel suggest that Park might have been less interested in the dichotomy of urban and non-urban human behaviours as studied by Simmel, but rather in the idea of society being constituted by multitudes of different relations (Häussermann and Siebel 2004, p.45). Thomas Gieryn also mentions Ferdinand Tönnie's conceptualisation of 'Cemeinschaft' and 'Cesellschaft' to have influenced ideas about "[...] the mosaic of small traditional villages that comprise (not without disruption, and pain) the modern big city." (Gieryn 2006, p.9)

13 Adele Clarke takes as an example the Normal Curve to illustrate the kind of interpretative bias involved in the research designs of the early scientific strands in the social sciences: "While the fringes or margins are literally contiguous with the centre, we are led to assume they are not constitutive of the 'normal'." (Clarke 2005, p.24) The field is smoothed out and variations are graphically positioned at either "end", suggesting them to constitute "opposites" rather than parts of the same process (ibid.),

14 Here I refer to the accounts of architectural history by Norbert Huse (2008) and sociologist Tilman Harlander (1999, p.253). See also the controversy about the Pruitt-Igoe housing estate, built in St. Louis, Missouri in 1956, demolished in stages between 1972 and 1976 (Jencks 2011, p.26). 
replace that which was conceived as unscientific intuition in the design process with a more systematic approach derived from systems theory and mathematical models (Frampton 2000, p.357; Cross 2001). Cedric Price and systems theorist Gordon Pask proposed deploying cybernetics to approach architectural problems during the early 1960s (Price 2003, pp.69ff; Mathews 2005). Since the 1980s, the Space Syntax methodology by Bill Hillier and others has employed mathematical tools for the analysis of space (Hillier 2007 [1996], p.1). While some understand the postmodern turn as a move away from the undisputed authority of the sciences, towards more complex and pluralistic notions of architecture (Jencks 2011, pp.40ff), technology and the sciences have never ceased to be an inspiration for architects. The gradual takeover of "Digitalism" (Colletti 2011) and the application of information technology in all domains of architectural activity, seems to have resulted in further changes in architecture's relations to science. This embraces questions of method and practice, as well as the speed and extent to which new ideas are shared. Addressing the relationship of architecture to science and art today, Bill Hillier suggests that

"Architecture [...] is both art and science in the sense that it requires both the processes of abstraction by which we know science and the processes of concretion by which we know art. [...] It is the fact that the architect designs with the spatial stuff of living that builds the science of architecture into the art of architecture." (Hillier 2007 [1996], p.7)

\subsection{About Raising New Questions and Taking a Risk}

During the period when modernism and its goal of establishing scientific standards in architecture and urbanism emerged, philosopher of science Karl Popper developed a critique of science ${ }^{15}$ based on the analysis of the production of scientific knowledge. Popper published his work under the title "Logik der Forschung" in Vienna in autumn $1934^{16}$, but it was not until 1959 that the English translation titled "The Logic of Scientific Discovery" (Popper 2002b [1934]) brought this part of his work to a wider audience. By then he was already well known for his enquiry into political philosophy and his critique of historicism. In "Open Society and Its Enemies", published in 1945 while in exile in New Zealand (Popper 2013 [1945]), Popper argues that essentialist views of history and the belief that history unfolds according to universal laws contribute to the formation of totalitarianism in societies. Returning to the sociology of knowledge and to the critique of scientific knowledge, Popper published "Conjectures and Refutations" in 1963 (2002a [1963]), which consists of an anthology of papers and lectures written by Popper between 1937 and 1960. Although Popper has predominantly written for the scientific community and for scholars in the philosophy of science, some of his ideas found their way into the work of theorists concerned with architecture, urbanism and design. In particular his juxtaposition of the utopian model and incrementalism, and his concept of the open society have been widely taken up in architectural and urban

15 In this critique, Popper partly excludes mathematics and logics, to which he refers to as "pure sciences" (Popper 1953, p.67, p.83).

16 The imprint states 1935. For information on translation and date of publication, see Popper (2002b, p.xii). 
theory (Rowe and Koetter 1978, p.122; Selle 1994, pp.49ff; Sennett 2007, p. $5^{17}$; Rieniets, Sigler and Christiaanse 2009, p.25). His concepts of "critical attitude" (Popper 1953, p.64) and learning from past mistakes seem to offer further connections for design-related forms of knowledge.

Popper's criticism of observationalist-inductivist empiricism and of inductivist generalisation as scientific method takes as a starting point the view that positive outcomes in an experiment can never conclusively verify a scientific theory - there could always be the yet undetected exception or anomaly challenging the theory (Popper 2002 b [1934], p.3ff). Accordingly, in the preface to "Conjectures and Refutations" Popper summarises his conceptualisation of scientific knowledge as follows:

"The way in which knowledge progresses, and especially our scientific knowledge, is by unjustified (and unjustifiable) anticipations, by guesses, by tentative solutions to our problems, by conjectures. These conjectures are controlled by criticism; that is, by attempted refutations, which include severely critical tests. [...] Criticism of our conjectures is of decisive importance: by bringing out our mistakes it makes us understand the difficulties of the problem which we are trying to solve." (emphasis in original, Popper 2002a [1963], pp.xi-xii)

In this paradigm, the most thoroughly developed method, research approach, theory or design proposition sooner or later become questionable. They are temporal in character and are eventually replaced, through a process of criticism and testing. Popper suggests that "the most important function of observation and reasoning, and even of intuition and imagination, is to help us in the critical examination of those bold conjectures which are the means by which we probe into the unknown." (Popper 1960, p.37). According to Popper, research endeavours that are refuted have not been made in vain. Refutations do not 'nullify', but rather open up new trajectories for research. Based on this chance to build upon past experience and the view that research should focus on the pressing problems of the present, Popper advocates pragmatist problem solving rather than addressing the speculative problems of a distant utopia (Popper 1947, pp.485f). The 'learning from our mistakes' is central to Popper's notion of tradition, for Popper observes that "[...] the tradition of critical discussion is the only practicable way of expanding [...] our conjectural and hypothetical knowledge" (Popper 1958, p.204). Ralf Dahrendorf, who refers to Popper's concepts in many of his writings, expands on this idea and applies it to human activity beyond the scientific domain, using the term "Entwurf" (design) (Dahrendorf 1986 [1967], p.II). He stresses that trial and error contribute significantly to the advancement of knowledge (ibid.) and demands, accordingly, that there should always be controversy about the assumptions that inform knowledge and collective actions (ibid.). This relates to Popper's proposition that social and political goals cannot be determined scientifically (Popper 1947, p.482) and that decisions on ends need to emerge from discursive realms beyond science (ibid.). Implicit in this view is the idea of the critical scientist, who engages in this discourse as an active member of the open society.

17 Richard Sennett mentions Karl Popper in one of the versions of "The Open City" (Sennett n.d., p.5). Further connections in this version of the text are made to Charles Darwin, Niklas Luhmann's concept of autopoiesis (ibid.), and the criticisms of Jane Jacobs (ibid., p.6), among others. 
Pertaining to the question of when a theory qualifies as scientific, Popper establishes, with reference to ancient Greek philosophy, the distinction between the "dogmatic" and "critical attitudes" (Popper 1953, p.64). Popper suggests that the propensity in humans to detect regularities in the environment, and to project expectations and laws upon nature could be subsumed as "dogmatic behaviour", and the corresponding mode of thought as "dogmatic attitude" (emphasis in original, ibid.). This kind of knowledge seeks to exclude observations and propositions that are not in line with the expectations (ibid.). Following Popper, the dogmatic provides stability and protects approximations from being prematurely rejected (ibid.). The "critical attitude", Popper argues, emerged as an alternative in non-dogmatic schools of thought ${ }^{18}$ and evolved further through cycles of cultural practice (ibid.). Similar to its dogmatic predecessor, the critical school draws from myths, expectations and hypotheses, but it is prepared to question, modify, or reject them (ibid., p.65). In the critical tradition, a theory is passed on together with the encouragement to critically engage with it and improve upon it (ibid., p.66).

If we were to position the productions of architecture and urbanism within Popper's model of the dogmatic and critical, we would, perhaps, find most of them drawn towards the dogmatic, for many of the activities in this field are concerned with the (re-)production of pre-defined outcomes. The corresponding research is directed towards known and widely recognised problems. It is preoccupied with optimisation and practical innovation within given frameworks, with the identification of best-practice projects, and typically includes the search for practical applications of technologies that have emerged in other disciplines. The kind of operational criticism prevailing in this dogmatic field seeks to increase efficiency, profitability and predictability. However, we may also find a number of decidedly critical productions. The critical is not reluctant to challenge existing frameworks and inherited ideas. In critical enquiry, the wider framing is seen as part of the problem under examination. Both orientations, the dogmatic and the critical, rarely occur in pure form. Architecture and urbanism occupy a field where the dogmatic and critical meet. As noted in the section on knowledge production, research in architecture and urbanism can choose whether to emphasise and work towards optimisation and efficiency, whether in this sense to follow the dogmatic route of a pre-defined project, or whether to emphasise the critical and in this way be challenged by epistemological openness. Different orientations are justifiable, for the critical relies on the dogmatic as its prime target, and the dogmatic needs criticism to maintain its capacity to deliver efficiency and reliable solutions to the multitude of recurrent standard problems that architecture and urbanism have to address every day. If seen through the lens of Popper's criticism, research in architecture and urbanism thus offers a series of different routes, each with its specific possibilities and limitations. As indicated by the title of this chapter, and explained in greater detail at a later stage, this research project follows a critical approach in which non-standard, non-predefined questions are raised and worked with.

Finally, Popper's proposal for judging the quality of a theory could be adapted to establish an indicative benchmark for a research project. In Popper's view, the scientific significance of a theory is defined by its explanatory power and the way it stands

18 Popper suggests that the school established by Thales was the first of its kind which did not pursue the preservation of a dogma (Popper 1953, p.67). 
up to and relates to criticisms (Popper 1958, p.209). Popper claims that on the level of theory "[...] we do not prefer every non-falsified theory-only one which, in the light of criticism, appears to be better than its competitors [...]" (emphasis in original, Popper 1953, p.74). Correspondingly, Popper proposes a clearly defined distinction between what he conceives as interesting, or uninteresting theory. He suggests that "[...] every interesting and powerful statement must have a low probability; and vice versa: a statement with a high probability will be scientifically uninteresting, because it says little and has no explanatory power" (emphasis in original, Popper 1953, p.77).

In summary, the series of methodological and epistemological principles of Popper's theory of knowledge may inform the setting-up of a research design in architecture and urbanism with the following objectives: to learn from past mistakes as well as existent criticisms of non-dogmatic examiners; to test new research results against past solutions, together with the claims of established theories; and to look beyond known problems and the framings associated with them. In line with Popper, it is justifiable for research to 'take a risk' because concepts with lower probability are more interesting, and because attracting criticism is prerequisite to the process of learning.

\subsection{Instability of Scientific Knowledge and its Movement 'Away From'}

The discontinuous development of the sciences are the subject of a series of key analytical and interpretative writings, which have produced doubts about the stability of scientific knowledge itself. Three years after the English translation of "The Logic of Scientific Discovery" by Karl Popper had been published (Popper 2002b [1934]), Thomas Kuhn initiated a controversy with "The Structure of Scientific Revolutions" (Kuhn 2012 [1962]). Kuhn's sociology and history of science suggests that scientific research is determined, governed and legitimised by temporal paradigms shared by scientific communities. The paradigm defines the types of problems that are admitted to the scientific process and provides the directions for solving them. Preceded by phases of crisis during which anomalies are accumulated, paradigms replace each other periodically through scientific revolution (ibid.) ${ }^{19}$. Imre Lakatos, a former disciple of Popper, takes both Popper's and Kuhn's propositions further and speaks of "research programmes" rather than research paradigms, whereby multiple research programs may coexist next to each other. The stabilising mechanism that enables continuity despite pressures of change in this model is defined as a "protective belt", which consists of "auxiliary hypotheses" that are placed around the "hard core" of the programme ("protective belt' and 'hard core' in single quotation marks in the original, Lakatos 1978, p.4, pp.48ff).

Thomas Kuhn suggests that the sciences, during recurrent intervals of crisis and transition, depend on the making of decisions that do not fully rest on scientific principles and that seek orientation in normative categories, such as the "future promise" of a theory (Kuhn 2012 [1962], p.156); that this process is framed by conditions of

19 In a similar way, for Michel Foucault "[...] these sudden take-offs, these hastenings of evolution, these transformations which fail to correspond to the calm, continuist image" (Foucault 1980, p.112) are periods during which new "regimes" (ibid.) of scientific truth are established through controversy and the reciprocal effects of knowledge/power, blurring the certainty of what "governs" (ibid.) scientific statements and how statements govern each other (ibid.). 
exceptional confrontation and criticism (ibid., p.147); and that the sciences move away from the concepts that have failed to provide satisfactory explanations of the world (ibid., p.170). Philosopher Ian Hacking highlights in his $50^{\text {th }}$ anniversary introduction to Thomas Kuhn's "The Structure of Scientific Revolutions" that the moving "away from" seriously challenged the view deeply embedded in the Western tradition that the sciences would follow a rational path of progress "towards" truth in the sense of an all-embracing account of nature and of the world (Hacking 2012, p.xxxv). After the idea of directionality in the development of nature had been questioned by Charles Darwin more than a hundred years earlier - not without lasting opposition (Beer 2008, pp.xxvi-xxxii) ${ }^{20}-$ Kuhn felt the need to raise the question whether it would "[...] really help to imagine that there is some one full, objective, true account of nature and that the proper measure of scientific achievement is the extent to which it brings us closer to that ultimate goal?" (Kuhn 2012 [1962], p.170). The ensuing controversy about scientific relativism is indicative of how challenging the idea must have been at that time.

Similarly, architecture and urbanism seem to struggle recurrently with their own crises of directionality. Popper's rejection of "utopian rationalism" (Popper 1947, p.484), which is based on the view that pursuing utopian ideals results in different degrees of violence in the long term (ibid.), entered architectural and urban theory where it has produced a dilemma. In their broad discussion of utopia in architecture and urbanism, Colin Rowe and Fred Koetter highlight the capacity of 'ideal cities' and utopias to make visible the gap between the actual and the possible and to provide visions of alternative futures (Rowe and Koetter 1978, ibid., p.49). Rowe and Koetter responded by distinguishing between utopia as blueprint "prescription" and utopia as "metaphor" (ibid., p.123) ${ }^{21}$, which enabled them to acknowledge the problematic of the blueprint while rescuing utopia as an operative model for architecture and urbanism. They suggested that the model, despite its obvious orientation towards the future, also connects with the past and with memory (ibid., p.49). If we relate this proposition to Thomas Kuhn's concept of movements in the sciences, and to the Popperian 'learning from our mistakes', it may define a movement 'away from' the shortcomings and failures of our past architectural and urban concepts, and, at the same time, a movement 'towards' a contingent future that is negotiated within an open and therefore contested field of possibilities. Positioning an architectural and urban research project within such a construct makes explicit that other ways of "doing architecture" (Awan, Schneider and Till 2011) are possible. It is in this context that the role of the researcher as "critical examiner" (Popper 1960, p.37) becomes political, that the researcher enters a discursive arena, and that established research and design routines need to be questioned and put to the test. We could claim that, if research in architecture and urbanism seeks to detach its research object, method or output from such questions, on the grounds of a proclaimed scientificity and dogmatic attitude, it omits an important aspect of research work. And further, if it seeks to work from behind a protective belt to stave off

20 Discussing this problematic in the introduction to Charles Darwin's "On the Origin of Species", Gillian Beer refers to Creationism or Intelligent Design as alternative, directional conceptualisations of evolution.

21 Rowe and Koetter use the term metaphor together with, or exchangeably with, "image" (ibid., p.14) and "prophecy" (ibid., p.48), or "reference" (ibid., p.14) or "model" (ibid., p.48). 
criticism $^{22}$, it may find it difficult to connect to issues of relevance beyond the narrow confines of a discipline.

\subsection{From 'Matters of Fact' to 'Matters of Concern'}

Recent controversy about post-truth politics (German 'postfaktische Politik') has highlighted the problematic of arguing on the basis of facts. The construct of the post-truth/ factual emphasises the instrumental ignorance of facts on the one hand, while asserting the credibility of facts on the other. However, problems with the latter arise if facts are used as if they speak for themselves - an issue repeatedly analysed and criticised by Bruno Latour in publications and a series of lectures and papers (Latour 2004; 2005; 2008). Based on his analysis of how we produce and use scientific knowledge today, Bruno Latour argues that we should replace the taken-for-granted attitude towards "matters of fact" with the less naive and less innocent concept of "matters of concern", which does not negate the political dimension and the tendencies of scientific practice (ibid.). In this alternative concept, scientific research is understood as an activity that is closely tied to the conditions in which it takes place, rather than following a linear and autonomous progression of knowledge. For Latour 'matters of fact' are the result of an "[...] amazingly narrow, specialized, type of scenography using a highly coded type of narrative, [...] a very precise repertoire of attitude and attention." (Latour 2005, p.38) Latour understands 'matters of fact' as being located within the artificiality and peculiarity of the scientific model, and as having originated from the epistemological distinction between 'primary' and 'secondary' qualities of objects in the tradition of early empiricism (ibid., p.13). According to this distinction, primary qualities are properties of objects that are independent from the observer and her perception, as for example motion, geometry and other properties related to the Newtonian concepts of space and time. As they are considered to exist in the object itself, this view claims that they can be determined with certainty and that they represent objective facts. Properties that rely on sensory experience in the observer, such as colour and sound, are defined as secondary properties. According to early empiricist view, this experience is connected with subjective judgement and cannot provide objective facts (ibid., pp.12f). ${ }^{23}$

Latour suggests typical problems and misunderstandings of this distinction to include the assignment of primary qualities to the human as if it was a category of objects (naturalisation) (Latour 2005, p.15), as well as a reductionist attitude towards objects, through treating them as being defined exclusively by their material aspects (ibid., pp.15f). He further suggests that although postmodern criticisms and deconstruction have significantly broadened the scope of critical enquiry, in particular of the concepts of modernity, these criticisms did not succeed in liberating themselves from the modernist divide between what was "social, symbolic, subjective, lived and what was material, real, objective and factual" (Latour 2008, p.6).

22 Patrik Schumacher demands such a protection for what he terms "avant-garde style" respectively "avant-garde research" (Schumacher 2010, p.280).

23 Latour traces back the distinction of primary and secondary qualities to the works of Calileo and John Locke (Latour 2005, p.12), and builds upon criticism formulated by Alfred North Whitehead and Gabriel Tarde, as well as Williams M. Ivins (Latour 2005). 
Latour refers to the proposed shift in attitude as "second empiricism" - as opposed to the first empiricism handed down through the history of science (ibid.). He suggests that "we don't have, on the one hand, a harsh world made of indisputable matters of fact and, on the other, a rich mental world of human symbols, imaginations and values" (Latour 2005, p.38). Latour argues that if it is acknowledged that "science is adding itself to the world" (emphasis in original, Latour 2005, p.24), a shared territory may be established in which the sciences represent one possibility - among others - "to fold oneself inside" the "flow of experience" (ibid.), rather than accelerating its reduction and disqualification (ibid.). Central to this second empiricism is Latour's concept of 'matters of concern', for which he provides the following analogy: "A matter of concern is what happens to a matter of fact when you add to it its whole scenography, much like you would do by shifting your attention from the stage to the whole machinery of a theatre." (ibid., p.39) Thus, 'matters of concern' come together with information about how, and for which purpose, knowledge is being produced, because "[...] they distinguish clearly the population of those for whom they matter." (ibid., p.47). While 'matters of fact' give authority to those who claim to be in the possession of indisputable knowledge - to "shut the dissenters' voice down" (ibid., p.39), 'matters of concern' build upon dispute and acknowledge the political dimension of objects and artefacts (ibid., p.47). In this sense, 'matters of concern' do not claim to be ahistorical and immune to change.

On the occasion of a keynote lecture given at the "Networks of Design" conference, Bruno Latour suggests that the distinction between 'matters of fact' and 'matters of concern' could be more clearly made through the concept of 'design'.

"When things are taken has having been well or badly designed then they no longer appear as matters of fact. So as their appearance as matters of fact weakens, their place among the many matters of concern that are at issue is strengthened." (Latour 2008, p.4)

According to Latour, there is a transitory aspect in designing, a link to shifts in possibilities and fashions (ibid., p.5). "Designing [...] is an antidote to hubris and to the search for absolute certainty, absolute beginnings, and radical departures." (ibid.) Political theorist Chantal Mouffe takes Latour's proposition further, suggesting that the work of designing, of composing and decomposing, is "[...] eminently political [for] it does not take place in a neutral terrain in which the observers could impartially decide if things have been composed in a 'good' or 'bad' way." (Mouffe 2013, p.81) ${ }^{24}$ Mouffe proposes that conflicting interests in this process have to be understood as articulations of hegemonic and counter-hegemonic struggles (ibid.). Despite these differences in the foregrounding of the political, Mouffe asserts that they both "[...] broadly belong to the same epistemological camp [...]" (ibid., p.80). They both seem to agree about the crucial role of criticism in reproductive processes, be it as 'design' or the more politically orientated "articulation" according to Chantal Mouffe (ibid., p.81). Being critical of criticism, Latour asserts that criticism itself has contributed towards the bifurcation of the world. In his essay "Why Has Critique Run out of Steam? From

24 In the article "Parteiisches Design" Jesko Fezer establishes a series of connections between Chantal Mouffe's conflict-centred perspectives and designing, and emphasises the distinction between politics and 'the political' (Fezer 2018, pp.165ff). 
Matters of Fact to Matters of Concern" Latour seeks to raise awareness for the effects of criticism on that which is criticised (Latour 2004). According to Latour, the self-affirmative routines prevailing in the social sciences have led to a crisis of "the critical landscape" (ibid., pp.237ff), which led him to the formulation of an alternative that is supposed to add to the criticised, rather than subtracting from it:

"The critic is not the one who debunks, but the one who assembles. The critic [...] offers the participants arenas in which to gather. The critic is not the one who alternates haphazardly between antifetishism and positivism ${ }^{25}[. .$.$] , but the one for whom, if some-$ thing is constructed, then it means it is fragile and thus in great need of care and caution." (ibid., p.246)

For Chantal Mouffe, this concept of criticism does not reach far enough. While for Latour the "adding of scenography" is an epistemological means to see the world as being constructed together with all the supporting machinery attached, Mouffe's interest is more in the machinery itself. In Mouffe's view, Latour's framings remain too narrowly defined, which, according to Mouffe, results in "[...] disempowering political effects because they preclude the possibility of revealing and challenging power relations." (Mouffe 2013, p.81) For Mouffe, criticism is a device to bring about change. Mouffe and Latour both seem to share the view that the production of knowledge cannot be considered a self-evident process. They demand research be accompanied by criticism; they also demand research problems be more broadly conceived, so as to include critical reflection on the enquiring self and the situatedness of the research project. In this way, research and theory have their blind spots, political tendencies, or otherwise silently accepted presumptions openly addressed, so that they can be approached as 'matters of concern'.

\section{Assembling Architectural and Urban Research Perspectives}

\subsection{Approaching the Urban as Open Construct}

Urban theorist Neil Brenner suggests that "the urban is a theoretical construct [and] not a pregiven site, space or object" (Brenner 2013, p.96). With reference to my previous remarks on the problems of research in architecture and urbanism, we could assert that urban research is not a pre-given site or self-evident process. In this sense, Brenner emphasises the significance of making explicit how the urban is approached in research, since

25 As part of his analysis, Latour provides the following definitions: "Antifetishists debunk objects they don't believe in by showing the productive and projective forces of people; then, without ever making the connection, they use objects they do believe in to resort to the causalist or mechanist explanation and debunk conscious capacities of people whose behavior they don't approve of." (Latour 2004, pp.240f) According to Latour's analysis, the two strands of criticism are strategically held separate and used at will by the critic, according to his or her momentous tactics (ibid.). 
"[...] questions of conceptualisation lie at the heart of all forms of urban research, even the most empirical, contextually embedded, and detail orientated. They are not mere background conditions or framing devices but constitute the very interpretative fabric through which urbanists weave together metanarratives, normative-political orientations, analyses of empirical data, and strategies of intervention." (ibid.)

The conventions and frameworks shared in a research community exert a significant influence on the type of questions that are raised or excluded (Biggs and Büchler 2011, p.66). The way the urban is conceptualised has influence on our choice of methods, the scale and depth of enquiry, the type of knowledge we seek to generate, and the envisaged nature of possible outcomes. According to Brenner, conceptualising the urban and the positioning of research within this conceptualisation become critical steps that have to precede any empirical and specific engagement with the urban domain (Brenner 2013, pp.96f). One of the first tasks, then, is to theoretically address the urban and to position the intended research accordingly. In order to distinguish the urban from the city, and process from built form, Henri Lefebvre draws a conceptual connection between movement and openness, and rejects the idea that the urban could be approached as closed and static object.

"The urban phenomenon is made manifest as movement. Therefore, it cannot achieve closure. The centrality and the dialectical contradiction it implies exclude closure, that is to say, immobility." (Lefebvre 2003 [1970], p.174)

It seems apparent that such an understanding of the urban cannot work on the basis of pre-defined concepts and methodologies that strive for closure. If, for the purpose of research, the urban is abstracted as a "zone of thought, representation, imagination, or action" (Brenner 2013, p.96), how far will we travel if the urban is limited by our imagination and projections alone? What does it mean, from the perspective of methodology, to think in terms of openness rather than in terms of demarcation and closure? How can we work within this paradigm, and how can we establish an argumentation, a research project? Pertaining to these questions, if we define as our point of departure the urban as a zone of thought which is essentially open, we will have to conceive of ways to exploit its potentiality while addressing the many conceptual and methodological challenges that come along with this decision.

\subsection{Reframing Critical Theory as Critical Urban Theory}

On the occasion of the "Cities for People, Not for Profit" international conference held at the Centre for Metropolitan Studies (CMS) in Berlin in 2008, Neil Brenner discussed the framework for a critical urban theory which connects to concepts that originated in the work of philosophers Max Horkheimer, Theodor Adorno, Jürgen Habermas and others (Brenner 2012, p.18). This discussion does not seem to be self-evident, for Bruno Latour suggested in 2004 that critical theory, as represented by the Frankfurt School, "[...] died away long ago". And indeed, the demolition of the iconic AfE Tower ${ }^{26}$ in Frank-

26 The 32-storey, $116 \mathrm{~m}$ AfE tower (acronym for 'Abteilung für Erziehungswissenschaft') accommodated from its opening in 1972 until 2013 seminar rooms and offices of the Social Science and Education 
furt in 2014, former academic home to members of the Frankfurt School, does not suggest it could have been otherwise. However, since the days of the Frankfurt School, the concepts of critical theory have migrated to other fields of enquiry, including architecture and urban theory. With the fading of the tradition in philosophy, these strands of critical theory found themselves challenged by the task of advancing the theory from within their disciplines on the one hand, and by means of connecting to each other on the other. Kenneth Frampton, for example, in the introduction to his history of modern architecture, highlights the significance of the ideas of the Frankfurt School for his work as a historian (Frampton 2007 [1980], p.9), as well as for the (re-)politisation of academic research in general. Pertaining to the relationship between architecture and scientific-empirical modes of knowledge production, in "The Mutual Limits of Architecture and Science“, Frampton demands that research and architectural practice be confronted with critical theory so that "[...] whether we like it or not, the interface between architecture and science returns to the political." (Frampton 2000, p.368) However, to speak of a clearly demarcated critical theory in architecture and urbanism would be misleading, for there is no single point of reference, no 'school', or unified discourse. Critical theory in this field may be conceived as a shared attitude, as a research perspective which may be used "[...] as a varied terrain in which to reconfigure architecture and its theorised interpretations." (Borden and Rendell 2000, p.16) Neil Brenner provides some orientation in this varied terrain by identifying, among the many sub-concepts of critical theory and with recourse to the root concepts developed by the Frankfurt School, a series of assumptions that could inform a contemporary, reframed critical approach to urban and architectural research (Brenner 2012, pp.1519). He suggests that:

1. Theory is to be considered as embedded within time/space of history and mediated through power relations. There is no privileged and neutral standpoint, for which reason theory needs to be reflexive. "Critical theory is reflexive." (emphasis added, ibid., p.15)

2. Theory requires a degree of autonomy and abstraction that allows criticism to operate beyond the constraints posed by the immediate and the specific. "Critical theory is theory." (emphasis added, ibid.)

3. The generalisations of means-to-ends rationales, which are aimed at improvement and efficiency without interrogating the dominant systems in which they operate, and which they ultimately reproduce, need to be questioned. "Critical theory entails a critique of instrumental reason." (emphasis added, ibid.)

4. And finally, the critical approach builds upon the fractures and contradictions within the social totality to formulate possibilities for alternative and emancipatory realities. "Critical theory emphasises the disjuncture between the actual and the possible." (emphasis added, ibid.)

departments at Johann Wolfgang Goethe University, the academic home of the Frankfurt School. It was designed by the federal architecture department of Hessen and was related to architect Ferdinand Kramer's restructuring plan for the university campus. Kramer, former member of Ernst May's 'New Frankfurt' team and living in exile in the United States since the late 1930s, had been appointed university architect by then rector Max Horkheimer. The concrete tower acquired an iconic status as a site of student protests and political action. 
Brenner emphasises that the reflexive capacity of the critical approach is instrumental in its adaptation to new problems and new questions that are continuously produced in the urban domain (ibid., p.18). With reference to the writings of Peter Marcuse, Brenner suggests that this capacity has enabled the critical approach to shift its theoretical orientation from the abstract, as the initial domain of the Frankfurt School, towards the more concrete issues of social change and urban transformation (ibid.).

Based on the considerations brought forward in this and the following section, I propose taking the critical perspective to support and inform the "interpretative fabric" (Brenner 2013, p.96) through which issues are approached in this research project. For this purpose, I refer to and draw from the works of theorists who are associated with a critical perspective on urban problems. They have different theoretical orientations, they do not share the same methods and would probably not use the label of critical urban and architectural theorist; what these theorists have in common, however, is their interest in raising inconvenient questions, in interrogating systems of dominance, and in proposing connections where none have been seen before. The texts to which I refer at various stages for this purpose include, but are not limited to, the writings of Henri Lefebvre and David Harvey together with texts that relate directly or indirectly to their theories and analyses, for example by Neil Brenner, Christopher Dell, Jesko Fezer, Christian Schmid, Edward Soja, the writings of Michel Foucault, and the writings of Bruno Latour and Adele Clarke on the critical reframing of methodologies and research problems. With regard to the interpretative fabric through which to approach space, I refer to Henri Lefebvre's writings on the social production of space, and, among others, to Martina Löw's theoretical framework for a relational concept of space.

\subsection{Making a Difference}

Addressing the practical consequences of the critical approach, Ian Borden and Jane Rendell assert that "any critical theory aims not only at the understanding of the world but also at the simultaneous transformation of both itself and that world 'beyond' theory." (Borden and Rendell 2000, p.13) The critical perspective in architecture and urbanism seeks to make a difference to spatial practice. Neil Brenner suggests that, "Rather than affirming the current condition of cities as the expression of transhistori-
cal laws of social organization, bureaucratic rationality, or economic efficiency, critical
urban theory emphasises the politically and ideologically mediated, socially contested
and therefore malleable character of urban space - that is, its continual (re)construc-
tion as a site, medium, and outcome of historically specific relations of social power."
(Brenner 2012, p.11)

If critical research seeks to make a difference, it can look to design, or designing, as a potential ally. To design means to work with, and exploit, the malleable character of the urban. Design is an activity that engages with the construction and reconfiguration of urban and architectural spaces. This raises the question of what the relationship between research, design, and urban and architectural practice consists in. Addressing the difficulties of challenging the gap between the real and imagined in design, Tomás Maldonado, former director of Hochschule für Gestaltung (HfG) 
Ulm suggested in 1972 that the designer has to address the constituents, politics and constraints of planning processes (Maldonado 1972, p.52). ${ }^{27}$ Maldonado, like Frampton, Borden and Rendell a few decades later, highlights the significance of a critical attitude when it comes to designing, suggesting that "Those who allow that design activity be conducted without recourse to a heightened critical consciousness - ecological or social - always end up departing from the specific reality of the situation." ${ }^{28}$ (Maldonado 1972, p.48, own translation) According to Maldonado, innovation and utopian propositions should be measured against their feasibility (ibid). For this purpose theory should be rooted in both utopian and real world realms, and should be based on sets of realisable actions (ibid). Maldonado emphasises the need to maintain both theoretical and practical operability in conditions of change. Drawing on the writings of Tomás Maldonado and critical planning theory of the 1970s, theorist and urbanist Jesko Fezer formulates a proposition for the [re-]framing of design in architecture:

"An architecture that strives for social relevance has to deal with how the complexity of social dynamics can be grasped and on what levels and with what methods one can approach them. Precisely because planning operates within a complex and contradictory social space, it articulates, positions, modifies, limits or represses intrinsic social desires and conflicts. It is precisely this that can be understood as the intentionality of architecture and planning - as a design attitude."29 (Fezer 2007 p.61, own translation)

Hence, speaking of a critical attitude in design means to connect to critical strands of research, to acknowledge its capacity to critically reflect on itself as a practice and its relation to dominant modes of production. Conversely, speaking of a critical attitude in architectural and urban research means to acknowledge its potential relevance for design, and therefore for the design of change. The critical perspective in architecture and urbanism emphasises the mutual relationship of research, design and the political. Despite the difficulties individuals and collectives experience when they combine a critical theory approach with a project, a growing body of work is dedicated to precisely this field. The authors of "Spatial Agency. Other ways of doing Architecture" speak of this work as a "critical practice" (Awan, Schneider and Till 2011, p.29), where

27 Tomás Maldonado's text "Environment and Revolt" (Umwelt und Revolte) (Maldonado 1972) is discussed in the German magazine "form und zweck" (1991) vol. 2+3 and more recently in Jesko Fezer's "Deprofessionalisierungstendenzen" (Fezer 2011). Fezer discusses Maldonado's theory of "scientific operationalism" in relation to design methods and participation.

28 Translated from German: „Wer darin einwilligt, dass Entwurfstätigkeit ohne den Beistand eines geschärften kritischen Bewusstseins - ökologisches oder soziales - ausgeübt wird, endet immer damit, aus der je besonderen Wirklichkeit auszuwandern." (Maldonado 1972, p.48)

29 Translated from German: "Eine Architektur, die um gesellschaftliche Relevanz bemüht ist, muss sich damit auseinandersetzen, wie die Komplexität gesellschaftlicher Dynamiken erfassbar ist und auf welchen Ebenen und mit welchen Methoden man auf sie zugehen kann. Gerade weil Planung innerhalb eines komplexen und widersprüchlichen sozialen Raumes operiert, faltet sie immanente soziale Begehren und Konflikte auf, artikuliert sie, bringt sie in Stellung, modifiziert sie, begrenzt sie oder verdrängt sie. Gerade das kann auch als Intentionalität von Architektur und Planung verstanden werden - als Entwurfs-Haltung." (Fezer 2007, p.61) 
Figure 2: "The arrival city needs the best schools", German Pavilion at the $15^{\text {th }}$ International Architecture Exhibition 2016, by Deutsches Architekturmuseum (DAM) general commissioner and director Peter Cachola Schmal, curator Oliver Elser, and project coordinator Anna Scheuermann

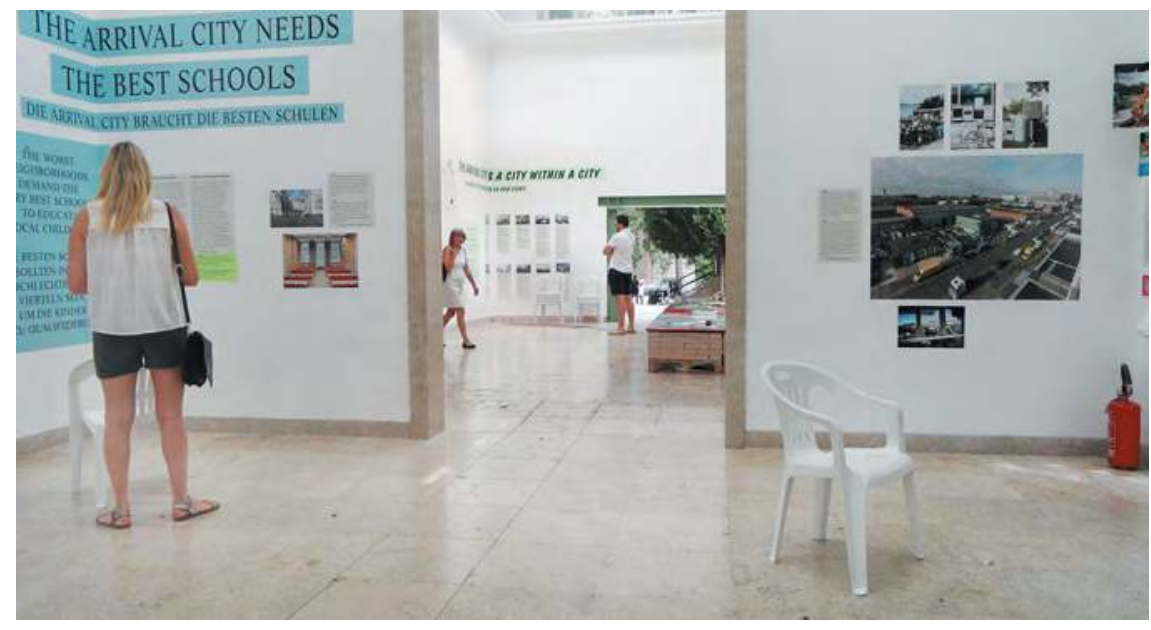

the agent "[...] is one who effects change through the empowerment of others, allowing them to engage in their spatial environments in ways previously unknown or unavailable to them, opening up new freedoms and potentials as a result of reconfigured social space." (emphasis in original, ibid., p.33). In the process, the spatial competence of designers connects with the spatial competence of participants and users, forming a joint space of learning and collective action. Critical urban and architectural practice seeks to make a difference and work towards practical change.

\subsection{Adding Urban Action: Pushing the Limits of What We Can 'See' in the City}

Many different disciplines share the understanding that the built environment holds information about the conditions and processes that have contributed towards its production. These include archaeology, anthropology, architectural theory, conservation, building history, cultural studies, geography, urban studies, to name but a few. From this perspective the built environment is understood to "[...] mirror the attitudes of past and present generations [...]" and to "[...] reflect the increasingly diverse and often conflicting preferences of numerous (and unequally influential) social groups." (Hassenpflug, Giersig and Stratmann 2011, p. 25) In the architectural and urban disciplines researchers and architects like Kevin Lynch (1960; 1972), Gorden Cullen (2010 [1961]), Robert Venturi (1992 [1966]), Colin Rowe and Fred Koetter (1978), Aldo Rossi (1982 [1966]), Rem Koolhaas (1994a [1978]), John Habraken (2000), and others, have pioneered environmental analysis in new ways of reading and interpreting the 'thick' information available in cities. In their work, morphologic, morphogenetic and typological research has established a systematic view of the historic city (Moudon 2004). Forms of urban analysis based on computational models, such as the space syntax methodology (Hillier 2007 [1996]), or the more politically oriented forensic architecture approach (Weizman 2012a; 2012b) continue to share the view that the built environment can 
be conceived as complex and ever changing recording and storage device for different kinds of information. Some of these perspectives assume that if they look closely enough, they will identify and subsequently be able to manipulate specific situations in the built environment through which they may connect to past and present ideas, to rituals and dreams, to social conditions and practices of the everyday. Other perspectives hope to see forms of organisation beyond the visible pattern of space, of hidden rules, of silent forms of domination. However, the multiple stories embedded in the built environment do not tell us what or how to see. Nor do they speak to us directly. The information has to be identified, decoded and interpreted. We necessarily bring previously formed knowledge and preconceptions to the practice of interpretation, for we cannot decipher information without making assumptions about the code. Our capacity to see defines what and how we see. It also defines what we cannot see. The knowledge we thus produce is fragmentary and incomplete. Problems of this kind are examined in semiology, but they seem to be of general relevance for any analysis that seeks to access information recorded in the built environment. ${ }^{30}$

Connecting to the work of Kevin Lynch, urbanist and theorist Thomas Sieverts refers to the city "[...] as the common product of the 'hardware' of the real, physical environment and the 'software' of perception and use. In the process of comprehending the city, both the 'hard' and the 'soft' world cannot be separated [...]" (Sieverts 2003 [1997], p.101). In this configuration, experiencing, using and interacting with the city is seen as an active part of the construction of the city. Hence, if urban and architectural analysis engages with urban phenomena by looking exclusively at the 'hardware' of the city, such as buildings, infrastructure, urban form, technical aspects or environmental conditions, it will elide the fields "where the action is" (Goffman 1967; Dellwing and Prus 2012, p.9 $)^{31}$.

Pertaining to the question of who, or what, acts upon the built environment, Hassenpflug et al. suggest that "apart from various professional groups (such as architects, investors, entrepreneurs, local politicians, members of municipal administrations, artists, etc.), it is the differing forms of citizens' collective action that contribute to shaping the physical and social appearance of urban spaces." (Hassenpflug, Giersig and Stratmann 2011, p.25) If we understand the city as the product of social, economic and political processes which are established and negotiated through collective human action, architects and urbanists cannot assume the study of built form, structure, or the study of the work of architects is sufficient for developing an understanding of urban reality. While walking through Baltimore, as well as observing Boston from Federal Hill, David Harvey speaks about what we can hope to see of urban reality in the built environment - if we look hard enough - and what will be hidden from view if we do not ask the right questions and if we do not look at the prevailing social and political conditions at the same time (Harvey 2000, pp.133ff; 2001, pp.128ff). Likewise, Henri Lefebvre suggests that, "for conflicts to be voiced, they must first be perceived, and this without subscribing to representations of space as generally conceived." (Lefebvre 1991 [1974], p.365). But how can we develop an enquiring architectural and urban

30 I would like to thank Tak Hoshino for having raised this issue in a conversation about urban analysis.

31 The term was coined by sociologist Erving Goffman in the late 1960 s as part of his research in the field of symbolic interactionism. 
Figure 3: Finishing touches to the large mirror installation 'Dalston House' by artist Leandro Erlich in Ashwin Street prior to the public opening, London 2013

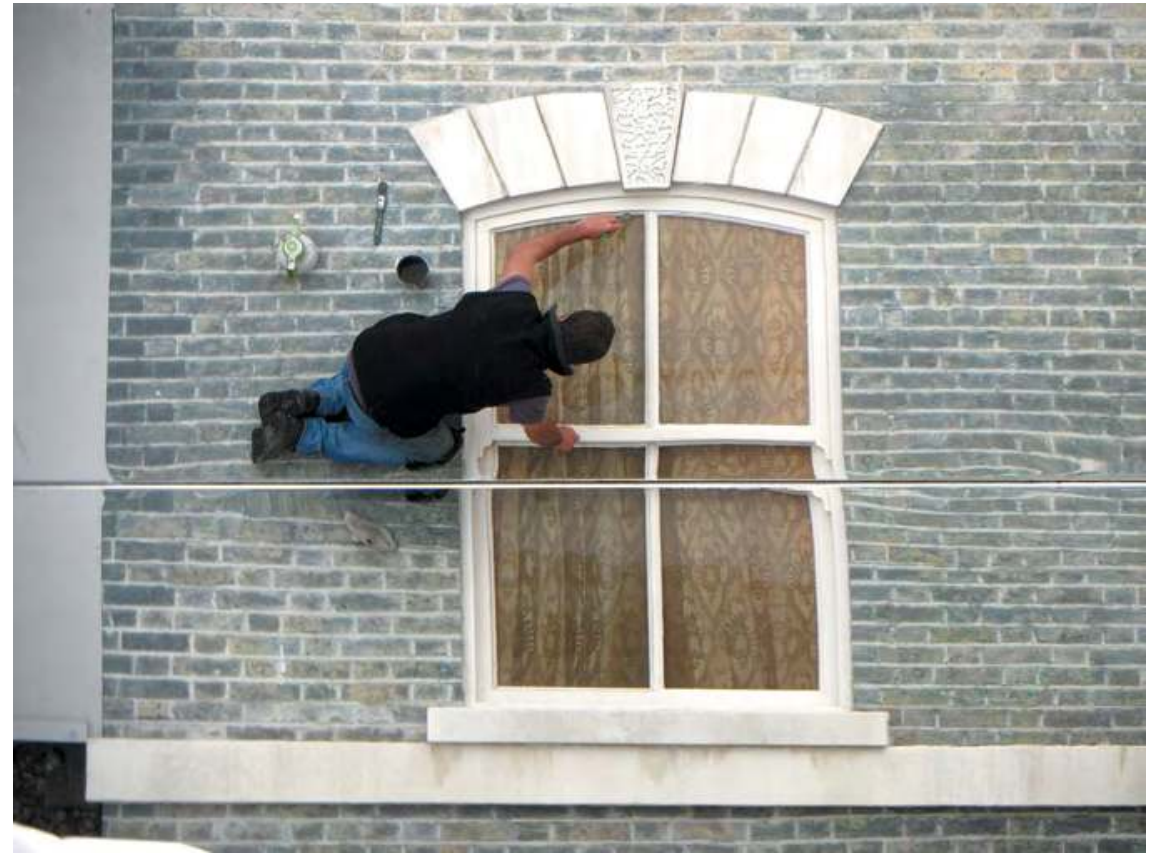

perspective on the built environment beyond the standard representations of architecture and urbanism? How can we enrich the scope of what we can see in the city?

New and sophisticated ways of representing and analysing the city as well as space itself have emerged since Kevin Lynch conceived his image-of-the-city approach. Architects and urbanists have sought to further develop and expand their repertoire of urban analysis together with the many other disciplines that engage with built environments. Our understanding of the built environment is constantly changing with the emergence of new problems and new questions, which, if we refer to Ian Borden and Jane Rendell "[...] offers the chance to see architecture as something other than buildings, compositional techniques or architect-based practices" (Borden and Rendell 2000, p.8). They suggest that, if we assume architecture is entangled with the material and ideological aspects of urban power, then, in order to more fully understand architectural practices, "[...] it is necessary to look at other arenas, other theoretical territories." (ibid.) It is thus incumbent on us to look into areas in which power relations are generated and negotiated, that is, into social process and action. But how can we add to architectural and urban enquiry an analysis that translates into human action? A possible theoretical framework for this undertaking is provided by Martina Löw's sociology of space in which space is conceptualised as "relational arrangement of social goods and people" (Löw 2016 [2001], p.134) and "spacing" and "operation of synthesis" as the simultaneous key processes through which space is 
constituted (ibid.) 32 $^{32}$ In asserting the need for and the epistemological advantage of working with relational concepts of space, Löw suggests that

"[...] changes to the phenomena of space can only be understood when we cease to assume two different realities - on the one hand space itself, on the other social goods, people, and their actions [...]. Thus, if space is not the rigid background of actions, but rather integrated in the context of action, then a changing practice of the organization of proximity can be brought into focus." (Löw 2016 [2001], p.226)

Architecture and urbanism are among the practices that organise proximity. Martina Löw's proposal that we relate space to action and vice versa provides a different perspective on the organisation of proximity, and therefore architectural and urban practice. Pertaining to the analysis and conceptualisation of cities, Martina Löw argues that

"Cities are generally viewed from a structural level. [...] It is still the case that not enough work has been done on the question as to how, for example, a city develops in action, that is, how Cologne, Hamburg, or Munich become a city for people who act." (Löw 2016 [2001], p.216)

The question of how cities develop in action is related to process, to shifts in spatial arrangements, to conflict and change. If we return to the idea of connectivity between scales, we could say that the above criticism and perspective could be applied to spatial arrangements at lower levels, such as a housing estate or spaces of the everyday, as well as higher levels, for example in the strategic (re-)positioning of cities in conditions of global competition. In either case, the process will be based on collective action, for

"The constitution of spaces in action is not as a rule done in isolation, but takes place in processes of negotiation with other actors. Negotiation of power structures is an immanent aspect of this process." (Löw 2016 [2001], p.191)

Based on these premises, I seek to raise new questions by means of combining architectural and urban theory with an empirical enquiry into urban action. In doing so, I hope to expand our critical view of architectural and urban productions, and push the limits of what we can 'see' in the city. Adding to architectural and urban research, an analysis of process and action raises methodological difficulties that have to be carefully addressed, but which, I believe, are offset by the chance to connect the material and social worlds in research rather than separating them, for the benefit of a richer, and thicker understanding of urban space and of architectural reality.

32 In the German original text, published in 2001, Martina Löw uses the phrase „relationale (An)Ordnungen sozialer Güter und Menschen", respectively the terms "Spacing", as in the later English version, and "Syntheseleistung" (Löw 2015 [2001], p.158). 


\subsection{Multi-site Research Approach}

In the preceding sections, I have argued for a mode of research that combines the study of the material world with an analysis of urban action; I have argued for an approach to the urban as an open construct; I have proposed that research in architecture and urbanism evolves around multiple framings of knowledge, and that the work of these disciplines connects to non-academic practice and process-based bodies of knowledge. All these postulates suggest that research problems in architecture and urbanism extend across different sites, together with the knowledge and the data related to them. Irrespective of research projects being organised within multidisciplinary, transdisciplinary, or other frameworks, issues about how disciplines choose to relate to each other have to be addressed, as well as the situation of dispersed knowledge, the availability of different sources of data, the potential conflicts between them, or the complexity of research questions. The challenges related to multi-site research are in this sense similar across the disciplines. Pertaining to the situation in the social sciences Adele Clarke observes an

"[...] increasing need for what is now being called multisite research-projects that examine multiple kinds of data from a particular situation of inquiry, including discourses. This involves diverse approaches that move us away from single-site, intensive, immersed ethnographies or interview studies of the past. Today we seek to better capture the increasingly complex, diffuse, geographically, discursively, and/or otherwise dispersed aspects of research topics of interest to scholars in the social sciences, humanities, and professions." (Clarke 2005, p.165)

Researchers need to think about what kind of data to gather, how and where to look for them, how to decide on their significance, and how to organise and integrate heterogeneous types of data so that they become productive (ibid., p.167). The degree of openness during the search for sites determines whether important information is collected or missed. On the other hand, if there is insufficient focus in the approach, researchers might find it difficult to defend their argument (ibid.) Also, as "it is rare that one can determine 'all' the 'proper', 'best', 'possible/feasible' sites in advance" (ibid., p.167), Clarke suggests that in multi-site research "one must, of course, reserve the right to add and/or delete additional sites later." (ibid.) Certain decisions as to the structure of the project, the sequencing of sites, the methods applied, or even the ultimate focus of the project may not have been made at the outset of the research process. Because of the multiple possibilities to choose from, there is no standard model to which multi-site research projects could refer. Consequently, if research is pursued as multi-site research, it needs to align its modes of enquiry with the specifics of each site, and with the specific development of the project. In the multi-site approach, a research project tends to be a multiple-methods project. 


\section{Grounding the Project: Situational Analysis and Grounded Theory Methodology}

\subsection{Turning to Social Science Methodologies: Situatedness of Research Problems}

Architectural and urban research share with research in the social sciences the problem of working within 'fields' of enquiry. The field is a concept that has been at the base of research in the social sciences since social anthropologists and ethnographers began to directly engage with social phenomena. In ethnography, the field is "where the action is" (Goffman 1967); it is where the world is produced in collective processes through actions, fixations and negotiations of meanings. The field is therefore the primary site of ethnographic analysis, for making first-hand observations, for 'doing' research through techniques of immersion and intersubjective participation (Dellwing and Prus 2012, p.53), and for "hanging around" (Shaffir, Dietz and Stebbins 1994, p.40; Kling and Kurbasik 2018, pp.283f).

The writings of Bruno Latour and others suggest that the deconstruction of modernism's epistemologically effective "envelopes" (Latour 2008, pp.8f) has led to a new understanding of the field and of research contexts. According to this new understanding, knowledge does not evolve along a single and linear trajectory of progress that points towards a final perfection. Research problems are rather seen as part of specific situations, as are the researching agents and the research process; research problems are situated within a complex web of relations, interactions, contradictions and contingencies. With the questioning of modernist 'envelopes', situations and fields of enquiry ceased to be conceivable as pre-given. While the 'envelope' had been instrumental for the production and maintenance of hard demarcations and the production of scientific objects that could be presented as matters of fact, its removal led to conditions that resist closure and that emphasise the connectedness of problems and phenomena rather than their isolation from each other. This in turn encouraged the development of new methodologies and research perspectives.

Ideas about the situatedness of knowledge and its production extend to the work of architects and urban designers. In his studies at the MIT during the 1980 s Donald Schön describes the production of design knowledge as the outcome of conversations with - and in - situations (Schön 1987, p.57). Designing is an activity that is situated, for it is dependent on the formulation of a research problem, on the designer's approach and skills, and on the (professional) tools used in the enquiry. At the same time, designing creates new situations by means of continuously reframing research problems during the process (Schön 1987, pp.57, 65; Knoll et al. 2011, p.22). Referring to Schön's descriptions of design knowledge production, sociologist Albena Yaneva suggests "[...] that architects need to engage with a pragmatist type of architectural inquiry that is a situation-based, distributed way of learning about architecture and its various entanglements rather than one that relies on a stable stock of systematic, scientific knowledge." (Yaneva 2012, p.68) However, architects and urban designers are likely to continue to draw on, and co-produce, systematic and scientific knowledge. As I have argued earlier, multiple framings and bodies of knowledge coexist with each other in architecture and urbanism. Architectural and urban researchers have a choice in terms of what kind of knowledge they produce and what kind of knowledge they work 
with. Because there are valid justifications for each of these framings, and because different bodies of knowledge may contribute in different ways to architectural and urban work, the question about which form of knowledge or research method to apply is not one that may be answered generally, but one that needs to be addressed for each architectural and urban research problem anew.

\subsection{Social Worlds/Arenas Theory, Grounded Theory Methodology and Situational Analysis}

Engaging with urban problems means engaging with different processes simultaneously and across different scales. Within a multiscalar research perspective on urban problems, the meso level, or medium scale, is of prime interest if the urban is understood as collective process and not as the mere aggregate level of many individuals. Highlighting the significance of this level for the production of both individual identities as well as the social, Clarke suggests the meso level is the site where "[...] individuals become social beings again and again through their actions of commitment [...]" (Clarke 2005, p.110). According to Clarke, four analytical methodologies that focus on the meso level can currently be distinguished in the social sciences: actor-network theory (ANT), assemblage theory, social worlds/arenas theory, and other variations of network theories (Clarke and Keller 2014, para.66), where Clarke asserts that "a particular strength of social worlds/arenas theory lies in its capacities to handle collective history and change over time." (ibid.) Observing the field of qualitative research in the social sciences, Clarke suggests that "today the qualitative research enterprise is moving beyond field notes and interview transcripts to include discourses of all kinds." (Clarke 2005, p. 145) She argues that "historical, visual, narrative, and other discourse materials and nonhuman material cultural objects of all kinds must be included as elements of our research and subjected to analysis because they are increasingly understood/interpreted as both constitutive of and consequential for the phenomena we study." (ibid.) We could claim that, for the same reasons, architectural and urban research should be including a broader range of constitutive and consequential elements in their frames of enquiry. Architectural and urban research may benefit from more systematic exploration of the relationship between human and nonhuman actors, between collective action and the material world, between discursive controversy and space-generating processes, especially if they intend to engage with such complex phenomena as conflict and change. Social worlds/arenas theory, as adapted in situational analysis, offers a series of interpretative and methodological assumptions that are useful for the study of conditions characterised by differences of perspective, shifting social configurations, negotiations, controversy, commitment, collective action, conflict and change. Adele Clarke explicitly characterises social worlds/arenas theory as a conflict theory (ibid., p.48).

Social worlds/arenas theory was first developed by Anselm Strauss in the late 1970s in a series of writings, including "A Social Worlds Perspective" (Strauss 1978b). The theory builds on Chicago School interactionism and the work of Robert Park; it draws from Mead's concepts of commitment and perspective, as well as from concepts developed by Georg Simmel (Clarke 2005, p.38). However, Strauss decentres the concepts of territoriality and integration which dominated the research of the early Chicago School. 
Figure 4: Representation of social worlds/arenas, adopted from Adele Clarke (2005, p.111); drawing by author

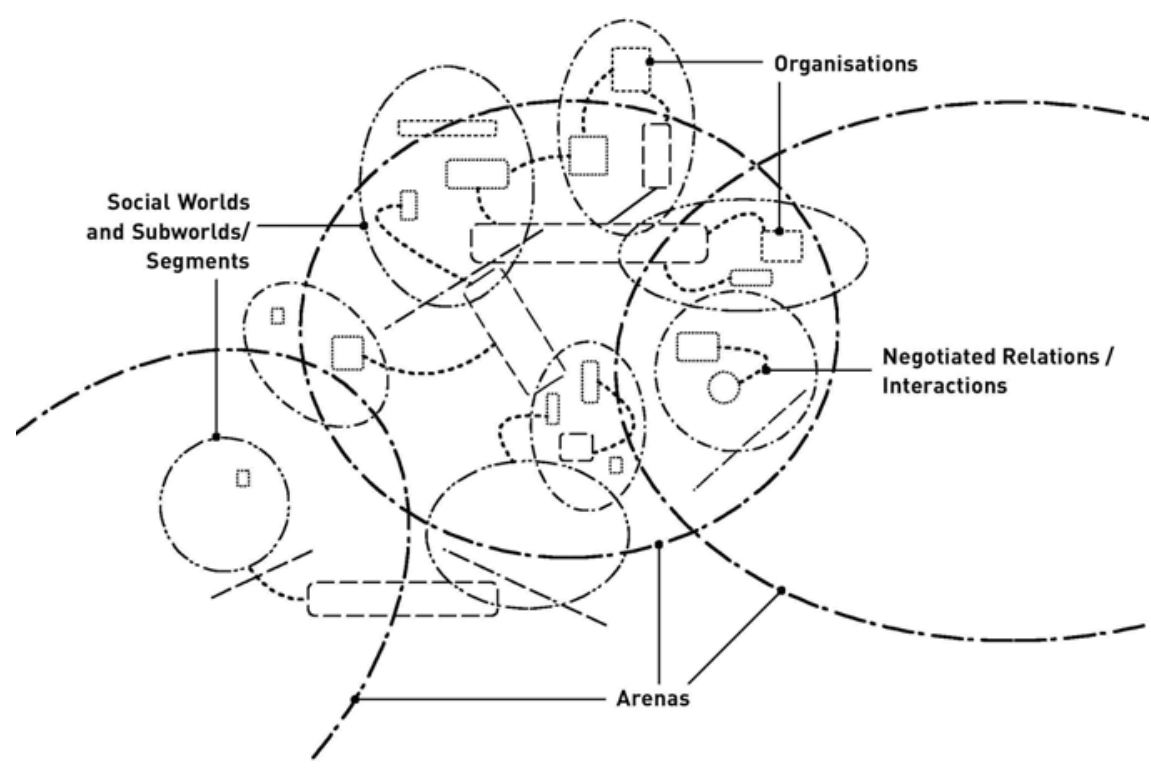

Boundaries of social worlds are now defined by the limits of shared practices, action and communication rather than by territorial features, or formal membership (Strauss 1979) $)^{33}$.

According to Strauss, there is at least one "primary activity" (Strauss 1978b, p.236) at the core of each social world, supported by "related clusters of activity" (ibid.). The clusters involve subprocesses, such as competing for appropriate sites to conduct the primary activity, as well as the funding and protecting of the site (ibid.). Other possible subprocesses may include organisational diversification, learning, expanding and invading (ibid.). Strauss asserts that "the discovery and study of such subprocesses and of their relationships, including conflictful and 'power' relationships, are essential parts of research into social worlds." (ibid., p.237) Anselm Strauss's theoretical propositions resulted in a series of case studies on various social phenomena. Lacking a general methodological framework at that time, Strauss recommended that case studies and substantive research, that is, research on specific phenomena, be accompanied by the gradual building of a general social worlds/arenas theory (ibid., p.243).

In the unpublished paper "Social Worlds and Spatial Processes: An Analytic Perspective", written in 1979, Strauss explicitly connects the social worlds perspective to spatiality, suggesting that spatial processes "[...] contribute to the creation, maintenance, and evolution of social worlds" (Strauss 1979). He confirms that social worlds should "[...] be thought of first and foremost in terms of their central activities [...] but to carry out those activities, space is also relevant." (ibid.) Hence, spatial aspects are

33 See Castells (2002, p.10) about the significance of territoriality and integration in the early Chicago School. 
explicitly part of the theory and analysed in relation to the process of the primary activity. Strauss observes the differences in the spatial frame to which social worlds may relate, suggesting that spatial aspects could play a decisive role during the phase when a new social world is established (ibid.); further links between process and space may be based on the invading, abandoning, maintaining, designing and restructuring of sites around which social worlds assemble (ibid). He emphasises that social processes and spatial processes are mutually related to each other "as conditions and consequences" (ibid.) - thus preparing the ground, together with other contemporaries of his time, for what would later be defined as the spatial turn in the social sciences and other disciplines. The new paradigm, which understands space as being relational and socially produced, and which distinguishes from space the geographically fixed position in the Euclidian model, opens up new ways of theorising space and social process (Löw 2016 [2001]). Currently, however, there is no elaborated model of how the relations of space and social worlds could be conceived, despite the ongoing shift in theoretical perspective, and despite the initial propositions brought forward by Anselm Strauss. Without claiming to deliver such a model, I seek to establish a series of connections between social worlds/arenas theory and spatial issues, with the aim of developing a suitable analytical approach to the specific kind of change observable in the Parkstadt Bogenhausen housing estate, and to add a new empirically grounded concept to urban and architectural theory.

Adele Clarke, a former student and co-researcher of Anselm Strauss's, reframed and adapted the social worlds/arenas theory for application in situational analysis (SA) (Clarke 2005; 2012; Clarke and Keller 2014; Clarke, Friese and Washburn 2018). Clarke introduced this new approach, which evolved in the tradition of Anselm Strauss's and Barney Glaser's grounded theory methodology (GTM or GT), to qualitative research in her book "Situational Analysis. Grounded Theory after the Postmodern Turn" (Clarke 2005; Morse et al. 2009, pp.194ff). The $2^{\text {nd }}$ edition of 'Situational Analysis', co-authored by Adele Clarke, Carrie Friese and Rachel Washburn, updates and establishes SA as qualitative methodology in its own right (Clarke, Friese and Washburn 2018). Entitled "Situational Analysis: Grounded Theory After the Interpretative Turn", it further clarifies the relationship of SA and GTM, stressing their shared roots in the pragmatist, interactionist and constructivist traditions, while also clarifying SA's distinctive analytical tools and capacities. Clarke et al. suggest that

"As an analytic approach distinct from CT, SA can be used on its own in studies centered on analysing and interpreting situations. Alternatively, SA can be used along with constructivist GT in the same project to also analyse and portray action-basic social processes-in that situation" (emphasis in original, Clarke, Friese and Washburn 2018, p.xxvi).

In the following, I will for the most part refer to SA's adaptation of the social worlds/ arenas model, as well as to the 'theory/methods package' of SA. Clarke's set of theoretical adjustments proposed for "pushing grounded theory around the postmodern turn" (Clarke 2005, p.19) offers a series of possible connections for the kind of architectural and urban research I have outlined earlier (own emphasis where not stated otherwise): 
1. "Acknowledging the embodiment and situatedness of all knowledge producers" and the resulting multiple framings of knowledge (emphasis added, ibid.).

2. Emphasising contingency and difference. Things could always have been otherwise. This results in an essentially open view of research problems (emphasis added, ibid., p.9).

3. "Grounded theorizing through the development of sensitizing concepts" rather than seeking to develop definitive, or formal theory (emphasis in original, in italics, ibid., pp.28).

4. Social worlds are produced and populated by human actors, institutional worlds, discourses, and non-human actors - a definition which includes architecture and urban actors (emphasis added, ibid., pp.45f).

5. Situational analysis explicitly turns to mapping as instrument of exploration, analysis and concept building, with the aim of producing "thick analysis" (emphasis added, ibid., p.xxxiii, p.30).

Clarke emphasises that arenas are sites in which multiple social worlds - or parts thereof - assemble for collective action and discourse production, suggesting that in social worlds/arena theory "we assume multiple collective actors (social worlds) in all kinds of negotiations and conflicts in a broad substantive arena focused on matters about which all the involved social worlds and actors care enough to be committed to act and to produce discourses about arena concerns." (Clarke 2005, p.37) Depending on the situation, "arenas usually endure for some time, and long-standing ones will typically be characterized by multiple, complex, and layered discourses that interpolate and combine old(er) and new(er) elements in ongoing, contingent, and inflected practices." (ibid., pp.37f) Hence, we could say that there is a temporal and historical dimension to arenas - which qualifies them as targets for research about process and change. Complex social worlds are not homogenous and characteristically develop subdivisions and segments. This occurs as a response to changing commitment, or as part of the realigning to shifting discourses and new organisation (ibid., p.48). Social worlds may intersect to form a new world, or subdivide into separate new worlds (ibid.). Pertaining to the individual, Clarke suggests that "people typically participate in a number of social worlds/going concerns simultaneously, and such participation usually remains highly fluid." (ibid., p.46) Hence, the analytical focus may be set on single or multiple arenas, on individual or multiple social worlds, but never in isolation, because all arenas/social worlds in which a single world participates are "mutually influential/constitutive of that world." (ibid., p.48) Conflicts are assumed to be present between different social worlds and within single social worlds, arising from differences in perspective, commitment and inscribed attributes, and are routinely addressed by actions such as negotiating, persuasion, educating, and discursive repositioning (ibid., p.49). They all imply some kind of change.

Within the theory we find stabilising and destabilising concepts combined. On the one hand, social worlds/arenas are constitutive for establishing (multiple) identities (ibid., pp.45f). Relational patterns produced by the assembling of social worlds, and most importantly the arena itself, act as points of reference and provide orientation in the situation. Discursive formations in the arena have the capacity to contain contradictory discourses through which "[...] some stability is achieved-however temporary, elusive, or conditional." (ibid., p.54) On the other hand, identities and 
concerns are destabilised, reconstructed and deconstructed, as well as the relations within the arena and between social worlds. Clarke's graphic representations of social worlds/arenas respond to key ontological concepts in the theory - assumptions about ambivalence, contradictions within the situation and of non-closure/non-holism - by means of permeability (dotted lines) and by leaving the boundaries of social worlds/ discourses open. The situation is represented as part of a social condition that cannot be exhausted, or fully grasped.

\subsection{Approaching Research Questions from within the Situation}

At the time of writing, there are very few, if any cases which use situational analysis (SA) for research problems raised from within the architectural and urban disciplines (Clarke, Friese and Washburn 2018, pp.374ff). Based on the set of theoretical premises assembled in the previous section, how far can situational analysis be integrated to research in architecture and urbanism? How accessible are the tools of situational analysis for architectural and urban analysis? Emphasising the versatility of the methodology and of its related methods, Adele Clarke encourages researchers to apply situational analysis to different fields of enquiry and to different research problems. According to Clarke, situational analysis is compatible with a wide range of empirical material and "[...] can support researchers from heterogeneous backgrounds pursuing a wide array of projects." (Clarke 2005, p.xxii) The arenas to which situational analysis has been applied so far are extensive and diverse; the majority of cases are centred on public health issues, human service practices, gender, or inequality (Clarke 2005; Clarke and Charmaz 2014; Clarke, Friese and Washburn 2018, pp.374ff). Accordingly, an intended secondary outcome of this research project is to show that situational analysis is a useful tool for engaging with urban and architectural research questions. The concept of 'situation' is central to situational analysis as well as architecture and urbanism, and could in this sense assist in connecting the three.

Situational analysis builds on a specific understanding of 'situation'. Rather than conceptualising the broader conditions of a situation as contextual background, as merely framing it, Clarke argues that "the conditions of the situation are in the situation" (emphasis in original, Clarke 2005, p.71). Pertaining to the relation between the constitutive elements, Clarke asserts that

"The fundamental assumption is that everything in the situation both constitutes and affects most everything else in the situation in some way(s). Everything actually in the situation or understood to be so conditions the possibilities of action [...]. People and things, humans and nonhumans, fields of practice, discourses, disciplinary and other regimes/formations, symbols, controversies, organizations and institutions, each and all can be present and mutually consequential." (emphasis in original, Clarke 2005, p.72)

Based on this premise, there are no constitutive elements that do not somehow appear in the situation under study itself - even when located at a great distance from the actual problem. Situational analysis thus offers a theoretical framework for approaching the local/global problematic in that it does not reduce the global to a de-territorialised space of flows that is external to the situation under analysis. Rather, it conceptualises the situation as a site in which local and global forces interact, confront, 
and co-constitute each other. The fundamental question raised by this perspective is "How do these conditions appear - make themselves felt as consequential - inside the empirical situation under examination?" (emphasis in original, ibid., p.72). Despite the resulting challenges for representation and integration, in particular if the focus of research is on narrowly defined problems or micro-scale actions, SA defines the situation as a privileged site of research from which all consequential and connected conditions may be observed and analysed. As a response to these representational challenges, and in order to provide a systematic grounding for the empirical analysis, Clarke suggests using specific mapping tools in the analysis of the situation.

Situational analysis' theoretical framing adopts the view from science and technology studies as well as from cultural studies that the human and the nonhuman are co-constitutive - that social worlds are as much constituted by materiality as materiality is constituted by the social (Clarke 2005, p.63 and p.153) Together they "[...] constitute the world and each other." (ibid.) Correspondingly, Clarke suggests that "any method that ignores the materialities of human existence is inadequate, especially today as humans and various technosciences are together transforming the planet from the inside out." (ibid., p.xxxv) This view is mirrored by criticisms in architecture and urbanism which emphasise the mutual relationship of the material and social worlds. Alban Janson and Sophie Wolfrum explicitly refer to the condition in which the material aspects of architecture interact with human perception, with the body, with social practices, as "situation" (Wolfrum and Janson 2016, pp.23f). As architecture cannot be conceived without this interaction, situations are constitutive of architecture (ibid.). They propose that architecture could be seen as a social discipline that produces complex situations in which humans participate individually and collectively, whereby architectural space, its qualities, physical properties and atmospheres reflect back on and co-produce the situation (ibid., pp.24f). Situations define the condition through which and in which we experience architecture (Janson and Tigges 2014, pp.284f). Highlighting the processual character of architectural situations, Alban Janson and Florian Tigges observe that, "as a rule, situations are not experienced in purely static terms, but instead through movement and active participation." (ibid.) In architectural situations, humans and objects are related with each other through perception, interaction, use and other performative acts. The relationship is influenced by the motivation and state of mind of the actors involved (ibid.). Janson and Tigges suggest situations are among the "fundamental concepts of architecture" (ibid.). In this sense, the architectural conceptualisation of 'situation' can be connected to the theory of relational space (Löw 2016 [2001]), as well as to situational analysis in multiple ways.

The theory of social worlds/arenas engages with social phenomena without resorting to either reductionist or holistic views of society. For Clarke, "[...] there is no such thing as 'society', but rather mosaics of social worlds, arenas, and discourses-some at quite large scales with vast audiences-but never everyone" (Clarke 2005, p.154). Social worlds are temporary and fluid - they never stand still (Strauss 1978b, p.237). The urban, then, could be conceived as a vast and unstable arena, embracing many other arenas and social worlds - but not all of them, for "even the largest arenas do not extend everywhere." (ibid.) Here, the concept of the urban as arena seems to relate directly to the urban as open construct. By means of the social worlds/arenas map it is possible to represent, on the one hand, the urban as a vast but accessible field of enquiry, and on the other hand, the limits of that which can be represented - indicated 
by the permeable and provisional boundary of the arena. The graphic representation points towards residues and spaces of otherness that cannot be fully identified and analysed.

Situational analysis integrates within its methodology a series of key ontological and epistemological assumptions of symbolic interactionism and pragmatism, the systematic rigour of empirically grounded qualitative research, in particular of grounded theory methodology and social worlds/arenas theory, as well as the criticisms of knowledge production raised by postmodernism and constructivism (Clarke 2005, xxxiii). In terms of research fields and materials, "situational analysis allows researchers to draw together studies of discourse and agency, action and structure, image, text and context, history and the present moment- to analyze complex situations of inquiry broadly conceived." (Clarke 2005, p.xxii) In terms of methods, "situational analysis offers flexible and elastic empirical tools [...] with which to deconstruct 'society' into mosaics of arenas organised around and through different kinds of discourses and action." (emphasis in original, Clarke 2005, p.178) Situational analysis assumes that collective action is negotiated between and through social worlds that partially and temporally participate in arenas. All elements that are constitutive of a situation are present in the situation. The situation is thus both a conceptual tool to envisage social reality, as well as a site of analysis. Based on these premises, situational analysis has the capacity to inform both the epistemology of architectural and urban research, as well as the toolbox of research methods. In this sense it may offer a new perspective on how urban environments change by connecting the social with the material and by connecting collective processes with a specific spatial situation.

\subsection{Discourse Theory and Situational Analysis}

Connecting to discourse theory is among the core proposals by Adele Clarke for the "pushing of grounded theory around the postmodern turn" (Clarke 2005, p.19). In this section, I discuss the situational analysis approach to discourse theory, and how it could be used in architectural and urban enquiry. I refer to the argument developed by Adele Clarke, as well as to Reiner Keller's work on discourse analysis and the sociology of knowledge. Reiner Keller co-edited the German translation of Adele Clarke's (2005) "Situational Analysis", which was published in 2012 under the title "Situationsanalyse. Grounded Theory nach dem Postmodern Turn" (Clarke 2012) ${ }^{34}$.

The rise in significance of discourse theory and discourse analysis since the beginning of the 1970 s is paralleled by the critical questioning of knowledge production and language as neutral medium of knowledge transmission (Clarke 2005, p.150). Clarke adduces the many roots of discourse theory, highlighting the contributions of social constructivism, in particular Berger and Luckmann's proposition that meanings and systems of reality are socially produced, as well as Foucault's theoretical contributions, in particular his concepts about the mutual relationship between power as knowledge and knowledge as power, and his ideas about the disciplinary formations through

34 Pertaining to the relation between discourse theory and SA, the $2^{\text {nd }}$ edition of "Situational Analysis" (Clarke, Friese and Washburn 2018) draws on the basic assumptions as outlined in the $1^{\text {st }}$ edition (Clarke 2005). In the following, I refer to the $1^{\text {st }}$ edition. 
which they operate (ibid., p.149) ${ }^{35}$. As with other concepts developed by Foucault, the notion of discourse is located in different analytical configurations. Initially associated with linguistic systems of signs which order the complexity of the world, the notion shifted to the practices that constitute the objects to which they refer (Keller 2011a, p.132), as well as to collectively exercised mechanisms of dominance related to these practices and objects (Clarke 2005, p.54, p.149). The specific Foucaultian understanding of discourses is centred on their capacity to open-up, or close-off, "conditions of possibility" (Clarke 2005, p.53). With reference to Foucault, Clarke speaks of the relatedness of discourses to "regimes of practices" (ibid., p.53) which "[...] must be sustained through performance of those practices over time." (ibid.) Discursive practices may be conceived as the means by which cultural knowledge, social action and institutions are achieved as well as enacted (ibid., p.152) ${ }^{36}$. According to Reiner Keller, institutions can be understood as the temporal and contested crystallisations of symbolically defined structures that bring order to the world (Keller 2011a, p.94). In this role they enable and restrict social actions. It is in this sense that Clarke highlights the consequential nature of discourses (Clarke 2005, p.153).

Relating discourse theory to social worlds/arenas theory, Clarke asserts that "discourses are typically produced by and representative of particular social worlds and arenas and the conflicts and contradictions within them." (Clarke 2005, p.160). Hence, arenas are sites in which different discourses - represented by different social worlds - compete with each other (ibid.). If a single social world is conceived in such a way that it contains multiple segments as outlined above, it could be understood as producing multiple and potentially conflicting positions on a single topic (ibid., p.161).

Addressing the relationship between different social worlds, Clarke asserts that "part of the work social worlds do is monitoring the discourses and actions of the other social worlds in the arenas in which they participate." (ibid., p.57) The Foucaultian perspective assumes that groups, individuals and institutions are engaged in collective operations of power, in disciplining and in surveillance. Pertaining to the work of professions and academic disciplines, Adele Clarke observes that

"Disciplines are implicated in projects of social control, including by the state, the professions (including education, medicine, etc.), and other agencies that ultimately serve the interests of dominant groups. [...] all disciplines and professions are constituted by and through particular discourses that privilege and marginalize varied sectors. Discourse analysis provides tools to deconstruct and analyze such regimes of truth-discourses through which we ourselves are varyingly disciplined and constituted as people and as scholars." (Clarke 2005, p.151)

35 Sociologist ]örg Strübing asserts the long tradition of 'discourse' as a concept in sociology (Strübing 2013, p.172). It appears, for example, in the 'universe of discourse' which was coined by George Herbert Mead in 1934 to describe the system of shared meaning, or context, when humans establish a thought (ibid.). According to Strübing questions of power and authority were secondary in these early concepts, whereas they became central to Michel Foucault, who applied the notion of discourse to an intermediate level in processes that generate sociality (ibid.). A discussion of Foucault's work and how it could be applied in the social sciences for discourse analysis and in the sociology of knowledge is available in Keller (2007; 2011a and 2011b).

36 Accordingly, the practical fields in which discourses are deployed are major targets of Foucaultian conceptualisations and analysis (Clarke 2005, p.154). 
Figures 5 and 6: Spatial intersection of two discourses respectively two 'regimes of practices': Disciplining and surveillance on the one hand, appropriation and everyday use on the other hand. Alexandra Road Estate, designed by Neave Brown of Camden Council's Architects Department in 1968, constructed between 1972 and 1978. London 2011
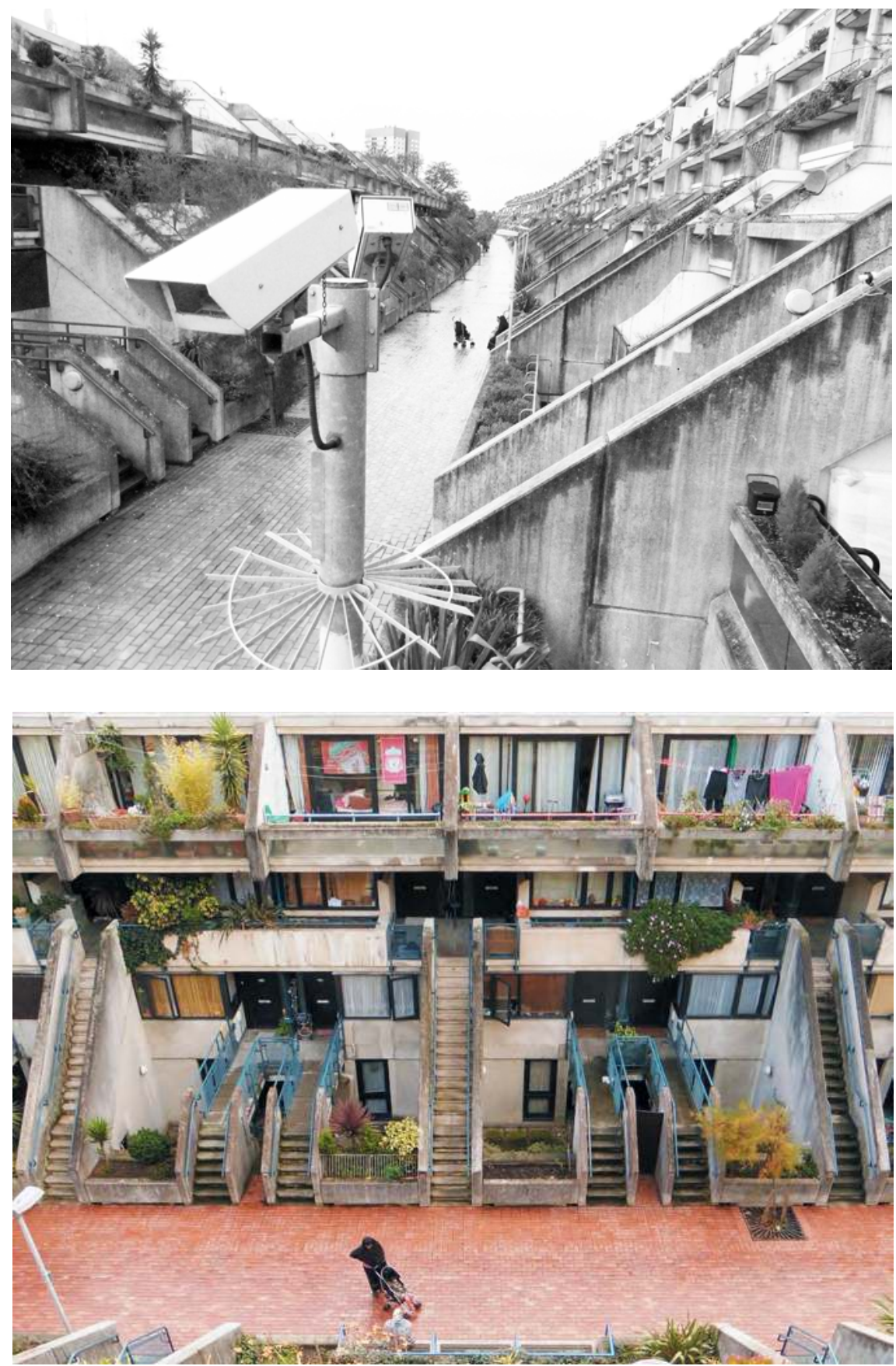
Hence, discourse analysis provides architects and urbanists with the conceptual tools to see themselves as participants in constellations of power, as co-producing discourses which are consequential for the built environment. Supported by institutionalised professionalism and academic procedures, architects and urbanists exert a degree of control in terms of who is admitted to discourse production, what may be said about the urban and about architecture, and what kind of settings are required for urban and architectural knowledge to count as such and become effective in institutionalised urban practice. Identifying actors with sufficient power to end controversy through closure is a key concern in discourse analysis. Situational analysis goes further in that it actively brings to the fore actors that lack such power. Clarke stresses that "situational analysis also (inspired by but also contra Foucault) intentionally seeks to represent all the social worlds and discourses in an arena, amplifying the silent and silenced, specifying implicated actors and actants, and seeking out their (usually quite marginalized) discourses." (emphasis in original, Clarke 2005, p.178) The knowledge generated by this perspective emphasises the contingent nature of decisions - it could have been otherwise - and aims at a better understanding of the situations in which decisions are made. Hence, if the analysis is combined with questions such as 'what kind of changes could we make in the situation so that things can be different, what kind of other positions are possible?', research begins to challenge existing regimes of change.

The analysis of discourses needs to address a series of difficulties. In terms of analytical location, discourses operate at different levels or scales (Clarke 2005, p.153). They evolve and do not stay still - as do our interpretations of and our associations with them (ibid.) In terms of conceptualisation, working with discourse theory that draws from Foucault means to engage with structuralist, poststructuralist and at times essentialist views that intersect in his work ${ }^{37}$. His forms of analysis are difficult to grasp as a method (Keller 2007, p.7 $)^{38}$. Pertaining to the study of urban phenomena, some discourses are

37 Jörg Strübing suggests that Foucault's concept of discourses is based on the premise that they have in themselves the generative power to produce and reproduce social reality and structures of knowledge (Strübing 2013, p.172). Here Foucault differs significantly from concepts that locate such generative powers exclusively in human actions, which resulted in a methodological gap with the constructivist-interactionist paradigm (ibid.). It is only recently that this gap is being gradually closed, for example through Adele Clark's introduction of discourse analysis to grounded theory methodology (Clarke 2005), or Reiner Keller's "Wissenssoziologische Diskursanalyse" (WAD) and "Sociology of Knowledge Approach to Discourse" (SKAD) (Keller 2007; 2011a and 2011b). Reiner Keller observes that while "The Archaeology of Knowledge" leaves room for an understanding of discourses as autonomous objects that could do things on their own, Foucault revised this interpretation with "The Order of Things" (Foucault 1981 [1970]) and the following series of genealogical analysis, in which he foregrounds social practices, mechanisms of power/knowledge, games of truth and conflict (Keller 2007, para.3).

38 Keller asserts that Foucault omitted a detailed discussion of method and that we do not exactly know how Foucault actually engaged with texts, what methods he deployed to read, analyse and structure his material. (Keller 2007, p. 7). According to Keller, Foucault did not become more precise than referring to the 'classic' meticulous modes of study of the historian, as well as emphasising the toolbox character of his work (ibid.). Hence we find seemingly contradictory statements in texts that are difficult to use in combination. In "The Archaeology of Knowledge" Foucault speaks, on the one hand, about discovering within the diversity of discourses "rules of formation" (Foucault 1972 [1969], p.38, p.166) - as basic principles "[...] that will be uniformly valid, in the same way, and at every point in time" 
more consequential than others, in that practices connected to them have lesser or greater transformative capacity in the built environment. Dominant discourses might obscure less powerful or contradictory discourses (Clarke 2005, p.54, pp.152f). This in turn influences the 'visibility' of discursive formations and their accessibility for architectural and urban analysis. Finally, the arena in which urban change is defined and negotiated is, conceptually, very large. However, "one important task of analysing discourses is noting their limits." (ibid., p.154) If we speak of architectural and urban theories, narratives and concepts, as I do in this research project, we have to keep in mind their limited range as well as the many other discourses that co-produce and influence the urban condition.

Addressing the different forms or types of discourses, Clarke asserts that situational analysis "[...] can draw upon multiple forms of discourse-narrative, visual, historical, and in varied combinations/hybridities" (Clarke 2005, p.156). As part of her general discussion about the kind of research material suitable for situational analysis, Clarke sketches out a possible direction for working with narratives, which I seek to further explore in this research project.

\footnotetext{
"It is usually (but not always) the analysis of particular sets of texts or narratives chosen because they are produced by a particular group or social world in which the researcher is interested, or because they are about a particular group or social world or thing(s) in which the researcher is interested. In essence, a discourse claims to properly and adequately describe how $X$ is (or should be) in the world, and a strong discourse analysis would deconstruct and analyze both the descriptions and the claims." (emphasis in original, ibid., p.150)
}

In this project, two fields in which discourses are co-produced and become effective are analysed. On the one hand, there are architectural and urban narratives, the practices, issues and materialisations to which they refer, including their effects on and relations to the broad arena of urban change. On the other hand, we have the collective process in the Parkstadt Bogenhausen housing estate. Hence, the analysis is on the one hand an enquiry into architects and urbanists asking 'How should we think about/ approach/design conflict and change?' And on the other hand an enquiry into residents, administrators and other actors negotiating and 'doing change' in and of their everyday urban environment, through engaging in the Parkstadt arena.

\subsection{Mapping and Drawing as Tools of Empirical Enquiry and Concept-Building}

I have pointed to the limited range of perception-based observational analysis when engaging with space and the city. Explorative drawing, diagramming and mapping define a set of techniques used in architecture and other disciplines to push the limits of what we can 'see'. Well known examples include Kevin Lynch's study of mental maps for Boston and Jersey City, the diagrams of Cedric Price and cybernetician Gordon

(ibid., p.166); on the other hand he emphasises that theorising about discourses "[...] is not trying to find in them a hidden law, a concealed origin that it only remains to free" (ibid., p.205). Keller concludes that it is difficult to speak of a "Foucaultian discourse analysis" (Keller 2007, p. 7), in the sense of it being reproducible. 
Pask for the Fun Palace project, or the poetic explorations of space in the drawings of Lebbeus Woods, Peter Salter, Smout Allen or Neil Spiller. In view of the complexity of urban phenomena, Raoul Bunschoten, Hélène Binet and Takuro Hoshino of the research collective CHORA suggest that "cities have become such dense, proliferating places that, in order to interact with them, to intervene in their development, one has to oscillate between working close to the ground (where the horizon is near, everything flows, textures are infinitesimal) and the more rarefied domain of diagrammatics in which relationships and the mechanics of change are described." (Bunschoten, Binet and Hoshino 2010 [2001], p.261) On this understanding, field work and analytical work intersect in the process-oriented diagram, an approach presented and discussed in CHORA's "Urban Flotsam" publication (ibid.). Likewise, in the introduction to the $2013 \mathrm{AD}$ issue on architecture and drawing, titled "Architectural Drawing: Grasping for the Fifth Dimension", Neil Spiller observes that "new protocols of drawing" are being developed by architects who seek to explore fields beyond the three dimensions of space and the dimension of time (Spiller 2013, p.14).

However, despite their analytical and inspirational power, explorative mapping and diagramming of this kind remain the exception. Considering the overall output of the profession, architectural drawings rarely address fields that are not directly related to building practice or building-related design work. In architecture and urban design, drawings are routinely used for the surveying of physical site conditions, for the fixation of building form, for the control of the construction process, or for the communication between design team, planning authorities, and other participants in building. Established drawing and mapping standards are highly conventionalised and therefore of limited use and range. Facing a similar dilemma, Albena Yaneva adapted Bruno Latour's "Mapping Controversies" approach, initially for the analysis of "architecture in the making" (Yaneva 2012, p.72), which since then she has extended to include the scale of urban issues (Yaneva 2016) ${ }^{39}$. Conceived as "research methodology and teaching philosophy" (Yaneva 2012, back cover), mapping controversies combines elements of actor-network theory with ethnography. Yaneva applies the sociological notion of "moving target" (ibid., p.45) ${ }^{40}$ to architecture, arguing that we should not conceive of architecture as a stable frame in which to situate social action. She defines architectural controversy as "[...] situation of disagreement among different actors over a design issue" (ibid., p.72), which includes aspects of technology, construction process and material. Yaneva suggests that through mapping controversies and the reconstruction of shifting actor-network constellations, the social and architectural may be approached "in their fluid states." (ibid., p.45)

Based on what I have discussed so far in terms of methodology, I propose that situational analysis could offer another useful and new perspective, based on its own assumptions and tools, through which the representational and analytical range of mapping in architecture and urbanism could be extended. The targets of mapping

39 Here as analytical tool in the "Hands-on Famagusta" Project, a long-term community-based project initiated and managed by Socrates Stratis in Cyprus (Stratis 2016).

40 In social science the "moving target" is a concept that characterises the dynamic nature of the sociological field, accelerated through digital networking and mobility, and which is increasingly challenging for researchers and ethnographers (Strübing 2013, p.66). 
analysis in this perspective are situations and social worlds/arenas in and through which change is collectively produced and negotiated.

Adele Clarke has the social sciences in mind when she highlights the benefits of producing and working with maps, suggesting that they interrupt working routines, enhance reflexivity in research, and "[...] provoke us to see things afresh." (Clarke 2005, p.30) Clarke understands mapping as a "cognitive process" (ibid.) which opens up spaces of knowledge. She asserts the capacity of maps to engage with and represent temporal, spatial and relational information:

"Maps work "[...] as discursive devices for making assemblages and connections-relational analyses. Maps are excellent 'devices to materialize questions' [...]—-devices for handling multiplicity, heterogeneity, and messiness in ways that can travel. Maps work well as spatial and temporal narratives. Maps allow unmapping and remapping. [...] one can move around on/in maps much more quickly and easily than in [...] text, excellent for analytic work." (ibid.)

Clarke's justifications are familiar terrain to architects and urbanists. The challenge to them, in the research context of situational analysis, is not the making of maps as such, but rather the kind of questions raised and the social science perspective involved. In mapping, the authors are always more than just observers - they are co-producers of the mapped situation, being immersed in the field, as well as being selective and guided by intentions. What is left out in mapping is as important as that which is shown. Thus mapping is not a neutral activity - maps are understood to have a political dimension (Clarke 2005, p.30; Garcia 2010, p.34). ${ }^{41}$

\section{Adapting the Iterative-Cyclical Research Model of Grounded Theory Methodology}

\subsection{Theoretical Sampling and GTM's Iterative-Cyclical Research Model}

Research that builds on conventional demarcation does so because it seeks to position a research object within a clearly defined, and therefore controlled, research domain. This domain is typically conceived as a closed field, which lends itself to systematic organisation and the application of sampling strategies according to (pre-)defined categories and structuring hierarchies. If we assume the urban to be an open construct, and if we refer to Henri Lefebvre's idea of the urban phenomenon as "movement" (Lefebvre 2003 [1970], p.174), as a dynamic condition that cannot achieve closure and thus

41 This means that the mapping of an existing situation also contains an element of 'designing' that situation, which is more than merely imagining a situation: if we draw an analogy to the Thomas theorem in the social sciences (Dellwing and Prus 2012, p.19, p.54), a design may be conceived as being 'real in its consequences', even if it remains unrealised. A design project may trigger discourse, and change the way we think about and act on real world issues, such as the unrealised Fun Palace project as the "socially interactive machine" (Mathews 2005, p.73). This is why it makes sense to also map designs, unrealised projects and narratives if they are present in the analysed situation - as theoretical or utopian ideas that exert performative power through producing a condition "[...] in which articulation itself generates a new reality". (Wolfrum and Brandis 2015, p.6) 
immobility (ibid.), we are facing a dilemma of demarcation, because representations and modes of analysis that resort to closure are likely to fall short of grasping the core quality of the urban condition. Hence, fixation, categorisation, and demarcation seem to be the wrong concepts to begin with. The question of sampling is directly related to this problem. Working with categories and representational sampling strategies is a well established method in the quantitative tradition of the social sciences (Rosenthal 2014, p.83). The sample is understood to adequately represent a given population or body of material. This provides the justification for researchers to apply their sample-based findings to the entire population.

Taking the qualitative research perspective, however, researchers assume that they do not know enough of the problem to justify working with predefined categories, conclusive hypotheses-testing, or sampling frames based on the exhaustive listing of all significant characteristics in a target population (Rosenthal 2014, pp.47ff; Strübing 2013, p.22). Consequently, we cannot enter the discursive analysis of urban and architectural narratives on the basis of a predefined 'population', or categorisation, for this would equate to closing the field of enquiry. How, then, should we conceptualise the research process? On which basis should we sample from the many architectural and urban narratives on conflict and change? What kind of data could support the ensuing case study? Adele Clarke suggests that "for a discourse study or discourse site within a multisite study, the data should offer both depth and range of variation." (ibid., p.186) If this proposition opens up the field of possibilities, how can we arrive at a manageable number of samples and along which paths should we organise the process?

The research process proposed in response to these issues is conceptually based on the iterative-cyclical model of basic grounded theory methodology (GTM). GTM uses 'theoretical sampling' as specific data collection method. According to Anselm Strauss, theoretical sampling is "[...] a means whereby the analyst decides on analytic grounds what data to collect next and where to find them" (emphasis in original, Strauss 1987, p.38). The dynamic process of data collection in theoretical sampling is controlled by the emerging theory or concept (ibid., p.39). It is an activity of "[...] gathering new data that speak specifically to the theoretical point" (Clarke 2005, p.185). With regard to our problem of selection, theoretical sampling means that narratives are selected and analysed on grounds of their assumed relevance to the analytical process. Strauss highlights that theoretical sampling involves "[...] much calculation and imagination on the part of the analyst (Strauss 1987, p.39). To keep track of the research process in GTM, notes, or "memos" are taken during the analytical movements (Strauss 1987, pp.109-130, pp.184-214; Clarke 2005, p.84).

Jörg Strübing visualises the basic GTM model as sequence of iterative loops that move back and forth between theory development, which is conceived as a process, and the empirical field (Strübing 2013, p.128). In the model, the development of a theory is sustained by the production of temporal hypotheses, which in turn deliver the criteria for theoretical sampling and inform the different aspects of fieldwork through deduction. 
Figure 7: Iterative-cyclical research model of grounded theory methodology (GTM), according to Strübing (2013, p.128); drawing by author

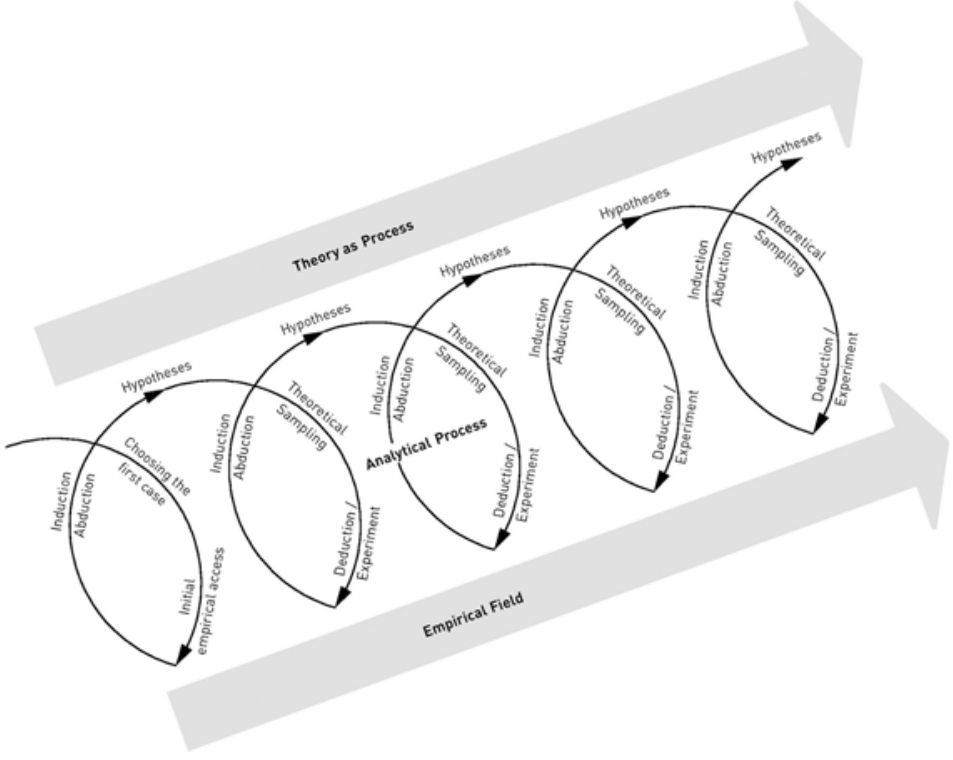

Figure 8: Adaptation of the iterative-cyclical research model. The discursive-interpretative process starts with the observation of asymmetric urban change, which then develops into an analysis of architectural and urban narratives; drawing by author

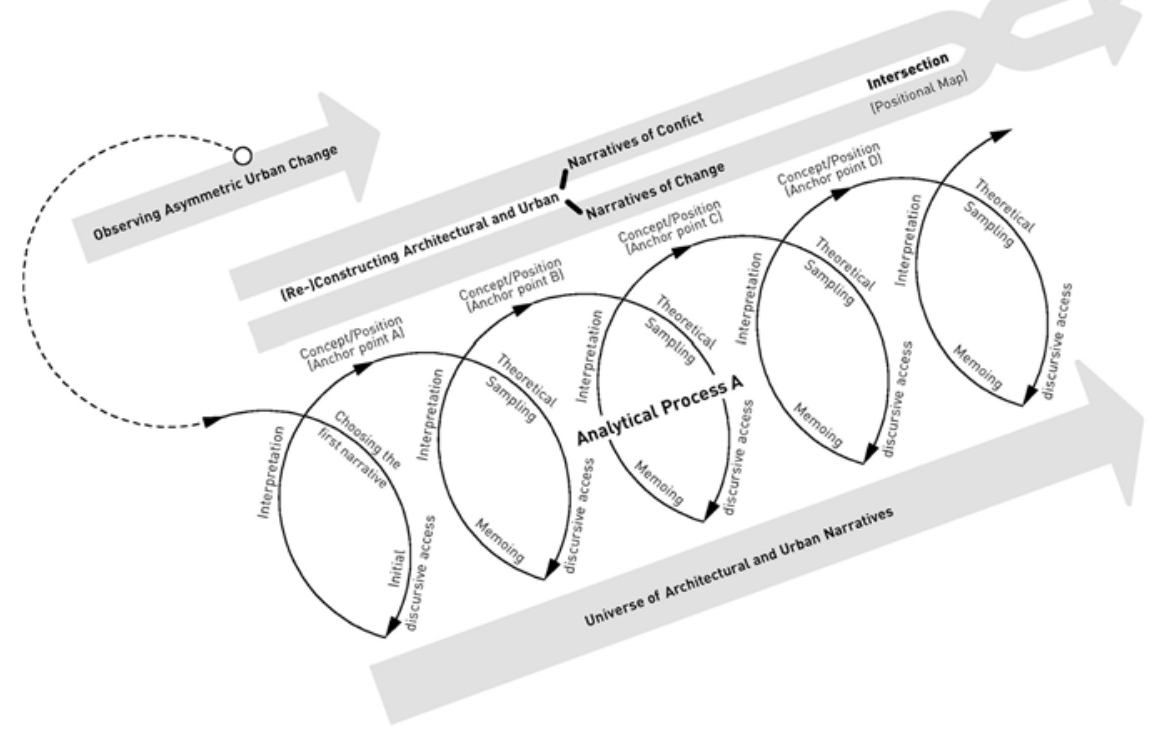


Figure 9: Graphic representation of the anchoring model used in Analytical Process A. Top: strand of enquiry into architectural and urban narratives, consisting of connected anchor points/concepts/positions. The points are generated step-by-step in the discursive-iterative research process. Bottom: relational and malleable character of the model.
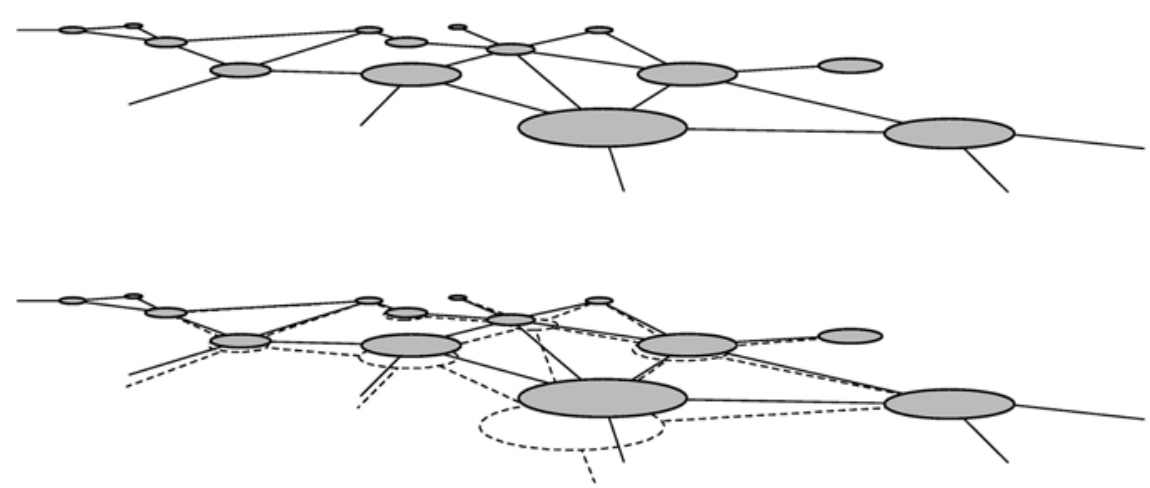

The work with the data obtained in and from the empirical field produces the next temporal hypothesis through induction/abduction (ibid.) ${ }^{42}$. While traditional GTM insists that all concepts need to "earn their way into the analysis, by emerging from the data" (Clarke 2005, p.75) ${ }^{43}$, Adele Clarke suggests in the proposed 'pushing GTM around the postmodern turn' that this could be insufficient if it is not combined with some initial sensitivity for blind spots and discursively constructed mechanisms of elusion (ibid.). She asserts that research projects need to be designed from the outset so that they "[...] explicitly gather data about theoretically and substantively underdeveloped areas that may lie in our situations of inquiry" (ibid., p.76) so as to prevent researchers stepping over them (ibid.). Moreover, Adele Clarke asserts "[...] that an 'analysis' of any kind is no more than one or a few 'readings' of a situation-understandings, interpretations." (Clarke 2005, p.xxvii) According to Clarke, it does not claim to scientifically confirm the "validity" of a hypothesis (ibid.). For this reason, I have modified the iterative-cyclical research model of traditional GTM according to Clarke's criticisms, as well as the specific requirements of the research project. This includes the opening up of the induction/deduction logical circle to accommodate the assumptions about knowledge production as theorised and used in situational analysis (Figures 7-11\}.

42 As both, theoretical sampling and the production of design knowledge take place within open fields of enquiry, it is not coincidental that the GTM model bears similarities to the iterative design process in architecture and other creative disciplines. For a discussion about integrating conditions of openness to design teaching see Knoll et al. (2011, pp.21f, pp.62f). The GTM model also bears similarities to the field of technical invention. Donald Schön suggests in "Technology and Change. The New Heraclitus", that "the pattern of invention is frequently an interplay or oscillation between phenomena and theory." (Schön 1967, p.235)

43 Adele Clarke refers to statements/methodological propositions by Glaser and Strauss, without providing a specific source. The statement is in quotation marks. The corresponding published statement can be found in (Strauss 1987, p.26), for example. 
Figure 10: Conceptual graphic representation of analytical intersection. The two essay-based strands of enquiry are intersected to establish a higher-density construct.

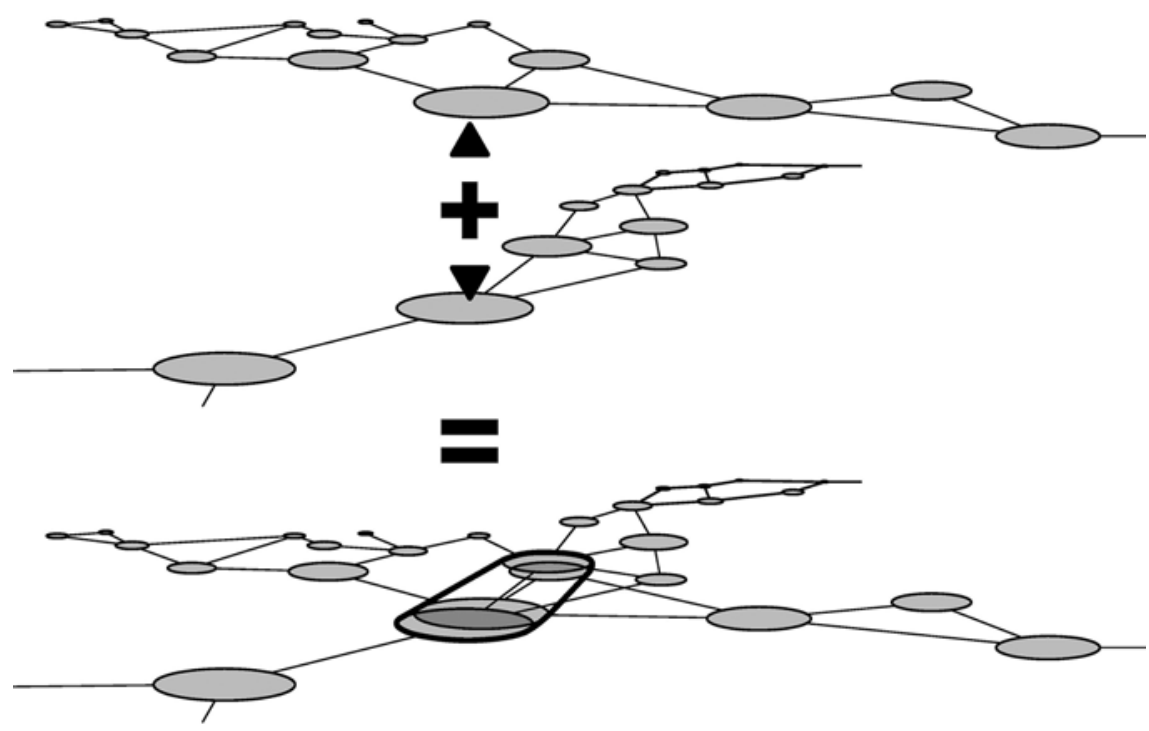

\subsection{Analytical Process A: Discursive-interpretative Analysis of Narratives}

In Analytical Process A, the basic GTM model is adapted to establish a sequence of iterative cycles that move back and forth between the universe of architectural and urban narratives on the one side, comprising the full body of narratives developed, used and maintained by architecture and urbanism, and on the other side, the specific narratives of conflict and change that are extracted from the full body and in this way analytically (re-)constructed. The latter is also the side in the process where the narratives are examined in terms of the concepts and positions they hold.

Architectural and urban narratives are embedded in written texts, visual material, design work, or realised projects. As this mixture of different material does not lend itself easily to line-by-line analysis and coding, which is the standard way of processing data in traditional GTM (Clarke 2005, p.xxxi), I propose applying a discursive-interpretative mode of enquiry to the analytical process. The discursive-interpretative loop takes as its point of departure the initial choice of a narrative, which is connected with the observed phenomenon and/or research interest. In order to not loose orientation, memos are written during the explorative movements and the interpretation process. The analysis of a narrative is meant to produce a position or concept. In some cases more than one concept may be identified in a single narrative. The number of concepts/ positions accumulates step-by-step as the analysis progresses. The side of extracted and (re-)constructed narratives and concepts is organised as two parallel strands, one for conflict and the other one for change. The insights and knowledge available at the end of each discursive-interpretative loop defines the starting point of the following cycle. It provides guidance for the next step of sampling, in terms of which narrative to choose and where to place the focus of enquiry. Generally, the theoretical sampling 
method provides orientation in the analytical movement from concept identification/development to the empirical field, but without targeting a pre-defined overall research goal. The steps of discursive access, memoing, interpreting and concept identification are distinct components conceptually, but they are closely connected to each other in the analysis. This is reflected by the style of short essays chosen for their representation and discussion in Chapters II and III.

In the iterative-cyclical model new research information is generated in a stepby-step process. Hence the process needs to include instruments that hold, organise, make available, and relate the preliminary research outcomes to each other. In GTM, this is for the most part achieved through memoing. In SA, this is complemented by mapping, which is primarily conceived as analytical tool, but which has also a holding capacity (Clarke 2005, p.xxii, p.xxvi, p.26, pp.125-124). The third kind of tool used for the holding, organising, and relating of information is 'anchoring', which I have purposely developed for the analytical movement through the narratives of conflict and change. The anchoring model draws conceptually from both, the GTM and SA tools, and is conceived as add-on that supports the analysis. It is a response to the condition of non-closure and the working with two parallel strands on the theory side of Analytical Process A. The model provides a horizontal, or linear connection between the concepts/positions that accumulate in each strand in the process. Each concept/position is conceived as anchor point that is related to other anchor points (concepts/positions). Together, they form a conceptual strand of malleable and preliminary fixations. The position of a single anchor point is not rigidly fixed in place. It is determined by the interpretative forces that act upon it as well as on its neighbours. In the proposed construct, each anchor point serves as potential origin of trajectories that probe the open field and influence the direction of the next move.

In this construct stabilising gravities are temporal in character, for they are challenged by each new concept that enters the process. Despite their conceptual holding capacity, the strands of connected anchor points have a tendency towards dispersion. They do not, conceptually, generate high levels of precision. My proposal for resolving this issue comprises several steps of focussing, starting with the conceptualisation of an intersection. In Euclidian geometry, the intersection of two lines produces a single and precise point. The strands in the above configuration are unlikely to produce a single point when intersected with each other. Moreover, if we think in terms of a single point in the intersection, we loose the conceptual quality, the malleable character of the relational construct. If we conceptualise the intersection more in terms of a matrix, which encourages movement through multiple combinatory readings, how could we avoid working with predefined categories and moments of premature closure? To resolve this problem, I propose adapting SA's 'positional map' and working with it in more than one way. Conceived by Clarke as mapping tool (Clarke 2005, p. xxii, pp.128f), the SA positional map represents positions that assemble around a contested problem, an issue, a concern. In our case, the key concern is concepts of change as represented in architectural and urban narratives of conflict and change. The positional map, as adapted for this project, is conceived as an intersection, as a high-density construct that brings together all the positions identified in the research process. It acts as memoing device for the overall process, it juxtaposes multiple and contradictory positions, and it has a heuristic capacity which will support the development of the 
Figure 11: Combination of the two main areas of enquiry: Analytical Process A (essay-based analysis of urban and architectural narratives) and Analytical Process B (case study element, working with empirical data). The processes follow their own analytical methods, but are closely related to each other.

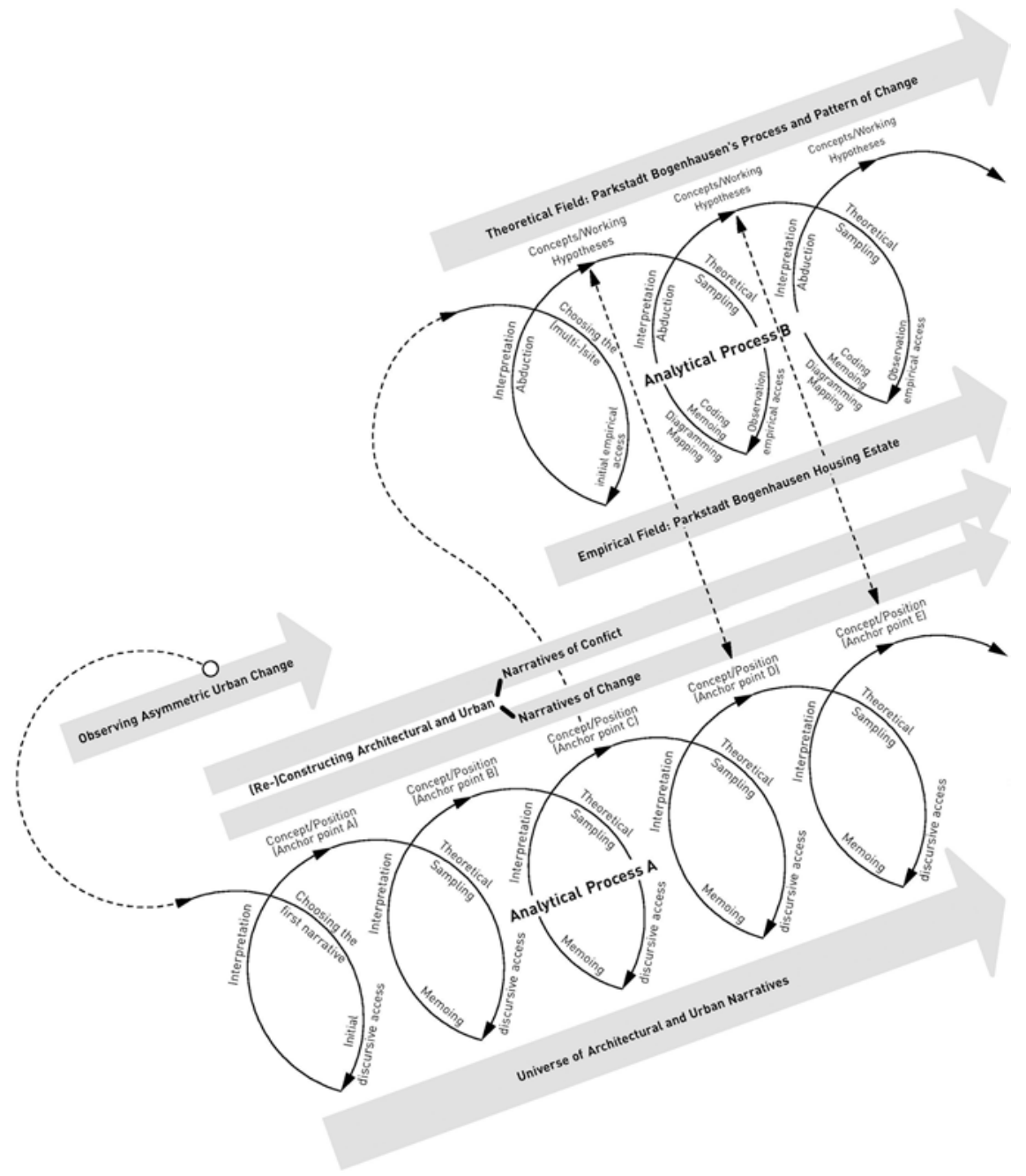

Redundant City concept. I will explain the positional map in greater detail in Chapter IV when intersecting the strands of conflict and change.

Based on the above methodological considerations, the main analytical tools and stages applied in Analytical Process A include

1. the iterative-cyclical research model, conceived as discursive-interpretative process (based on adapted GTM model and situational analysis)

2. theoretical sampling (incremental sampling of narratives, 'on analytic grounds')

3. essay-based memoing, interpreting of the narrative data, anchoring (malleable fixations) 
4. identification and constructing of concepts/positions

5. two parallel strands of enquiry: narratives of conflict and narratives of change

6. intersecting the two strands together with their concepts in the positional map

\subsection{Analytical Process B: Case Study Element. Working with Empirical Data}

The case study element in the second part of the analysis requires a different process design. In the case study, the analytical focus shifts from architectural and urban narratives to the empirical field. Again, the iterative-cyclical GTM model is at the base of the process, but this time it is combined with a two-stage coding exercise of text-based material (Strauss 1987, pp.27-33; Clarke 2005, p.xxxi) as well as extensive mapping and diagramming. The mappings draw conceptually from situational analysis. They are extended and adapted to the specific research context. The research logic within the loops follows the basic GTM movement, which oscillates between empirical field and theory. The outcome of the process are preliminary, or hypothetical, sub-concepts about the collective process of change in the Parkstadt Bogenhausen housing estate. They are further tested and elaborated in the synthesis stage of the overall concept development.

The main analytical stages and methods applied in Analytical Process B include

1. case study element (Parkstadt Bogenhausen housing estate)

2. iterative-cyclical research model, conceived as empirical-interpretative process (based on adapted GTM model and situational analysis)

3. theoretical sampling (sampling of multi-site data, 'on analytic grounds')

4. coding, memoing (two-stage coding of text-based empirical material)

5. interpreting the material

6. diagramming, mapping (social worlds/arenas, timeline, identification of negotiated concerns)

7. comparative analysis (the case study in context)

8. constructing of sub-concepts/working hypotheses about

9. pattern of change of the Parkstadt Bogenhausen housing estate

If we combine Analytical Processes A and B in a single graphic representation, we obtain two iterative-cyclical sequences that connect to their respective research areas, and to each other (Figure 11). In Process A, each new interpretation produces a new concept/position and new questions, which provide guidance for the selection and exploration of further narratives. The narratives not chosen in one loop define the pool of residues from which the samples in the subsequent loop are selected. Process $B$ analyses the condition of change in the Parkstadt Bogenhausen housing estate, moving back and forth between empirical field and concept construction. I will discuss this process together with the kind of data chosen in the case study chapter. Both processes are conceived as open processes according to the previously defined perspective on the urban as open construct. They deliver the data for the final stage of concept development, in which the Redundant City concept is generated. For clarity and legibility, the graphic representation of the Analytical Processes A and B shows regular loops and arrows. However, this should not create the impression that the iterative-cyclical processes is linear and advances in a straight and predictable line. Rather, deviations and 
uncertainties are as much part of the enquiry as the directionality established through critical reflection and theoretical sampling.

Finally, I would like to make a brief remark as to the relationship between the critical approach, which I have outlined further above, and GTM, which I have discussed in the preceding sections. The research project is based on a multi-site/multiple-methods approach. Questions of compatibility inevitably arise in research designs that draw from different methods and methodologies. Adele Clarke's 'pushing of grounded theory around the postmodern turn', as well as the work of others who have aimed to move GTM in new directions, have strengthened the connections between GTM and the critical perspective. Kathy Charmaz asserts in her article "Grounded Theory in the 21th Century" (Charmaz 2005) that they may even reinforce each other. Her reflections on GTM in social justice studies seem to be general enough as to be applicable to a broad range of research designs, and which in this sense encourage the combination of GTM and the critical perspective:

"A grounded theory informed by critical inquiry demands going deeper into the phenomenon itself and its situated location in the world than perhaps most grounded theory studies have in the past. This approach does not mean departing from grounded theory guidelines. [...] Grounded theory details process and context-and goes into the social world and setting [...]. Grounded theory contains tools to study how processes become institutionalized practices. Such attention to the processes that constitute structure can keep grounded theory from dissolving into fragmented small studies." (ibid., p.529)

\section{Methodological Conclusions}

Research in architecture and urbanism cannot be assumed to be a routine or pre-given process. Research in these disciplines occupies different epistemological locations and produces knowledge that is framed in different ways. The complex and at times contradictory nature of this knowledge needs to be addressed if naïve objectivism, compartmentalised discourses and the reproduction of partial knowledge are to be avoided. Because there are valid justifications for each of these framings, and because different bodies of knowledge contribute to architectural and urban research in different ways, researchers need to define which kinds of knowledge and research perspectives they intend to relate to - for each enquiry separately and anew. Rather than perceiving the diversity of knowledge as an obstacle to research, we can take it as a unique resource, in particular if we understand urban and architectural issues as something that cannot be grasped in isolation and from a single perspective.

Approaching the urban as open construct - for which I have argued at the outset of this research project - means to call into question the separation of macro and micro scales of conceptualisation, the uncritical adoption of concepts of static space, the insistence on hard disciplinary demarcations and reductionist framings of problems, the privileging of specialist positions, and the divide between social and material worlds. Drawing from the writings of Karl Popper, Bruno Latour, Neil Brenner, Adele Clarke and others, I have assembled a series of research propositions as a response to these challenges, that on the one hand address the methodological and epistemo- 
logical problems identified, and on the other set out an interpretative fabric through which I seek to raise questions and develop a different view of urban and architectural problems. I propose to refer to this particular form of research as a 'situated and critical project'.

Taking as a methodological starting point the idea of the urban as an open construct requires that an adequate level of non-closure be maintained in the research process, while ensuring research precision and scrutiny. For this purpose, I propose adapting the iterative-cyclical research model of grounded theory methodology (GTM) together with the mapping tools provided by situational analysis (SA). GTM and SA do not start with a predefined population in the empirical field, a hypothesis that is to be verified, or a systematics based on fixed and exhaustive categories. While demarcating draws a rigid frame around research objects, separating them from other disciplines and contexts, GTM and SA work with theoretical sampling, memoing and coding, respectively mapping, on the basis of an open research process. Rather than applying a predefined frame to the research problem, or accepting the systematic production of blind spots as a result of rigorous demarcation, they move conceptually along an incremental analysis of field-related data and generate theory or concepts in the course of the process. For the purpose of this study, I have developed 'anchoring' and 'intersecting' as additional memoing and analytical tools. 'Intersecting' is conceived as device for the assembling of concepts/positions in architectural and urban narratives of conflict and change, as well as a heuristic device for the development of the Redundant City concept. By means of intersecting, I seek to establish a high-density construct with the aim of adding an additional layer of research precision and depth to the analysis.

Based in these methodological considerations, the research process evolves along three main trajectories:

1. Analytical process A (discursive-interpretative analysis of narratives, intersecting conflict and change)

2. Analytical process B (case study element, working with empirical data)

3. Concept development (Redundant City concept)

Critical urban theory informs the interpretative fabric for the research project. Theory in the critical perspective is seen as being embedded within the time/space of history, and therefore mediated through power relations. There is no neutral standpoint from which to produce and engage with theory, which means research needs to reflect on itself. Critical urban theory challenges the generalisations of means-to-ends rationales that aim at optimisation and efficiency without questioning the dominant systems in which they operate, and which they ultimately reproduce. The critical approach views the wider framing as part of the problem under examination. Hence, if we intend to emphasise the critical rather than the dogmatic, theory requires a level of autonomy and abstraction that allows it to move beyond the constraints of the immediate and the specific. The critical approach emphasises the gap between the actual and the possible, the contradictions within urban reality, and the contingent nature of urban processes. It points towards alternative urban practices and other ways of 'doing'. In line with the critical perspective, the concept of 'matters of concern' assumes that the choice of methods, the methods themselves, and the way we interpret data are bound 
to expectations, to disciplinary fixations and to paradigmatic traditions. The concept addresses the political dimension of research and of knowledge by highlighting the instrumental nature of knowledge, its connectedness to power, as well as the problem of neutrality in scientific practice. If we conceive of the researcher as critical examiner, then it is a role that cannot be confined to narrowly defined scientific domains, for she or he will be expected to justify the research in terms of how it could - or should - be of concern. If orientation and directionality is required in this process, it may be sought in a double trajectory at once away from and towards - learning from our past mistakes, coupled with collectively produced ideas of and for the future, based on the view that things could always be different.

In perspectives that emphasise the relationship between the material and the social, architecture and human actors are seen as mutually co-producing spatial situations. Architecture and the built environment, equipped as they are with a multitude of institutionally, culturally, economically and otherwise produced properties, reflect back on the situation, as do human actors with their presence and intentions in the situation. I have outlined a research approach for the case study which works on the basis of analysing 'situations'. Situational analysis provides a range of methodological justifications and tools for a critical enquiry into mixed situations. SA integrates basic assumptions of GTM and social worlds/arenas theory to form a conflict theory. It has the capacity, among other things, to represent and analyse controversies, negotiations, commitment and collective action. It assumes that issues of broader concern are negotiated between and through social worlds that partially and temporally participate in arenas. Situational analysis assumes that all elements that are constitutive of a situation are present in the situation. The situation is thus both a conceptualisation and representation of social reality, as well as a site and unit of analysis. In SA, mapping and diagramming are instruments of empirical analysis as well as concept-building. I propose applying social worlds/arenas theory and situational analysis to the study of urban phenomena, assuming that they offer a unique perspective on urban and architectural narratives of conflict and change, as well as the pattern of change observed in the Parkstadt Bogenhausen housing estate.

Engaging with urban problems means engaging with different processes simultaneously and across different scales. The project combines theory with empirically grounded analysis. It is arranged around a multi-site/multiple-methods research approach. Based on an understanding of the urban as collective process rather than a mere aggregate level of individuals, the meso-level, or medium scale, is of particular research interest in this project.

Donald Schön suggests that "phenomena are always more than theory encompasses, and frequently outside or in conflict with theory." (Schön 1967, p.235) He asserts that phenomena that contradict theory, or that are not covered by existing theory are important "sources of novelty" (ibid.) through which new knowledge can be developed. In this sense, I have argued that architectural and urban research further extend their range of enquiry to explore more systematically the relationship between human and nonhuman actors, between collective action and the material world, between discursive controversy and space-generating processes - in particular if we wish to engage with complex phenomena such as urban change. I have brought together criticisms that raise doubts as to the usefulness of constructing intellectual and institutional boundaries if we intend to engage with complex urban, and therefore social, questions. 
I have argued for engaging with the urban as open construct, because of and in spite of the multiple mechanisms and interests that seek to achieve closure. In this research project, I seek to raise new questions by connecting architectural and urban theory to discursive arenas and to situations "where the action is" (Goffman 1967; Dellwing and Prus 2012, p.9). In doing so, I hope to expand the critical view of architectural productions and push the boundaries of what we can 'see' in the city.

Adding to architectural and urban enquiry an analysis of process and social action is not without risk, for it raises specific methodological difficulties and has to withstand the criticisms of more than a single discipline. Research conducted under the premise of openness will necessarily leave residual and unaddressed problems. It will not be exhaustive or systematically complete. However, I believe that this is offset by the chance to develop a richer, and thicker understanding of urban and architectural reality. 

Figure 12: Hacker-Zentrum business and residential complex, by

Ernst M. Lang, Klaus von Bleichert and Gernot E. Car 1970-1974,

refurbishment works, Munich 2017

\section{Domain-Specific Narratives of Conflict}

"The litany of the myth is by now familiar: a condition of violent and rapid change, unprecedented in the history of mankind, has produced a [...] moral and political crisis of such dimensions that catastrophe is surely imminent [...]. Before it is too late society must rid itself of outmoded sentiment, thought, technique; and, if in order to prepare for its impending deliverance, it must be ready to make tabula rasa, the architect, as key figure in this transformation, must be prepared to assume the historical lead [...] as a front-line combatant in the battle for humanity."

Rowe, Colin and Koetter, Fred (1978) Collage City, Cambridge MA, pp.94f, emphasis in original

"Our work as urbanists aims to shape the narratives of urban development, focusing on the stages in which a particular project unfolds. [...] Rather than a lock-step march towards achieving a single end, we look at the different and conflicting possibilities at each stage. Keeping these possibilities intact and leaving conflict in play opens up the design system. [...] All good narrative has the property of exploring the unforeseen, of discovery [...]."

Sennett, Richard (2007) The Open City, London, p.296

"We need more and better understandings of the various 'narrative machineries' and the discourses they produce."

Clarke, Adele (2005) Situational Analysis. Grounded Theory After the Postmodern Turn, Thousand Oaks CA, p.31 


\section{Introducing a Narrative-Based Analysis of Conflict and Change}

\subsection{Narratives in Architecture and Urbanism}

Mark Rakatansky suggests that "Architecture is permeated with narratives because it is constituted within a field of discourses and economies (formal, psychological, and ideological), to any one aspect of which it cannot be reduced, from any one of which it cannot be removed." (emphasis in original, Rakatanski 1991, p.199) In this section, I introduce the narrative as a distinct category of architectural and urban production, together with an outline for a narrative-based analysis of conflict and change. I refer to Mark Rakatansky's text "Spatial Narratives" (ibid.), Catherine Riessman's enquiry into narrative methods in the social sciences (Riessman 2008), and the work of Willy Viehöver on the analytical integration of discourses and narratives (Viehöver 2011). Viehöver in turn draws from Jean-François Lyotard's, Magaret Somers's and Paul Ricoeur's writings on the ontology of narratives, types of narratives, narrativisation, structure and other properties (ibid., pp.199ff), as well as from Maarten Hajer's concept of "discourse coalition" (ibid., p.201). Based on Mark Rakatansky's approach, I suggest that architectural and urban narratives are, firstly, devices through which single concepts can be connected to each other as well as to architectural and urban practice; secondly, means by which these relationships can be memorised, communicated and debated; and thirdly, embedded within the various discourses in society and that they in this sense do not occur in isolation.

Narratives in architecture and urbanism are produced within and for different bodies of knowledge. They travel easily from one discipline to another, transgress boundaries, connect architectural and urban theory with the practical work of architects, urbanists and other actors. When architects and urbanists refer to, and work with narratives, they regularly do so with reference to their own work or concrete spatial situations. Narratives may assume the form of both, theorisations as well as actual spatial work. Narratives, if seen as the establishment and communication of relationships between different concepts and practices, are at the heart of architectural and urban work. They are vehicles through which knowledge and ideas are communicated, memorised and put to effective use in processes of realisation. Narratives are consequential and more than mere theoretical objects when they enter design work and in this way urban and architectural productions. In this respect, narratives are closely related to discourses, they are part of discursive formations. However, rather than conceptualising narratives as a particular form of discourse (Viehöver 2011, p.201f), I propose with recourse to Mark Rakatansky that architectural and urban narratives could be conceived of as segments of discourses, informing and co-constituting discourses, but that are not identical with them. Hence, for the purpose of the analysis, narratives could be seen as the links in a hierarchical model which integrates concepts and practices with discourses. Researchers, designers, practitioners, theorists and other actors in the field of architecture and urbanism have developed complex narratives around conflict and change. Based on the proposed model, we may approach architectural and urban narratives of conflict and change as a distinct field of analysis and at the same time look at the level of concepts and practices, as well as the broader discourses of conflict and change within the grand discourse(s) of and in society. 


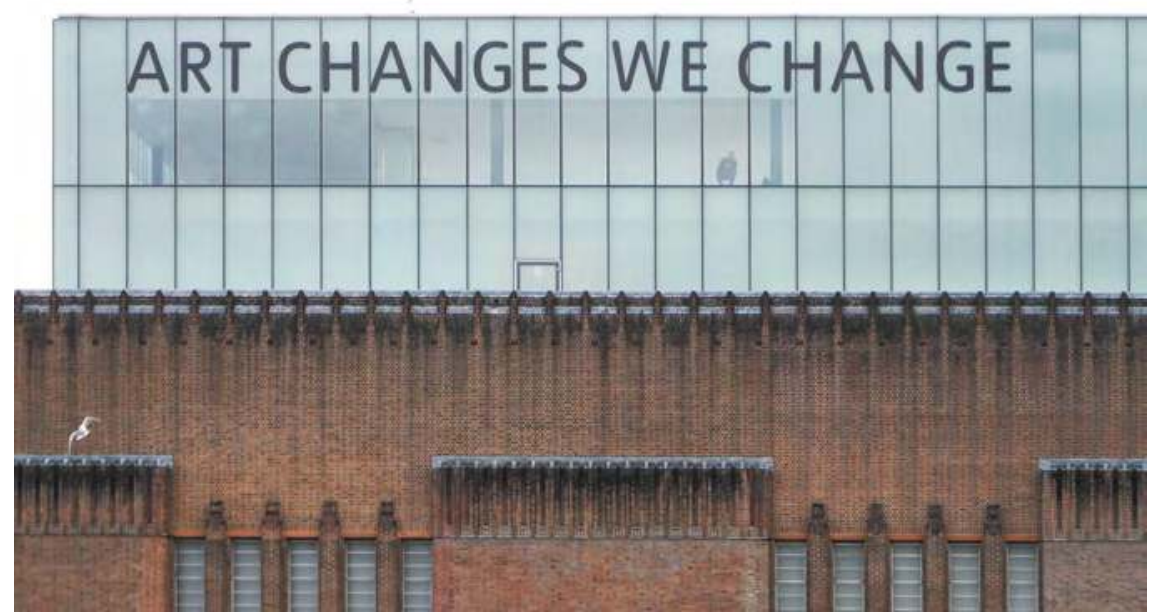

According to Catherine Riessman, narratives are regularly used "[...] to remember, argue, justify, persuade, engage, entertain, and even mislead an audience" (Riessman 2008, p.8), but also "[...] to mobilize others, and to foster a sense of belonging." (ibid.) If conceived as sense-making tools, narratives "do" things for individuals, groups, institutions, and other actors (ibid., p.8). Hence, narratives embody high levels of intentionality, and they are closely related to a wide array of everyday practices (ibid.). An enquiry into urban and architectural narratives of conflict and change, therefore, has to include along with theoretical content, line of argumentation, or justification of a proposed idea, the enquiry into intentionality and their effects on how we 'do' conflict and change in urban and architectural practice. Collectively constructing urban reality means engaging in complex situations of social interaction. Riessman argues that

"Narratives do political work. The social role of stories - how they are connected to the flow of power in the wider world - is an important facet of narrative theory." (ibid.)

According to Riessman, narrative analysis may be applied to many different sources due to the universality of the form (ibid., p.4). Narratives may be found in myths, stained glass windows, biographies, scientific theories, archival and organisational documents (ibid.), research work, interpretations (ibid., p.6); and, as I have argued above, also in the work of architecture and urbanism. Riessmann suggests that all narrative texts and materials share similar ways of integrating contingency. Through the consequential linking of actions, ideas and events, they impose a meaningful pattern on that which would otherwise be disconnected and random (ibid., p.5). Yet, despite these common characteristics, narratives are highly contextual and bound to the situation in which the narrating occurs. This has implications for their analysis. Riessmann cautions that

"Narratives are composed for particular audiences at moments in history, and they draw on taken-for-granted discourses and values circulating in a particular culture. 
Consequently, narratives don't speak for themselves, [...] they require close interpretation [...]." (ibid., p.3)

Drawing from the writings of Magaret Somers, Willy Viehöver suggests that narratives enable collective communicative practices. By means of narrative work, actors construct and transform meaning, develop understanding and constitute their own collective identities (ibid., p.197). He distinguishes between different types of narratives, of which the following three seem to be of relevance for our research situation (ibid., pp.199ff):

1. Ontological narratives relate to myths about origins and modernisation; they define the level of meta-narrative which acts as the referential framework for other narratives

2. Public narratives are attached to institutions and cultural formations beyond the level of the individual, such as the family, workplace, professions, nations

3. Conceptual narratives are produced by experts and scientists as analytical and explanatory models. They are typically embedded within specific frames of reference, contain specialist vocabulary, and follow a specific explanatory strategy

According to Viehöver, narratives can be selectively appropriated; they may change the directionality of interactions; they may define the boundaries between competing discourses (Viehöver 2011, p.202). Narratives are devices for collective learning. New situations are integrated with existing narratives through narrativisation (Narrativisierung") (ibid., p.202) ${ }^{1}$. Narratives have stabilising as well as transforming capacities - they are sites of possibilities for the construction of new worlds (ibid.). Hence, acts of transforming, adapting or extending narratives can be seen as acts of changing social reality. If humans change their shared narratives, they change the meanings and the consequential practices associated with them (ibid., p.204). Catherine Riessman observes that "[...] speaking out invites political mobilization and change as evidenced by the ways stories invariably circulate in sites where social movements are forming." (Riessman 2008, p.8) Like Riessman, Viehöver understands narratives as devices for the positioning of the individual self and collectivities in networks of relations (Viehöver 2011, p.199). If individual actors share and co-produce public narratives with the purpose of communicating, categorising, giving structure and meaning to a complex situation, they engage in what Maarten Hajer and others define as discourse coalition ("Diskurskoalition") (Hajer, cited in ibid., pp.201f). If applied to the proposed hierarchical model that relates concepts and/or practices to discourses, we could speak at the level of narratives of a 'narrative coalition'. In this sense, what kind of narrative coalitions do architects and urbanists establish in order to realise their projects and put to the test their concepts of conflict and change?

Based on these premises and questions, architectural and urban narratives of conflict and change can be understood as devices that give structure to complex ideas; they serve the purposes of integration, appropriation, memorising, communication, discussion and dispersion. Architectural and urban narratives can be understood as

1 „Im Prozeß der Narrativisierung werden situative Ereignisse und Konstellationen in den bestehenden narrativen Rahmen eingearbeitet [...]" (Viehöver 2011, p.202). 
being consequential through their connectedness to and immersion in practice, design work, and controversy. Architectural and urban narratives of conflict and change do not exclusively reside in the domain of theory; rather, they are woven into the practices and materialisations of discourses. Hence:

1. Architectural and urban narratives of conflict and change, which establish and communicate relationships between concepts as well as practices and in this sense address, interpret and visualise conflict and change in multiple ways, may be found in different areas, for example:

2. The built environment, the physical world created by humans; practises of conflict and change inscribed into materialities; practices of observing and interpreting change; competing processes of realisation/building

3. Design work, the movement between conceptual, material and social worlds; the tool-box of design instruments; design controversies

4. Institutional and regulatory practices, through which conflict and change are categorised, managed, restricted and controlled

5. Legitimisations of power relations; agreements about who/what can induce and control change; agreements about that which can be said and known about conflict and change, and what not; professionalism; the justification of practices and existing/desired conditions

6. Interactive relationships between architects, professionals, stakeholders and actors; individuals and collective bodies; negotiation and controversy; silences; practices of inclusion and exclusion; differentiations

7. Education and research, through which ideas and practices of conflict and change are explored, categorised, connected, memorised and dispersed

8. Appropriation and everyday practices, ways of 'doing' conflict and change; participation/non-participation; relational orderings; everyday use and production of spatial situations

The term 'domain-specific' in the headers of the present and the following chapters indicates that the analysis is focussed on narratives produced by architects and urbanists, often intended for other architects and urbanists as specialist recipients, as well as on narratives by researchers and theorists working in the field of architecture and urbanism. However, the theoretical sampling process is not blind to narratives and concepts that are located elsewhere. I will make use of the flexibility provided by the method to include positions from other fields at a later stage in order to substantiate the findings developed in the positional map.

By means of assembling architectural and urban narratives of conflict and change I do not seek to construct a history of ideas, either as coherent continuity, as discontinuous ruptures, or as evolution of inferences and events; nor do I analyse them in terms of internal structure or linguistic detail. Rather, the analytical goal is to clarify the narratives' conceptualisations of conflict and change and their relatedness to spatial and transformative practices; to map the positions of embodied concepts in the discursive field; to sketch out the positions' pattern of dispersion; and to identify the silences and marginalised positions that may help us to develop a better understanding of asymmetric and unexpected conditions of urban change. 


\subsection{Starting and Ending the Iterative-Cyclical Process of Analysis}

If we organise our narratives of conflict and change as two closely related, but separate strands of enquiry up to the point of their intersection, should we start with the enquiry into change, or with conflict? As my observations of asymmetric change have generated the initial research interest, it would seem obvious to begin with the narratives of change prior to assembling the narratives of conflict. However, conflict as a less evident concept in architecture and urbanism - seems to define a smaller field of narratives to choose from. Urban and architectural narratives of conflict tend to address specific issues, which makes it easier for the theoretical sampling process in terms of navigating, making plausible selections, and identifying single positions. Before I discuss change, I will therefore first engage with architectural and urban narratives of conflict. Once assembled, the narratives of conflict will serve as referential field, which will help us to keep the focus while we analyse change. The goal here is not to mirror the narratives, make a comparative analysis, nor to develop an explicit and elaborate typology of conflict and change, but to develop two strands of conceptual anchor points, and to work towards their intersection in a positional map.

The second problem is the question of the beginning, of choosing the first sample for the analytical process. Adele Clarke suggests that not having complete knowledge of all key discourses is a likely scenario for the initial stages of a research project, and typical for qualitative research rather than the exception (Clarke 2005, p.185). Hence the first selection has to be made without having a full picture of architectural and urban narratives of conflict and change. Furthermore, if the urban is understood as open construct, then there is no apparent beginning to whatever aspect we are interested in. In the opening words of "The Order of Discourse", the inaugural lecture held by Michel Foucault at the Collège de France in 1970, Foucault wished he "[...] could have slipped surreptitiously into this discourse [...]" (Foucault 1981 [1970], p.51) - his discourse about discourse, which he was about to initiate as the programme for his subsequent research; he wished to circumvent the celebration of a beginning, which, in his view, was but an affirmative institutionalised ritual. Hence, if I follow conventions in architectural history and look at the moment when architecture is commonly understood to have made a decisive step towards its manifestation as distinct discipline during the Renaissance period, I will do so not without noting that there could have been a different beginning.

However, choosing this entry for the enquiry has the advantage of starting with the argument that conflict has informed the ontological and epistemological base of architecture and urbanism and that it had evolved as tacit knowledge embedded in spatial practice before it became more explicitly articulated and discursively exploited in the modernist era. The analysis then shifts to narratives that developed as a critique of modernism, and that changed the way we approach conflict in urban practice today. The narratives move through different urban periods and scales. The sequencing is thematic rather than chronological. They cover established positions in architectural and urban historiography, as well as positions that are more marginal and hypothetical, ranging from the logics of geometry and the logics of choice, to positions that are critical of the neoliberal city, and to practices of the everyday.

The final issue to be addressed at this stage is the question of when to stop the process. In GTM as well as in SA the iterative-cyclical movement and the mapping process 
are stopped when the findings "add up to the same thing" (Strauss 1987, p.26) ${ }^{2}$, thus reaching a point of "theoretical saturation" (ibid., 21). In the words of Adele Clarke, "[...] data collection itself should continue until nothing analytically useful is being collected - until further analysis is no longer provoked by the new materials." (emphasis in original, Clarke 2005, p.186). Saturation is, like other elements in GTM and SA, not numerically determined. It can be applied to individual research tools, like maps, as well as to the distillation of concepts in a narrative, or the overall study. In practice, maps are saturated when adding further information does not change the core message of the map (ibid., p.108, p.135). Likewise, concepts are saturated when analysing further data does not significantly alter the concept. This requires researchers to keep track of intermediate research stages and findings, which is achieved through memoing, and to pursue the research process up to the stage when the maps, concepts, or core messages are sufficiently stabilised.

Pertaining to the following analysis of urban and architectural narratives of conflict and change, this means that the process stops on reaching analytical saturation on two different levels:

1. on the level of the single narrative, so that the underlying concept can be assigned a position in the positional map later on in the theoretical intersection

2. on the level of the overall analysis of narratives, so that sufficient concepts/positions and data are available for the drawing of conclusions and for the development of the new concept

In the analysis we have to take into account the general tendency in the field towards vagueness and ambiguity - a phenomenon observed and criticised by John Habraken who suggests that

"Confusion in terminology is typical for architectural discourse. Other professions those of medicine, law or engineering, for instance - define themselves by a precise vocabulary employed for internal communication. Architects take pride in coining their own words to describe the world as they see it, aiming to promote a personal or tribal vision." (Habraken 2008, p.290)

Hence, the discursive-interpretative analytical process needs to cover sufficient context within the narratives so that the concepts or positions embedded within them may be identified with the required level of accuracy. 


\section{Conflict as Category of Disciplinary Self-Affirmation}

\subsection{Integrative Capacity of Pre-Modern Spaces of Emplacement and Social Agreement}

In urban history and urban sociology, the typical early European city is understood to be organised as clusters of more or less homogeneous neighbourhoods and autonomous territories that co-exist side-by-side within the city walls (Mumford 1961, p.310). Georg Simmel provides an early account of this spatial order in his theory of the development of early European urban society (Simmel 1995a [1903], p.136). Within these neighbourhoods and territorial units, property was organised on the basis of parcelled plots, which were embedded in the feudalist system of taxation and legal status (Conzen 1960; Slater 1981, p.211). Patterns of territorial and social organisation are a common reference in architects' and urbanists' affirmative reconstruction of the division between public and private domains. Theorising the difference between traditional and modernist forms of urban organisation, historian and architectural critic Alan Colquhoun suggests that in the historic city "the public realm was representational; it not only housed activities of a public and collective nature but it symbolized these activities." (Colquhoun 1971, p.83) Colquhoun asserts that the historic distinction between public and private is, perhaps, not just a territorial distinction, established through physical boundaries, but also based on the distinction between different kinds of human actions. "The private realm, on the contrary, though still comprised of aesthetic formulae common to the whole of society, was not representational in a public sense and was the property of individuals who were free to use them much as one uses everyday language, as a personal possession." (ibid.)

The social relevance of a building would be read and understood by medieval urban society, through a system of legible codes embedded in the materiality, typology, siting and scale of the building. It found its expression in the building's location in the city and its association with a particular neighbourhood, its relation to public space, the dimensions of the building, its visual presence, the use of ornament and the symbolic meaning associated with it. The standard parcelled plots were typically long and narrow, and arranged with their short sides along the street. Main buildings, or "plot dominants" (Conzen 1960, p.31), were usually facing the street and various extensions, yards or gardens developed towards the back as "plot accessories" (ibid.). If the desire for representation of wealth and social status demanded a larger building, this could be achieved by extending further into the depth of the plot, or by adding adjacent parcels to form a larger plot. The town palace erected between 1512 and 1515 by the Fugger merchant family in Augsburg in the South of Germany demonstrates how the wealthiest family in the town managed to integrate their desire for representation into the city's plot system, without violating the existing territorial framework. Conversely, single plots could be subdivided to accommodate households with lower economic strength, or businesses which required less space (ibid., pp.37f). The length of street frontage and the size of the plot were then as now a publicly legible measure of wealth. We can imagine how potential conflicts between different representational or spatial requirements in the private domain could be negotiated and resolved within this system of spatial order. 
Whether conceptualised as "morphological period" or "typological process" in the research traditions of Michael Conzen, or Gianfranco Caniggia (Whitehand 2001, p.107), or as "pattern language" by Christopher Alexander (1979), theorists of the historic city commonly propose that pre-modern building was based on collectively produced, implicit forms of knowledge, and stabilising structural conditions. For John Habraken "[...] the house type is perhaps the most widely shared experience in a culture" (Habraken 2008, p.3). Habraken speaks of "Type as Social Agreement" (Habraken 1988), observing that the effect of working with building types is "[...] that the houses are perceived as individuals, - each having their own identity - but of the same family." (ibid., p.9) The agglomeration of building types in the historic city produces "continuous fields" (Habraken 1987a, p.8), which offer a high degree of variation within a clearly defined framework of possibilities (ibid.). The plot system acted as stable territorial and organisational element in the field. The fixation of plot boundaries was reinforced by the physicality of the densely built-up city (Slater 1981, p.211). The coalescence of 'hard' site and 'soft' asset, the aggregation of legal, economic, social, or religious constructs on urban territories, and the resulting embodiment of meaning, produced a city that was intrinsically related to individual people's lives, social practice as well as the functioning of urban society (Simmel 1995b [1903], pp.212f). Accordingly, buildings during this period were identified by their names, rather than numbers. With radical change caused by fire, aggression, or epidemics being imminent and inevitable, the striving for territorial continuity took precedence. Michel Foucault refers to this kind of pre-modern space, based on hierarchies and stability in place-fixation on the one hand, and the temporality and insecurity associated with individual life on the other hand, as "space of emplacement" (éspace de localisation) (Foucault 1984 [1967]), thus giving a distinction to the spatiality of the infinite and "extension" (l'étendue) (ibid.) that was to follow.

The narrative of the historic European city and its integrative capacity serves as the backdrop for a series of contrasting narratives of spatial conflict and discontinuity, of which key narratives include the introduction of the autonomous architectural object and the perspective principle, $19^{\text {th }}$ century urban restructuring, and the realisation of the modernist city.

\subsection{Cities as Sites of Rupture and Self-Referential Architectural Intervention}

Reconstructing a series of influential "narrative[s] of the development of modernism" (Vidler 2008, p.1) in architecture and urbanism, Anthony Vidler identifies in the work of Manfredo Tafuri ${ }^{3}$ the recurrent theme of "[...] the uncovering of moments of 'crisis' in history that ruptured seemingly fundamental continuities [...]" (ibid., p.162). Vidler provides as an example Tafuri's portrayal of Brunelleschi as a character that played a "paradigmatic role" in the crisis, through breaking "radically with the medieval past" (ibid., p.172). Similar tones prevail in the reflections of Alan Colquhoun, for example when he suggests that "[...] Brunelleschi revolutionized existing building procedures by proposing that a building was something that should be conceived as total project and carried out according to a preconceived plan." (Colquhoun 1971, p.84) Proposing that Brunelleschi redefined architectural practice as a form of "episteme, or certain knowl-

3 Vidler relates in particular to Manfredo Tafuri's "Teorie e storia dell'architettura" (Tafuri 1970 [1968]). 
edge" (emphasis in original, ibid.), Alan Colquhoun asserts that "not only buildings but also entire cities were projected in this manner and reflected the triple values of the Renaissance: political meaning, geometrical construction, and conscious totality." (ibid.) Architectural and urban histories conventionally present the Renaissance as the period during which architecture emerged as a self-reflexive and self-referential discipline (Tafuri 1970 [1968]; Colquhoun 1971; Rowe and Koetter 1978; Lefebvre 1991 [1974]; Habraken 2005; Vidler 2008) ${ }^{4}$. The shift is understood to have affected the way space and buildings are conceived. According to Colquhoun, it made possible the conceptualisation of the physicality of the city "[...] as a solid, carved up by streets, hollowed out by squares, and articulated by public buildings" (Colquhoun 1971, p.84), in other words, the urban fabric has become a generic matter into which distinct objects and autonomous architectural forms could be placed. On this interpretation, the historian portrays the Renaissance architects and their sponsors as approaching the city as zone of architectural experimentation and radical intervention. In this kind of narrative, conflict is seen as a constituent aspect of architectural self-referentiality and self-reflexive practice.

Narrative conventions argue the shift in the conception of space being related to the invention of the perspective projection, as well as the concepts of the ideal city and the autonomous object: conceived by the architect, the autonomous object demanded that spatial and visual control extend beyond the traditional plot boundary and into the wider built environment; the perspective provided a powerful design instrument in achieving this task; sites and buildings could be related to others on the basis of a verifiable and reproducible system of spatial order; spatial hierarchies and configurations of dominance could be conceived and tested by means of drawing, painting or model-making. And indeed, the "rationalisation of sight" (Latour 2005, p.45) ${ }^{5}$, the establishment of perspective as a standardised tool of representation, enabled people to share ideas in an as yet unknown way, thus creating a versatile platform of communication and intellectual exchange.

Both the strengths and limitations of the perspective projection arise from its clearly defined principles. In urban environments, the chances for coherently designed systems to interfere with the non-perspective spatial arrangements of the existing city were high. Perspective interventions inevitably encountered resistance. As a result, the projects had the tendency to leave the restricting realm of the medieval city, seizing the open countryside as easily accessible territory for architectural intervention and representation of wealth (Mumford 1961, pp. $485^{6}$ ). If this was impractical, or if status and power had to be demonstrated within the city limits, the project would have to be realised within the existing built environment. The inevitable conflict was then resolved by either violence or compromise ${ }^{7}$. For, if there was the possibility for "[...]

4 The number of references on this topic could be greatly extended. I am listing the titles to which I refer in this section.

5 Bruno Latour borrows this expression from Williams M. Ivins (Ivins1973 [1930), cited in Latour 2005, p.45)

6 Lewis Mumford refers to Leon Battista Alberti (1485) on this issue. See also Oswalt (2000, p. 73).

7 The Cortile degli Uffizi in Florence by Giorgio Vasari, which left the surrounding urban fabric intact at the expense of the size of the project could be considered a compromise (Rowe and Koetter 1978, p.68). Other schemes, like Maximilianstraße in Munich, are former out-of-town developments, which did not 
architectural structures [to be] inserted as critical ruptures with the past and shifters of significance for the present", as Vidler paraphrases Tafuri's argument (Vidler 2008, p.173), there was also the option of choosing the opposite principle of integration. Even the more fundamental interventions, such as Georges-Eugène Haussmann's undertakings in Paris, or the restructuring of Turin, seem to have produced compromise and negotiated fields of co-existence, adaptations to spatial resistance, and site-specific outcomes - despite the instrument's universality (Jöchner 2001) ${ }^{8}$. Hence, violent rupture on the one side, and evasion, adaptation, or integration on the other side, seem to define basic responses to the problems imposed by the perspective on the city. Architectural and urban histories which emphasise conflict and crisis in their narratives tend to foreground rupture and radical urban intervention.

Contextualising the 'ideal city' as instrument in the education of a privileged Renaissance minority, Colin Rowe and Fred Koetter present two picturesque drawings by Sebastiano Serlio' to illustrate their 'operative' narrative in "Collage City" (Rowe and Koetter 1978, p.14). The drawings show on the one hand an irregular medieval townscape, and an idealised perspectival urban arrangement on the other. The educationally informed envisaging of a process of "[...] convert[ing] a world of random and mediaeval happening into a more highly integrated situation of dignified and serious deportment" (ibid., pp.14f), as Rowe and Koetter call it, seems implicitly to embody the same kind of conflict zone as described above, in which the existing is forced to accommodate the new, or, more radically, the ideal city seeks to establish a new order by replacing the existing city. In this hypothetical configuration the architect would be concerned with the primacy of a single big idea. To use the well known metaphor from Isaiah Berlin, adopted by Rowe and Koetter later on in the book, the architect would have to assume the role of a "hedgehog", as opposed to the more versatile "fox" (ibid., p.92).

For several centuries, perspectival and axial systems have served representations of different forms of power, ranging from representations of absolutism to representations of civic pride. Irrespective of motivation, if the intervention seeks to maintain its state of completeness and integrity, it will seek to control space beyond the period of its construction. Once established and materialised, perspective arrangements may become "grand urban rules" (Lehnerer 2009) that affect future urban development. Today, 'borrowed' vistas dating from previous periods still dominate large territories of cities. The current London View Management is an example of the persistence of the concept (Lehnerer 2009, pp.136f) ${ }^{10}$. Organisations which are authorised to interpret

require high levels of either violence or compromise for their realisation. For illustrations of the historic situation see Rowe and Koetter (1978, pp.130f).

8 Cornelia Jöchner's research of the historic urban development of Turin in Italy demonstrates how the urban layout was modified to embody meaning and representation that was specific to the geopolitical configuration of Savoy, rather than following a generic pattern of urban development (Jöchner 2001).

9 Sebastiano Serlio made these two drawings as stage designs, the „Comic Scene“, showing a „typical” mediaeval street irregularly lined with gothic buildings of different scales, which are effectively reducing the stage to a flat canvas, and an idealised "Tragic Scene“, with buildings of "classic" or antique appearance lined up to the effects of an ordered perspective view (Rowe and Koetter 1978, p.14).

10 Many thanks to Jason Mabelis, director of architectural visualisation company RockHunter, who, during a journey through Richmond Park, showed me the protected vista from King Henry's Mound 
and decide on related matters act from within rigidified positions of power, because the rules of perspective are non-negotiable. In this way, vistas in cities are part of the 'narrative coalitions' that are constructed within the broader discourses of urban conflict and change.

Finally, the paradigm of the architectural object, of the architectural intervention as the hedgehog's 'single big idea', as well as the concept of self-referentiality in architecture are closely linked to the concept of autonomy in architecture. Anthony Vidler suggests that

"The idea of 'architectural autonomy', the notion that architecture, together with the other arts, is bound to an internal exploration and transformation of its own specific language, has surfaced periodically in the modern period. Whether as a way of classifying the qualities of architectural 'form' [...], or as a way of defining the role of the architect in an increasingly specialized professional world, the assertion of autonomy has been a leitmotif of modernism since the end of the nineteenth century, if not earlier." (Vidler 2008, p.17)

Vidler suggests that both modernism and approaches critical of modernism have developed concepts of autonomy in architecture (ibid.). Concepts of autonomy have emerged from the criticism of a pure functionalist argumentation in design and the perceived poverty of technocratic environments (Huse 2008, p.94) ${ }^{11}$, as well as from the view that architecture is essentially an autonomous form of artistic expression. In 1962, Austrian Architect Hans Hollein demanded an "absolute architecture" (ibid.), liberated from ends other than those defined by architecture itself, conceived to embody the highest achievements of elitist cultural production (ibid., p.92). The autonomy of architecture presupposes that a distinction can be made between ends defined by, or from within, architecture and ends defined by the social context in which it operates. With this distinction, autonomous architecture seeks to concentrate control in the hands of the architect or the architectural programmer, if we consider the digital versions of the autonomous project - in particular over the design process as the presumed core aspect of architectural work. Concepts of an autonomous architecture emphasise the idea of an 'outside' and in this sense maintain the inherited idea of 'rupture'. However, if the autonomous architectural project is confronted with the outside of urban reality, or with the requirements of everyday use (ibid., p.94) ${ }^{12}$, it has, in common with the

across South-West London towards St Paul's Cathedral, which from this point is some 10 miles away. The vista extends across Putney, Fulham, Chelsea, Westminster and the City, and in this way influences what is happening on the ground.

11 Norbert Huse provides as an example Oswald Matthias Ungers' and Reinhard Gieselmann's 1960 manifesto "Zu einer Neuen Architektur", which demands an architecture that is liberated from the aesthetic uniformity of functionalism, and that provides meaning and an attitude of responsibility rooted in the local.

12 Huse takes Peter Eisenman's House III, completed in 1971, as an example for an autonomous architecture where the architect conceives of users as potential threat to the coherence and perfection of the architectural project (Huse 2008, p.94). Peter Eisenman's Houses I-IV unfold in absolute space along a series of carefully executed geometrical operations, establishing a dialogue between author and architectural form. Conflict beyond the problem of architectural form, for example induced by everyday use, is excluded and defined as external. 
perspective system and despite its own claims, more than just one possible response, or process, at its disposal.

\section{Ambivalent Tactics of Conflict in Modernist Urbanism}

\subsection{The 'Lone Actor' and the Modernist 'Envelope'}

Today's cities and urban environments are, to a large degree, shaped by processes and concepts that have their origins in modernist planning. Engaging with the contemporary urban condition means to be confronted with the fixations and residues of modernist planning thought and modernist space. Looking at the long history of conflict in architecture and urbanism, modernism produced unique and ambivalent narratives of conflict in these fields, which in turn provoked the development of alternative narratives and counter-narratives. In the following I relate to two narratives about modernism that theorise this ambivalence on the basis of two metaphors: the modernist "envelope" (Latour 2008, p.8), and the "lone actor" (Koolhaas 1994a [1978], p.246).

With recourse to philosopher Peter Sloterdijk's concept of 'spheres', Bruno Latour suggests that "a modernist is someone who lives under a vast dome, and who sees things as though sitting under a huge architecture, the globe of Science, the globe of Reason, the globe of Politics" (Latour 2008, p.9). In this metaphorical description, the dome serves as the protective "envelope" (ibid., p.8) that defines a global 'inside' for the modernist project to unfold, whereby the presence of the 'envelope' is not made explicit. The powerful "life support systems" (ibid., p.9) required to maintain the 'inside' are taken for granted. In this sense, Latour's metaphor bears similarities to Imre Lakatos' previously discussed concept of "protective belt" (Lakatos 1978, p.4), but on a larger scale, or Neil Brenner's "context of context" (Brenner 2013, pp.92). Applied to architectural and urban theory, modernist 'envelopes' embody all that which allows modernism in architecture and urbanism to operate the way it did and still does. According to Latour, the making explicit of modernism's 'envelopes' during the second half of the twentieth century resulted in the gradual disintegration of modernist thinking (Latour 2008, p.9), which included the abandoning of the idea of nature as "the outside of human action" (ibid., p.10). What had been defined as self-contained is now seen as being part of vast redistribution networks (Latour 2010, pp.2f). Latour demands that, as a response to this shift in perspective, we should exchange the epistemology of "matters of fact" for that of "matters of concern" as discussed earlier (Latour 2008, p.10; 2010, p.5).

Rem Koolhaas's seminal retroactive manifesto for Manhattan, "Delirious New York" (Koolhaas 1994a [1978]), presents an alternative narrative of modernism. Unique urban programmes, such as "eating oysters with boxing gloves, naked, on the ${ }^{\text {th }}$ floor [...]" (ibid., p.155), are, according to this narrative, not inventions of single architects, public policy advisors or marketing specialists; they are seen as the products of collective action, of a process for which no script had been written and no plan conceived. The assembling and condensing of different practices and situations - Coney Island; the ambivalent skyscraper as freely programmable volume; the struggle for media attention; consumerism; the urban grid on the limited space of the peninsula; the resulting "culture of congestion" (ibid., p.10, p.125) - are portrayed as having resulted in the 
unique Manhattan condition, in "Manhattanism" (ibid., p.10). Koolhaas suggests that upon refusing to adopt the reductionist discourse of modernism, Manhattan's inhabitants, institutions, materialisations, and processes created their own discourse - a discourse that is both the product and the producer of metropolitan practices. He introduces the metaphor of "lone actor" (ibid., p.246) ${ }^{13}$ to make explicit the difference between the idea of Manhattanism and of a modern architecture that fails to perform when confronted with the metropolis:

\begin{abstract}
"The transformation of the speculative into the undeniably 'there' is traumatic for modern architecture. Like a lone actor who enacts an absolutely different play from that of other actors on the same stage, modern architecture wants to perform without belonging to the scheduled performance: even in its most aggressive campaigns of realization it insists on its otherworldliness. For this subversive play within a play it has cultivated a rhetorical justification. [...]. Modern architecture is invariably presented as a last-minute opportunity for redemption, an urgent ${ }^{14}$ invitation to share the paranoiac thesis that a calamity will wipe out that unwise part of mankind that clings to old forms of habitation and urban coexistence." (ibid.)
\end{abstract}

Both metaphors, the 'lone actor' and the modernist 'envelope', serve as the starting points for a speculative conceptualisation of the modernist approach to conflict. The metaphors can be understood to represent two basic principles: on the one hand, conflict is actively pursued to advance the modernist project; on the other hand, undesired kinds of conflict are strategically demarcated and externalised. Hence, based on Latour's and Koolhaas's narratives about modernism, we could say that modernism relates to the problem of conflict in the following ways:

1. Conflict is actively pursued in the modernist project, in order to

a. create a sense of urgency, in an attempt to eliminate concerns and lengthy debate..$^{15}$

b. demonstrate preparedness to actively and aggressively pursue modernist goals.

c. establish clearly defined demarcations, thus strengthening the modernist profile.

d. claim for the prerogative of interpretation, thus contributing towards the construction of a stable conceptual core. This allows dissenters to be disciplined or expelled more easily, at the cost of producing conceptual scarcity through the exclusion of speakers and ideas.

2. Undesired kinds of conflict are strategically demarcated and excluded in order to

a. avoid addressing problems for which modernism has not (yet) developed adequate tools and solutions. This move reduces the "traumatic" component in realisations as cited above.

13 I would like to thank the chair's team at BTU for the discussion of this passage.

14 The concepts of urgency and congestion are discussed in more detail in chapter III.

15 This will also be disussed in more detail in chapter III, along the writings of Karl Popper on utopia and violence (Popper 1947). See also the citation of Latour on "matters of fact" and empiricism (Latour 2005, p.47) in the following section. 
Figure 14: Taken for granted externalisation of problems. Langton Close, Mount Pleasant, London 2011

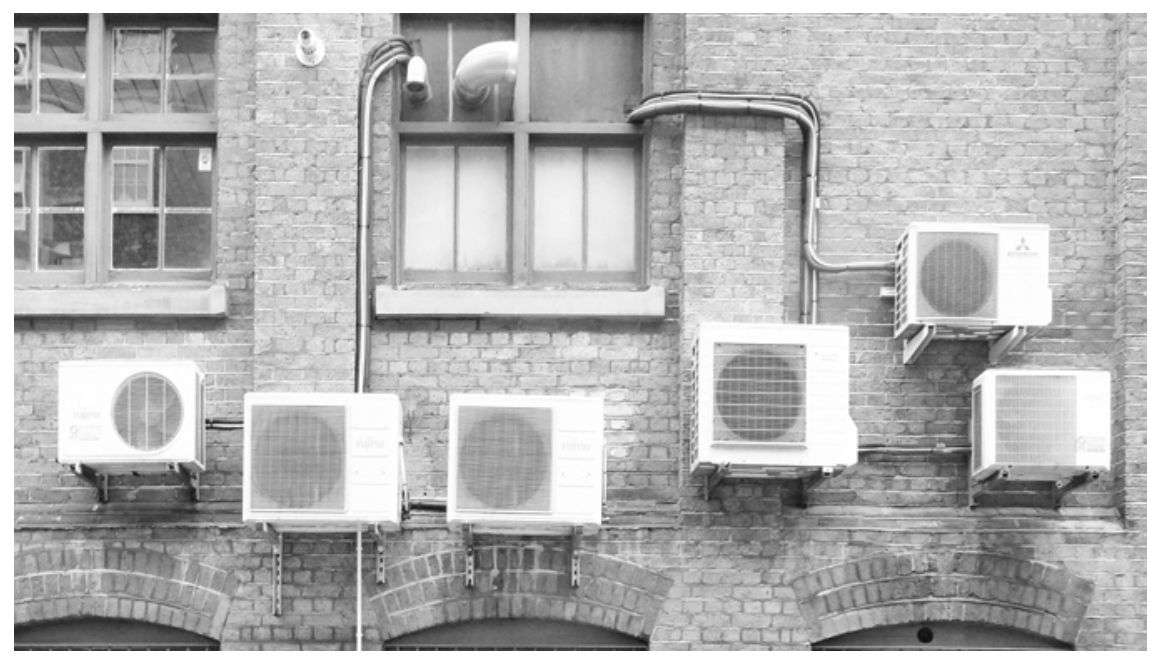

b. allow for various degrees of simplification. This ensures manoeuvrability in large scale projects and designs.

c. isolate problems so that they may be defined and approached as scientific problems.

d. give preference to assumed scientific modes of argumentation, thus strengthening the position of authorities, specialists and professionals through matters of fact.

By being able to act on the basis of both principles, simultaneously if required, modernism in architecture and urbanism seems to have created a flexible tactical base for the positioning of its social agendas and its economic and aesthetic arguments. Modernism's ambivalent relationship towards conflict may be identified in different fields of architectural and urban activity, such as communication (internal and external), problem analysis and conceptualisations, planning and design process, building construction, as well as in modernism's avant-gardism and asserted anti-historicity.

\subsection{Narratives of Urban Simplification and Externalisation of Conflict}

The complexity of the city causes major difficulties for planning and architecture. Planning history provides examples of simplifications that guided urban development, like Berlin's Hobrecht Plan of 1862. The plan defined the framework for the projected sewer system of the city. Although the plan is based on a single function and devoid of spatial or other concerns, it structured Berlin's rapid urban expansion during the following decades and shaped large parts of the city as we know it today (Oswalt 2000, p.7, p.33), in particular the tenement districts that were soon to attract fierce criticism (Hegemann 1963 [1930]). Another historic example of simplification is the Manhattan grid, which emerged as highly speculative "courageous act of prediction" (Koolhaas 1994a [1978], p.18) from the Commissioners Plan of 1811 (ibid.). The focus in this section 
is on examples of simplification and externalisation of conflict in modernist narratives, which I contrast with some of the modernist-critical responses of later critics.

Colin Rowe's and Fred Koetter's proposition that metabolism and similar movements $^{16}$, as well as the Corbusian Radiant City, "[...] suffer from [...] disregard of context, distrust of the social continuum, the use of symbolic utopian models for literal purposes, the assumption that the existing city will be made to go away" (Rowe and Koetter 1978, p.38), could be seen as being part of a modernist-critical narrative that asserts simplifications to be at the core of the modernist approach. Jane Jacobs, for example, suggests that Le Corbusier's modernist Radiant City

"[...] had a dazzling clarity, simplicity and harmony. It was so orderly, so visible, so easy to understand. It said everything in a flash, like a good advertisement." (Jacobs 2011 [1961], p.23)

However, the narrative of simplification and externalisation seems to have its origin in the statements of the initial advocates of modernism rather than in the criticisms of later generations. In view of the perceived crisis, the authors of the CIAM La Sarraz Declaration asserted that simplification would be a necessary requirement for achieving more efficiency, and therefore affordability, while opposing the maximisation of profits in the building sector. The proposed simplifications notably include the conceptual phase and design stage of projects. The authors claimed that

"[...] 3. The need for maximum economic efficiency is the inevitable result of the impoverished state of the general economy. 4. The most efficient method of production is that which arises from rationalization and standardization. Rationalization and standardization act directly on working methods both in modern architecture (conception) and in the building industry (realization). [...] 5. [...] (a) [and hence] they demand of architecture conceptions leading to simplification of working methods on the site and in the factory; [...]." (CIAM 1928, p.110)

Similar narratives were established in the discussion about minimum dwelling standards ('Wohnen für das Existenzminimum') during the $2^{\text {nd }}$ CIAM conference held in Frankfurt in the following year, as well as during the Brussels conference on rational building ('Rationelle Bebauungsweisen') in 1930 (ibid., p.270). For the modernist design process, simplification and externalisation seem to have offered some significant advantages, as the process did not have to respond to all design parameters at the same time. This produces conditions of high manoeuvrability and allows ideas to gain momentum, if only at the outset of a design project, and only temporarily ${ }^{17}$. Yet, if used as a general blueprint for design and realisation, the outcome is likely to fall short of the initial expectations. Through breaking down complex problems into smaller ones, modernism sought to render them accessible to standardised solutions, financing requirements, and outcome-orientated methods. In his 1971 essay “The Superblock” Alan

16 Rowe and Koetter use the term „science fiction” (Rowe and Koetter 1978, p.38).

17 This proposition relates to the concept of 'strategic selectivity' in design, which is based on the temporary suspension of complexity. The discussion about the concept evolved between Julia Zillich, Richard Knoll, Henri Praeger and myself in the context of design teaching/design theory. 
Figure 15: Simplification and externalisation of conflict in the functional city: unobstructed flows of segregated traffic-pedestrians, cycle lane, local traffic, flyover for fast traffic; efficient and hygienic housing, southwest-facing; parking and green spaces in between. Mittlerer Ring near Candidplatz, Munich 2013

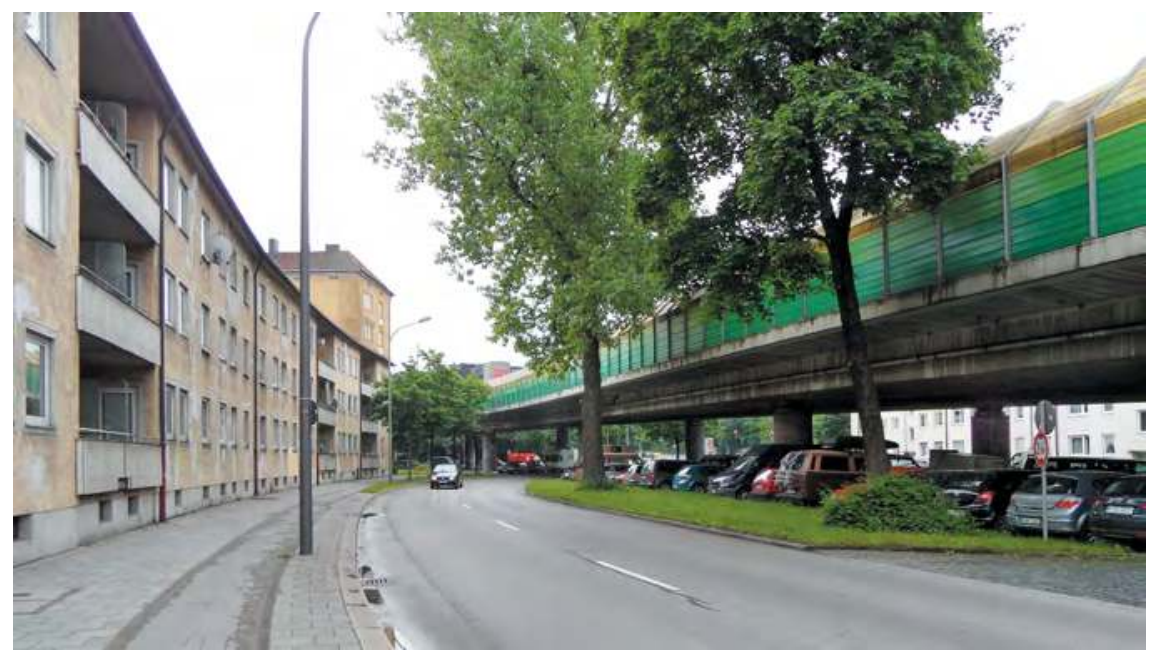

Colquhoun observes how "[...] the regulations covering light angles, zoning laws, and laws relating to plot ratio and density all tend to reinforce the tendency toward breaking up the city fabric into large discrete lumps, each of which is under unified financial control." (Colquhoun 1971, p.83) Brazil's capital Brasilia is a prominent example of modernist urban planning, which is based on superblocks, a tree-like hierarchy, as well as the externalisation of social and other conflicts from its initial plan. ${ }^{18}$ Christopher Alexander shows how the tree-like organisation was used to simplify urban complexity to a manageable level, arguing that this also reduced Brasilia's environmental quality (Alexander $1965^{19}$ ).

18 Lucio Costa's 'Plano Piloto' (Wolfrum and Nerdinger 2008, pp.284f) strictly separates different uses and is organised according to a tree-like hierarchy. It is conceived as static object, which, once constructed, is meant to retain its shape to convey the intended symbolic meaning. Notions of time, change, adaptation, transformation are absent from the concept. It is conceived as a timeless project. The case of the worker's settlement is symptomatic for this approach. It was constructed at some arbitrary location 'outside' of the scheme and was understood to disappear once the 'actual' city was constructed. The worker's settlement was not seen to be part of the city and was, therefore, not assigned a place in the 'superquadras' - the future residential areas in the wings of the 'Plano Piloto'. This approach places 'object' over 'process'. It speaks of the inability to integrate a situation of 'difference' into the 'planned' city. In doing so, it also speaks of a particular idea of the future social composition of the city. The worker's settlement did not disappear. Brasilia's organisational hierarchy is analysed by Christopher Alexander in "A City is not a tree" (Alexander 1965), who presents the design as an example of the classic modernist tree.

19 Alexander argues that tree-like hierarchies, if strictly applied as an organisational model to the planning of cities, produce poor urban environments, for they lack the richness of relations between groups and levels that are characteristic in systems that have grown over time. With this essay Alexander introduced a new category of criticism of the modern city, for he adds to the more common 
The narrative reconstructed in this section assumes that in modernist planning the process of simplification evolves along stages of abstraction and systematisations of information, and retains only that which is considered as being relevant to the project. Abstraction, systematisation and the breaking down of problems into smaller sub-problems have various predecessors in design history and are not unique to modernism. However, the modernist approach tends to systematically exclude categories that are not compatible with the modernist doctrine. Problems that are considered non-scientific, non-quantifiable, non-functional are not admitted to the process. Problems that are too complex as to be resolved with the tools available are defined in such a way they become manageable. This results in the selective elimination of complexity and externalisation of conflict from the domain of intervention. Modernist strategies of externalisation continue to be in use today. Externalisations are realised in everyday life by burdening the non-privileged with excessive commuting ${ }^{20}$; by placing hazardous and low-income jobs elsewhere; by postponement, for example in the treatment of nuclear waste; or by collectivisation of climate change. If seen from the perspective of economics, the externalisation of conflict is aligned to the externalisation of production costs. The narrative of externalisation and simplification highlights modernism's preference for greenfield sites, self-contained housing estates, new town projects and urban renewal based on large-scale demolitions. The German technical term 'Flächensanierung', used to describe this kind of urban renewal, reduces urban complexity to mere 'surface area'21.

Modernism anxiously seeks to keep pace with technology and the sciences. Kenneth Frampton relates Le Corbusier's 'Plan Voisin' proposal for Paris in 1925 to the slogan "A city made for speed is a city made for success." (Frampton 2007 [1980], p.155) In "Speed and Politics", Paul Virilio develops a conflict-centred narrative of urban and territorial restructuring along the evolution of military technology, social organisation, politics and economy (Virilio 2006 [1986]). His narrative includes the formation of the middle-age polis, the omni-directionality of naval movement, and the organisation of the nation states' territories as infrastructure networks, before, finally, space surrenders to time in the de-territorialised software society, where the time available to take decisions is diminished by the ever growing speed of information processing and by automation (ibid.). The narrative of speed could be interpreted as a variation of

perspectives of phenomenology and sociology that of systems theory, set theory and emergence of form, suggesting that reductionist concepts on the system-level of the city to play a role in the production of estrangement in modernist cities. Alexander proposes a "semi-lattice" (Alexander 1965) as alternative to the deterministic modernist tree, which is a structure that allows multiple connections between elements and across scales.

20 Hans-Bernhard Reichow's cell-like diagrams, for example, depict pockets of modernist car-friendly city ("autogerechte Stadt") that can be attached to any traffic artery (Reichow 1959). They exemplify a kind of modernist model of conflict externalisation which can be effectively communicated and reproduced.

21 During the 1970s, the practice of ,Flächensanierung' increasingly encountered resistances, not least because its justification and procurement was deeply rooted in technocratic thinking and in this sense in modernist simplification. For a historic account of the accompanying debate in Germany see (Krau 2010, pp.35ff). I would like to thank Prof. Christiane Thalgott, former head of Munich's planning and building control office ('Stadtbaurätin'), for the conversation about urban transformation and for kindly pointing to this publication. 
the narrative of simplification and externalisation: for the purpose of gaining speed, modernist practices of externalisation and simplification can be used to reduce decelerating 'weight', and save time.

The narrative of simplification and externalisation of conflict may be extended to the field of expert-layperson communication, as well as the role of specialists. The assigning of privileged positions to experts and professionals in modernist projects, combined with the restriction of public access to specialist debates can be seen as a specific form of simplification. In this way, projects can be realised on the basis of the 'lone actor' attitude in the name of efficiency and scientific rationality, without the need to compromise. The modernist specialist seeks to establish an effective armament of 'matters of fact' through scientific justification. Reflecting about the instrumentalisation of scientific claims and specialist opinion in controversies, Latour suggests that the "indisputable presence [of matters of fact] was at once turned into a way of stopping the dispute." (emphasis in original, Latour 2005, p.47) The insistence on matters of fact, the practices of simplification and externalisation, and the anxious exclusion of non-compatible problems could be conceived as forming the "protective belt" (Lakatos 1978) that was assembled around the core of the modernist programme by its advocates. The combined tactics of agitation, simplification and externalisation contributed towards the unparalleled success of post-war modernism, for it strengthened and shielded the methodological and argumentative base as well as the operative modes of realisation in the alliance of politics, finance, marketing and urban planning. However, the profession gradually realised that institutionalisations and simple reproductions of modernist principles had compromised the "image of the modern city" (Rowe and Koetter 1978, p.33), while accepting that, despite its social agenda, "[...] modern architecture had not, ipso facto, resulted in a better world." (ibid.)

I conclude this section with a remark on selectivity and omission, which is a general issue in narrativisation, and therefore in narrative analysis. Simplification and other characteristics of the modernist approach are commonplace and the subject of established criticisms, to which I have briefly referred above. However, the period which is associated with modernism and post-war modernism is characterised by numerous variations within the modernist movement, by parallelisms, and alternative movements (Vidler 2008; Wolfrum and Nerdinger 2008; Jencks 2010; Sturm 2013). A narrative about simplification in modernism is a simplification in itself.

\subsection{Dialectic Process: Conflict and Change in Socialist Modernism}

"Nejmenší byt" - The Minimum Dwelling, was collated as a research compendium in the wake of the 1930 CIAM congress in Brussels by Karel Teige (Teige 2002 [1932]), one of the leading figures of the modernist movement in Prague and Czechoslovakia, and consists of a series of essays, drawings, diagrams and illustrations. The translators of the 2002 English translation describe the text as "[...] a mélange of ideological rhetoric, radical proclamations, scientific reportage, and utopian reveries." (ibid., p.viii) In the essay "Toward New Forms of Dwelling", Teige asserts that

"Guided by the principles of the dialectical-materialist method, architectural work has the potential to become a powerful factor influencing development in all spheres of human behavior, including ideology: architects [...] must actively and aggressively par- 
ticipate in the creation of a new economy, a new society, and a new social human being." (ibid., p.379)

The certainty and claims to authority are of the familiar modernist kind, as well as the idea of the architect as social engineer. However, the belief in dialectics as generative principle in the production of architectural form, typologies, functional organisation, urban-rural relations, and their capacity to interact dialectically with the social, distinguishes socialist modernists and their narratives from other proponents of modernism. ${ }^{22}$ The dialectic principle establishes a specific form of ambivalence: the focus, or argument, shifts repeatedly between two poles, producing conflict and movements of thought, while modifying the poles and the directionality of the argument. Like Hannes Meyer and other architects and urbanists in the Marxist tradition, Teige understands architecture and urbanism as a political practice. His approach connects a socialist-pragmatist attitude with progressive ideas (ibid., p.377), not without radicalism. Teige demands that "[...] the architectural avant-garde must essentially assume a destructive role in the capitalist context: it must promulgate with all its energy the negation of existing cities and existing ways of dwelling [...]" (ibid., p.12). However, the type of conflict conceptualised by Teige is not of the sudden and violent one-off eruption. It is embedded in the dialectic process, and not accidental. Destruction in the dialectic model implies subsequent construction, the building of something new, which contains, to a certain degree, that which had been destroyed (ibid., p.13). Taking the development of a new collective dwelling typology as an example, Teige explains that

"Dialectical negation is the driving force of progress and takes place within its contradictions. At the same time, these contradictions are resolved by a synthesis on a higher level than those that existed at the starting point: having evolved after the bourgeois dwelling with its specialized spaces has become obsolete, the universal dwelling space of the collective dwelling should not be confused with past versions of primitive living spaces. It instead represents a higher dwelling type, enlivened by architectural creativity, which adds dialectical understanding of negation to the positive comprehension of that which exists now - that is, the bourgeois dwelling layout-by the necessary negation and elimination of redundant elements." (ibid, p.16) ${ }^{23}$

22 Architectural sociologist Heike Delitz asserts the uniqueness of Teige's approach, as it combines the dialectic principle with an explicit sociological perspective (Delitz 2009, p.30). Also, Karol Teige does not conceal his discontent and criticism of the cult of the master and the capitalist productions of his modernist contemporaries. He accuses architects like Le Corbusier, Loos, Mallet-Stevens or Mies van der Rohe to have abandoned the social project of modernism, in favour of designing "new versions of opulent baroque palaces" (ibid., p.6).

23 In contrast, Lefebvre's idea of the urban as movement requires a dialectic model that does not come to an end through conclusion or synthesis. See the discussion of meta-narratives at the beginning of chapter III. 
Figure 16: Students' accommodation in a former worker's residence built during the socialist era, East Germany. Students show their discontent with the federal state government's policies in the academic sector by displaying messages in the windows: "BTU FOREVER", Cottbus 2012

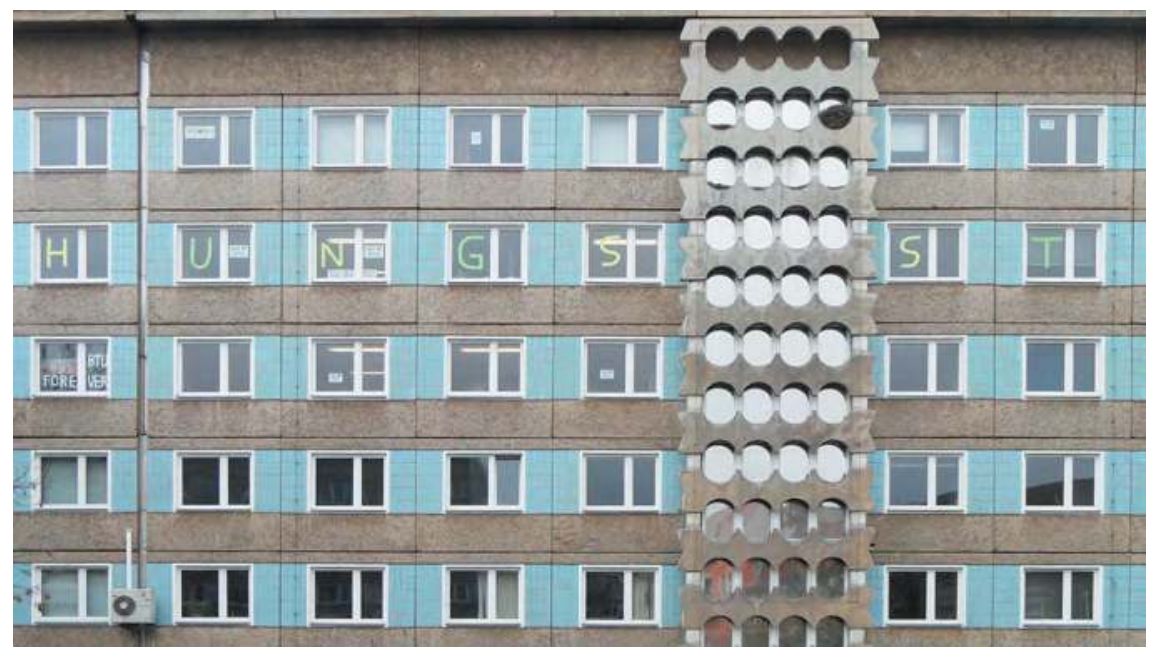

Despite the radical shift caused in and through the process, "[...] a continuing nexus remains, as two countervailing tendencies are operative in each process of transformation: these are continuity and change." (ibid, p.16) Teige envisages the overall speed of change as a "gradual process" (ibid., p.403), for "[...] the shift from an individual to a collective style of life can be accomplished only by reeducation, never by force." (ibid.) Although Teige uses the dwelling typology to explain the dialectic process of built form, his description above seems general enough as to be applicable to different levels or scales. Teige's belief in the power of dialectics is at the base of his specific narrative of conflict and change. The narrative seems surprisingly contemporary with regard to changing programmes in buildings, adaptability and obsolescence, even 'facadism', as well as the critical conclusions drawn from them:

"Rejecting the idea of a house built for eternity has serious consequences [...] today's city buildings must constantly submit to change. Houses in the city change into offices, hotels, cafés, ateliers, and so on; the statistics on such adaptations teach us how quickly a city house can change. Where adaptation is impossible or difficult, or where the floor plan of a building does not allow for different and variable layouts, the costs of conversion mount uncontrollably. Our cities today are actually more like stage sets: behind their facades buildings change constantly. Or, put more succinctly, these are modern ruins. Unfortunately, we continue apace to build more such ruins. The rapid rise in the cost of land itself leads to the shortening of the useful life of a building: buildings are demolished relatively early in order to free a valuable site for new development." (ibid., pp.14of, in footnotes) 


\title{
3.4 Complex Reductionism in Present-day Modernisms
}

According to Rowe and Koetter, two divergent trajectories emerged from the crisis of modernism during the late 1950 s and the ensuing period of uncertainty ${ }^{24}$. Some considered the Corbusian city as the mere starting point of the true modernist project that had yet to be conceived and brought to perfection, while others abandoned the modern city as failed experiment. Rowe and Koetter suggest that the project of advancing the modernist cause included "the cult of science fiction" (ibid.), the perfections of high-tech and eco-tech, and various computational approaches to complexity, such as systems-theory, space-syntax and parametric design (Rowe and Koetter 1978, p.38). Pointing to the limits of computational methods in the analysis of urban and social reality, David Harvey criticises in 1973 that

\begin{abstract}
"Systems modelling attempts to trace interaction and feedback within a totality, but by having to define fixed categories and activities it loses the flexibility to deal with the fluid structure of social relationships which exists in reality. It can be used to deal with certain limited problems (the optimal design of some transport system for example), but it cannot be used for broader purposes - 'optimising the city' is a meaningless phrase." (Harvey 2009 [1973], p.303)
\end{abstract}

Since then, refinement in method and concept as well as increased computational capacity have led to an antipodal movement. While today's tools are far more advanced, and therefore distant from what had been available in the past, their growing precision and capacity brings them closer to the initial modernist vision of a scientific, universal, all embracing model that can be fully controlled. As a consequence, projects that exploit computational intelligence and work with the idea of fully controllable models are anxious to distance themselves from the simplifying and reductionist modernisms of earlier eras. Key sections of Patrik Schumacher's two volume work, subtitled "A New Framework for Architecture" (Schumacher 2010) and "A New Agenda for Architecture" (Schumacher 2012), seek to promote computational modelling and to establish a unified narrative of architecture that is centred on parametricism. Theorising about "Parametricist vs Modernist Urbanism" (Schumacher 2012, p.680), Patrik Schumacher claims contemporary parametricism offers an alternative to modernism, which according to Schumacher produced order without complexity, as well as post-modernist "laissez-faire", which produced complexity without order (ibid., p.680). While the pragmatic approach in current urbanism is seen by Schumacher as accommodating "[...] the richness of societal life-processes [...]" (ibid.), he argues that it fails to articulate urban complexity in a meaningful way. Schumacher asserts that

"Parametricism affords the build up of a complex visual and semiological order that facilitates orientation by making the complex order of the urban life-processes legible. Parametricism is able to coordinate pragmatic concerns and articulate them with all their rich differentiations and relevant associations. The danger of overriding real

24 Rowe and Koetter discuss this shift with special reference to the situation in the United Kingdom. But we may assume that similar, if not identical, symptoms of doubt and the search for alternatives prevailed in many other places during this period. 
life richness are minimized because variety and adaptiveness are written into the very genetic make up of Parametricism." (ibid., p.680)

In this proposition, the richness of differentiation is (pre-)programmed and located within the paradigm of parametricism. Schumacher rejects the idea that there should be competing paradigms or a richness of different, complementary narratives through which researchers in architecture seek to approach urban reality, arguing that "the historical justification for this freewheeling discursive culture has vanished." (ibid., p.712) Schumacher asserts that parametricism is capable of finally overcoming the state of crisis and period of uncertain experimentation that followed the dissolution of the initial modernist paradigm (ibid., p.712). Consequently, in his epilogue to "A New Agenda for Architecture", he argues for an end to the controversy about the way forward, and for the leading role parametricism should assume in the future (ibid., p.712). Schumacher demands sceptics to stop questioning the methodology of parametric urbanism as such, that is, the 'hard core' of the programme and its 'protective belt', or 'envelope'. What is left for conflict in the narrative, it seems, are problems of optimisation.

\subsection{Planned Obsolescence and Creative Destruction}

Planned obsolescence aligns production, technological renewal, realisation of surplus value, and consumption with each other for the purpose of mutual acceleration. It is based on the implicit agreement between consumers and producers about the purposefully limited lifetime of consumer goods. Narratives that foreground change in the phenomenon tend to be linked to discourses about modernist ideas of progress, economic development and innovation (Fernandez 2006, p.43). Conversely, narratives that foreground its conflictual aspects tend to be linked to discourses about consumerism, environmental issues, and alienation (ibid.). The critical perspective goes further in that it understands planned obsolescence as an inherent function of the capitalist mode of production, foregrounding the destructive power and the contradictory aspects of the process (ibid.; Brenner 2013, p.107). This perspective is related to Joseph Schumpeter's concept of creative destruction (Schumpeter 2003 [1943], pp.83f) and to Marxist theories of surplus value, accumulation/devaluation and spatial fix (Harvey 1982, p.221, p.231; 2001, p.335ff).

If products are designed for a limited service life in the expectation that consumers will replace them with a newer generation of products after a certain period of use (Fernandez 2006, p.43), production and innovation can be conceived and calculated as economic cycle. Planned obsolescence is related to the belief in innovation, optimisation and technological progress, however defined, and the idea that consumers appreciate sharing in this process through incessantly high levels of consumption. The incentives provided by this system are seen in lower production costs based on savings through using components with specified service lives, as well as in the benefits of improving products incrementally in step-by-step processes (ibid.). Producers hope to generate long-term sales volume through repeated replacement cycles, supported by advertising campaigns and strategies that exploit the interest in novelty on the part of the consumers. John Fernandez observes that "eventually this frenzied consumption settled into what we now have - a market with select hot spots of planned obsolescence 
(such as automobiles) and a general infusion of the strategy across all product types and industry sectors." (ibid.)

Could we therefore also speak of a consumer-oriented, planned obsolescence in architecture, or even of a planned obsolescence in urbanism? In building practice architects and engineers align their concepts and specifications with the projected design lives of the buildings and structures in their projects. Buildings and structures intended for short periods of use are designed and detailed differently if compared to structures that are intended for longer periods of use. In this sense, the design of a building or structure contains, implicitly or explicitly, the design of its anticipated lifespan. However, because design strategies, modes of production, and consumer/ user preferences are entangled with each other, and because all materials and structures deteriorate over time, distinctions between a 'naturally' occurring end of life, unintended obsolescence and planned obsolescence are difficult to make. With reference to the research by Daniel M. Abramson about the history of the term obsolescence, John Fernandez discusses three discourses that had been instrumental in its conceptual formation (ibid., pp.41ff). Firstly, the consumer discourse is understood to cover all aspects of modern consumption, including architectural form (ibid., p.42). Its focus is on what Fernandez describes as "dilemma of obsolescence" (ibid., p.43) - the commercially exploited coupling of the end of utility with the consumption of something new - which in turn is seen as "[...] not only an opportunity for but the raison d'être and a primary engine of capitalism.” (ibid., p.43)

Secondly, the finance and building investment discourse is understood to have developed around the task of explaining and predicting the flux of buildings and related flows of capital (ibid.). However, according to Fernandez, the precision of analytical tools developed for this purpose did not result in a "[...] holistic understanding of the nature of building lifetimes." (ibid., p.42) ${ }^{25}$ Thirdly, the discourse on urban renewal, which is closely related to the finance and building investment discourse (ibid.). Urban centres seem to be places where the three discourses on obsolescence join heritage discourses and the contesting of urban centralities, with the consequence of establishing a particularly intense zone of conflict and change. Rem Koolhaas's observes in "The Generic City" that

"In our concentric programming (author spent part of his youth in Amsterdam, city of ultimate centrality) the insistence on the center as the core of value and meaning, font of all significance, is doubly destructive-not only is the everincreasing volume of dependencies an ultimately intolerable strain, it also means that the center has to be constantly maintained, i.e., modernized. As 'the most important place:' it paradoxically

25 Fernandez suggests that the simulation models used by experts to make statements about the future performance and the life of buildings have reached high levels of complexity and are at the base of life-cycle assessment models (LCA), as well as of most assessment calculations required for sustainable design ratings (Fernandez 2006, p.105). However, Fernandez also says that predictions about the actual lifetime of buildings are difficult to make. Uncertainties accumulate with the life of a building (ibid., pp.56f). In practice, many buildings are in use for either longer or shorter periods if compared to their anticipated design lives. Next to material properties, economic and social conditions are seen to exert a significant influence on the actual lives of buildings (ibid., p.57). 
Figure 17: Obsolescence and creative destruction at work in Haggerston, London Borough of Hackney. The Kingsland Estate, built in 1949, is prepared for demolition after the majority of the residents voted in favour of urban renewal in 2007. East London 2013

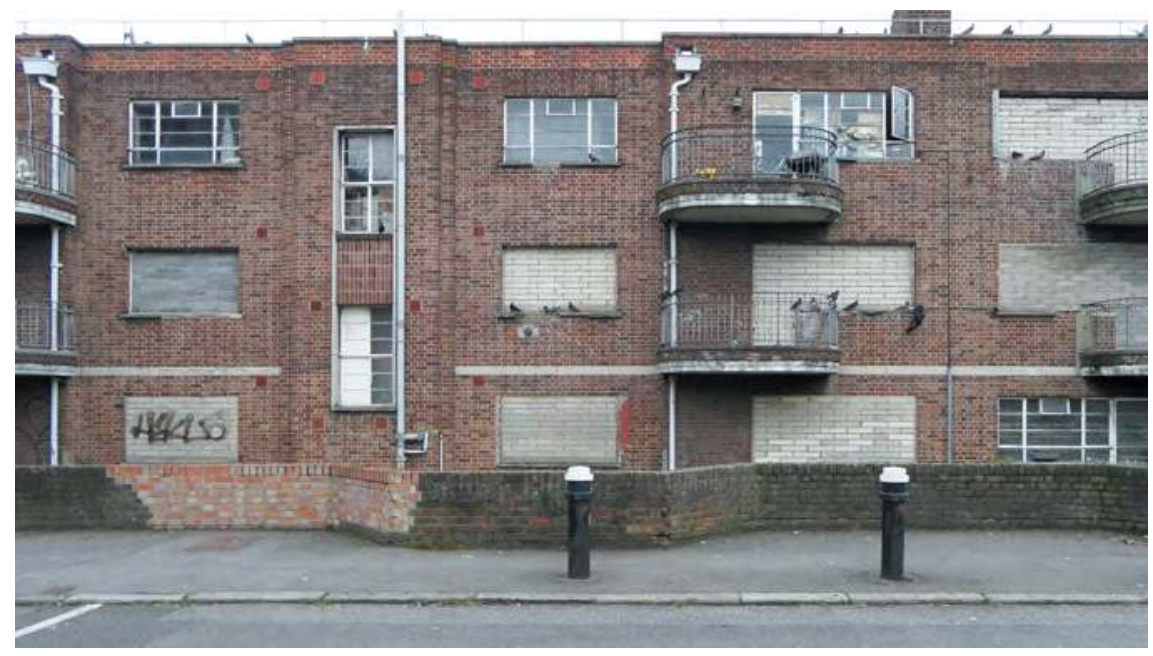

has to be, at the same time, the most old and the most new, the most fixed and the most dynamic; it undergoes the most intense and constant adaptation, which is then compromised and complicated by the fact that it has to be an unacknowledged transformation, invisible to the naked eye." (emphasis in original, Koolhaas 1994b, p.1249)

Fernandez suggests that the discourse on obsolescence and urban renewal has been centred on an "anthropomorphic metaphor of the city" (Fernandez 2006, p.42), which compares the city to a breathing organism that is in need of specialist care. It followed that "the solutions of the surgical removal of structures, renewal of neighbourhoods and the complete replanning of entire districts of cities were considered to be appropriately bold measures to combat the malaise of the modern city." (ibid., p.42) Urban renewal conceived in this way is based on the idea that urban form and sociospatial arrangements could become obsolete, and that, as a logical consequence, they could be 'renewed'. "Obsolescence of urban form meant that physical solutions could be brought to bear as social and economic 'cures'." (ibid.) In this approach certain kinds of inherited urban form are classified as outdated and are said to attract - and even cause - poverty, crime and ethnic tension (ibid.). The argumentation aligns with the belief that architecture could 'generate' society and that by means of making adjustments to architecture the social could be effectively changed (Yaneva 2012, p.36). The 'cure' is argued to stabilise both the 'body' of the city as well as the social body. Variants of this discourse are still with us today, in both modernist and modernist-critical thinking, for example in the myths of Sarcelles or Pruitt-Igoe. The critical perspective rejects naturalising explanatory models and locates the actual problem in the crisis-driven capitalist system. Neil Brenner argues that "the creative destruction of urban landscapes" (Brenner 2013, p.107) has to be seen in the context of a transformative process which is of global scale: 
"Capitalist forms of urbanization have long entailed processes of creative destruction in which socially produced infrastructures for capital circulation, state regulation, and sociopolitical struggle, as well socioenvironmental landscapes, are subjected to systemic crisis tendencies and are radically reorganized. Urban agglomerations are merely one among many strategic sociospatial sites in which such processes of creative destruction have unfolded during the geohistory of capitalist development." (ibid., pp.107f)

Hence, while creative destruction could be seen as a constant that is intrinsic to the capitalist mode of production, its sociospatial and environmental expressions vary over time, together with the locations where they become effective and destructive. The capitalist mode of production is dependent on the establishing of ever new "geographies of extraction" (Sassen 2014, p.219). Conceptualisations and the analysis of related phenomena seek to keep pace with this process. Pertaining to the current urban condition, Neil Brenner shifts the focus to the relationships between urban change, its potential beneficiaries, and constellations of power:

\begin{abstract}
"What is the specificity of contemporary forms of creative destruction across place, territory, and scale, and how are they transforming inherited global/urban geographies, socioenvironmental landscapes, and patterns of uneven spatial development? What are the competing political projects, neoliberal and otherwise, that aspire to shape and rechannel them?" (Brenner 2013, p.108)
\end{abstract}

According to Fernandez, "the driver of creative destruction [...] has had a major influence on our assessment of the worth of buildings in society today." (ibid., p.34) However, models of evaluation that reduce the value of structures, spaces and buildings to their monetary value and future profitability are likely to miss the values that cannot be translated into figures. Insisting on calculable "matters of fact" while excluding "matters of concern" (Latour 2005, p.39, p.47) may be conceived as a means to keep public debates aligned with the logics of creative destruction. Arguments that include factors like emotional attachment, the production of meaning and personal assignments of value struggle to survive in this discourse (Friedman 1999; Brand 1994). As a consequence, projects that are primarily investment-driven can do so at the expense of other concerns, which often means that they are experienced as severe ruptures in the spaces of the everyday (ibid.). Fernandez concludes his discussion of the three discourses of obsolescence by connecting to the broader discourse of change:

"Whether invoked by accountants and real estate developers to argue for escalating demolition and construction of buildings and urban districts entirely or used as the foundation of a new paradigm for disposable, adaptable architecture, the various discourses are essentially ideologies for facilitating change - ideologies against permanence." (ibid., p.43) 


\section{Political Spaces of Urban and Architectural Conflict}

\subsection{Challenging Regimes of Truth and Professionalised Design Authority}

The 1950 s building programmes offered Europe's disillusioned modernisms a new perspective. By then they had abandoned their radical utopian ideals, in keeping with the more moderate goals of either the welfare state or planned socialism, but also in response to the totalitarian experiences of the immediate past (Conrads and Neitzke 2003). Since the mid 1940s, criticism and discontent from within the modernist movement had gained momentum (Frampton 2007 [1980], p.271), which culminated in the official demise of CIAM in the 1959 meeting in Otterlo. This event is considered a general turning point in the history of modernism (ibid.; Huse 2008, p.41). The prevailing uncertainty of this period becomes apparent if we juxtapose Hans Reichow's proposal for the car friendly city "Die Autogerechte Stadt. Ein Weg aus dem Chaos" (Reichow 1959) and Jane Jacobs's "The Death and Life of Great American Cities" (Jacobs 2011 [1961]), published at around the same time. While Reichow offers a 'solution to chaos', by means of optimising segregated flows of cars and people, Jacobs exposes the shortcomings and limits of functionalism, arguing for the gradual "attrition of automobiles by cities" as the alternative to the "erosion of cities by automobiles" (ibid., p.349). Publications like psychologist Alexander Mitscherlich's widely read analysis of post-war built environments in (West-)Germany articulated feelings of uneasiness (Mitscherlich 1965). Measured against its initial promises, modernist urban planning had in the view of many failed to develop answers to the growing number of urban problems. The discontent gradually evolved into a broader critique of authoritarian planning practice and professionalism, as well as a critique of the contradictions in the urban condition. The publication of Henri Lefebvre's major criticisms of the urban falls into this period, starting with "Le droit à la ville" in 1968, "La Révolution urbaine” in 1970 and „La Production de l'Espace” in 1974 (Lefebvre 1996 [1968]; 2003 [1970]; 1991 [1974]).

The 1968 Triennale in Milan is a real and conceptual site, where criticism and action converged in a dramatic way, for which reason it became a popular reference in architectural historiography for this period of transition and in this way a narrative. The Triennale was themed "Il Grande Numero" and organised around a central exhibition curated by Italian architect Giancarlo de Carlo (Nicolin 2008) ${ }^{26}$. De Carlo's approach was deliberately not to foreground analysis of form and structure, but rather processes and phenomena related to and emerging from society's ongoing transformations and conflicts (ibid.). This included the unresolved relationship of urban history and technological progress as well as the problem of not loosing sight of the individual

26 Paola Nicolin's analysis "Beyond the Failure: Notes on the XIVth Triennale", provides a reappraisal of the event as well as insights into the specific local situation. Up to the XIVth Triennale the exhibition had been conceived as an expo-like event in which national economies presented a mix of art, consumer goods, architecture and technology. Assuming the preparations for the Triennale in 1965, De Carlo was supported by the Scientific Committee, which, for a period, included Aldo Rossi, as well as the research unit of the Triennale, Centro Studi, and the teams of contributors including Arata Isozaki, Aaldo van Eyck, Alison and Peter Smithson, Archigram, Shadrach Woods, György Kepes and others (Nicolin 2008, pp.92f). 
as protagonist of change, despite the 'great numbers ${ }^{27}$ and in view of the emerging phenomenon of mass consumerism (ibid., p.94) ${ }^{28}$. The course of events that brought the exhibition to its premature ending contributed towards its lasting legacy. On 30 May 1968, the day of the opening, students and activists occupied the building and initiated discussions on the means of cultural production and its societal grounding and relevance. The photograph of the sit-in, showing Giancarlo De Carlo debating in a forum-like setting, is today part of architecture's narrative iconography ${ }^{29}$. It stands for the challenging of institutionalised design authority and the return of architecture to the political. However, Paola Nicolin's analysis shows that the Triennale had been more than the clashing of (architectural) establishment and open expression of discontent. While the core exhibition was conceived as critical reflection on the crisis of urbanism and its political dimension, and as an open invitation to participate in the urgently needed debate about re-orientation, visitors could not fail to notice the discrepancy between the ambitious theme of the core exhibition and the large commercial sections with exhibits such as a sauna (Sack 1968). Moreover, the exhibition was located in the fascist Palazzo dell'Arte of 1933 and the Triennale itself represented institutionalised forms of power, the exclusiveness of cultural production, and structures of arrogance ("Arroganz der Selbstverständlichkeit") (ibid.). Paola Nicolin concludes, that "ultimately, the Triennale of May 1968 could not have been anything but contested, like every other institution at that time, even if it formulated itself as an example of 'dissent' from within." (Nicolin 2008, pp.97f)

27 The term of 'great numbers' takes up earlier CIAM concerns (Nicolin 2008, p.88). It could be seen as a critical reference to the La Sarraz Declaration of CIAM in 1928, which, during the more aggressive phase of architectural and urban modernism, demanded "reduction of certain individual needs henceforth devoid of real justification; [for] the benefits of this reduction will foster the maximum satisfaction of the needs of the greatest number, which are at present restricted." (Frampton 2007 [1980], p. 269) Nicolin stresses the intended distinction between the notions of "mass" and "great number". In the latter, the individual is seen in its uniqueness as part of a "civilization of large numbers". (Nicolin 2008, p.94)

28 With the intention to stimulate debate and critical reflection on the crisis of modernism, the introductory sections of the core exhibition included "Mistakes", "Information" and "Perspectives", not without polemic intent (ibid., p.97). Among the self-critical views on architectural and urban production were Alexei Gutnoff's and Ilia Ledgiava's installations who confronted the problem of large scale planning and the individual, or the arrangement of hundreds of drawer cases by Saul Bass and Herb Rosenthal to address the problems of creativity in conditions of mass production. Some panels and installations sought to directly address injustice and political problems of the present. Dutch architect Aldo van Eyck presented large format images of buildings shelled by US military operations in Vietnam, Arato Isozaki's "Electronic Labyrinth" mixed medieval apocalyptic scenes with documentations of the nuclear devastation of Nagasaki, while the controversial installation "Youth Protest", made by Andrea De Carlo and the Italian filmmaker Marco Bellocchio in collaboration with the painter Bruno Caruso, featured an urban barricade assembled from consumer waste, cobblestones and an upside-down car. Large photographic prints showing situations of contemporary protest from different locations in the world, including Paris and Berlin, are arranged as scenic backdrop (Nicolin 2008, p.95).

29 Photo by John McKean 1968, in: McKean, John (2004) Giancarlo De Carlo. Layered Places, Fellbach, (Edition Axel Menges) 
Figure 18: Il Quadrilatero social housing scheme in Trieste. Residential superblock comprising 468 units for approx. 2500 residents, which seeks to combine a strong social agenda with the challenge of working with and for 'large numbers'. Commissioned by Azienda Territoriale per l'Edilizia Residenziale ATER. Designed by Carlo Celli et. al., constructed 1969-1974 (1983). Sadly, the communal spaces along the 'rue interieure' are currently neglected. The estate is a stigmatised locality in the city. Rozzol Melara, Trieste 2017

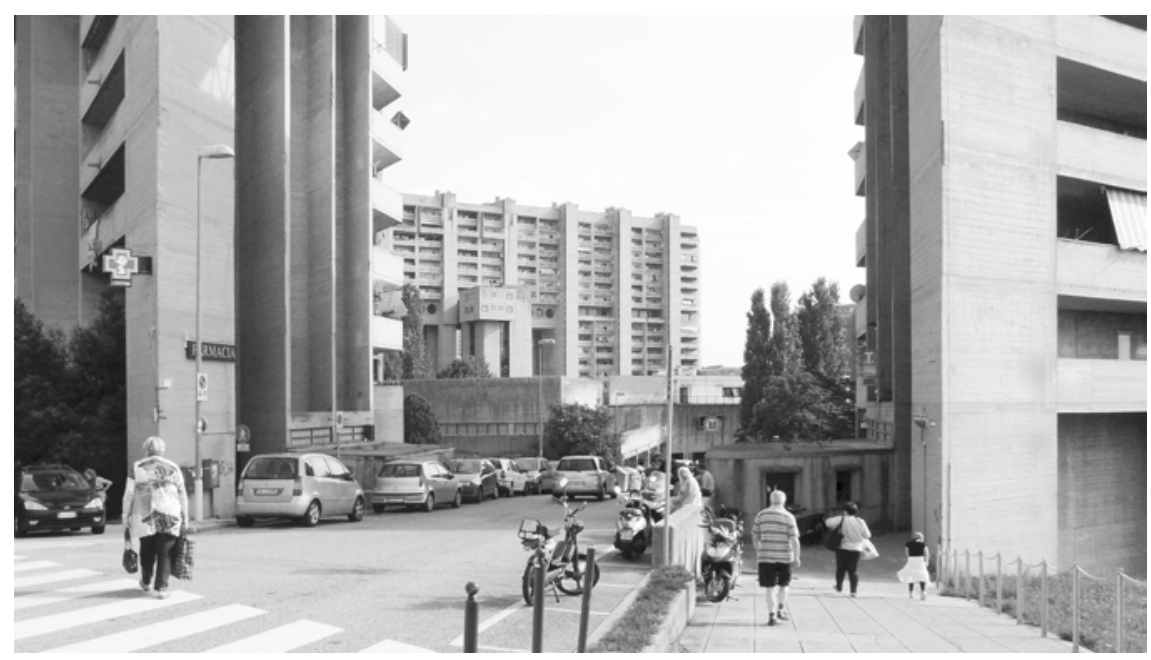

With the essay "Architecture's Public" (De Carlo 1971), De Carlo continued to critically and publically reflect upon the premises of modernism, starting from when they had been formulated in the CIAM declaration of 1928. The essay is based on a lecture given at a conference in Liège in 1969 (ibid., p.3). De Carlo's optimistic trust in change is paired with the criticism of architecture serving capitalist ends before human welfare; of resources being spent on ideologically motivated armed conflict rather than on the improvement of habitats (ibid., p.8); of the contradictions inherent to architectural and urban productions in view of a possible, if any, future role of architects and urbanists. De Carlo criticises the repressiveness inherent in standard planning and building, which is based on the assumption that, when it comes to the question of change, "[...] it is easier, quicker and more profitable to condition people than to condition the environment." (ibid., p.17) De Carlo sets against the current mode of "authoritarian planning" the idea of an open "process planning" (ibid., pp.15ff). With this new concept, he proposes a dialogic and dialectical form of co-operation, in which the user participates “[...] as protagonist in a progressive action" (ibid., p.16). De Carlo's proposition aimed to fundamentally change the relationship between builders and users, whereby the users assume the role of co-authors, strengthened in their position and taking an active role. De Carlo famously suggests that

"in reality, architecture has become too important to be left to architects. [...] therefore all barriers between builders and users must be abolished, so that building and using become two different parts of the same planning process. Therefore the intrinsic aggressiveness of architecture and the forced passivity of the user must dissolve in a 
condition of creative and decisional equivalence where each - with a different specific impact - is the architect, and every architectural event-regardless of who conceives it and carries it out - is considered architecture." (De Carlo 1971, p.11)

At the core of De Carlo's proposal is the idea that users should have the power and means to change their environment as needed and desired. In his view, not only those who can afford change should be able to do so, but all users irrespective of status and income (ibid., p.16). In order to achieve this goal, De Carlo suggests that basic assumptions on the mode of production, including the [...] private and exclusive way of using land" (ibid., p.18), may have to be substantially revised. Hence, issues that had previously been externalised and suppressed, in the name of a homogenising modernist agenda, are required to take a central position in the process. De Carlo anticipates new, 'disorderly', unpredictable architectural qualities to emerge, similar to the kind of qualities that are "[...] manifested sporadically in the margins not already controlled by institutional power." (ibid., p.15)

Today, users continue to struggle with the built modernisms inherited from the past. De Carlo's criticism and ideas still seem highly relevant, particularly in residential uses, where the difficulties to adapt the privately and collectively used environment is, perhaps, most directly felt. The protesters' generation of the 1968 Triennale in Milan has established and inspired subsequent initiatives towards alternative modes of space production, process-led design, participative models, experimental self-built structures, and user empowerment. In the years that followed, architects like Ottokar Uhl, John Habraken, Walter Segal, Ralph Erskine, and others have explored alternative practices in which design authority and ideas about spatial arrangements were not pre-givens, but the result of a negotiated process.

\subsection{The Everyday as Site of Resistance and Emancipatory Practice}

The everyday developed into a diverse field of enquiry during the course of the various turns in the social sciences, cultural and urban studies, social geography and other disciplines. It offers, together with concepts such as the marginal, pop culture, the body, gender or queer space, a unique perspective through which different research problems may be approached. Architectural concepts of the everyday have existed since housing and the ordinary built environment had been defined as sites of professional work. The everyday has broadened, among other things, the understanding of how the social interacts with the spatial, which in turn has influenced the way questions of spatiality are approached in urban and architectural practice today. The 'Frankfurt Kitchen', designed by architect Margarete Schütte-Lihotzky in 1926, could be seen as a paradigmatic combination of architectural design work and the everyday. The close study of everyday actions and spatial configurations informed a design based on efficiency, spatial economy, convention and ideas of emancipation (Führ 1996) ${ }^{30}$. The critique of efficiency-thinking, functionalism and the perceived poverty of newly built environments in turn established its own perspectives on the everyday, as for example through the writings and analyses of Kevin Lynch (1960), Jane Jacobs (2011 [1961]),

30 A more detailed discussion of the 'Frankfurt Kitchen' is provided in chapter III, section "Deterministic and Non-Deterministic Models of Change" as excursus in the footnotes. 
Figure 19: Spaces of everydayness, creativity and urban resistance: 'Bellevue di Monaco' social cooperative housing and community project in central Munich. The project provides a home to young migrants, cultural events and community work. The initiative successfully challenged a townhall decision to demolish the 1950s building. Müllerstraße 6, Munich 2018

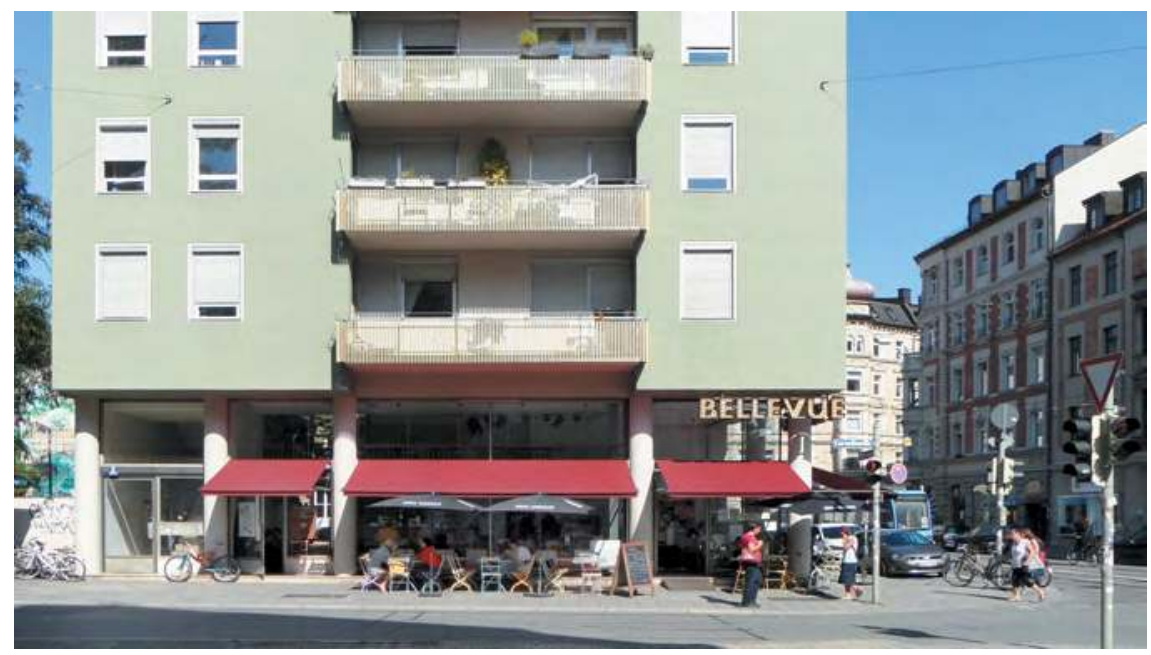

Christopher Alexander (1979), William Whyte (1980), Jan Gehl (2011 [1987]), or through the photographs of street life in Bethnal Green by Nigel Henderson for Team X's critique at CIAM (Frampton 2007 [1980], pp.271f). Concepts of the everyday have influenced the studies of townscapes and high-streets (Cullen 2010 [1961]; Venturi, Scott Brown and Izenour 1977 [1972]) of pop-culture and Disney World, of the vernacular and do-it-yourself. The hypothetical everydayness of body/machine relations became the theme of numerous drawings and installations during the 1960 s and 70s, while Superstudio's anti-consumerism visions of the everyday unfolded in a hybrid-world of naturalness and monumentality (Frampton 2007 [1980], pp.288f). Today, references to the everyday are made in the collaborative and process-orientated work of practices like muf architecture/art (Heilmayer 2010), raumlaborberlin (Bader 2004; 2006; raumlaborberlin, Maier and Heidelberger Kunstverein 2008), Jesko Fezer and ifau (Fezer et al. 2011), subsolar (Hebert 2012), Assemble Studio, Bernd Kniess, and Ton Matton (Wolfrum and Brandis 2015), and the many others who position their projects in this field (Awan, Schneider and Till 2011).

Kanishka Goonewardena suggests that four principal concepts of the everyday may be identified in current theory, based on the theoretical perspectives of Adorno and Horkheimer; Heidegger; Lefebvre and Debord; and De Certeau (Goonewardena 2008, p.130) ${ }^{31}$. Among them, the concepts developed by Henri Lefebvre are of particu-

31 Kanishka Goonewardena (2008, p.130) distinguishes between the following four major concepts of the everyday: 1. Adorno's and Horkheimer's representation of the "culture industry", in which everyday life is devaluated under late capitalism, individual activity limited to passive consumption and privileged forms of autonomous art understood to offer a last refuge for the opposing of a totalitarian world. 2. Heidegger's critique of the modern world in which he equates everyday life with everydayness (Alltäglichkeit), through which the "how" of "Dasein" unfolds in an all-pervasive and indif- 
lar relevance to those who study and theorise about the everyday in its connectedness to the urban, to macro-scales of enquiry and the political. Lefebvre's writings reflect a lifelong interest in the everyday, in particular his project "Critique de la vie quotidienne", which evolved through three major publications in 1947, 1961 and 1981, and which has contributed towards an understanding of the everyday as a conceptual site of emancipation and of political resistance (Goonewardena, Kipfer et al. 2008) ${ }^{32}$. Henri Lefebvre conceptualises the everyday as the dialectically defined intersection between economic, administrative, and technological imperatives acting as colonisers of space and time, and of categories of individual actions and choices that escape such forms of domination (Lefebvre 1991 (1947), p.37, p.248; 2008 [1981], p.127; Ronneberger 2008, p.135).

In the everyday, passive consumption is confronted with the productive creativity of the individual. In suggesting the everyday to be at "[...] the intersection of the sector man controls and the sector he does not control [...]", Lefebvre relates the everyday to conflicting forms of power and change (Lefebvre 1991 [1947], p.21). As a site of analysis, the everyday is seen to make explicit the contradictions within the larger economic and societal domains. In the second volume of the "Critique of Everyday Life", Lefebvre uses the "conflictive, polyvalent" micro/macro relationship to further elaborate on this condition, suggesting that the macro "[...] makes every effort to contain, absorb and reabsorb the 'micro' [...]", which in response "[...] puts up a resistance". (Lefebvre 2002 [1961], p.141). Hence, the everyday can be defined as a potential site of discontent and subversive practice, where groups and individuals may strive for their own urban ideas of the "possible-impossible" (Lefebvre 2003 [1970], p.179) ${ }^{33}$. If conceived in this

ferent way (and thus belongs to Heidegger's category of “inauthenticity"). 3. Lefebvre's and Debord's notions of the everyday as that which remains when all specialised activities are removed, leaving an essential residue that intersects with contradictive and invasive forms of power. 4. De Certeau's idea of a "creative consumer" who exerts forms of resistance through practices of the everyday rooted in consumption rather than production, and in the cultural rather than the political. Among these, Lefebvre's and Debord's concepts are most closely tied into a critique of the spatial and the urban, for which reason they tend to exert greater appeal to urban geographers, urban sociologists and critical urbanists than do the others. Moreover, Heidegger does not lend himself easily for 'Left-Heideggerian' appropriations, and Adorno and Horkheimer's association of the everyday with passivity would provide a rather weak basis for the assembling of a critique that is directed towards change. Critical enquiry that struggles with Lefebvre's 'totalising' argumentation, and which prefers to emphasise on difference that is less concerned with radical transformation, tends to turn to De Certeau's approach and the more moderate forms of resistance in creative consumption. Despite the significant differences in approach and intentionality, these concepts do not exist in isolation to each other and have led towards combined adaptations in architecture and urbanism that have produced further differentiations in this field.

32 Christian Schmid locates Lefebvre's initial recognition of the everyday as early as 1925, when Lefebvre, as member of the 'Philosophes' group, engaged in debate with friends of the surrealists (Schmid 2010, p.115). While surrealism, conceived as a way-of-life, sought to overcome the everyday through poetical practices, the 'Philosophes' group saw their approach towards the everyday as a form of revolution (ibid.). This seems to be significant to our discussion as it emphasises Lefebvre's theorising about the everyday to embody a perspective towards change that emerges from the dialectics of the possible-impossible.

33 Excursus: Based on the understanding that the concept of the everyday is closely related to the concept of the lived, controversy emerged as to whether the lived of Lefebvre's triadic dialectics of the 
Figure 20: (Re-)appropriation and alternative urban practices. Community garden and street art at former live stock market, Munich 2014

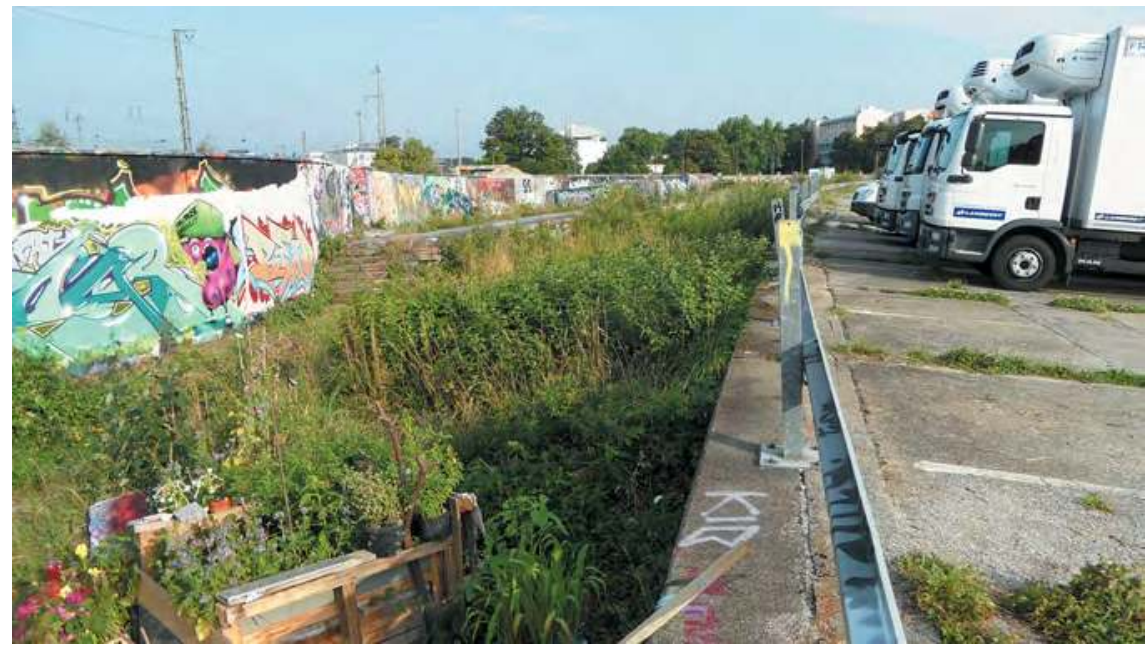

way, the everyday qualifies as a site of critical spatial enquiry as well as an arena for political action, in which dominant systems of space production may be challenged through choice and alternative spatial practices. We could say that two kinds of resistances meet in the everyday. The resistance 'from below' seeks to maintain the spaces and practices it has established for itself, however limited they may be, while the resistance of dominant processes 'from above' seeks to assume control of them and in this way accelerate its own process. Hence, we are looking at

production of space may be defined as privileged site of analysis (Schmid 2010, p.309). For Soja, the lived is closely related to the question of individual and collective choice, suggesting that "it is political choice, the impetus of an explicit political project, that gives special attention and particular contemporary relevance to the spaces of representation, to lived space as a strategic location from which to encompass, understand, and potentially transform all spaces simultaneously." (emphasis in original, Soja 2000 [1996], p.68) In the first postscript to "Thirdspace", titled "On the Views from Above and Below", Soja takes up his interpretation of lived space as site of struggle and resistance and relates it to everyday life, which in this instance is defined as level of urban analysis as well as "concrete abstraction for the socialized microspatiality of the urban" (ibid., pp.310f).

Like other aspects of social practice within the conceptual model of Lefebvre, the everyday is understood to embody all three dimensions of the production of space, the perceived, the conceived and the lived. If the everyday is understood to be socially produced, then it seems that there cannot be a practice of the everyday without simultaneously combining the 'lived' with a physical presence in the 'perceived', that is the material, and the 'conceived' as mental projection of spatial concepts and spatial organisation. Hence, Christian Schmid argues that interpretations of the 'lived' as privileged site of struggle are not fully compatible with Lefebvre's theory (Schmid 2010, p.309). Assuming that the category of 'lived space' is more or less equal to 'spaces of representations' in the Lefebvrian triadic model (Schmid 2010, pp.222ff), Schmid suggests that "Lefebvre never made explicit his strategic 'preference' for the spaces of representations" (ibid., p.69), thus criticising Edward Soja's proposition that "lived social space, more than any other, is [...] the space of radical openness, the space of social struggle" (Soja 2000 [1996], p.68). 
1. Resistance as concept of emancipatory struggle embedded in practices of individual and collective appropriation and actions of the everyday; and at

2. (Counter-)Resistance emanating from the various interacting mechanisms that represent and reproduce the prevailing hegemonic order, and that seek to channel or supress emancipatory activity.

In the wake of the French political Left attaining power during the 1980s, as well as the general crisis of the socialist project, Lefebvre emphasises in the conclusion to the $3^{\text {rd }}$ volume of "Critique of Everyday Life", that the outcome of a radical social transformation cannot be "[...] faster growth or a mere change of political personnel [...], but different growth - that is to say, qualitative development, and hence a greater complexity, not a simplification, of social relations." (emphasis in original, Lefebvre 2008 [1981], p.165). Klaus Ronneberger suggests that Lefebvre's project of analysing and interpreting the everyday is related to the fundamental belief that alternatives are possible (Ronneberger 2008, p.135). "Insofar as the critique of everyday life shows how people live, it articulates at the same time an indictment against the strategies from which the everyday emerges and reveals the arbitrariness of the dominant order." (ibid.) Hence, according to Ronneberger, Lefebvre's "[...] analysis of the extant must always take into consideration insurgent forces and the question of liberation." (ibid.) However, the practices of the everyday that during the era of Fordism offered possibilities of resistance, and that in this respect were important points of reference for Lefebvre's critique of the everyday, have been partly absorbed by capitalism and subsumed into the service of the neoliberal project. Ronneberger observes that "once mobilized against capitalism, attributes like 'subjectivity' and 'creativity' are now important resources for processes of economic valorization." (ibid., p.141) Hence, given the potentialities created by contemporary urban initiatives that build on practices of the everyday, it is not surprising that institutionalised forms of urban practice have a tendency to control, contain, and exploit their transformative capacity.

In the article "The City of Everyday Life. Knowledge/Power and the Problem of Representation", John Friedmann explicates how planning has the tendency to evolve via abstraction and large scale thinking, whereby statutory representations of the city retain their static "aura of inevitability" (Friedmann 1999, p.5). Drawing on the writings of Lefebvre, Friedmann argues that meanings associated with the built environment are formed through experience and shared in communications of the everyday (ibid., p.8). Friedmann observes that the city of the everyday, composed of multiple appropriations and meanings, is not adequately represented in decision making processes (ibid.). In Friedmann's view, this is partly because the everyday is not widely audible, due to its very own nature, as well as the difficulty of distinguishing between exclusively personal meanings, and meanings that are more widely shared and agreed upon (ibid.). Berlin based architect and urban researcher Saskia Hebert draws similar conclusions when in her study of Halle-Neustadt she identifies the discrepancies between technocratic readings of space on the one hand, and individualised forms of "resistance through dwelling" as a response to this problem on the other (Hebert 2012, p.10). The selective and technocratic reading of urban space could be interpreted as a resistance to change on the side of the institution, for if the everyday was to be fully acknowledged as transformative urban process in its own right, established institutionalised practices would have to be fundamentally revised. Friedmann's and 
Hebert's observations seem to raise two questions for an urban practice that seeks to work with the everyday: How to identify, represent and analyse everyday practices and meanings so that they can be more widely shared and communicated? And how to make everyday actions and communications drivers in processes of collective forms of appropriation and transformation? In view of the continued pressure on cities, the everyday as site of resistance will remain a key narrative for researchers and activists who approach the urban from critical perspectives.

\subsection{Forensic Work and Commoning in Contested Spaces}

The "Forensic Architecture" perspective connects everyday spaces with conflict, violence and the built environment. It is a specific way of looking at and working with highly politicised situations, in which actions and events are entangled with the materialities of space. Architect and theorist Eyal Weizman speaks of an "urbanisation of conflict" (Weizman 2012a, p.236), in which the city relates to conflict on several levels: The city stages acts of conflict, including violence, and serves as backdrop for its mediatised representation. The city partakes in these acts, through architectural construction or destruction (ibid., p.254). In this way, the built environment, conceived as "thick surface of the earth" (ibid.), becomes the depository of political events and processes (ibid., p.251). Based on the evidence of violence that is traceable in the built environment, the synthesising logic of architectural design is conceptually reversed in Forensic Architecture - it reconstructs processes of destruction. Because materialisations in space do not provide a consistent picture of time as suggested earlier, and because architecture is only a weak sensor for registering political forces and cannot speak for itself (ibid., p.252), Weizman introduces the role of "interpreter" who detects, analyses and translates the traces imprinted on the urban fabric (Weizman 2012b, p.9), so that the conditions of conflict become audible and explicit. The resulting construct of Forensic Architecture is made of three elements (ibid.):

"thing" (that does not have a voice of its own) - "interpreter" - "forum"

Theorising on 'European Urbanity', the main theme of the EUROPAN 8 competition, Weizman had already demanded that "contemporary methods of architectural intervention may look beyond the social organisation of tolerance and cooperation to uncover Europe's topology of enmities, and the city as a common area of conflicts." (Weizman 2007, p.142) The view of the city as shared territory of conflict allows architectural and urban practice to become political, not only because associated research is covering a political subject, but also because it is mobilised within the political space of multiple forums (Weizman 2012a, p.250). Weizman suggests that Forensic Architecture defines a "new field of spatial thought-practice" (ibid.). The 'architecture' in the approach is not concerned with the design of a building, but rather with establishing an "expanded field of spatial investigation, imaging and representation" together with a platform of exchange and communication to which Weizman refers as "forum" (ibid., p.250). "Forensic Architecture must thus be grounded in both field-and-forumwork; fields being the sites of investigation and analysis and forums the network-assemblages of political spaces in which analysis is presented and contested." (Weizman 2012a, p.250). He concludes that forensic architectural research is not averse to archi- 
tectural construction, but rather depends on it to produce the spaces in which it can resonate (Weizman 2012a, p.253). Weizman highlights the etymological connectedness of "forum" and Latin "forensis" - as that which pertains to the forum - meaning the rhetorical skill of presenting a case before an audience (Weizman 2012b, pp.8f).

Forensic Architecture engages with situations of uncertain and often conflicting media representations. In this approach information is not taken-for-granted. With access to actual sites of conflict being restricted, the approach operates on the basis of alternative sites and sources of evidence - it operates on the basis of an analytical, forensically reconstructed in-between. Where the control of access and information is systematically used and abused, the ambiguity and uncertainty of being in-between requires a methodological response. This is why both interpreters as advocates of the investigated issue, as well as the forum in which possible interpretations are collectively evaluated and shared, are essential elements of the process. We can see how the forensic role of "interpreter" relates to the researcher as "critical examiner" (Popper 1960, p.37), and how the "forum" finds its equivalent in Latour's "arena" of critical engagement (Latour 2004, p.246). What distinguishes Forensic Architecture is its capacity to engage with highly contested spaces where conflict operates at its most violent and destructive level, demanding from interpreters and forums the highest possible degree of responsibility. However, although the perspective's current main focus is on sites of terrorism, zones of war, and the spatial management of conflict in Palestinian territories, the more general idea of Forensic Architecture as an "archaeology of the very recent past" (Weizman 2012b, p.10), which through discourse, or the forum, is connected with the future, makes it a concept that can be also applied to other, less violent situations in which architectural analysis seeks to assume the double role of sensor and agent of change $e^{34}$.

Where the "urbanisation of conflict" (Weizman 2012a, p.236) has established a permanence of conflict, the work in the field may be extended so that long-term commitment to a specific situation is possible. Site analysis may then be combined with acting within spaces of conflict, and the hope of changing them. The "Hands-on Famagusta" project engages with different permanences of conflict in Cyprus (Stratis 2016). Inter-communal conflicts and the war in 1974 have converted the island into a territory of enclaves, demilitarised zones, segregated communities and mentalities of division. Spaces in Cyprus are highly contested and politicised. The initiators of "Hands-on Famagusta" understand the project to be part of "commoning processes that challenge dominant divisive narratives, offer alternatives to segregating urban reconstruction approaches, and advocate for the transformation of ethnic conflicts into urban controversies." (ibid., p.6) With this agenda, the project clearly transgresses the confines of a narrowly defined architectural project. Consequently, co-initiator of the Hands-on Famagusta project and editor of the "Guide to Common Imaginaries in Contested Spaces", Socrates Stratis, asserts that frameworks of acting, representation and learning have to be addressed prior to working on physical interventions in the field (ibid., p.15). In spaces that are defined by enclaves and borders more than by territorial continuity, the concept of thresholds and in-between spaces assumes a specific meaning together with the architectures that engage with them. Referring to the work

34 Many thanks to Henri Praeger for sharing his ideas about the forensic reading of change, as well as providing insights to his practical work at Praeger Richter Architekten, to which I refer at a later stage. 
Figure 21: Forensic Architecture. Installation by Eyal Weizman et al. at the Venice Biennale. Micro-analysis of a drone strike in Miranshah, Pakistan, based on a video still taken after the attack. The Forensic Architecture investigation proofed that the destruction and killing of people had been the result of a drone strike and not of an accident as claimed by members of the army. Venice 2016

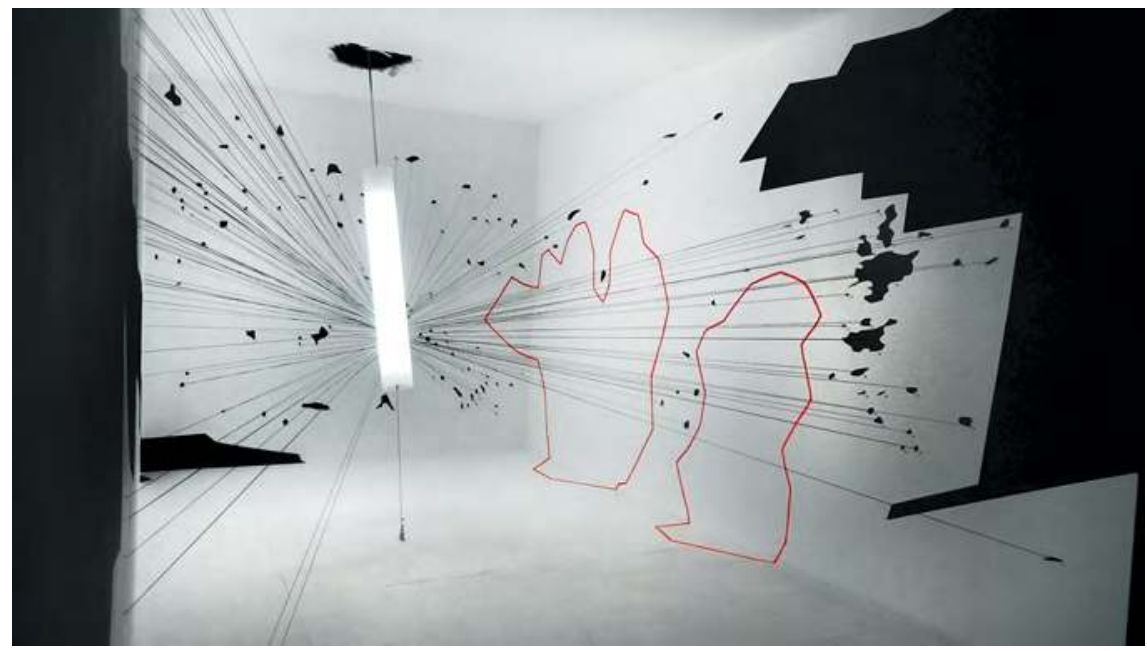

of activist and architect Stavros Stavrides about thresholds (Stavrides 2010) ${ }^{35}$, Stratis suggests that "the new role of architecture is about [...] advocating for urban porosity by transforming edges to urban thresholds, thus confronting trends behind territories of exclusion responsible for shutting out the urban commons." (ibid., p.15) The creation of new thresholds and the redefinition and appropriation of in-between spaces is part of a set of "commoning practices" (ibid., p.44) that include counter-mapping, the learning from other situations of urban division, the collective reconstruction of controversies, roundtable sessions and workshops, the making productive of design knowledge in the common imagining of alternative futures, as well as the temporary activation of contested spaces through excursions and movements through the contested field (ibid., pp.13ff) - literally and conceptually as "moving project" (ibid., p.13). The moving project takes advantage of the conceptual prioritising of relationality and temporality over fixation, and of the opportunity to experience and debate thresholds, divisions and connections from different perspectives. The Hands-on Famagusta project includes elements of the "Mapping Controversies" method by Albena Yaneva (Yaneva 2012, 2016), which provides an environment of joint mapping, debating and learning. Supported by the method, local and external knowledge about the situations of concern is brought together and shared between communities and across divides.

35 Many thanks also to Stavros Stavrides for the conversation at the Porous City conference about thresholds and porosity, architectural activism, and the article "Urban Porosity and the Right to a Shared City" (Stavrides 2018). 
The commons initiative seeks to develop alternatives to strategies of conflict containment that cut permanently through people's everyday lives, and to city reconstruction practices that are optimised to the requirements of global capital. Hence, rather than accepting divides and their official representation as the undesirable but seemingly unavoidable end-point of a conflict, alternative practices work towards the redefinition of situations as common zones of conflict, with the goal of establishing "common urban imaginaries in contested spaces" (Stratis 2016, p.44). From this perspective, conflict is seen as having a "permanent and potential generative aspect" (ibid.) that may be mobilised in the service of "civic empowerment, mediation, and negotiation" (ibid.).

\subsection{Urban Age versus Urban Extraction}

According to Neil Brenner, the discourse established around urban issues constitutes one of the dominant meta-narratives of the present (Brenner 2013, p.85). Broad sections of current academic research, institutional programmes and public debate relate to urban questions and urbanisation. The growing significance of the urban as well as current institutional reorientations and global spatial transformations are, according to Brenner, related to three major strands of conflict and change (emphasis added, Brenner 2013, pp.87-89, p.103):

1. Our understanding of the geographies of urbanisation is increasingly based on extended city regions and complex heterogeneous urban morphologies, superseding concepts of urban-rural divide and models of polycentricity. The urban condition is defined by the conflicting and simultaneously occurring processes of agglomeration and extension.

2. Transnational networks and regulatory frameworks are established in major world economic regions, which selectively territorialise global investment in economies and infrastructure, as well as concentrating flows of resources, labour and capital.

3. The urban domain is a main arena of sociopolitical struggle and collective action under conditions of globalised capitalism, neoliberalism and fundamental change.

The growing scale and significance of flows and processes that exceed the legislative reach of the nation state have changed the conditions in which planning and architecture operate. The redistribution of investment and wealth, formerly the domain of the nation state, is increasingly affected by supranational interests. Broader frameworks may be established at European Union level or other supranational levels, yet, in the absence of binding agreements, this task is effectively entrusted to the allocation capacity of the global market. Protagonists of the 'Urban Age ${ }^{136}$ conceive of this trend as a unique chance for cities to further develop their strengths based on heterogeneity, innovation and competitiveness, as allies of the private sector in the pursuit of prosperity. Hence, city governments have to decide whether and to what extent they are willing to share in the idea of the city as "growth machine" (Hesse 2018, p.79) ${ }^{37}$. The authors of

36 The term is associated with the 'Urban Age Project' of the London School of Economics, LSE and Deutsche Bank's Alfred Herrhausen Society.

37 Hesse borrows this term from Harvey Molotch (Molotch 1993, cited in Hesse 2018, p.79). 
Figure 22: Sony distribution centre set alight during violent protests against inequality, racism and urban marginalisation in London and other British cities, Enfield near London 2011

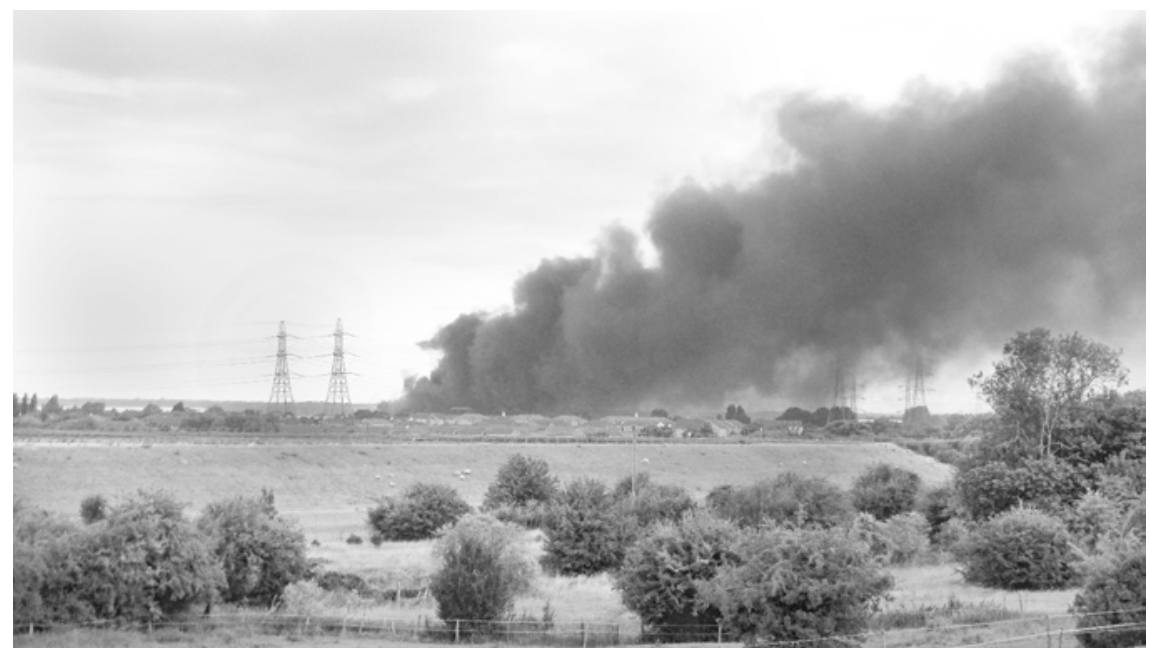

"An Agenda for the Urban Age", a position formulated for the Endless City catalogue of the Urban Age Project, demand that

"Cities must move to the forefront of national and supranational agendas and priorities. [...] The urban age cannot be delivered by government alone; it requires new partners in the private sector. Cities do not just make nations rich; they make corporations rich. And, it is in the self-interest, the shareholder interest, of corporations to advance a full vision of prosperity of cities." (Katz, Altman and Wagner 2007, p.481)

The categorisation of cities as potential and potent partners of the private sector is based on the assumption that such a partnership is aligned with the requirements of the market rather than with the requirements of projects that prioritise social and ecological agendas over profit. For urbanists critical of neoliberal urban policies, the proposed alliance of the entrepreneurial local government with agents of the global corporate economy are seen sceptically, whereby the kind of envisaged 'prosperity of cities' is thoroughly questioned (Fezer 2010). What is presented as a strengthening of the role of cities on the global level, or more precisely, on the level of the global market, can be conceptualised, with recourse to Henri Lefebvre, as an assault on the city "from above" in connection with a corresponding market-driven, consumerist assault "from below" (Lefebvre 2003 [1970], pp.94; Schmid 2010, p.175). The pressure exerted on cities from above and below raises the question of the extent to which the transformation of cities may be still influenced by planning intent (Sieverts 2003 [1997]; Burdett and Sudjic 2007; Fezer 2010; Hesse 2018). According to Jesko Fezer, the current situation in many cities is characterised, on the one hand, by economised and de-politicised urban spaces withdrawing from democratic and critical practice, resulting in a "post-political" condition and the blocking of urban policy (Fezer 2010, p.17). On the other hand, the inability of the market to effectively address inequality and ecological disaster is 
seen as a disqualifying failure of post-political governmentality and market-led regulation (ibid.). Fezer suggests that because of these challenges and uncertainties, cities should not resort to passivity and, instead, assume an active role in transformative processes, "[...] since neoliberalism as a practice is embedded in the urban context; it always takes place in national, regional, or local contexts and relies on their respective institutional and political parameters, local regulatory practices, and political controversy." (ibid., p.17)

In the urban age, the crisis of cities is tied to the networks of the global economy. Conceptualising the global corporate economy as the "geography of extraction" (Sassen 2014, p.219), Saskia Sassen describes in her analysis "Expulsions. Brutality and Complexity in the Global Economy" how corporate interests develop and employ instruments of highest complexity to exploit the human, natural and financial resources of the planet with "often quite elementary outcomes" (Sassen 2014, p.219). According to Sassen, cities in the Global North are not exempt from this process and its negative consequences, despite the "impression of overall prosperity" (emphasis in original, ibid., p.28). Sassen suggests that while effects may not be as severe or visible as in other regions of the world, marginalisation and growing inequality do occur, taking the form of expulsions "[...] from life projects and livelihoods, from membership, from the social contract at the center of liberal democracy." (ibid., p.29) The increase in the foreclosure rate of homes in Europe in the wake of the banking crisis serves Sassen as an example of how the global finance industry and the realm of the everyday are connected with each other (Sassen 2014, pp.48f). Urban property and housing is seen to be directly involved in and affected by the current realignments in the financial market (Hesse 2018, p.79). However, to portray the local as victim of global processes would be misleading. Residential property is increasingly seen as investment and traded as an asset by private households alongside corporate and institutional investors (Dell 2013). The privatisation and "financialisation" (Hesse 2018, p.79) (18 $^{38}$ trend in housing is likely to persist, while the debt level of municipalities is repeatedly argued to set tight limits as to their ability to pursue a more active role in urban processes (ibid.) However, critics argue that local government policy as well as local action can make a difference, despite these constraints (Fezer 2010, p.17; Hesse 2018, pp.80-83). The situation of the Parkstadt Bogenhausen housing estate, which I examine in the case study element, has to be seen against the background of the multiple interests assembled around property and residential space, as well as the conflicting agendas and strategies that intersect in the city.

38 Hesse borrows this term from an article by Ludovic Halbert and Katia Attuyer (Halbert and Attuyer 2016, cited in Hesse 2018, p.79). 
Figure 23: Boarded-up entrance to Print House during violent protests against inequality, racism and urban marginalisation in London and other British cities. The building is managed by the community-based, not-for-profit Bootstrap Charity. Dalston, London Borough of Hackney 2011

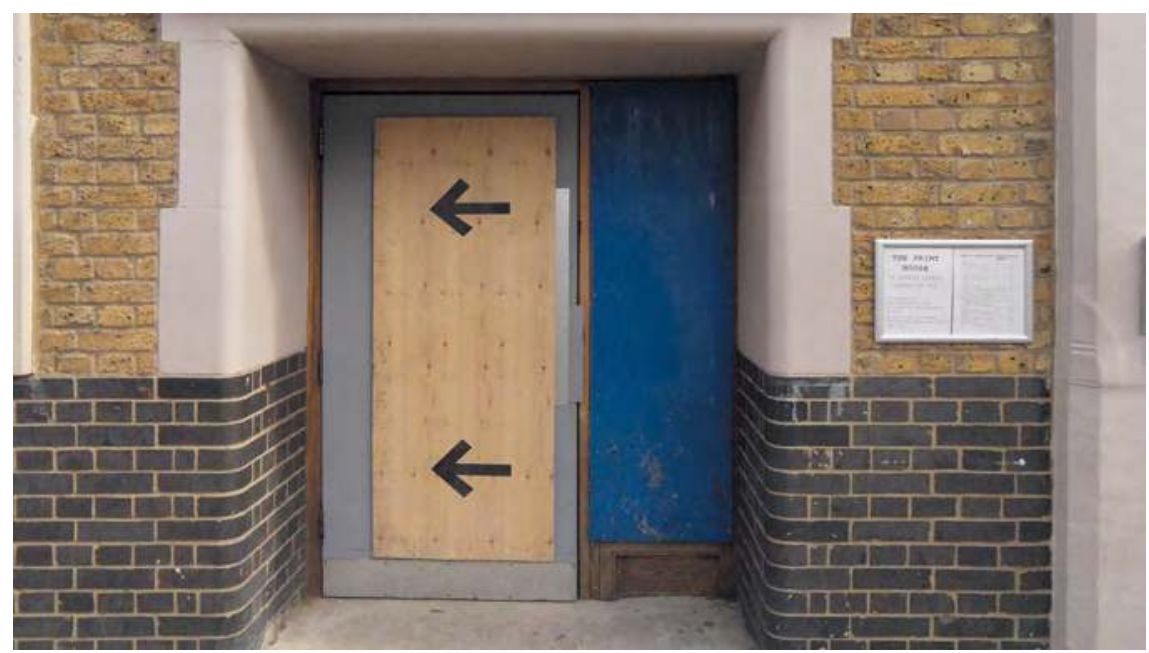

\section{Conflicts Between Centrality and Choice}

\subsection{Contested Urban Centralities}

In this final section of the enquiry into narratives of conflict, I establish a series of conceptual anchor points that are related to different ideas of centrality. Despite the difference in how conflict articulates itself in the concepts examined, they share a common principle: centrality is understood as defining a privileged, and therefore contested urban condition. The first concept in my discussion is Lefebvre's dialectically defined, non-static centrality. This is followed by the discussions of the fringe-belt phenomenon as a distinct zone of morphological collisions, and the logics of geometry and choice that occur in conditions of urban shrinking. Next, the "paradox of centrality" (Hillier 2007 [1996], p.266) is discussed as a basic concept of the Space Syntax model, in which problems of centrality and spatial conflict are made operable as problems of geometry and urban form. And finally, I discuss the concepts of "capsularization" (De Cauter 2001) and co-existence in the context of dispersed urban environments.

Lefebvre's concept of centrality is closely related to his conceptualisation of the urban. Theorising about urban form in "The Urban Revolution", Lefebvre suggests that "[...] the essential aspect of the urban phenomenon is its centrality, but a centrality that is understood in conjunction with a dialectical movement that creates or destroys it." (emphasis in original, Lefebvre 2003 [1970], p.118) ${ }^{39}$ Lefebvre positions centrality within

39 Christian Schmid observes that Lefebvre introduces the concept of centrality as a kind of theorem, without explicit recourse to other theories or authors. Schmid identifies within the work of Lefebvre three areas which open up the possibility to speculate about possible theoretical connections: the an- 
a simultaneous process of accumulation and dispersion (ibid., pp.119f). Centrality is conceived as a "pure form" (ibid., p.118) of changing relations rather than as a fixed locality. Content or programmes are understood to be exchangeable and therefore not constitutive of centrality (ibid., p.116, p.118). According to Lefebvre, the centrality of the urban establishes proximities and encounters between "[...] products and producers, works and creations, activities and situations." (ibid., p.117) It facilitates multiple relationships (ibid.). Hence, Lefebvre combines in his idea of centrality a relational understanding of space with the movements of a dialectic process. Lefebvre's centrality is not static. Changing relations and dialectical movements generate differences. For Lefebvre, "[...] the urban situation [is] where different things occur" (emphasis in original, ibid., p.117). In this sense, the "[...] city constructs, identifies, and delivers the essence of social relationships: the reciprocal existence and manifestations of differences arising from or resulting in conflicts." (ibid., p.118) Conflict is seen as product and producer of differences, and therefore as a generative force. Centrality condenses by negating the distance between conflicting contents (ibid.). Centrality is a producer of conflict and "drama"; it is "the source of latent violence" (ibid.). Concentration accelerates processes. The compression of distance translates into proximity of differences and the compression of time. Conceived in this way, centrality acts as an urban catalyst. Lefebvre's dialectic allows him to conceive of centrality as accommodating both the structures and mechanisms of power and the state, as well as the possibility of radical social change (ibid., p.106; Schmid 2010, pp.183f). Centralities are prime targets of power and highly contested zones of urban intervention.

Lefebvre's concept of centrality differs significantly from conceptualisations based on concentric hierarchies, as in the model of central places (Schmid 2010 pp.186) ${ }^{40}$, the garden city, or other poly-concentric schemes. While these models seek to reduce conflict, through segregation, as in the garden city, or through even spatial distribution and homogenisation, as in the model of central places, dialectical interpretations of centrality work with the foregrounding of conflict and destabilising movements:

"[...] during its realization, this concentration flexes and cracks. It requires another center, a periphery, an elsewhere. An other and different place. This movement, produced by the urban, in turn produces the urban. Creation comes to a halt to create again." (Lefebvre 2003 [1970], p.118)

cient Greek and Latin tradition of defining the polis as site of thought and innovation; the concentration of people, capital, means of production, needs and desires as conceptualised by Marx and Engels; and the concepts of the Situationists (Schmid 2010, pp.177f).

40 Christian Schmid draws a brief comparison between Walter Christaller's and Lefebvre's models to establish the uniqueness of Lefebvre's conceptual approach. Walter Christaller's theory of central places, initially developed to describe patterns of spatial distribution in southern Cermany, became the guiding principle, as a model, for regional planning in post-war (West)Cermany, and well into the 1990 following the German unification process. At the core of the model is the premise of a homogenised space and of economic efficiency. In view of the fact that the model was applied to occupied Poland during the 1940 s by NS geographers, the factual and ideological capacity of the model to reinforce systems of domination cannot be denied. 


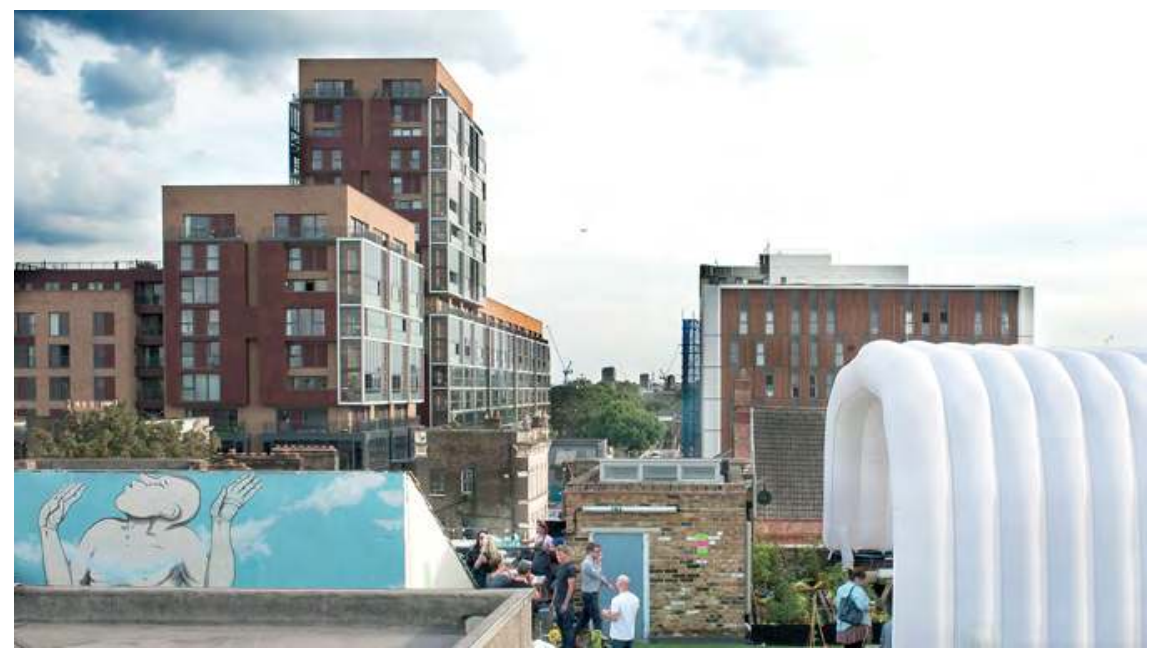

In this passage, Lefebvre establishes a connection between the accumulating movement towards centrality and the opposite movements towards dispersion and the periphery. Lefebvre argues that for a broader understanding of urban phenomena, concepts like network need to be included in the conceptualisations (ibid., p.121). Lefebvre associates networks with exchange and communication (ibid.), suggesting that "[...] the urban is also defined as the juxtaposition and superimposition of networks, the assembly and union of those networks, some of which are constituted on the basis of the territory, some on industry, and others on the basis of other centers within the urban fabric." (ibid.) Based on Lefebvre's propositions, today's material, digital or social networks could be seen as producing new urban proximities. Practices, processes, people, products - of and in the network - may intersect to establish a new 'form' of relations and centrality. Existing centralities may be integrated, ignored, bypassed or kept at a distance. Dispersion and redistribution into the network may occur when the condensing capacity of the centrality is challenged, or if it fades away. In this sense, there is a temporal aspect to centrality and networks. Examples of temporal centralities could be seen in the 2013 protests of Taksim Square and Gezi Park in Istanbul, or the protests in the centre of Hong Kong in 2014. During both events state power sought to suppress the protests by gaining control over the physical and digital locations around which the discontent had assembled. The convergence of persisting protest, state power and the media contributed towards the establishment of the events as globally recognised, temporal centralities. The pro-democracy protesters' extensive use of FireChat and other 'off-the-grid' messaging apps in Hong Kong produced in itself a new and temporal centrality based on a local, distributed Bluetooth network. 


\subsection{Capitalism's Contradictory Movement between Fixation and Expansion}

Lefebvre's idea of the urban and of centrality have contributed to the epistemological reframing of urbanisation and cities as sites of critical analysis (Brenner 2014, p.15). Neil Brenner takes up Henri Lefebvre's notion of the urban as process of simultaneous concentration and dispersion, and connects it to the concept of an extended urbanisation that is effective on a planetary scale (ibid., p.17). The title of Brenner's edited volume about the study of planetary urbanism, "implosions/explosions" (Brenner 2014), reflects this contradictory condition. Implosion is understood as concentration and agglomeration, while explosion defines successive cycles of expansion of built-up territory and the intensification of interspatial connectivity and flows across places and scales (ibid.). "The notion of implosion-explosion thus comes to describe the production and continual transformation of an industrialized urban fabric in which centers of agglomeration and their operational landscapes are woven together in mutually transformative ways while being co-articulated into a worldwide capitalist system." (ibid., pp.17f) Cities in this theoretical construct continue to play a key role in processes of transformation, but they are conceptually positioned in "[...] a new vision of urban theory without an outside." (emphasis in original, ibid., p.15)

Brenner's conceptualisations are related to Marxist theories about the geographical and spatial restructuring of the planet according to the requirements of capitalist production. He explicitly points to the parallels between Lefebvre's concepts and David Harvey's descriptions of fixity and motion in the circulation of capital (ibid., p.29, footnote 16). In "The Limits to Capital", David Harvey sets out a conceptualisation of urbanisation and geographical transformations based on the theoretical frameworks of Marx's "Capital", and "Theories of Surplus Value", and the "Grundrisse" (Harvey 1982, p.xiv). Among the phenomena analysed by Harvey is capitalism's contradictory movement between fixation and expansion. Here, a basic conflict is seen between the capitalist's investment in infrastructure and other material assets that are needed for production, and the systemic tendency of the capitalist mode of production towards expansion, short turnover times, and circulation rather than fixation. The capital invested in material assets is defined as "fixed capital" (ibid., pp.204ff), because it has a comparably long turnover time as it passes on its value to manufactured products. Harvey emphasises that "fixed capital is not a thing but a process of circulation of capital through the use of material objects [...]." (ibid., p.205). Typical material assets used and gradually consumed in the production process include harbours, ships, railroads, planes, dams, power plants and networks, data infrastructure, as well as factory buildings, offices, warehouses and storage facilities. According to Harvey, the capitalist is facing a dilemma when investing in a production facility, as the capital is tied up in a specific location, technology and production process for a certain time. During this period the capital cannot be moved without loss. It is vulnerable to devaluation if it is not 'at the right place, at the right time' from the perspective of capitalist production. Fixed capital may accumulate over time as production expands, but in doing so it establishes a whole range of fixations and barriers of different kinds, which capitalism ultimately seeks to overcome (ibid., p.394). Harvey takes transport infrastructure as an example to illustrate the inherent conflict in the relationship between fixed capital and capitalist production, pointing to the effects this has on the restructuring and exploitation of capitalist landscapes: 
"[...] capitalism in general requires perpetual reductions in the cost and time of movement, the elimination of all spatial barriers and the 'annihilation of space by time'." (ibid., p.379)

"[...] capitalism seeks to overcome spatial barriers through the creation of physical infrastructures that are immobile in space and highly vulnerable to place-specific devaluation. [...] At some point or other, the value embedded in the produced space of the transport system becomes the barrier to be overcome. [...] Strong devaluations and re-structurings within the transport system, with all that this implies for the shaping of spatial configurations and levels of spatial integration, then become inevitable." (ibid., p.380)

Harvey observes that "capitalism increasingly relies upon fixed capital (including that embedded in a specific landscape of production) to revolutionize the value productivity of labour [...]" (ibid., p.394). As large fixed capital investments are often backed by the state and supported by national economies rather than being funded by individual capitalists, there is a common interest in safeguarding the investments from rapid devaluation. This would be the case when whole industries re-locate and leave non-amortised infrastructures idle. Planning, regulatory frameworks, subsidies and other measures are deployed to influence and mediate the effects of capital circulation, accumulation, devaluation and movement (ibid., p.397). However, due to the nature of the capitalist system, restructuring is all too often resolved through sudden devaluation and severe crisis (ibid., p.398). The "inevitable uneven development of capitalism" (ibid., 428) produces, among other things, the familiar sight of de-industrialised regions, vast brownfield sites, environmental pollution, decreasing incomes, shrinking cities, and migration.

\subsection{Fringe Belt Collisions and Shrinking along the Logics of Choice}

The term fringe belt occurs for the first time in a diagram by geographer Herbert Louis, published in 1936, which shows Berlin's urban development cycles in the form of irregular concentric rings in the city plan (Whitehand 2001, p.105; Rossi 1982 [1966], p.74) ${ }^{41}$. Michael G. Conzen, to whom H. Louis had been a mentor, developed the concept further and applied it to the study of English towns (Conzen 1960; Whitehand 2001; Moudon 2004, p.28). Economically, the fringe belt is associated with a temporary period of low land values in combination with low demands for housing, which had been preceded by a period of high land values and high levels of housing construction (Whitehand 2001, p.105). Characteristic of fringe belt areas are large-scale buildings, often institutional or representational, contiguous vegetated areas, a lack of housing, lower densities, and gaps in the network of radial roads resulting in low permeability (ibid.).

In the historic city functional elements which were considered vital but potentially threatening were banned to peripheral areas. Hospitals, cemeteries, prisons, leather manufacturing and so on were typically treated in this way. The resulting territorial organisation was made up of two zones, the higher-density inner zone which could be

41 In the English edition of "The Architecture of the City", first and second names of H. Louis are confused with each other. 
organised according to the conventions of the orderly, and an external zone, more or less unplanned, which accommodated all things that did not fit this inner order of the city. The external zone developed as a distinct morphologic entity on either side of the city fortifications (ibid.), forming the first fringe belt in a succession of further fringe belts that developed over the centuries, in particular in large cities. Cyclical changes in urban development meant that the anxiously maintained state of segregation worked only up to the point when spatial expansion made the former divisions obsolete.

Philipp Oswalt takes up the concept to reframe the development pattern of Berlin in the course of his speculative conceptualisation of Berlin as city without form ("Stadt ohne Form") (Oswalt 2000). Based on his observations of different phases of urban expansion as the result of shifts in the socioeconomic and the political situation of Berlin, Oswalt develops a narrative of fundamental successive transformations in fringe belt areas (Oswalt 2000, pp.73ff). He suggests that repeated attempts to exclude the unwanted ("das Unerwünschte") from Berlin's city territory had always failed in the long term (ibid.). Sooner or later the unwanted had to be reintegrated or addressed in some way, as a result of further territorial expansion. He suggests that during these recurring situations the orderly was confronted with the disorderly; the hitherto excluded and the included had to establish new relationships with each other. Oswalt refers to this situation as the collision ("Kollision") (ibid., p.73) of formerly separated qualities. They find their expression in the dichotomies of core/suburb, clean/threatening, urban tissue/object, socialism/capitalism (ibid.). Based on the observations made in Berlin, Oswalt highlights the dynamic nature of morphologic processes and collisions, questioning a static reading of centre-periphery models (ibid.). Accordingly, he suggests that changing spatio-urban relations inflicted by political change and alternating phases of expansion have led to the successive repositioning of boundaries, the blurring of morphologically defined demarcations, and the development of new zones of in-betweenness (ibid., p.79). The ongoing dissolution of the urban/rural divide is understood to have led to the establishment of new spatial interfaces (ibid.). The territories which had been the products of concepts of separation are portrayed as now being populated with a mix of competing programmes and desires, which today, as Oswalt asserts, would be most visible in the inner metropolitan region (ibid.).

Conflict, collisions and productive encounters are also central to CHORA's conceptualisation of the urban condition. The research collective is among the few theorists who give similar weight to conflict and change in their discussions. According to CHORA,

'cities consist of many components that are 'in motion', that have speed, evolve. An action in a city-the insertion of a building, law, infrastructure-intensifies or diminishes these components and their developmental processes. Acting in the complex dynamics of cities requires the insertion of a singularity, a new condition, a rupture, which encounters existing components 'in motion' and harnesses their potential. These encounters create confrontations and conflicts, but also sympathies, correspondences." (Bunschoten, Binet and Hoshino 2010 [2001], p.348)

While fringe belt collisions are characteristic of alternating cycles of urban expansion, the dynamics of shrinking results in different patterns of conflict and different patterns of spatialchange. In the essay “The Compact City", Markus Hesse describes how Figure 25: 
Collisions in Munich's outer fringe belt. Heating and power station Heizkraftwerk Nord, seen fromRingstraße. ParkstadtBogenhausen'sheatingsystemissuppliedbythisplant, Munich 2017

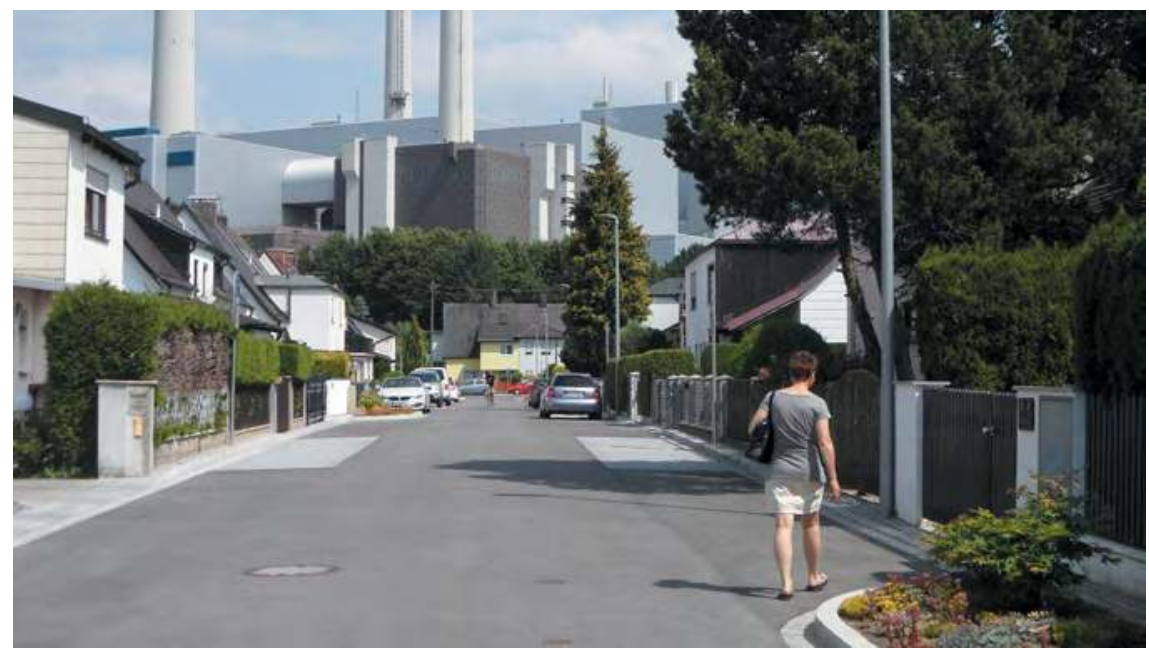

the "Logics of Geometry" and the "Logics of Choice" interact as major competing drivers of urban transformation in the context of shrinking cities (Hesse 2006). According to Hesse, spatial artefacts like cities feature an inherent tendency towards concentration. Hesse argues this tendency to be the result of savings based on agglomeration, and therefore an economical category (ibid., p. 180). What is referred to as the 'compact city' he suggests has evolved in a balancing process of agglomeration/density and spatial expansion. Hesse conceptualises the driving forces behind compactness as the "Logics of Geometry" (ibid.). He proposes that the compact city produced a series of qualities which are valued today, while also being responsible for the many problems that ultimately lead to the departure from the compact city model at the beginning of the $20^{\text {th }}$ century.

The second transformative force identified by Hesse is the "Logics of Choice" (ibid., p.181). According to Hesse, availability of cheap energy combined with modern mobility and communication changed traditional rules of agglomeration fundamentally. In the fortified city outward expansion occurred in intervals, usually at great cost. This step-by-step pattern of growth formed, according to Hesse, the predominant type of expansion until the invention of new modes of transport and the effects of industrialisation allowed for and demanded a different organisation of the city. Hesse argues that as a result, urban growth today produces urban patterns of spatial development defined by choice rather than by geometry (ibid., p. 182). The corresponding pattern of spatial development is then seen as a contradictory movement between centrality and dispersal, driven by the simultaneously acting "Logics of Geometry" and "Logics of Choice". By means of this urban dialectic, Hesse argues that in shrinking cities the former step-by-step mode of expansion is not simply reversed to produce smaller urban entities that retain their compactness. Instead, the logics of choice allow individual preferences to have their collective influence on the spatiality of the shrinking process. This process tends to produce fragmented islands, rather than a smaller but consistent and compact urban form (ibid., pp.182f). The concept of centrality, in Hesse's 
proposition for the shrinking city, is distributed among nodes in a fragmented urban landscape, from which locally established compactness interacts more freely with the structures of the post-industrial era (ibid.).

\subsection{Space Syntax and the Paradox of Centrality}

Space syntax is based on the assumption that urban development evolves along "configurational invariants of built environment processes" (Hillier 2007 [1996], p.69), that can be mathematically represented and analysed. Bill Hillier, co-founder of the methodology, emphasises the "non-discursive" character of the technique (ibid.). Space syntax is used to identify and describe the characteristic properties of spatial arrangements and forms, with the goal of generating "architectural and urban objects" (ibid., p.74) that can be directly compared on the basis of their configurational patterns. Methods based on space syntax are used to represent existing spaces in cities or buildings, as well as in the assessment of design proposals ranging from urban layouts to floor plans and façades. In the analysis of spatial configurations in planned housing areas and housing estates the method is combined with social data to identify deficiencies in orientation, safety or accessibility (ibid, pp.4f, pp.138ff). Bill Hillier suggests the metric and the visual properties of space produce two different types of conflicts. The first conflict is referred to as "paradox of centrality" (Hillier 2007 [1996], p.266). In systems of circular shape, the centre is prioritised through effects of integration. This can be shown, for example, when connections between different points are drawn within the shape, representing journeys. If journeys are made from all points to all other points, or if origins and destinations of journeys are randomised, more journeys along shortest paths will pass through the centre and the central area than anywhere else (ibid, p.80, p.266). Circular shapes thus offer advantages in terms of movement economy (ibid.). However, this gravity towards the centre is counteracted by the tendency of systems to relate to external systems, such as existing concentrations in the periphery, or the attractor effect of major traffic routes to external destinations, thus shifting the prioritisation away from the centre and changing the regular radial pattern of integration. Hillier observes that

"[...] the more integrating the form - that is the more it approximates the circular form

- then the more its most integrated internal zone is maximally segregated from the external world, and, by definition, from any other aggregates that are to be found in the vicinity of the system. In other words, maximising internal integration also maximises external segregation. This is the 'paradox of centrality'." (ibid., p.266)

Hence, internal and external integration produce a conflict of divergent forces. Hillier suggests that "Growing urban systems must respond to the paradox of centrality, because [...] urban forms seem to need both internal and external integration." (ibid.) The second conflict theorised in the methodology results from the tendency towards maximisation of "intelligibility" and "visibility" of urban form, i.e. visual integration, which prioritises linearity over compactness (ibid.). The two paradoxes are understood to exert a significant influence on the way cities grow and operate. Space syntax methodology seeks to capture interdependencies on an abstract and aggregate level. This approach accounts for its accuracy, as well as its constraints. Patrik Schumacher places 
the space syntax methodology in the context of the critical responses to modernism, expressing some personal sympathy with the approach (Schumacher 2010, p.46). The emphasis of the non-discursive and the scientific are elements in the methodology that connect to the modernist premise of scientific accountability, in similar ways as the complex reductionism of Parametricism connects to them. In space syntax centrality, integration, accessibility and other properties are defined as purely mathematical configurations and geometric properties of form.

Critics of the approach suggest the methodology would not sufficiently distinguish between spaces of different quality, such as the nuances in the public or private character of urban spaces (Franck 2010, p.4). Schumacher raises doubts about the simplification of perception in the model (Schumacher 2010, p.46). Furthermore, space syntax is criticised for lacking capacity to deal with space-time problems (Franck 2010, p.4). Proponents of the methodology may argue that while this might be true for problems framed by the phenomenologist perspective, the model can represent change in sequences along a genealogy of spatial urban form, despite the freezing of space in the moment of analysis. Conceptually, the model is closely linked to the idea of urban form as product and precondition of evolutionary spatial process. Hillier observes that "the distribution of integration in an urban system, together with its associated built form and land use patterns, is [...] a kind of structural record of the historical evolution of the system." (Hillier 2007 [1996], p.269) The space syntax methodology holds the promise of a technical fix to a wide variety of problems. However, the accuracy of analysis in the model presupposes the exclusion of issues that cannot be mathematically represented and computed. If the methodology is used in the analysis of complex urban situations without adding additional perspectives from other disciplines, problems may end up being defined too simplistically. For example, if the task for a local authority is to improve the conditions on a housing estate, it might find it convenient to think in terms of fixing the spatial integration of a circulation system, rather than having to address problems of urban inequality and exclusion.

\subsection{Capsularisation and Connectivity in Cities Without Cities}

Thomas Sieverts describes the "Zwischenstadt", or "Cities Without Cities", as spaces in which different movements, agendas and processes co-exist and interact with each other, sharing a unique field of possibilities (Sieverts 2003 [1997], p.3). The contradictions in and the characteristics of the Zwischenstadt are seen as the "[...] result of innumerable individual, and - considered on their own - rational decisions" (ibid.). According to Sieverts, the Zwischenstadt has grown over time in former suburban and other loosely populated areas in the metropolitan region of large urban centres. (ibid., p.4). New regional infrastructure networks and diversification have made them less and less dependent on the centre. The resulting patterns of organisation and conglomeration are neither city nor countryside; they are characterised by the co-presence of residential areas, leisure centres, business parks, dispersed patches of agriculture, as well as large infrastructures such as power plants, airports, or disposal sites, which serve the distant core (Sieverts 2000; 2003 [1997], p.4, p.50).

The Zwischenstadt is portrayed as having the capacity to let different and potentially conflicting processes unfold simultaneously, unlike the modernist city, which sought to separate uses, scales and forms of organisation in the name of conflict eva- 
sion, efficiency, cleanliness, and as part of its overall strategies of simplification and externalisation. However, what appears as a giant integrative network that connects and enables disparate functions and the unexpected to co-exist in proximity to each other is at the same time a system that leads to segregation and fragmentation. Sieverts observes that through specialisation, division of labour and dispersal "[...] dayto-day living is now organised in spatial and temporal 'islands' with specialised functions" (Sieverts 2003 [1997], p.76). For Sieverts, the consequences of this process have direct implications for the social and political, suggesting that the "[...] city regions run the risk of disintegrating in political, social and cultural terms into a series of selfish and competitive urban fragments made up of different income groups and lifestyles, in particular [...] if socioeconomic disparities combine with large-scale segregation." (ibid., p.60)

Sieverts emphasises the link between the way people organise their daily lives in the dispersed city and the low environmental quality this behaviour tends to produce. The space between different destinations is reduced to a vector, the journey from point to point is less defined by the actual space through which it passes, but rather by travel time and direction. In such a configuration, space becomes negated and superseded by speed, and traffic routes "[...] for the most part, do not provide any quality of life" (ibid., p.76). In the Zwischenstadt, groups of all ages rely on individual mobility to connect the specialised uses in the city region, including children, who are assisted by their parents to safely bridge the distance between their different locations of activity. Sieverts observes that "this form of organisation of day-to-day living has led to the impoverishment of and a decline in the significance of the immediate environment." (ibid., p.77) According to Sieverts, the lack of mobility is a contributing factor to social exclusion, as those who cannot afford mobility or are unable to participate in individualised forms of mobility due to health conditions or age might find it difficult to cope with the distances between destinations by themselves (ibid., p.26). Hence we could say that practices of the everyday in the dispersed city are to a certain degree dedicated to the negotiating of conflicts and negative effects that evolve as a consequence of its spatial and organisational arrangement.

Philosopher Lieven De Cauter pushes the Cities Without Cities phenomenon to its dystopian limits and sketches out the concept of "capsularization" (De Cauter 1998; 2001). The capsule is seen as a constituent part of the network condition in neoliberalised economies and suburbanised daily lives (De Cauter 2001, p.125). In De Cauter's narrative, the capsule populates the networks, assuming different forms and being embedded in different spatial constellations. The capsule could be a consumer product - the smart home, the transport capsule; it could be an institutional unit - the nucleus family, the capsularised community; the capsule may be a simulated public space - the all-in hotel, the campus, the historical city centre (ibid., p.126). 
Figure 26: Unexpected coexistences in the 'Zwischenstadt'. High-rise 'capsule' Süddeutsche Verlag building, designed by GKK Architekten in 2008, and grazing sheep, East Munich 2017

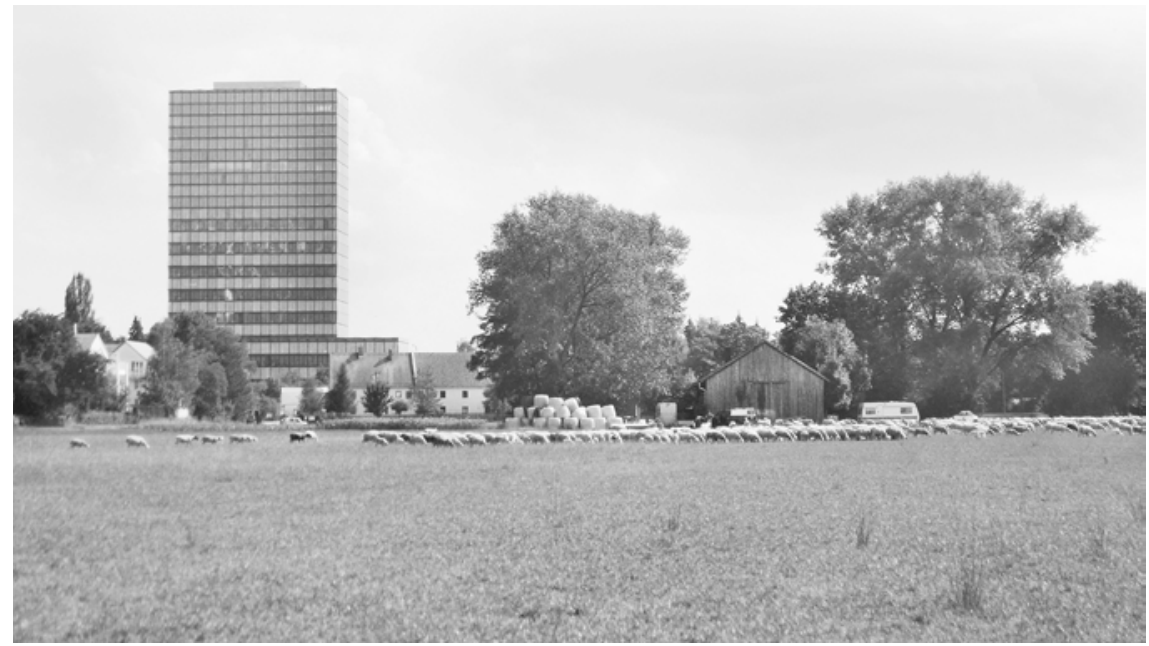

De Cauter observes that "our everyday life can be described as a movement, using transportation capsules, from one enclave or capsule, our home, for instance, to another [...]" (ibid.) According to De Cauter, capsularisation is based on capsular technology like the car and the internet, coupled with feelings of exclusion, fear, and ignorance on the one hand (ibid., p.124), and the mutual amplification of what he terms "hyperindividualism" and suburbanization on the other (ibid., p.125). De Cauter conceives of the capsule as the "ideal tool for control" (ibid., p.130), which enables users to selectively connect with other capsules and their hyperindividualised contents. Undesired characteristics or elements of the outside are separated from the inside, which is under constant surveillance. In this sense, capsularisation eliminates the traditional uncertainties of the urban; it eliminates the collective urban space as zone of social encounter. The capsule masks, externalises and displaces conflict to the remaining less capsularised and less privileged groups in the urban domain. Control and simulation eliminate unplanned spontaneity (De Cauter 1998, p.46). The capsule can be seen as a defensive device that buys into assumed safety by replacing the urban with simulation and voluntary self-containment. Hence, capsularisation is meant to produce two different zones of conflict: the low or zero-level zone inside the capsule, by means of control, exclusion and defensive measures, and the remaining high-level zone, the outside. De Cauter suggests that "the grimmer and uglier outside reality becomes, the more hyperreality will dominate the inside, the capsular society." (De Cauter 2001, p.127) Like the modernist 'envelope', capsularisation could be seen as a means to externalise and mask conflict; it is a form of envelope for the hyperindividualised self. Against this scenario, De Cauter brings forward the concept of "cosmopolitan urbanity" (ibid., p.131), emphasising the systemic limits of capsularisation:

"Of course one should not forget that capsularization is always local, and is essentially a minority phenomenon: the outside is always bigger than the inside. So when describing this single deeply rooted tendency in our society, we cannot deny that many different 
things are going on outside this logic. Outside the archipelago there is a sea of various of interactions in old and new forms of community. We can only hope that all sorts of networking will prove stronger than capsularization." (ibid.)

Hence, despite enabling new forms of encapsulation, the network and the Zwischenstadt seem to also provide the means to resist the capsule. They have the capacity to connect multiple situations with each other, globally and in a non-capsularised, open way, beyond the historically limiting factor of the proximities offered by the local and the centre.

\section{Preliminary Findings}

In this chapter I have assembled a sequence of architectural and urban narratives that are related to conflict in different ways. The selection evolved on the basis of theoretical sampling as outlined in the methodology section. At this stage we cannot assume the process to be saturated in the sense that further research into conflict would not add new insights. We have, however, an idea about some of the main areas in which conflict is theorised, that is, the discursive fields in which narratives of conflict in architecture and urbanism are located. We have also identified a series of concepts within the narratives. The proposed method is to now shift the focus of enquiry to the narratives of change and in this way establish the second strand of anchor points in the analytical process, before returning to conflict for its theoretical intersection with change. Only then can we see if the concepts are of sufficient density to establish the required level of saturation.

At the outset, I theorised the specific kinds of narratives produced in architecture and urbanism. The discussion in this chapter was arranged in four sections, starting with the historic city and its appropriation as site of rupture and architectural intervention. This was followed by narratives that reveal modernism's ambiguous relationship with conflict. The third section evolved along a series of concepts which are, above all, grounded in the political. In the final section the problem of centrality was presented as a source of conflict from different perspectives. Looking at the overall set of narratives and concepts, we can say that conflict is understood to originate from a multitude of different sources. Conflict is associated with shifting power relations, the contesting of centralities, creative destruction and competing modes of production. Conflict is also associated with the development of new ideas, desires and innovations, the imposition of new utopias upon past utopias and traditions, or the introduction of new patterns of urban organisation. The contradictions characteristic of the urban condition are conceptualised by some narratives as leaving residues that evade institutionalised practices of conflict resolution.

It seems that in the analysed architectural and urban narratives, the urban is seen as going hand in hand with the production of conflicts. They describe different patterns, practical manifestations and relations of conflicts with each other. Irrespective of the nature or type of conflict, the narratives assume that conflict is an ever-present phenomenon in the urban condition. They work with different intensities of conflict and different levels in the foregrounding of conflict. 
I propose that up to this point the following preliminary findings could be generated in the analytical process:

1. In the analysed narratives, the urban condition is seen as going hand in hand with the production of different kinds of conflict, making them an ever-present phenomenon in the city.

2. The narratives work with different intensities of conflict and different levels in the foregrounding of conflict.

3. In some narratives, there is an instrumental and operational dimension to conflict. Seemingly opposing attitudes towards conflict - appropriation and evasion - are used in combination to pursue a single goal.

4. One form of conflict may relate to other forms of conflict. Different kinds of conflict do not necessarily exclude each other. Macro-level forms of conflict may define the framework into which more local levels of conflict are embedded, establishing a 'context of conflict'.

5. Some critical urban practices define and recognise conflict as a creative force in the city. We could speak of this as an emerging 'practice of conflict'. It challenges institutionalised forms of conflict resolution as stabilisers of dominant forms of space production.

6. Accordingly, the richness of narratives and concepts is in stark contrast with the exclusive focussing on conflict resolution in institutionalised discourses and professional practice.

7. Conflict embodies the concept of change. Change is both product and driver of conflict. Urban formation may be analysed as a combined history of conflict and change.

8. The concepts of 'practice of conflict' and 'context of conflict' point towards two promising locations for empirical analysis:

a. in the everyday, which could be understood as the intersection of economic-technological imperatives, acting as colonisers of space and time, and of categories of individual actions and choices that escape domination; and

b. in the meso-level, respectively the level of collective action.

The preliminary findings and concepts assembled so far are taken to the next research stage in the following chapter, where they serve as additional reference in the analysis and the theoretical sampling process. 


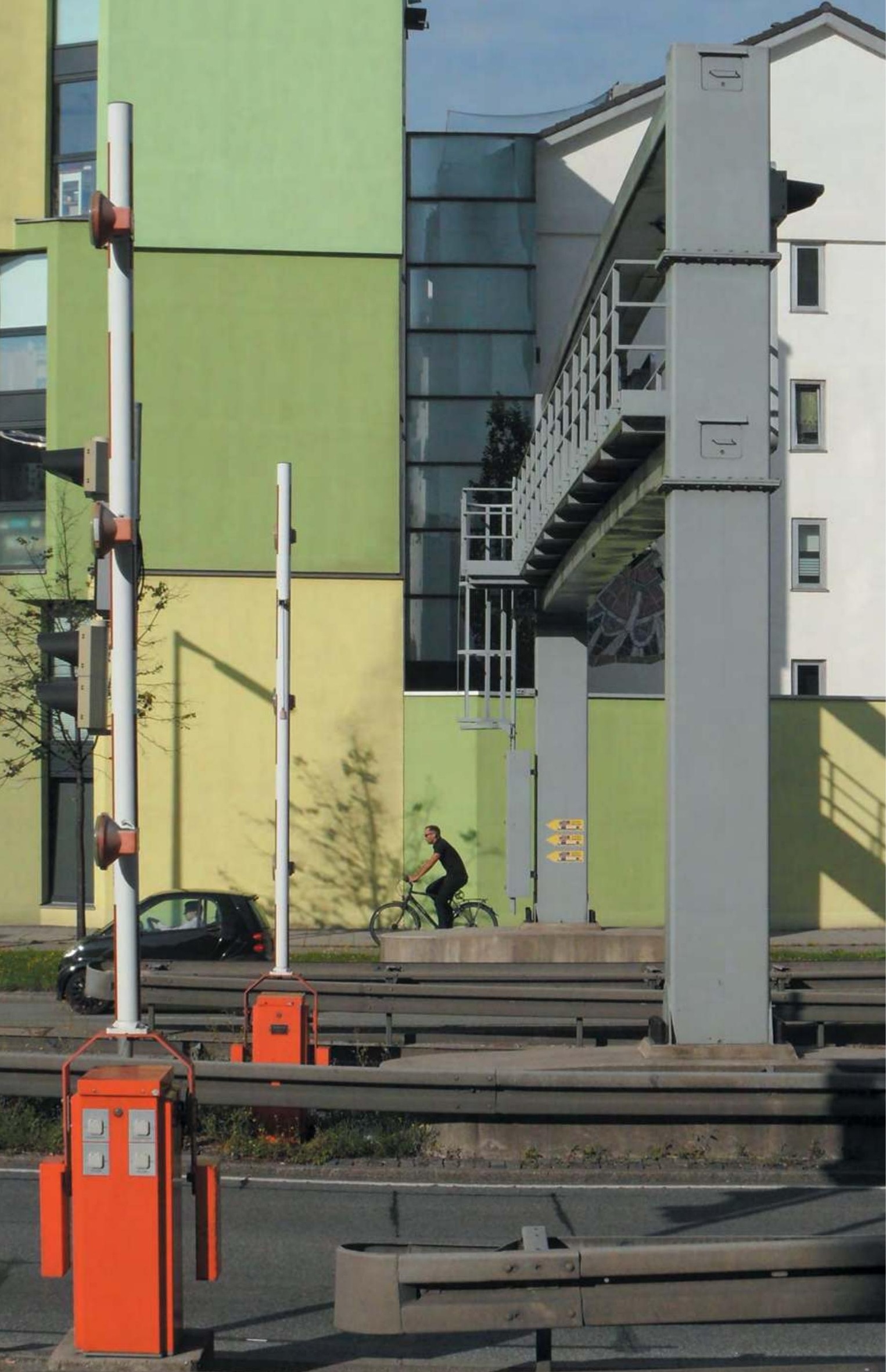


Figure 27: Richard-Strauss-Straße tunnel approach; residential additions by Léon Wohlhage Wernick to a 1950 s housing estate, completed in 2009, Munich 2017

\section{Domain-Specific Narratives of Change}

"The world around us, so much of our own creation, shifts continually and often bewilders us. We reach out to that world to preserve or to change it and so to make visible our desire. The arguments of planning all come down to the management of change." Lynch, Kevin (1972) What Time is this Place?, Cambridge, MA, p.1

"By looking at the architectural form as an instance of a continuous process of change, we become interested in the mechanisms of transformation. That we can learn from change is not new. In all observations, scientific and otherwise, change and movement reveal the structure of what is observed. In our case, change is brought about by people designing, making, and inhabiting the environment. We have to deal with human constructs, and hence the complexities we observe are of our own making."

Habraken, John N. (1987a) The Control of Complexity, in: Places Journal, vol. 4, no. 2, p.15 


\section{Dialectics, Evolution and Autopoiesis in Meta-Narratives of Change}

\subsection{Framing Architectural and Urban Theory through Meta-Narratives of Change}

Among the narratives of change in architectural and urban theory are some that engage with the nature of change itself rather than with practical concepts and material consequences. They are located on a meta-level of conceptualisation and may thus be defined as architectural and urban meta-narratives of change. They seem to mirror the grand principles, or ontologies, of change that have emerged in philosophy, natural history or the social sciences. The most influential principles of change, if we leave aside the realms of mythology, are, perhaps, dialectics, evolution and autopoiesis. We use them to conceptualise processes of transformation and adaptation, or to explain how variations and differences occur; but we also use them to better understand ourselves and the changing world(s) we live in. All architectural and urban narratives of change in this chapter are framed by one of the three principles of change - or by a combination of them. In the following sections, I discuss selected works of Henri Lefebvre, Christopher Alexander and Patrick Schumacher as examples of architectural and urban theory that approach change from the meta-level of conceptualisation.

The overall goal of my enquiry into narratives of change is not to provide a comprehensive or stabilising systematics of change and of its multifaceted expressions. In line with my epistemological and methodological considerations, I seek to assemble a strand of concepts and ideas that I may then intersect with conflict. As in the previous enquiry, the selection of narratives is guided by the combined strategies of anchoring and theoretical sampling.

\subsection{Dialectic Movements and the Urban as Contingent Process}

In my discussion of the modernist approach towards conflict, I have discussed Karel Teige's vision of architectural and social progress as an application of the classic dialectical sequence thesis-antithesis-synthesis, whereby the synthesis represents a higher level of development (Teige 2002 [1932]). In this section, I discuss Henri Lefebvre's critique of dialectical analysis and his influential triadic model, taking his more complex form of dialectics as an example of a meta-level narrative of change. Lefebvre used dialectics as a conceptual framing for different research questions. He brought it to full analytical expression in the concept of the production of space and the urban revolution. Henri Lefebvre's triadic dialectical model is prerequisite to an understanding of his ideas about space and the urban condition. It is recognised as a unique contribution towards dialectical analysis (Schmid 2010, p.314). For Lefebvre, dialectics is the driving force behind the becoming of things, as well as an epistemological principle of understanding and getting to know these things. The theory of the production of space, which according to Christian Schmid could be understood as the outline of a social theory, emphasises temporal-spatial dimensions (ibid.). The urban, as conceptualised by Lefebvre, is the ever-changing product of dialectical movements, and therefore populated by conflicts, contradictions and residuals. In the first chapter of "Elements of Rhythmanalysis: An Introduction to an Understanding of Rhythms", titled "A Critique of the Thing" (Lefebvre 2013 [1992], pp.15ff), Lefebvre develops a 
Figure 28: Residues as source of creative practices, heterogeneity, dysfunctions, instability, versus managed change. Speicherstraße, Munich 2017

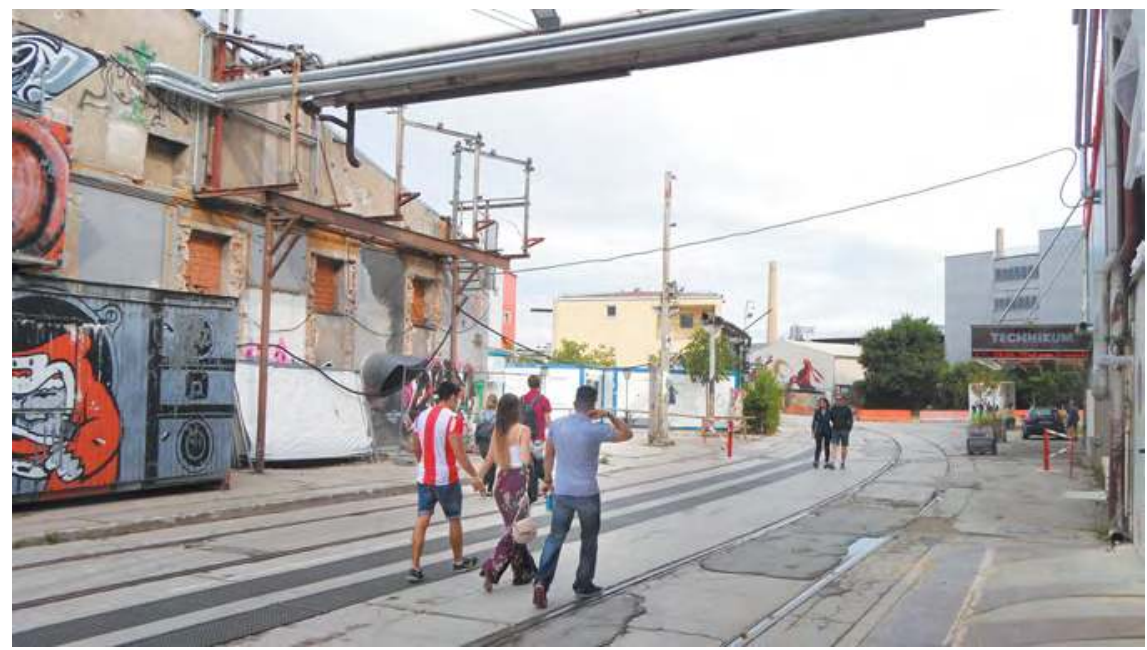

reconstruction of the dialectic tradition, which, according to Lefebvre, shifted from critical "dialogue" over classical dialectics to more open forms of dialectical analysis (ibid., pp.2of). Lefebvre suggests that the method of "dialogue", or "dual analysis", allows the representation of a pair of opposites, whereby each side is given a separate voice (ibid.). Lefebvre relates the method to the traditions of the religious, metaphysical, or ideological, criticising the limited range of an analysis that attributes universal value to a single opposition (ibid., p.21). He argues that such a form of dual analysis is reductive and isolates relational aspects from their contexts (ibid., p.21). Lefebvre suggests that the second stage in the development of dialectics evolved around the Hegelian model of thesis - antithesis - synthesis. Acknowledging the model's capacity to engage with complex problems (ibid.), Lefebvre criticises its inability to open up new perspectives for the future, because the initial condition of conflict is brought to a conclusion (Schmid 2010, p.92). In the model, the discursive and dialectic operation terminates with the synthesis and paralyses further action. Uncertainty gives way to a condition of stability. Synthesis in this model is understood to represent a higher truth, or, as Christian Schmid suggests, in more contemporary terms a 'solution' (ibid.). According to Schmid, Lefebvre positions his dialectic approach closer to Marx's model of dialectic change (ibid.). This model is based on the sequence of affirmation-negation-negation of negation ("aufheben"), in which the negation of negation initiates the following sequence by representing a new affirmation. Again, this model is not satisfactory for Lefebvre, as Schmid observes, for it implies a sequential linearity and gaps that are impossible to bridge. Moreover, it is seen as falling short of adequately representing the contingent nature of human interactions, their deviations as well as the simultaneity of contradictory movements (ibid., pp.111f).

To overcome these shortcomings, Lefebvre introduces a triadic dialectical model, in which he seeks to maintain the dialectic conflict rather than dissolving it (Lefebvre 2013 [1992], p.21). The dialectical relations defined by three terms are assumed to raise new contradictory relations, without ever completely resolving the conflicts. Accord- 
ing to Schmid, the double meaning of the German term "aufheben" is important to Lefebvre in the re-conceptualisation of Marx's 'negation of negation'. The term embodies the connotation of overcoming on the one hand, and of retaining, or preserving, on the other hand. If understood in this double sense, the dialectical contradiction is both, overcome and retained in the dialectical process (Schmid 2010, p.312) ${ }^{1}$. Based on this idea, the triadic dialectical model seeks to establish a conceptual and analytical process in which new contradictions and residues are perpetually generated and the transformative quality of the operation is maintained. Lefebvre suggests that

"Dialectical analysis observes or constitutes relations between three terms, which change according to circumstance; going from conflict to alliance and back again. [...] The analysis does not isolate an object, or a subject, or a relation. It seeks to grasp a moving but determinate complexity (determination without determinism)." (Lefebvre 2013 [1992], p.21)

In Lefebvre's model there is no fixed 'thesis' to begin with, which would suggest a beginning and therefore also an implicit ending, a terminal synthesis. In Lefebvre's model one term may affirm the other while negating the third, only to negate the second upon combining with the negation of the third. The resulting multitude of movements is conceived to include the unexpected, the contradictory, and to allow different constellations to simultaneously inform analysis. Lefebvre is careful to keep the model separate from other established modes of thought (Lefebvre 2013 [1992], p.22). However, Schmid notes that, despite Lefebvre's continuous efforts to elaborate his particular dialectic approach, critics find it difficult to adopt the underlying logic without either resorting to a functionalist (Marxist) or idealist (Hegelian) tendency in their interpretations (Schmid 2010, pp.307ff).

Lefebvre applies his concept of triadic dialectics to different fields, assuming it to be a universal principle (Schmid 2010, p.313). His triadic model of spatial dimensions is only one triadic figure among others; in rhythmanalysis Lefebvre works with the triad of 'melody-harmony-rhythm' (Lefebvre 2013 [1992], p.22); elsewhere he uses the three concepts of 'form-structure-function' (Lefebvre 1991 [1974], p.147). Among these figures, the spatial dimensions of the perceived-conceived-lived are at the base of his conceptual framing of the production of space. Schmid underlines that the model is not to be read as an object that unites three subcategories in synthesis, producing a totality of reified space, in the sense of an absolute entity that has a presence on its own (Schmid 2010, p.311). Rather, according to Lefebvre, the production of space is always the product of practice, of human interactions and their productivity (Lefebvre 1991 [1974], p.68, p.84; Schmid 2010, p.85). Schmid further asserts that the figurative core area in Lefebvre's triadic model of the production of space remains empty (ibid., p.245). Whatever the configuration, it leaves a residue between the three terms, as something that cannot be fully revealed and made accessible. The void evokes the idea of an openness, a contingent possibility that ultimately escapes dialectic approximations. It cannot be exhausted and it will not disappear. Hence, the contradictions brought forward through analysis and critical discourse are meant to retain their movement and cre-

1 Own translation. Christian Schmid uses the two words "überwinden", respectively "bewahren" (Schmid 2010, p.312). 
ative momentum. In this sense, the model may be conceived as the problematising opposite of the solutions and closures aspired to in modernist planning and institutionalised processes of change. Christian Schmid asserts that the triadic principle of change and production reveals the problematic of reductionism and systematisations of human life, because they fail to recognise that which cannot be captured by categories (ibid., p.108), as well as the temporal aspects of the urban and the production of space (ibid., p.316). In raising the question whether "contradictions [can] be articulated in propositions or in formulas without contradiction?" (Lefebvre 2013 [1992], p.22), Lefebvre expresses his doubts as to the conceptual and epistemological range of discourses that operate according to the principles of "truth" and "coherence" (ibid.).

Christian Schmid suggests Lefebvre's idea of residues informed his dialectical thinking, in the sense that residues escape categorisation and abstraction and act as sources of spontaneity, creative instability, and becoming ("poiesis") (Schmid 2010, p.108). Lefebvre conceives of residues as potential resources for creative practices that operate on the basis of heterogeneity, non-convergence of different worlds, discrepancies, dysfunctions, and conflicts (ibid., p.109). He juxtaposes non-reducible residues and the mechanisms that seek to control or negate them, for example religion, the machine, bureaucracy, or the state (ibid., p.108). If , according to Lefebvre, it is impossible to completely describe the richness and complexity of life on the basis of theoretical models and operations, then there is always a non-reducible, vital and residual element that escapes abstraction, stabilisation, and in this sense the control through the mind and institutions (ibid.). Schmid suggests that the assembling of residues could be conceived as an act of revolt against the suppression of life's transformative powers (ibid.) This means that concepts of conflict and change which seek to eliminate contradictions through categorisation, demarcation and conflict resolution are - from the perspective of dialectical thought - neglectful of the very nature of the urban condition.

\subsection{Evolution through Unfolding, Deep Invariants and Repetitive Process}

The work of Christopher Alexander conceptualises and engages with evolutionary and generative problems of change in different ways. In "The Timeless Way of Building" (Alexander 1979) Alexander elaborates a full theory of complexity, spatial quality and the generating of form. Although "The Timeless Way of Building" was published two years after the more widely known "The Pattern Language", Alexander initially conceived it as the first volume in a series of publications ${ }^{2}$, in which "The Pattern Language" is volume two. "The Timeless Way of Building" defines the conceptual foundations for the pattern language, while "The Pattern Language" describes the more detailed aspects of implementation. My focus in the following discussion is on the key notions and concepts of Alexander's early evolutionary model and those aspects that make the model a meta-level narrative of change.

As the title of the publication suggests, Alexander is interested in the inner structures and workings of processes that produce quality in the built environment, beyond the level of short-lived trends. He explores the idea of an unfolding building process that enables practitioners as well as lay-persons to engage with and participate in alternative

2 Center for Environmental Structure Series. The series amounts to five titles as of 2015. 
ways of building. For Alexander the problem of building, and therefore the problem of the built environment, starts with the problem of representation. He criticises standard terminology as too unspecific to adequately represent spatial properties, asserting that houses, streets, windows or doors "[...] are merely names, and the underlying things which they refer to keep on changing [...]" (Alexander 1979, p.85). He further suggests they would not convey the culturally induced differences in use and interpretation related to them (ibid., p.73). In tackling this problem, Alexander proposes that relations between spatial constituents can be used in representations and analysis rather than object-centred conceptualisations. For this purpose, he provides the following general definition of relations: "[...] Within a context of type $\mathrm{X}$, the parts $\mathrm{A}, \mathrm{B}, \mathrm{.}$. . are related by the relationship r" (ibid., p.90). A set of relationships in space is named "pattern", whereby the pattern contains further patterns of relationships (ibid.). Patterns of spaces are understood to be mutually related to patterns of events, where neither is seen as the 'cause' of the other (ibid., p.92). The patterns are organised in a series of thematic sets of patterns (ibid., p.384), which establish what Alexander famously refers to as "pattern language" (ibid., pp.167ff). According to Alexander, a pattern language "[...] defines the limited number of arrangements of spaces that make sense in any given culture [...] and it actually gives us the power to generate these coherent arrangements of space." (ibid., p.186) The number of possible variations, however, is unlimited (ibid., p.187). Each building task is understood to have its own language, for example "[...] the town as an entirety [...] and each small building task within the town [...]" (ibid., p.358). According to Alexander, it is the shared pattern language that enables relative permanency to coexist with change in the built environment (ibid., p.357). Pertaining to the stable core of pattern relations, Alexander speaks of "background of the variation" (ibid., p.94) or "deep invariants" (ibid., p.98). Hence, a pattern language could be conceived as a basic principle of change, which combines continuity with variation. Alexander uses the metaphor of organism to describe the relationship of slow-changing "invariants" and the levels on which change is fast and most apparent.

\begin{abstract}
"An organism, which seems at first sight like a static thing, is in fact a constant flux of processes. [...] The organism which exists today is made of different materials from the organism of yesterday. It preserves those broad invariants, which define its character within the flux. Yet even these are changing slowly, over time. [...] A town or building also is a constant flux of processes. [...] As in an organism there is a process going on which shapes new buildings constantly, destroys the old, replaces and rebuilds and modifies the fabric. But again, just as in an organism, there is also something which remains the same - there is an invariant continuity behind the flux, a character, a "thing", a "structure", which remains the same." (ibid., pp.356f)
\end{abstract}

As patterns are understood to be independent from each other, they can be changed or improved individually, one at a time (ibid., p.345). For the same reason, patterns can be shared and integrated into different pattern languages around the world (ibid.). Alexander asserts that "it is this one simple fact, which guarantees that the evolution of pattern languages will be cumulative." (ibid.) The act of building with the pattern language is seen as a piecemeal step-by-step process, which allows the "unfolding" (ibid., p.372) of patterns in a sequence. Accordingly, large and complex structures like towns are seen as the aggregate product of multiple, incremental and small-scale 
Figure 29: Street scene 'Im Tal'. Relations between groups of people, seating arrangements, sidewalk, shops, trees, and street could be described by means of the pattern language, Christopher Street Day, Munich 2018

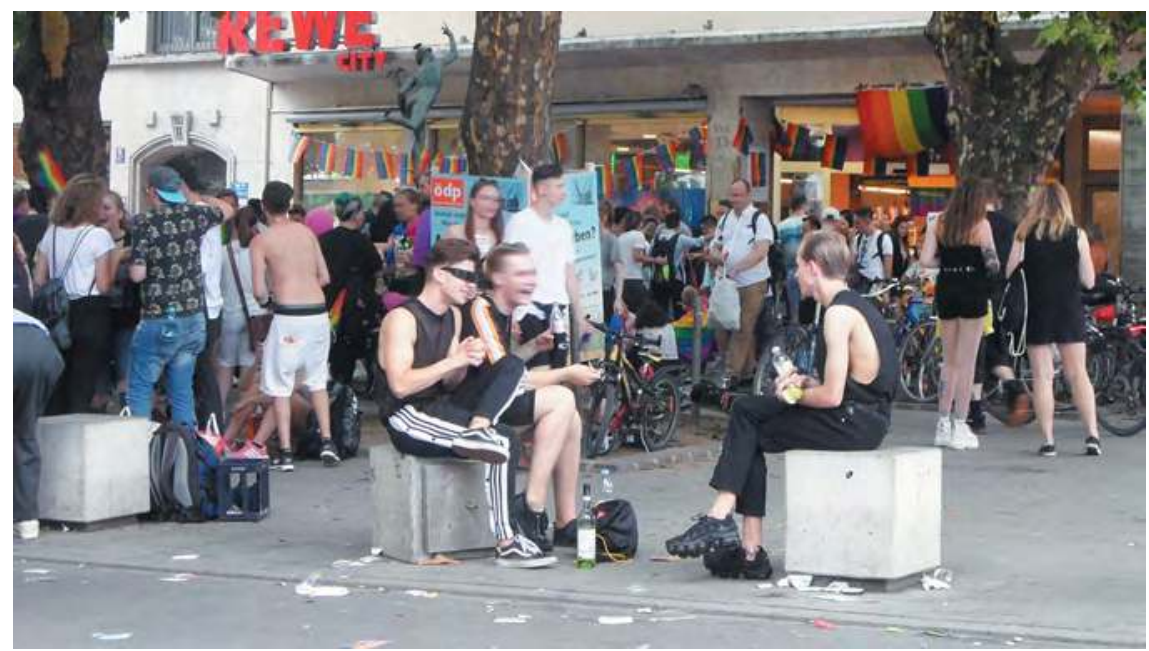

interventions (ibid., p.191, p.496, p.508). With the speed of modern construction in mind, Alexander states that past changes in the built environment occurred slowly and in small increments, where the changes followed the rule of "one pattern at a time" (ibid., pp.385f).

Alexander's meta-level narrative of change seeks to provide the framework for operational knowledge and productive processes, such as building, repairing, or designing. ${ }^{3}$ Alexander asserts in "Notes on the Synthesis of Form" that designing is to exert control (Alexander 1964, p.19). Accordingly, the pattern theory is closely related to the question of who controls what and how control is used and institutionalised (Alexander 1979, p.238). Alexander presents the pattern language as an egalitarian instrument of building, which can be applied to all situations and learned through practice. It is conceived as alternative to the modernist system of change.

However, Alexander observes that the shared pattern language, forming a body of accumulated knowledge, has undergone substantial ruptures in the past. That, more-

3 If the pattern language is used as a method of repair, Alexander believes it could improve existing situations or on-going projects, or it could close the gaps that had been left over by modernist planning (Alexander 1979, pp.484f). The ultimate goal of repair, according to Alexander, is to achieve a state of true "wholeness", a condition that sees "wholeness" on every single level of pattern relations (ibid., p.485). Alexander conceives of repair as a process that is adaptable, for the point at which repair commences is always different, depending on the found situation. Moreover, ongoing repair constantly changes the situation or object in which it operates. Alexander states that "In the commonplace use of the word repair, we assume that when we repair something, we are essentially trying to get it back to its original state. This kind of repair is patching, conservative, static. But in this new use of the word repair, we assume, instead, that every entity is changing constantly: and that at every moment we use the defect of the present state as the starting point for the definition of the new state." (ibid., p.485) Accordingly, Alexander concludes that "when we repair something in this new sense, we assume that we are going to transform it [...] the idea of repair is creative, dynamic, open." (ibid., p.485) 
over, it has vanished from building practice in the modern world and is now lost in its original form. According to Alexander, the moment of "breakdown of language" (ibid., p.225) coincided with industrialisation (ibid., p.231), the division of labour (ibid., p.232), and anonymous mass production (ibid., p.235). Alexander claims that, as a consequence, buildings began to be "less human than they used to be" (ibid., p.237), lacking life and quality (ibid.) by including an increasing number of patterns that are "more dead" than "alive" (ibid., p.126). He suggests that in the ensuing mix of dead and alive, some patterns are "relatively stable, and self-sustaining" while others are "relatively unstable and self-destroying." (ibid., p.127) The "dead" pattern is held to be incapable of "[...] containing its own forces, and keeping them in balance." (ibid.) Resorting to the metaphor of organism, Alexander asserts that, as a consequence, "[...] these forces leak out, beyond the confines of the pattern where they occur, and start to infect the other patterns." (ibid.) "Dead" patterns are seen as preventing the system from further developing its own qualities and from improving. In this sense they are seen to be a negative vector of change and adverse effects on the overall system. They are associated with destruction and the production of obsolescence, bringing the evolutionary process of the pattern language to an absolute halt. "The delicate configuration which is self-creating, and in balance with its forces, is for some reason interrupted-prevented from occurring, placed in a position in which its configuration can no longer recreate itself." (ibid., p.130) Alexander suggests that modern societies seek to compensate for the lost sense of order and natural process of change by means of "artificial forms of order based on control" (emphasis in original, ibid.), established through urban design, mass production, system-building and centralised planning control (ibid., p.238). He refers to these instruments as "[...] totalitarian efforts, [...] [which] cannot create a whole environment, because they are not sufficiently responsive to the real needs, forces, demands, problems, of the people involved." (ibid.) Based on these observations, Alexander asserts that "adaptation of buildings to people becomes impossible." (emphasis in original, ibid., p.239) For Alexander, the severity of the problem requires "[...] a shattering revision of our attitude to architecture and planning" (emphasis in original, ibid., p.240), by means of re-introducing a shared pattern language, which would then gradually change society from below and from within.

Alexander's narrative has sparked controversy since its first publication. For instance, Rowe and Koetter criticised the physical outcomes of the process as falling short of expectations, speculating that the "inhibiting characteristics of commitment" demanded by the method are a possible cause (Rowe and Koetter 1978, p.96). On the one hand, Alexander seemed to have bracketed out a large part of the contemporary discourses and urban reality when he published the book in the late 1970s, leaving this task to texts like "A City is Not a Tree" (Alexander 1965). The narrative conveys a preoccupation with towns, the campus, and the village rather than city, and a vision of a suburban arcadia. Perhaps because of the claimed "breakdown of language", the narrative is reluctant to provide examples of new buildings that are "alive" (ibid., p.225, p.126). On the other hand, the narrative pioneered process-based strategies, whereby the combination of unfolding and the structuring systematics of language provided ample connections for digitalised applications that were to follow. The theory developed over decades, and continues to be a reference and field of enquiry for a community of researchers and practitioners. "The Timeless Way of Building" explicitly distances itself from the modernist frameworks that had been dominant and effective 
when the theory was first published, thus affirming its status as an alternative metalevel narrative of change.

\subsection{Architecture as Self-Referential Autopoietic System}

While dialectic and evolutionary meta-level framings of change are part of traditions that date back to the $19^{\text {th }}$ century and before, autopoiesis is a concept that did not take shape until the second half of the $20^{\text {th }}$ century. In my brief discussion of autopoiesis as meta-level framing of change, I relate to the work of sociologist Niklas Luhmann and to Patrik Schumacher's architectural adaptation of the theory. Autopoiesis may be understood as a process of self-production and reproduction in systems, based on the capacity of systems to maintain and observe their function without relying on major external interference. It is a generative principle and therefore a principle of change. Autopoiesis was first described and conceptualised by Humberto Maturana and Francesco Varela in the 1980s as a phenomenon in living organisms (Luhmann 1995 [1984], p.34). Niklas Luhmann applies this "supertheory" (ibid., p.5) to a systems theory approach to society, proposing that social systems are established through the self-referential communication of differences and the corresponding "system/environment distinction" (ibid., p.37). Social systems constantly strive to reproduce themselves and maintain their function (ibid., p.11). They increase their internal complexity over time, which Luhmann refers to as the "temporalization of complexity" (ibid., p.47). This process is not concerned with "[...] returning to a stable state of rest after the absorption of disturbances, but with securing the constant renewal of system elements-or, more briefly, not with static but with dynamic stability." (ibid., p.49) Self-observation in social systems ensures that communications are reproduced as elements that are compatible with the system, so that subsequent communications can connect to them (ibid., p.37). Autopoietic communications are based on codes of differentiation A/notA, as well as on "double contingency" (ibid., p.38): systems, or elements within systems, that communicate with each other anticipate the other's possible responses (ibid.) ${ }^{4}$. This also means that "no part of the system can control others without itself being subject to control [and] that any control must be exercised in anticipation of counter-control." (ibid., p.36) With regards to the internal structure of autopoietic systems, Luhmann emphasises that "all structural change, whether adaptation to the environment or not, is self-change" (ibid., p.350). Changes in social systems are, according to Luhmann, always based on communication (ibid.). For each system, the environment is 'everything but itself'. In this sense the environment is different for each system. It offers the opportunity of having contact to many other systems (ibid., p.182). Autopoietic systems are open to their environment and at the same time self-referentially closed (ibid., p.37, p.350). The environment is more complex than the system, resulting in an "asymmetrical" relationship between them (ibid.).

Conflict and contradiction assume operational roles in the autopoietic system. Conflict ensures the continuation of communication between two systems in cases where contradictions occur, based on a communicated 'no'; "[...] and for a while the conflict takes over autopoiesis [...]" (ibid., p.389). The "negative version of contingency"

4 Here, Luhmann draws a cautious link between the resulting "mutualistic" situation and dialectics (ibid., p.38), but he is skeptical about an operative, dialectical self-description of society (ibid., p.431). 
that is active in this situation "[...] leaves what positively happens completely open [...]" (ibid.). According to Luhmann, "conflicts are social systems, indeed, social systems formed out of occasions that are given in other systems but that do not assume the status of subsystems and instead exist parasitically." (ibid.) In this sense, conflict has the capacity to connect different systems with each other.

Luhmann suggests that in the differentiated modern society, and among the many social systems in operation, special "societal function systems" (ibid., p.426) fulfil core tasks in the reproduction of society, like the economy, politics, religion, education, law and art. While he conceives of architecture as subsystem of art, Patrik Schumacher suggests that architecture constitutes a societal function system in its own right (Schumacher 2010, p.146). Schumacher published "The Autopoiesis of Architecture" as a two volume, 1200 page long proposition for "A New Framework for Architecture" (2010) and "A New Agenda for Architecture" (2012), with the purpose of articulating a unifying theoretical framework for architecture's epistemological self-description (Schumacher 2010, pp.xi-xii), as well as "[...] contributing to the ongoing vitality of the autopoiesis of architecture, and thus to the further innovation of the built environment." (ibid., p.55) Schumacher claims architecture features all elements that are characteristic of a societal function system, like its own sets of codes, mechanisms of self-regulation and reproduction, differentiation and communication (ibid., pp.19ff). He suggests that architecture, if defined as societal function system, is demarcated by its "ultra stable" boundary which is inscribed to the very structure of society (ibid., p.26). In the epilogue section of volume 2 , Schumacher declares the ultimate goal of his theory to be the termination of the observed state of crisis and intensified controversy in architecture that followed the rejection of the modernist doctrine during the 1970s (Schumacher 2012, p.712). Asserting that Parametricism has now assumed the leading role in architectural development, Schumacher calls for a return to a state of normality, in which cumulative research and practice be conducted "under the banner of Parametricism" (Schumacher 2012, p.712). Being aware of the unresolved questions related to the outline of a general theory, Schumacher suggests that his version of the autopoiesis of architecture should be understood as bold conjecture, which is to be further debated, tested and elaborated (Schumacher 2010, p.54).

With regard to the relationship of the architectural and the political, Schumacher distinguishes the architectural societal function as "the ordering of social communication via the provision of spatial frames" (emphasis in original, ibid., p.448) from politics as "the ordering of social communications via the provision of collectively binding decisions" (emphasis in original, ibid.). On the one hand, Schumacher confirms that designs/buildings can "potentially, but not necessarily" be political (ibid., p.456). He acknowledges that some architectural projects may become a "[...] political issue to which further political communications connect" (ibid.). Architecture "[...] can certainly serve political agendas formulated and empowered within the political system [...]" (emphasis in original, ibid., p.457), or be entangled with "urban micro-politics" (single quotes in original, ibid., p.474). On the other hand, he asserts that architecture, if it is understood as autonomous societal function system, can only respond to "resolved and thus depoliticised politics" (ibid., p.459). Schumacher identifies public competitions as a possible situation where a political, or micro-political agenda may be legitimately articulated from within architecture (ibid., pp.477). As a rule, however, he suggests that the purposeful admission of "political debate within architecture over- 
burdens the discipline" (ibid., p.448) and "leads to communicative dysfunction within the architectural discourse." (ibid., p.459)

In view of the double contingency in the necessary communication between systems, as well as the intersystem relation of "interpenetration" (Luhmann 1995 [1984], pp.213ff), different, non-architectural perspectives are noticeably absent in Schumacher's outline. He argues with reference to conceptual clarity, that the terms 'political' and 'architecture' should be used in strict separation, the term 'political' be reserved for the communications of the political social function system, and 'architectural' for the communications of the architectural social function system. He then transfers this distinction at the systems-theoretical level without mediation to the field of architectural theory and practice, suggesting that political questions be left with the clients or politicians (Schumacher 2012, p.476). Addressing this problematic assertion of autonomy and the foregrounding of closure in his review of Volume 1, Marjan Colletti highlights the "fluid and migratory" aspects of architecture (Colletti 2011). He suggests that binary codes always imply a third condition - the error, the else, or the other - which includes instances of misinterpretation, subversion or superimposition by other systems (ibid.). Likewise, Ignacio Farias suggests with reference to Luhmann that "conflicts and disputes are, in fact, instances in which communication shows its potential

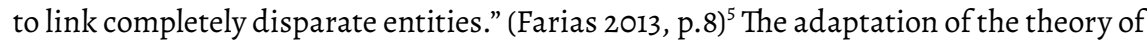
autopoiesis shows the difficulty and the limits of developing, and practically applying, meta-narratives to architecture and urbanism. While meta-level framings enable us to connect phenomena to complex theory, they also remind us, through their co-presence and specific weaknesses, that other perspectives are possible, and, perhaps, needed.

\section{Narratives of Change as Critical Response to Modernism}

\subsection{Bye-Bye Utopia, or Utopia as Agent of Change?}

As I have argued in the first strand of analysis, the dominant narratives of modernism favour fast, linear - and therefore predictable - change over complex and unpredictable process, which presupposes some kind of operational support by mechanisms of simplification, externalisation and exclusion. In the following sections, I look at a series of narratives of change that emerged during the 1960 s and the following decade as criticisms of modernism. Being assembled around a shared attitude towards modernism rather than a shared set of methods (Rowe and Koetter 1978, p.36), they question the modernist urge for radical change in the face of an increasing impoverishment of the urban environment; they criticise modernism's selective interpretation, or exclusion, of history; they assert that time and change are closely tied to concepts of space, and challenge the authoritative and static masterplan through ideas of the urban as process. As part of this shift, we observe a swift move away from the utopia of the ideal modern city towards the heterogeneous city in search of possible alternatives.

5 This critique is not directly related to Schumacher's proposed autopoiesis of architecture. Farias theorises about Luhmann's concepts of virtual attractor and mechanisms of differentiation, suggesting that communicative links may be established on the basis of reference to previously rejected communications (ibid.). 
"Bye-Bye Utopia", an installation and a series of lectures and debates curated by raumlaborberlin in the Kunsthaus Bregenz exhibition hall in 2010, featured an arena-like structure made of apartment doors reclaimed from obsolete dwelling blocks in Halle-Neustadt, a new town built during the German Democratic Republic (GDR) era (Bader et al., 2010). The structure performed in multiple ways, accommodating changing patterns of use and appropriation. During public events, the arena became a space of critical and creative debate, a space of encounter. Spatially, the arena dissected the ground floor area of Peter Zumthor's exhibition hall, as if defining two different worlds. The sole connections between the two spaces were provided by a vertical emergency slide suspended from the top of the structure, or by leaving the hall through the main entrance and re-entering the building from the rear. Both connections, internal as well as external, produced forms of movement that are unusual for an exhibition. The slide evoked an experience of playfulness, but also one of uncertainty, discomfort and speed. The detour around the building passed through urban public space, as a metaphoric journey through the polis, the space of politics. Most visibly, the metaphoric political dimension was present in the arena made of doors. The reclaimed materials testified to buildings and structures that represented a bygone socialist utopia. The doors, initially identical according to the logics of prefabrication and, perhaps, of a homogenising socialist doctrine, had changed over time through everyday use. Thus the arena marked the intersection of institutionalised and abstract forms of power with the individualism and nonconformity of the everyday. Conceived as an open forum, the arena hosted workshops and debates concerned with the future, while quite literally building on the relics and experiences of the past. Hence, "Bye-Bye Utopia" seems to have embodied a 'movement-away-from' with an open and contestable 'towards' - a combination which I have theorised in Chapter I. It suggested that utopias, even if they have become obsolete, are of relevance for the present. Moreover, it represented the collective work of coping with and managing the transition between the past and an uncertain future. Writing about the projects of raumlaborberlin, Nishat Awan, Tatjana Scheider and Jeremy Till suggest that, by means of highlighting problems rather than solving them, they "[...] try to open up a space of communication and negotiation in which relations can be made and conflicts played out, and they acknowledge that for them architecture is foremost a social phenomenon." (Awan, Schneider and Till 2011, p.191).

Karl Popper's criticism of the utopian model, written two years prior to the establishment of the GDR in 1949, reads like an abstract forecast of the course of events that led to the state's self-dissolution in 1990, and in this sense to the conditions which formed the working basis for raumlaborberlin's collective project in Halle-Neustadt. For Popper, the process of change in the world of a single utopian idea, be it scientific, political, or social, is the opposite of discursive openness and collective creativity. According to Popper's theorisation in "Utopia and Violence" (Popper 1947, pp.477-488), the utopian process tends to be based on enforced continuity and "the use of violent methods for the suppression of competing aims [...]" (ibid., pp.483): 
Figure 30: Rhombi House by OnOff-Sam Carvalho, Marius Busch, Suzanne Labourie, Berk Asal, Anika Neubauer, Nick Green. Shabbyshabby Apartments, organised by raumlaborberlin and Münchner Kammerspiele, Munich 2015

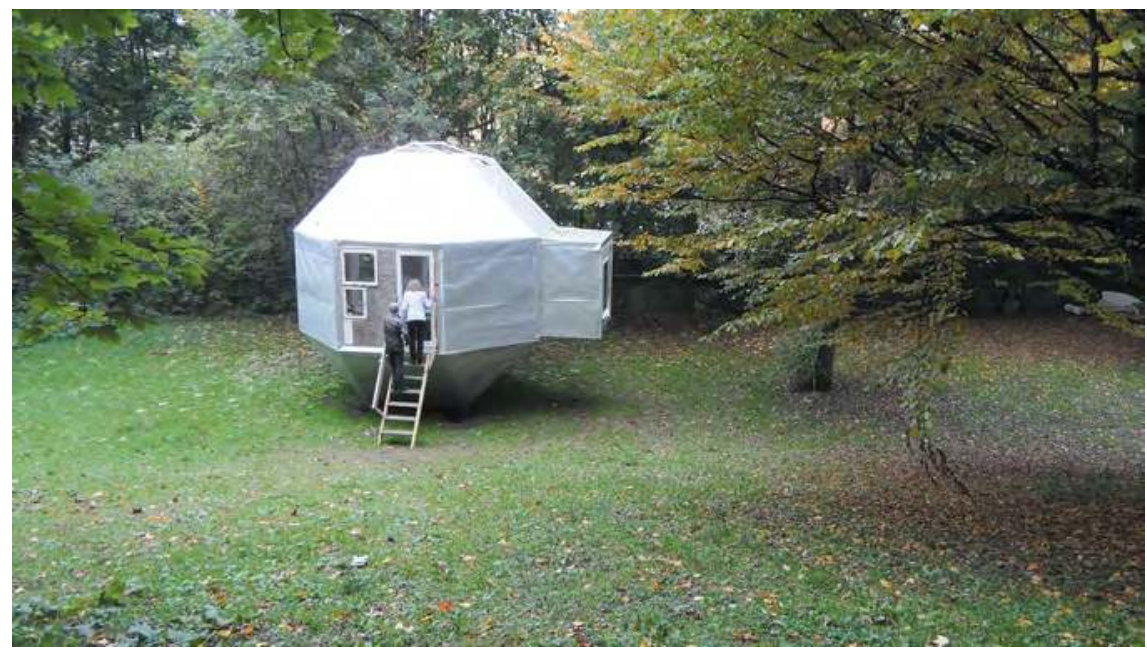

"For unavoidably, the period of Utopian construction is liable to be one of social change. In such a time ideas are liable to change also. Thus what may have appeared to many as desirable when the Utopian blueprint was decided upon may appear less desirable at a later date. If this is so, the whole approach is in danger of breaking down. For if we change our ultimate political aims while attempting to move towards them we may soon discover that we are moving in circles." (ibid., pp.483f)

Hence, the long-term success or failure of an utopian idea is, in Popper's view, not so much determined by its initial promise, but rather by its capacity to compete against and suppress other ideas. Karl Popper's criticism of the utopian method asserts that the process towards realisation may lead to "[...] propaganda, the suppression of criticism, and the annihilation of all opposition." (Popper 1947, p.484) For Popper, who advocates an open society based on individual choices on the grounds that knowledge is provisional and that its production requires critical reflection and the presence of alternatives, the displacing mechanisms of the utopian model are a threat to rational thought, as well as to the open society. For, in order to pursue the ultimate goal, "the utopian engineer must in this way become omniscient as well as omnipotent." (ibid.)

In "Collage City", Colin Rowe and Fred Koetter trace the long-standing tradition of utopian thinking in architecture and urbanism (Rowe and Koetter 1978, pp. 9ff). Taking up Popper's criticisms, Rowe and Koetter discuss the dilemma to which theory and design practice in architecture and urbanism have to respond when they work with the utopian model (ibid., pp.121ff). Based on their analysis of architectural history, Rowe and Koetter assert that the model has proved its usefulness in architectural and urban design thinking, in the formulation of new ideas and alternatives, and in this sense as agents of change; however, they do not deny that projects based on prescriptions may lead to problems like modern architecture's "lamentable lack of tolerance" (ibid., p.132). In order to rescue the operative potentiality of utopia for architectural and urban work 
in the light of Popper's criticism, they reject the blueprint and advocate a "utopia as metaphor and Collage City as prescription" (emphasis in original, ibid., p.181). This construct is understood to neither surrender to "scientific 'certainties' or the simple vagaries of the ad hoc" (emphasis in original, ibid.). It seeks to reconcile design vision with urban coexistence and incremental change. In this sense, Rowe and Koetter's late 1970s text mirrors the postmodern dismantling of utopia as single big idea and the simultaneous emergence of alternative architectural and urban practices. And indeed, as "Bye Bye Utopia" seems to suggest, the utopian model still abides with us today as urban heritage and collective memory, as object of criticism, as the mini-utopias in incremental processes, and as a reference for those who are working towards and within constellations of change.

\subsection{Typomorphology - Built Form as Process}

Claiming the joint study of type and urban form constitutes an exclusive 'domain-specific' narrative of change would be to misrepresent its joint origins in urban geography and architecture, as well as mask the fact that it thrives in many multi-disciplinary research settings today. However, it has informed architecture and urban design in profound ways, both in research as well as in design education, and there are numerous domain-specific adaptations of its methods and concepts. In this section I seek to identify some of them in the theoretical sampling process, albeit without contextualising beyond the focal area.

Anne Vernez Moudon, in her discussion of different strands of typomorphological studies, points out that the question whether modernism has to be seen as rupture or as continuity in the history of cities had not been answered unequivocally (Moudon 2004, p.23). Some theorists in this field hoped that modernism was but a temporary aberration in the way cities are produced and that the initial historical process would be restored (ibid.). Some saw in modernism a discontinuity that was to prevail and as such would eventually establish a new continuity, while others were able to connect modernism with the changing history of the urban past (ibid., p.38). Consequently, the hopes and expectations associated with the study of urban morphology varied greatly and, as a result, the way outcomes in research were generated and used. In her comparative overview of the research field, Anne Vernez Moudon speaks of different traditions, where research clusters in Italy, the United Kingdom and France have developed distinct profiles. The Italian tradition is closely connected to the work of Saverio Muratori, who exerted a strong influence on Aldo Rossi (ibid., p.19), among others, and later to the work of Gianfranco Caniggia, who continued to make the study of urban process operational for architectural and urban design (ibid., p.19). The tradition in the United Kingdom is understood to have developed from the pioneering work of cultural geographer Michael Conzen, who established a framework for the study of built landscapes based on "town-plan analysis" (ibid., p.27). In this analysis, street pattern, plots and buildings are represented in complementary drawings and observed in their development over time (ibid., p.28). Conzen's systematic approach, which included the study of Berlin and a series of smaller towns in North England, led to the formulation of concepts like the "fringe belt" (ibid., p.28) or the "burgage cycle" (ibid., p.29) (as mentioned earlier in the chapter on domain-specific narratives of conflict), or the "morphological frame" (Whitehand 2001, p.107). The concept of morphological frame 
"[...] relates to the fact that the way in which forms are created on the ground [...] acts as a long-term constraint on subsequent change. Plot boundaries and especially streets exert a powerful long-term influence. [...] Thus town plans are powerful influences on future forms, with residual features being passed down through successive generations of society, often over very lengthy periods." (Whitehand 2001, p.107)

Informed by his work, the Urban Morphology Research Group (UMRG) based at the University of Birmingham has conducted research into urban morphology since the 1980s (ibid., pp.28ff). The French tradition draws from a long academic interest in type and typology. The experience of radical urban transformation resulting from the construction of new towns at a large scale united critics and researchers of different disciplines to study both the urban tradition as well as the phenomenon of the modernist city in order to develop practical knowledge that could be applied to the urban crisis. Henri Lefebvre is understood to have accompanied and supported this process, in particular with his writings on urban appropriation and practices of the everyday (ibid., p.33). Moudon suggests that "Lefebvre's teachings fostered interdisciplinary work and a rapprochement with the social sciences, and encouraged the search for a socially responsive and responsible architecture." (ibid., pp.33f) As the French research cluster operated within a multi-disciplinary research environment, social and economic issues could be addressed in a different way, as was the case in the more formal or structural approaches of the other traditions (ibid.). The 'Laboratoire de recherche: Histoire architecturale et urbaine - Sociétés' (LADRHAUS) is the centre of the cluster today (ibid., p.34). Moudon comments on a comparative morphological study by the cluster, making explicit its relevance for both, design issues and social process:

"The particular cases studied show that good models used to design the city oscillate back and forth between the need to control and provide order in city design and the need to create environments that respond to the needs and actions of their immediate inhabitants. This puts in question the value of a global composition of the city (an underlying concern and general direction in the evolution of urban design theory), proposing instead an emerging definition of city from through the incremental acts of many people." (Moudon 2004, p.40)

Moudon suggests that typomorphology's definition of type as entity of building volume and the plot of land on which the buildings are located distinguishes it from other research approaches that work with the concept of type (ibid., p.18). Unlike Durand, who developed a systematics of placeless building types, typomorphology is interested in the joint study of building structure and open space. The land and the way it is parcelled and organised is conceived as the link between the scale of the building and the scale of the city. The type is morphogenetic and not static. It is understood to be "[...] defined by time - the time of its conception, production, use, and mutation." (ibid., p.18) These terms establish a direct connection between time and human action. It is the time during which humans act on and with the forms they have created or inherited. The concept of typological process or "tipologia processuale" (ibid., p.20), which is central to the morphogenetic research interest, is then not an evolution of pure form, but rather the continuously changing relationship between humans and form. Moudon stresses Caniggia's role in theorising this kind of change, because unlike oth- 
ers in the Italian research perspective he "clearly states that the physical city is not an object but a process: cities are built incrementally with many small elements being juxtaposed." (Moudon 2004, p.20) Moudon asserts that in so doing, Caniggia “[...] portrays an extremely dynamic picture between human action and built world, whose production is the result of a dialectic, or an active relationship, between human action and 'environmental reaction'." (ibid., p.21) This interaction is either based on "spontaneous conscience" or on "critical conscience" (ibid.). The first kind is an "immediate understanding of what is necessary to make a building" (ibid.) in the way of vernacular or common houses. The second kind of interaction is based on a self-conscious process that may result in specialised structures or monuments (ibid., p.21). A similar distinction is proposed by Christopher Alexander in "Notes on the Synthesis of Form" (Alexander 1964 pp.58ff), which I discuss in the next section.

Finally, typomorphological research highlights the connectedness of built form across different scales. The relations across scales establish links within the abstractions used to represent the built environment. Also, there are the relations between built form and processes of collective human action - of city building, and making, as embodied in the practices humans employ to structure and control the world. The focus on long term urban transformation and its relatedness to human action has made typomorphology and similar research approaches a source of inspiration for researchers who are interested in the joint study of built form and collective processes. Anne Vernez Moudon has conducted her own extensive study of urban change in the Alamo square neighbourhood in San Francisco (Moudon 1986). Other descriptive and interpretative works on transformation, like Stewart Brand's "How Buildings Learn: What Happens After They're Built" (Brand 1994), or John Habraken's “The Structure of the Ordinary" (Habraken 2000), have strong connections to this field.

\subsection{Alexander - Conflict and Change in the Synthesis of Form}

In "Notes on the Synthesis of Form" (Alexander 1964) Alexander laid the conceptual foundation for the series of research enquires and publications that were to follow, such as the "Pattern Language" (Alexander, Ishakawa and Silverstein 1977), "The Timeless Way of Building" (Alexander 1979), or the more recent four-volume work on "The Nature of Order', in which he develops a universal understanding of emergent structures, including cities, and how they relate to the human self. Alexander's work allows a multitude of different connections to be made. With respect to setting a focus, I concentrate on Alexander's notions of the design process, conflict and change as conceptualised in "Notes on the Synthesis of Form", starting with his proposition about how design, form and context relate to each other:

"The form is a part of the world over which we have control, and which we decide to shape while leaving the rest of the world as it is. The context is that part of the world which puts demands on this form; anything in the world that makes demands of the form is context. Fitness is a relation of mutual acceptability between these two. In a problem of design we want to satisfy the mutual demands which the two make on one another. We want to put the context and the form into effortless contact or frictionless coexistence." (Alexander 1964, p.19) 
Figure 31: Ridley Road Market in Dalston, London Borough of Hackney. The local area has changed considerably over the last few decades, although the street layout and many building plots have retained their boundaries. The market has been in operation for more than 100 years. East London 2014

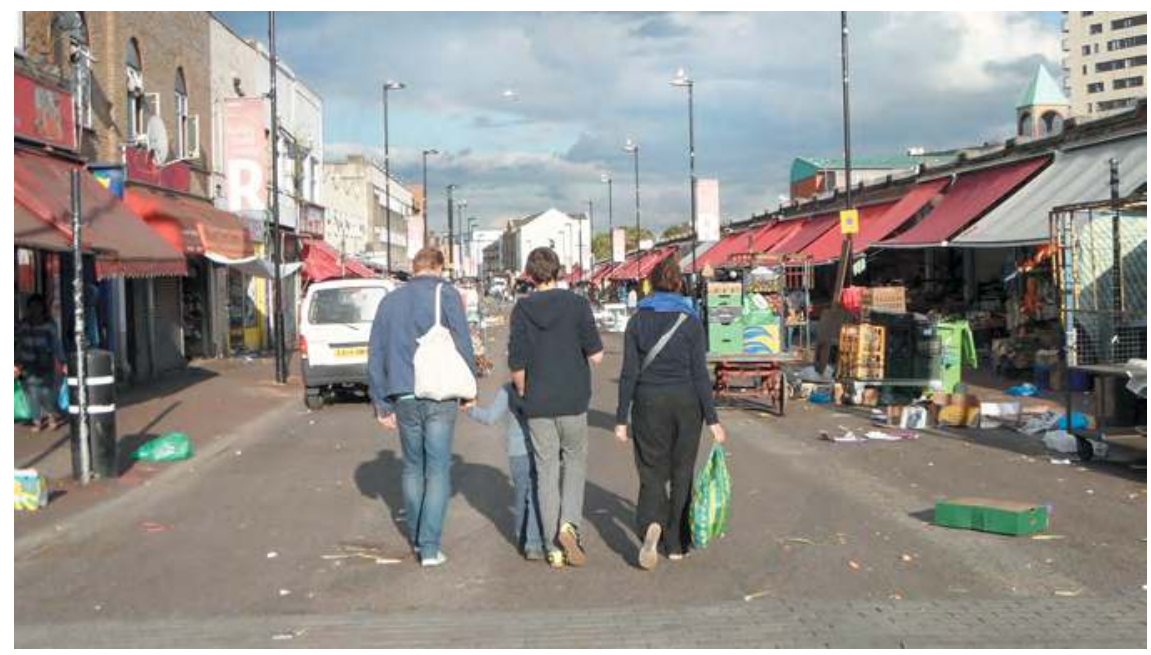

In this construct, the level of "frictionless coexistence" between form and context becomes the measure of "fitness", whereby conflict, as a concept, assumes a double function. It acts as analytical indicator, which shows where problems are located in form-context relations; and conflict brings analytical capacity and guidance to the design process. If "good fit" is defined as the absence of "misfits" (ibid., p.27), if the design "solution" to a problem is understood to be the elimination of conflict, then the elimination and avoidance of conflict defines the route the design process needs to pursue. As the context as well as the criteria of "good fit" are likely to change over time (ibid., p.37), the process is never complete, because imperfections in the relation of form and context will produce changing residues of conflict.

Alexander identifies two processes through which form is typically generated. The "unselfconscious process" is characterised by repetition and by passing on successful forms from generation to generation (ibid., pp.46ff). The rules by which forms are generated are not made explicit when taught and become evident only indirectly when mistakes are corrected. There is no specialised builder or designer. The person who uses the form is the one who builds and maintains the form. In the unselfconscious process, the builder assumes the role of an agent rather than of the inventor of form (ibid., p.53). Changes to form, technique or building material are made only if misfits accumulate up to a certain threshold. Adjustments are typically limited to the affected subsystem and never to the complexity of the entire form. Beyond such adjustments, change is avoided, in particular if the form is part of a tradition and attached to myth and ritual (ibid., p.46). Hence the form in the unselfconscious process resists change and the rules for producing this form are "rigidly maintained" (ibid.). The speed of change is in equilibrium with the demands imposed on the form by the changing context. The process is slow enough for both agents and form to adapt (ibid., p.51). However, Alexander suggests that the principles of gradual adjustment, or 
adaptation over time, are by themselves not sufficient to explain the enduring fitness of good form in certain building traditions (ibid., p.37). According to Alexander, systems that produce and maintain well-fitting forms tend to combine dampened feedback on the global level, manifest in the rigidity provided by tradition and convention, with immediate feedback on the local level (ibid., p.51). Yet, while acknowledging the unselfconscious process operates reliably within its own bounds, Alexander believes it to be unsuitable for the kinds of problems we are facing today (ibid., p.73). Alexander argues that the second kind of process, conceived as the "selfconscious process", emerged along the formation of architecture as a discipline (ibid., pp.55ff). Knowledge of how to design and how to build became formalised as generalised principles, readily available for institutionalised education as well as for academic and professional criticism. Whereas in the unselfconscious process the individual who builds the form is merely an "agent" unburdened by having to invent the form, the selfconscious process demands unique solutions to a long list of problems from the individual (ibid., p.58f). However, the complexity involved in this process tends to exceed the capacity of the average designer (ibid.). To overcome this difficulty, design practice resorts to various strategies of problem-restructuring, simplification and categorisations (ibid., pp.61ff). According to Alexander, such categorisations tend to reflect the way we identify a problem by means of language, for example as "safety" or "production cost", rather than corresponding to the true structural logics of the design problem (ibid., p.69). Alexander suggests this mismatch of problem and problem description is counterproductive in the search for well-adapted solutions, thus contributing to the accumulation of unresolved problems in the built environment (ibid.).

Alexander concludes that neither the unselfconscious nor the selfconscious process would provide adequate design frameworks for approaching contemporary design problems. The weaknesses and strengths in the two processes, in particular in their distinct modes of problem description and decision-making, define the starting point of the alternative process brought forward by Alexander. This process is composed of the problem analysis "program" (ibid., p.84), and the development of corresponding "constructive diagrams", which provide a unitary description of the problems (ibid., p.90). The program is a tree of requirements based on the inner structure of the design problem. Drawing from set theory, Alexander conceives of the program as a hierarchy of subsets, ranging from the most complex level, the overall design task, to the simpler levels of individual sub-problems. Each constructive diagram seeks to describe a state in which context and form fit each other. When each sub-problem on each level is represented by a constructive diagram, the overall design problem is represented coherently and as an entity. Alexander refers to this step of synthesis as "realization of the program" (ibid., p.84) Upon realisation through integrating sets of diagrams, conflict is likely to occur between some of them. The conflict originates in the objectives provided by different fit/misfit variables. Alexander suggests the sequencing of conflicts is an essential factor in the process. The earlier a conflict occurs, the more flexibility is available to develop a solution.

"At the beginning of the process [...] implications are therefore not yet frozen in any explicit diagrammatic form; they are still flexible enough to be successfully integrated with one another in spite of conflicts. The further along in the process we are, the more our thoughts about these implications have been forced by their complexity to become 
concrete, whether diagrammatically or conceptually, and the more their rigidity resists further modification." (ibid., p.123)

Based on this brief enquiry into Alexander's Notes on the Synthesis of Form, we can say that both conflict and change are at the core of his conceptual framework. In the unconscious process, the accumulation of conflict triggers the cycle of adaptation until a new equilibrium is achieved. In the selfconscious process, conflict is associated with criticism, design education and innovation. It is Alexander's intention to overcome the deficits of reductionist practices by means of a fundamental revision of the selfconscious process. Having said that, Alexander's attitude towards conflict is characterised by ambiguity. He does not conceptualise conflict as major driver of change, or more specifically, of the design process. For Alexander, there is an imperative to resolve conflict and to move away from it towards conditions of integrity, equilibrium and, to use the term cited earlier, of "frictionless coexistence" (Alexander 1964, p.19).

\subsection{Rossi - Urban Permanence and Change}

Aldo Rossi's “The Architecture of the City" (1982 [1966]), first published in Italian in 1966 as "Larchitettura della città", engages among other aspects with conditions of asymmetric change in the (historical) development of cities. Since the book was published, it has been criticised for its inconsistency and lack of structure, yet it developed into a fundamental theoretical text in architectural and urban theory during the second half of the $20^{\text {th }}$ century (Jencks 2011, p.44). Charles Jencks asserts Rossi's texts and projects have "[...] fought the battle for the contextual city, a continuation of Team X's ideas but at a more radical level [...]" (ibid.). The work grew within an increasingly politicised context, as Rossi's involvement with the conceptual and scientific preparations for the Milan Triennale 1968 seems to suggest (Nicolin 2008, p.91).

Paolo Carpi et al. (2014) review the original text for the Arch+ magazine from the perspective of the present. They suggest that Rossi, at the time of writing "Larchitettura della città", was self-consciously immersed in the modernist tradition of urbanised and industrialised Northern Italy and not yet orientated towards the more subjectivist and autobiographical perspective which he assumed at a later stage when he advocated the idea of the autonomous project (Carpi et al., p.16). They emphasise, however, that together with other critical modernists Rossi rejected the idea brought forward by "naïve functionalism" that the city could be sufficiently classified, and therefore reproduced by aggregating single functional elements (ibid.; Nicolin 2008, p.91; Rossi 1982 [1966], pp.46f). Consequently, in "Larchitettura della città" Rossi starts his theorising and analysis with the city, suggesting that urban complexity always precedes architectural intervention. Urban complexity is seen as "a priori" to architecture; its origins cannot be determined with certainty and the sole acceptable perspective on the city is from "within" (Carpi et al., pp. 2of). However, Carpi et al. suggest that Rossi's simultaneous insistence on "type" as the principle that generates the city from simple to complex established a fundamental contradiction (ibid., p.23).

Carpi et al.'s observations could be extended. The city in "Larchitettura della città" is, on the one hand, seen as being produced through the work of human actors, as "a human creation par excellence" (ibid., p.57); on the other hand, the city is seen as producing itself as a "totality" (Rossi 1982 [1966], p.32) in the sense of a reified collective 
subject, as a "[...] mode of being [that] implies a will to exist in a specific way and to continue in that way." (ibid., p.162) Rossi assigns to the city the status of object (of creation) and subject (as acting entity with an ontological presence): "urban architecture - which, as we have repeated many times, is a human creation - is willed as such [and ...] every city possesses a personal soul [...]" (ibid.). For Rossi, symbolic meaning can be inscribed in objects in such a way as to be a property of the object itself. Objects that have been constructed "[...] testify to values; they constitute memory and permanence." (ibid., p.34) In this way, Rossi seeks to resolve the problem of modernist bifurcation, the distinction between object and subject, of architecture and society. Rossi asserts that "the city is as irrational as any work of art, and its mystery is perhaps above all to be found in the secret and ceaseless will of its collective manifestations." (ibid., p.163) Hence, the conceptual framing of the city based on contradictions and ambiguity establishes limits to analysis, while at the same time opening up the analytical field. Addressing the legacy of the work, Carpi et al. suggest Rem Koolhaas' "Delirious New York" has taken some of the ideas in the book further (Carpi et al., 2014, p.18).

Change, including asymmetric change, is one of the fundamental principles in Rossi's concept of the city. He observes that "destruction and demolition, expropriation and rapid changes in use as a result of speculation and obsolescence, are the most recognisable signs of urban dynamics." (Rossi 1982 [1966], p.22) Within this constantly changing environment there is "[...] the persistence of a city's basic layout and plans [...]" (ibid., p.59) and there are "forms of permanence in urban monuments [that ...] offer themselves as primary elements, fixed points in the urban dynamic." (ibid.) According to Rossi, "[...] dwellings cover the major portion of the urban surface and rarely have a character of permanence [...]" (ibid., p.61). "Dwelling areas", on the other hand, are seen as more permanent elements in the city, in which the single residential building changes, but not the residential use (ibid., p.61, p.69, p.97). Hence, in terms of dynamic processes, Rossi distinguishes between the single dwelling that is subjected to constant change, dwelling areas of greater permanence, and primary elements around which things assemble. Primary elements "[...] participate in the evolution of the city over time in a permanent way [...]" (ibid., p.86). They function as "nuclei of aggregation" (ibid.) and as "catalysts" (ibid., p.87). Primary elements "[...] have the power to retard or accelerate the urban process" (ibid., p.63). They embody "that which characterises a city" (emphasis in original, ibid., p.99), but "[...] they also characterise the processes of spatial transformation in an area larger than the city." (ibid., p.87) According to Rossi, if primary elements survive for longer periods of time, as a sign of both "quality and destiny" (ibid., p.101) they may be defined as "monuments" (ibid.). He suggests that "to give permanence" may be understood as a past that we are still experiencing in the present (ibid., p.59).

Rossi distinguishes between two categories of permanences:

1. "Vital" permanences that act as "propelling" elements in the evolution of the city (emphasis added, ibid., p.59), for example, the reprogrammed Palazzo della Ragione in Padua

2. "Pathological" permanences that have ceased to make active contributions to the life of the city (ibid., p.22). These permanences stand "virtually isolated" (ibid., p.59) and "nothing can be added" (emphasis added, ibid., pp.59f). 
According to Rossi, both categories of permanence, the "vital" and the "pathological", are "essential" (ibid.) to the city, for "[...] in both cases the urban artifacts ${ }^{6}$ are a part of the city that cannot be suppressed because they constitute it." (ibid., p.60) In terms of the constitution of monuments, Rossi is

"[...] inclined to believe that persistence in an urban artifact often causes it to become identified as a monument, and that a monument persists in the city both symbolically and physically. A monument's persistence or permanence is a result of its capacity to constitute the city, its history and art, its being and memory."(ibid.)

This view suggests that there are external and internal factors that make a monument, and that persistence may suffice for an urban artifact to become a monument, without the necessity of having a specific significance at the time of construction. An urban artifact may acquire its status as monument over time. Rossi suggests that the "context" (ibid., p.60) of a permanence may provide information as to its condition, whether it is vital or whether it "[...] stands outside of technological and social evolution" (ibid.), as "isolated and aberrant" (ibid.). With regard to residential areas in the city, Rossi asserts that "[...] its preservation is counter to the real dynamic or the city; so called contextual preservation is related to the city in time like the embalmed corpse of a saint to the image of his historical personality." (ibid.) At first sight, this statement seems surprising given Rossi's interest in the history of urban dwellings. However, Rossi is looking at very long timelines. His enquiries about the city embrace the full span of its production, from the very beginning, which could be so remote in the past that it cannot be determined with certainty, up to the very present. The three cities to which he refers throughout his text are Athens, Rome and Paris. They all date back to Roman or Pre-Roman times. They feature permanences, as monuments, that date from this early period, while literally all residential buildings that we see in these cities today are comparably new. They have been preceded by generations of earlier buildings that vanished at some stage in the past.

This raises the question as to how fast a residential area needs to change without assuming the pathological state as conceptualised. Although Rossi does not provide a definite answer to this question, he becomes more specific upon introducing the notion of 'obsolescence': "For our purposes, we will define this phenomenon as characterised by a group of buildings - which may be in the neighbourhood of a certain street or may constitute an entire district - that has outlived the dynamics of land use in the surrounding areas." (ibid., p.96) For Rossi, then, the question whether an area is obsolete and in this sense pathological has to be determined from within its specific context and through comparative analysis. As noted above, he conceives of obsolete and pathological residential areas as being aberrant urban conditions in the city: "Such areas of the city do not follow life; often they remain islands for a long time with respect to the general development, bearing witness to different periods in the city and at the same

6 "The Italian 'fatto urbano' comes from the French 'faite urbaine'. Neither the Italian nor the English translation 'urban artifact' [...] adequately renders the full meaning of the original, which implies not just a physical thing in the city, but all of its history, geography, structure, and connection with the general life of the city. This meaning is the one intended throughout this book. - Ed" (Editor's note in the 1982 publication, Rossi 1982 [1966], p.22) 
time configurating large areas of 'reserve'." (ibid., p.96) As if to support the general ambiguity found in "Larchitettura della città", Rossi's descriptions of this aspect are both critical and at the same time point to some kind of specific quality. On the one hand, he gives reason to believe that in the name of an urban vitality it would be better to avoid pathological conditions, through reprogramming, adaptation and modification (ibid., pp.59f). On the other hand, if conditions of obsolescence and pathological permanent elements have gained a foothold in a specific area of the city, Rossi sees in them a certain potentiality as 'reserve'. But again, he leaves unclear whether to him this could be a reserve for future urban development, or if it could be the urban equivalent of a 'nature reserve' - a place of retreat and conservation.

\subsection{Lynch - The Environmental Image of Time}

After having published his work on the visual and mental image of the city (Lynch 1960), Kevin Lynch turned to problems of change and time and in this way extended his study of human interaction with the built environment and time-bound processes. In "What time is this Place", Lynch speaks of a "personal image of time" (Lynch 1972, p.1) that needs to be understood and integrated to the processes through which we organise transformations. The notion allows him to locate the past and the future in the shifting "now", as "the heart of our sense of time" (ibid., p.65) and as the framing in which we continuously re-produce our images of the future and the past (ibid.). Kevin Lynch asserts that "The spatial environment can strengthen and humanize this present image of time, and I contend that this function is one of its vital but most widely neglected roles." (ibid.) More than other architectural theorists, Lynch is interested in what people actually do and how they interact with existing situations. How do people adapt to new environments? How do they cope with and respond to change? How could people who are affected by change, voluntarily or involuntarily, actively contribute to the situation and thus exert control over the process?

Lynch emphasises the need to address the users' perception of change, their awareness of shifting conditions, their means of knowledge to organise and control change, the values they attribute to change (ibid., p.207). His analysis moves from external to internal, from large to small, beginning with a series of case studies on moments of substantial change in the histories of London, Stoke-on-Trent, Cuidad Guayana in Venezuela, and Havana. This is followed by discussion of the ambivalent relationship of place, personal memories, and identity construction; the problems of conservation; and the means to communicate the past and the future in the present. An ever present subtext in his analysis is the lack of any single way to look at time-related phenomena, and that there is no single image of time, the past, the present, and the future. Different concepts of time, such as the abstract time of the sciences, objective social time, and individual rhythms and times, may oscillate between synchronised states or those in conflict with each other (ibid., pp.65ff). Lynch criticises the modernist view that defines change as "[...] a troublesome but ephemeral gap between the old and the new [...]" (ibid., p.207) without acknowledging the potentiality and effects of the actual process. He claims that the modernist 'form follows function' doctrine is inadequate for the design of space, because space relates to human activity and therefore to process and time (ibid., p.72). Theorising about different kinds of change, Lynch suggests that 
Figure 32: Eastern Curve Garden, community project in Dalston since 2009, muf, J\&L Gibbons, EXYZT, and others, East London 2018

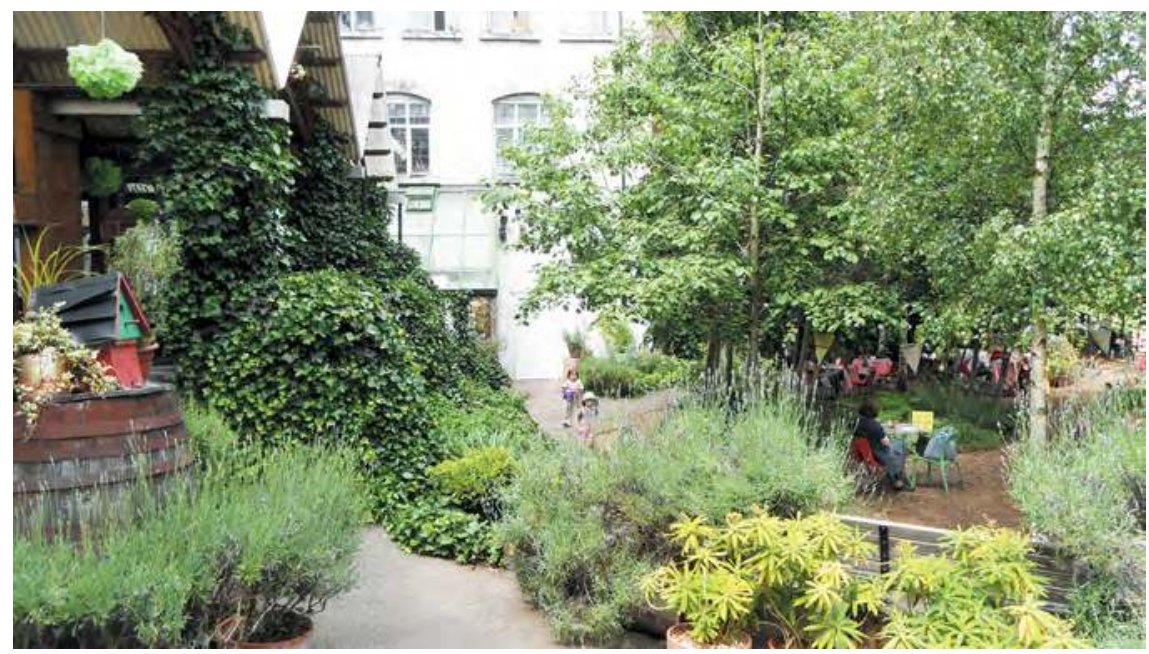

"A change in the environment may be growth or a decay, a simple redistribution, an alteration in intensity, an alteration in form. It may be a disturbance followed by restoration, an adaptation to new forces, a willed change, an uncontrolled one." (Lynch 1972, p.190)

Lynch asserts that while "managed" change is generally meant to establish a more desirable condition, or mitigate adverse effects (ibid.), there would be also costs. Along with economic and technological costs, Lynch points to social costs and possible negative psychological effects, such as disorientation, fear, regret, rage, desolation (Lynch 1972, p.190). In Lynch's view, people struggle most with changes that are imposed from the outside, too fast to be accommodated, perceived as being unjust, or not matching expectations (ibid., p.205). Lynch asserts that in order to avoid these difficulties, appropriate processes of change

"[...] should be legible and fairly rapid, concentrated in time and space to make a noticeable difference, yet made up of moderate increments that can be deferred without disrupting the entire process. First actions must be successful, however limited. Actions should build in intensity with time, the familiar 'bandwagon' technique. Active groups must derive clear benefit from the change. Even better, the benefit should be widely diffused, and many small groups be involved in initiating the action. We should increase the information about the present and the future, raise realisable expectations, and educate to new needs." (Lynch 1972, pp.205f)

Here, Lynch addresses what I will discuss in more detail at a later stage - the connectedness of change to individual and collective learning. For Lynch, thinking about the future requires the production and sharing of information. Accordingly, selecting and distributing communications is seen as a political act, which demands citizens share in the politics of communicating change (ibid., p.100). To facilitate this aim, Lynch pro- 
poses to "[...] demystify (and sometimes debunk) sophisticated forecasting techniques and to make them available to local groups for the preparation of alternative predictions." (ibid., p.101) Furthermore, Lynch emphasises the need for transparency, in particular in situations of conflict. "Where conflicting interests are involved, the change may still be acceptable if disagreements are openly aired and adjudicated before the change occurs and there is no obvious injustice [...]." (Lynch 1972, p.205) Neither of these claims have lost their appeal and urgency, for rising digital capacities continue to provide an ever growing and powerful pool of tools to specialists and their expert predictions. Addressing the political nature of managing change, Lynch provides a list of counterstrategies and deliberate misrepresentations that may be used by actors to disrupt, slow down, or prevent change from happening. (Lynch 1972, pp.206) Lynch emphasises that the way we perceive, represent and theorise change determines the way we deal with and manage change (Lynch 1972, p.207). From his long list of management options, I have extracted two positions - the fully controllable process and the recurrent work of maintenance - that to me seem to be highly relevant for the later case study:

1. "[...] change as completely controllable process, a problem to be solved, whose terminus is more important than its becoming. The variables with which he deals are few, the total course foreseen, and the objectives fixed. The process itself can be scheduled in detail or neglected as trivial." (emphasis added, ibid., p.207)

2. "The alternate decision model of maintaining the status quo demands powerful control (or weak forces of change), as well as a high valuation on the received state. The objective is clear, but predictions must be accurate and consensus strong. Maintenance is a useful model for the retention of stable function against the action of wellknown, equally stable (usually natural) forces that tend to degrade it. Otherwise, the conditions appropriate to maintenance are found only in some special cases: historic districts [...] where high costs of control are justifiable. [...] Under the guise of recurrent renewal, however, maintenance may be a way of adjusting to new forces, without a conscious admission of the fact." (emphasis added, ibid., pp.211f)

With a few exceptions, architectural building projects are conceived and realised in the first mode - the scheduled and closed process. The realisation of the Parkstadt Bogenhausen housing estate during the 1950s, which I discuss in the case study, falls in this category. The ordering system of financing, scheduling, distribution of risks, building regulations, planning legislation and expectations of all those involved are geared towards a predictable, highly controlled process and a pre-defined 'product'. In this mode of change, the realisation stage is disconnected from the phase of actual use and is in this sense closed once the financial and other similar issues are settled. In complex and large building projects, like the construction of a housing estate, unforeseen problems are likely to occur. Lynch observes that "in a more sophisticated plan, any uncontrollable disruptions will be forecast and a set of contingency plans prepared that will all converge again to the same desired end." (ibid., p.207) Lynch concludes with a series of speculative propositions for alternative framings of time/environment constructs, the goal being the operability of the theory and the enrichment of our images of time. The skills needed for producing such alternatives would, in line with Lynch's pragmatist approach, "develop in the doing" (ibid., p.226). The propositions brought forward 
Figure 33: Culture of congestion in the East End, 24hour Beigel shop at Brick Lane, Tower Hamlets, London 2017

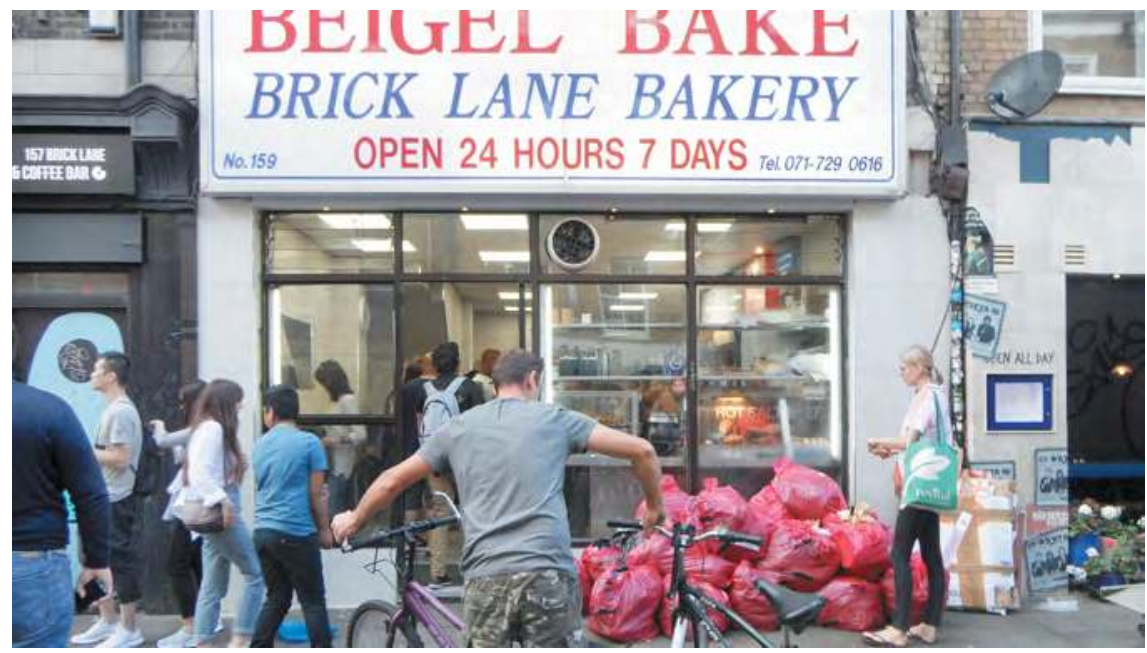

include, among others, a prototype habitat, simulation techniques and spatial action research (ibid.,pp.228f). Stressing the difference between these modes of change and the utopian model, Lynch asserts that "[...] they would begin with the real present and show how any new features would grow out of that existing situation" (ibid., p.229), rather than being guided by some distant image of the future - not dissimilar, perhaps, to the approach proposed by Karl Popper. In his final remark, Lynch argues for the joint consideration of space and time. "It is evident that we should think of an environmental image that is both spatial and temporal, a time-place, just as we must design settings in which the distribution of qualities in both time and space are considered." (ibid., p.242)

\subsection{Koolhaas - Culture of Congestion}

Manhattan has attracted and continues to provoke researchers and theorists of different backgrounds to analyse and speculate about the urban condition. Christopher Alexander used Manhattan as an example to show how a pattern language creates a coherent urban environment based on the repetitive, uniform use of patterns (Alexander 1979, p. 194). In the picture supporting his argument, tower blocks and a roof-top car-park are shown from an elevated perspective, whereby the more specific characteristics of the city remain mysteriously immersed in winter smog (ibid.7). Kevin Lynch mapped and analysed the visual form of New Jersey with Manhattan's skyline marking the eastern edge (Lynch 1960, p.27). "Delirious New York" is Rem Koolhaas's speculative and selective reconstruction of Manhattan's biography (Koolhaas 1994a [1978]). More than any other reference I have identified in the theoretical sampling process, it is conceived in Catherine Riessman's sense as a narrative "[...] to remember, argue, justify, persuade, engage, entertain [...]" (Riessman 2008, p.8), but also "[...] to mobilize others, and to foster a sense of belonging." (ibid.) 
Based on his observation of different obsessions with novelty, the effects of the capitalist economy, and the physical constraints of the Manhattan peninsula, in "Delirious New York" Koolhaas develops the concepts of "Manhattanism" (ibid., p.10, pp.110ff) and the "Culture of Congestion" (ibid., p.10, p.125) to describe the unique Manhattan condition. Conflict, continuity and change are ever present subtexts of Koohlhaas's narrative. In the introduction, Koolhaas asserts that "Manhattan's architecture is a paradigm for the exploitation of congestion." (emphasis in original, ibid., p.10) Manhattanism is defined as "unformulated theory [...] whose program - to exist in a world totally fabricated by man, i.e., to live inside fantasy — was so ambitious that to be realized, it could never be openly stated." (emphasis in original, ibid.) Koolhaas concludes his analysis with the proposition that the qualities of a metropolitan urbanism, as represented by the Culture of Congestion, should finally enter public debate, so that a new approach to urban design and a rethinking of modernism and the city become possible (ibid., p.293). He argues that "the Metropolis needs/deserves its own specialized architecture, one that can vindicate the original promise of the metropolitan condition and develop the fresh traditions of the Culture of Congestion further." (ibid.) In the analysis, the Manhattan block, established through the 1811 Commissioner's Plan (ibid., p.18ff), and the skyscraper, established as new architectural building type during the first decade of the $20^{\text {th }}$ century (ibid., p.82), are both identified as units and enablers of the Culture of Congestion. Koohlhaas emphasises the dichotomy of the grid - as the persisting element being fixed in space and time - and the contents of the blocks, which are constantly transformed on the basis of speculative development (ibid., p.18ff). Koolhaas suggests that in this way the grid organises two-dimensional territory, whereas the block acts as three dimensional enabler of urban space and time, in ever changing constellations.

"The Grid's two-dimensional discipline also creates undreamt-of freedom for three-dimensional anarchy. The Grid defines a new balance between control and de-control in which the city can be at the same time ordered and fluid, a metropolis of rigid chaos." (ibid., p.20)

"Since Manhattan is finite and the number of its blocks forever fixed, the city cannot grow in any conventional manner. [...] It follows that one form of human occupancy can only be established at the expense of another. The city becomes a mosaic of episodes, each with its own particular life span, that contest each other through the medium of the grid." (ibid., p.21)

The grid as conceptualised by Koolhaas is not neutral. Its indifference to topography and context is seen as an expression of mental domination over nature (ibid., p.20). The rectilinear standard prioritises economic efficiency and speculation over traditions of city form ${ }^{8}$, yet it is also seen as defining limits to the realisation of single inter-

8 In the 1811 Commissioner's Plan avenues are $100 \mathrm{ft}$ (30m) wide, standard streets $60 \mathrm{ft}(18 \mathrm{~m})$ and fifteen crosstown streets $100 \mathrm{ft}$. The avenues-facing side of the blocks is $200 \mathrm{ft}(61 \mathrm{~m})$ in width. The street-facing side ranges from $922 \mathrm{ft}(281 \mathrm{~m})$ in the inland section of Manhattan, and is reduced to $650 \mathrm{ft}(198 \mathrm{~m})$ near the river front, because the increased commercial activities there at the time justified a higher density traffic infrastructure. Hence the system prioritises avenues over streets by means of their respective 
ests and totalitarian intervention (ibid.). Koolhaas conceives the Manhattan condition as a life laboratory for alternative metropolitan urbanisms, suggesting that modernist schemes like Le Corbusier's masterplan for the United Nations Headquarters had to first go through substantial modifications before being admitted to the Manhattan context (ibid., p.277ff).

In the analysis of Manhattan's skyscrapers, Koolhaas identifies hybridism and the separation of content and shell as two fundamental principles that reconcile the rigidity of buildings with the demands of constant change. Where novelty is considered an end in itself, the perpetual cycle of transformation can never be fast enough. Koolhaas observes that, as the required productive life of a large building extends over a long period of time, the renewal cycles of building and content demanded the conceptual and structural separation of shell and content (ibid., p.100). This enabled change to occur recurrently inside the building without having to alter the more rigid components of the building structure. Koolhaas argues that on grounds of sheer size and external permanence the skyscraper assumes the status of an "automonument", devoid of meaning, which "[...] has to satisfy the two conflicting demands to which it is constantly exposed: that of being a monument [...] and at the same time that of accommodating, with maximum efficiency, the 'change which is life,' which is, by definition, antimonumental." (ibid., p.100) Automonument and antimonument seem to converge in the Downtown Athletic Club. Koolhaas' famous analysis of the Downtown Athletic Club building shows how in a hybrid building the stacking logic of the skyscraper produces a unique mixture of changing programmes along the vertical axis (ibid., pp.154). Koolhaas speaks of a "social condenser", "definitive instability" and "[...] a machine to generate and intensify desirable forms of human intercourse" (ibid., p.152). However, despite his celebration of the urban quality of hybridity, the narrative leaves the readership, perhaps intentionally, with an uneasiness about gender issues and exclusion (ibid., pp.157f).

\subsection{Failure as Agent of Change. The Myth of Pruitt-Igoe}

Theorising about the production of knowledge, Karl Popper made explicit the significance of learning from our past mistakes (Popper 2002a [1963], pp.xi-xii). If conceived as a materialisation of knowledge, and a way of producing knowledge, the built environment is, perhaps, populated by numerous failures and mistakes. Many of them will never be noticed, not all mistakes matter, some mistakes produce unexpected qualities which we then wish to retain. To speak of mistakes in architecture and urbanism is, however, not as straightforward as it may appear. Mistakes can be made in areas like construction technology, building regulations, cost calculations, time schedules. To speak of mistakes or failures when it comes to design quality is problematic, because the true/false distinction hardly ever applies. Hence, the learning from past mistakes in this field is by necessity bound up with controversy, because mistakes or failures cannot be determined with certainty on the basis of a true/false distinction, or as "matters of fact" (Latour 2008, p.4). In the absence of certainty, comparative terms like better, more, or worse seem to be more useful and appropriate. However, once a problem or mis-

clear width and by means of the rectangular 1:3 proportion of the rectangular block in the grid. The avenue is a route of fast changes, as blocks have their short sides orientated towards it, while the street is the route of slow changes. 
take is identified, the difficulties continue. The framing of the problem and the kind of methods applied in the analysis and interpretation are likely to be subjected to further controversy. The way we look at a design-related problem influences the way we learn from the problem. The cases of Pruitt-Igoe in St Louis, Sarcelles near Paris, Robin Hood Gardens in London, and other contested modernist projects have demonstrated how different actors claim authority over discourses and compete with their interpretations. In these contested fields, coalitions of strategic thinking and investment interests all too often offer 'solutions' which are based on the irreversible destruction of an existing architectural scheme (Trapp 2018; Stengel and Aquilar, in press).

The myth of Pruitt-Igoe is an example of failure-instrumentalisation in the discursive arena of modernist social housing (Bristol 1991). It reduces a complex narrative to a "single story" (Adichie 2009; Kling, in press). The project, located in St. Louis, Missouri, consisted of 33 uniform buildings, each 11-stories high, providing a total number of $2870^{\circ}$ units on the 23 ha site. The first buildings were occupied in 1954, and soon after its completion in 1956, living conditions on the estate began to decline, resulting in a constant loss of residents throughout the 1960s, while poverty, crime and neglect rose in inverse proportion (ibid.). From 1968 onwards, residents were encouraged to leave the estate in preparation for its complete demolition, which followed in stages between 1972 and 1976 (ibid.). The decline and ultimate abandonment of the estate sparked worldwide debate. In her 1991 article, Katharine Bristol traces the origins and effects of different explanations for the deteriorating condition in the estate, as well as the project's ultimate failure. She argues that analytical and interpretative selectivity contributed towards the mystification of Pruitt-Igoe, in particular among architectural and urban professions, who began to perceive the estate's demolition as a failure of architectural modernism (ibid., p.163, p.166).

At the core of Bristol's argument is the claim that architects and planners sought to put themselves in a position of authority by asserting that the problem of PruittIgoe was predominantly a problem of architectural design, from which it conveniently followed that the 'solution' would be located within their respective domains (ibid., p.170). At the same time, authorities and policy makers had the advantage of having a clearly defined external cause which they could publicly blame. This allowed them to ignore the adverse effects of demographic development in St Louis and the high rates of unemployment. They were also silent about persistent underfunding, the difficulty of establishing a functioning maintenance routine and the unfavourable division of responsibilities between local and federal authorities in the social housing sector at that time (ibid., pp.166f). According to Bristol, "[...] the myth is more than simply the result of debate within architectural culture: It serves at a much more profound level the interests of the architecture profession as a whole." (ibid., p.170) The myth exploits the media-effective, traumatic ending of the estate, asserting that a different kind of architecture would be required to avoid similar failures occurring in the future. The most prominent advance in this direction was, perhaps, Charles Jencks' declaration of the death of modernism and his call for a turn to post-modern architecture to fill the gap. A documentary film titled "The Pruitt-Igoe Myth" (Freidrichs 2011) has brought the project back to public attention, taking up the problem

9 In Katharine Bristol's article a figure of 2700 is given for the projected number of units. The final number was, according to other sources not specified here, 2870 units. 
Figure 34: Eastern block of Robin Hood Gardens by Peter and Alison Smithson, designed in the late 1960 s and completed in 1972. The future of the estate had been uncertain for several years due to ongoing controversy over redevelopment and heritage preservation. The western block is now demolished. Balfron Tower by Ernö Goldfinger, completed in 1967, can be seen in the background. London 2011

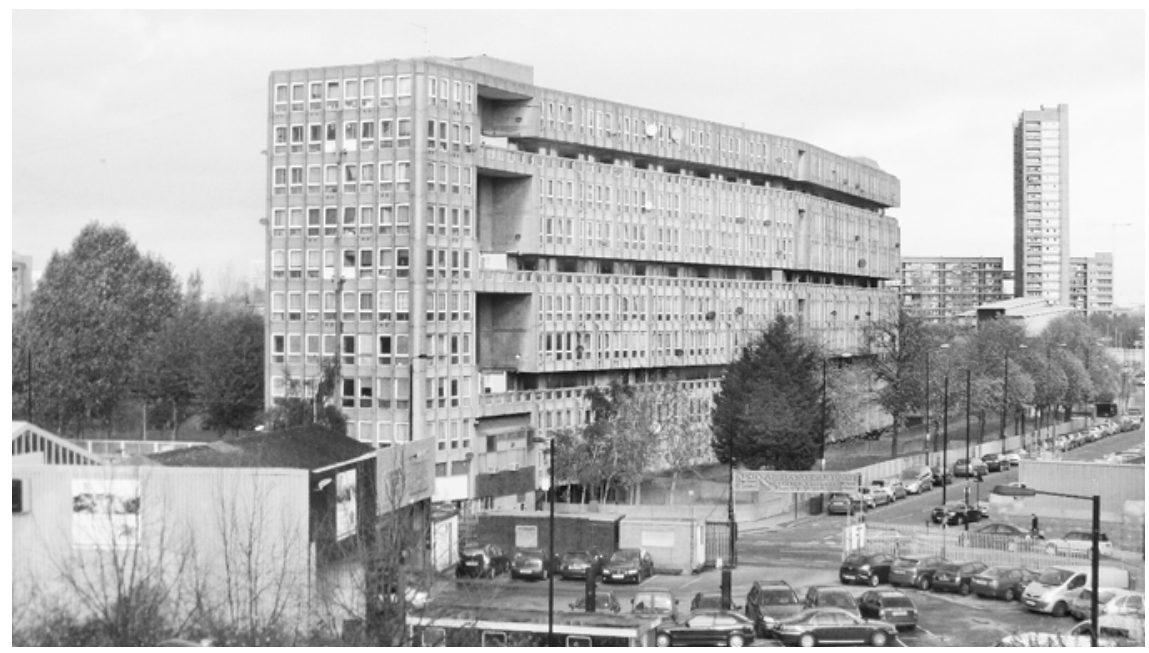

of mystification and emphasising the need to apply a wider frame to understanding the collapse of the Pruitt-Igoe estate. Bristol concludes for the case of Pruitt-Igoe, that

"by continuing to promote architectural solutions to what are fundamentally problems of class and race, the myth conceals the complete inadequacy of contemporary public housing policy. [...] The myth is a mystification that benefits everyone involved, except those to whom public housing programs are supposedly directed." (ibid., p.170)

The persistence and vitality of the myth means that it continues to be consequential, within and beyond architectural and urban discourses. Approaching Pruitt-Igoe today, for the purpose of learning from our past mistakes, the initial question would need extending: What can we learn from the failure and what can we learn from the myth of Pruitt-Igoe? Some critics choose to follow an affirmative path and build on the myth in their arguments. In the lecture "Stadt als Entwurf" (City as Design) given at TUM in 2014, Vittorio Lampugnani presented Pruitt-Igoe together with the Parisian satellite town Sarcelles ${ }^{10}$ as examples of architectural projects that had not been designed to respond to the "un-plannable" and that, as a consequence, resisted transformation (Lampugnani 2014). Lampugnani suggested that such schemes are at risk of being replaced or demolished when they reach a state in which resistance to change inhibits essential transformations, arguing for a different, more responsive kind of architecture as a sustainable solution to the problem (Lampugnani 2013; 2014). Acknowledging

10 The Parisian 'grand ensemble' of Sarcelles lent its name to a health condition called "Sarcellite", which was associated with depression, alienation and deprivation (Lampugnani 2013). Hence the town suffered from a similar kind of stigmatisation as had Pruitt-Igoe. 
the role of social and economic effects in the failure, Lampugnani asserted that, in the case of Sarcelles, the essential cause ("wichtigster Grund" or "Urgrund") of the problem was in its architecture (Lampugnani 2014), thus choosing to argue from within the established conceptual framing of Sarcelles and Pruitt-Igoe. An alternative path of learning from St Louis was pursued by raumlaborberlin in 2016 and 2017 (raumlaborberlin, Foerster-Baldenius et al. 2018). The collective activated their space buster vehicle and visited the people currently living in the proximity of the former PruittIgoe estate. The site of the housing estate had not been redeveloped after its demolition, and is at the present moment one of the many vacated or underused plots of land in the central area of St Louis. The idea of the visit was to develop an understanding of the current situation together with the local residents, to learn from their problems and initiatives, to reappropriate abandoned spaces, and to collectively work on urban change (ibid.).

The case of Pruitt-Igoe demonstrates that failures are often more ambivalent than researchers might be willing to admit and that interpretations of failures are not void of bias. The continuation of myths may create a sense of urgency, but it comes at the cost of reducing complexity to a single story. The questioning of myths demands architects and urbanists take a more differentiated view when approaching problems in the built environment, be more critical with their assessments, and allow controversy enter the process of 'learning from past mistakes'.

\section{Designing and Doing Change}

\subsection{Deterministic and Non-Deterministic Models of Change}

The following narratives shift the focus to design work and how change is approached in and through design. This includes perspectives that analyse areas which are located outside the scope of professional design work. The first concepts discussed in this section evolve around deterministic and non-deterministic models of change. The design disciplines frequently associate change with the term flexibility. Tracing the history of this concept in architecture, Tatjana Schneider and Jeremy Till observe that the meaning of the term flexibility has changed over time (Schneider and Till 2007, p.20). During the 1920 s and early 1930s, a period which they describe as having developed a very strong interest in flexibility for the first time, the "realities of flexibility" and the "rhetoric of flexibility" established two principal approaches that continue to inform ideas of flexibility today (ibid.). Schneider and Till identify "on the one hand a pragmatist response to the necessities of the minimal dwelling, and on the other a more polemical stance that allies flexibility with new modes of living and mechanised technology, both of which are seen as progressive traits of modernity." (Schneider and Till 2007, pp.20f) They propose that the modernist equation of flexibility with progress is based on the logic that "[...] something that can move escapes the shackles of tradition, something that can be changed is forever new." (ibid., p.5) However, the modernist fixation of and ideological claim to the term flexibility, combined with the experience 
of practical failure ${ }^{11}$, prompted criticism and stimulated the search for alternative responses to the problem of change. Adaptability as one of these newer concepts refers to the capacity of spaces to accommodate different uses, primarily through the way spaces and circulation patterns are organised. This concept generally works without relying on physical changes (ibid., p.7). Accordingly, Schneider and Till propose that designers have two principle options for positioning themselves and their work with regards to change. "Hard" tactics are used where "[...] the designer works in the foreground, determining how spaces can be used over time" (ibid.), while "soft use allows the user to adapt the plan according to their needs, the designer effectively working in the background" (ibid.). The softer tactics provide spaces whose function is not predefined. They generally require a certain level of excess space (ibid.).

Based on this distinction, two principle approaches, or models, may be identified through which architectural and urban design seeks to respond to change in design practice. One model conceives of change as something that occurs within a given framework of possibilities. This category is based on predictability. The other model subsumes the unexpected, the unforeseen, the spontaneous and is based on uncertainty. The design of deterministic spaces identifies and integrates the scenarios which they are supposed to accommodate. It enables change to occur within a pre-defined framework. It is usually economics, practicability or convention that determine the number of possible configurations in this approach. In this respect, deterministic systems can be considered closed systems ${ }^{12}$. Non-deterministic models, in contrast, build on the capacity of the unexpected. Instead of forecasting possible future changes, non-deterministic models allow new scenarios to enter and appropriate spaces, interact with its elements, and produce new scenarios. Depending on the interactions performed in and through the spaces, new configurations and spatial arrangements may emerge. Hence, the non-deterministic model is an open system. Based on the properties identified above, the two main models through which designers approach the problem of change may be represented as follows:

\section{Deterministic model:}

hard tactics - design in foreground - flexibility - closed system

\section{Non-deterministic model:}

soft tactics - design in background - adaptability - open system

The 'De Meerpaal' project by Frank van Klingeren in Dronten, Netherlands ${ }^{13}$, designed in 1965 and completed in 1967, could be considered an experimental prototype for soft

11 Considering the practical aspects of flexibility, mechanically enabled flexibility is seen has having regularly failed in the past, in particular for office spaces, as mechanical systems, despite their cost and intention, turned out to be inconvenient to operate, inefficient, or outdated before they could come into accepted service. This raises the question as to what extent digital concepts like the Smart Home or Smart Office will be facing similar problems in the future.

12 This does not mean that the unexpected does not occur in deterministic systems. Rather, the design seeks to control and therefore transform it, so that the outcome corresponds to the pattern of expected results. There is no permanent place for the unexpected in the deterministic model as it represents a potential threat to the stability of the system.

13 I would like to thank Prof. J. Kühn for pointing to the rich heritage of experimental Dutch architecture. 
and adaptable use in community orientated design (Rieniets, Sigler and Christiaanse 2009, p.25). Conceived as multipurpose open space, it is meant to be freely appropriated by different user groups. Part of the concept is the hope that through the self-determined mix of uses, new situations and spatial constellations can be generated. The project presupposes a general preparedness to accept incompleteness and compromise, because spaces which are geared towards neutrality may provide "[...] the most neutral solution to the specific problems, but never the best, the most appropriate solution" (Hertzberger 1991, p.146) It is both an opportunity as well as obligation, for the users to co-produce the space and generate the kind of atmosphere they wish to experience there. Conversely, the 'Frankfurt Kitchen' could be considered the uncompromising prototype of a flexible but non-adaptable device, organised as a highly specialised, tight-fit and mono-functional spatial arrangement ${ }^{14}$. Flexibility and mono-functionality in this context are modernist strategies to avoid and minimise conflicts on the basis of simplification and externalisation as discussed earlier. Here, the approach is to eliminate conflicts from being reproduced in daily routines through design work, which is in the hands of the expert architect or designer. Arguing from the perspective of practice in housing production, John Habraken suggests that the striving for efficiency dominates processes of designing, financing and building, which is seen as cause of the excluding of occupiers and users from the design process:

14 Excursus: The 'Frankfurt Kitchen' designed in 1926 by Austrian architect Margarete Schütte-Lihotzky is a site where everyday practice, architecture and a series of explicit and implicit intentionalities intersect. On the one hand it lends itself to an analysis of design features and architectural detail, and on the other hand it allows questions to be raised as to the social, political and economical imperatives it implies. The 'Frankfurt Kitchen' was installed in Ernst May's social housing programme 'New Frankfurt' during the 1920 s and eventually to more than 10,000 dwelling units in Frankfurt alone. It was featured in the CIAM II exhibition of 1929. The design applies Taylorism as guiding principle in the organisation of movements and activities. The elimination of spatial conflicts through design was meant to produce smooth and efficient workflows, pursuing the ultimate goal of minimising both, time and space requirements. The larger economical framework for this design is defined by quantity and efficiency - the provision of decent dwellings for as many people as possible by means of scaling down the size of the dwelling to an acceptable minimum (May 1930, p.10). Discussing the problem of "practical aesthetics" (Führ 1996), Eduard Führ argues that assumptions on norms and conventions are embedded in the 'Frankfurt Kitchen', and that the use of the kitchen would reaffirm and reproduce these norms and conventions through everyday practice. He draws special attention to the wall-mounted ironing board which requires the kitchen door to be closed for it to be used, thus isolating the ironing (then presumed female) person in the kitchen; making the door to open outwards solved this problem at a later stage (ibid.). In this sense, simple aspects of everyday life seem to be co-functioning as reproductive agents in the service of the efficient society. The concept of domestic efficiency points to the contradictions that become apparent in the everyday. On the one hand it could be seen as part of an ongoing emancipatory project. On the other hand, freeing up more time for consumerist activity as well as for recreational reproduction of labour seems to be also serving the requirements of capitalist production. Today, the 'Frankfurt Kitchen' is recognised as the forerunner of the contemporary western kitchen, complete with all the consumerist desires it evokes. It is one of the iconic markers that accompany the paradigmatic shift in the production of housing during the 1920s. It embodies and represents the problems and issues defined by the multiple frameworks for the production of housing at the time. It pioneered the colonisation of everyday life by tight-fit functionalism. 


\begin{abstract}
"We $\mathrm{e}^{15}$ are all the product of a culture, already more than a century old, in which the exclusion of the inhabitant is regarded unavoidable and efficient. [...] A common methodology is applied: The design of any housing project begins with the floor layout. Once these are known, everybody can do their part: consultants can design structure and services, builders can calculate, bankers can assess financing, developers can figure marketing. Without a predetermined floor plan the familiar system of mutual accountability and cooperation is destabilized." (Habraken 2008, p.292)
\end{abstract}

Today, the task of the two dimensional floor plan is increasingly assumed by proprietary Building Information Modelling (BIM), which may result in the divide between specialists - who are in control of the model and privileged in terms of access - and non-specialists widening. In some projects, non-deterministic elements are combined with deterministic elements in such a way that the dichotomy no longer seems to hold. The Fun Palace project, conceived by architect Cedric Price, theatre producer Joan Littlewood and cyberneticist Gordon Pask in 1964, proposed the ultimate withdrawal of the architect from the project (Price 2003). It was meant to place decisions on programmatic and spatial configurations in the hands of collective interaction, for maximum empowerment of, as well as enjoyment for the users. The Fun Palace is designed as a site of "[...] constant change, impermanence, process and interchangeability [...]" (Mathews 2005, p.90), in which potential conflicts are eliminated by means of intelligent programming before they even emerge. The architect, understood to have abandoned his or her authoritarian grip on space, re-enters the scene in the guise of the powerful programmer through the back door.

\title{
3.2 Control Hierarchies and Layers of Change
}

Hierarchies are used to organise and give structure to complex systems. For John Habraken hierarchies provide a possible conceptual framework for dealing with complexity in design (Habraken 1987a; 1987b) as well as for the control of change. In the essay "The Uses of Levels" (Habraken 2002 [1988]), Habraken suggests that the organisational structure of the built environment could be conceptualised as a hierarchy of distinct levels of intervention and distribution of power. Changes at higher levels in the hierarchy are seen as affecting lower levels to a greater extent than the other way round (ibid., p.6), which means that lower levels tend to accommodate change more easily and with a greater frequency (ibid., p.16). Habraken proposes a five-level hierarchy for the physical constituents of the built environment, comprising "urban structure" at the highest level, ranging through "urban tissue", "building", "infill" to "furniture" at the lowest level (ibid., p.8). Based on the hierarchy, Habraken discusses different configurations in control distribution and how this could affect the way users appropriate the built environment ${ }^{16}$. In the professionalised, top-down scenario, the levels of urban structure and urban tissue are controlled by municipal authorities, planning professionals and other specialists; the building and its infill by architects and building specialists; and finally the furniture by individual users (ibid., p.9). In the "sites

15 John Habraken speaks to architects, as an architect.

16 Habraken suggests that control distribution might be different during the design phase and the use of the physical constituents (ibid., p.9). For clarity, I do not make this additional distinction. 
and services" scenario, the building is constructed by the users, which means they are in control of the building, infill and furniture levels (ibid., p.9). In the "core houses" scenario, professionals and builders provide an empty shell, half a building, or small shelter that is then gradually appropriated or expanded by the users according to their needs and resources. In this scenario, the control of the building level is split between users and professionals (ibid., p.10). The award winning housing projects by Chilean practice Elemental, led by Alejandro Aravena, are based on this distribution of control (Awan, Schneider and Till 2011, p.44). Both scenarios have been used extensively in economies where family income available for building purposes is very limited.

The proposed "support/infill" scenario, however, is argued to be well suited for use "in large apartment buildings for relatively high density situations" (Habraken 2002 [1988], p.12). Habraken suggests that if the level of "building" is conceived as mere "support", the range of individual user control can be extended. In this scenario, the supporting structure of the building is controlled by the collective of owners if it is a condominium, or otherwise by a housing association or global owner, while the infill, comprising all partitioning walls and the horizontal distribution of services, is fully controlled by the individual user (ibid., p.12). The support/infill approach is the basic idea of Open Building, an initiative advocated by John Habraken and others for housing reform, which emerged in the Netherlands and other places during the 1980 (ibid., pp.12ff). The strict separation of support and infill is meant to enable users to make changes to their units more easily, small or large, without interfering with the rest of the building. Next to increased levels of user control, it is understood to be more efficient in the long term (ibid., p.13). The support/infill model has recently gained momentum through the growing number of participatory and cohousing projects in European cities. In Germany, variations of the model are currently being tested and experimented with in competitions and built projects, for example by BeL Sozietät für Architektur with "Grundbau und Siedler" in Hamburg (Wolfrum and Brandis 2015, pp.123ff), or the "Ausbauhaus Neukölln" by Praeger Richter Architekten in Berlin (Praeger and Richter 2017). Moreover, the principle of providing a simple and robust support structure is seen to offer advantages for open design processes in which spatial arrangements, as well as the distribution of territorial and temporal user control are collectively negotiated (Heinemann 2018, pp.67f).

In "How Buildings Learn. What happens after they are built", published in 1994, Stewart Brand shifts the perspective to everyday processes of change (Brand 1994) in search for answers to the question 'How do buildings change if they are not intentionally designed for change by professionals?'. Brand draws from a large body of comparative studies comprising past and present situations in the built environment, in particular research into life-cycles of commercial buildings, post-occupancy research and maintenance cycles, as well as Christopher Alexander's work (Alexander 1979), and Anne Vernez Moudon's “Built for Change” (Moudon 1986). As part of his conceptualisations of change, Brand introduces a layered model based on a temporal hierarchy of life cycles. The model consists of six "shearing layers of change" (Brand 1994 pp.12ff)",

17 The model is an extended and generalised version of a four layered model which Brand attributes to British architect Frank Duffy (ibid., p.13). The graphic representation of the model uses line thickness to symbolise rigidity and changeabilty, as well as the number of arrows to represent the typical number of changes during the overall life time of the building. 
ranging from "site" to "stuff", which define the external as well as the internal components that make a building. Each layer is assigned a typical lifetime. The site's lifetime is conceived as accommodating "generations of structures" (ibid., p.13), the structure itself is understood to last for 30-300 years, with most structures not lasting for more than 60 years due to causes that are external to the model; the skin is given a life of 20 years while the services are linked to a 7-15 years renewal cycle; pertaining to the space plan, in "turbulent commercial spaces" (ibid.) the plan is altered after 3 years, in "exceptionally quiet homes" after 30 years (ibid.). Finally, "stuff", comprising furniture and all movable items, is subject to frequent changes and replacements (ibid.). According to Brand, buildings are typically organised in such a way that fast layers are easily accessible to the users and occupiers to facilitate frequent changes. Providing arguments for using the model in design practice, Brand cites Frank Duffy, who suggested that "[...] you avoid such classic mistakes as solving a five-minute problem with a fifty-year solution, or vice versa." (Duffy cited in ibid., p.17)

Broadening the above proposition, Brand relates the shearing layers to corresponding "levels of responsibility" which involve different partners (ibid.). These include the individual or family, the landlord, the community, the state (ibid.). With reference to modes of organisation in ecosystems, Brand suggests that the overall system is dominated by slow components (ibid.). Within this slowly changing framework, trends of fast change are gradually integrated (ibid.). Brand concludes that "the quick processes provide originality and challenge, the slow provide continuity and constraint." (ibid., p.18) Pertaining to the question of change in everyday spaces and buildings, Brand asserts that "a building 'learns' only through people learning, and that individuals typically learn much faster than whole organizations.” (ibid., pp.188f) Hence, Brand's process-oriented idea of buildings takes as a starting point the active user. He demands that users be given the opportunity to change their environment by themselves and according to their needs - irrespective of ownership status - for which reason Brand suggests that "a building is something you start." (Brand 1994, p.188) Based on the same ideas, Habraken's approach advocates the extension of user control so that users can always start anew with their individual projects of appropriation and change.

\subsection{Admitting Uncertainty and Imperfection to Design}

When Stewart Brand asserts that "all buildings are predictions. All predictions are wrong" (Brand 1994, p.178), he touches upon the problems of fixation and uncertainty. The act of building is by necessity accompanied by certain kinds of fixations. As discussed above, the concept of adaptability gains its value from the anticipation of change that cannot be predetermined with certainty. There may be changes during the preparatory phase or the design process, changes during construction, changes through use and during the lifetime of the structure. If designers choose to follow the non-deterministic model in design - soft tactics, design in the background, adaptability, open system - they will have to address the question of how far to push the design and where to leave decisions with others. This has significant implications for the conceptual framing of design. Tatjana Schneider and Jeremy Till suggest that "to design a building with the specific intent for it to be changed in any way is to accept that the building is in the first place in some way incomplete, or even imperfect." (Schneider and Till 2007, p.8) However, John Habraken observes that the professions 
in architecture and urbanism struggle with the idea of sharing design work with others, of admitting change and imperfection to the design process, not least because of fear of loss of authority and the idea of the "myth of the master deciding everything" (Habraken 1987a, p.15). In view of the discrepancy between the qualities we should be striving for and design reality, Habraken suggests that

\begin{abstract}
"We tend to stress the constancy and immutability of the architectural form and do not readily take change into consideration when designing. [...] We need new attitudes that allow the qualities of daily life in the environment—variation and spatial development, thematic richness, and adaptability over time-to support our architecture in an efficient way. Without such qualities, environmental forms will maintain the poverty and rigidity we all deplore." (ibid.)
\end{abstract}

The multitude of mechanisms that intersect in architectural and urban productions planning legislation, building regulations, investment strategies, mortgaging, professionalism, user expectations and convention, all seem to have their share in the control of the process, and in this way contribute to the rigidity and poverty in quality. The idea of a culture of uncertainty, incompleteness, and even of imperfection, seems to contradict the way processes are defined and regulated at the present moment. However, Habraken's observations imply that, if the routine reproduction of non-adaptable spaces and in this sense of poor quality are to be avoided, attitudes will have to change as well as the distribution of power and control in decision-making processes. Analysing the capacity of buildings to change in relation to their (im)perfection, Brand distinguishes between "low road" and "high road" buildings, according to their typical location in cities (Brand 1994, p.24). Both types are understood to feature specific adaptive properties, where low road buildings, due to their purpose and non-representative nature, are understood to accommodate changes more easily in comparison to high road buildings (ibid., p.24, pp.38ff). Brand suggests that occupiers, if enabled through ownership or other forms of empowerment, tend to apply the technique of "satisficing" to carry out alterations (ibid., pp.165ff). The composite term of "satisfy" and "suffice", borrowed from decision-making research and systems theory, depicts a process in which, instead of finding an optimum solution to a problem, people seek choices that are good enough for the purpose and that reduce the impact of problems to a level that makes them tolerable (ibid.). According to Brand, the repetitive application of "satisficing" establishes a kind of evolutionary process, in which the movement is away from a given problem, rather than towards a distant goal (ibid., p.188). Brand asserts that in this sense evolution "[...] doesn't seek to maximise theoretical fitness; it minimises experienced unfitness." (ibid.) ${ }^{18}$ Hence, Brand argues that "satisficing" on the one hand, and striving for the optimum solution on the other hand, are two principal ways of approaching problems (ibid., p.158ff) which mirror the competing desires and interests of both the individual (ibid.) and the modern capitalist society (ibid., p.72ff).

18 This process is mirrored by lan Hacking's juxtaposition of the western tradition of scientific progress and the model of evolution (Hacking 2012, p.xxxv), as briefly discussed in section "Instability of Scientific Knowledge and Its Movement 'Away From'”. It is also taken up in Kevin Lynch's concept of "develop in the doing" (Lynch 1972, p.226) as discussed earlier. 
Figure 35: Responding to changing requirements. Improvised retrofitting of circulation at the Southbank Centre, London 2017

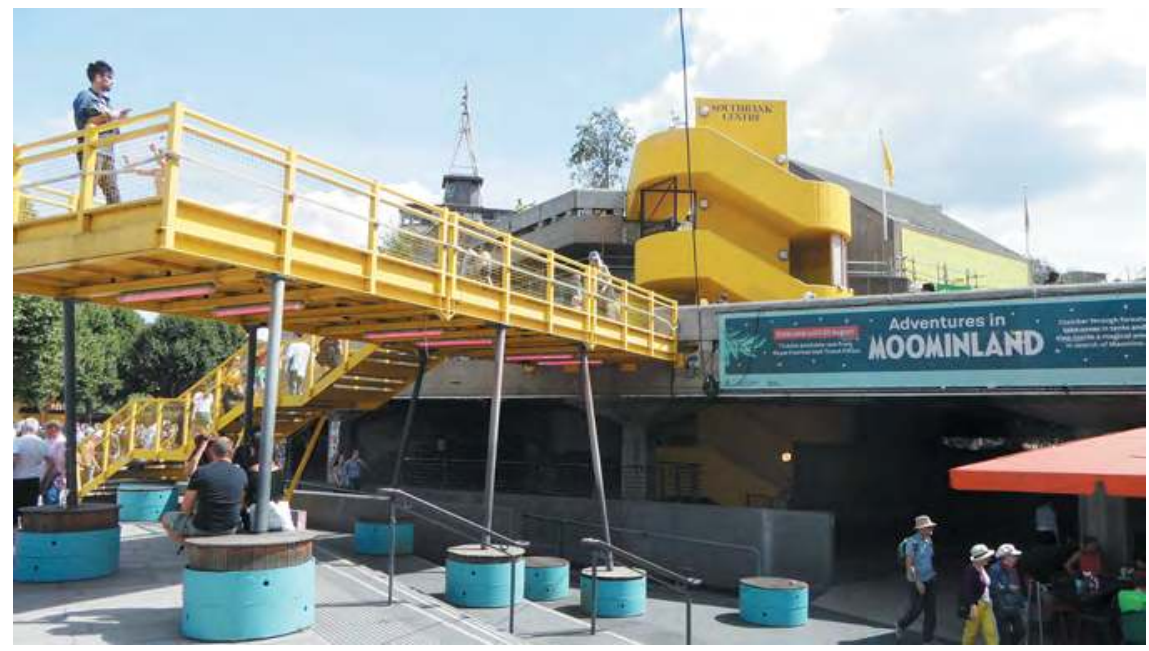

In line with Habraken, Brand asserts that the building industry, the building process, the market, professionals and legislation collectively fail to produce buildings that respond to the changing requirements of the users, as well as to the changing requirements of technology and other factors that are involved in change. It seems that alternative narratives of uncertainty and imperfection do not easily develop in the sheltered zones of professionalism and spatial routines. In view of these and other difficulties, Thomas Sieverts explicitly points to the possibilities that uncertainty can bring to design if it is approached in a positive way, if "uncertainty is understood as 'a challenge', as an adventure in urban development, as a space that cannot be determined and fixed but can be shaped through the projection of an activating image [...] in order to conceive it as an open space of possibilities." (Sieverts 2003 [1997], p.161) For the purpose of escaping the routines, protagonists often work at the interface of art and performance, community work, action research, the everyday, and other practices that enable them to assemble new and existing agents of urban and architectural change around alternative conceptual and practical framings of openness, uncertainty, incompleteness and imperfection. Recent initiatives that seek to explore and extend the possibilities of spaces of imperfection and uncertainty include, for example, the designing for "coexistence" (Rieniets, Sigler and Christiaanse 2009), the working with the "suboptimal" (Fezer and ifau 2011), or the theorising of the "Kaputt" (Aquilar 2018).

\subsection{Performative Production of Liminal Situations and In-Between Spaces}

Over the last two decades, the performative has emerged as a new field of architectural research and design activity (Wolfrum and Brandis 2015). The performative in architecture and urbanism relates to concepts that emphasise the mutual relationship between participants, space and actions unfolding in time. Participants are held to change the spatial setting through their presence and interactions, while the space influences the way humans feel and interact with each other in the situation. In this 
configuration, both worlds - the social and the material - are seen as being dynamic and as co-producing conditions of change. What distinguishes the performative from the notion of 'performance' is the framing of the situation. During performative acts the distinction between the categories of performer, spectator and space is blurred. All participants that are present in the situation are seen as jointly contributing to the performative production and enactment of the situation (Fischer-Lichte 2015, pp.33f). Constituent core qualities of the performative are unpredictability, ambivalence, shifting perceptions and the transformative power of the situation (ibid., p.31; Wolfrum 2015, pp.28f). A growing number of urban interventions and projects have explored - and put into practice - the performative capacity of spatial situations in the service of transformative processes. These interventions tend to be highly contextual and seek to link the specific local conditions with macro-scale phenomena such as urban restructuring, shrinking or migration; they provide a temporal home for debates and collective action; they act as spatial images or markers; they gather activities around a common interest or concern, often in conditions that are transitional in character and difficult to grasp. Hence, the performative is connected to the concept of in-betweenness, in both a temporal as well as spatial sense.

In the 2001 publication "Urban Flotsam", the research collective CHORA brought forward a theoretical framework for interventions in "environments undergoing radical change and/or conflict" (Bunschoten, Binet and Hoshino 2010 [2001], p.378). The framework includes the concept of "liminal bodies" (ibid.), where "the term liminal literally means 'in between', and indicates a period outside of the normal flow of time." (ibid., p.360) Borrowed from Victor Turner's anthropologic research into rituals of passage, where it means the brief transitional phase between two rituals when a person does not hold any defined social status, the liminal defines an ambiguous condition of in-betweenness, of instability (ibid.) ${ }^{19}$. According to CHORA "[...] the liminal is cut out of everyday existence as a kind of ritualized or orchestrated form of instability or disorder." (ibid.) Liminal bodies, then, define a kind of spatio-temporal in-betweenness, where in CHORA's adaptation "the term body deliberately leaves open the nature of this physical presence, which may range from a group of people convening regularly in space, to a tent [...], or a heavily used footpath" (ibid., p.348) ${ }^{20}$. Liminal bodies are seen as creating a strong sense of identity during processes of change, as they act as "[...] recognizable feature that 'names' a place." (ibid.) They establish temporal and spatial "connectivity, linking global conditions to local concerns and actions." (ibid.) Change, as I concluded in the previous chapter, tends to be entangled with conflict. CHORA understands conflict as bringing people and divergent ideas together, rather than separating them from each other. CHORA asserts that conflicts are capable of "[...]

19 Bunschoten, Binet and Hoshino relate their use of the term to the reading of "[...] 'Betwixt and Between' by the American anthropologist Victor Turner, who uses the term 'liminal' to describe a phase during which an initiate is instructed in the conflicts of life and is shown 'monsters', figures combining different and juxtaposed factors of life." (Bunschoten, Binet and Hoshino 2010 [2001], p.360) The same connection to ritual theory, or the 'liminal' and Victor's work is proposed by Erika Fischer-Lichte for the performative (Fischer-Lichte 2015, p.35).

20 Despite the difference in grounding, the emphasising of instability and ambiguity bears similarities to Georg Simmel's concept of threshold or 'in-betweenness', as developed by him in the essay "Bridge and Door" (Simmel 1994 [1909]). 
Figure 36: Central workshop unit and bar at the 'Shabbyshabby Apartments' event. Project teams, visitors and curators intermingle and in this way produce a unique situation.

Organised by raumlaborberlin and Münchner Kammerspiele, Marstallplatz Munich 2015

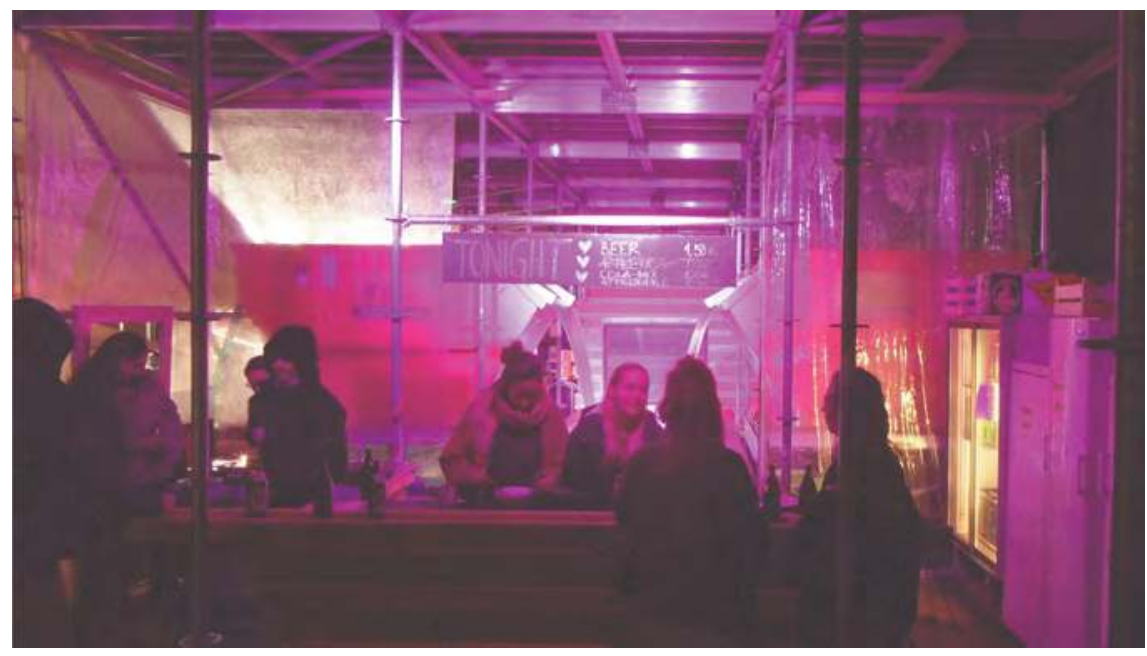

Figure 37: Lückenfülle, urban intervention conceived and realised by Leila Unland, Nick Förster, Maria Schlüter and Sophie Ramm, Maxvorstadt Munich 2016

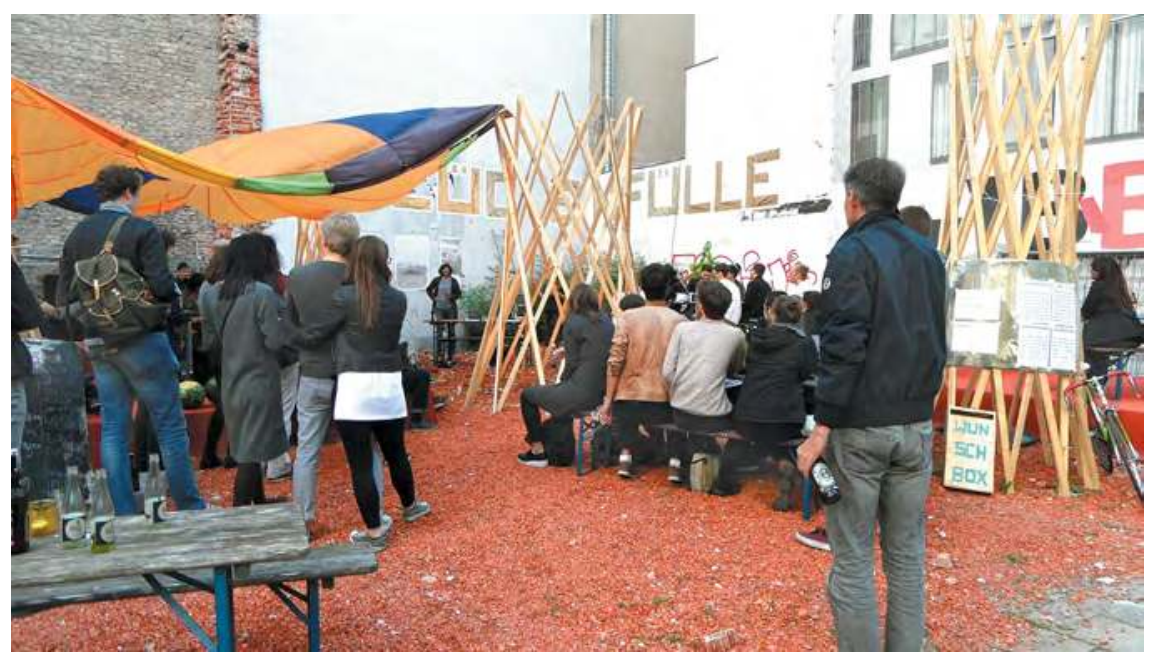

triggering interaction between actors and agents that otherwise would not meet." (ibid., p.353) Conflicts are seen as "stepping stones" which in turn "[...] are instruments for managing urban change." (ibid., p.353) Accordingly, CHORA asserts that "the management of urban change thrives on the cycle of conflict, negotiation, (non-)settlement." (ibid., p.358)

The "Lückenfülle" project by Leila Unland, Nick Förster, Maria Schlüter and Sophie Ramm brought people and ideas together on a rather unlikely site in one of Munich's inner city neighbourhoods. The group curated and built a space that, for the period of 
several weeks, developed into a situation of exchange and action. The project was part of a design studio that engaged with questions of urban change and migration at the Chair of Urban Design and Regional Planning in Munich in $2016^{21}$. The "Lückenfülle" connected in-betweenness, the liminal, and the performative in different ways. Filling the spatial and temporal gap (German 'Lücke') of a redevelopment site, the intervention provided a platform for planned and spontaneous encounters, discussions and play. Another example of recent academic work in this field is the 'Liminal States' design studio which was held at Oxford Brookes University in 2012-13. In the brief to the project, unit leaders Carsten Jungfer and Emu Masuyama speak of "negotiation of desires", of observing "relational phenomena", and of exploring "threshold conditions across multiple scales" (Jungfer and Masuyama 2013). The project site included different urban situations on Old Street, London EC1. As part of their design projects, students developed full scale spatial devices that could be used for performative interactions in the public domain (ibid.).

Similarly, the collaborative raumlaborberlin draws on the liminal qualities of found or generated urban situations in much of their work and engages with them in a performative way. Some of raumlaborberlin's projects are organised around "mobile activators" (raumlaborberlin 2018). The evocative "kitchen monument" and the "space buster" are perhaps the best known among them, consisting of a mobile technical unit and a translucent inflatable space that can be set up on different sites and adapted to local conditions (raumlaborberlin, Maier and Heidelberger Kunstverein 2008, p.98; Awan, Schneider and Till 2011, p.191; raumlaborberlin, Foerster-Baldenius et al. 2018). The kitchen monument is defined as "[...] a prototype with which to construct temporary communities." (raumlaborberlin, Maier and Heidelberger Kunstverein 2008, p.98) Since 2006, it has hosted meetings, community workshops and other events in different locations throughout Europe, providing a modest yet powerful spatial framing for collective action in public space. According to the initiators, the inflatable "investigates emotional anchoring spots within cities, in public places; the spheres of interaction between city dwellers and city users." (ibid.)

The space buster is inspired by the kitchen monument and has been touring New York and other US American cities since 2008 (raumlaborberlin 2018). In 2016 and 2017 it hosted a series of workshops and events in St. Louis, Missouri, were it engaged with the transformation of inner city neighbourhoods, including the area of the former Priutt-Igoe housing estate (raumlaborberlin, Foerster-Baldenius et al. 2018). Making use of its enabling capacity, the space buster hosted groups of neighbours and volunteers, who built a butterfly garden that is also used as a community space. In this sense, rather than simply documenting change, the project produces actual change. Similar performative elements and spatial arrangements are part of the work of EXYZT, muf, Assemble, ifau, zectorarchitects, and others, where the sites of urban interventions are often either characterised by high levels of instability, undergoing a phase of rapid urban transformation, or by stagnation (Awan, Schneider and Till 2011; Wolfrum and Brandis 2015; Kling and Jungfer 2018). They may be relics of processes that have ceased to be functional at some stage in the past, such as industrial wastelands or disused petrol stations. Sometimes they are simply left-over spaces in the city, such as the

21 Course leaders Sophie Wolfrum, Sofia Dona and Heiner Stengel, Chair of Urban Design and Regional Planning, summer semester 2016. 
space below highway infrastructures or on roof tops. These sites seem to have escaped, at least temporarily, the regulated machinery of efficiency and "financialisation" (Hesse 2018, p.79) that otherwise dominates the production of space in cities (Kling and Jungfer 2018). The performative production of liminal bodies can be seen as the realisation of kinds of micro-utopias in urban practice - as the temporary activation of urban residues that transform a given urban situation. They are both products and co-producers of urban change.

\section{Speeds and Rhythms of Change}

\subsection{Gradual Change and Cataclysmic Change}

John Friedmann suggests in "The City of Everyday Life. Knowledge/Power and the Problem of Representation" that the small spaces and lived-in, everyday environments in cities are associated with a web of meanings that are produced by their inhabitants (Friedmann 1999, p.5). ${ }^{22}$ According to Friedmann, changes to everyday spaces have a direct impact on these meanings and therefore on individual people's lives. As part of his criticism of the blindness of dominant planning instruments towards small spaces and the shared meanings they convey, Friedmann suggests that two different experiences of change occur in everyday environments. The first mode, according to Friedmann, is the experience of "gradual change" (ibid., p.9). Friedman locates gradual change in multiple sources, such as technology, demography, market conditions, migration (ibid., p.9). In terms of intensity and speed, Friedmann suggests that "given sufficient time to adjust, changes of this sort are seen as part of the normal course of life." (ibid.)

The second mode of change identified by Friedmann is "[...] disruptive of shared meanings and the social relations on which these meanings depend [...]" (ibid.). Examples provided by Friedmann include "the construction of major thoroughfares [...] market-led but state-approved gentrification of low-rent districts [...] the cumulative location of unwanted facilities - prisons, garbage incinerators, land fills, chemical storage tanks - in poor people's neighborhoods, a well known strategy adopted by the state when it seeks the path of least resistance." (ibid.) ${ }^{23}$ The list of interventions implies that both the speed and the scale of change may be of relevance for the way people experience transformations in their everyday environment. Friedmann suggests that "[...] dynamic change occasioned by planned interventions that are conceived at macroand meso-scales frequently leads to the alienation of the city's lived spaces, causing

22 Upon framing the everyday, Friedmann explicitly refers to the writings of Henri Lefebvre, among others (ibid., p.6).

23 We can observe these strategies in almost any city. On the occasion of the "Porous City" conference in Munich in March 2018, Paola Viganò presented a map of Greater Paris, which showed that the neighbourhoods of low income groups are often located in the proximity of 'unwanted facilities' and uses which cause massive and disruptive change. Munich seems to be following a similar pattern. Its landfill, incinerator, wastewater treatment plants, nuclear research reactor, and airport are all located in the less privileged northern areas. The plans for a third runway were put on hold after public protests in 2012. 
widespread anomie, destroying individual as well as social meanings as well as community bonds, and deepening an already pervasive sense of powerlessness on the part of local inhabitants." (ibid., p.4) With reference to the writings of Christopher Alexander, William Whyte and Kevin Lynch, John Friedmann states that "[...] it is probably true that most people generally prefer gradual change to change that is unexpected, sudden, and massive, especially when it affects the intimate spaces of their habitat." (Friedmann 1999, p.9) According to Friedmann, disruptive changes may lead to alienation, in particular if the transformation is imposed on the city of the everyday without prior involvement of the affected population (ibid.). Hence he rejects "[...] the sudden invasion of the city of everyday life by the state." (ibid.) Likewise, highlighting the significance of gradual change, in particular in housing, John Habraken asserts that

"change over time is important. The recognition that things change over time and must improve over time is perhaps the single most important new aspect introduced in our thinking about housing. Housing projects and neighborhoods must grow and develop over time. There is no such thing as an instant environment" (Habraken 2002 [1988], p.3)

Habraken's assertion, however, is also directed against the idea that the preservation of the status quo, or lack of change, could be a desirable option. Jane Jacobs arrives at similar conclusions for the scale of the city and the neighbourhood level:

"City building that has a solid footing produces continual and gradual change, building complex diversifications. Growth of diversity itself is created by means of changes dependent upon each other to build increasingly effective combinations of uses. [...] All city building that retains staying power after its novelty has gone, and that preserves the freedom of the streets and upholds citizens' self-management, requires that its locality be able to adapt, keep up to date, keep interesting, keep convenient, and this in turn requires a myriad of gradual, constant, close-grained changes." (Jacobs 2011 [1961], pp.293f)

Yet, gradual change does not inevitably produce positive outcomes. Jacobs takes as an example the gradual "erosion of cities by automobiles" and the growing amount of space dedicated to vehicular traffic (ibid., p.349). In line with her argument for a liveable city, she proposes the "attrition of automobiles by cities" (emphasis in original, ibid., p.363) as a possible countermeasure - a tactic based on gradual, positively communicated change, which is meant to re-allocate traffic space to other uses. In Jacob's view, "attrition tactics should be applied where conflicts exist between traffic flow and other city uses, and as new conflicts of this kind develop." (ibid., p.370) In her view, long-term transformation is revolutionary in its cumulative effects, yet, "[...] like any strategy aimed at keeping things working it has to be engaged in as a form of evolution." (ibid., p.363) In this sense, gradual urban change, as conceived by Jacobs, is the product of positive or negative cumulative urban practices, where the most negative erosive changes "[...] are by no means all thought out in advance" (ibid., p.369). Hence, if it is true that people adapt more easily to gradual change, this does not mean that any kind of gradual change is desirable. 
"The changes required or wrought by erosion always occur piecemeal—so much so that we can almost call them insidious. In the perspective of a city's life as a whole, even the most drastic steps in the process are piecemeal changes." (ibid., p.369)

Jacobs works with further differentiations in her argument. She relates the question of fast or slow, big or small to the questions of funding and who takes initiative for change. According to Jacobs the kind of capital used, the framing by legislation and other conventions, influence the type and speed of transformative processes that occur in cities (Jacobs 2011 [1961], pp.291ff). Pertaining to her analysis of urban renewal projects, Jacobs distinguishes between "cataclysmic money and gradual money" (ibid.). Despite her frame of enquiry being the nation state, and more specifically the Unites States of America as welfare state during the 1950s and 1960s, Jacobs's observations in terms of effects remain valid in the contemporary urban condition. We see cataclysmic money originating from the nation state, from supranational levels, and to an ever growing extent from the global level (Sassen 2014). The speed of global capital, if it aligns with local neoliberal policy, has the capacity to cause severe rupture to people's everyday lives in the urban, in particular if it operates in the deregulated spaces provided by the weakening nation state (ibid., p.18). In the capitalist economy and the "spaces of capital" (Harvey 2001), the speed of change could be seen as a problem of turnover rate, reinvestment and absorption of surplus value (Harvey 1975, p.245; 2008, p.25, p.29). Hence the term 'cataclysmic' may be associated with a broad range of disruptive changes that have their origin in different practises and systems ${ }^{24}$.

The speed of change as envisaged by Friedmann and Jacobs is one that is perceived and constructed in individual actors' minds, relative to their experience of the everyday. Because of differences in conditions, personal circumstance and collective constructions, the speed of a given transformation tends to be perceived differently. An analysis based on the distinction between gradual change and cataclysmic change, therefore, would not only enquire into 'what change does', but also into 'how change is perceived', thus addressing the mutual relationship between the (changing) environment and the (changing) perception of the actors involved.

24 They could be the product of public money or global capital; they could be related to public policy or to the extracting of profits for global corporations, or by a combination of them. A well known historic example of cataclysmic change that collided most radically with gradual change is the transformation of Paris during the reign of Napoleon III in the second half of the $19^{\text {th }}$ century, supervised by the prefect of the Seine Department, Baron Georges-Eugène Haussmann. On the one hand, there was the existing urban grain which accommodated change within the building plot according to the specific requirements of the site, whereby initiative for such gradual change had typically been taken by the users or owners of the site. On the other hand, there was the momentum of the big project, the implementation of the new avenue system (Frampton 2007[1980], pp.23f; Harvey 2008, pp.25f). The initiative had been with the state, which provided the instruments to address the inevitable conflicts. However, despite the efforts directed towards coherence, the collision between the existing and the new produced numerous oddly shaped urban blocks, abrupt change of scale, and unexpected urban situations. 


\subsection{Incrementalism and the Speed of Learning}

In view of the growing awareness of the limits of established planning processes, as well as the experiences with cooperative models in the IBA restructuring projects of the Ruhr area in Germany ${ }^{25}$ during the 1980s and 1990s, Klaus Selle demands the rethinking of planning, as a practice and as a discipline (Selle 1994). In the publication "Was ist bloß mit der Planung los?" (What is happening to planning?), Selle raises a series of conjectures as to the possible future issues of the discipline and the questions and implications that emerge from them. He observes that planners have discovered the multitude of other actors that are entangled in urban situations ("Entdeckung der Akteure", ibid., p.63), with the result that processes are increasingly opened up. Selle asserts that cooperative models and project-based work offer alternatives to the centralised model of 'decide (internally) - announce - defend' (ibid., p.73). The new kinds of processes observed by Selle have in common that they develop gradually in increments, thus contrasting with approaches in planning that are anxious to deliver rapid results. The basic questions for Selle are: What kind of goals may be achieved with a process that evolves in small steps? Within which configurations does it work, and for whose benefit? (ibid., p.53) At the outset of his enquiry Klaus Selle stresses the term increment to be etymologically related to 'increase' ("Zuwachs"), and that in this sense it is associated with positive change (ibid., p.53). According to Selle, the step-by-step nature of the process does not exclude the possibility of striving towards fundamental change (ibid.). The capacity of incrementalism in this respect is that agreement about the next step or action does not require consensus about a distant goal. Selle understands cooperative and open processes as offering the possibility of arriving at incremental consensus-based solutions ("konsensfähige Lösungen"), provided that conflicts and divergent interests are openly addressed, defined and negotiated (ibid., p.73). Pertaining to the role of conflict in cooperative and open processes, Selle cites Karl Ganser and Thomas Sieverts, the 'doers' of the IBA in the Ruhr area ("IBA-Macher"), who assert that the practical IBA process relied to a large degree on the optimum level of conflict ("optimales Konfliktniveau"). This optimum level is understood to have created a sense of urgency, without the feeling of being overwhelmed by the problems, as well as a sense that joint action and agreement would be possible (ibid., p.228f). However, Thomas Sieverts states a decade later that the standard legal and administrative frameworks would still struggle to adequately address and integrate incremental change (Sieverts 2003 [1997], p.81). He observes that "[...] with the help of traditional planning tools, these changes are difficult to plan and control both at the level of the local community and the city regions, because for the most part the changes are comparatively small-scale measures of reutilisation, reconstruction, expansion, repair and modernisation" (ibid.) As day-to-day actions and "working in the fine grain" are seen as being indispensible to mobilising the ever growing number of "disused resources" (ibid.) in the 'Zwischenstadt', and as growth in many situations has ceased to be the characteristic pattern of change (ibid.), Sieverts demands that a new type of responsive planning must be developed together with a "[...] new perspective to understand and implement small-scale day-to-day tasks of planning as components of a long-term restructuring strategy." (ibid., p.82) The gradual pace of change, in this configuration,

25 International Building Exhibition IBA 'Emscher Park'. See also (Sieverts 2003 [1997], 121f). 
is conceived as an opportunity of jointly working on ideas - or "images" - of possible futures that can be shared, discussed, improved and used for orientation in the process (ibid.). ${ }^{26}$

In the introduction to the 1971 edition of "Concise Townscape", Gordon Cullen draws a connection between the observed deficits in the newly constructed built environments and the unprecedented volume and speed of urban construction in Europe during the post-war era. According to Cullen, "the speed of change prevents the environment organisers from settling down and learning by experience how to humanise the raw material thrown at them." (Cullen 2010 [1961], p.13) Since then, the actors involved in this process have gone through multiple cycles of learning. Selle's and Sievert's criticisms suggest that the opening-up and adjustment of processes have to be conceived as a continuous process. With reference to John Friedmann's concepts of empowerment and planning, Selle suggests that in cooperative processes, due to the ever increasing awareness of the complexity of problems and instability of knowledge, the paradigm "from knowledge to action" is shifting towards "learning and action" (Selle 1994, p.292). Hence, the incremental process of change is increasingly seen as a process of cooperative and collective learning. Klaus Selle asserts that incremental cooperative action offers participants the chance not only to learn from each other, but also to more easily integrate external experiences into the process, for instance from comparable cases. Selle speaks of the dynamic of dialogic processes of learning ("Dynamik dialogischer Lernprozesse", ibid., p.71).

Learning how to conceive of, produce and manage change, both on the level of buildings or the level of urban environments, is connected to learning how to cope with change. Coping with change is a condition that involves both, groups and individuals. The sharing and integrating of coping experiences during a process may reduce feelings of "sudden invasion" as described by John Friedmann (Friedmann 1999, p.9). If groups and individuals were to have the opportunity to let their coping experience flow into processes in a meaningful way, not only in terms of goals and actual content, but also in terms of speed, they would, perhaps, find it easier to agree on transformations in the first place and assume a more active role in the process. Swift changes continue to be an option, but the learning and coping dynamic would determine the pace of change rather than the other way round.

Hence, if Lynch, Brand, Selle, Sieverts, and others assert in their narratives that learning how to shape and re-shape the built environment is a process that requires time and that needs to connect to communities and private lives, what could prevent actors from allocating sufficient coping and learning time to the process? In practice, we see that time schedules and the pace of change are often determined by external factors that are difficult to influence or beyond the control of single participants. Temporary uses on a site may have a fixed end date in expectation of a new development, or public funds may have to be spent within a certain time frame. However, pertaining to the relation of speed of change and capital flows, Jane Jacobs asserts that

26 For a historic account of the introduction of step-by-step processes and openness to urban planning, as well as the shifting notion of the term , Leitbild' in Cermany, see (Krau 2010, pp.75ff). For exemplary images of change that had been developed as part of the IBA Emscher Park see (Sieverts 2003 [1997], pp.116ff) 
"The city building money operates as it does not because of its own internal necessities and forces. It operates cataclysmically because we, as a society, have asked for just this." (Jacobs 2011 [1961], p.309)

\subsection{Rhythms of Change}

During the 1980s, Henri Lefebvre begins to explicitly theorise on rhythms, first as an aspect of everyday life, and then as an instrument of analysis and as a complex field of knowledge (Lefebvre 2013 [1992], p.2) ${ }^{27}$. Initial ideas about rhythms had already been offered in "The Production of Space" (Lefebvre 1991 [1974], pp.205ff and p.405). Two essays, written together with Catherine Régulier, further explored this topic (Lefebvre 2013 [1992], pp.80-106) ${ }^{28}$, which finally led to the publication "Eléments de rythmanalyse: Introduction à la connaissance des rythmes“. This is Lefebvre's last book and was published posthumously in 1992, one year after he passed away at the age of 90 . Lefebvre distinguishes between two main categories of rhythms: linear rhythms, and cyclical rhythms (Lefebvre 2013 [1992], p.18). He suggests the cyclical originates from natural phenomena such as day and night, seasons, waves and tides, while the linear is more related to social practice and human activity, such as the monotony of repetitive actions and movements, or the imposition of structures (ibid.). The linear as observed by Lefebvre on the streets is "the daily grind, the routine, therefore the perpetual [...]" (ibid., p.40), but it is also "made up of chance and encounters" (ibid.). It is characteristic of Lefebvre's dialectical approach that these categories are not fully separable. They may shift from one state to the other, depending on perspective, and they occur simultaneously. They produce compromises and disturbances through their interaction (ibid., p.18). As a result, even in the most controlled environments, rhythms never repeat themselves in an identical way (ibid., p.17).

Lefebvre refers to the occurrence of multiple rhythms as polyrhythmia (ibid., p.25). He suggests that multiple, or polyrhythmic rhythms tend to be either in a "eurythmic" state or, conversely, in an "arrhythmic" state (ibid.). In the context of everyday life, Lefebvre understands eurhythmia to unite different rhythms with each other in "normal everydayness" (ibid.), which for Lefebvre is related to the "normed" (ibid.), while the arrhythmic is seen to unite rhythms "in discordance" (ibid.). The transition between the two states constitutes a condition of significant change, for "the discordance of rhythms brings previously euryhthmic organisations towards fatal disorder." (ibid.)Lefebvre further explores the moment of rhythmical collapse and describes the transitional phase between different modes of rhythms, or the complete abandoning of rhythmic relations as temporal space of possibilities and the new.

27 See Stuart Elden in the introduction to his translation of "Eléments de rythmanalyse: Introduction à la connaissance des rythmes" (Lefebvre 2013 [1992]).

28 The first essay by Lefebvre and his wife Catherine Régulier: 'The Rhythmanalytical Project', was first published in French in 1985. The second essay, 'Attempt at the Rhythmanalysis of Mediterrenean Cities', was first published in French in 1986 and added to the 1992 French publication of Lefebvre's "Eléments de rythmanalyse: Introduction à la connaissance des rythmes". All three essays were published in English as “Rhythmanalysis. Space, Time and Everyday Life” (Lefebvre 2013 [1992]). 
Figure 38: Winter in Munich's central park 'Englischer Garten', view along Schwabinger Bach, Munich 2016

Figure 39: The same view in summer. The comparison reveals a polyrhythmic situation in which different seasonal, social and urban rhythms interact with each other, Munich 2016
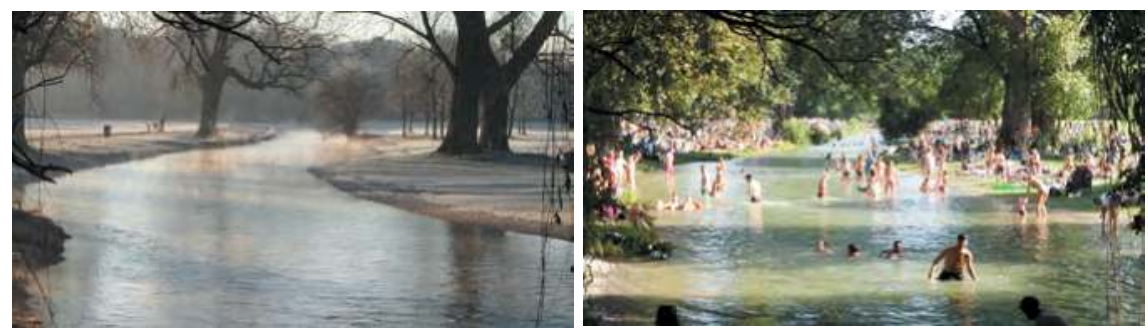

"All becoming irregular [dérèglement] [...] of rhythms produces antagonistic effects. It throws out of order and disrupts; [...] It can also produce a lacuna, a hole in time, to be filled in by an invention, a creation. That only happens, individually and socially, by passing through a crisis." (ibid., pp.52f)

Henri Lefebvre relates rhythms to the everyday, the body, to work, the media, institutions and the city, as well as to the more obvious field of music. These categories, in turn, are related to his broader critique of capitalism and the production of space. According to Lefebvre, "everywhere where there is interaction between a place, a time and expenditure of energy, there is rhythm." (Lefebvre 2013 [1992], p.25) Lefebvre's definition implies that 'expenditure of energy' is a precondition for interactions, or rhythms, to occur. This energy is supplied as well as received by the categories involved in the process. If conceived in this way, rhythms are effectively components of systems that transmit and exchange energy. Rhythms may be put to work and made productive, through which they acquire a certain use-value. Productive rhythms are assigned an exchange-value if they participate in the market (ibid., p.49). According to Lefebvre, the capitalist model is based on "[...] the rhythm of producing (everything: things, men, people) and destroying (through wars, through progress, through inventions and brutal interventions, through speculation etc.)," (emphasis in original, ibid., p.65) thus highlighting the violence that may be reproduced through rhythms. Correspondingly, Lefebvre suggests that institutionalised systems of power seek to control and use rhythms towards their own ends (ibid., p.50).

In contemporary urban theory, the concept of rhythms is used, for example, in the analysis of commuting and use of space (Franck 2004, 2010, p.7). Georg Franck suggests that rhythms are "the epitome of a stable process" (Franck 2010, p.7), because they are made of activities that return to their initial states over and over again (ibid.). Relating the concept to design and planning practice, Franck suggests that "the activities that architects and planners call space-uses are of the characteristic form of a process that returns to the point, or state, from which it had started." (ibid., p.9) In this sense, mixed programmes could be conceived as assemblages of different rhythms. Franck contrasts stable rhythmical activities with dynamic processes that are instable, such as agglomeration. According to Franck, economies of scale and the accumulation 
of central functions prevent the system from returning to its initial state and produce self-amplifying effects (ibid., p.10).

Lefebvre asserts that the study of rhythms by the "rhythmanalyst" (ibid., p.13, pp.29-36) presents a new method of analysis based on a theory of rhythms, that "[...] could change our perspective on surroundings, because it changes our conception [...]" (emphasis in original, ibid., p.26). Lefebvre's outline of the method includes propositions on the practical aspects of identifying and interpreting rhythms. According to Lefebvre, the difficulty for the rhythmanalyst upon engaging with the study of rhythms in the environment is "[...] to perceive distinct rhythms distinctly, without disrupting them, without dislocating time." (ibid., pp.29f) In doing so, the rhythmanalyst prioritises time over space, without omitting the spatial, and is understood to develop an awareness for "presence" (ibid., pp.32f). To Lefebvre, one of the ways to grasp the complexity of rhythms is through the seeming paradox of situating oneself "simultaneously inside and outside" (ibid., p.37). For example, he suggests that pertaining to the observation of rhythms on the street, a suitable position of in-betweenness could be taken on a balcony (ibid.). The temporality of rhythms and their differences makes recollection an essential tool for rhythmanalysis (ibid., p.45). Conversely, there is a memorising capacity in the performing of rhythms.

According to Lefebvre, "Rhythms always need a reference; the initial moment persists through other perceived givens." (ibid., p.46) Due to the relativity of rhythms, Lefebvre demands that every study of rhythms be necessarily comparative (ibid., p.97). For the analysis of urban rhythms, this means that they have to be distinguished, and in this sense separated, before they can be jointly analysed (ibid., p.103). Lefebvre conceives of the human body as sensor and measuring instrument, as it allows the rhythmanalyst to compare the multitude of external rhythms to the analyst's own internal rhythms (ibid., p.20, p.46). "We know that a rhythm is slow or lively only in relation to other rhythms (often our own: those of walking, our breathing, our heart)." (ibid., p.20) Lefebvre's conceptualisation of rhythms is integrative in that other discourses such as ecology, social psychology, or conservation may be related to each other in new ways. Lefebvre asserts the connectedness of different worlds to each other through rhythms, suggesting that

"If there is difference and distinction, there is neither separation nor an abyss between so-called material bodies, living bodies, social bodies and representations, ideologies, traditions, projects and utopias. They are all composed of (reciprocally influential) rhythms in interaction." (ibid., p.51)

\section{Preliminary Findings}

As in the previous chapter, I have assembled a sequence of architectural and urban narratives, this time with the focus on change. The selection evolved on the basis of theoretical sampling, which operated for the most part in parallel with the enquiry into the narratives of conflict. As in the previous chapter, we cannot assume the process to be fully saturated. However, the analysis has generated a body of concepts which I take to be of sufficient size for the setting-up of the theoretical intersection in the following research stage. The analysis developed in four sections, starting with dialectics, evolu- 
tion, and autopoiesis as conceptual bases for urban and architectural meta-narratives of change. This was followed by the juxtaposition of a series of narratives that emerged as critical response to modernism, including a body of texts that continue to be fundamental in architectural and urban theory. The third section focussed on issues that are more design and practice-related, including deterministic and non-deterministic models of change, levels and layers of change, uncertainty and imperfection, in-betweenness and the performative in architecture. In the final section, I analysed a set of narratives about speeds and rhythms of change and linked them to problems like coping and learning.

Urban and architectural narratives of change are tools to conceptualise, communicate, integrate, memorise, instrumentalise, or politicise processes and conditions of change. They do not constitute a consistent or homogeneous body of knowledge. Some narratives maintain an abstract and theoretical level of analysis and discussion, while others are more interested in the interactions of change and design, or the practical aspects of change. These latter narratives work towards the making operable of theory, in the sense that they seek to draw concrete conclusions for architectural and urban practice. Some conceptualisations of change are connected to projections of alternative futures or utopias, small and large. Critical enquiries into change seek to theorise inequality, deregulation, financialisation, the effects of the capitalist economy on the everyday, or the global conditions of urbanism. Typomorphological narratives examine change as a problem of urban and architectural morphology, typological process and urban form. Historic and contemporary modernisms have established a tradition of reductionist representations of change that are based on ever growing amounts of data that are made operable in design and urban planning models. Conceptualisations of change that are aligned with professional architectural and urban practice are typically oriented towards the various stages of design and construction. In this field, change is conceived as a problem that needs to be addressed in the development of the project brief, in the setting-up of the realisation process, in the detailing and costing, and finally in scenarios for the post-occupancy stage. In the professional world, change tends to be associated with concepts like risk management, steering groups, change management, resilience, or flexibility.

Like conflict, change is an ever present phenomenon in the urban and in the city. Complex frameworks of agreements and legislations seek to control and influence processes of change. To control change means to maintain or, conversely, to challenge the stability of a given system or a given set of conditions. Change in the urban is related to the political and to questions of power. If we maintain the view that conflict and change are mutually related, that conflict embodies the concept of change, and that change is both product and driver of conflict, then seeking to resolve conflict in the sense of eliminating conflict from a given process must be interpreted as an attempt to bring change to a halt. Strategies of conflict resolution are therefore bound up with the question of who may benefit from the termination, or suppression, of transformative processes. These questions are positioned within constellations of power in which change, or non-change, are negotiated.

The narratives conceptualise and work with different intensities of change. Some narratives of change emphasise the 'doing' component in architecture and urbanism, the negotiating, the acting and making, while other narratives evolve around continuity, stagnation, invariance or repetition. However, they have in common the view that 
architectural and urban productions are, despite their possible appearance as stabilisers and solid 'objects', generated through acts of change and entangled in situations that give rise to further change. Buildings, infrastructures, or materials are understood to change together with the controversies, perceptions, interactions, encounters and spatial relations that are linked to them. This seems to apply even if built artifacts survive for a long time, or where almost no physical change is detectible. Speeds of change in the narratives vary considerably. Speed is seen to depend on multiple parameters and be tied to the frameworks which regulate, enable, discourage or seek to make impossible change. Hence, the speed of change is seen as being connected to agency and intentionality. Speeds and rhythms of change are perceived and experienced in their relatedness to other processes and rhythms, like the human body. Terms like fast and slow, incremental or cataclysmic are relative, requiring a comparative other. Urban and architectural narratives of change offer possible interpretations of change to which individuals and groups may refer when they develop their own understandings of change. Past narratives speak to us today through materialisations, practices, legal frameworks. Narratives themselves travel in time. In terms of the relationship of conflict and change in the narratives, we can say that the narratives of change in the analysis each work with a different idea and level of conflict. It seems that the theorising of conflict is almost absent in the narratives that evolve around low intensities of change. Conversely, narratives that work with high intensities, or radical forms of change, tend to make conflict a major part of their conceptualisations.

Based on the discussion and observations made in this chapter, we may sum up the analytical process with the following preliminary findings:

1. Change is seen as a fundamental principle that permeates all levels, spaces and social spheres. Like conflict, change is an ever-present phenomenon in the urban and in the city.

2. Dialectic movement, evolution and autopoiesis are recurrent meta-level framings of change.

3. Urban and architectural narratives of change are instruments to conceptualise, appropriate, memorise, communicate, instrumentalise, and politicise processes and conditions of change.

4. They do not constitute a consistent or homogeneous body of knowledge. They approach change in different ways, for example, through critical enquiry, reductionist models, analysis of form, or design-related concepts.

5. Narratives and interpretations of change compete with each other in the discursive field of change. They form narrative coalitions and dissolve to form new coalitions.

6. Complex frameworks of agreements and legislations seek to exert control of processes of change. To control change means to maintain or, conversely, to challenge the stability of a given system or a given set of conditions. Change in the urban is related to questions of power and the political.

7. Narratives themselves change and travel in time. They embody changing practices, interpretations, images, meanings. They change by being re-narrated and comprehended in different ways. 
8. The way we experience rhythms and change depends on our individual and collective perceptions. This has influence on how we respond to, cope with, and evaluate change.

9. Buildings, infrastructures, or materials are seen to change together with the controversies, interactions, encounters and spatial relations that are linked to them. The non-human and human are related to each other through change.

10. The narratives conceptualise and work with different speeds and intensities of change.

Architectural and urban productions are, despite their possible appearance as stabilisers and solid 'objects', generated through acts of change and are part of situations that are sources of further change. In this sense, architecture and urbanism may be conceived as disciplines and practices of change. 


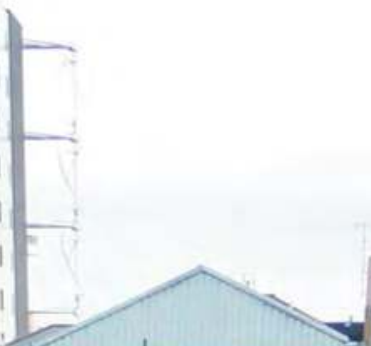

I1

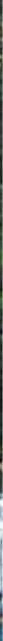

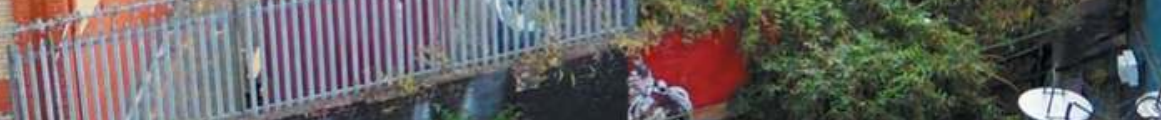
IIIIIIIIIIII IIIIIII) 
Figure 40: View across 40FT Brewery and The Dusty Knuckle Bakery towards the Eastern Curve Garden community project, rear of Sainsbury's

supermarket and new residential developments, Dalston, London 2016

\section{Intersecting Conflict and Change}

"[...] I can see no limit to the amount of change, to the beauty and infinite complexity of the coadaptations between all organic beings, one with another and with their physical conditions of life [...]."

Darwin, Charles (2008 [1859]) On the Origin of Species, Oxford, p.84

"The members of a plant community adapt themselves to one another as all living things adapt themselves to their environment, but there is no conflict between them because they are not conscious. Competition takes the form of conflict or rivalry only when it becomes conscious, when competitors identify one another as rivals or as enemies."

Park, Robert and Burgess, Ernest (1921) Introduction to the Science of Sociology, Chicago, p.507 


\section{Positional Maps as Analytical and Heuristic Device}

\subsection{Intersecting Conflict and Change: Approach and Methodological Framing}

The following analytical stage comprises the intersecting of the two strands of enquiry into architectural and urban narratives of conflict and change. With this operation I seek to establish a high-density construct that adds a new layer of research precision and depth to the analysis. At the core of the intersectional operation is the positional map. The map is based on Adele Clarke's methodological framing and draws from the practical examples discussed in the 2005 introduction to situational analysis (Clarke 2005, pp.125ff), as well as the edited volume "Situational Analysis in Practice" (Clarke, Friese and Washburn 2015, pp.177ff). I have discussed the specific capacities of mapping earlier, proposing that mapping, diagramming, and drawing are well established practices of analysis, knowledge production and knowledge distribution in architecture and urbanism. Applying a social science mapping instrument to architectural and urban research problems means connecting to - as well as extending - the analytical and representational mapping repertoire in architectural and urban research. In the following, I sum up the basic methodological assumptions of positional maps, together with the adaptations proposed for the map's use in the analysis of architectural and urban narratives of conflict and change: ${ }^{1}$

1. "By focusing on the full range of articulated positions, positional maps assist analysts in seeing complexity, variation, and controversy and division where once only binaries and/or longstanding, oversimplified divisions may have appeared. This often enables analysts to see established lines of controversy and division in fresh ways." (emphasis in the original in italics, Clarke, Friese and Washburn 2015, p.177)

2. Hence, positional maps are analytical heuristic devices that can help us see things differently. It offers an analytical "space between" (ibid., p.127).

3. Positional maps make it easier to "[...] see that which one does not expect [...], grasp or understand" (ibid., p.127). They allow researchers to temporarily step outside research routines and research identities to assume a different perspective (ibid.).

4. Positional maps counteract centralising and stereotyping tendencies in analysis (ibid., p.126).

5. In positional maps we can show positions of dominant concepts along marginal ones that tend to be overlooked in their shadows.

6. Positional maps may raise our awareness of positions not taken in the field, which Clarke refers to as "silences" (ibid., p.126).

7. According to Adele Clarke, positional maps can be developed from "a range of discursive materials gathered through fieldwork, participant observation, interviewing, texts, and documents of various kinds, including websites, for example." (Clarke 2005, p.177)

1 For this purpose, I have added my own emphasis to the text. Emphasis in the original is in italics. 
8. In our case, the discursive material is from narratives, in which articulated concepts, statements, design projects, images, interventions, and other architectural and urban works are combined.

9. Each architectural and urban narrative under study is linked to one or more specific concepts of conflict and change. A concept is understood to represent the position(s) taken in the narrative.

10. Positional maps can deal with conditions of openness - in line with the premises of qualitative research - and, in doing so, they reduce the risk of analytical bias and premature closure.

11. "Emphasis is on the map rather than particular positions." (ibid., p.126)

As stated earlier in the analysis, narratives change and travel in time; they form coalitions and dissolve to form new coalitions; they embody changing practices, interpretations, images, meanings; they change through being re-narrated. As a consequence, temporality enters the mapping and has to be addressed. Rather than working with a series of positional maps that seek to map positions at different time intervals, or working with an animated digital interface, the idea is to show all positions in a single map, irrespective of when they entered the architectural and urban discourses. I have chosen this alternative, for we can then see how the concepts of all narratives under examination are distributed within the discursive field, and how they relate to each other. Furthermore, the positions identified in the narratives have their peaks and troughs, and it would be difficult to determine their effective theoretical lifespan. Once they are articulated, positions in architectural and urban narratives may become materialised and institutionalised, thus being effective for extended periods of time. The naming of the concept will in most cases allow its adequate location within the history and theory of architecture and urbanism.

Although authors' names are provided for the majority of concepts in the proposed map to facilitate their identification, the single position should not be understood to 'represent' the author(s) in the map. In line with the assumptions of situational analysis (Clarke 2005, pp.126f), the position has to be seen as part of the broader discourses on conflict and change. A position that is articulated in public is available for appropriation by others. The understanding here is that the sharing and debating of concepts makes them a common good. Concepts may be adopted by different groups, professional, non-professional or institutional, in their own ways of working with conflict and change. Accordingly, a key assumption of positional maps is that "individuals and groups of all sorts may and commonly do hold multiple and contradictory positions on the same issue." (Clarke 2005, p.126) In our case, the architectural and urban disciplines use many of the assembled concepts of change simultaneously, together with all other actors that work with them.

\subsection{Setting up the Positional Map}

So far, the analysis has concentrated on the identification and interpretation of domain-specific narratives that have informed, and continue to inform, the conceptualisations of and discourses on conflict and change in architecture and urbanism. In keeping with the intended openness of the research process, the selection and inter- 
Figure 41: This figure shows an "[...] Abstract Positional Map that portrays positions on a particular issue in the larger specific situation of concern. There are two main axes, and an infinity of positions is possible. The analyst tries to lay out the axes in terms of 'more versus less', if this seems to work." (Clarke 2005, p.128). Figure adapted from Adele Clarke (ibid., p.129).

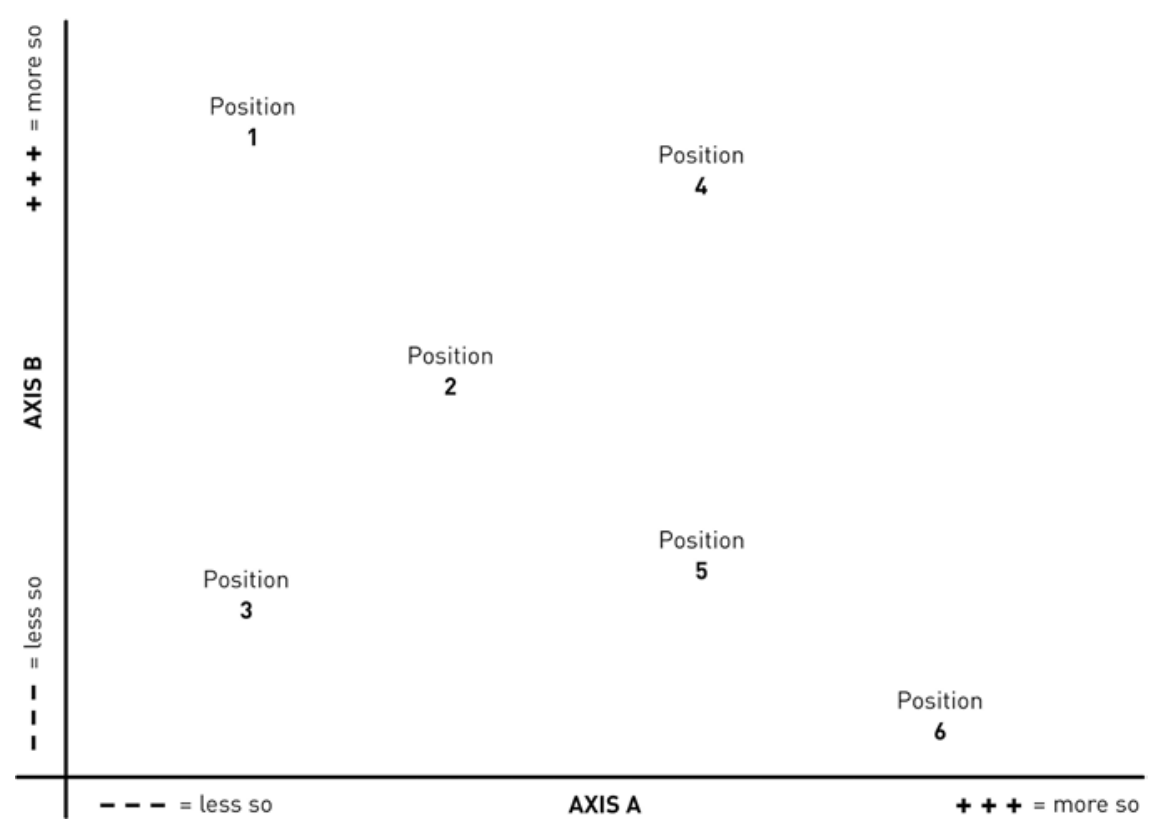

pretation of narratives evolved as per the adapted iterative-cyclical research model of GTM, which does not start with a predefined population in the empirical field, a hypothesis that is to be verified, or a systematics based on fixed and exhaustive categories. Its preliminary outcome is a series of key concepts, or positions, that are embedded within architectural and urban narratives on conflict and change. Each narrative holds one or more positions that can be placed in a positional map.

The positional map discussed in this chapter grew over time. I do not provide a detailed account of the positional map's evolution, but my discussion of the narratives and their thematic clustering give a general idea of the production process. I introduced the positional map to the research process at an early stage, so that the map could act as memoing device and inform the theoretical sampling process. By means of accommodating positions in a step-by-step process that ran in parallel with the analysis of the narratives, the positional map provided a general overview of the concepts discussed so far, guidance about where - and how - to search next, and finally evidence of saturation. Hence, the diagram functioned as "operational visualisation" (Strauss 1987, p.143) during the analytical process. The map integrates all individual concepts within a single, open field of positions. However, there is no final version of the map. Despite the level of detail and saturation it has acquired, the positional map is by methodological necessity always in a work-in-progress state. While up to this point the main interest has been the single narrative and the positions within them, the overall positional map is now shifted into the focus. 
Figure 42: Abstract Positional Map showing different positions, defined by axes 'Intensity of change' and 'Foregrounding of conflict'.

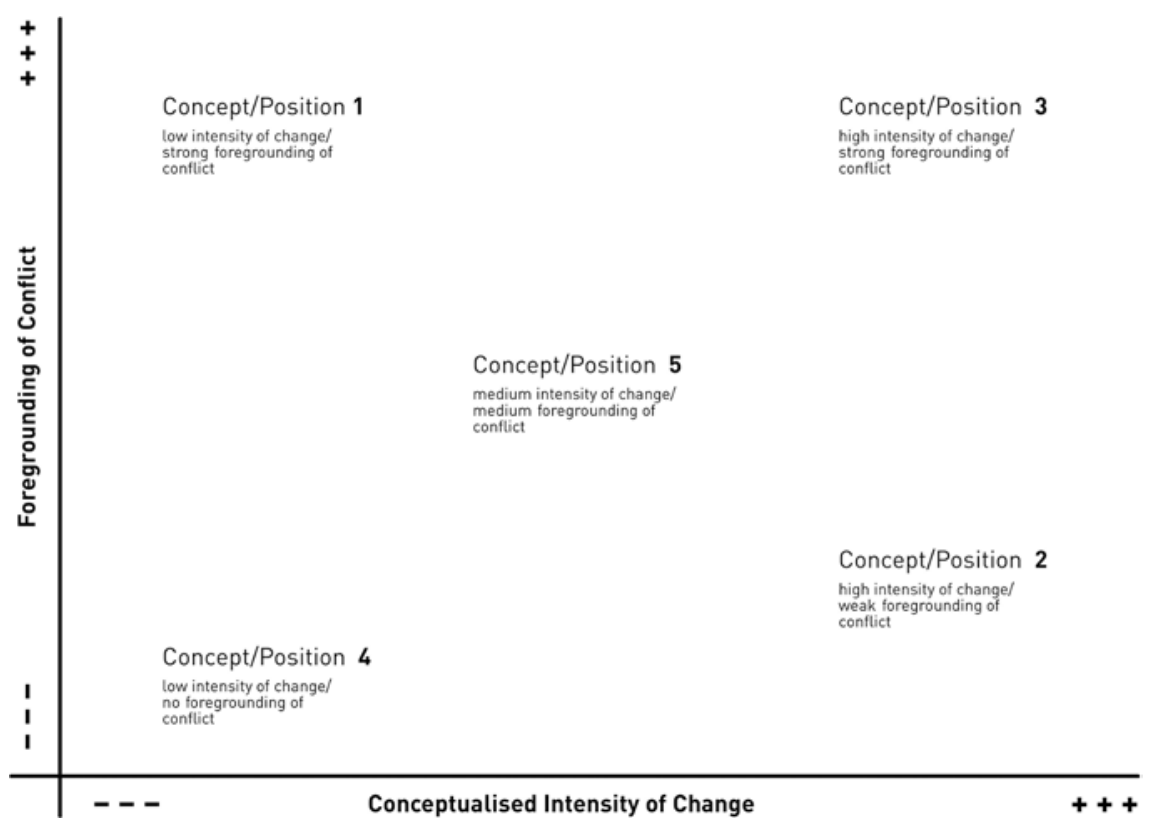

On the positional map, two axes define the field of intersection. In line with Clarke's conceptualisations, there are no numerical values assigned to them. The tendencies +++ 'more so', respectively --- 'less so', provide orientation and relational precision as well as the desired degree of looseness. The locations of positions, therefore, are indicative only and should not be mistaken for fixed points within a coordinate system. The horizontal axis defines a continuum of intensities of change, according to the conceptualisations in the narratives. The axis begins with very low intensities of change and gradually moves to higher and the highest intensities of change. The vertical axis defines a continuum for the foregrounding of conflict in the narrative. Narratives of change that do not foreground conflict are positioned on the lowest level along this axis. Positions with a strong foregrounding of conflict range at the top. In the narrative material, a strong foregrounding of conflict usually goes hand in hand with the explicit addressing and theorising about conflict, as well as with assigning to it a constitutive role in the conceptualised condition of change.

\subsection{Approach to Interpretative Issues and Difficulties in the Positioning}

Having set up the basic structure of the positional map, a series of issues arise from assembling and placing individual positions. Among the concepts that I have analysed in the overall process are four which seem to define extremes - not in the sense of a single position but rather in the sense of defining a perimeter that runs parallel to the axis. Christopher Alexander's "frictionless coexistence" (Alexander 1964) represents a kind of change in which conflict is absent. There are no inharmonious movements, struggles that consume energy, or forms of attrition. Frictionless means, quite literally, 
that neither speed nor intensity of change make a difference. In the mode of "frictionless coexistence" conflict does not co-constitute the unfolding of change. It is in this sense a positional exception, because our previous discussion of conflict and change suggested that conflict and change tend to be mutually related to each other. Hence, I propose Alexander's concept is aligned with the horizontal axis, extending across the full continuum. There is no foregrounding of conflict throughout the concept, irrespective of the intensity of change. Conversely, in Lefebvre's concept of contested urban centralities (Lefebvre 2003 [1970]), conflict is defined as basic urban condition. It prevails in the urban across all possible intensities of change. I allow this concept to extend across the upper section of the positional map, representing a strong foregrounding of conflict for all conditions of change that are associated with the concept. The next in the line of special positions, utopianism, is linked to the highest intensity of change, where it is understood as the striving for the ultimate 'other'. In terms of conflict, however, the level of foregrounding may vary. Some utopian models are based on gradualism, which is free of conflict, others on radical rupture and change. Utopianism, therefore, covers the full continuum in the foregrounding of conflict, ranging from weak to strong. Finally, obsolescence can be understood as the ultimate failure to accommodate (further) change. If a space, situation, or structure is obsolete, it has ceased to participate in change. If defined in this way, it represents the lowest intensity, or zero intensity, of change. Practical limits to this interpretation occur, for instance, when a condition that is defined as obsolete by some may still be useful to others. Nevertheless, for the purpose of the analysis, we can say that the concept of obsolescence occupies the position with the lowest intensity of change. Like utopianism, it may be associated with different levels in the foregrounding of conflict, ranging from zero to the strongest level. From this I distinguish the concept of planned obsolescence, which is connected to cyclical renewal and therefore to a higher intensity of change.

The next issue arises in terms of the positioning process itself. For most concepts, a straightforward guess as to the approximate position can be made. The difficulty starts with the fine tuning. For this task, the idea of connected anchor points, as outlined in the methodology section, and the interpretative use of 'conceptual proximities' help to determine the final location of a position on the map. For example, adaptability and flexibility are closely related concepts, which implies - as a starting assumption - that they are located in proximity to each other on the map. Their first and provisional positioning is based on the assumption that both positions stand neither for zero nor for radical intensities of change, suggesting that we place them somewhere in the middle of the horizontal axis. Historically, flexibility is understood to have gained theoretical significance in modernism - suggesting a position close to other modernist positions. In order to determine their relative position to each other, further assumptions are necessary. As flexibility engages with predefined problems, while adaptability consciously takes into consideration the creative capacity of users and occupiers to deal with situations of change, and therefore of conflict, I have assumed the foregrounding of conflict in the concept of adaptability to be higher if compared to flexibility; I have also assumed the intensity of change to be potentially higher in the concept of adaptability, due to its avoiding of pre-determined fixations. The positioning of flexibility and adaptability in the map serves as an example of the scope of factors that are typically considered in the fine-tuning. The same kinds of difficulties - and movements to overcome them - apply to all other positions on the map. However, bearing in mind 
that we are working within a malleable construct, there are methodologically intended limits as to the fixation of positions. A degree of ambiguity will remain. Likewise, some positions seem to have a greater degree of fuzziness in themselves than others. For example, the concept of change associated with the "space buster" (raumlaborberlin 2018) may be working with a strong foregrounding conflict in one particular urban space (e.g. the blocking of a residential street in the $\mathrm{UK}^{2}$ ), and in another situation it might be emphasising joint action, play, and the act of coming together, which seems to suggest a weaker foregrounding of conflict.

Further difficulties arise because the positions refer to change on very different scales. Urban practices of "guerrilla gardening" (Awan, Schneider and Till 2011, p.152), or certain kinds of "liminal bodies" (Bunschoten, Binet and Hoshino 2010 [2001]; Jungfer and Masuyama 2013) are based on small scale interventions that generate high intensities of change, which are typically limited to a small area. If considered at an urban scale, they could be almost invisible. To avoid concepts that operate on large scales from dominating the map, I have assumed intensities of change to be relative to scale. It is not the absolute intensity and effect of change that matters, but the intensity relative to the scale to which the concept relates. Methodologically, this is based on the idea that in positional maps "the goal is to represent the positions articulated on their own terms." (emphasis in original, Clarke 2005, p.126) Further issues arise in terms of multiplicity and variation. Narratives change upon being re-narrated, for which reason different versions of the same narrative may occur. Moreover, a specific urban issue may be the subject of more than one narrative. In this instance, the positions and concepts used in each narrative are likely to be different. For example, the positions taken by officials and authorities in the discourse about urban renewal are likely to be different to the positions of communities who are affected by its consequences, for example by cataclysmic change and problems of individual and collective coping. In antagonistic situations, each perspective is likely to work with its own narratives, concepts and positions. Narratives may seek to achieve interpretative authority over an issue as part of a controversy. The non-critical modernist position, for instance, reduces and simplifies conflict to a set of technical problems that can be 'managed' and 'solved' by specialists. This position is subsumed in the concept 'modernist externalisation'. Conversely, modernist-sceptical positions seek to bring the contradictions of the modernist approach into full view and work with a strong foregrounding of conflict. I have assigned to this position on modernism a higher level in the foregrounding of conflict, subsumed in the concept of modernist "envelopes" (Latour 2008, pp.8f). Similarly, the concept of gradualism occurs in different narratives and therefore in different positions on the map. As argued earlier, narratives do political work and compete with each other. For the same reason alliances are conceivable. Narratives may share concepts and positions with each other.

Finally, the relationship between 'intensity of change' and 'foregrounding of conflict', which is represented by each position, should not be understood as cause-effect relation. While in some narratives this connection is made, the positional map is explicitly

2 In this instance raumlaborberlin was working with the 'kitchen monument', the cousin of the space buster. 
Figure 43: Intersecting the narratives of conflict and change. Work-in-progress positional map showing positions taken in different architectural and urban narratives.

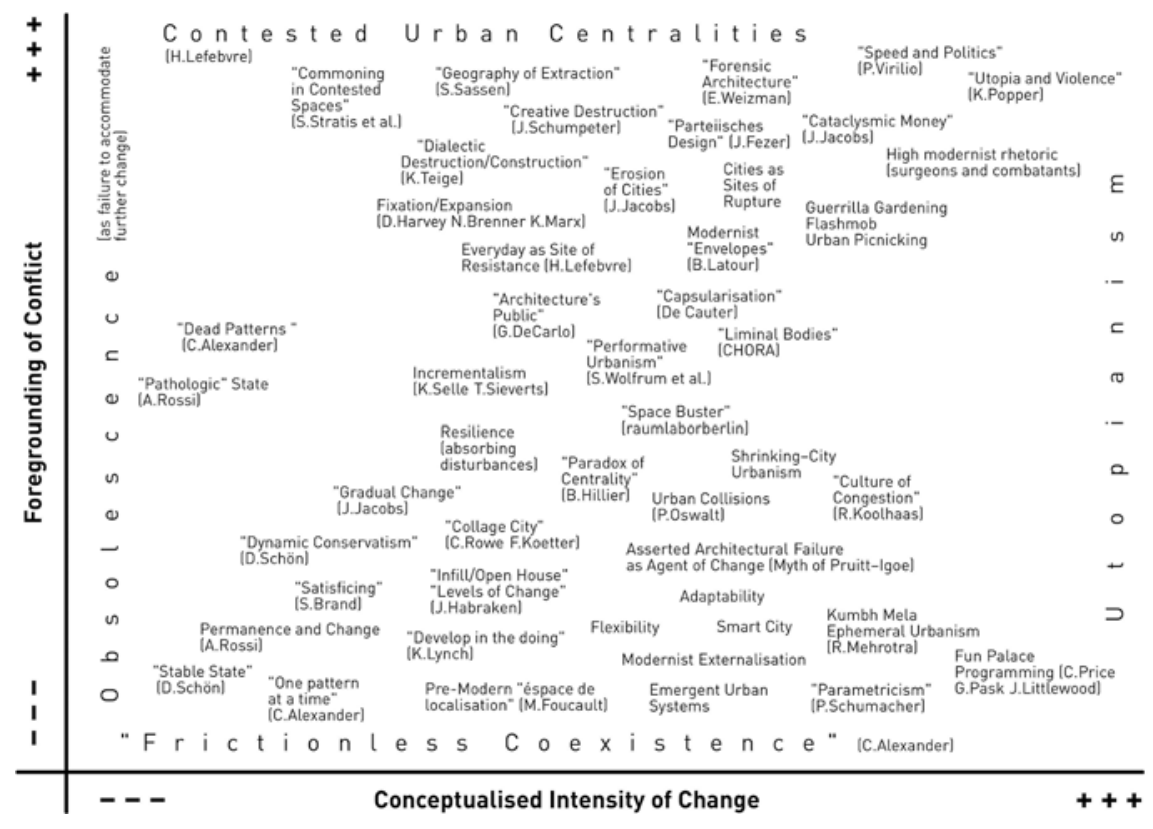

not about identifying causality in single concepts. A strong foregrounding of conflict in a concept does not mean that conflict is seen as the 'cause', the 'result' of, or 'precondition' for a given intensity of change. The level of foregrounding indicates the degree of the articulated visibility of conflict in the concept, its general argumentative consideration and integration, its being emphasised.

\section{Conceptual Voids at Low and High Intensities of Change}

\subsection{Observing the Overall Pattern of Positions}

With all individual positions in place, we can now proceed with the analysis of the overall pattern in the map. We notice that the positions are not spread evenly across the field. There are two voids in the pattern, together with a zone of higher density running from bottom left to top right between them. The first void indicates that there are few positions that combine low intensities of change with a strong foregrounding of conflict. Likewise, the second void indicates that there are few positions that combine high intensities of change with a medium foregrounding of conflict. The diagonal is the area in the positional map in which the foregrounding of conflict is directly proportional to the intensity of change. Low intensities of change occur in combination with a weak foregrounding of conflict in the narrative, medium intensities of change with a medium foregrounding of conflict, and high intensities of change with a strong foregrounding of conflict. The proportional relationship seems to correspond with everyday experience, which lets the pattern appear 'natural'. In this sense, the map 
exposes a potential source of bias. Simply because some of the concepts seem to suggest that the higher the intensity of change, the higher the conflict involved, does not mean that this is 'naturally' so. Architectural and urban narratives are constructed. They serve humans in their conceptualising, communicating, generating, or controlling of processes of change. In this sense, there is nothing natural, or pre-given, in the implied proportionality. The pattern in the positional map mirrors, first of all, the proportionalising tendency that seems to reside in the conceptualisations and interpretations of change.

For now, it has to remain open whether the tendency could be related to aspects that are located in social processes, in human behaviour, psychology, or in the dominant mechanisms through which humans manage change. In the course of enquiring into the response of large organisations to change, and their efforts invested in retaining their existing structures, theories and technologies, Donald Schön observed that "social systems resist change with an energy roughly proportional to the radicalness of the change that is threatened." (Schön 1971, pp.38) This and other, similar observations may provide clues as to possible, more fundamental, explanatory models to the questions raised by the observed tendency.

The gradual emergence of the two voids during the analytical process resulted in the intensification of research efforts in these areas. This was supported by extending the field of enquiry to include narratives of specialist discourses, as well as narratives that are rather remotely related to architecture and urbanism. The setting-up of the positional map as work-in-progress research instrument facilitated the adding of positions on a trial basis, to see how this would influence the pattern. Some of the concepts that have not made an appearance in the previous discussion of narratives of conflict and change fall in this category, for instance the Kumbh Mela religious gathering as conceptualised by Rahul Mehrotra in "Ephemeral Urbanism" (Lepik, Giustina and Ursini 2017), or "guerrilla gardening" (Awan, Schneider and Till 2011, p.152), flashmob, and urban picnicking (Haid 2013). Further positions entered the map while working on the case study element, for example Donald Schön's "stable state" (Schön 1971, pp.9-30) and "dynamic conservatism" (ibid., pp.31-60) ${ }^{3}$. Despite my attentiveness to the issue in theoretical sampling, the voids continued to persist and became characteristic of the positional map. The later additions reinforced the pattern that was already visible, rather than changing it. The substantial number of concepts identified, coupled with the analytical sensitivity of theoretical sampling, led me to assume that further additions were unlikely to change the core message of the map. In line with the methodological propositions of GTM and SA, I interpreted this as a sign of saturation (Clarke 2005, p.108, p.135).

3 Donald Schön's concepts are discussed in more detail as part of the construction of the Redundant City concept. 
Figure 44: Positional map showing the void at low intensities of change.

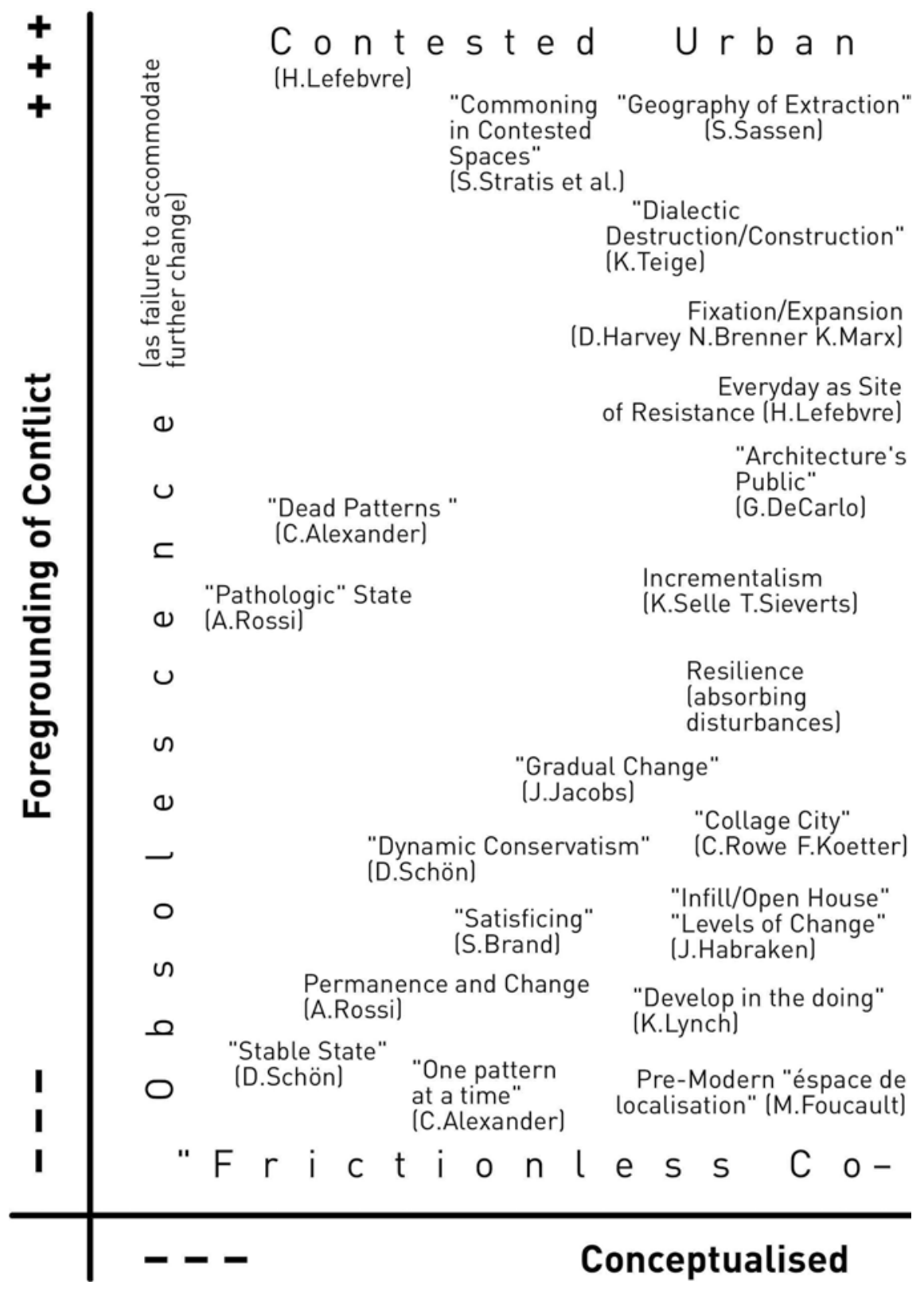


Figure 45: Positional map showing the void at high intensities of change.

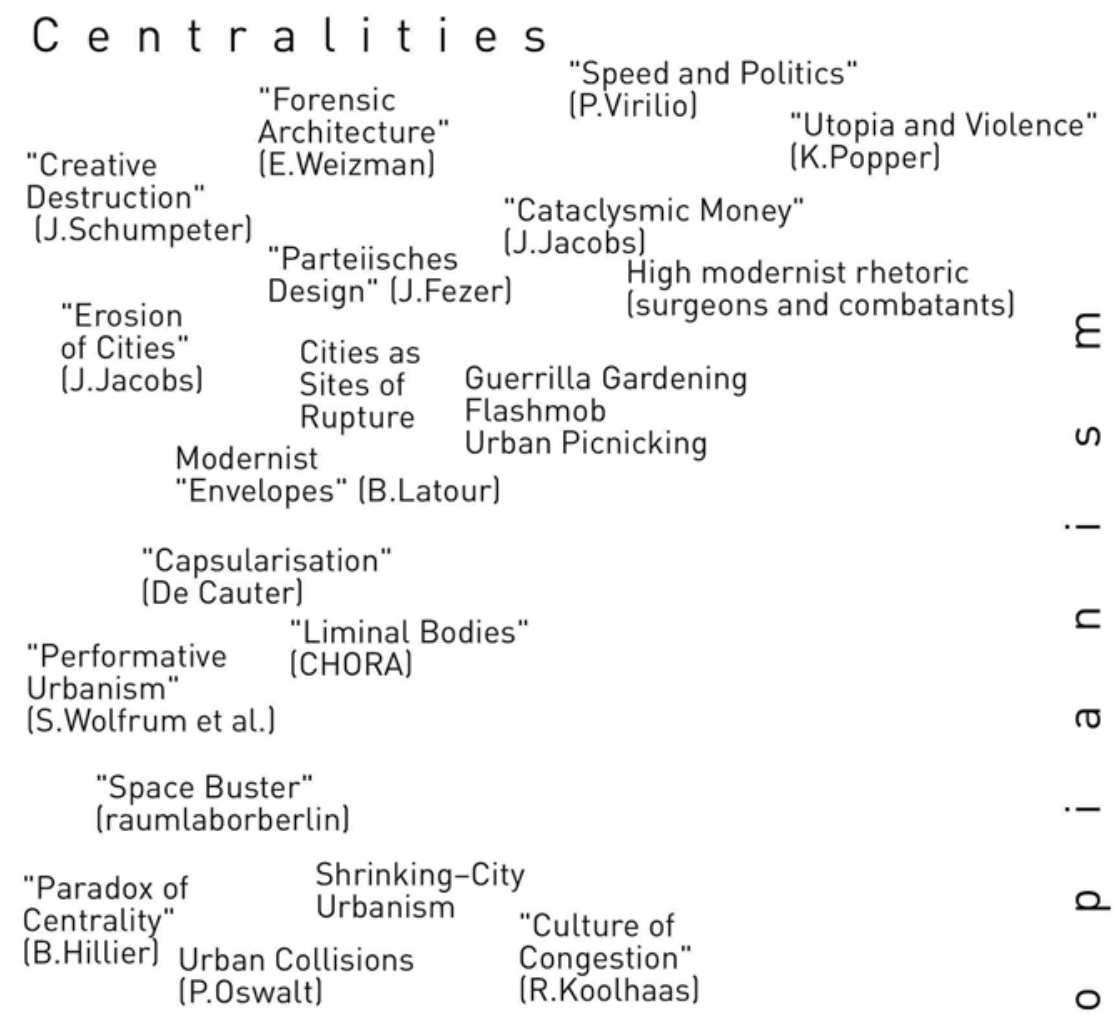

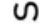

"Envelopes" (B.Latour)

"Capsularisation"

(De Cauter)

"Performative

"Liminal Bodies"

Urbanism"

[CHORA]

(S.Wolfrum et al.)

ర

"Space Buster"

(raumlaborberlin)

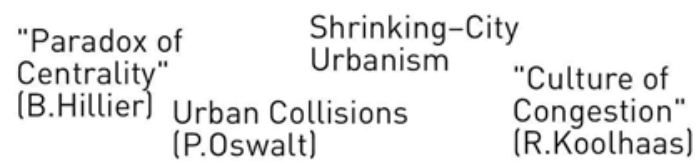

Asserted Architectural Failure

as Agent of Change (Myth of Pruitt-Igoe)

Adaptability

Flexibility Smart City

Kumbh Mela

Modernist Externalisation

Ephemeral Urbanism

[R.Mehrotra] Fun Palace

Emergent Urban

Systems

Programming (C.Price

"Parametricism"

G.Pask J.Littlewood) (P.Schumacher)
e $x$
$s \mathrm{t}$
e $n$
c e
[C.Alexander]

\section{Intensity of Change}




\subsection{Why There Should be More Concepts For Low and High Intensities of Change}

The justification of why there should be more concepts in the regions of low and high intensities of change is at this stage limited to a few remarks. The positional map will continue to evolve and serve as a heuristic device in the research process, whereby further issues are clarified. The observation of asymmetric urban change, in particular in the Parkstadt Bogenhausen housing estate, defined the point of departure for this research project. In specific ways situations of asymmetric urban change tend to be related to low and high intensities of change, as well as to conflict. On a more general level, we could say that fast urbanisation and high intensities of change are characteristic of many regions of the world. Conversely, a broad range of urban phenomena operate on the basis of low intensities of change. This is the case with sites that are disconnected from economic dynamics or other facilitators of change, but also for sites where divergent intensities of change produce conditions of asymmetry. As in the Parkstadt Bogenhausen housing estate and its neighbouring areas, situations which follow different trajectories of change may coexist side-by-side. Different kinds and intensities of change are often neighbours.

Since the dissolution of the modernist paradigm of unlimited growth led to the insight that urban problems cannot be approached through growth-based scenarios alone, conceptual alternatives to high intensities of change have gained in significance. The concepts of incrementalism and process-based development have informed planning discourses as part of the restructuring of de-industrialised areas and inner city situations (Selle 1994; Ministerium für Landesentwicklung und Verkehr des Landes Sachsen-Anhalt 2010). They are also seen to be useful in the understanding and enabling of the multiple small-scale adaptations that occur in dispersed urbanised areas (Sieverts 2003 [1997]).

Furthermore, the challenging of modernism's protective "envelopes" (Latour 2008, pp.8f) has brought to full view the consequences of a politics of externalisation of conflict. Conflicts of all kinds are being publically addressed in digital networks and the media. Information about conflicts is supplied and exchanged globally. Access to this information has become part of everyday routines. Consumers are increasingly aware of the effects their choices have for other places. Cities continue to be sites where controversies over conflicts are fought out in the open. Cities themselves are the concern of many controversies. The flow of private capital into the housing market, the redistribution, accumulation and extraction of capital investment have changed the social and material landscapes of many cities (Harvey 2001; Sassen 2014), asserting their role in processes of conflict and change. Concepts about agonistic forms of conflict have raised the awareness of the kinds of conflict that are difficult if not impossible to reconcile (Mouffe 2013) and have informed new conflict-centred approaches to designing, for example Jesko Fezer's "Parteiisches Design" (Fezer 2018). This is paralleled by the growing interest in ideas like urban commons or the ethical question about the nature and the possibilities of a good life in the city (Stavrides 2016; Ott 2018). Cities are contested zones in contemporary urban struggles (Stavrides 2010; 2018; Stratis 2016; Kling and Jungfer 2018).

However, as we have seen in the analysis, the theorisation of conflict in architecture and urbanism seems to be strangely underdeveloped for conditions of low and 
high intensities of change. Moreover, many concepts in architecture and urbanism are theorised in such a way that they do not directly relate to the social or political. The keeping separate of material and social worlds and the anxious maintaining of disciplinary boundaries makes it difficult for concepts to travel and connect. This results in the exclusion of issues and the difficulty the disciplines have contributing their spatial and other specialist knowledge to public urban debates. In this situation, rather than insisting on the disciplines' expertise in 'problem solving' according to their own narrowly defined terms - which all too often has resulted in disappointment and frustration - the disciplines could put greater emphasis on their expertise in the detecting, identifying, and spatio-temporal analysis of conflicts and conditions of change (Kling and Kurbasik 2018). The knowledge produced in this way could be shared and debated with others to inform collective processes and matters of urban concern. The goal would not by necessity have to be a solution, but maybe just further steps in effecting change. The growing awareness of situations of conflict, the growing significance of process-led and collectively negotiated change, demand new conceptual approaches to conflict in architecture and urbanism. Understandings are required which go beyond the idea of conflict as temporary condition that disappears with conflict resolution. Stronger levels in the foregrounding of conflict could extend the repertoire of conceptualisations in architectural and urban theory, analysis and practice. The integration of alternative approaches of conflict could provide new possibilities for connecting to other concepts and practices, including those of other disciplines.

\section{Preliminary Findings}

The intersection of architectural and urban narratives of conflict and change has generated the following observations:

1. The positional map has produced a new level of integration and conceptual densification in the research process.

2. We see how positions about change are distributed in the positional map according to intensity of change and foregrounding of conflict, and how they relate to each other.

3. The positions are not spread evenly across the field. We can observe two positional voids in the pattern, together with a zone of higher density running from bottom left to top right between them, indicating a proportionalising tendency in the distribution.

4. There are a limited number of positions that combine:

5. low intensities of change with a strong foregrounding of conflict

6. high intensities of change with a medium foregrounding of conflict

Based on these observations and our above discussion, the following propositions can be made:

1. The theorisation of conflict in architecture and urbanism seems to be strangely underdeveloped for conditions of low and high intensities of change. 
2. The growing awareness of situations of conflict, the growing significance of process-led and collectively negotiated change, seem to demand new conceptual approaches to conflict in architecture and urbanism.

3. Many concepts in architecture and urbanism are theorised in such a way that they do not directly relate to the social, or the political.

4. Disciplinary thinking and the keeping separate of material and social worlds makes it difficult for concepts to travel and connect.

5. This results in the exclusion of issues and the difficulty the disciplines have contributing their spatial and other specialist knowledge to public urban debates.

6. In this situation, rather than insisting on the disciplines' expertise in 'problem solving' according to their own narrowly defined terms, the disciplines could put greater emphasis on their expertise in problem detecting, identifying, and spatio-temporal analysis.

7. Stronger levels in the foregrounding of conflict could extend the repertoire of conceptualisations in architectural and urban theory, analysis and practice.

8. The integration of alternative approaches of conflict could provide new possibilities for connecting to other concepts and practices, including those of other disciplines.

9. The knowledge produced in this way could be shared and debated with others to inform collective processes and matters of urban concern.

With these considerations, observations and propositions in the background, the void and its adjacent concepts in the region of low intensities of change defines the site for which I propose to develop a new concept of change in the next stage of the enquiry. 



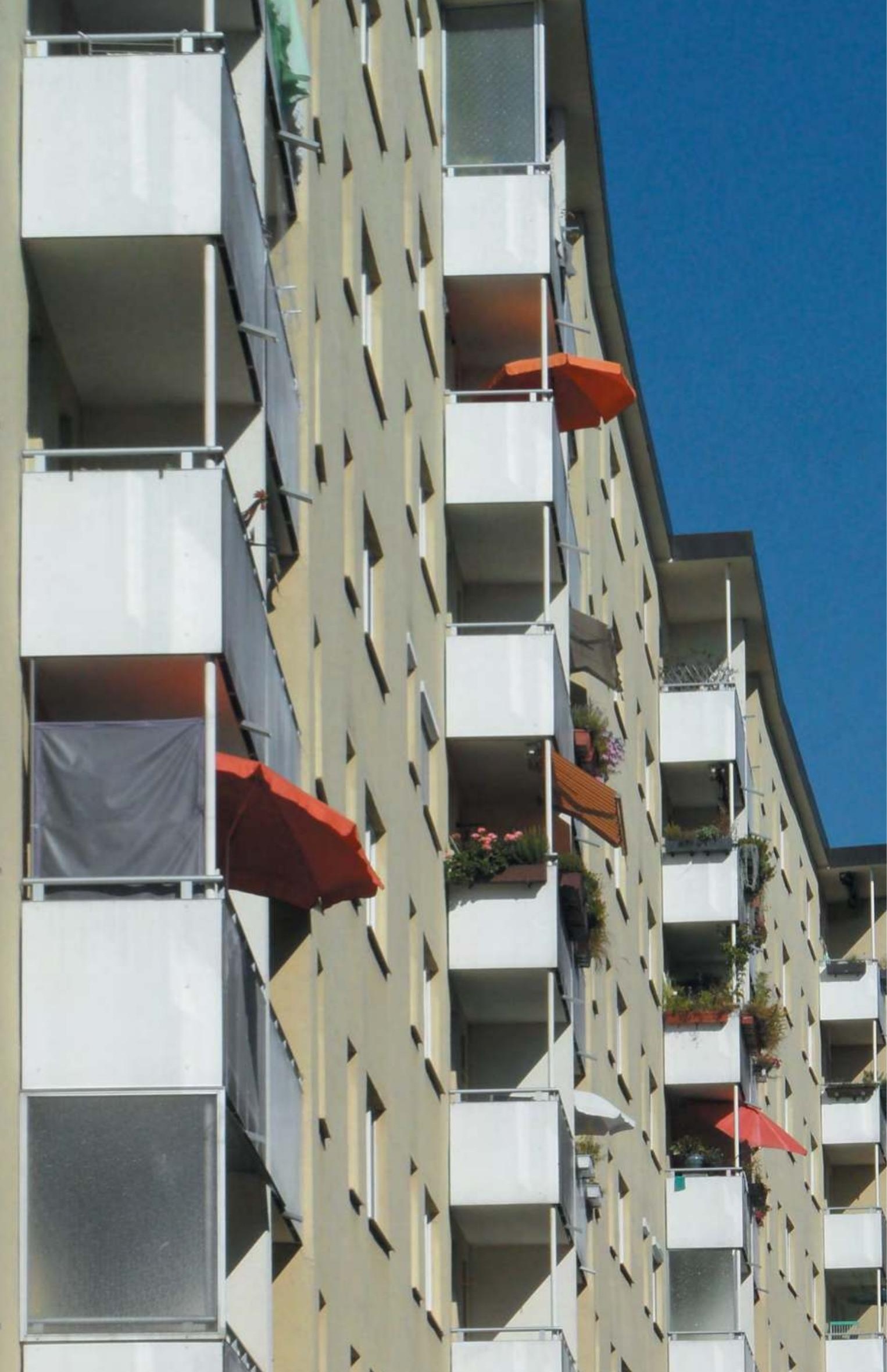


Figure 46: Parkstadt Bogenhausen housing estate,

Buschingstraße 55-63, Munich 2017

\section{Constructing a New Concept of Change}

"The struggle for control of urban spaces is an ambivalent mode of sociation, one that cuts systematically across the whole of everyday life: in and by producing themselves, groups produce exclusive spaces and then, in turn, use the boundaries they have created to define themselves."

Berking, Helmuth. Frank, Sybille. Frers, Lars. Löw, Martina. Meier, Lars. Steets, Silke and Stoetzer, Sergej eds. (2006) Negotiating Urban Conflicts. Interaction, Space and Control, Bielefeld, p.9

"Most difficult of all, perhaps, and quite at the heart of the city experience, is to find some objective way of recording how residents think about the place in their minds: their ways of organizing it and feeling about it. Without some knowledge of this, one is hard put to make an evaluation, since places are not merely what they are, but what we perceive them to be."

Lynch, Kevin (1983) A Theory of Cood City Form, Cambridge MA, p. 354 


\section{Zooming in: The Parkstadt Bogenhausen Housing Estate in Munich}

\subsection{Justifying Empirical In-Depth Analysis}

Upon discussing the research goals and the proposed methodology at the outset of this book, I defined the new concept as the envisaged outcome, rather than formal theory. I do not intend to establish a theory about the voids on the positional map described in the previous section, or work towards their stabilisation by developing a coherent framework or theoretical fixation. For the same reason, I do not at this stage work towards the new concept on the basis of extending and juxtaposing the positions identified in the analysis of narratives so far, although the theoretical base seems to have developed a sufficient degree of thickness to support this option. Rather, for the purpose of constructing an empirically grounded concept that defines a new position on the map, I focus on a specific urban situation, leaving behind, at least temporarily, the abstract level of architectural and urban theory. In this sense the research process draws methodologically from Jane Jacobs, who on confronting the problematic of generalisations and abstractions in modernist planning highlighted the need to engage with the specific:

"City processes in real life are too complex to be routine, too particularized for application in abstractions. They are always made up of interactions among unique combinations of particulars and there is no substitute for knowing the particulars." (Jacobs 2011 [1961], p.442)

The case chosen for analysis is the Parkstadt Bogenhausen housing estate in Munich. Focussing on a single case allows the analysis to engage with the situation in greater depth. The research process is meant to generate and assemble empirical data that is substantial enough to support the development of a new concept. The basic question is if the Parkstadt arena, and therefore the Parkstadt Bogenhausen housing estate, participates in urban and architectural change, and if so, in which ways and with which possible consequences?

Being a local resident enabled me to observe the estate over a period of several years - at times consciously through the eyes of the critical architect and urbanist, at times unconsciously and immersed in practices of the everyday. Like all other co-owners of the estate, be they residents or non-resident owners, I am connected to the collective decision-making process, which deals with current affairs and which co-determines the future trajectory of the estate. My observations and my participating in the process led me to the perception that there is something special about the estate, that its dynamics are different when compared to the city around it. The specificity of the estates' trajectory raised some of the questions that led to the formation of this research project. In studying a case that is on my doorstep, I follow a research tradition established by Robert Park, Kevin Lynch, Henri Lefebvre, Jane Jacobs, David Harvey, and others. Harvey, who throughout his work as a researcher and activist sought to relate theory and criticism to the actual urban conditions that he found at his place of residence, conceives this connectedness to local issues as a means of providing a reallife grounding to academic work, but also to put academic knowledge to the test and to make a difference (Harvey 2000, p.16, p.20). Being local, as a researcher, facilitates 
Figure 47: Parkstadt Bogenhausen housing estate, shopping centre and restaurant, Munich, photo 1970 ( ) by Kurt Otto (published in: Neue Heimat Bayern Gemeinnützige Wohnungsund Siedlungsgesellschaft mbH 1971)

Figure 48: Parkstadt Bogenhausen housing estate, shopping centre and former restaurant, Munich 2016
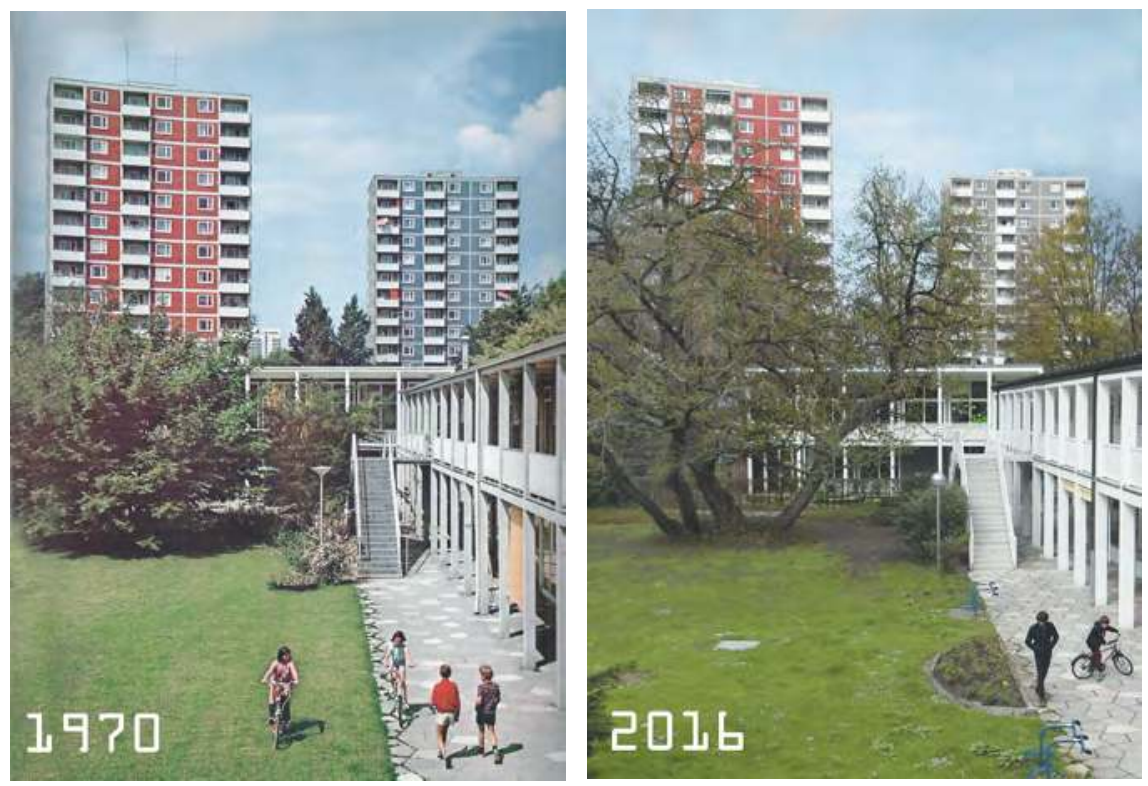

Figure 49: Location of the Parkstadt Bogenhausen housing estate in the Munich metropolitan region, 2016. Map adapted from https:/geoportal.bayern.de/geoportalbayern/

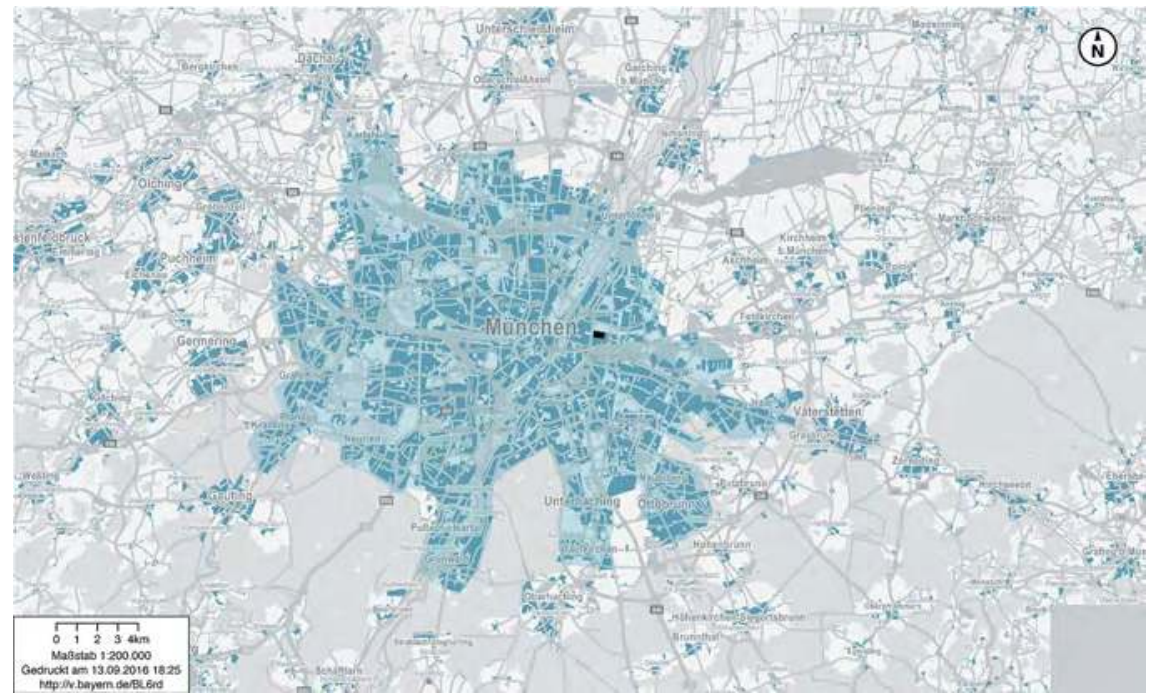


access to people, processes, observations and information. It provides opportunities for participating and engaging in local actions, debates, and situations. At the same time it raises issues with respect to method and the way material is used, interpreted and presented. As in any kind of field work, it requires the researcher to critically reflect on her or his own position in the field.

\subsection{Housing Estates as Sites of Urban Enquiry}

Transformative processes in housing estates relate to the wider dimensions of urban change. Tatjana Schneider and Jeremy Till suggest that "of all building types it is housing - and in particular public housing - that is most exposed to outside influences." (Schneider and Till 2007, p.14) The problem of change is a collective process and relates to questions of power. Theorising the constitution of space through the establishing of spatial relations in action, Martina Löw proposes that

"the constitution of spaces in action is not as a rule done in isolation, but takes place in processes of negotiation with other actors. Negotiation of power structures is an immanent aspect of this process." (Löw 2016 [2001], p.191)

Research into the production and changing of spaces engages with problems that tend to cross over - and therefore challenge - disciplinary boundaries. This raises difficulties in how we represent, analyse and practically respond to phenomena of urban and architectural change. The exclusion of either micro or macro scales in analysis (Soja 2000 [1996], p.310; Brenner 2013), as well as the tendency to think in categories of objects rather than process and the performative (Wolfrum and Brandis 2015) further contribute to the difficulty, in particular when we approach the more nuanced transformations in cities. Understanding how housing estates change over time defines such a nuanced and process-based problem. Many housing estates were and still are designed without future changes in mind. Yet housing estates do change, irrespective of the original design intent. The question, then, is not 'if' housing estates change, but rather 'how' they change. As we have seen in the preceding analysis, there are multiple ways to conceptualise and engage with problems of change in architecture and urbanism. Too narrowly framed forms of analysis have produced bias, such as the persistent and instrumentalised myth of Pruitt-Igoe (Bristol 1991). Hence, as argued in the methodology section, I propose to combine in the research approach architectural/spatial perspectives with process-based perspectives and social dimensions. The analysis, then, will include collective processes and the practices and politics of 'doing' change.

Housing estates have an ambivalent relation to the city. On the one hand they co-constitute the city as agglomeration of goods, people, and ideas, while on the other hand the planning of large housing estates "[...] has literally set itself against the city and the urban to eradicate them." (Lefebvre 1996 [1968], p.79) Housing estates tend to be linked to rigid urban hierarchies, if often with insufficient territorial integration (Hillier 2007 [1996], pp.138ff). They occupy an intermediate level between the levels of the dwelling and the city. They relate to the intrinsic web of social interactions and spatial practices of the everyday, as well as to the more abstract levels of planning thought, institutions and urban organisation. Housing estates may be conceived of as privileged 
Figure 50: Parkstadt Bogenhausen housing estate seen from the town hall tower in the city centre, Munich 2013

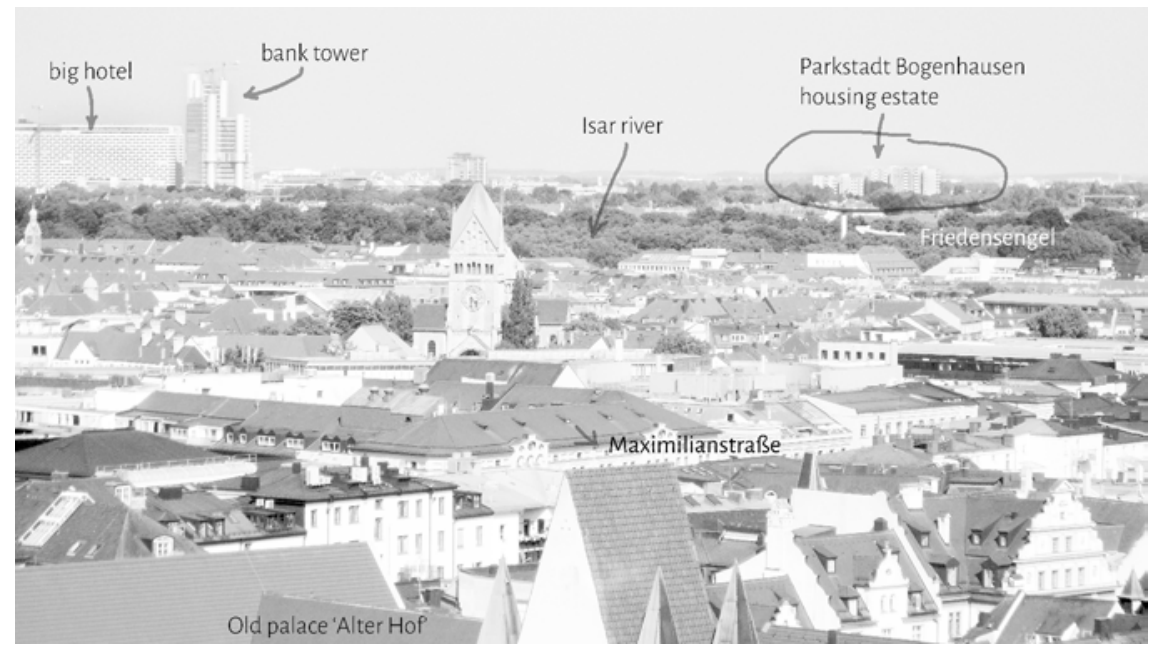

sites of enquiry, for we may approach them from either above or below, and conversely, probe into the micro or macro if we take the estate as point of departure. This has obvious advantages for modes of analysis which seek to connect to different discourses, different levels of power and different areas of social interaction. Housing estates define a situation of convergence. They may act as pivotal or focal point within an open field of enquiry. The methodological setting-up of the case-study element draws from this specific capacity. The problematic of housing estates has been the subject of many critical enquiries in the past, of which I have briefly discussed the case of Pruitt-Igoe. In his 1971 essay "The Superblock", Alan Colquhoun theorises the preconditions for and architectural consequences of organising the modernist city on the basis of large single entities (Colquhoun 1971). Colquhoun suggests that, irrespective of the specifics of each site, there would

"[...] always [be] one common factor: the enormous reserves of capital that exist in the modern economy which enable either private or public agencies, or a combination of both, to gain control over, and make a profit from, ever larger areas of urban land. [...] The financing of a piece of land by a single agency usually results in the buildings on this piece of land being consciously designed as a single entity. The larger the area of land, the larger the volume of building that is subject to a single architectural concept." (ibid., p.83)

Hence, if we encounter a single concept from this era, its architectural and urban characteristics have to be seen as being closely related to specific forms of social organisation, modes of production, and flows of capital. Many housing estates were constructed by a single agency and follow the idea of a single concept. If basic decisions about ownership, levels of control and project size precede the architectural process, major parameters that determine the ways and the capacity in which architecture can respond to change are established before architectural design has even begun. A dis- 
cussion about how design concepts may contribute to change, therefore, will seek to address the broader situation in which design and change are positioned.

\subsection{Divided Biography of the Parkstadt Bogenhausen Housing Estate}

The history of Parkstadt Bogenhausen housing estate is closely related to the history of the Neue Heimat group. The origins of Neue Heimat (NH) date back to the 1920s, when it was one of many non-profit housing associations owned and managed by the trade unions in Germany. In 1954, all housing associations of the trade unions in West Germany were united to form a single, non-profit enterprise under the parent company Neue Heimat in Hamburg. NH was owned by the Federation of German Trade Unions 'Deutscher Gewerkschaftsbund' (DGB). The Parkstadt Bogenhausen housing estate was commissioned in 1954 by GEWOG ('Gemeinnützige Wohnstättengesellschaft von $1910 \mathrm{mbH}^{\prime}$ ), an affiliate company of $\mathrm{NH}$, also seated in Hamburg. The Neue Heimat Bayern (NHB) ${ }^{1}$ acted as developer ('Maßnahme- und Bauträger') and assumed the management of the housing estate during the following decades. In 1962, the ownership of the estate passed from GEWOG to the parent company Neue Heimat, and finally to Neue Heimat Bayern in 1967 (Neue Heimat Bayern 1981; Bernst 2006, p.43; Stracke 2011, pp.158f; Lepik and Strobl 2019, pp.134-136).

In 1954, the planning department of $\mathrm{NH}$, then directed by CIAM co-founder and initiator of the 'Neues Frankfurt' housing programme, Ernst May (Harlander 1999, p.248), developed an initial proposal for the Parkstadt Bogenhausen housing estate in Munich. The design of a unified project on a single superblock became possible after the urban layout sketched out by Theodor Fischer half a century earlier had been altered (Wolfrum et al. 2012, p.258). May's proposal was rejected by the local authority on grounds unknown today (Seidel 2008$)^{2}$. Subsequently, an urban design competition was held. Munich architect Franz Ruf's scheme was awarded first prize. Ruf developed the master plan for the site and worked on the design of several buildings in the estate, for example the central shopping centre. Other contributing architects include Johannes Ludwig, Hans Knapp-Schachleiter, Helmut von Werz, Matthä Schmölz and Johann Christoph Ottow. The landscape design was by Alfred Reich (Neue Heimat Bayern 1981). The estate was designed for approximately 6000 residents $^{3}$, complete with

1 NHB names are not consistent in the literature. In NHB's report on the occasion of the $25^{\text {th }}$ anniversary of Parkstadt the developer of Parkstadt is named "Neue Heimat Bayern, München", while the report's corporate author is named "Neue Heimat Bayern CmbH" (Neue Heimat Bayern 1981). In the report of 1971, NHB is named "Neue Heimat Bayern, Gemeinnützige Wohnungs- und Siedlungsgesellschaft mbH, München" (Neue Heimat Bayern 1971a, p.16). This name is also used by Karin Bernst in the $50^{\text {th }}$ anniversary report of 2006 (Bernst 2006, p.43). In the English supplement to the 1971 report, the name "Neue Heimat Bayern Non-profit-making Building Society Limited, Munich" is used (Neue Heimat Bayern 1971b, p.1). For clarity, I use the name 'Neue Heimat Bayern', or 'NHB', assuming that the full company name is "Neue Heimat Bayern, Gemeinnützige Wohnungs- und Siedlungsgesellschaft mbH, München".

2 The plans and documents relating to this initial design proposal by the office of Ernst May are lost, respectively cannot be located (Seidel 2008).

3 The 1971 report provides a figure of 6000 residents (Neue Heimat Bayern 1971b, p.3); the exhibition catalogue of 2019 speaks of an initial target number of 8000 residents (Lepik and Strobl 2019, p.134). 
Figure 51: Parkstadt Bogenhausen, view across the housing estate towards the west and the city centre, Munich 2013

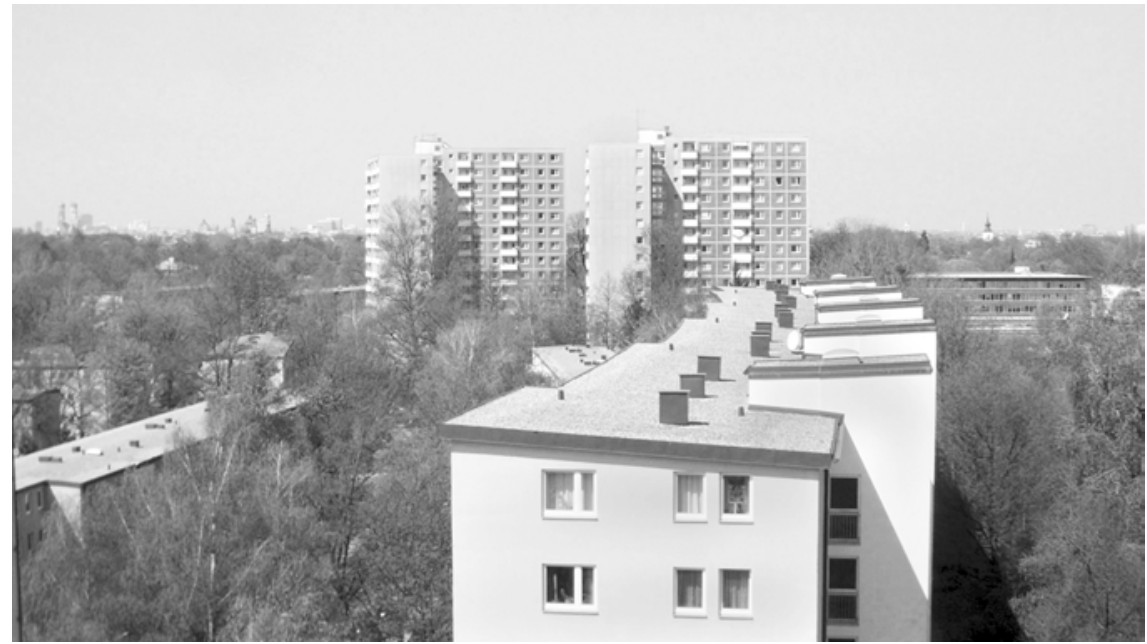

local shops, restaurant, kindergarten, school, central laundry, recreational facilities and estate heating plant (Neue Heimat Bayern 1971b, p.3). Two congregational community centres were built in the proximity shortly after the completion of the estate.

The housing estate is included in the 15th anniversary report of NHB, which was published in 1971 in German, English and French (Neue Heimat Bayern 1971a and 1971b). The English supplement is titled "15 Years of Housing Construction and Town Planning by the $>$ Neue Heimat Bayern $<-$ Non-profit-making Building Society Limited, Munich, 1955-1970" (Neue Heimat Bayern 1971b, p.1). The "Bogenhausen Park Town" is presented as "Munich's first self-contained residential estate" (ibid., p.3).

In line with the concept of "planned neighbourhoods" (ibid., p.2) ${ }^{4}$, the scheme provides a mix of different building types and apartment sizes, based on the idea that this would contribute towards the establishment of a mixed residential community. The buildings are situated within open green spaces and are connected by a scenic drive and a network of footpaths. The estate comprises point blocks, slab blocks of various heights, and low-level housing. 135 units of terraced housing are located in the eastern part of the scheme and were sold on the private market upon completion. All other residential and commercial units remained with the NH group with the exception of the restaurant. The western part of the estate has a floor area ratio of approximately 0.95 , the eastern terraced housing area approximately $0.73^{5}$. The development of the estate was financed without access to publicly subsidised funding, due to the high asking price by the municipality which owned the land (Harlander 1999, p.272). As a result, rents exceeded the local level in 1956 by $40 \%$ (ibid.). However, in 1970, the NHB administration

4 See also Tilman Harlander about „neighbourhood-units” (Harlander 1999, p.241), as well as Werner Durth in the same edited volume (Durth 1999, p.51). Harlander locates the concept of neighbourhood-units within an international modernist discourse, while suggesting that in the case of Germany parallels with the NS concept of „Siedlungszelle" can not be disregarded (Harlander 1999, p.241).

5 Based on own calculations. 
Figure 52: Parkstadt Bogenhausen housing estate, occupying an urban superblock. Today's commonhold-type entity according to WEG is marked in blue, while the other areas of the urban scheme are marked in beige, 2016. Map adapted from https://geoportal.bayern.de/ geoportalbayern/

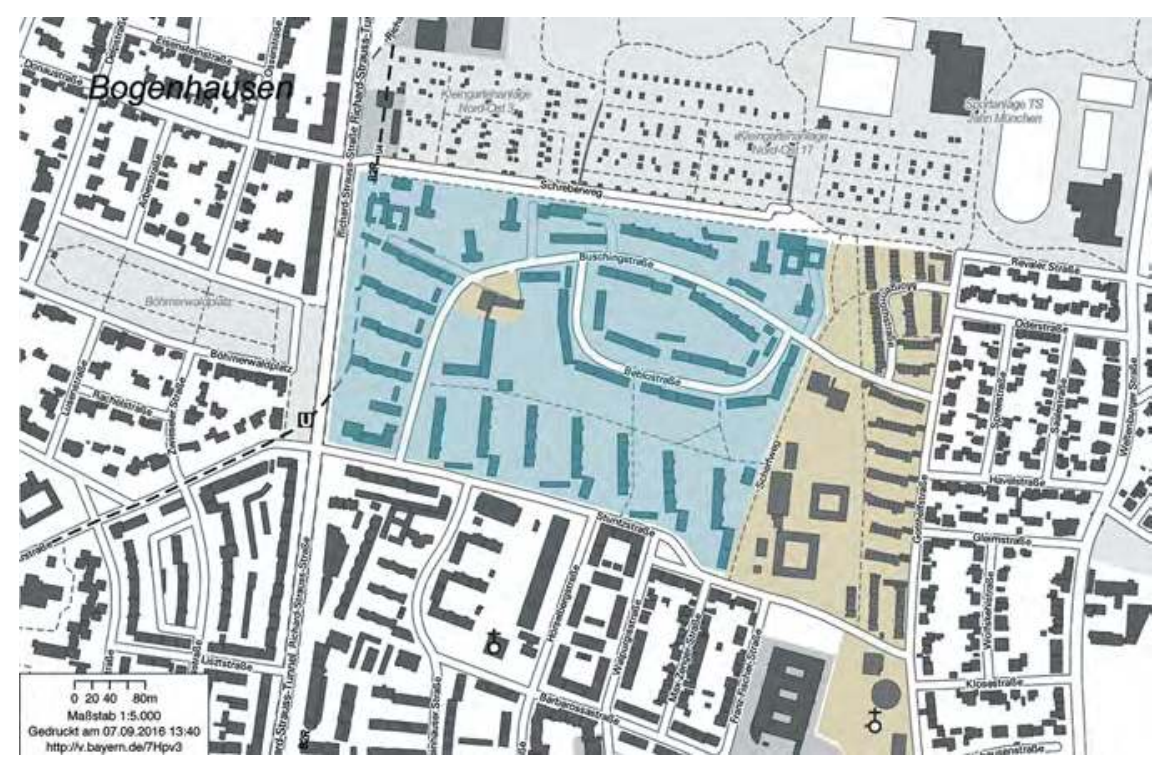

was able to confirm that the rents in the estate had reached a level $40 \%$ below the average (Neue Heimat Bayern 1971b, pp.3f). Towards the end of the 1970s, the Neue Heimat group had to deal with financial difficulties, management problems and cases of corruption (Fuhrich et al. 1983). The group decided to sell parts of its housing stock as a response to the situation (Bernst 2006, p.48). Eventually, the group was wound up in stages. In the case of Parkstadt Bogenhausen, the planned sale of individual dwelling units required the estate to be converted into a commonhold-type entity according to the WEG (Wohnungseigentumsgesetz 2014 [1951]), which was enacted in 1984 with the adoption of the commonhold declaration ('Teilungsurkunde'). The entity was established on estate-level rather than on the level of single buildings. Hence, all 1960 residential and commercial units are contained in a single WEG construct.

Today, Parkstadt Bogenhausen is understood to be the largest entity according to WEG in Germany (Bernst 2006, p.48) ${ }^{6}$. Occupying 15ha of urban land, it has the size of an urban quarter. Initially, the units were exclusively sold to the occupiers, or their closest relatives (Wittemer et al. 2006, p.134). Despite the specific circumstances, the conversion of the estate into a WEG construct and the subsequent sale of the trade union property may be classified as a privatisation process. In 1989, 572 residential units of the Parkstadt Bogenhausen housing estate were left with the NHB

6 No official comparative data on the size of WEC entities in Germany is currently available. Statements about Parkstadt Bogenhausen to be the largest WEC entity in Germany are reproduced in different sources, for example in (Bernst 2006, p.48), and were confirmed by the administration, and others. 
Figure 53: Parkstadt Bogenhausen housing estate, view across the big lawn, Munich 2017

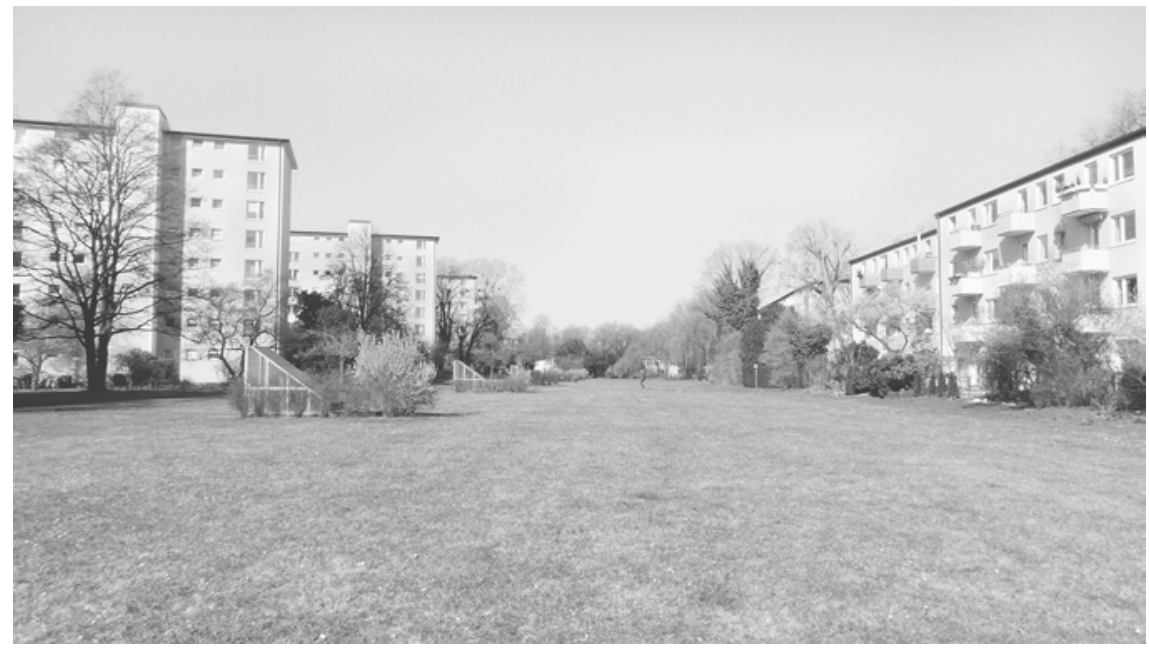

(Wohnungseigentümergemeinschaft Parkstadt Bogenhausen 2016) ${ }^{7}$. By then, the larger part had already been privatised. In 1990, the private investor Doblinger Unternehmensgruppe $\mathrm{GmbH}$ acquired Neue Heimat Bayern together with its remaining assets in the housing estate. The overall number of residential units that passed from NHB to the Doblinger Unternehmensgruppe $\mathrm{GmbH}$ for almost one billion Deutsch Marks was in the region of 33,000 (Hupe 1990). Nearly half of them were located in the Munich area (ibid.). The investor renamed NHB as Bayerische Städte- und Wohnungsbau $\mathrm{GmbH}$, and transferred the former NHB housing stock to the group's newly established subsidiary company Wohnungs- und Siedlungsbau Bayern GmbH \& Co. OHG (Bernst 2006, p.48). During the following 15 years, the units held by the company in the Parkstadt Bogenhausen were gradually sold on the private market. The housing estate was listed in 1992 on grounds of its ensemble character and the quality of the estate as a whole (Denkmalliste Bayern 2017a, 2017b). Within the ensemble, the shopping centre and the adjacent restaurant are listed as individual buildings. The two church buildings in the proximity, which are linked to the estate in terms of planning history and in terms of community life, are also listed. Since its foundation in 1984 the successor organisation to the NHB, Bayerische Städte- und Wohnungsbau GmbH and its corporate reconfigurations, have been entrusted with the estate's administration on behalf of the WEG collective.

Despite the continuity in terms of administration and inhabitants, we can speak of a divided biography of the estate, in that the estate's current WEG period was preceded by almost thirty years of single ownership and centralised management. From a research point of view, this offers the advantage of drawing comparisons between the two periods. It also allows us more clearly to distinguish between research into the

7 Karin Bernst provides a figure of 672 residential units for 1989 (Bernst 2006, p.48), while the annual meeting minutes of the same year provide a figure of 572 residential units, 9 commercial units, and 297 garages (Wohnungseigentümergemeinschaft Parkstadt Bogenhausen 2016). For consistency I use the 572 figure of the annual meeting minutes in the following mappings. 
historic past, and research into the urban present. While the first phase is historically closed, the second phase could be seen as part of an ongoing process. Hence, it lends itself to committed, "future-orientated research" (Denzin 2000, p.915) that seeks to make a difference by enquiring into the possible future(s) of the estate.

The design and development of Parkstadt Bogenhausen Housing estate in Munich between 1954 and 1956 has to be seen within the wider context of post-war (re-)construction, the acute housing crisis that prevailed during this time, and the restructuring of West Germany as capitalist economy and modern welfare state. The beginning of the nationwide building programme in West Germany is framed by two processes. The adoption of the new Housing Act (Wohnungsbaugesetz) on 28 March 1950 and its implementation on 24 April 1950 provided the legal framework for housing construction (Diefendorf 1993, p.140, p.237; Beyme 1999, p.102; Harlander 1999, p.264), while the lengthy public controversy about reconstruction laws and the draft general building law did not come to a conclusion until 1960, when the new building law ('Baugesetzbuch') was finally adopted (Diefendorf 1993, pp.221ff; Harlander 1999, pp.267f). The European Recovery Program ERP, which had been implemented through the Economic Corporation Administration ECA between 1948 and 1952, provided assistance in terms of funding, organisational models and conceptual orientation (Diefendorf 1993, pp.142ff; Durth 1999, pp.61ff). Despite its comparably small absolute volume, historian Jeffry Diefendorf suggests that the ERP's multiplier effects should not be underestimated (ibid., p.143). In 1949, the year when both the Federal Republic of Germany and the Germany Democratic Republic were established, statistics provide a figure of 222,000 newly constructed residential units for the FRG territory (Statistisches Bundesamt 2000, p.49). Production increased sharply to 372,000 units in 1950 and reached a first peak in 1956 with 591,082 units (ibid.). A total of 5.4 million units were constructed between 1951 and 1960 in the Federal Republic (ibid., p.47). It remained on roughly this level until 1975. Against this background, the Neue Heimat group rose to become the largest building enterprise, housing stakeholder, and major policy advisor in the Federal Republic of Germany (Bernst 2006, p.47). Numerous large-scale housing projects and urban development schemes that were realised by the Neue Heimat group are part of the built heritage in German cities today (Lepik and Strobl 2019).

Hence, we can say that the significance of the Parkstadt Bogenhausen housing estate is defined by both the generic and the specific. Like many other housing schemes of the same period, the estate is influenced by modernism and the sociopolitical agenda of the time. It was built within the modernist framework of conflict evasion, simplification, tight-fit-functionalism, and deterministic models of space. The welfare state's homogenising tendency is inscribed in its spatial layout, its architectural language, and the way it was organised and managed. It combines both ideas of humanist universality as well as economical rationality and uniformity (Hiller et al. 2017). In this respect, the estate is one of many similar examples of housing construction dating from the late 1950s. Architectural research dealing with the legacy of modernist housing makes use of the similarities between different schemes and emphasises their shared origins. On this basis, it is possible to produce research knowledge thatcan be applied to typical - or generic - problems in housing. The generic quality in the Parkstadt Bogenhausen housing estate enables us to connect to this knowledge in different ways. Hence, there is reason to expect the findings of the case study to be have necessary relevance for other, similar estates. 
Figure 54: A different view of the Parkstadt Bogenhausen housing estate. Each folder represents 10 units at the administration's local office. Paper-based administration is, however, in the decline, Munich 2018

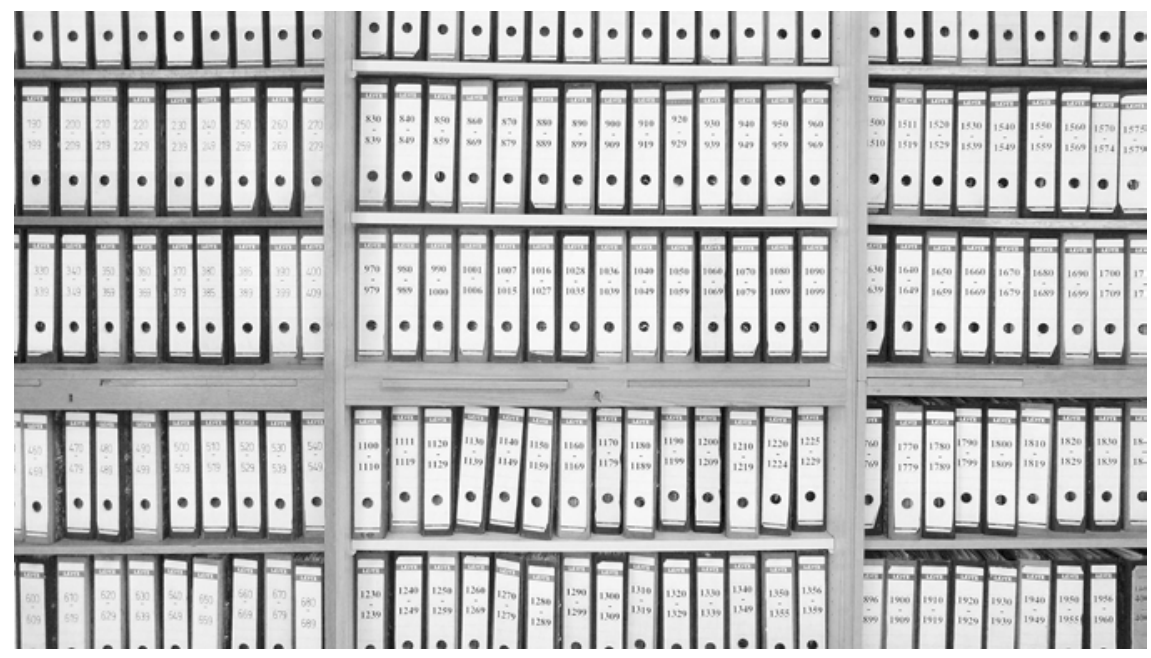

However, there is no such thing as 'the' housing estate (Kling, in press). The limits of comparability and the possibility of thinking in generalisations are defined by the specific. The estate is located in a specific city that follows its own trajectory of development - a condition conceptualised by Helmuth Berking and Martina Löw as the "intrinsic logic" of cities (Berking and Löw 2008; Löw 2008; Löw 2016 [2001], p.xvii). The estate is situated within a web of relations that operate on different scales that connect to different actors, institutional arrangements, and different interests. The specific lies also in the size of the estate's current ownership organisation, in the outcomes of the collective decision-making process, and in its contingent future.

Finally, the case study engages with a WEG entity, which is the largest of its kind in Germany. This implies advantages in terms of positional clarity of the analysis, as well as limitations in terms of comparability.

\subsection{Commonhold-Type Ownership According to the WEG}

The WEG act ('Wohnungseigentumsgesetz'), first approved in 1951, regulates commonhold-type property rights in Germany (Wohnungseigentumsgesetz 2014 [1951]). The property right consists of a clearly defined and self-contained spatial unit ('Sondereigentum'), usually a single apartment or, in mixed-use developments, a commercial unit. This right is combined with a share in collective property rights ('Gemeinschaftseigentum'), such as the plot of land on which the property rights are situated, the communal areas, the building structure, and the external envelope of the building. The property defined in this way may be bought and sold independently from the other property rights in the WEG entity. Each commonhold-type entity is established on the basis of a commonhold declaration ('Teilungsurkunde'), which sets out the extent of the properties, the rights and obligations of its members, the allocation of votes, and charges. 
The collective of property right owning members ('Wohnungseigentümergemeinschaft') is a legal body in its own right. It may enter into contracts, take legal action, and assume liabilities. The collective appoints the housing administrator, usually an external company, and elects members to the advisory board ('Verwaltungsbeirat'). The legal body adopts decisions in formal meetings, usually by a majority of the members present, in which each owner of a property right exercises a single vote, depending on the provisions, regardless of unit size. The formal meeting is held regularly, usually once a year, with the option of having non-regular meetings ('Wohnungseigentümerversammlung'). The advisory board may be trusted with special tasks, such as conducting audits. The board tends to meet on a more regular basis and is in contact with both the administrator and the members. Commonhold-type property rights are established in many countries, acting as legal frameworks for ownership in condominiums, multi-occupancy buildings, and similarly organised properties. In 2002, it was introduced in the UK to complement the traditional freehold/leasehold system (Commonhold and Leasehold Reform Act 2002).

\subsection{Housing Estates Beyond 'Mass Housing'}

To engage with a 1950s housing estate means to engage with and connect to the criticisms that frame the different phases of post-war urbanism and housing production during the second half of the $20^{\text {th }}$ century. The reconstruction phase and late modernism have been, and continue to be, the subjects of fierce controversy. Large areas of the built environment are organised according to modernist principles. They are part of today's urban heritage. Housing projects dating from this phase have reached a lifetime of 40 to 60 years. Most of them have already experienced some kind of modernisation or reconfiguration. A growing number are currently being replaced by urban renewal schemes, or are in this sense endangered. Financial interests and short term political thinking are often opposed to the long-term commitment that seems to be required for housing estates. Some "discourse coalitions", to use a term by Maarten Hajer introduced earlier (Viehöver 2011, p.201), may choose to instrumentalise the needs and problems of local communities to their own ends - Pruitt-Igoe, Sarcelles, or Scampia continue to be discursive sites for the formation of "single stories" (Adichie 2009; Kling, in press).

However, housing estates and modernist urban developments are, above all, meaningful places, homes, and workplaces in the lives of many residents and users. Decades of occupation, appropriation, and sometimes neglect or reconfiguration have generated the estates we know and experience today. Many of them have diversified (Kling and Ott 2019) and are today home to heterogeneous, vibrant communities. Each period and political system has experimented with and developed its own versions of housing estates, resulting in a diversity that is unique if compared with the architectures of private housing. The combination of social vision and collective pragmatism produced the unique historic constellations in which post-war housing estates could be realised. Their architectural qualities are once more appreciated, without brushing aside the problems many of them may be facing. There is a growing public interest in both late modernist heritage as well as housing, which finds its way into publications, exhibitions, public debates, design competitions, and on-site projects - not least because of 
Figure 55: 'The revolutionary Prussian's Ghetto' (Gäbelein 2005). The title reproduces the former, rather unhappy nickname of the housing estate, which alluded to the high percentage of residents which initially did not come from the Munich region (Krack 2006, p.112). The newspaper article is pinned to the information board at the administration's local offices, conveying a sense of shared pride, Munich 2018

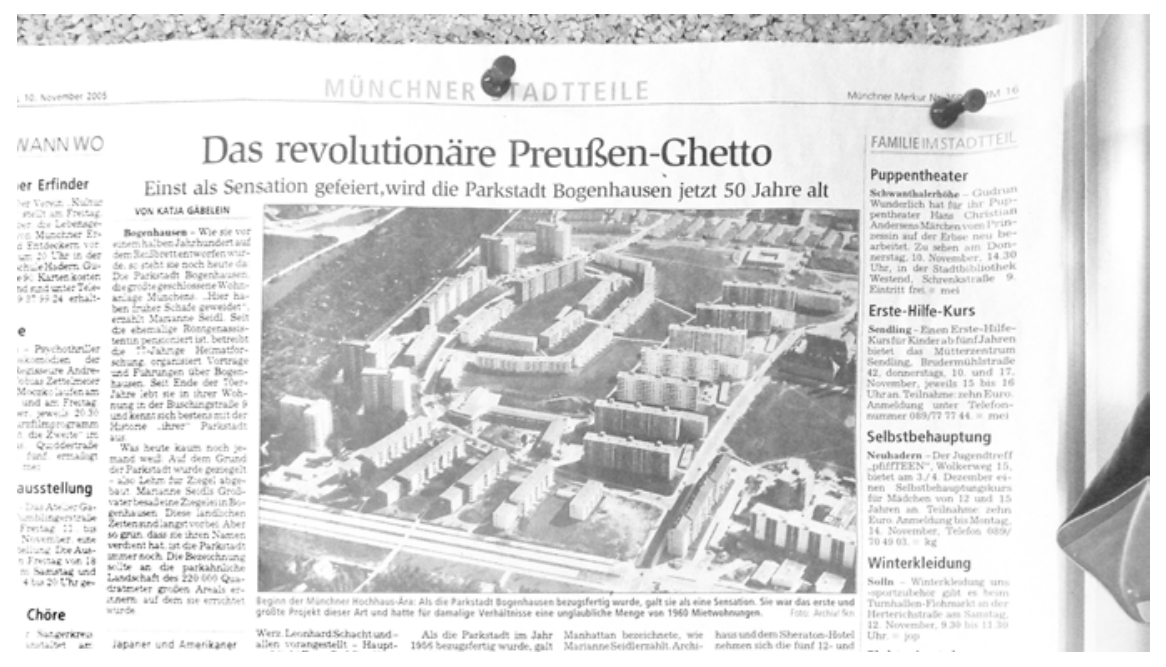

the housing crises and rising rents in European cities. The generalising stigmatisation of housing estates seems to have gradually given way to more differentiated views.

In the contemporary debates on housing, interest groups, architects, historians, and local communities seek to raise awareness of the agenda of the post-war planning generation, and the particular urban and architectural qualities it has produced (Krack 2006; Braum and Welzbacher 2009; Harnack and Stollmann 2017; Lepik and Strobl 2019). Focussing on change and the relationship between space and social processes, Maren Harnack showed how four social housing schemes in London ${ }^{8}$ experienced a 'comeback' in terms of the way they are perceived by the housing market and appropriated by the residents (Harnack 2012). Based on her studies, Maren Harnack suggests that we should be more critical in questioning practices of demolition and subsequent reconstruction, and assign greater weight to softer approaches, management issues, individual needs and choices, as well as authenticity (ibid., pp.216f). Berlin's application to host the International Building Exhibition IBA in 2020 included a study on possible ways to further enhance the quality of life in the city's late modernist housing estates and large scale residential developments (Benze, Gill and Hebert 2013). EUROPAN, the leading architecture and urbanism competition for young professionals and theorists has repeatedly included 1950s, 60s, and 70s housing estates to their competition briefs as part of the competition's gradual shift from the single building towards more complex urban situations (Rebois 2010). What seems to unite these recent research projects and design proposals is the movement away from the

8 Maren Harnack's case studies include Keeling House by Denys Lasdyn, Trellick Tower by Ernö Goldfinger, Brunswick Centre by Patrick Hodgkinson and Aylesbury Estate by F.O. Hayes. The analysis is based on different architectural and sociological methods. 
dismissive concept of 'mass housing' and towards perspectives that seek to engage with local situations in new and unconventional ways. Rather than defining architecture and urban design as the organisation of built form, they highlight and work with their connectedness to social processes and complex spatial relations.

Applied research and professional work concentrates on the solving of immediate and practical problems. Its research into housing estates is usually dedicated to its physical and material properties, energy efficiency, optimisation of floor plans, comfort standards, financing, practical management, or questions of image and marketability. Some approaches seek to extend the scope of questions raised in this field ${ }^{9}$. However, where housing corporations, the building industry, and the federal governments act as the main clients and sponsors of research, agendas tend to be predefined, economic questions foregrounded, and power relations and political questions excluded, or at least uncritically reproduced. The research produced in this way receives its strength through the narrow and precise frame it applies to the broad field of housing. It is demand-driven and aimed at the production of matters of fact. Without questioning the merits and justification of such research, we should not expect it to go far beyond the specific requirements and interests of the client. If we seek to extend the analytical sensitivity in research projects, different research perspectives need to be included.

\section{Empirical Grounding: Mapping Transformative Interactions}

\subsection{Combining Different Mapping Perspectives}

The problems and challenges associated with housing estates are multi-facetted. They rarely reside within a single disciplinary domain. In the proposed analysis of the Parkstadt Bogenhausen housing estate in Munich, I will not focus on known problems such as construction defects, tight-fit functionalism, comfort issues, accessibility, conservation, energy efficiency, or the lack of quality in open spaces. These problems need addressing, not only in the Parkstadt Bogenhausen estate but in any housing estate, and they are being addressed. The phenomena I am interested in - the strange pattern of change observed in the Parkstadt Bogenhausen housing estate - requires the research to extend, and to a certain degree leave aside the standard toolbox of architectural and urban analysis.

Based on the methodological considerations discussed earlier, I propose to include the following broadening analytical perspectives in the case study:

9 For example the projects sponsored by the Wüstenrot-Stiftung which seek to combine research with design innovation and architectural theory. The foundation hosts annual workshops relating to contemporary issues in housing and urbanism and supports publications and research projects, for example the design orientated "Raumpilot" (Jocher and Loch 2010). Their 2008 workshop and symposium (Zukunfts-Werkstadt Wohnbauen) in Frankfurt, for example, explored the possible transformation of the 38 storey AfE tower in Frankfurt a.M.. The author had the opportunity to visit the workshop led by Inken Baller and Günter Barczik. 
Figure 56: Parkstadt Bogenhausen, stationary shop and café at the shopping centre, Munich 2018

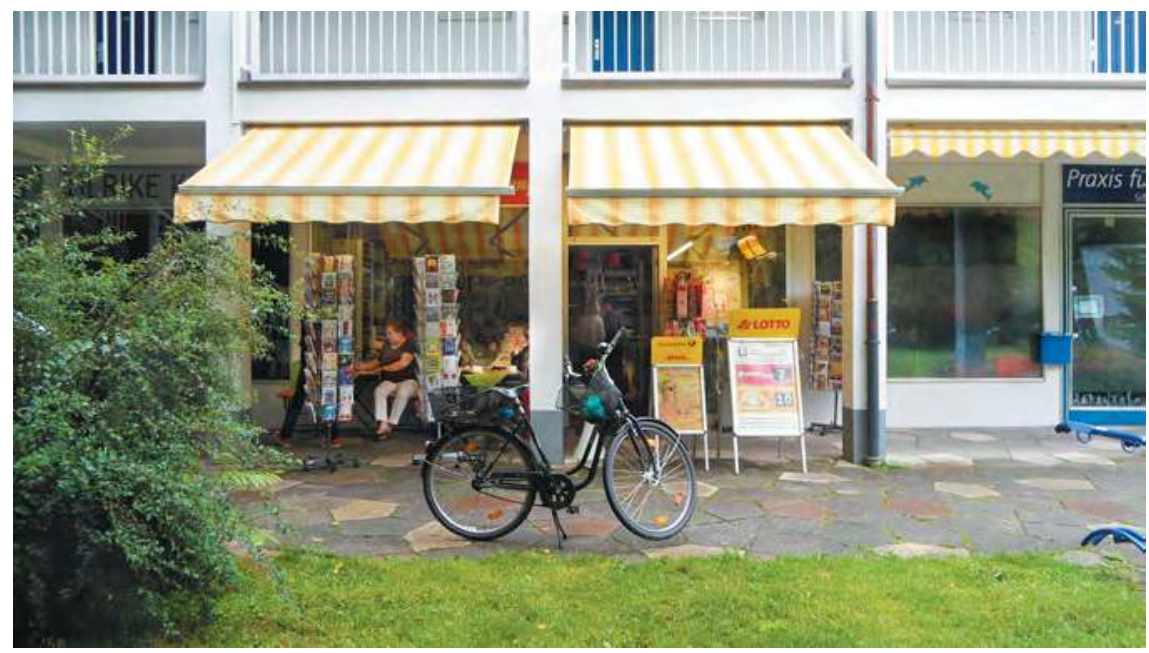

1. Arena/social worlds perspective: The WEG-framed housing estate may be conceptualised as an "arena" in which the collective co-produces itself through repetitive acts of decision-making. Multiple "social worlds" intersect in the arena and make it a space of convergence and conflict. The social worlds/arenas theory was first proposed by Anselm Strauss and subsequently reframed and further developed by Adele Clarke for application in situational analysis (Clarke 2005, p.19). The theory emphasises contingency, difference and the presence of all relevant actors and structural conditions "in the situation" (emphasis in original, ibid., p.71), including human actors, institutional worlds, discourses, and non-human actors. Through this perspective, I seek to extend the analytic range of architectural and urban enquiry, and at the same time establish a site of analytical convergence.

2. Timeline perspective: Interactions may be conceived as space/time bound events that unfold as contingent process. Decisions are not conceptualised and analysed as isolated events, but in their relatedness to preceding and following decisions and in their wider context. The timeline emphasises the political and the generative power of discourses (Clarke 2005; Clarke, Friese and Washburn 2018) and of controversy (Yaneva 2012). It raises the question of alternatives, and reconstructs sequential and rhythmical aspects of interactions (Lefebvre 2013 [1992]). In this sense, it connects to the temporal analytical dimension in situational analysis and its "[...] capacities to handle collective history and change over time." (Clarke and Keller 2014)

3. Multi-scalar perspective: This perspective is based on the understanding of the problem as related to, and influenced by, processes that are located on different scales. A multi-scalar perspective allows us to approach the situation from above and below, taking advantage of the estate's privileged position at the intersection of micro-narratives and the urban scale. The resulting movement through micro-, meso- and macro-perspectives raises problems in terms of keeping the research in 
focus, but it reduces the risk of producing blind spots through rigorous demarcation (Brenner 2013).

In the following analysis, different mapping techniques are applied to each perspective. I have outlined the basic methodological considerations in Chapter I of this book, to which I add further explications in the following sections. The case study evolves along four different types of mappings: Perspective 1 translates directly into a single map, the mapping of the Parkstadt arena. Perspectives 2 and 3 are combined to produce, firstly, an extended timeline diagram which may be conceived as representing the 'situational process', secondly a tabular list of categories and codes which assembles the decisions made during the annual meeting of the collective, and, thirdly, a series of negotiated concerns. Pertaining to the relationship of researcher and actors in the field, I follow Albena Yaneva's injunction that the idea "[...] is not to teach actors what they are incapable of understanding but to learn from them how to observe their collective existences." (Yaneva 2012, p.4) I had the opportunity to present an intermediate stage of the case study project at the Third Oikonet International Conference on 'Global Dwelling: Sustainability. Design. Participation', which was held in Manchester on 23.09.2016 (Kling 2016).

\subsection{Mapping the Parkstadt Arena: Social Worlds/Arenas Perspective}

I have outlined some basic assumptions and methodological principles of situational analysis and of the related social worlds/arenas theory in Chapter I of this book. Situational analysis assumes that issues of broader concern and collective action are negotiated between and through social worlds that partially and temporally participate in arenas. In terms of analysis, all elements constitutive of a situation are understood to be present in the situation (Clarke 2005, pp.71f).

Arenas are sites in which different social worlds participate. Social worlds are not homogenous and characteristically develop subdivisions and segments. Groups and individuals participate in multiple social worlds and arenas simultaneously. Boundaries between social worlds are permeable, subject to negotiation and shifting agreements. The partial and temporal character of social worlds distinguishes them from concepts such as community, while, at the same time, commitment to joint action distinguishes them from the casual commitment to a scene. Clarke suggests that, if "commitment to action" (ibid., p.113) is chosen as delimitating factor between social worlds, then both, action as process, as well as social entities of action - social worlds and arenas - may be empirically analysed (ibid.). Typical questions in the analysis are related to patterns of collective commitments, the 'work' of each world, the kind of commitments conceived by the participants in terms of fulfilling them, self-descriptions, perception of other worlds in the arena, actions taken and anticipated, the organisation of the social world, sites of collective action, or the relationship of different social worlds (ibid, p.115). Conflicts of different kinds are assumed to be present throughout the arena. Hence, Clarke suggests that "while some actors (individuals, collectivities, and even worlds) might prefer not to participate in a particular arena, their dependencies (usually but not always for resources) often coerce their participation." (ibid., p.110) Based on the premises of social worlds/arenas theory, I seek to represent and analyse conditions that are characterised by shifting social configurations, negotiations, 
controversy, commitment, collective action, and conflict in the mappings that are to follow. However, as in any form of representation, decisions have to be made as to what is sensibly included to the mappings. Donald Schön has theorised this problem for the field of public learning. His use of the term 'situation' predates Adele Clarke's concept of situational analysis, but in this instance both uses seem to be largely compatible with each other:

"For one thing, the issues taken to be important at any given time represent a selection from a total body of information which is of enormous complexity. The inventory of issues [...] is never adequate to the situation; it never succeeds in exhausting what might be the set of issues to be drawn from that situation. The ultimate basis for this fact is epistemological; there is simply more in a situation than can be conceptually abstracted from it." (Schön 1971, pp.141f)

Mappings are abstractions and will remain incomplete if compared to that which is mapped, even if they strive for completeness. Mappings of social worlds/arenas are unlikely to exhaustively grasp the intrinsic web of social relations. However, rather than responding by excessive data accumulation, the chosen theoretical sampling process will be extended "on analytic grounds" (Strauss 1987, p.38) where this is useful or necessary.

The data used for the mappings originates from different sources. For reconstructing the first phase of the estate up until 1984, I draw from publications made on the occasion of the $15^{\text {th }}$ anniversary of the NHB (Neue Heimat Bayern 1971a and 1971b), respectively the $25^{\text {th }}$ anniversary of the Parkstadt Bogenhausen housing estate (Neue Heimat Bayern 1981). The edited $50^{\text {th }}$ anniversary book (Krack 2006) provides a rich description of the history of the estate, which includes the personal memories of residents, members of the administration and other actors involved with the Parkstadt Bogenhausen housing estate. The section "Parkstadt heute" by Werner Wittemer, Roland Krack, Karin Bernst, and Jan Grossarth (Wittemer et al. 2006) offered valuable information on everyday life and local initiatives for the timeline study. Further material was obtained from the Parkstadt Bogenhausen website, designed and managed by Werner Wittemer, including information on local history, the estate's architecture, past and present activities, as well as different online forums (Wittemer 2006) ${ }^{10}$. "Stadt am Stadtrand" (Town at the Edge of Town) is the title of a 1969 publication, in which the results of an extensive sociological study of four large housing schemes in Munich, including the Parkstadt Bogenhausen housing estate, are presented and discussed (Zapf, Heil and Rudolph 1969). While the findings seem to be too distant as to be applicable to the present condition, it can be read as an account of the main concerns related to the life in new housing estates of the time, as well as the basic premises used by the researchers" ${ }^{11}$ Ferdinand Stracke's "WohnOrtMünchen. Stadtentwicklung im 20.

10 The website www.Parkstadt-Bogenhausen.de has been online since 2000 . The website is still maintained, but no further information has been added since the $50^{\text {th }}$ anniversary of the housing estate in 2006, except in the forums.

11 The study formed the starting point for an actor-centred timeline comparison between the Parkstadt Bogenhausen and Hasenbergl housing estates which I developed together with Max Ott on the occasion of the Neue Heimat exhibition (Kling and Ott 2019). The exhibition, curated by Hilde Strobl of the 
Jahrhundert" (Stracke 2011) ${ }^{12}$ provides a broadly conceived overview of Munich's urban development process during the 2 oth century. Its focus on housing makes it a valuable resource for the contextualising of individual housing projects in Munich. A portrait of the Parkstadt Bogenhausen housing estate is provided complete with figure-ground plan and exemplary floor plans (ibid., pp.158f). The structure of the publication makes it possible to draw direct comparisons between schemes of the same period, like the Siemenssiedlung in Obersendling (ibid., pp156f), as well as between preceding and subsequent housing projects. Finally, there are further articles and press coverings used in the analysis, to which I do not directly refer here.

For the second phase I draw, again, from the edited $50^{\text {th }}$ anniversary book (Krack 2006) and other published material. A major source of material is provided by the minutes of the annual meeting of property right owners (Wohnungseigentümergemeinschaft Parkstadt Bogenhausen 2016). The use of archived material is gaining significance in social research, not only because it continues to multiply, but also because electronic means improve its accessibility and availability for digital data mining (Clarke 2005, p.183). Pertaining to the use of archived material in situational analysis, Adele Clarke asserts that organisational documents, minutes, websites, or reports are produced by organisations to present themselves, to address particular audiences, and, in doing so, provide the researcher with additional information about the world in which she or he is interested (ibid., p.152). The minutes contain different kinds of information. On the one hand, they address different topics and provide a formal account of the decisions made. On the other hand, they contain implicit information about the relations between different actors, the emergence and closure of discourses, or the constellations of power inscribed into institutionalised processes. My decision to choose formalised communications as the main source of empirical material rather than interviews was in part influenced by the specific situation of being immersed in the field. And finally, information of different kinds is inscribed in the estate itself. The estate may be conceived as a device for the fragmentary physical recording of past transformations and collective human action, an aspect which I have discussed on a more general level earlier.

The goal of the mapping of social worlds/arenas that I discuss in this section is to identify, locate, and relate to each other the various collective actors, institutional worlds, and nonhuman actors that engage in the 'Parkstadt arena'. The arena is not identical with the 'Wohnungseigentümergemeinschaft Parkstadt Bogenhausen' as defined in the commonhold declaration ('Teilungserklärung'), because it includes other social worlds that commit to the discourses in the Parkstadt arena. Despite this, the arena becomes tangible and visible in the annual meeting of the 'Wohnungseigentümergemeinschaft'. The meeting is the institutionalised situation in which, among other issues, change (or non-change) is collectively negotiated. The participants in the meeting are part of different social worlds that assemble around, and meet within, the arena. Participants may be committed to the ongoing concerns of more than one social world.

Architecture Museum in Munich, showcased the enormous building and development output of the Neue Heimat group in West Germany between 1950 and 1984 (Lepik and Strobl 2019).

12 Professor Ferdinand Stracke held the Chair of Urban Design and Regional Planning at TUM between 1989 and 2003 (Stracke 2011, p.384). 
Figure 57: Map showing the Parkstadt Arena and participating social worlds

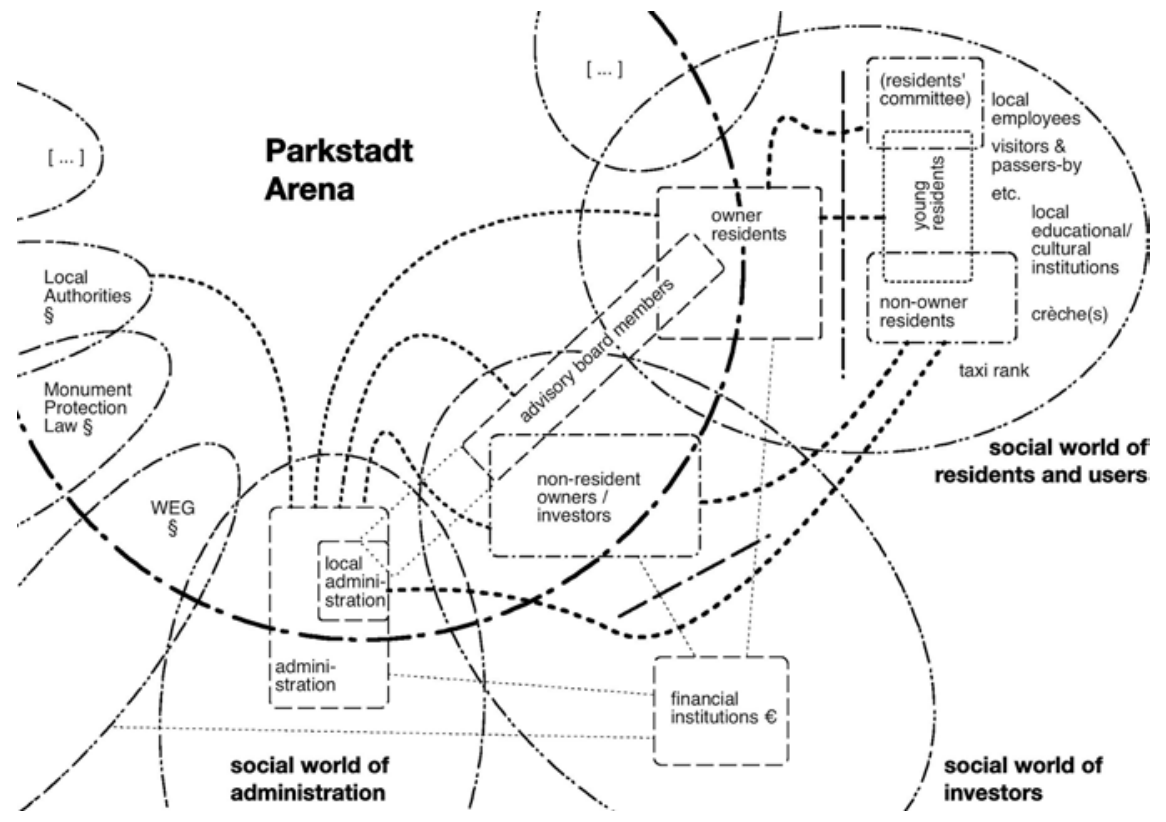

The main social worlds include local residents and users, investors, and the administration. There are other social worlds that participate in the arena, for example WEG legislation, planning and building regulations, preservation, or the housing market. These social worlds are implicit human or nonhuman actors in the situation. They are, at times, referred to in the meeting minutes and they have their specific impact on the pattern of change we observe in the housing estate. The graphical non-closure of the arena suggests that there are more social worlds than shown on the map.

Probably the most obvious social world is composed of local residents and users. What is characteristic of this social world is that not all local residents and users participate in the arena. The vertical line indicates that there are restrictions. Among the residents, only property owners are entitled to vote and actively participate in the Parkstadt arena; non-owner residents, young residents, locally employed, or the more casual users of the estate, are not admitted to the decision-making process. If they wish to participate, they can only do so indirectly. Non-owner residents may speak to their landlords or to the local administration ${ }^{13}$, young residents to their owner parents, and locally employed, or local businesses, to the owners of the rented commercial units. Likewise, residents' committees have indirect access to the arena through owning residents. This subworld is put in brackets to indicate that residents' committees in the Parkstadt had limited lifetimes in the past. There is no active committee at the present moment. The social world of investors comprises non-resident owners as well as institutions that have a financial interest in the estate. Institutions act indirectly upon the social worlds and subworlds that engage in the arena, by defining interest

13 The link between non-owning residents (tenants) and local administration was confirmed through interviews. 
rates, terms and conditions of financing, and influencing the market situation. Resident owners are also shown to have a financial interests in the estate, since these partly overlap with the world of investors. The administration of the estate is part of a larger organisation, which in turn is part of the social world of estate administrators. The local administration operates a site office. Some of its staff are local residents. However, not all owner residents and non-resident owners participate in the arena, despite their entitlement to do so. At the annual meetings, between 300 and 400 votes are typically cast, which is less than $20 \%$ of all votes and below the $50 \%$ threshold required by law. It is due to a special clause in the housing estate's commonhold declaration that the annual meeting constitutes a quorum irrespective of size. Hence, if we compare the absolute figure with the number of actors who are related to the housing estate and the Parkstadt arena, we see how small the actual number of decision-makers is.

The social worlds/arenas map shows what kind of multiple social worlds assemble in and around the Parkstadt arena, and how they relate to each other. In the arena, social worlds form changing coalitions, establish situations of confrontation or agreement. They touch and interpenetrate each other, or otherwise seek to maintain distance. Each social world is associated with its specific ongoing concerns, practices, actions, or commitments, which contribute to the process of change in the Parkstadt Bogenhausen housing estate. The arena and its participating social worlds reconfigure themselves and are thus in a fluid state, while at the same time providing a degree of structural stability for the collective process.

\subsection{Mapping the Overall Situational Process: Timeline and Structural Conditions}

The second type of map seeks to represent the overall situational process of the Parkstadt Bogenhausen housing estate. The map, or diagram, is arranged along a timeline that covers a period of more than sixty years up until the present, starting with the design and construction phase of the estate in the 1950s. The map shows connections across different scales, as well as the decision-making process in its broader context, including ownership status, formation and reformation of resident groups, decisive events, and the presence of visible and less visible actors in the situation.

The upper section of the diagram shows how ownership changed from single ownership, through an intermediate process of privatisation, to the current dispersed form of ownership. Following the conversion and subdivision of the estate according to WEG in 1984, the NHB property rights as of 1990 passed to the investor Doblinger Unternehmensgruppe $\mathrm{GmbH}$, which completed the step-by-step sale by 2001 (Wohnungseigentümergemeinschaft Parkstadt Bogenhausen 2016). In the middle section, directly above the timeline, major events of change and transformative interactions are shown. Up to the year 1984 the single owner, GEWOG Gemeinnützige Wohnstättengesellschaft von $1910 \mathrm{mbH}$, or the $\mathrm{NHB}$, controlled the process of making changes and alterations to the estate. Since 1984 this authority has been with the 'Wohnungseigentümergemeinschaft Parkstadt Bogenhausen'. Every change that affects the entity is formally approved at the annual meeting of owners, with the exception of non-structural changes to the interior of private units. The map shows all decisions made in this way since 1984, whereby each decision is assigned a four digit number. The decisions unfold along the timeline and are arranged in horizontally running sequences 
Figure 58: Timeline and structural conditions: Mapping the overall situational process

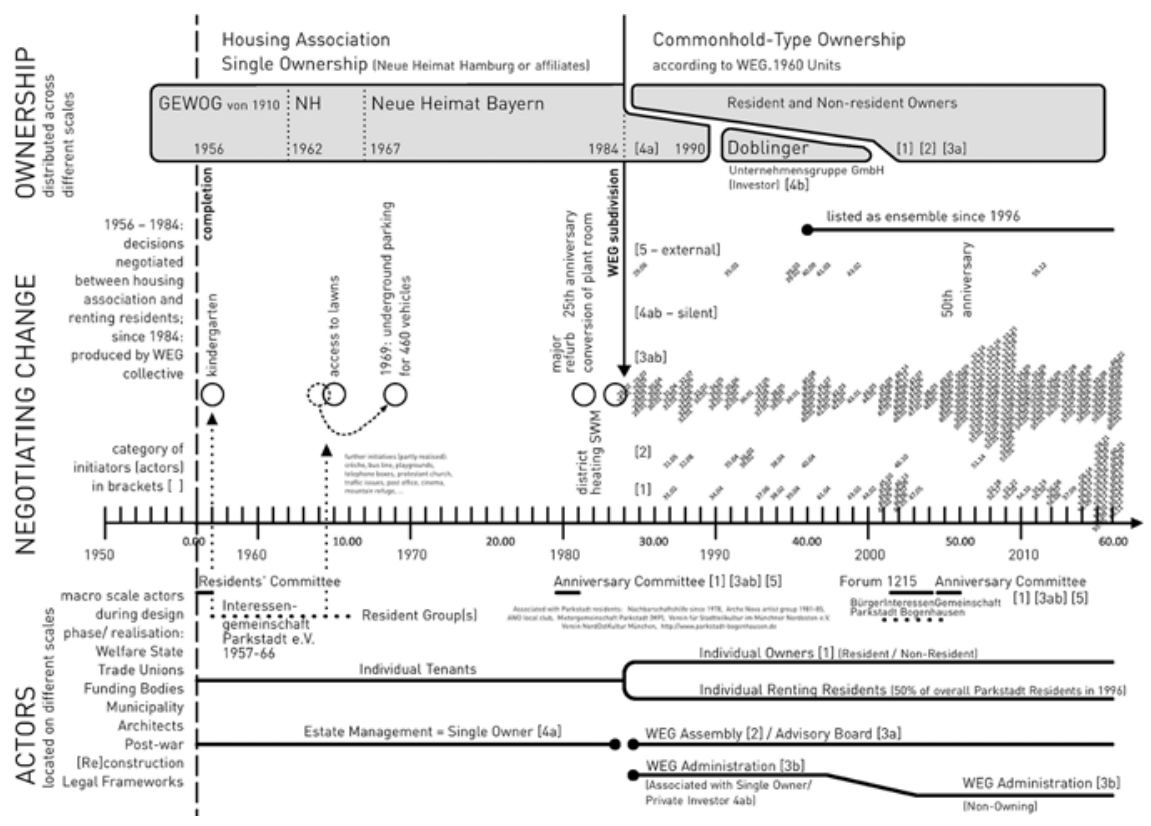

according to actor category. They form the cloud-like pattern in the middle section of the diagram. The categories indicate which group of actors introduced the respective topic to the decision-making process.

The categories comprise individual owner residents [1], the collective of owner residents (enacted during the annual meeting) [2], the advisory board [3a], administration [3b], housing association [4a], investor [4b], and external actors [5]. The category numbers in brackets are also used in the upper section about ownership and the bottom section about groups of actors. More detail on categorisation, and more detail on how the cloud-like pattern of single decisions was developed is provided in the following section. The constellation of actors is not static. The lower section of the diagram shows status changes of institutions and residents, as well as the formation of neighbourhood groups and interest groups. The list of actors is not exhaustive. It is focused on the participants in annual meetings as stated in the minutes and as identified in the social worlds/arenas map.

The presence of actors related to the macro scale is indicated in the left column at the beginning of the timescale. These actors include the welfare state, trade unions, funding bodies, professionalised practices of planning and architecture, the municipality, and legal frameworks. They are co-producers as well as the products of dominant practices and discourses. For the most part, they remain in the background of the process, except during the design and construction phase of the housing estate, and again during the establishing of the commonhold-type entity according to the WEG, when their actions are in the foreground. The overall process may be conceived as a form of negotiated order (Strauss 1978a), which relates to different scales. Continuously negotiated local processes among residents, owners, the administration, and neighbourhood groups are framed by the large-scale negotiations that affect WEG 
legislation, global funding and organisational aspects. Anselm Strauss refers to them as the "structural conditions pertaining to the phenomena under study" (emphasis in original, ibid., p.257).

\subsection{Mapping Recorded Decisions: Categorising and Open Coding of Meeting Minutes}

The third kind of map is based on the minutes of the collective's formal annual meetings (Wohnungseigentümergemeinschaft Parkstadt Bogenhausen 2016) and shows detailed sequences of negotiated concerns. In this section, I provide a brief description of how I have generated analytical data by categorising and open coding. In the next section, I focus on the identification of single concerns and their translation into thematic maps.

The annual meeting minutes are drafted by the administrator, approved by the advisory board, and subsequently forwarded to all members of the collective ('Wohnungseigentümergemeinschaft'). The opening section of the minutes provides information about attendees and figures on the number of voting members present, date and duration of the meeting, and the list of topics. This is followed by the summaries of the reports of the administrator and the head of the advisory board. The central section of the minutes is dedicated to the voting and decision-making process. The wording of each voting item is stated at full length. The number of approvals, non-approvals, and abstentions are listed for each item, occasionally accompanied by brief references to topic-relevant discussions. Further information is typically recorded in the closing section of the minutes. This may include proposed agenda items for the next annual meeting, announcements, recommendations, or general notes. The first annual meeting took place as part of the establishing of the entity according to the WEG in 1984. The mapping covers the period from 1984 to 2016 . The annual meeting minutes from which the data for the mapping is extracted cannot be assumed as being neutral in an objectified sense. Although minutes are meant to represent factual and rational information, and although we accept them as such in common practice, they are situated within constellations of power, permeated with intentionality, and controlled by restrictions in terms of authorship. Following the paradigm of qualitative research, the subtexts contained in the minutes are treated as an integral part of the material rather than as non-factual 'noise' that needs to be eliminated.

In the analysis, the minutes are subjected to a simultaneous process of categorising and coding. All decisions that have produced changes in the housing estate, or that are related to change in one way or the other, are identified and listed. 284 such collectively made decisions were identified in the annual meetings for the period between 1984 and 2016. Decisions that are recorded in the minutes but that do not result in changes in the sense of the analysis are not included. Typical decisions that are not included are granting discharge to the administration for the budget implementation in the previous year, deciding on estate levies, or electing advisory board members. In the list, each decision is given a unique four-digit number, stating the year since completion of the estate in 1956 on digits one and two, while digits three and four count the number of decisions within that year. The decision is then assigned to one of the corresponding subcategories within each main category. The main categories comprise actors/initiators; change status; type of change; spatial unit affected; value/size of negotiated item. 
Figure 59: Categorising and first section of the $1^{\text {st }}$ coding cycle (open coding), based on the information provided by the minutes of the annual meeting (Wohnungseigentümergemeinschaft Parkstadt Bogenhausen 2016). Detail.

\section{PARKSTADT BOGENHAUSEN TIMELINE STUDY 1984 - 2016} DATA EXTRACTED FROM MINUTES OF ANNUAL MEETINGS 1984 - 2016
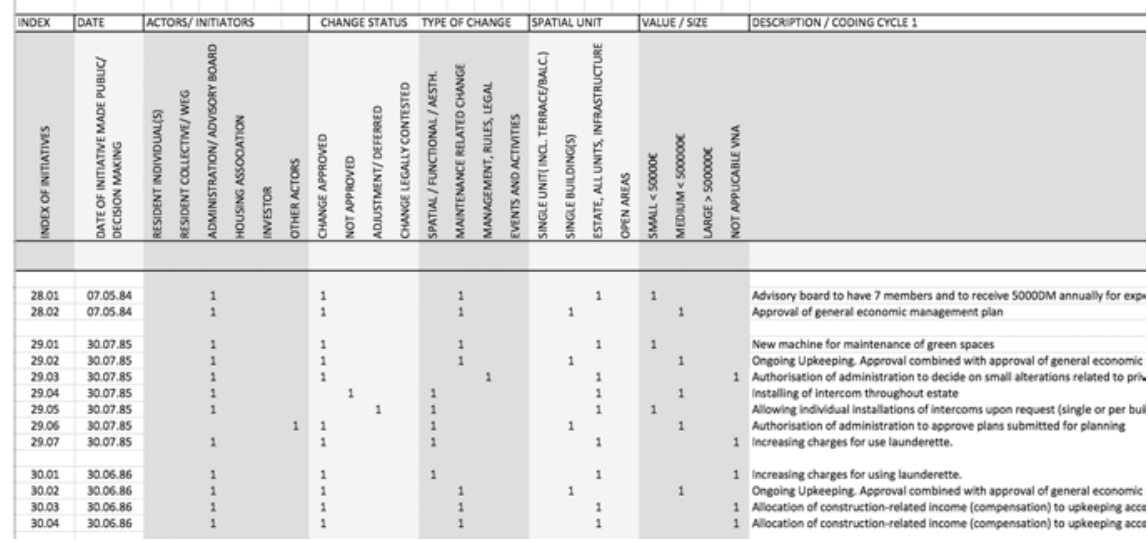

For the purpose of the analysis, actors/initiators are defined as the respective group which introduces the respective voting item to the decision-making process. For the category of actors/initiators, the subcategories include individual residents, the collective of residents (enacted in the annual meeting), the administration/advisory board, housing association (Neue Heimat Bayern), the investor (Doblinger Unternehmensgruppe $\mathrm{GmbH}$ ), and other actors. Where no specific reference is made in the minutes as to the actor, it is attributed to the joint subcategory of administration and advisory board. The next set of subcategories indicates the status of the decision made and ranges from approved, not approved, deferred, and legally contested. This is followed by the subcategories that specify the type of change, which comprise in the first column spatial, functional or aesthetical changes, in the second column maintenance related changes, in the third column management, rules and legal, and finally activities and events in the fourth column. There is some overlap in these subcategories and in some cases it is difficult to assign a decision to a single subcategory. The main distinction between the first and second column is the factor of novelty. Something that had not existed before is listed in the first column, whereas the second column is related to maintenance work, upkeep, and repairs. Further sets of subcategories describe the spatial unit affected by the decision, and the value/size of the proposed change. Here, the distinction is between single unit, single building(s), the entire estate including its infrastructure, and open areas. In the value/size subcategory the distinction is made between small - up to $€ 50,000$, medium - up to $€ 500,000$, large - above $€ 500,000$, and not applicable. The system of categories and subcategories forms the basis for a complementary quantitative analysis, which I establish further below. 
Figure 60: Categorising and coding of meeting minutes. Full list including $1^{\text {st }}$ and $2^{\text {nd }}$ coding cycles and the basic sequence of decisions. The list is scaled down to provide an overview while maintaining the confidentiality of the material.

PARKSTADT BOGENHAUSEN TIMELINE STUDY 1984 - 2016
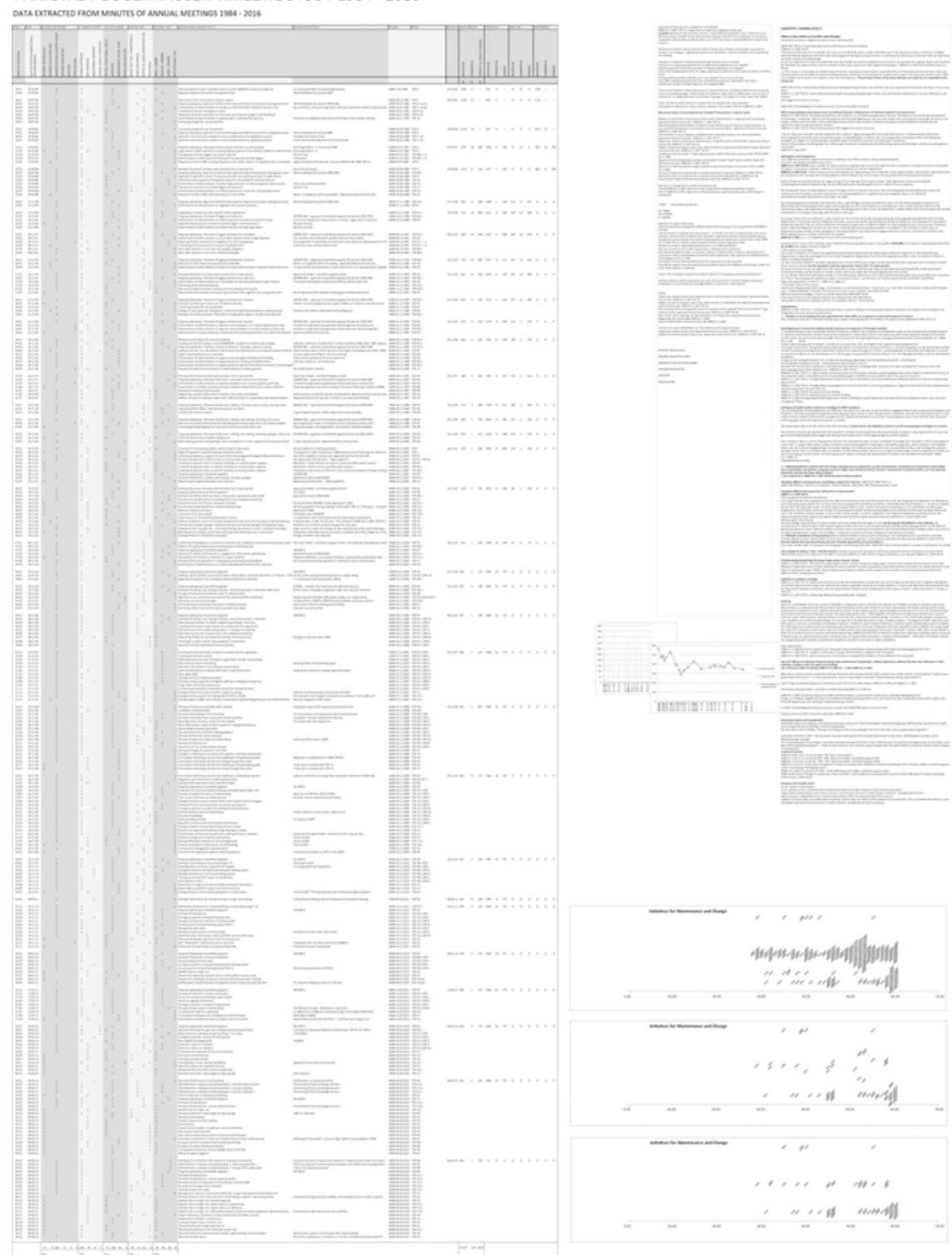

Finally, each single decision on the list is integrated into a process of "open coding" (Strauss 1987, pp.55ff) in the $1^{\text {st }}$ coding cycle, followed by 'thematic coding' in the $2^{\text {nd }}$ coding cycle. In open coding, which is an instrument used in GTM, a series of tags or keywords that characterise the decision in concise form are assigned to each item on the list. Coding in GTM is typically applied to a line-by-line analysis of transcripts of interviews or similarly detailed material. In our case, it is used for the coding of the 
voting items which are reproduced in the meeting minutes. 'Thematic coding' is an add-on instrument which I have developed for the purpose of the analysis. Its functioning and outcomes are introduced in the following section.

\subsection{Mapping Negotiated Concerns: Thematic Coding and Detailed Sequences}

In the second step, the timeline is re-introduced to the analysis. The previously defined categories allow us to arrange the decisions in different ways along the timeline. For this mapping exercise, the categories of actors/initiators and decision status define the basic organising principle, together with the timeline. Each subcategory of actors/ initiators is assigned a horizontal line along which the voting items are listed, not dissimilar to musical notation. Approvals or deferrals are shown in light grey, whereas non-approvals or legally contested decisions are in black. As we can see in the resulting pattern, there are great differences in terms of the number of decisions made per year, as well as in terms of who raises voting items. In thematic coding, the focus is on identifying negotiated concerns, or controversial themes, within the decision-making process. Single decisions that relate to each other are connected by means of a dotted line. The connection may be explicitly stated in the annual meeting minutes, or otherwise be implicit in the data. The codes produced in the open coding of the $1^{\text {st }}$ coding cycle assists in the identification of possible thematic connections. Key events and other information that are of significance to the negotiated concern are identified in the coded data and superimposed on the pattern. In this way, the otherwise abstract pattern of the decision-making processes are made visible in the data through a series of thematic sequences that span over shorter or longer periods of time. They visualise the shifts in intensity, the pauses, as well as the ruptures and unexpected turns. In terms of saturation, or the amount of information added to a thematic map, the goal is to balance plausibility and legibility. More information could always be added. However, in line with the methodical propositions of situational analysis, the focus is on the overall map rather than on the single event or information.

Practically, thematic coding as developed for this mapping exercise progresses as an iterative process, where negotiated concerns are provisionally mapped, analysed, and fed-back into the coding process. The concerns identified so far are "loitering" and "ball games", which evolve around issues like inclusion/exclusion and the control of open spaces; "decision making", which is about the process itself and which relates to questions of participation and the distribution of power; "silent investor" as the mapping of the rare instances in which the investor is visible in the arena; "maintenance project" as the recurrent and dominant common concern; "individual modifications", which show the struggle between individual appropriation and the collective/administration; and finally "intercom", which illustrates how many steps and decisions may be required to introduce a seemingly small change. Trusting in the self-explanatory capacity of each diagram, I limit my descriptions to comments and the provision of background information. 
Figure 61: Sequence "loitering"

\section{SEQUENCE "LOITERING" 1997 - 2016}

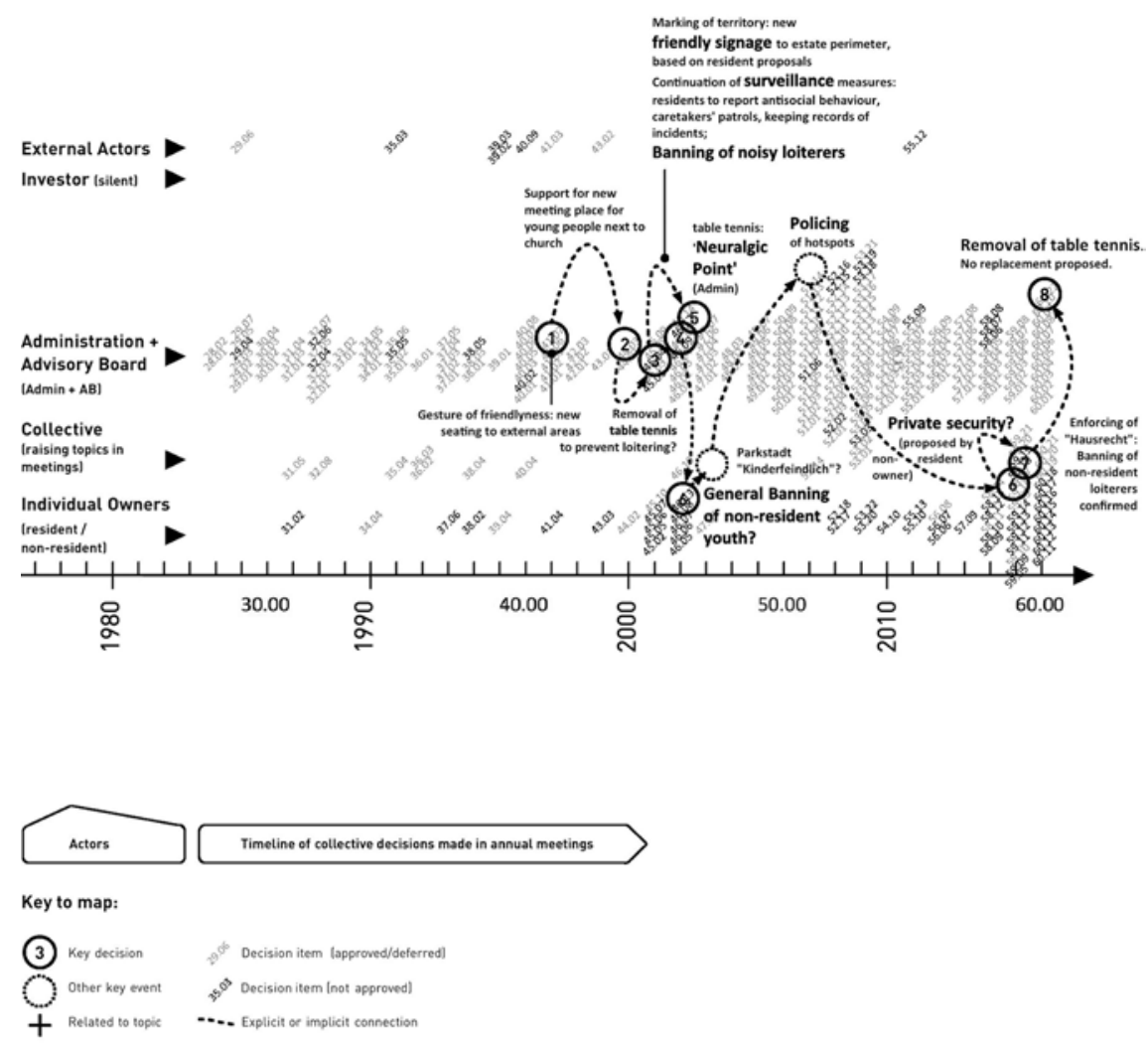

The concern "loitering" could be considered a specific aspect in the negotiated relationship between owners and young local users. The map shows that loitering has been a recurrent topic at the annual meetings. It involves external actors other than the groups of young people themselves, such as the local authority, a local sponsor, or the local police. The collective supported the sponsored construction of a small covered meeting place for young people opposite the primary school in Stuntzstraße in 2000. The general provision of seating, the upgrading of play equipment and the installation of welcoming signage along the perimeter of the estate were initiated as measures to improve the quality of outdoor spaces and encourage its use. However, in 2001, the first complaints about noise in the table tennis area next to the shopping centre were reported in the minutes. The proposal to remove the table tennis tables as a counter measure was discussed in the annual meeting, although it did not lead to a formal decision. Further reporting of noise nuisance and littering occurred in the following years, together with the discussion of measures like the banning of non-resident young people from the estate grounds, or increasing the level of surveillance. 
Figure 62: Sequence "ball games"

SEQUENCE "BALL GAMES" 1993 - 2010

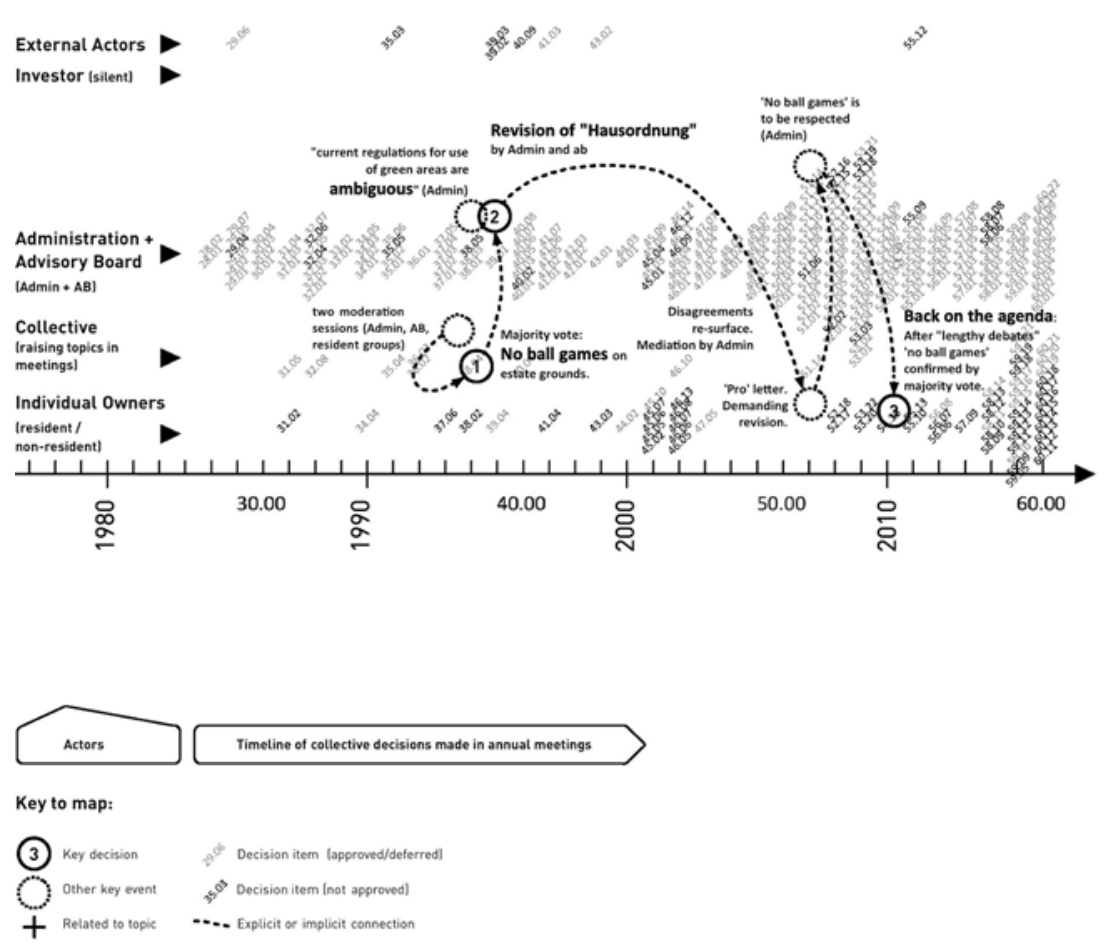

The proposal to introduce more restrictive measures has repeatedly led to controversy about the appropriateness, practicality, and the more fundamental question whether restrictive measures would be desirable. The most recent event in this sequence was the decision to finally remove the two table tennis tables. Their removal was argued to have become necessary because of the bad condition of the tables. Although no explicit connection to the issue of loitering had been made, it seems that in this way the problem of loitering, together with its more fundamental issues, was effectively redefined as a problem of maintenance. Replacing the tables was not discussed as an option. While in earlier debates the collective had struggled to agree on the removal of the table tennis tables in the sense of an explicit restrictive measure, it had no difficulties with their removal on grounds of maintenance. Hence, it seems that the argument on the grounds of maintenance may be used by actors to influence a controversial decision, or even achieve closure in a difficult dispute of an initially different concern. As indicated in the social worlds/arenas map, young local users are excluded from direct participation in the Parkstadt arena. We see that, although young residents and users are directly affected by the decisions taken in the arena, they had not been invited to participate directly, or submit their views in a statement. Accordingly, no opinions or 
Figure 63: Sequence "maintenance project"

SEQUENCE "MAINTENANCE PROJECT" 1985 - 2016
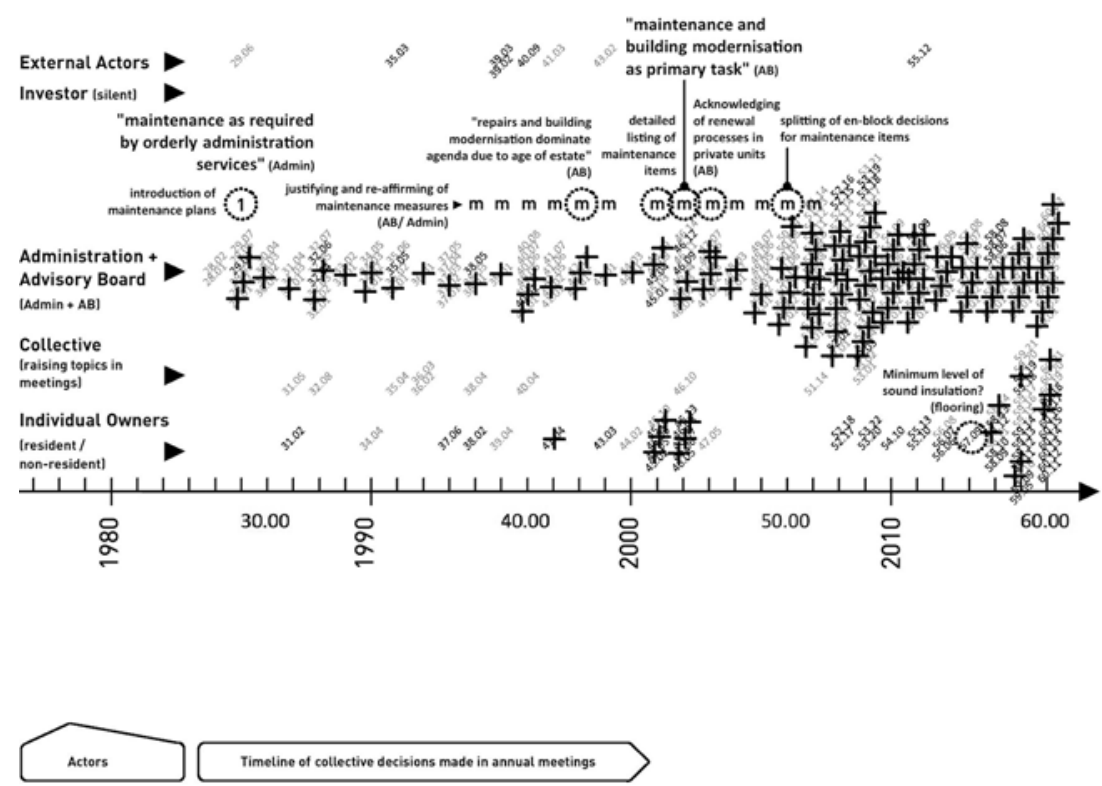

Timetine of collective decisions made in annual meetings

Key to map:
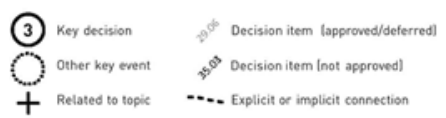

$m$ Justification of maintenance project
in reports of Admin/AB

reactions of young people regarding the issue of loitering are recorded in the minutes. The information in the minutes reflects the discourse and views of the owner residents, non-resident owners who act on behalf of their tenants, as well as the administration on the issue. The sequence "ball games" is characterised by a similar asymmetry in terms of its representation.

The "maintenance project" represents the decision-making process related to the maintenance of the buildings, infrastructures and open spaces on the estate. Maintenance (German 'Instandhaltung') is the technical means by which the existing is kept to a good standard through repair, renewal and piecemeal improvement. It has been a major common concern since the establishment of the commonhold-type entity in 1984. The pattern shows a significant increase in the number of decisions debated and taken (decisions related to maintenance are marked ' + ' in the diagram). The beginning of the increase seems to coincide with the estate's 50 $0^{\text {th }}$ anniversary in 2006.

It is preceded by a series of justifications and statements in favour of maintenance by the administration or the advisory board (marked ' $\mathrm{m}$ ' in the diagram). The increase is 
Figure 64: Sequence "intercom"

SEQUENCE "INTERCOM" 1985 - 2007

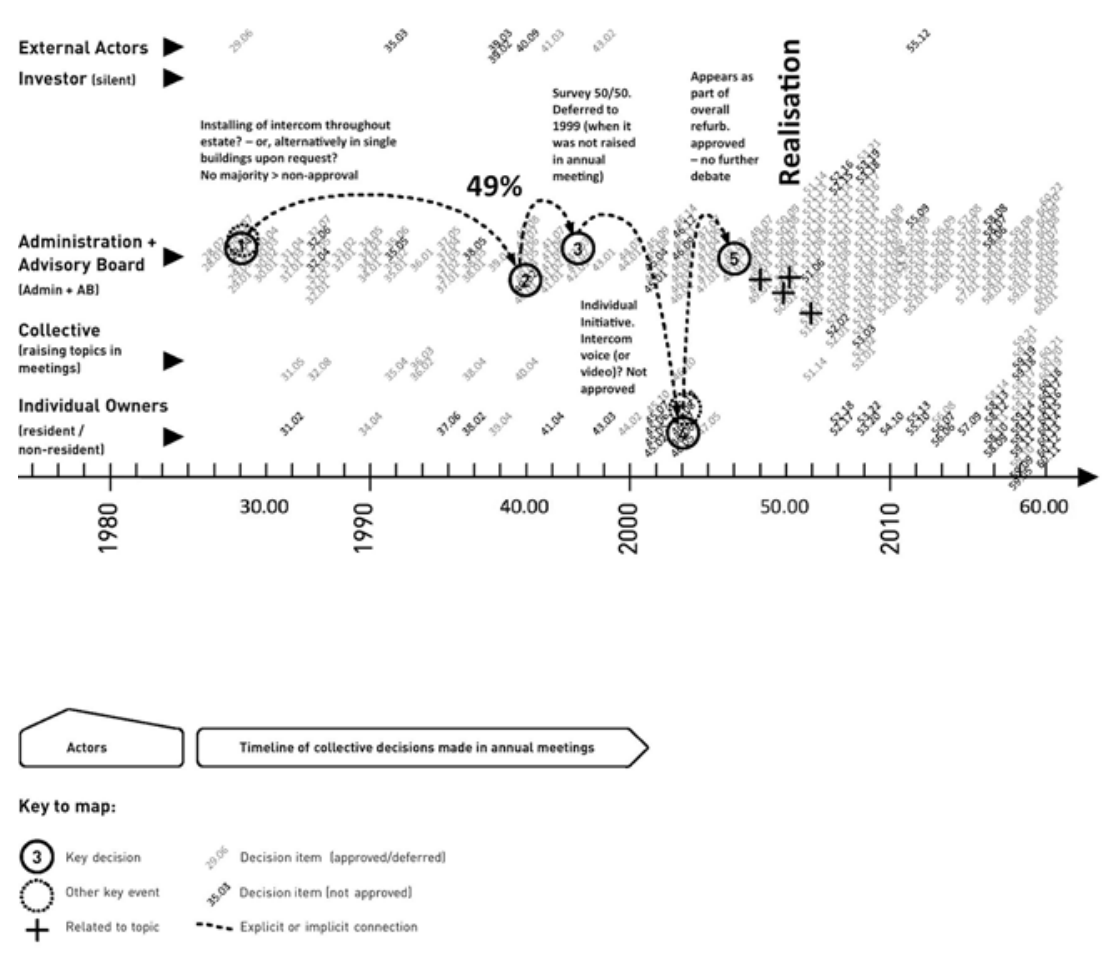

almost certainly influenced by the increasing age of the buildings and infrastructure, but as we have seen in the sequence about loitering, the argument based on maintenance may also be used to close a debate. Maintenance issues clearly outnumber other kinds of decisions. Since 2001, maintenance works have been listed in greater detail in the minutes. In 2006 the en-bloc voting over maintenance items was replaced by an item-per-item procedure. The duration of annual meetings increased accordingly. While up until 1989 it had been $\mathrm{hhr}$, it is reported to be more than $2.5 \mathrm{hrs}$ in 2003 and the following years. Today, maintenance is the single most important concern. It dominates the decision-making process in the Parkstadt arena.

The sequence "intercom" is a sub-concern within the general maintenance project and shows how long it may take for a seemingly straightforward proposal to be realised after being raised in the annual meeting. The first proposal to replace the original intercom system of 1956 was initiated by a resident in 1985. It was declined by majority vote. The topic resurfaced in the years 1996, 1998 and 2002 in different configurations, until a replacement was agreed upon in 2004 without major debate. The new system was installed during the following years. By 2007 , every unit had a new intercom. 
Figure 65: Sequence "silent investor"

\section{SEQUENCE "SILENT INVESTOR" 1989 - 2004}
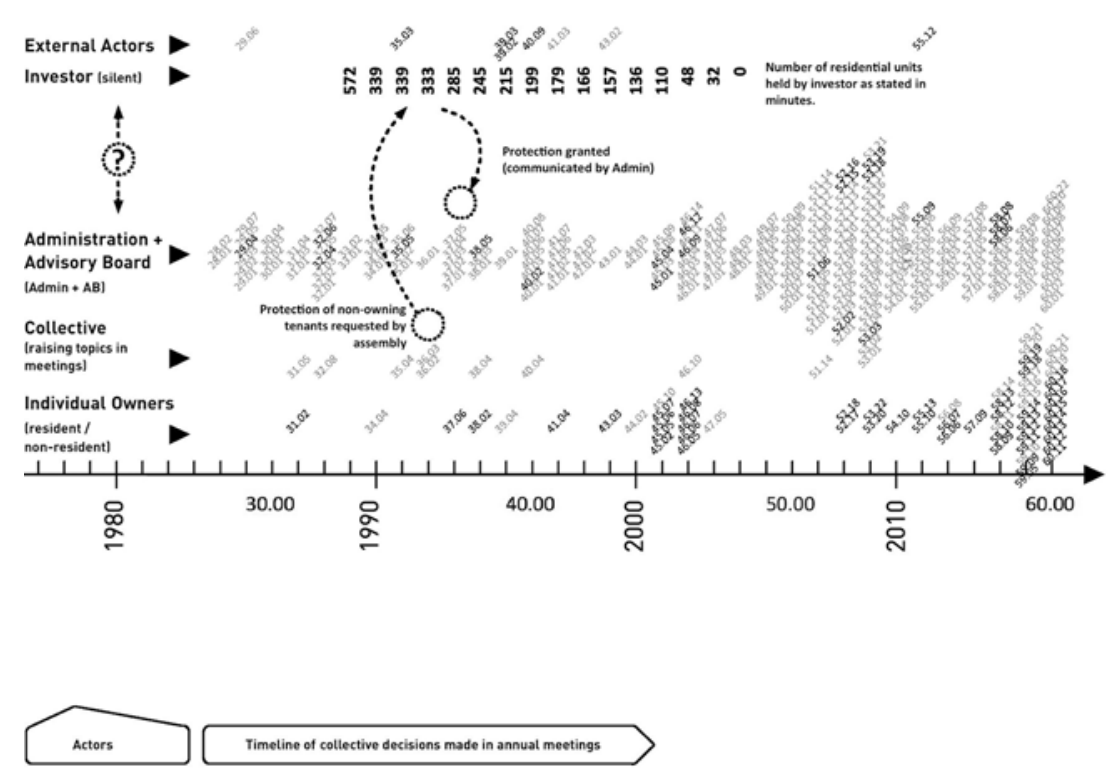

Timeline of collective decisions made in annual meetings

Key to map:

(3) Key decision

The sequence "silent investor" evolves around the few traces the investor left in the annual meeting minutes. This theme is different insofar as it accompanies the negotiation process rather than being its subject. The investor is at no point recorded as speaking subject or speaking organisation. In this respect, the records of the silent investor seem to mirror the preceding phase. For the years 1984 to 1990, when the NHB was the largest private owner in the commonhold-type entity according to WEG, the minutes provide no records as to NHB representatives as speaking subjects. There are, however, traces of NHB's and the investor's existence in the minutes. Between 1989 and 2003, the number of units held by NHB and the investor is provided on the first page. There is also the occasional information about the restructuring of the investor's organisation. In 1992, the assembly requested that the management of the Bayerische Städte- und Wohnungsbau $\mathrm{GmbH}$ be asked to grant to the tenants protected status. ${ }^{14}$ This was confirmed by the administration in the following year.

14 Following the sale of NHB and its remaining assets in the Parkstadt Bogenhausen, the tenants organised themselves in the tenant's association "Mietergemeinschaft Parkstadt" (MP) for the purpose of protecting their rights against potential threats from the investor or future landlords (Wittemer et 
The administration found itself confronted with an ambivalent situation when the commonhold-type entity according to the WEG was established in 1984. On the one hand, it was supposed to fulfil the duties of an administrator on behalf of all owners, while on the other hand, the administration was effectively controlled by the NHB. The situation did not change in principal when the control of the administration passed from the NHB to the single investor, Doblinger Unternehmensgruppe $\mathrm{GmbH}$ in 1990. For more than a decade the investor owned the largest single package of residential units in the estate.

This raises the question as to how the NHB, and later the single investor, exerted their influence on the decision-making process in the Parkstadt arena, or whether they had an interest in the process at all. For, as stated earlier, the overall number of residential units acquired by the Doblinger Unternehmensgruppe $\mathrm{GmbH}$ in 1990 from the NHB was in the region of 33,000 (Hupe 1990), while its asset in the housing estate was comparably small. In the absence of any records in the meeting minutes, we can only speculate. Did the administration exercise its influence on the decision-making process in such a way as to make the outcomes of the annual meetings acceptable to the NHB, and the investor? Did the administration feed the investor's interests directly into the process? Or did the NHB and later the investor simply have no reason to participate directly in the Parkstadt arena $?^{15}$ There is no evidence in the annual meeting minutes that the conflict of interest was seen as an issue in the arena. At least in the minutes, it was accepted as a 'given' beyond dispute or criticism. Hence, the sequence "silent investor" tells us something about the relationship between the NHB, the investor, and the Parkstadt arena, as well as the occasionally obscured distribution of power in the collective process.

al. 2006, pp.134f). The association obtained legal advice by the specialist lawyer and later major of Munich, Christian Ude (ibid.).

15 This proposition was raised in one of the interviews. 
Figure 66: Sequence "individual modifications"

SEQUENCE "INDIVIDUAL MODIFICATIONS" 1985 - 2016
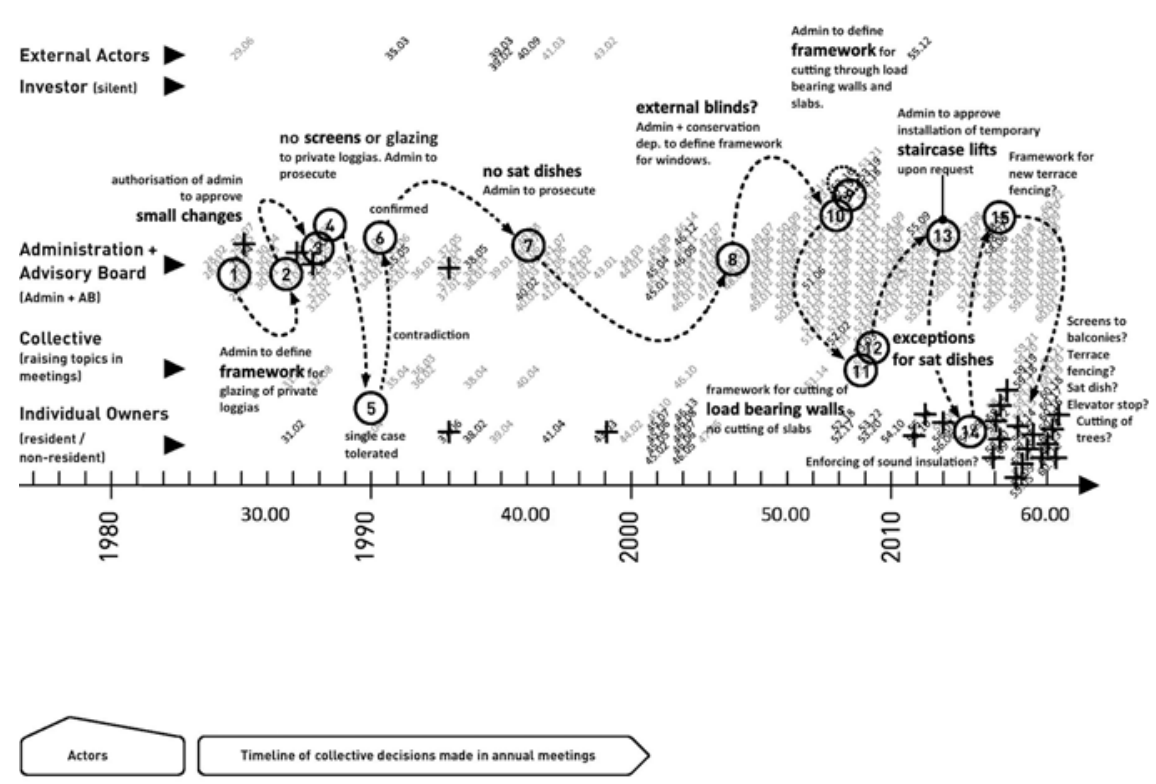

Timeline of collective decisions made in annual meetings

Key to map:

(3) Key decision 1 Decision item Iapproved/deterredl

The sequence "individual modifications" follows the struggle of individuals and groups to appropriate space and to achieve greater autonomy in decision making. In line with the federal WEG legislation, the collective confirmed in 1985 that it would not accept votes on building level in addition to the statutory estate level vote. The issue came up in connection with the intercom system. A similar instance occurred in 2001 in connection with electrical upgrading. This means that if the (owner) residents of a single building wish to make changes to 'their' building, they will have to wait for approval in the annual meeting. It does not matter whether the residents in the respective building were to cover the costs by themselves, or whether others are not directly affected. As a result, changes that are desired by the residents of a single building may take a long time, or may not be realised at all, because the co-owners on the estate have to grant their approval first. For example, the residents of a single building cannot choose the finishes of the external wall or the communal staircase independently. They cannot decide independently about the use and organisation of the open areas adjacent to the building, or choose to retain an existing front door, or have it replaced with a new one. 
Figure 67: Sequence "decision making"

\section{SEQUENCE "DECISION MAKING" 1985 - 2016}
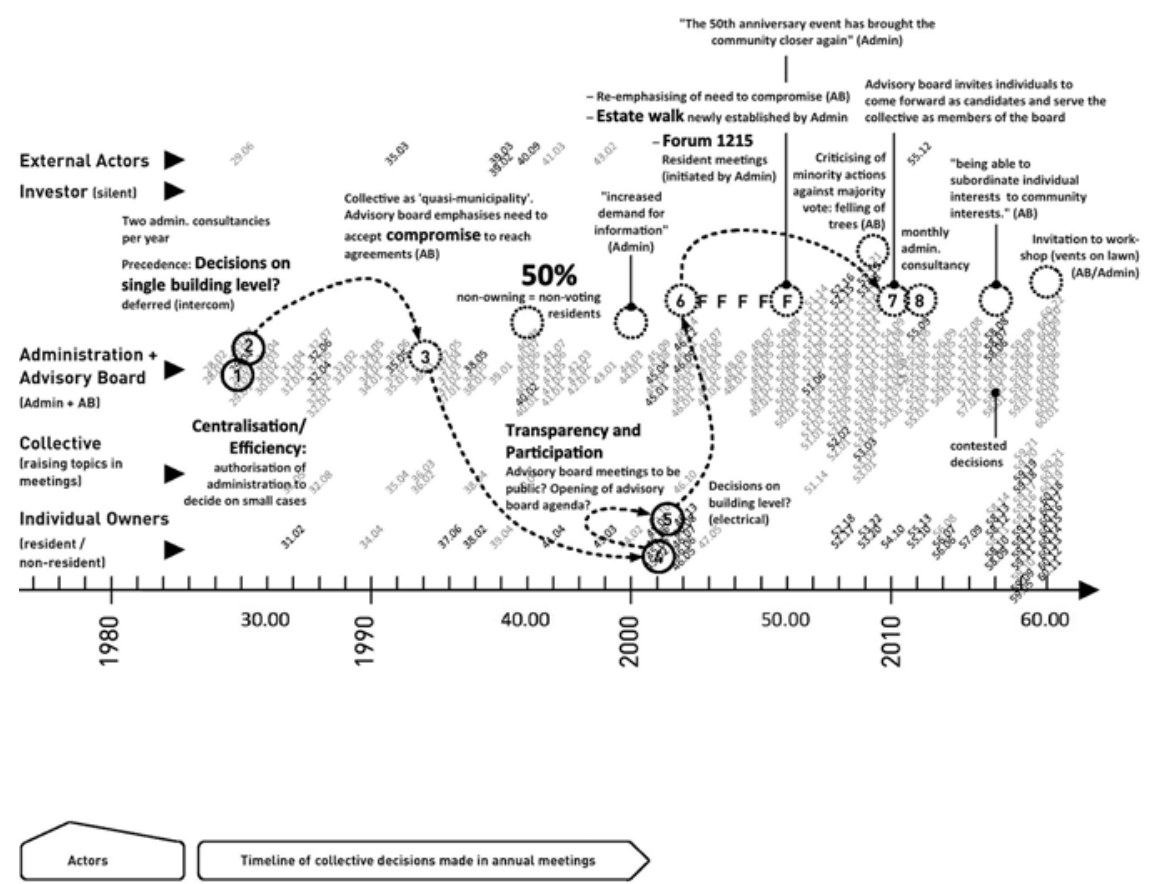

Timeline of collective decisions made in annual meetings

Key to map:

(3) Key decision 1 Decision item (approved/deferred)

It is not surprising then, that we find statements of discontent with the way decisions are made, side by side with self-affirmative justifications. The sequence "decision making" assembles instances of explicit and implicit moments of self-reflection, criticism, adjustments to the way information is circulated, and competing and contradictory interpretations of emerging situations. In 1992, the advisory board suggested that the WEG collective could be seen as a quasi-municipality given its size ("[...] die nach ihrer Größe schon eine politische Gemeinde sein könnte [...]", Wohnungseigentümergemeinschaft Parkstadt Bogenhausen 2016). Hence, eight years after the commonhold-type entity according to the WEG had been established, actors begin to explicitly articulate the potential power the collective holds. We find repeated comments as to the uniqueness of the collective in terms of the number of units and the size of the territory it controls (ibid.).

Throughout the timeline, we also find appeals by advisory board members and the administration to uphold a sense of community, accept compromise, and refrain from what they think would be selfish proposals. Statements of this kind seem to promote the view that WEG entities should be non-political in character and consensus-oriented. However, in 2001 an owner member brought forward the idea of opening up the advisory board meetings to all members of the collective, as well as granting them 
permission to raise agenda items in the advisory board meetings. The proposer argued that there should be more participation and transparency in the process. The request was declined by the advisory board with reference to existing WEG legislation, backed by the argument that final decisions are made in the annual meeting and that owners had the opportunity to directly speak with the board members. The administration added that owners who are interested in the work of the advisory board would be free to run for a position on the board. In the years 2013 and 2014, a series of decisions were legally contested by individual owners. This is a new phenomenon with the only other instance of this kind having occurred in 1996. For 1996, it is also recorded that the number of non-resident owners had passed the $50 \%$ threshold. Hence, while prior to the estate's privatisation in 1984, all residents had also been tenants, and during the 1990 most residents were owners, the composition of local residents has become more heterogeneous in terms of their ownership status.

\subsection{Triangulating by Adding a Quantitative Perspective}

I have discussed different qualitative mapping techniques together with their use in the case study analysis at various points in the previous chapters. In this chapter, I introduce a quantitative analytical perspective. It provides additional information about the process in the Parkstadt arena and adds further thickness to the interpretative base. In the chapter on methodology, I outlined that the kind of multi-site research pursued in this research project involves the use of multiple methods. Glaser and Strauss assert that

"Different kinds of data give the analyst different views or vantage points from which to understand a category and to develop its properties; [...] theoretical sampling for saturation of a category allows a multi-faceted investigation, in which there are no limits to the techniques of data collection." (Claser and Strauss 1967, p.65)

Multiple methods can be applied to all stages in the research process. Uwe Flick highlights the long tradition of using different methods simultaneously in ethnographic field work, by referring to the 1933 Marienthal study by Marie Jahoda, Paul Lazarsfeld and Hans Zeisel (Flick 2011, p.51). Assuming different perspectives is understood to enable the researcher to identify convergences and divergences in the data and in the interpretation (ibid., p.74). There are various ways to achieve this, for example by combining different methods within the same research perspective (ibid., pp.41ff), or by combining qualitative and quantitative data, methods, and results (ibid., pp.75ff). Using different methods for the purpose of approaching the phenomena under study from multiple perspectives is sometimes conceptualised as 'triangulation' in the social sciences. The term triangulation is borrowed from surveying, where a triangulation network of accurately measured points are generated to geometrically describe the earth's surface (ibid., p.11). In this method, a single point is repeatedly located by measurements, for example, with the assistance of a theodolite. Earlier approaches in the social sciences conceived triangulation as a means to ensure objectivity in research, to test hypotheses, and to verify the validity of statements (ibid., pp.17ff). However, it became apparent that in qualitative research there are no same units, as equivalents to points, that could be measured (ibid., pp.17, 20). For, the methods used to collect 
and interpret data inevitably always co-constitute the phenomenon under study in a specific way (ibid., p.17).

Newer approaches understand triangulation as a means of developing a richer and more profound knowledge of the phenomenon under study, without insisting on verification. Accordingly, the quantitative perspective as well as the other triangulating methods used in the case study analysis are not there to confirm the validity of the mappings, but to broaden and deepen the interpretative basis of the mapping analysis. Flick recommends that qualitative methods not be combined with quantitative data in such a way that the data is transformed into "quasi quantitative" (Flick 2011, p.88) data, because in this way it would loose its qualitative-situational context (ibid.). He observes that the full integration of a quantitative and qualitative approach is yet to be developed, for which reason they are currently combined as one after the other, one next to the other, or as one dominating the other (ibid., p.95). The approach pursued in the Parkstadt Bogenhausen case study is in this sense no exception.

The data for the quantitative enquiry is drawn from the list of coded and categorised annual meeting minutes ${ }^{16}$. The sample is identical with the sample used for the mappings, and comprises 284 decisions that are related to change. It covers a period of 33 years, beginning with the establishment of the commonhold-type collective in 1984, when the single ownership of the estate was converted into a dispersed form of ownership according to the WEG.

The first set of diagrams shows how the total number of change-related decisions adopted in the annual meetings is distributed among different actors/initiators according to value/size, respectively approval status. The categories value/size are based on the simple distinction small, medium, large (S, M, L), to which I have added a fourth category for items that are not priced, such as a change of estate rules. $S$ relates to costs up to $€ 50,000$, L to costs above $€ 500,000$, and $M$ for the interval between them. If a cost are not explicitly stated in the minutes, it is allocated on the basis of a cost estimate made by the author. As we can see in the first table, decisions dealing with issues that fall in the $\mathrm{S}, \mathrm{M}$ and 'not applicable' categories are almost equal in numbers, while the number of decisions dealing with large sums is significantly lower. Looking at the entire period, we could say that on average one single large item is negotiated almost every year.

Pertaining to the question of who raises topics, of who formulates the voting items about which the collective decides in the meeting, the figures suggest that individual owners have the majority in no category. The highest number of initiatives brought forward by individual owners are found in category $S$ (38), while the number is significantly lower in category $M$ (4), and almost non-existent in L (1). According to the meeting minutes, the NHB as well as the investor Doblinger Unternehmensgruppe $\mathrm{GmbH}$ have not authored any topics. As outlined above, I have named the mapping of the investor's process 'silent investor' to reflect this specific aspect in the process. The collective initiatives developed from within the annual meeting have an ad hoc character. They usually emerge as the outcome of debates. This distinguishes collectively

16 Sampling methods in which the sample for the triangulating method is taken from the sample of the first method is discussed as "verschränktes" (interlaced) sampling by Uwe Flick (Flick 2011, pp.101f) . 
Figure 68: Total number of decisions according to value/size of negotiated item and initiator. $S<€ 50,000 ; L>€ 500,000 ; M=$ interval in between.

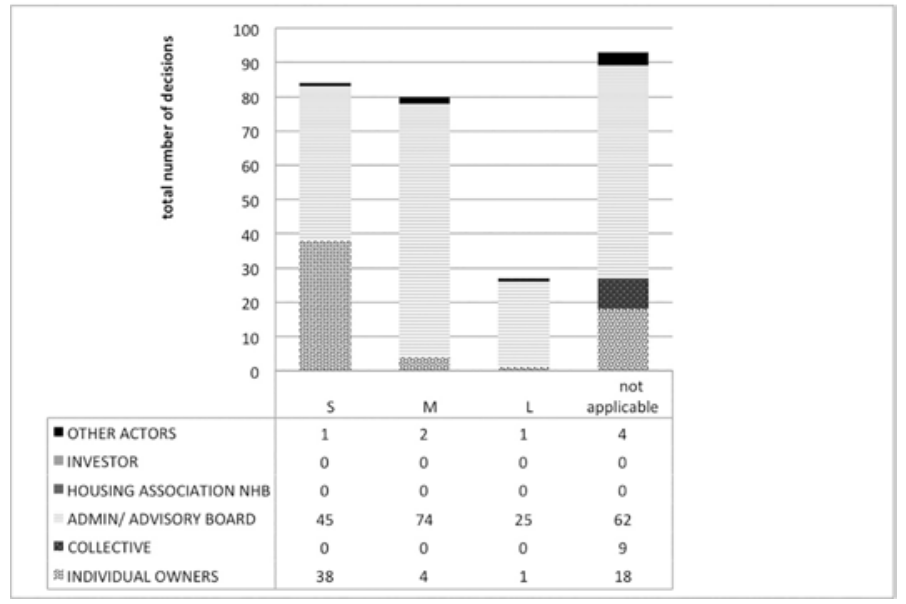

Figure 69: Total number of decisions according to approval status and initiator.

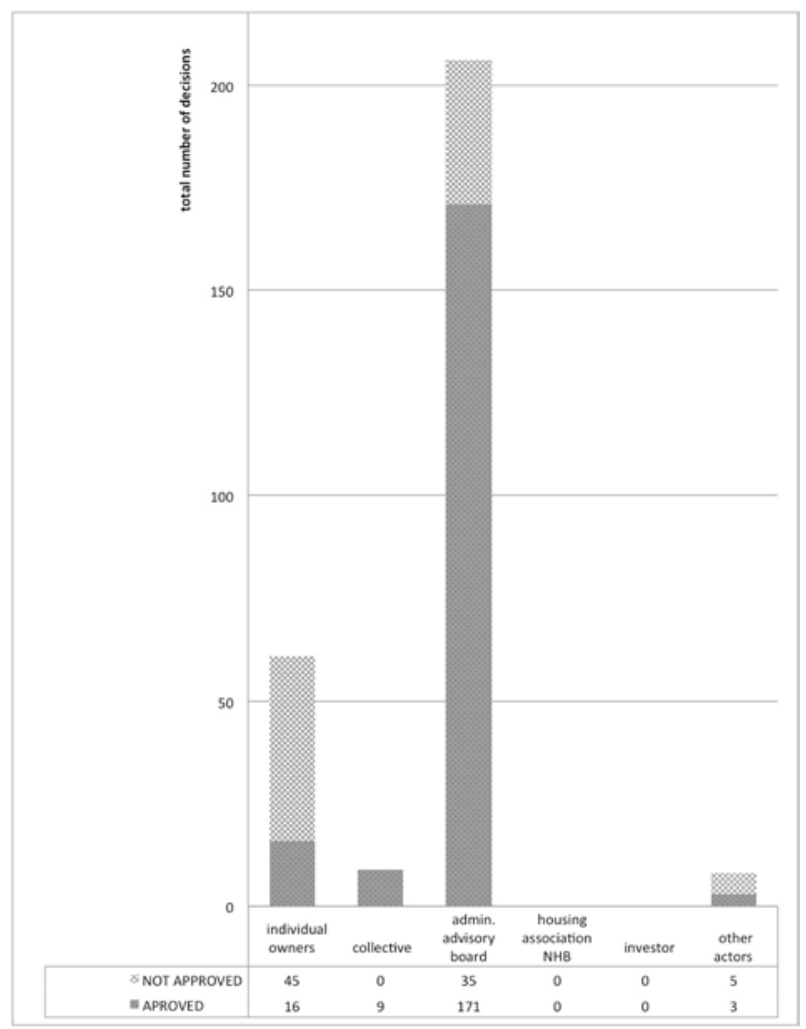


developed initiatives from the initiatives that are brought into the meeting by individuals or by the administration/advisory board. However, as collective processes include the actions of individuals, the distinction pertaining to whether a topic is raised by individuals, a group, or by the collective is not always entirely clear. The figures suggest that if the collective raises topics, they are likely to be related to issues in which the cost factor is not foregrounded, such as questions of management or estate rules ('Hausordnung'). Initiatives that involve larger sums seem to almost always pass through the administration/advisory board channel before they enter the annual meeting. Propositions brought forward by individuals only rarely involve medium or large sums.

If we relate the number of approvals/non approvals to the different groups of initiators, we see that all initiatives brought forward by the collective were approved (9), that the majority of initiatives brought forward by the administration/advisory board were approved (171 approved versus 35 not approved), but that the majority of issues raised by individuals were rejected (16 approved versus 45 not approved). However, despite the apparent likelihood of not receiving approval, individual proposals have risen in number during the recent past, which is shown in the overall timeline diagram and in the mapping of negotiated concerns.

The second set of diagrams concentrates on the decisions that achieved approval during the annual meeting. The first diagram relates the negotiated value/size to initiator, the second diagram the spatial unit affected by the decision to initiator, and the third the type of change to initiator. In the first diagram, we again have the distinction between small, medium, large $(S, M, L)$, plus a category for items that are not priced. The administration/ advisory board has raised the majority of decision items in each category. The imbalance between administration/advisory board and other actors, which we have identified in the corresponding diagram of the first set, is now further increased. We see that almost all approvals in the M, L and 'not applicable' categories relate to initiatives by the administration/advisory board. Topics raised by individual owners play a role in the S category, but we have to consider that only 12 out of a total of 38 proposals by individuals achieved approval. For the administration/advisory board, the ratio of 39 to 45 is much higher in the same category. If we compare the corresponding diagram of the first set and the second set, we see also that whenever the collective raised a new topic ad hoc during the annual meeting, it would result in a majority supporting the issue (9). However, these instances relate exclusively to issues that do not directly involve costs.

In the second diagram, we see that successful propositions brought forward by individual residents predominantly addressed either open spaces (10), or the alteration of single units (5), and in one instance the single building. Compared to the total number of 61 topics raised by individual residents, the success rate of 16 in the three relevant categories is very low. The larger part of proposals by individuals to make alterations to single units were not approved. We can also see that the overall number of approved decisions in the category of single units is very low in comparison to the issues related 
Figure 70: Number of approved decisions according to value/ size of negotiated item and initiator.

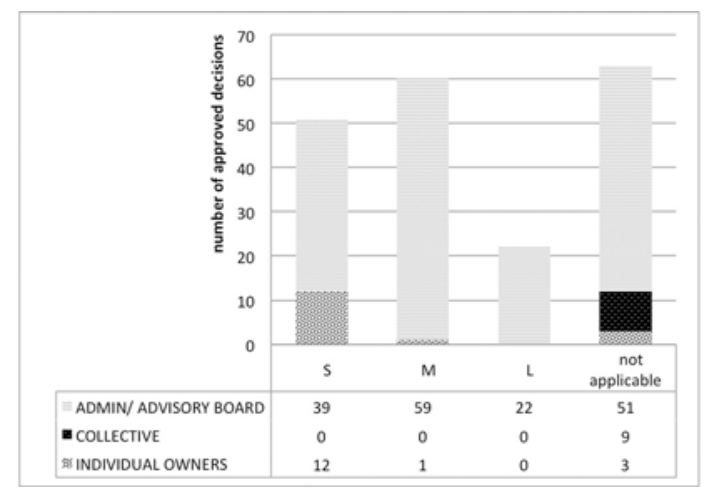

Figure 71: Number of approved decisions according to spatial category and initiator.

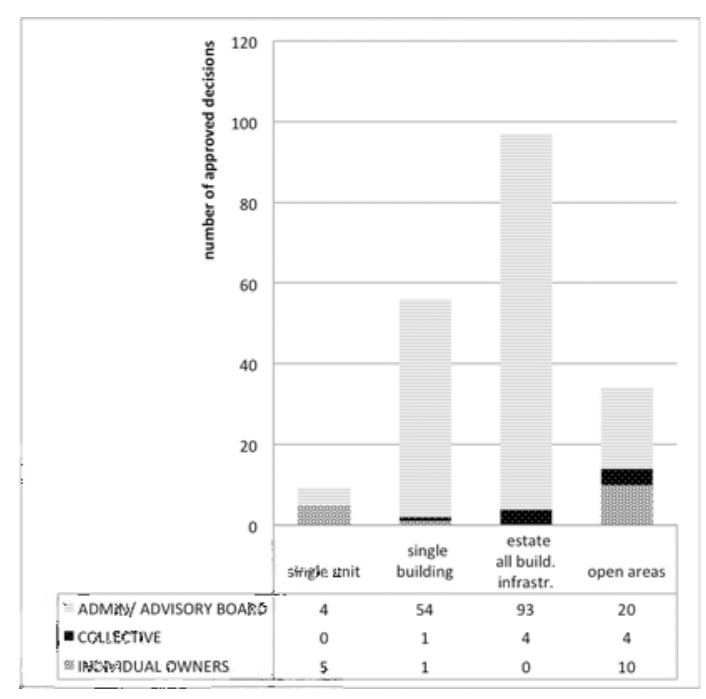

to single buildings, or to the overall estate and its infrastructure. However, as we shall see further below, it is exactly in this category where modifications and changes occur in the estate, despite the many non-approvals. Looking at the approved topics raised by the collective, we see that they are evenly distributed between open areas (4) and the overall estate or its infrastructure (4), with only 1 item addressing a single building.

Finally, the diagram on types of change confirms the dominance of the maintenance project, which in turn is dominated by the administration/advisory board. 114 of a total of 119 approved decisions in this category were raised by the administration/ 
Figure 72: Number of approved decisions according to type of change and initiator

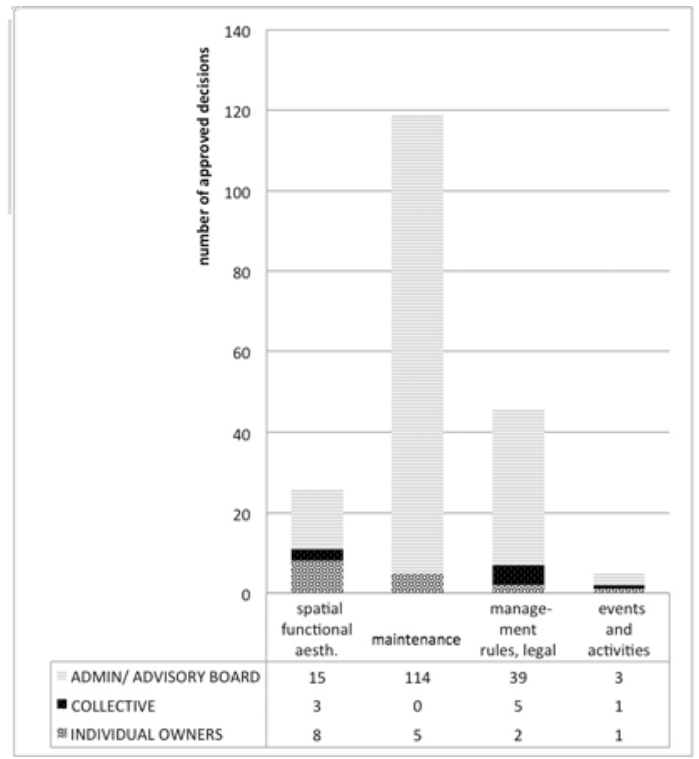

advisory board. The management/rules category is smaller in terms of numbers, but it is dominated by the administration/advisory board in a similar way. Only the spatial/functional/aesthetic category as well as the events and activities category are more evenly mixed.

\subsection{Triangulating by Adding Contextual Data from the Field}

In line with the multiple-methods approach, data from participant observations and expert interviews are used to further substantiate, contextualise, and triangulate the coded data of the meeting minutes, and to critically re-examine the information that I have assembled in the mappings. The data was generated in parallel to the mappings. Living in the field of study provides ample opportunity for making observations and engaging in interaction. Of the countless local conversations I had during the last few years of living in the estate, many were implicitly or explicitly related to the neighbourhood, to life on the housing estate, and to local issues. They accumulated, over time and together with other local information, into a personal 'image' of the research field. This image gave rise to the sense that the Parkstadt Bogenhausen housing estate is somehow different and that in terms of theory, there did not seem to be an architectural and urban concept that accurately described the situation. Ethnographically generated data is indispensable for the understanding of spatial practices, for it is in the field that spatial practices become effective and do their work.

The approach to the case study takes the special condition of being a permanent resident on the housing estate into account. On the one hand, the proximity is used in generating data through direct interactions with and in the field; on the other hand, it is balanced through working with archived and other text-based material, which 
establishes a certain distance. Living in the field means that personal everyday interactions and tacit knowledge tend to intermingle with critical reflection and observation.

The annual meeting of the 'Wohnungseigentümergemeinschaft' became a regular site for making participant observations. Its course follows a predefined routine. A few weeks prior to the annual meeting the invitation is sent to all owners together with the meeting agenda. The agenda lists the topics and questions that are to be discussed, as well as the decisions that need to be made. In this sense, it defines the standard and the kind of topics and questions that are considered legitimate for the meeting. The annual meeting is held in a large function room on the first floor in of one Munich's beer halls. It holds several hundred people. The way the space is organised during the meeting reflects the roles assigned to, or chosen by each participant. Through the agenda, routine and spatial arrangement, procedures are pre-structured and hierarchies reproduced. Owners present their invitations to members of the administration in the foyer, where they sign the attendance lists and are handed voting cards for the meeting. The meeting is chaired by the head administrator, who usually takes his or her seat at the centre of a podium. A long conference table runs across the full length of the podium, seating representatives of the head administration, local administration and advisory board. The function room is furnished with long rows of tables and chairs. If required, a screen is used to communicate figures, technical issues, or other visual content. Participants on the podium share several microphones among them. There is a single floor-standing microphone placed at the centre of the function room for all other participants. Participants usually have a drink or a meal during the meeting. The overall atmosphere is unexcited and focussed. Participants are conscious of the long-standing cooperation between administration, advisory board and owners.

During the meetings, large annual budgets are routinely negotiated. The expenditure of large sums on regular maintenance items are approved within a few minutes. The maintenance project rarely gives rise to controversy. Small scale interventions, in particular if they are related to the interests of individuals more than to the collective, tend to be discussed with disproportionate rigour and allocation of time. Having said that, discussions in the sense of many individuals making contributions to a single issue are the exception.

The meeting minutes play a key role in the institutionalisation of negotiated outcomes. They convert that which is said and agreed upon into 'matters of fact'. Through participating in the meetings it became clear that the meeting minutes, although directly related to the events taking place during the meeting, have to be treated as a separate category. They are not mere abstractions of the meeting, or condensed representations of it. They cannot be understood in isolation from the situation in which they are generated.

The many practices and daily activities in the housing estate provided a rich empirical basis for making further observations. Comparative observations showed that residents develop individual practices to generate external spaces that are meaningful to them. This is most evidently the case in the use and spatial arrangement of ground 
Figure 73: Annual meeting of the 'Wohnungseigentümergemeinschaft', half an hour prior to the scheduled beginning, Munich 2016

Figure 74: Shortly after the meeting. The podium can be seen at the far end of the meeting hall, where participants engage in face-to-face conversation, Munich 2016
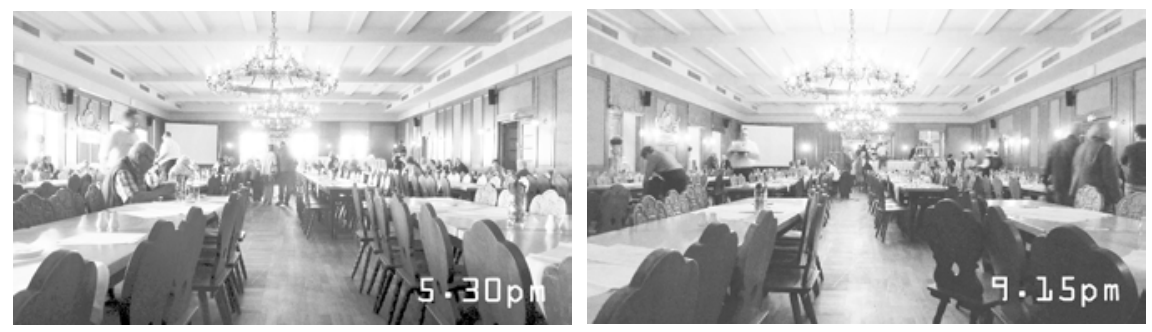

floor terraces. Balconies provide less opportunities, but nevertheless are also appropriated in different ways. Other small situations of appropriation are observable in converted garages. Some are used as storage spaces or for hobbies like servicing motorbikes. Ephemeral spatial situations of appropriation are established when groups gather in the open without making physical changes to the environment. Not all forms of appropriation seem to be compatible with the estate rules, or the sense of order implemented by the administration and the team of caretakers and gardeners. However, they are tolerated or ignored, at least for some time, until the administration or neighbours take action. Local shopping, walks in the style of the urban 'flâneur', or visits to community events offered insights into the many things residents do locally and how they interact in places of the everyday. In this part of my ethnographic work, I produced field notes and photographic records.

Interviews provided a major source of data from the field. For practical reasons I have limited the number of interviews and interview-like conversations to 12 . Interviewees included members of the advisory board, local administration, head administration, and local residents. The interviews and conversations took place at various locations, including offices, private apartments and open spaces. The participants are considered experts in the situation. The interviews and interview-like conversations added thickness to the analysis, which proved useful in particular for the understanding and interpretation of the mapped processes. The interview sessions had a typical duration of 1-2 hours and followed a set of questions which I had prepared for each session individually in the style of semi-structured interviews ('Leitfadeninterview'). The session started with a brief outline of the research project. The first question invited the interview partner to describe his or her work in the field. This was followed by questions about the situation on the estate, about relations in the Parkstadt arena, and about conditions of change. Records of the conversation were kept by taking notes during the interview session, which at times involved the interviewees in the clarification of intended meanings. The main content of the interview and details about the situation were typed up immediately after the interview. Some participants took up the offer to comment on the text generated from the interview and to propose amendments. This gave me the opportunity to have a second meeting and to ask follow-up questions. The interview-like conversations evolved more spontaneously and were generally shorter. They were recorded in similar ways. The semi-structured inter- 
views and interview-like conversations provided information about the collective process, they contributed towards the concept-building of the Redundant City, and they resulted in adjustments to the mapping of the Parkstadt arena.

Finally, the $50^{\text {th }}$ anniversary edited volume by historian Roland Krack provided ethnographic data about different aspects of everyday life on the estate along with local history and architectural information (Krack 2006). Many individuals contributed personal stories, private pictures of family situations on the estate, or other data, like adverts or newspaper articles. The publication has the character of what anthropologist Clifford Geertz conceptualises as "thick description" of the field (Geertz 1973, p.10). Covering a timeframe of fifty years, the publication provides a richly illustrated record of continuity and change on the housing estate. In this respect, the $50^{\text {th }}$ anniversary publication was also a useful companion to the socio-spatial study "Stadt am Stadtrand" of 1969 (Zapf, Heil and Rudolph 1969).

\section{Comparative View of Other Situations of Change in Munich}

\subsection{Munich's Housing Crisis and Long-Term Residential Development Plan}

Having focused in detail on the collective process in the Parkstadt Bogenhausen housing estate in Munich, I now propose to extend the field of enquiry. In the following spatial analysis, I compare the situation on the housing estate to other sites and conditions in Munich. The goal of the comparative view is to develop a contextualised understanding of the process in the Parkstadt arena.

As part of my conclusion, I find that the spatial dynamics of Parkstadt Bogenhausen housing estate are unique in the sense that, firstly, it does not participate in general processes of transformative growth and densification in Munich; secondly, it does not participate in the specific restructuring process which is characteristic of many other housing estates in the city; and thirdly, it is located in an area that is otherwise characterised by multiple building activities and instances of spatially effective urban change. In the spatial analysis, I refer to basic statistical data provided by the authorities, to information about ongoing building projects in Munich, and to my previous analysis of the Parkstadt Bogenhausen housing estate. I use photographically recorded data to illustrate and substantiate the argument.

Munich is growing. The city experienced a significant increase in population during the first half of the $20^{\text {th }}$ century. This was followed by a phase of stagnation in the wake of the Olympic games in 1972, when growth was diverted to suburban areas in the metropolitan region ${ }^{17}$. The city resumed growth in 2000 , which continues up to the present (Landeshauptstadt München 2015a, pp.12f). In 2013, the city had a population of

17 Analysts refer to this area as „Planungsregion München“, or „Region 14“. It comprises Munich and 8 administrative districts bordering Munich (Landeshauptstadt München 2015a, p.9). 
Figure 75: Parkstadt Bogenhausen, private garden arrangement, facing the broad communal lawn, Munich 2018

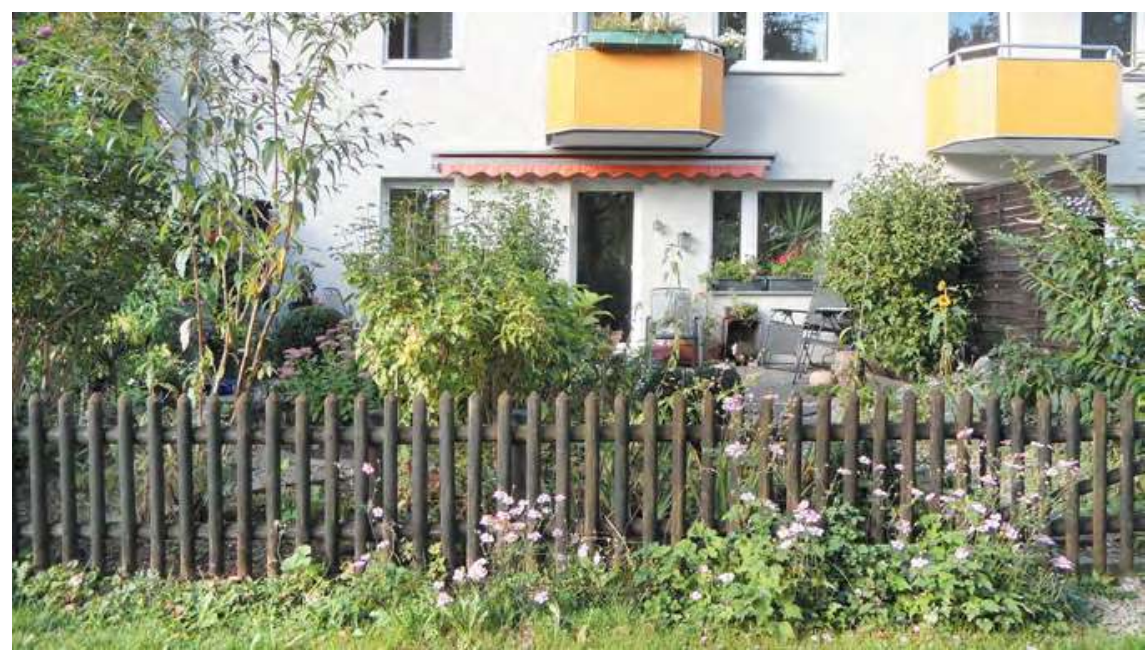

1,493,000 (ibid., p.9). The metropolitan region comprising Munich and its eight bordering administrative districts had a population of $2,460,000$ (ibid.). Analysts expect the city's population to increase by 230,000 inhabitants in the period from 2013 to 2030 , which is equal to $15.4 \%$ in growth and amounts to an overall population of $1,723,000$ (ibid., p.47). The city and the metropolitan region are confronted with a growing demand for new housing, educational facilities, infrastructure, and commercial space. Rates of housing production do not keep up with actual demand, resulting in a housing crisis and the highest rents and property prices in Germany (Landeshauptstadt München 2016b, pp.70, 82). The crisis is further fuelled by changing socioeconomic parameters and the current incentives to invest global capital in urban property (ibid., pp.70ff; Trapp 2018).

The city administration has developed a long-term residential development plan "LaSie" ("Langfristige Siedlungsentwicklung"), as a response to the crisis (Landeshauptstadt München 2011). The plan is aligned with the strategic development plan "Perspektive München", which was adopted in 1998. The current version of the LaSie plan defines three main processes through which new housing is provided (emphasis added, Landeshauptstadt München 2016a, pp.20ff):

\section{Densification of}

a. existing housing estates and low-density developments of the post-war era ("Nachverdichtung von Wohnbausiedlungen einheitlicher Prägung")

b. suburban areas, by means of private initiatives and piecemeal process

2. Conversion of formerly non-residential areas to residential and mixed-use areas

3. Medium and large-scale urban developments on greenfield sites in peripheral areas 
The capacity to construct new housing in the short and long term is estimated to be 61,200 units between 2015 and 2035 (ibid., p.22), which indicates that the crisis is likely to continue. Of particular interest in relation to our case study is the densification of existing housing estates as defined in category ra.

In 2009, the authorities commissioned a series of studies on the development potential of different urban situations (Landeshauptstadt München 2009), which subsequently informed the LaSie long-term residential development plan (Landeshauptstadt München 2011). In the study on qualified densification ("Qualifizierte Verdichtung"), different spatial strategies of densification are tested in a series of models and scenarios (ibid., pp.12-21) ${ }^{18}$. The study shows the kind of morphologies that may be produced through processes of spatial densification for uniformly structured housing estates ("einheitlich strukturierte Wohnsiedlungen", ibid., p.21), low-density residential areas, and mixed-use higher density areas in central locations. It suggests that high quality urban environments may be created in all three processes if a series of critical issues are addressed, including the upgrading of infrastructure, paying attention to open space, questions of mobility or renewable energy, and questions of ownership (ibid.). In terms of time scale, the study concludes by proposing that uniformly structured housing estates in single ownership are more suitable to short-term densification projects than low-density and mixed-use areas, which, according to the study, may unfold their development potential more easily in the long term (ibid.). It is indicative of the authorities' approach that uniformly structured housing estates that are in dispersed ownership are excluded from the LaSie residential development plan as if this was self-evident (ibid.; Landeshauptstadt München 2016a, pp.19f; 2016b, p.21).

In the following analysis, I seek to show that different processes of densification, urban renewal and restructuring occur in the local area around Parkstadt Bogenhausen. They include the categories mentioned in the 2009 study. We also see that their spatial impact, and therefore the visibility of urban change, is much stronger in comparison to the spatial impact of changes in the housing estate.

\subsection{Spatial and Structural Transformations in the Local Area}

In the areas adjacent to the Parkstadt Bogenhausen housing estate, spatial and structural transformations occur on multiple sites and define different urban situations. They are connected to processes that operate on different scales, while having a significant impact on the spatiality of the local context. In the analysis, I focus on a series of projects in the proximity, without claiming to cover all spatial and structural changes. The idea is to show the diversity of phenomena involved, including differences in intensity, scale, and transformative speed.

18 Contributors (according to imprint): TUM | Lehrstuhl für Integriertes Bauen, Prof. Dietrich Fink; Fink+]ocher, Architekten und Stadtplaner; steidle architekten, Architekten und Stadtplaner, Johann Spengler; mahl.gebhard.konzepte, Landschaftsarchitekten und Stadtplaner, Andrea Gebhard; consultants: TUM | Lehrstuhl für Bauklimatik und Haustechnik, Univ.-Prof. Dr.-Ing. Gerhard Hausladen; Clock Liphart Probst \& Partner, Rechtsanwälte, Rudolf Häusler; Planungsbüro, Dipl.-Ing. Michael Angelsberger; Verkehrsplanung und Städtebau, Michael Angelsberger. (Landeshauptstadt München 2011, pp.12-21) 
Figure 76: Location of Parkstadt Bogenhausen housing estate and adjacent areas, Munich 2015. Map adapted from https:/geoportal.bayern.de/geoportalbayern/

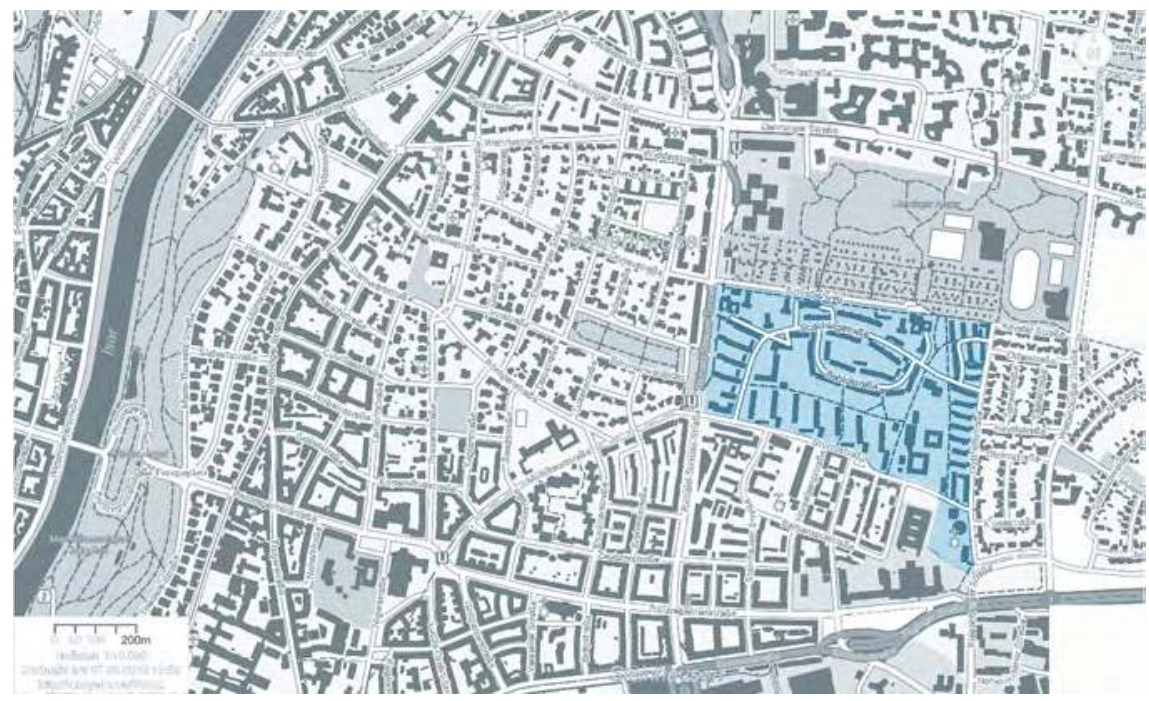

The by far largest transformation during the past few years was brought to the local area by the tunnelling of the "Mittlerer Ring" ring road. The ring road was designed and realised during the second half of the $20^{\text {th }}$ century as part of the general reorganisation and optimisation of the city for automobile mobility. Rising levels of traffic, congestion, and pollution were taken as arguments in a debate to improve the ring road, which resulted in a public referendum ("Bürgerentscheid") in 1996 in favour of three tunnel projects at different locations - at that time against the majority in the city council. The ring road is named Richard-Strauss-Straße in the area of our analysis and defines the western boundary of the estate. The tunnel system in this section of the ring road was constructed between 2003 and 2009 , at an overall cost of around $€ 321 \mathrm{~m}$. The tunnel project extends over $2.7 \mathrm{~km}$, where the tunnels have an overall length of approximately $2.0 \mathrm{~km}$ (Krack 2006, pp.130f). The project improved the environmental quality in the area, which in turn led to the upgrading of buildings and open spaces in the proximity, but also to rising property prices and rents. Special infill-housing was added to an existing housing estate next to the northern tunnel approach, which I discuss in the following section.

The area to the north of the housing estate is occupied by Denninger Anger green, beyond which Arabella Park was constructed as an urban sub-centre ("Stadtteilzentrum") between the 1970s and 1990s (Krack 2006, pp.30f). The U4 underground line has had its terminus here since 1988 (ibid., pp.128f) and links with buses and a tram line. The sub-centre accommodates corporate headquarters, large hotels, health services, shopping facilities, residential uses, as well as the local library and a farmers market. A phase of redevelopment and modernisation is currently under way. The new Arabesca office building replaced an existing 12 storey structure; the listed landmark HVB tower of Hypo-Real Estate, designed by the architect Bea and Walther Betz and completed in 1981 (ibid., p.31), received a complete overhaul together with a new façade; 
the existing BayWa tower received a similar treatment and an extension; finally, a new shopping centre at the junction of Richard-Strauss-Straße with Denninger Straße opened in 2009.

Further large scale urban restructuring occurred in the mixed-use area towards the south of the housing estate. A new urban gateway ensemble is currently being constructed around the Vogelweideplatz. Designed by Enrique Sobejano and Fuensanta Nieto on the basis of their winning competition entry in 2009, the scheme comprises 5 tower buildings of different sizes. Other projects in the area include the Einstein shopping centre, which was completed in 2009; the current development of former railway land right next to the centre; and several replacements of existing higher density multi-storey buildings in the same area.

In Zaubzerstraße towards the south-west, a 1970s commercial building is currently being replaced to make way for higher densities and more intensified uses. The concrete structure defined the southern edge of a mixed-use development of the same period, comprising residential uses and offices.

A different form of local transformation has occurred through the replacement of single family homes with larger multi-occupancy buildings. This process prevails in the lower density residential areas towards the west and east of the housing estate. It is regulated by the federal building law $\$ 34$ BauGB and has resulted in piecemeal densification and upgrading, but with an at times significant impact on the local setting. In some cases, the density on a single plot has more than tripled. Newly built homes in the western area yield some of the highest prices for residential property in Munich. The growing number of residents in the area has increased the demand for child-care and educational facilities. The local primary school on Stuntzstraße and the secondary school Hausenstein Gymnasium have both been enlarged during the last few years. Besides the apparent and clearly visible kinds of changes are many others that are more subtle in terms of their spatial impact and legibility.

During the year 2016 a vacant office block, formerly used by Siemens, was converted to a temporary home for refugees. The Denninger Anger green was made more durable by means of paving or renewing the footpaths and cycle tracks in the park during 2016. The allotment association bordering the housing estate to the north has now started to subdivide existing garden plots. The significance is small in terms of its contribution to local change, but the full bearing of it may be better understood if we take into consideration that no routine subdivisions occurred since the association was established in 1932.

Summing up, it is apparent that the local area is a site of multiple changes and of significant building activities. We see different types of projects that result in different spatial and structural changes, ranging from small scale building activities on single home plots, to interventions within densely built-up areas, to large infrastructure projects, and finally to corporate activities that are connected to the global scale. We are not looking at isolated events, but at continuous and clearly visible processes of urban restructuring, creative destruction, upgrading, accumulation and densification. 
Figure 77: Demolition of a 1960s office building in Stuntzstraße/ Hörselbergstraße, directly to the south of the housing estate. The new development was completed in 2017 and is mainly residential, Munich 2015

Figure 78: Demolition works of a 1970s structure near Parkstadt Bogenhausen. The building accommodated a local supermarket and services, Zaubzerstraße, Munich 2017
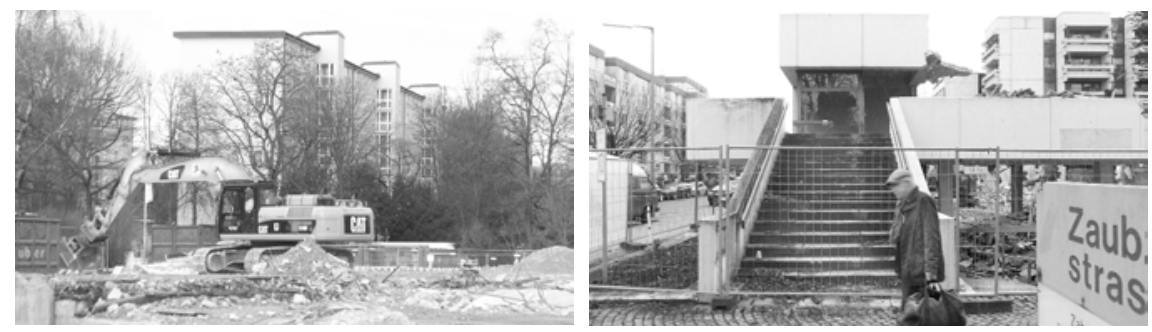

\subsection{Observing Change in other Housing Estates in Munich}

In the second comparative analysis, I place the focus on housing schemes in Munich that are similar to Parkstadt Bogenhausen housing estate in terms of typology, urban morphology, and period of construction. Some of them are located in the proximity, others are further away. The aim of this analytical step is to support the view that Parkstadt Bogenhausen's specific transformative process is not primarily the product of its architectural properties. However, as we are looking at single cases that are all unique in their own ways, there are limits to the generalisations, which means that I treat the findings as a tendency rather than as a proof.

Housing schemes dating from the late 1950 s and 1960 s may be encountered at any location in Munich, including the historic centre. As the city developed in a more or less concentric form up to the 1960s, the larger housing schemes of this period are concentrated in a belt that encircles the city core at a certain distance. Many of the schemes of this period are located in the proximity of the Mittlerer Ring ring road, as mentioned above, or near the radial traffic arteries that connect the centre with the metropolitan region. The densification policy of the city and other goals, like improved sound insulation of buildings next to heavy traffic roads, has brought a series of current restructuring projects on the way. Projects are entitled to funding by the "Wohnen am Ring” funding scheme (Landeshauptstadt München 2017, p.18). It ensures, among other things, that standard architectural competitions are part of the procurement process, as well as special competitions like EUROPAN 12. The neighbourhoods along the south-eastern segment of the ring road have participated in the urban restructuring programme 'Soziale Stadt' since 2007, which integrates different measures to improve community services and social infrastructure, as well as the local economy and built environment (Landeshauptstadt München 2017). As information on these projects is widely available, I restrict myself to the brief description of four exemplary projects. 
1. Housing estate Amberger Straße: infill development between existing residential blocks, lining the northern tunnel approach of Richard-Strauss-Straße (Mittlerer Ring). Winning competition entry by Léon Wohlhage Wernick 2005, completed in 2009. Client Bayerische Versorgungskammer/Versicherungskammer Bayern (Léonwohlhage Gesellschaft von Architekten mbH 2009).

2. Piusplatz urban renewal scheme: upgrading, densification and diversification through architectural reconfiguration and refurbishment, addition of new buildings, new social infrastructure, improved connectivity and open areas. 03Architekten, commencement of construction 2017 (Landeshauptstadt München 2017, pp.14ff). Owned and managed by GEWOFAG.

3. Housing estate Badgasteiner Straße in Sendling-Westpark: densification and diversification of existing 1950 s housing through constructing new offices for the local estate administration, new façades and roof top extensions to existing buildings. Kaufmann. Lichtblau Architekten, München, Schwarzach, completed in 2012. Owned and managed by GWG München (GWG München 2016).

4. Siemensstadt München: addition of a new, 17 storey residential tower by Steidle Architekten, completed in 2007, following a competition win in 1994 and a law suit initiated by local residents. All existing residential buildings in the estate dating from 1954 are listed as single buildings. The listing entry explicitly acknowledges the high quality of the overall urban layout of the estate. The integration of the tower by Steidle Architekten serves as an example of how new structures may be successfully added to existing ensembles or ensemble-like building arrangements. Client SWG Siemens Wohnungsgesellschaft (Holl 2007).

The list of renewal and improvement schemes of and around housing estates could be greatly extended. Based on the above and other examples, it seems that we have to revise an assumption that prevails in the criticisms of modernism and tight-fit functionalism - that because of the difficulty in changing, modernist housing cannot change. The architecture-centric myth of Pruitt-Igoe is exemplary of a simplifying kind of criticism which claims that resistance to change and other complex problems would disappear if the architecture was different. The above references and examples demonstrate that there is an ongoing process of reconfiguration and restructuring of housing estates dating from the 1950 s and 1960s in the Munich region, where adaptations are shown to be possible in multiple ways. From this perspective, it is difficult to maintain the view that resistance to change is principally a function of architectural properties. Despite the inevitable difficulties that come with changes to the built environment, we observe that residents, housing associations, professionals and authorities are prepared and capable of taking up the challenge to modify functionalist structures so that they continue to contribute to the quality of life in the city. We cannot, therefore, claim that the specific pattern of change in the Parkstadt Bogenhausen housing estate is primarily the product of tight-fit functionalism and other potentially inhibiting architectural properties. 
Figure 79: GWG housing estate Badgasteiner Straße. A 1950s building is visible in the background, Munich 2013

Figure 80: Housing estate Amberger Straße. Protective new housing by Léon Wohlhage Wernick 2009, the Parkstadt Bogenhausen housing estate can be seen in the background, Munich 2017
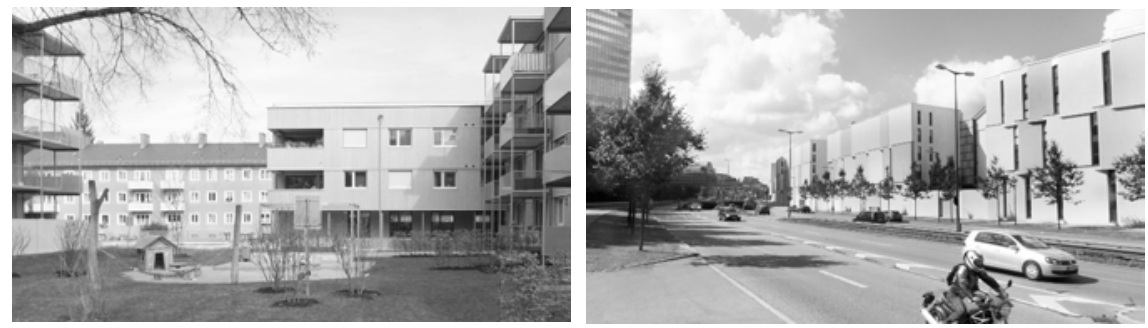

The transformation of mid-20 $0^{\text {th }}$ century housing estates in Munich is currently under way at a grand scale. The process includes internal upgrading, typological diversification, improvements of accessibility and open spaces, energy performance, and other changes. Estates are transformed spatially, by means of fundamentally reorganising estate layouts and their relation to the urban environment. The greater the number of projects of this kind, and the greater their local impact, the more it becomes apparent that the Parkstadt Bogenhausen housing estate is somehow different. Based on the empirical and comparative data, we can consider the proposition that this difference is rooted in the way the estate is owned and organised, in the conditions defined by the Parkstadt arena, and in the collective's approach to conflict and change.

\subsection{Placing the Changes in the Parkstadt Bogenhausen Estate in Context}

Following the contextual analysis, how do the changes in the Parkstadt Bogenhausen housing estate compare to the multitude of changes that could be identified in the local area as well as in other housing estates in Munich? Since 1984, changes to the structure, infrastructure, or communal areas are documented in the minutes of the annual meeting in accordance with the WEG requirements. Changes that are not recorded in the minutes typically include modifications that do not require authorisation by the collective. These could be internal refurbishments and alterations of non-load bearing partitions, or minor changes commissioned by the administration/ advisory board as part of the approved maintenance works, such as replacing a bicycle stand. The mix of commercial uses in the small local mall is also commensurate with this type of change. As long as the units retain their commercial function the individual owner is free to choose a tenant or commercial use for the property. In addition, there might be changes that are not covered by any form of authorisation but that are tolerated, ignored, or that remain unnoticed. Some of the garages are used in alternative ways. Residents use them as workshops for their motorbike or for bike repairs, for the storage of household items to compensate for the lack of space in the apartments, or for storing material and equipment needed to operate a small building business. The tendency towards bigger cars, for which the comparably small garages built in 1956 are becoming increasingly unsuitable, may have contributed towards these conversions. 
Figure 81: Three units comprising 1, 2, and 3 bedrooms are arranged on the standard floor plan in building Buschingstrasse 57-63. The non-load bearing partitions of the 3 bedroom apartment are marked in black. Typical internal reconfigurations of the 3 bedroom apartment through changing non-load bearing partitions are shown below.

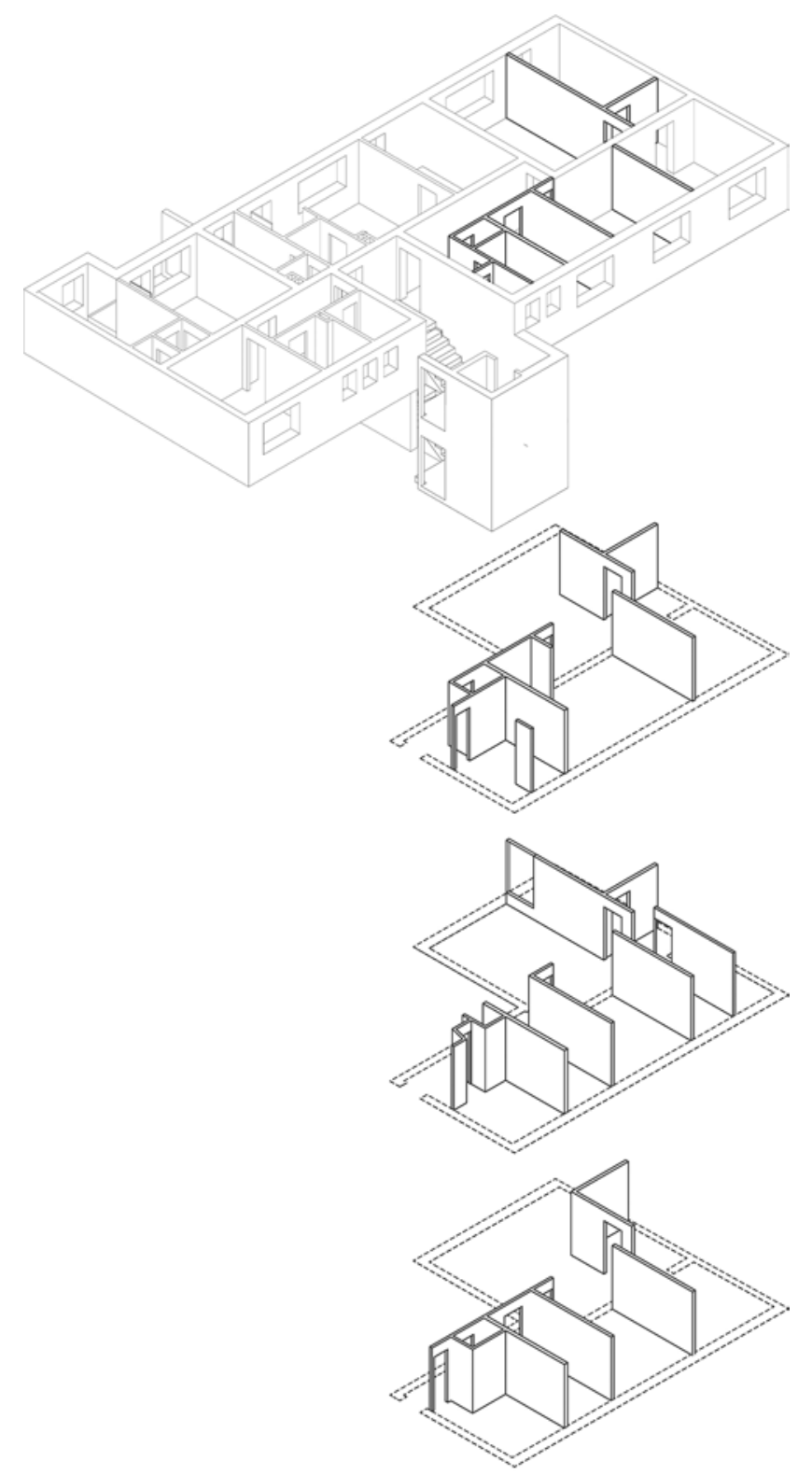

Finally, the contextual analysis in the previous section suggests that transformations that occur in the proximity of the estate may directly influence the situation on the estate. The construction of the Richard-Strauss-Tunnel serves as an example. Changes of this kind are beyond the control of the collective. 
Based on these contextualised considerations, changes in the Parkstadt Bogenhausen housing estate can be categorised in the following way:

1. Changes dating from the period of single ownership prior to establishing the commonhold-type entity according to WEG in 1984.

2. Changes that are authorised on the basis of collective decisions made in the annual meetings since establishing the commonhold-type entity in 1984. I have analysed these changes in detail in the previous sections.

3. Changes that directly affect the estate which are beyond the sphere of control of the WEG collective.

4. Changes made by residents, non-resident owners or the local administration without being recorded in the annual meeting minutes. This category includes changes that

a. do not require authorisation by the collective, such as internal refurbishments and alterations which are regulated by WEG legislation

b. are minor in extent and effect so that the administration carries them out without formal approval as part of the maintenance works

c. are non-authorised and tolerated or ignored, or that remain unnoticed

Based on the information assembled in the timeline diagram and the annual meeting minutes we can at this stage confirm that all changes with major spatial impact beyond the scope of the maintenance project predated the formation of the commonhold-type organisation. All structural, infrastructural and other similar changes that have affected the Parkstadt Bogenhausen housing estate since its completion in 1956 fall into the phase of single ownership, that is, prior to 1984. They include the construction of the underground parking area below the big lawn, the construction of the twolevel parking garage next to the Buschingstraße 65 tower, the introduction of district heating, which in turn freed up space for the local administration's new offices in the disused boiler house.

While the comparative analysis could be further extended, it seems justifiable to propose that we are indeed looking at a unique phenomenon. The estate does not seem to participate in the current spatial dynamics of the local area. It does not change in the same way and with the same transformative speed as other housing estates in Munich. The analysis reveals an asymmetry in the pattern and speed of change if we compare the situation in the Parkstadt Bogenhausen housing estate with other situations in Munich. The comparative analysis shows that the observed phenomenon cannot be explained with reference to the estate's architectural properties, differences in economic or demographic parameters, or the local urban context. Likewise, as I argue in the following section, the phenomenon cannot be conceived as the self-evident consequence of the listing of the estate as building ensemble.

\subsection{Heritage Preservation as Enabling Framework for Change}

The justification for the listing of buildings, structures or other parts of the built environment as "built monuments" is based on a shared agreement about their preservation. In Section I (Scope), Article 1, Paragraph 1, the Bavarian Law for the Protection and Preservation of Monuments provides a general definition of monuments, stating that 
"monuments are man-made things or parts thereof from a past epoch whose preservation, because of their historic, artistic, urban design, scientific or folkloristic significance, is in the interests of the general public." (Monument Protection Law 2009 [1973]) The paragraphs that follow provide definitions of what qualifies as a 'built monument':

(2) Built monuments are structures or parts thereof (including historic decorative details) from a past epoch which possess the significance listed in Paragraph 1 [...]

(3) Built monuments can also include more than one structure (historic district or Ensemble); every individual building in the Ensemble need not fulfill the requirements of Paragraph 1, if the townscape, square or streetscape as a whole is worthy of preservation." (ibid.)

Since 1992, the housing estate, including green spaces and the eastern low rise residential area, is listed as Ensemble E-1-62-000-69 "Parkstadt Bogenhausen" according to Paragraph 3 (Denkmalliste Bayern 2017a). The central complex of retail units, restaurant, deck access apartments, which are designed by architect Franz Ruf, as well as the sculpture of social housing advocate Dr. Paul Busching by artist Seff Weidl, are listed according to Paragraphs 2 and 3 (Denkmalliste Bayern 2017b; Krack 2006, p.128). The listing of buildings, ensembles or other "man-made things" has effects on the way they change. That the idea of preservation is seen as being directly related to questions of change is mirrored in the explicit addressing and regulation of change in the Monument Protection Law. Section II (Built Monuments), Article 6 of the law regulates "Measures on Built Monuments", in particular the need to obtain permission for the demolition, alteration or relocation of built monuments or parts thereof. If we focus on the ensemble category, then the regulations for modifications read as follows:

(1) [...] "Whoever wishes to alter an Ensemble only must have permission, if the alteration concerns a structure, which is for itself a built monument, or if this could affect the appearance of the Ensemble."

"(2) Under the provisions of Paragraph 1 [...], permission can be prohibited insofar as important reasons favor the unaltered preservation of the existing condition. Under the provisions of Paragraph 1 [...], permission can be denied if the planned action would lead to an adverse effect on the character, the appearance or the artistic effect of a built monument and important reasons favor the unaltered preservation of the existing condition." (Monument Protection Law 2009 [1973])

This first paragraph makes clear that no permission for internal alterations and similar changes is required if the buildings that are part of the ensemble are not listed as individual built monuments according to Article 1, Paragraph 2, provided the appearance of the ensemble is not effected. The second paragraph limits the conditions under which alterations "can be prohibited" (ibid.) to changes that have adverse effects on the character, the appearance or the artistic effect of the ensemble ${ }^{19}$. This means for most parts of the Parkstadt Bogenhausen housing estate, the listing does not affect the way internal mod-

19 In this sense the protective goal of 'ensemble' may be compared to a conservation area in the UK, in which alterations and changes are acceptable as long as they do not adversely affect the overall character of the area. 
ifications are made. Individual owners do not require permission from the Local Monument Protection Authority. They will in most cases inform the local administration and the neighbours, and then start with their internal building project. Likewise, alterations that are located within the common areas of buildings require approval from the annual meeting, but not from the Local Monument Protection Authority. Only if alterations affect the appearance of the ensemble is permission from the authority required, and only if the proposed alterations will have adverse effects on the character, the appearance, or the artistic effect of the ensemble, can they not be granted permission.

My observations of the annual meeting suggest that among the owners there is a degree of uncertainty as to the exact status of listing, and, moreover, as to what practical implications the listing has for the housing estate. Participants in the expert interviews were well-informed about the status, but they shared the view that changes to the appearance of the estate would most likely be evaluated by the authorities as having adverse effects, and that they would therefore not be permitted. The uncertainty among owners and specialists points to a general difficulty in heritage preservation, as well as in planning. In many negotiated cases, there does not seem to be a sharp line between that which is permitted and that which should be rejected on grounds of adverse effects. Moreover, if there is a line, it tends to shift on the basis of the shifting values assigned to building and heritage preservation. In view of these uncertainties and difficulties, how may owners, the administration, as well as the authorities respond to issues like accessibility and mobility, diversification of uses, new forms of collective living, renewable energy, use of external areas, the needs of the elderly, the housing crisis, or densification in housing estates? The controversy about new ventilation shafts to the underground parking area in 2017 has actuated these questions for the Parkstadt Bogenhausen.

Building projects located within the historic and listed part of the Munich district of Bogenhausen demonstrate that the protection of built heritage and changing the built environment are not mutually exclusive. The provision of new housing in the large yard of the historic building block defined by Prinzregentenstraße, Braystraße, Einsteinstraße and Versailler Straße is such an example (Palais Mai 2015). The northern perimeter of the block is occupied by the St Gabriel church, dating from the $19^{\text {th }}$ century. The church building, the vicarage, and a residential building on the southern perimeter are listed as individual buildings (Einzeldenkmal). The entire urban block is listed as a building ensemble (Ensembledenkmal), as are all other blocks and open spaces in the neighbourhood, forming the Bogenhausen ensemble (Denkmalliste Bayern 2017c). This area of Munich is to a large degree based on the urban design framework established by architect Theodor Fischer and his team in 1901 (Wolfrum et al. 2012). In Palais Mai's residential scheme, two five-storey apartment buildings accommodate 66 residential units, while a smaller third building is used as a childcare facility. The scheme replaced rows of garages and a car park. The siting of the new buildings and the underground parking area ensured that the existing mature trees could be retained. All open spaces in the yard area were redesigned and newly landscaped. The project received an honourable mention for its approach to combining new build with the existing ('Preis für Stadtbildpflege der Stadt München') and is seen as a successful example of urban densification (Palais Mai 2015). Subsequently, a large portion of the existing buildings along the perimeter were refurbished and further residential space was constructed within the attics of the historic buildings facing Braystraße. 
An example of significant change to a listed built monument in the local area is the construction of a new residential building next to a $19^{\text {th }}$ century villa in Scheinerstraße 11 (Denkmalliste Bayern 2017d). The new building designed by David Chipperfield Architects comes without ornament or other detail and is in stark contrast to the villa. It connects with the listed building in a rather unusual way. Although the new building has major effects on the villa and the open space in front of them, it can be considered a successful transformation. The mass of the new building, its proportion and positioning add a new spatial quality to the existing situation of the square. The new building has a quality of its own that corresponds to the quality of the listed building and the wider surroundings - albeit on its own terms. What is deserving of criticism, though, is that the new building does not provide affordable housing, or that the perimeter walls are higher than in other parts of the area. But these issues are problems of urban policy rather than preservation. We also find among the 77 ensembles that are currently listed in Munich, the historic city centre and the Olympic park and sport village constructed for the Olympic Games in 1972. Both ensembles are particularly sensitive to change. Nevertheless, change of use and new building construction do occur in both of them. New structures and buildings have been integrated to the Olympic park since its listing in 1998. In 2008, Munich's urban development department held a workshop on the future development potential of the park (Landeshauptstadt München 2008). Likewise, since the end of the 1980s, a conservation framework makes alterations of all kinds a routine undertaking in the historic centre. Pertaining to the integration of existing fabric and new building projects in the historic city centre, the framework states that

\begin{abstract}
"Preserving the historical cityscape is important for the identity of the city as a whole, but at the same time, modern architecture and development make an important contribution to the city's image as an economically dynamic and culturally accessible city. To unite the traditional and the modern in Munich's city center, new structures need to be carefully integrated into existing ones. [...] This will be ensured by competitions and competitive processes." (Landeshauptstadt München 2007, p.70)
\end{abstract}

Hence we could say that in all cases presented, preservation is the guiding framework for change - and not the inhibiting factor. However, in view of the immobilising effects of institutionalised preservation that are still felt in practice, Jorge Otero-Pailos criticises the narrowly framed "authorized heritage discourse" (Smith 2006, cited in Otero-Pailos 2016, p.16) ${ }^{20}$ and advocates a more open and differentiated approach to

20 The listing of entire city centres as World Heritage Sites in expanding urban cities has brought the conflicts between established concepts of preservation and the reality of urban dynamics to full light. Vienna is currently struggling to make compatible her plans for internal development with the protection status of the historic city centre. Other cities like Riga or Dresden were going through similar processes in the past. The many situations of uncertainty and conflict suggest that preservation is not a pre-given site or self-evident process. Emphasising the contingent side of preservation, Jorge Otero-Pailos asserts that "[...] preservationists have always played a much more active role on the choosing, one might even say co-creating, heritage objects. But their role has been unacknowledged, or sometimes even consciously concealed." (Otero-Pailos 2016, p.22) 
Figure 82: Residential development within a listed building ensemble Braystrasse, designed by Palais Mai, completed in 2015, Munich 2017

Figure 83: New residential development designed by David Chipperfield Architects Berlin, in collaboration with Mark Randel Architekten (Berlin) and DOMO Architektur (Munich, LP4-8), next to listed $19^{\text {th }}$ century villa in Scheinerstrasse. Completed in 2016, Munich 2018
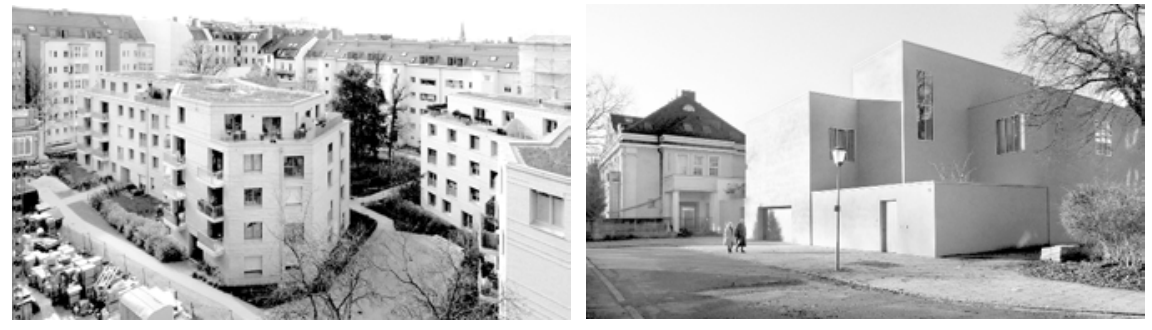

preservation. He asserts that heritage and preservation are not self-evident ends in themselves and collectively constructed, rather than just being 'out there'. Questions of preservation in cities are seen as being entangled with social, economical, as well as political concerns (ibid.). Hence, the burden, responsibility, and challenges of preservation in urban situations cannot be left solely to the heritage specialists.

\section{Constructing the Redundant City Concept}

\subsection{Working towards a Synthesis: Assembling Empirical and Theory-Based Findings}

In the following stages of concept-building, I bring together the previous findings and interpretations in a process that is based on a series of synthesising steps. In the first step, I assemble the conclusions of the mappings and the comparative analysis. I then turn to the positional map and exploit its heuristic capacity by establishing new discursive relations between the mapped process and the positions in the intersection of conflict and change. I propose that, if we seek to embrace the full process of the Parkstadt arena, we need to work with a dual position in the map. The idea is to make visible the silences and contradictions in the situation. I then introduce the complex and ambivalent notion of redundancy, which lends its name to the new concept. In the final stage, I establish the Redundant City concept, drawing from the conclusions from each part. The concept is conceived as the combined outcome of empirical research and of a critical enquiry into architectural and urban theory. It stands at the end of two open analytical processes that have evolved as connected iterative-cyclical research sequences. The diagram in Figure 84 shows what has been achieved so far in the analysis. The diagram in Figure 85 shows how in the synthesis the different research elements contribute to the construction of the new concept. Both the universe of architectural and urban narratives of conflict and change, as well as the study of the Parkstadt Bogenhausen housing estate inform and support its development. 
Figure 84: Diagram showing the two main strands of analysis together with their mapped outcomes.

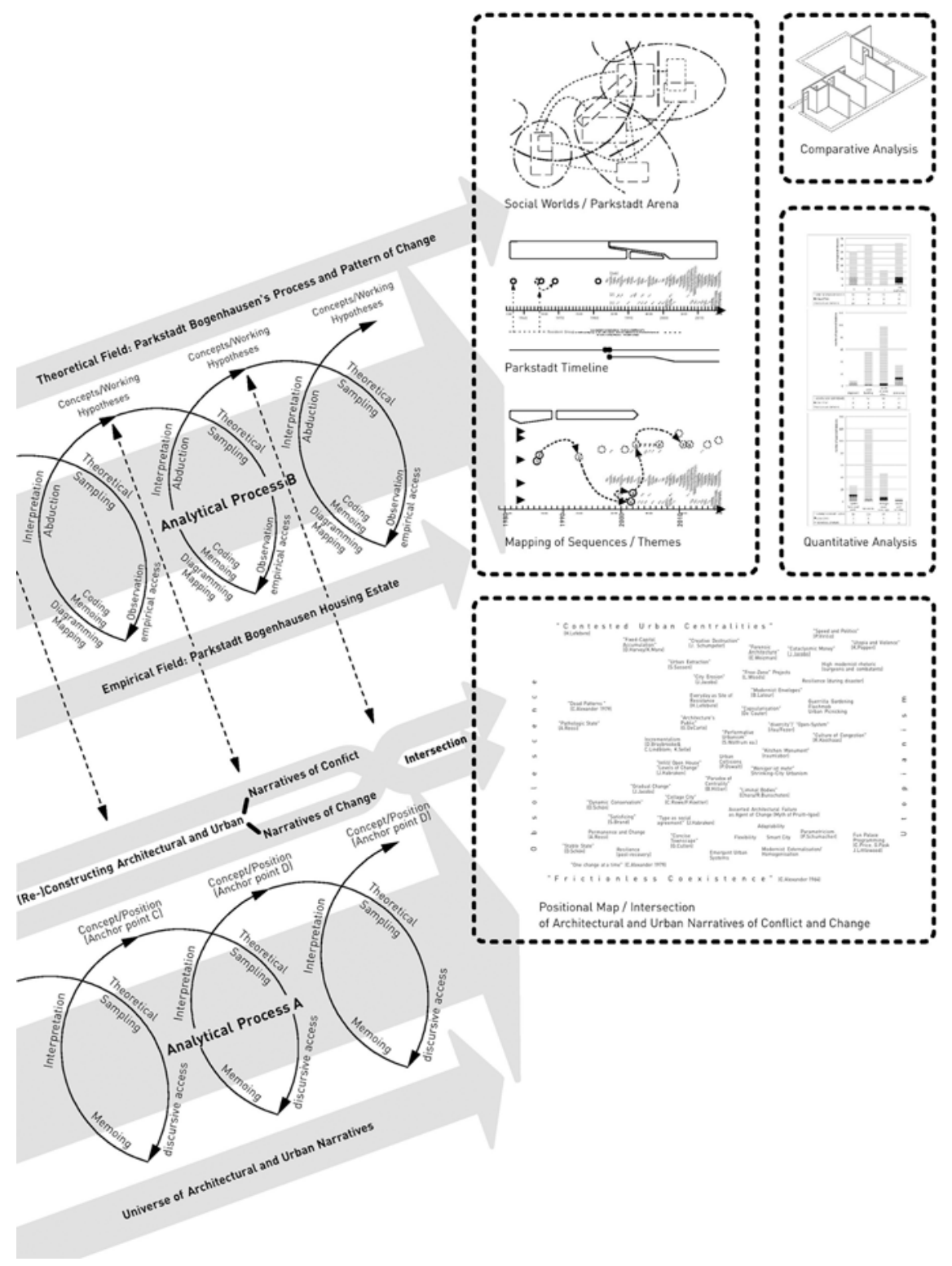


Figure 85: Diagram showing the main elements of analysis, interpretation, and conceptbuilding in the synthesis.

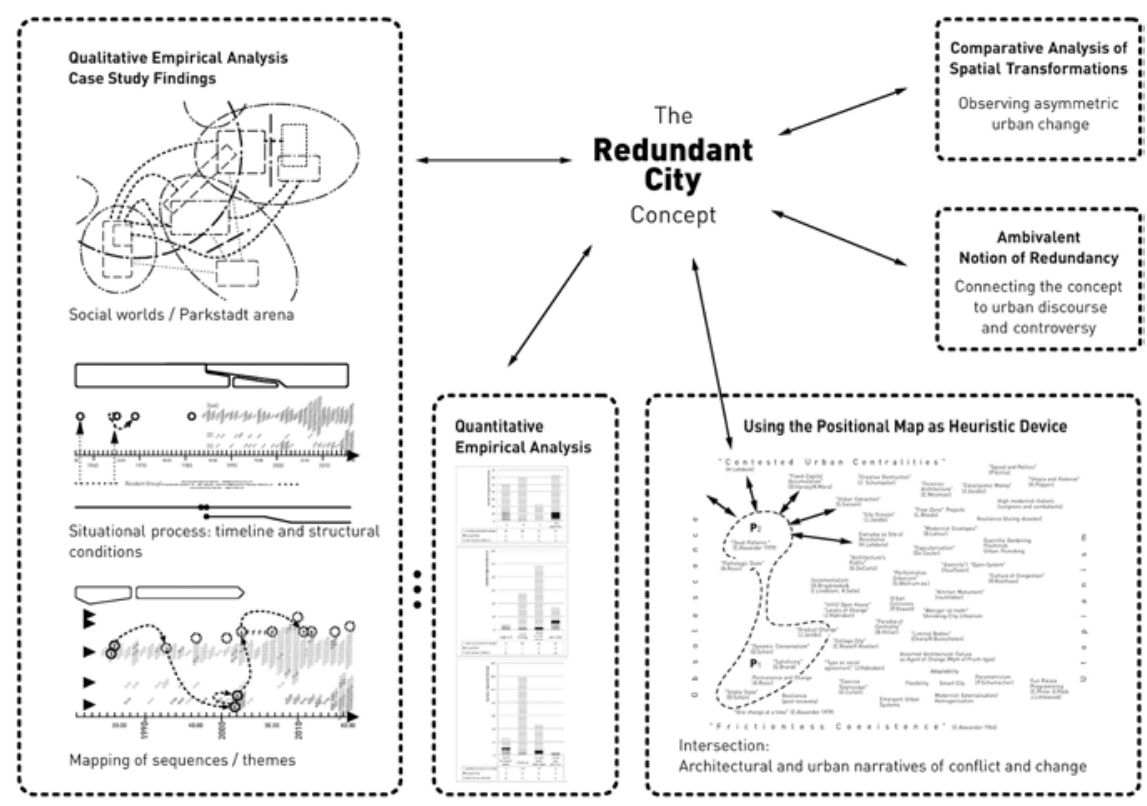

Redundant City is, therefore, neither the sole outcome of empirical research, nor of reflective theorising. Only through the combination of both fields of research has it been possible to advance to this point, and from there to proceed with the construction of the Redundant City concept.

\subsection{Empirically Grounded Characteristics of the Housing Estate's Process of Change}

At the outset of the investigation into the Parkstadt Bogenhausen housing estate, I stated that there is no such thing as 'the' housing estate. Modernist housing estates tend to be based on the principles of universality as well as of economical rationality and uniformity (Hiller et al. 2017). At the same time, if we understand housing estates as being situated within relational constructs of space, and as following their individual trajectories of development, which are connected to multiple actors, processes, spatial interpretations, and desires, they cannot be reduced to their generic and material properties. For the purpose of analysing the process of change in the Parkstadt Bogenhausen housing estate, I have adapted the iterative-cyclical GTM model to the specific case and included the methodological assumptions of situational analysis. In this sense, the findings and concepts developed with the methodology could be understood as being 'grounded in the situation'. In the first step of working towards a synthesis and the Redundant City concept, I assemble, discuss, and interpret the characteristics of the process identified so far on the basis of the GTM analytical process, the situational analysis mappings, and the comparative analysis. 
Figure 86: Parkstadt Bogenhausen, residential tower on Buschingstraße, view towards Arabellapark corporate headquarters, Munich 2017

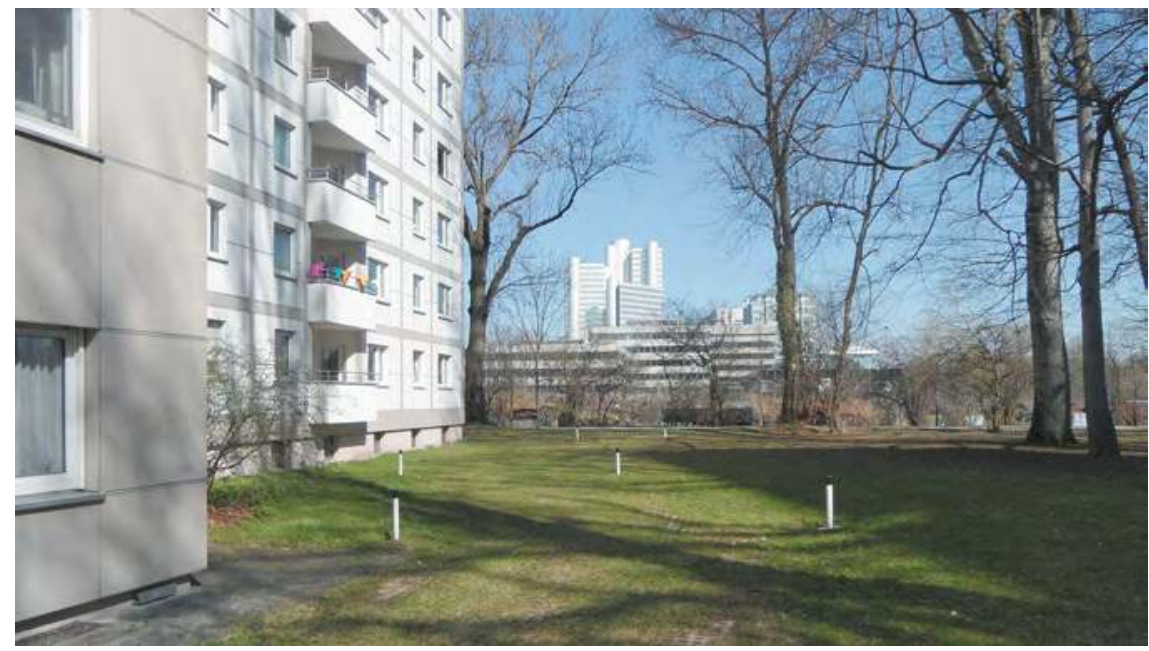

\section{Asymmetric Urban Change}

The comparative analysis shows that the housing estate neither fully participates in the overall dynamics of change that prevails in the metropolitan region, nor does its pattern of change correspond with the kind of changes observable in the local area, or in other housing estates in Munich. This is not self-evident, because we can assume that the estate is subjected to the same general demographic, social, environmental and economic conditions as the cases in our comparative study. Property sales in the estate follow the overall tendency to rising property prices and rents. The estate is not located at the urban periphery or any other disadvantaged location of the city, nor can we speak of the estate as being stigmatised in any way - it is not perceived as a place where problems accumulate. Munich's recently updated 'Mietspiegel', the political tool used to track and influence the level of rents in the private rental sector, confirm the estate as a desirable residential area ('gute Lage') (Landeshauptstadt München 2016c). Even so, the way the Parkstadt Bogenhausen housing estate has changed is very different to the development of other housing estates, for as we have seen, estates with similar morphology and typology are currently subjected to substantial restructuring and spatial transformation.

Likewise, we cannot observe any signs of economic stagnation in the surrounding urban area. Hence, the comparative view suggests that differences in transformative speed and extent of spatial change cannot be attributed to architectural properties, or to location. If we juxtapose the situation in the Parkstadt Bogenhausen housing estate and the overall dynamics in and of Munich, we can clearly see the asymmetry between them.

\section{Rigidifying and Pre-structuring Effects in the Arena}

The mappings suggest that the actions of the estate's process are co-determined and limited by the framework in which they are situated. In the social worlds/arenas map we see the connections and boundaries through which communication and the decision 
making processes are pre-structured. The structure defines which group is authorised to participate in decision making, it defines the sequential order in decision-making processes, it defines different and nested inside/outside relationships. Some of the pre-structuring conditions are more rigid and solidified than others. In particular, WEG legislation provides a framework for the process that is highly institutionalised. The rigidity in the WEG framework means that core relations within the Parkstadt Bogenhausen arena cannot be changed without changing the WEG legislation at large. The legal framework pre-dates and pre-structures the collective process in the Parkstadt Bogenhausen arena. The mapping of self-reflexivity in the collective process, as presented in the diagrammed sequence "decision making", shows that issues relating to the practice of administration, which involves reference to WEG legislation, heritage preservation, planning and building control, are frequently questioned. There is, however, no questioning of the basic organisation of property rights, of control hierarchies, or the questioning of the more fundamental fixations in the arena. Hence, while the practical application of WEG and other legislative bodies in the administrative process produces controversy, the overall rigidifying and pre-structuring mechanisms are left unchallenged. These mechanisms and pre-givens have to be seen as part of a much larger framework governing the urban condition. In the introduction to the edited volume "Negotiating Urban Conflicts", Helmuth Berking et al. suggest that "[...] manifold lines of potential conflict run up against institutional regimes designed to guarantee urban security." (Berking et al. 2006, p.9) The situation defined by the Parkstadt arena could be conceived as an institutionalised space that relates different social worlds to each other, including the materialities, agendas, and structures that co-produce them. Martina Löw highlights the ordering and enabling, as well as the restricting and rigidifying effects of institutionalised spaces:

"Institutionalized spaces secure the orderly cooperation of people. They provide security in action, but also restrict the possibilities of action. Both together, the routines of everyday action and the institutionalization of social processes, guarantee the reproduction of social (and thus also spatial) structures." (Löw 2016 [2001], pp.144f)

In the foreword to the 2016 English edition to the "Sociology of Space", Löw asserts the structuring and pre-structuring effects of spatial arrangements on human actions, including the institutionalised layout of a floor plan in a dwelling (Löw 2016 [2001], p. xix). Based on the understanding that spaces are reproduced through repetitive routines in everyday life, Löw identifies two different ways of introducing changes to the reproduction process:

"Changes to individual spaces emerge as possible in relation to necessity, physical desire, other people's manners of action, and the state of being considered 'other'. Changes to institutionalized spaces or spatial structures must take place collectively with reference to the relevant rules and resources." (ibid., p.233)

The individual dwelling unit can be seen as belonging to both categories. It is entangled with the world of personal needs and desires, as well as with the world of rules and conventions. On the Parkstadt Bogenhausen housing estate, individual modifications to private units are routinely performed as long as they do not require approval 
by the collective. However, there are conventions that influence decisions on how to make changes. The individual dwelling unit has to be seen within a hierarchy of institutionalised spaces that extend across different scales from the room to the city. Hence, changing one's own 'individual' unit space implies working within collective constellations.

In its current version, WEG legislation cannot respond to differences in the ratio of non-owning residents and non-resident owners. While prior to the privatisation of the Parkstadt Bogenhausen housing estate all residents where equal in that they were tenants, and in the years following the privatisation most owners of single units were residents, the current situation has become more complex and heterogeneous. The social worlds/arenas map shows how non-owner residents are excluded from direct participation in the collective decision-making process. This group includes all tenant residents as well as young people and other members living in the households of owners. If the number of non-resident owners is on the rise, which is the case in the Parkstadt Bogenhausen housing estate, a growing non-resident group of owners will be deciding on matters that affect all groups and individuals on the estate. There will be, perhaps, a growing interest in the short-term letting of apartments, a disinterest in local issues and emotional detachment from the actual life on the estate. The not-sharing of local concerns could be a growing source of conflict in the future.

The pre-structuring and institutionalised pattern of relations is embedded within the hegemonic system of power relations based on private property, which in turn cannot be changed without challenging the overall hegemonic system of space production. Hence, we could say that the form of ownership and the corresponding decision-making process play a major role in the production of the observed differences. But we cannot define WEG legislation as the single cause of the phenomenon.

In Germany, the standard form of organising residential property in multiple private ownership is defined by the WEG. Commonholds and condominiums represent a well established type of residential property in Germany and in other countries. However, WEG entities are usually much smaller in size, and often limited to a single building. Consequently, their collective process is assembled around a smaller arena, which means that problems of communication, conflict management and collective action can be addressed in more immediate ways (Hess et al. 2015a; 2015b).

The analysis shows that the observed phenomenon in the Parkstadt Bogenhausen housing estate is influenced by its formative circumstances, legal framing of property rights and organisation of ownership, uneven distribution of knowledge/power, size of the arena, institutionalised and pre-structured relations, and channels of communication. The structural conditions contribute to the differences between Parkstadt Bogenhausen and other housing estates of the same period. The arenas of change in these residential neighbourhoods are composed in an entirely different way, which in turn results in the differences in their decision making process and management of change. 
Figure 87: Parkstadt Bogenhausen, garden elevation of apartments above shopping centre, Buschingstraße, Munich 2016

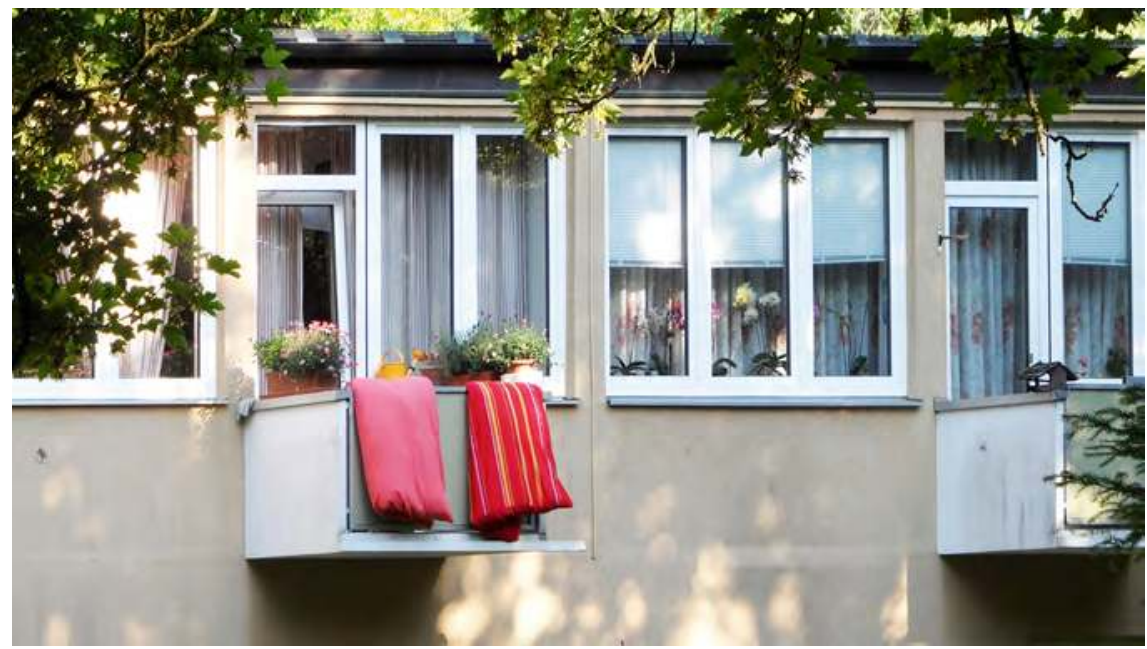

\section{Dominance and Integrative Capacity of the Maintenance Project}

The participants in the process of Parkstadt Bogenhausen housing estate have made the maintenance project the key concern of their interactions, assigning to it a dominant role, which helps to position and structure other concerns. As maintenance accounts for the biggest part of the collective's spending, its dominating role in the decision-making process seems to be self-explanatory. There is a general agreement about maintenance being an essential precondition to safeguard the quality of the built environment in the estate in the long term. However, could there be other factors that contribute to the dominance of the maintenance project? For the foregrounding of maintenance seems to go hand-in-hand with the supplanting, or silencing, of other concerns. The sheer number of decisions dedicated to the maintenance project reduces the time that is available for other concerns and other debates during the annual meeting. Also, it affects the way resources are assigned in the local and central administration offices and among the members of the advisory board. The recurrent foregrounding of maintenance in the minutes and reports of the administration and advisory board, as opposed to change, seems to have a legitimising function for the current distribution of power in the decision-making process.

As mentioned earlier in the discussion of narratives of change, Kevin Lynch proposes that "maintenance is a useful model for the retention of stable function against the action of well-known, equally stable [...] forces [...]." (Lynch 1972, p.207) We could say that besides wear and tear, changes of building regulations and general building standards are typical 'forces' that have influenced the way maintenance is operated in the Parkstadt Bogenhausen housing estate, as well as the extent of the measures taken. In the minutes, we see many comments and self-descriptions, in particular of the administration and the advisory board members, which directly refer to the maintenance project. The administration has developed a unique expertise in managing the administrative requirements of Germany's largest 'Wohnungseigentümergemeinschaft'. The control of the maintenance project is the integral part of the overall 
Figure 88: Parkstadt Bogenhausen, major maintenance works to deck access area of the shopping centre, Munich 2017

Figure 89: Parkstadt Bogenhausen, container for private refurbishment works in one of the tower blocks, Buschingstraße, Munich 2017
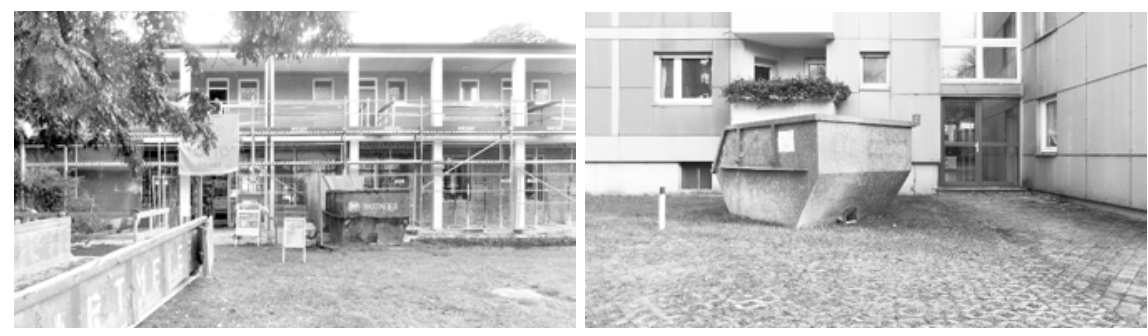

management process. Lynch observes that on the one hand the maintenance model "demands powerful control", and on the other hand, "predictions must be accurate and consensus strong" (ibid., p.211). The model follows a "fully controllable process" (ibid., p.207), where the objectives are fixed and scheduled in detail (ibid.). Maintenance provides the opportunity to demonstrate and apply the acquired expertise over and over again. All actors who are involved in this process have an interest in keeping the situation as it is. It allows them to maintain and control a continuous and stable process through which they then can connect to the collective and the arena.

Maintenance work may disguise processes of change (ibid., p.211). The meeting minutes suggest that the small changes introduced in each maintenance cycle are often accepted without debate. The maintenance project seems to silence conflict and controversy in the process, because true change is never explicitly addressed. However, the incremental changes established through maintenance may accumulate to more substantial effect over time. In this way, questions about who controls and holds the power over change are rarely debated in the open.

However, there is more to the maintenance project than power relations, the response to material deterioration, or the desire to gradually raise comfort levels. The maintenance project has an integrating capacity, because it requires the constant efforts of individuals to support the process. Highlighting the significance of maintenance to social worlds, Anselm Strauss suggests that

\footnotetext{
"Proper maintenance depends not only on obvious resources like money, skill, time and wo/manpower, but also on symbolic resources such as the 'the will' to spend the resources or the essential requirement that some sites are so important that they must be maintained at a very high level (the beautiful lawn courts at Wimbledon; St. Peters in Rome). Maintenance requires the efforts not only of in-world members but those of worlds which intersect if only on the matter of maintenance: plumbers, painters, architects." (Strauss 1979)
}

The maintenance project has a stabilising function for single social worlds - the social worlds of residents, investors, the administration, or the contracted professionals but also for the arena itself, into which the participating social worlds bring their commitments, which they can share with others. Hence, it would be reductive to conceive 
of the Parkstadt Bogenhausen arena primarily as a site where different and conflicting positions collide which each other. For it is also a site where common ground is established, where ideas are shared, and where collective identities are constructed. To challenge the dominance of the maintenance project is to challenge the current mode of space production as well as the positions of the administration and the advisory board. It means to engage with problems of collective identity and the very foundations of some of the social worlds that participate in the Parkstadt Bogenhausen arena. Hence, would the challenging of the dominant maintenance project lead to a reorientation of the collective process?

\section{Established Assumptions on Preservation Are Left Unchallenged}

Preservation practice has effects on the way buildings, ensembles, and ultimately the city change. My brief discussion of heritage preservation in Munich and the local area concluded with the view that the changing of the built environment, including substantial adaptations, can be realised within the framework of the Monument Protection Law. The law addresses and balances both the need to protect and preserve specific qualities of the built environment, and the need to adapt the built environment to the changing demands of residents and users. Critics of an "authorized heritage discourse" (Smith 2006, cited in Otero-Pailos 2016, p.16) advocate a more open and differentiated approach to preservation and criticise the normalising and immobilising effect of institutionalisation. A similar institutionalising effect seems to be at work in the Parkstadt arena. The material collected and the data generated in the study suggests that the question of which kinds of change could be realised beyond that which has been going on since 1984 has not been raised so far. Hence, established assumptions about preservation are currently left unchallenged in the arena. However, if we acknowledge that the criteria we use to define the significance of built monuments, as well as the kind of changes appropriate to them are the result of negotiations and agreements, and that the criteria as well as agreements are inevitably bound to their specific time, then it seems justifiable if not, indeed, necessary that preservation practices be re-examined at regular intervals. In this sense, to what extent could the Redundant City concept provide a new perspective on the situation?

\section{Failure to Accommodate Changes Proposed by Individual Owners}

The mappings provide a clear picture of the dominance of the maintenance project, which in turn is effectively controlled and dominated by the administration and the advisory board. Yet they also show that there is a growing number of issues raised by individuals or groups in the collective. The first cluster of such initiatives emerged in the years leading up to the $50^{\text {th }}$ anniversary of the estate. During this period the estate administration asked for ideas for the event and invited the residents to participate in the preparations. Many groups and individuals contributed towards the process, thus strengthening the connection and increasing the level of communication between individuals and the administration. This could have triggered the increase in issues 
Figure 90: Parkstadt Bogenhausen, off-street parking, Beblostraße, Munich 2017

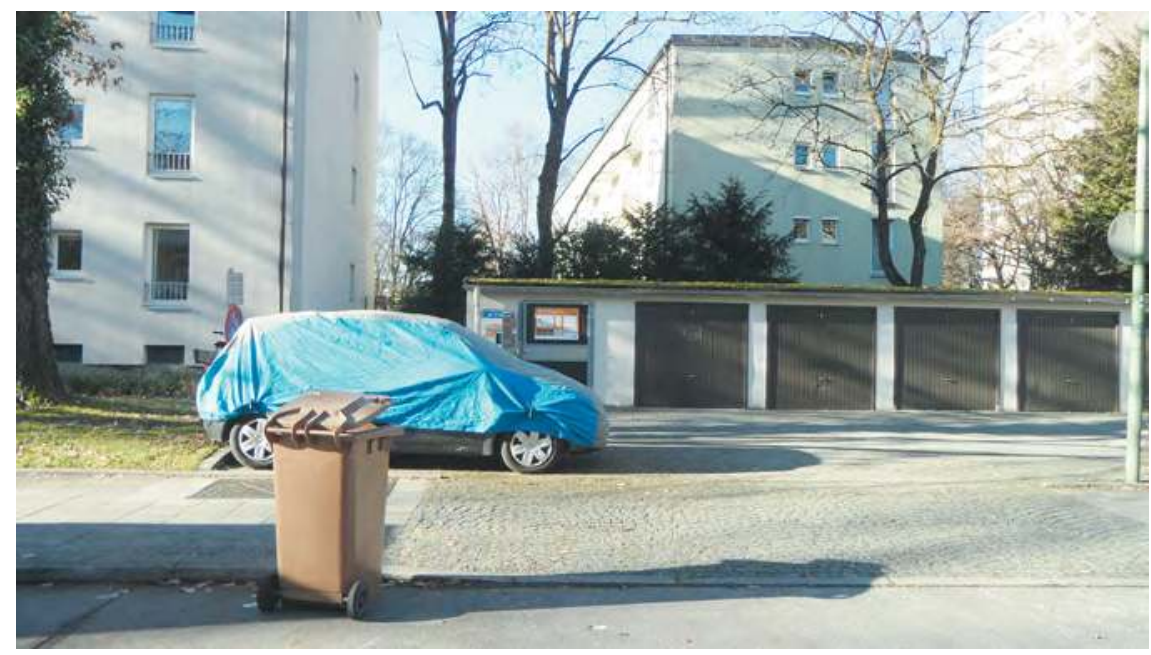

raised by individuals and groups. If seen in isolation, it could be interpreted as a shortlived phenomenon in the wake of a singular and exceptional situation. However, a second cluster has developed in the recent past. While it is, perhaps, too early to speak of a general tendency, it clearly indicates that the situation is at the present different if compared to the process during the 1980 s and 1990s. The pattern of decisions suggests that individuals and groups participate more actively in the decision-making process. Individual participants bring their own ideas more directly into the arena and raise their voices more frequently. We can only speculate that, perhaps, they feel that there is a need to do so. The pattern seems to mirror the general trend in other arenas of urban change, namely the demand for and generation of more participation in urban affairs by a growing number of actors and stakeholders who are increasingly concerned about the unsatisfactory outcomes of the dominant modes of space production. The shift in the Parkstadt process could indicate that an increasing number of proposals enter the arena directly, without taking the path through the advisory board or administration. This could be interpreted as a sign of the institutions' decreasing integrative capacity. However, the quantitative perspective in the analysis shows that the majority of initiatives brought forward by individuals are rejected at the annual meeting. This means that even though there are a growing number of proposals to have things changed on the estate, which is paralleled by increased levels of participation in the decision-making process, it does not currently result in increased levels of change. In this respect, we may speak of a failure in the estate's process to accommodate the growing number of individual initiatives in an adequate way. 
Figure 91: Parkstadt Bogenhausen, mobile grocery shop on its weekly tour, Buschingstraße, Munich 2018

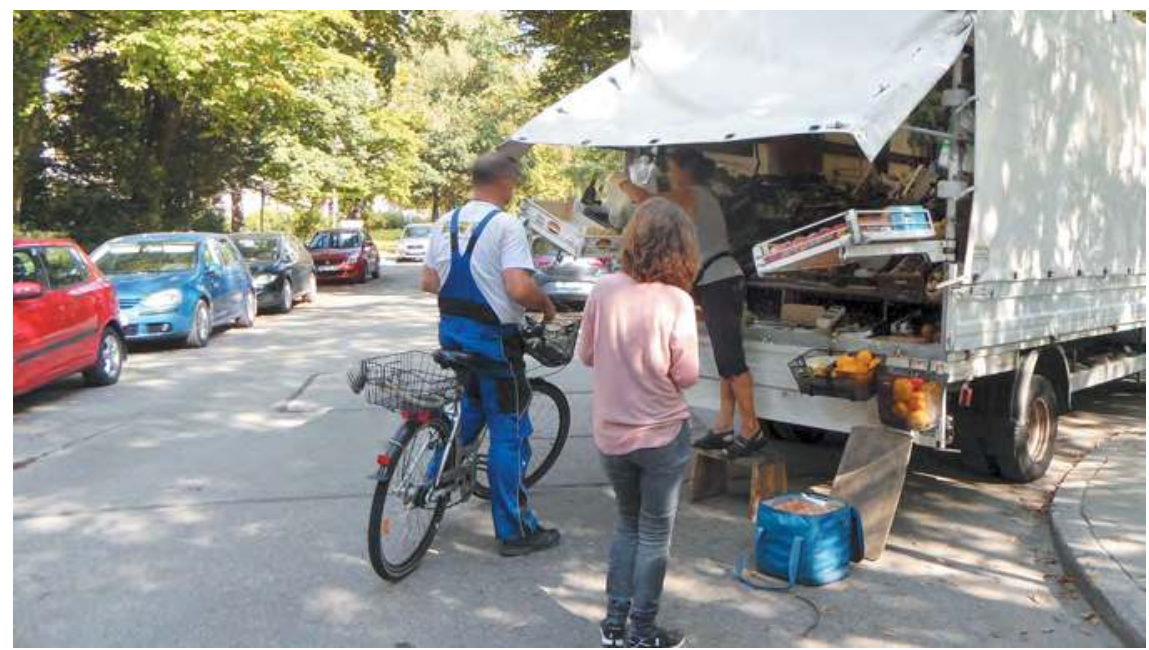

\section{Limited Empowering Effect of Ownership}

The timeline reveals that the more substantial changes, representing real transformations, such as the construction of the large underground parking area and the parking deck, the abandoning of the central heating plant in favour of municipal district heating, or the privatising of the estate to form the collective according to the WEG, fall in the first period of the estate's existence - when it was owned and managed by the Neue Heimat group. During the same period, changes to the single rental unit were controlled and kept to a minimum by the strict rules that were in place during this phase. The pattern of change assumed a new form with the establishment of the commonhold-type entity according to the WEG. Since 1984, all major expenditures have been dedicated to the maintenance project rather than real change. At the moment of writing, for example, a major refurbishment of the underground parking area is on the way.

However, multiple real changes do occur - within the confines of the single unit. Owners modify the spatial layout through relocating partitions, they open up kitchens and reconfigure bathrooms. Individual owners bring an increasing number of propositions that are subject to approval to the annual meeting. Yet they tend to be small in scale and are related to single units or local situations rather than to the estate as a whole. Finally, some propositions seek to prevent change from happening, for example when owners ask other owners to refrain from using spaces in ways that are not covered by the estate rules. Hence, today we see sporadic changes to the communal parts of the estate and its collectively used spaces, almost no structural changes, and massive changes in the private unit. Considering the overall timeline of the housing estate, we could say that corporate or single ownership facilitated the making of changes that become effective on the structural and urban levels, but slowed down or even prevented changes on the level of the (rented) single unit. Conversely, the dispersed form of ownership since 1984 reversed this condition and shifted the centre of activity from large-scale to small-scale adaptations. Local resident and contributor to the $50^{\text {th }}$ anniversary book Werner Wittemer observed that the transition in status from rent- 
ing residents to owning residents did not result in a substantial change in attitude and behaviour (Wittemer et al. 2006, pp.134f). According to Wittemer, residents who were able to buy their flats in the years after the conversion in 1984 continued to feel and behave like tenants. Wittemer uses the term "Miet-Eigentümer" (tenant-owner) to describe the condition (ibid., p.134). He suggests the continuity in the estate's local and central administration have contributed towards this phenomenon (ibid.). This could provide a possible interpretation of the striking absence of decision items raised by individual owners during the first two decades after the conversion, until a new generation of owners began to assume a more active role in the annual meetings.

Yet the overall urban configuration seems to have rigidified with the privatisation. This is not self-evident, as WEG legislation assigns a significant extent of control over the estate to the collective of owners. They control higher levels as is usually the case in residential areas (Habraken 2002 [1988]). It seems that the empowering potential of ownership does not become effective on the estate level, or indeed the urban level. Changes in the estate remain limited to small-scale alterations and the confines of the private unit. In his review of "Flexible Housing" by Schneider and Till (2007), John Habraken highlights the significance of ownership when it comes to questions of adaptability and change. According to Habraken "[...] home owners will change their houses no matter what, even when the latter are functionally determined when bought, because ownership is empowerment; while units for rent tend not to be adapted to a user's wishes even when technically flexible." (Habraken 2008, p.291) The studies by Anne Vernez Moudon in the Alamo Square neighbourhood in San Francisco (Moudon 1986), Stewart Brand's investigation into how people modify their private dwellings (Brand 1994), and the 1969 photographic portrait of Pessac (Lefebvre 1972 [1969]), which explicitly engages with tight-fit functionalism, seem to confirm Habraken's position.

However, the process in the Parkstadt Bogenhausen housing estate seems to be different. The estate is privately owned, and almost $50 \%$ of owners live on the estate themselves. Non-resident owners who lived in Parkstadt at some stage in the past may still feel personally attached to the estate. The owner's collective actions, however, do not result in the changing of collectively used and managed spaces - staircases, access decks, rooftops, or open spaces - beyond general maintenance and small-scale upgrading. In particular, the open areas between the buildings seem to offer ample space and opportunity for the addition of new collective uses. It seems that of the many ideas people in cities have developed over the last half century in terms of appropriation of spaces, sharing, or ecology, not many have become spatially effective in the estate yet.

\section{Striving for Closure and Homogenisation}

The social worlds/arenas map clearly shows that not all local residents and users participate in the arena. The vertical line indicates that there are restrictions. Only property owning residents and non-resident owners are entitled to vote and actively participate in the Parkstadt arena; non-owning residents, non-adults, locally employed, neighbours, or the more casual users of the estate are not admitted to the decision making process. If they wish to participate, they can only do so indirectly. Stressing the inequality inscribed in institutionalised modes of space production, Marina Löw suggests that "the opportunities to constitute space can be enduringly enhanced or confined due to limited or broader access to social goods, due to limited or broader 
Figure 92: Parkstadt Bogenhausen, mobile market stand on parking area adjacent to shopping centre, Munich 2018

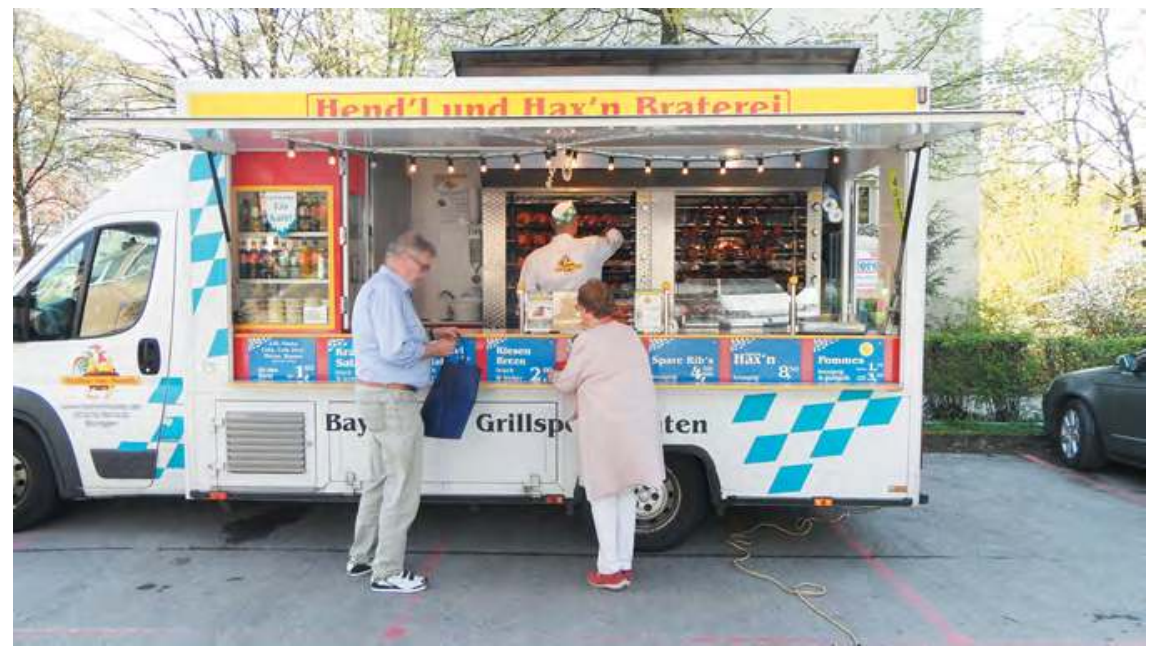

knowledge, due to limited or broader access to social positions, and/or due to membership or non-membership." (Löw 2016 [2001], pp.191f) Despite the theoretical permeability of the social worlds' boundaries, the often specialist commitments around which each social world assembles allows the Parkstadt arena to appear fairly closed. The common concerns, or the work of each social world, are narrowly focussed and are in this sense strong delimiting and homogenising factors. Theorising about the significance of maintaining boundaries in the social production of space, Helmuth Berking et al. suggest that "the struggle for control of urban spaces is an ambivalent mode of sociation, one that cuts systematically across the whole of everyday life: in and by producing themselves, groups produce exclusive spaces and then, in turn, use the boundaries they have created to define themselves." (Berking et al. 2006, p.9) Pertaining to the strong division within the social world of residents and users, we can say that the subworld of owning residents constitutes a collective 'us' that is institutionally closed off against a non-owning 'them' (Mouffe 2013, p.5). However, the meeting minutes seem to suggest that there could be mechanisms other than institutionalisation that work towards homogenisation. Theorising about uniformity in the behaviour of people, Karl Popper asserts that "[...] first, they are afraid of irregularity and change and therefore afraid to originate irregularity and change: and secondly, because they wish to reassure others of their rationality or predictability, perhaps in the hope of making them act in a similar way." (Popper 1948, p.177) For Popper this behaviour is seen to support the emergence and persistence of traditions (ibid.). Likewise, historical geographer Jeremy Whitehand of the Urban Morphology Research Group speaks of "imitative behaviour" and "neighbour effects" in his interpretations of empirical data collected about spatial transformations in residential neighbourhoods (Whitehand 2001, p.107). However, if we speak of homogenisation and the striving for closure in the Parkstadt arena, we also have to speak about them being counteracted by the everyday diversity in the Parkstadt Bogenhausen housing estate. 
Figure 93: Parkstadt Bogenhausen. Some of the garages accommodate alternative uses, partly because they are unsuitable for larger cars. Munich 2017

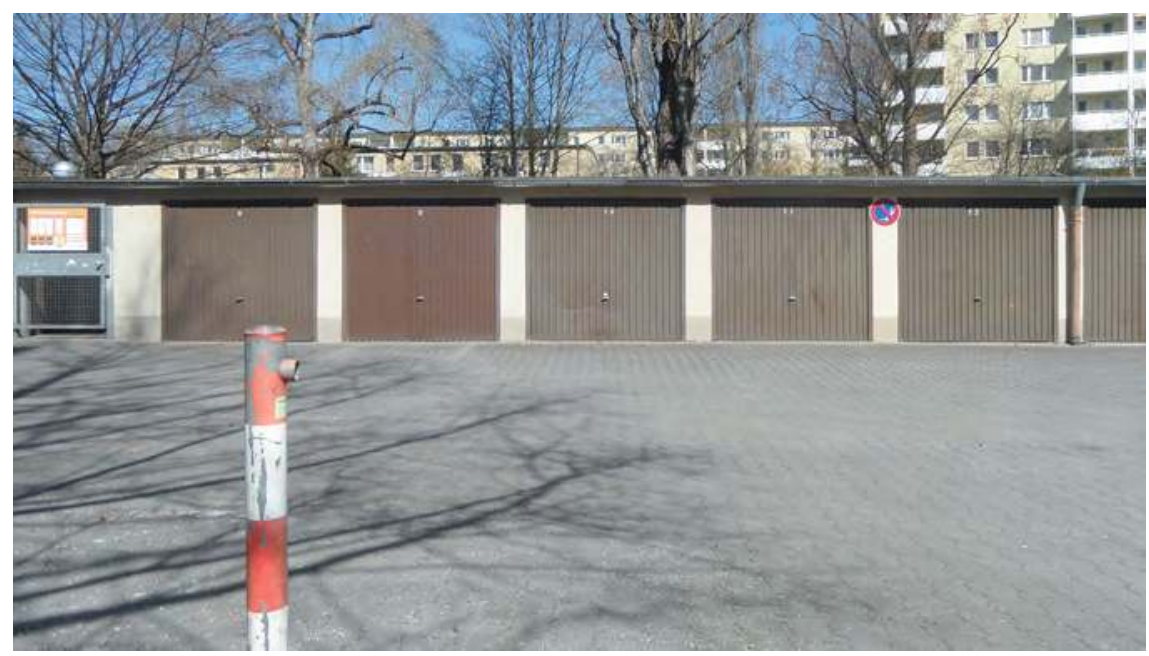

\section{Loss of Interaction on the Urban Level}

The minutes do not tell us if and to what extent desires for large-scale changes exist in the estate. But they tell us that there is no discourse centred on this issue at present. It is through the comparative view which relates the process of the Parkstadt Bogenhausen arena to other housing estates and processes in Munich that we can see the effects of this absence in the built environment, and it is through the timeline study that we see it was different in the past. The structural effects of the Parkstadt arena and the foregrounding of maintenance seem to contribute towards a condition in which the collective process stays disconnected from discourses that are of prime concern in other social worlds/arenas, for example densification and diversification, that is, the housing crisis and the need to restructure the city to provide additional space for housing and for a growing number of different spatial practices. As stated above, the timeline shows that the more substantial changes fall into the first period of the estate's existence, when it was owned and managed by the Neue Heimat group. This was also the period when a strong residents' committee, initiated as "Einwohner-Ausschuß" and renamed "Interessengemeinschaft Parkstadt e.V." (IG) in 1957 (Wittemer et al. 2006, p.141), was able to develop and negotiate proposals with the estate administration, and the owner NHB. Issues included the construction of a kindergarten, crèche, playgrounds, underground parking area, as well as the provision of access to the lawns, all of which were realised. The residents' committee maintained close contacts to members of the city council and the political domain. Further initiatives concerned public transport, telephone boxes, traffic issues, air pollution, a new post office, cinema, protestant church, or a recreational chalet in the mountains. The residents' committee dissolved in 1966 (ibid.). A new residents' committee was established in 2001, which was active during the following years. Named "BürgerInteressenGemeinschaft Parkstadt Bogenhausen" (BIG) (ibid., p.142), its members and supporters sought to address problems of transit traffic, parking, the estate restaurant, establishing a young peo- 
ples' meeting area, and other local issues (ibid., pp.142f). Both residents' committees have exerted their influence on the process of change in the Parkstadt Bogenhausen housing estate. The IG was active during the first decade of the estate's existence and was perhaps for this reason more successful at - or more concerned with - connecting to a broader range of issues.

This is not to say that contemporary initiatives, or the commonhold-type entity according to the WEG in its present form, cannot connect to the urban. For, the Parkstadt Bogenhausen collective has demonstrated, if only sporadically, that it has the capacity to interact on the urban level, and that it can take decisions that are consequential beyond the limits of the estate. For instance, when the collective demanded protection for the tenant residents against eviction when the private investor took over NHB's housing stock, it sent out a signal into the public domain that it would not approve undue hardships inflicted on their non-owner neighbours. When, in 1993, the city administration asked all owners to make a levy payment towards the newly opened Denninger Anger Park, which is located to the north of the estate, the owners united to challenge the city, and succeeded. During the construction of the Richard-Strauss-Tunnel, BIG campaigned together with the collective for better traffic management in the area. However, despite these occasional events of resistance and 'not in my backyard' actions, it seems more difficult, or for whatever reason less interesting for the collective, to assume a pro-active role in generating true urban change.

As we can see, the questions generated through the mapping process and the empirical analysis begin to raise issues that are of wider concern. They begin to connect to urban discourses that belong to the urban arena at large. At this point in the analysis, I propose to leave behind the realm of meeting minutes, for they do not explicitly address or establish connections to the urban and the discourses associated with it. Hence, in the following step, I position the process of interpretation at the intersection of urban and architectural narratives of conflict and change, making use of the map's synthesising and heuristic capacity.

\subsection{Dual Position: Discursive Movements in the Positional Map}

In the following stage of the synthesis, I return to the positional map and establish a series of discursive movements between the positions of different concepts and narratives. As noted earlier, this exercise is not about filling the void in the map, or about stabilising the void by means of a comprehensive theoretical framing. The positional map is conceived as a heuristic device, through which we can look at the universe of architectural and urban narratives in a different way. It is a device for developing a broader understanding of architectural and urban theory at the intersection of conflict and change. In this sense, I now seek to exploit the map's capacities for developing a broader understanding of the process in the Parkstadt Bogenhausen housing estate.

The comparative analysis shows that the overall process of the Parkstadt Bogenhausen housing estate is defined by comparably low levels and low intensities of change. Munich is changing, and with it, the Parkstadt Bogenhausen housing estate, but it seems that the process of the estate is very different to the transformations we observe in the local area and in other housing estates in Munich. So, how can the positional map help us to better understand the situation? To begin with, we need to 
Figure 94: Parkstadt Bogenhausen. This local supermarket, designed by Franz Rufand formerly organised as single units, ceased operating in summer 2017. The building works carried out as part of its conversion to residential use resulted in controversy and the calling of a special meeting of the 'Wohnungseigentümergemeinschaft' in 2019-a rare case in the estate's administrative history.

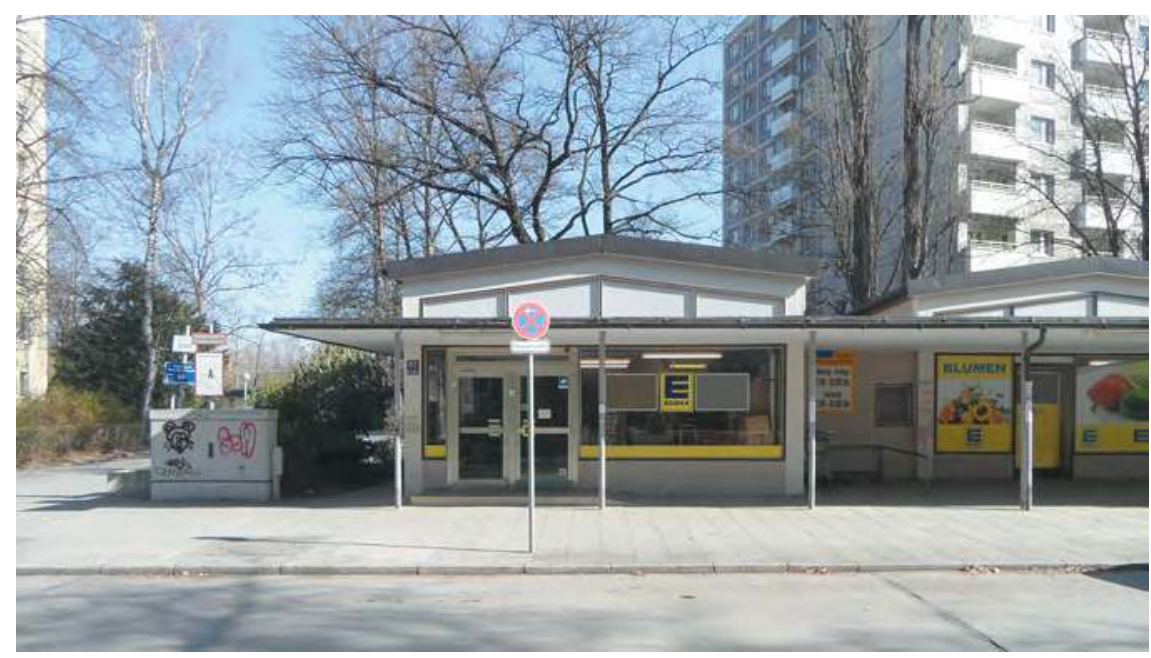

identify the area within the positional map that is of relevance to the case under study. Low intensities of change are arranged above the '---' section of the horizontal axis. It seems justifiable to position the overall Parkstadt process in this section of the horizontal axis. But should it be associated with lower or higher levels in the foregrounding of conflict?

While producing the map, we have encountered positions that relate to a single issue, but work with two different levels in the foregrounding of conflict. For example, the construction of a new highway through an inner city neighbourhood is by some associated with technological progress, and seen as part of a gradual evolutionary process towards better mobility networks and individual freedom in the sense of the modernist project; for others it is the epitome of cataclysmic change, erosion of cities, of capital flows that are ignorant of the intrinsic web of existing relations that define a locality. Hence, a single project or process might be connected to different positions and narratives of change, depending on the interpretative perspective from which it is seen. I propose that we look at the process in the Parkstadt Bogenhausen housing estate in a similar way - from different perspectives - as no single position seems fully to describe the pattern of change we observe in the case study. The idea is to generate a more differentiated view of the Parkstadt arena and its collective process by means of juxtaposing the institutionalised concept of change, which is to a large degree represented and co-produced by the descriptions in the annual meeting minutes, with other, more critical positions in the map. The outcome of this approach is, as I show in the following, a position that is not fixed to a single location in the map, but one that moves between a weak and strong foregrounding of conflict. The resulting dual position is composed of the institutionalised position P1 and its complementary critical position P2 (Figure 95). 


\section{Institutionalised Position P1: Weak Foregrounding of Conflict}

We have seen in the analysis of the meeting minutes that the self-descriptions and statements reiterate and justify the piecemeal, step-by-step process in the Parkstadt Bogenhausen arena. The dominant maintenance project is represented and realised as long term commitment which follows a trajectory of gradual development. The short-term, medium-term and long-term maintenance plans developed by the administration and advisory board provide the scheduled framework for this project. This goes hand-in-hand with a weak foregrounding of conflict in the communications. If references to conflict or disagreements occur in the minutes, they are usually framed by the view that they should, and will be resolved in the collective process. Notions of persisting crisis or fundamental conflicts are absent in the minutes. The dominant, or 'official' narrative of change which is used to describe and reflect on the collective's process does so without foregrounding conflict. While difficulties are addressed in the narratives, basic or more fundamental conflicts are not made part of the narrative. Hence, we can say that the institutionalised position is defined by low intensities of change in combination with a weak foregrounding of conflict. I have named this position $\mathrm{P}_{1}$.

At the very bottom of the map, covering the full length of the horizontal axis, is Christopher Alexander's concept of "frictionless coexistence" (Alexander 1964, p.19). The concept is not a priori related to low intensities of change, because fast but frictionless changes are also conceivable. Yet, if it is read in connection with Alexander's "one change at a time" (Alexander 1979, pp.385f), Aldo Rossi's concepts of permanence and change (Rossi 1982 [1966]), and Donald Schön's "stable state" (Schön 1971, pp.9-30), the positions in this area of the map are sufficiently clarified and focussed. It seems justifiable to say that these frictionless, stabilised, piecemeal, step-by-step positions come very close to the self-descriptions of the Parkstadt Bogenhausen process. However, rather than closing the discussion of $\mathrm{P}_{1}$ at this stage, I propose to connect to further positions that are located in the proximity.

The pattern of actions in the Parkstadt Bogenhausen process can be related to Donald Schön's concept of "dynamic conservatism" (Schön 1971, pp.31-60). As mentioned earlier, it entered the positional map while working on the case study element. The concept was developed by Donald Schön as part of his analysis of change in large organisations. Schön observed that changes and agents of change are admitted to a system as long as the subjectively experienced stability and continuity are not adversely affected (ibid.). The threshold beyond which the "stable state" is seen to be threatened tends to be fairly low. "Dynamic conservatism" is a collective process that aims at reducing the intensity and impact of change. Based on implicit agreements rather than an explicitly articulated strategy, its ultimate purpose is to contain the effects of change and re-establish some kind of "stable state" (ibid.). Accordingly, Schön suggests that "resistance to change [...] is a function of the system itself" (ibid., p.48), rather than the planned outcome of individual decisions. He provides different examples of corresponding actions of resistance. "Selective inattention" and "counter-attack" (ibid.) pursue either active or passive responses. "Containment and isolation" is seen to produce a condition of "compartmentalization" (ibid., p.49) over the long term, where "the system as a whole breaks down into units or territories, each of which walls itself off from the others" (ibid.). "Co-option" is the attempt to "absorb agents of change and de-fuse, dilute, and turn to their own ends the energies originally directed towards 
change" (ibid., p.49). If change cannot be avoided with these measures, actors may go for "least change", whereby that which has to be given up is minimised (ibid., p.50). If applied to the positional map, "dynamic conservatism" means the implicit agreement among actors to avoid higher intensities of change and higher levels in the foregrounding of conflict.

The ambitious maintenance project realised by the administration, advisory board and the collective of owners can be understood to operate in the service of "dynamic conservatism". The empirical data of the case study shows that there has been consistency in the agreement on large maintenance items since the WEG collective was established in 1984. This contrasts with the rejection of the majority of small-scale and often cost-neutral changes proposed by individuals. Agendas other than maintenance, such as greater individual diversity, have regularly failed to make it beyond the annual meeting hurdle. Hence, we may speak of a dominant discourse that has developed around the maintenance project. It is meant to secure the market value of residential property, legitimise the estate administration's programme and therefore its power status, silence possible conflicts, work as integrative device, and support a collectively shared "dynamic conservatism". However, "dynamic conservatism" is not limited to the maintenance project. If we consider, for example, the recurrent issue of 'loitering', "dynamic conservatism" ensured, on the one hand, that access to the estate was not restricted despite individual requests to do so. On the other hand, instead of actively supporting a space for loitering, the collective opted for 'least change'. In this case it meant that the informal meeting area was made less attractive. The collective implicitly assumed that in this way the initial state of non-disturbance could be re-established.

The concept of "dynamic conservatism" can also help us to better understand why the collective's control of higher levels of spatial organisation, comprising the levels of urban tissue, open spaces, and circulation infrastructure (Habraken 2002 [1988], p.8), continues to lack transformative effect. No significant changes have occurred on the higher levels since 1984. What we see, however, is substantial change and upgrading on the levels below the collectively controlled domain. Owners have made numerous modifications to their private units over the years on the basis of "satisficing" (Brand 1994, pp.165ff) with the support of a local builder, or as do-it-yourself, where needed skills "develop in the doing" (Lynch 1972, p.226). Changes typically include the removal and repositioning of non-loadbearing walls, new bathroom arrangements and kitchens, the complete renewal of finishes and flooring, or the connecting of two units to form a large unit. In this sense, owners treat the single unit as a kind of modifiable "infill" to the structural "support" of the building (Habraken 2002 [1988], p.12), with the limits pre-defined and tightly set by the loadbearing walls and the external envelope. On the micro-level, owners control change autonomously. They define the scope of works and the extent of change that is appropriate to their needs. Conversely, the very same ownership status does not seem to produce transformative action on the higher levels. Here, the efforts are almost always directed towards the maintenance project. Hence, the process of change in the housing estate is characterised by the paradoxical situation of having substantial changes on the level of the single unit, while on the higher levels change is almost absent. The loss of interaction on the urban level as 
Figure 95: Dual position of the observed process in the housing estate: connecting to and moving between positions of different concepts and narratives of change

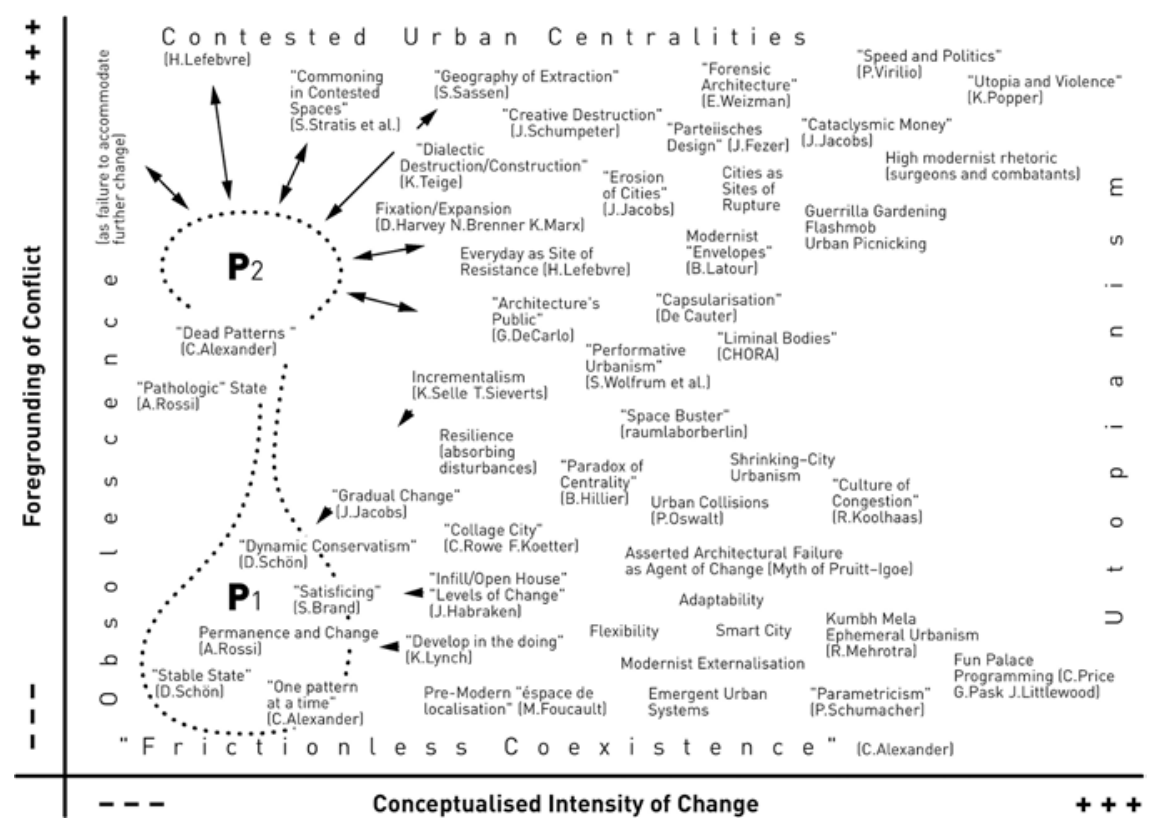

well as "dynamic conservatism" both result in the collective not having to engage with questions of design. The production and use of design knowledge is currently not part of the arena's work.

As we have seen, the 'frictionless' concepts in the bottom left corner of the map assume that through step-by-step processes the emergence of conflict can be avoided. However, if we connect this to Jane Jacob's concept of "gradual change" (Jacobs 2011 [1961], pp.293f), and further to "incrementalism" (Selle 1994, p.53, p.73; Sieverts 2003 [1997], pp.81f), two positions come into play which acknowledge and actively work with conflict. They claim that because of the pervasive presence of conflicting interests in cities and urban environments, incremental and gradual change is the most viable way to arrive at decisions in complex transformative processes. They emphasise the situatedness of change within contested spaces, power networks, and the wider condition of urban conflict.

\section{Complementary Position P2: Strong Foregrounding of Conflict}

The next stage in the movement through the positional map brings us to the higher levels in the foregrounding of conflict, and therefore to position P2. We are now confronted with the conceptual void, which provides only a very limited number of positions in this area of the diagram. The first question at hand is whether we could speak of a "pathological" permanence (Rossi 1982, p.22, p.59), or a "dead" pattern (Alexander 1979, p.127) upon interpreting the overall process in the Parkstadt Bogenhausen housing estate.

According to Rossi, permanences are "pathological" (Rossi 1982 [1966], p.59) when they have ceased to make active contributions to the life and "vitality" of the city (ibid.). He speaks of isolated areas to which "nothing can be added" (ibid., pp.59f). These propositions 
seem to mirror some of the phenomena observed in the Parkstadt Bogenhausen estate. But because Rossi does not provide a detailed description of his concept, its applicability and theoretical range is limited. We can, however, use the concept to arrange some of the case study findings in a specific way. The empirical data suggests that no changes of spatial, functional, or programmatic relevance for the surrounding urban area have resulted from the collective WEG process. There is also no evidence of the owners collectively participating in urban debates. From this, however, we cannot infer that the Parkstadt Bogenhausen housing estate has ceased to make active contributions to "the life of the city" (ibid., p.100). But we can say that the housing estate does not participate in the same transformative dynamics as other housing estates in Munich do, and it does not mirror the urban dynamics of the surrounding area. In this sense, the specific situation of the Parkstadt Bogenhausen housing estate has, perhaps, indeed led to a certain detachment from the city, not in a physical, social, or economic way, but in terms of its transformative process. While individual owners and residents continue to extensively 'add' to the estate, within the confines of their individual units and therefore on the micro-level, the findings seem to support the view that, to paraphrase Rossi, 'nothing can be added' to the estate on a larger scale. To speak of the Parkstadt Bogenhausen housing estate as being in a 'pathological' state, however, would be to reiterate the reifying concept of the city as organism and the modernist myth of the architect as the city's redeeming surgeon.

Alexander's "dead" pattern (Alexander 1979, p.127) is no less provocative, but it is difficult to connect to it from outside of his specific evolutionary model of transformation of the 'pattern language', and the 'timeless way of building'. To speak of 'dead' patterns makes sense only if patterns, or spaces, are conversely conceptualised as being "alive" (ibid., p.126). The empirical study of Parkstadt Bogenhausen and its analytical interpretation are based on the view that spaces cannot have a life on their own. In line with the pragmatist paradigm, spaces are not seen as conveying a hidden meaning that resides in spaces themselves and that exist outside human imagination, memory, and interpretation. However, the more recent relational concepts of space open up alternatives for making connections between the material and social worlds, and therefore to different ways of relating space to things that are 'alive'. If such an interpretative path is pursued, it makes sense to speak of 'dead' relations, or of relations that have ceased to be productive and meaningful.

The position of Rossi's concept of 'pathological' permanence enables us to relate to the concept of obsolescence in the positional map. As outlined earlier, obsolescence is defined as one of four primary categories on the positional map. It represents the lowest intensity of change (---), that is, the inability, or failure to accommodate further change. The concept of obsolescence is sometimes used together with a weak foregrounding of conflict, sometimes with a stronger foregrounding of conflict, depending on the situation, for which reason I have proposed to represent it as linear position, or category, that runs parallel to the vertical axis. Rossi works with a strong foregrounding of conflict. He briefly suggests that obsolete or pathological urban areas could be seen as "reserves" (ibid., p.96). I have already stated that Rossi left it unclear whether a reserve is for future urban development or for retreat and conservation, whether the reserve is meant to generate the new or to preserve the existing, or whether it is meant to offer these possibilities simultaneously. Irrespective of whether the omission and ensuing ambiguity was intended by Rossi or not, it seems to open up possible interpretations of 
the observed process in the Parkstadt arena and the housing estate, for which reason I take the idea of an ambiguous situation further in the Redundant City concept.

If we move even higher up in the positional map, we approach the concepts with the strongest foregrounding of conflict. It is, perhaps, no coincidence that the majority of positions in this area of the map belong to the more critical perspectives on the urban. Henri Lefebvre's concept of 'contested urban centralities' (Lefebvre 2003 [1970], pp.117f), which is, like obsolescence, defined as one of the four main categories in the positional map, represents the strongest foregrounding of conflict. It can be applied to conditions of both low and high intensities of change. In the proximity to P2, his concept is understood to go with low intensities of change. At this end of the spectrum, it defines a situation of conflict in which there is no, or very little change. This could be, for example, a situation in which a highly dominant process, group, or institution occupies a central position within urban power structures, while blocking access to power, and therefore the power to change, for other, weaker processes, groups or institutions. It defines a situation in which power structures are fiercely contested, but, because of the asymmetry involved, with no measurable movement or success. Further concepts in this area of the map seem to be relevant to the situation, for example David Harvey's and Neil Brenner's adaptation of Marx in the concept of 'fixation/expansion' (Harvey 1975; 1982, pp.379f; Brenner 2014, pp.15ff), Joseph Schumpeter's "creative destruction" (Schumpeter 2003 [1943], pp.83f), Saskia Sassen's "geography of extraction" (Sassen 2014, p.219), Jane Jacobs's "erosion of cities" (Jacobs 2011 [1961], pp.349), and Henri Lefebvre's 'everyday as site of resistance' (Lefebvre 2002 [1961], p.141). These concepts all work with lower intensities of change. Other concepts in the proximity of $\mathrm{P} 2$ that seem to be relevant to the situation are positioned at a slightly greater distance, representing a midrange intensity of change. They include Bruno Latour's modernist "envelopes" (Latour 2008, pp.8f), De Cauter's "capsularisation" (De Cauter 2001), Sophie Wolfrum's and Frhr. von Brandi's "performative urbanism" (Wolfrum and Brandis 2015), Giancarlo De Carlo's “architecture's public” (De Carlo 1971), and Philipp Oswalt's 'urban collisions' (Oswalt 2000, pp.73ff).

The data shows that references to concepts with a strong foregrounding of conflict, whether architectural or more related to everyday life, do not occur in the meeting minutes and other official communications that circulate in the Parkstadt arena. This is not self-evident, because multiple connections could be made from within and around the Parkstadt arena. The proposition brought forward is that the absence of references to critical positions is one of the many outcomes of the arena's work. WEG legislation and other social worlds define the problems that are admitted into the arena, together with the problems and questions that are to be excluded. The scope of what can be legitimately put up for discussion is limited. Issues like the externalising effects of modernism's 'envelopes', capitalist expansion through financialisation, urban extraction, obsolescence, or capsularisation are left unchallenged. Likewise, discourses about the everyday as site of resistance and alternative urban practices, or the establishment of an urban commons do not leave their mark in the arena. This is not to say that there is no controversy in the arena, or that actors do not relate to conflicts in the annual meeting at all. If participants in the social world of residents give a voice to critical positions in the meeting, which is rarely the case as repeated observations have shown, they are likely to be classified as being off topic, and are at best included in the official records as a short note. This supports the view that position P1 
could be conceived as the 'official', or institutionalised, position. The disregard of the more critical positions has the effect that the concepts and narratives with a weak foregrounding of conflict are for the most part taken for granted. They are at the base of the institutionalised process and appear to a certain degree as objectified urban reality in the arena (Berger and Luckmann 1966, pp.60f).

The positions encountered in the Parkstadt arena are connected to pre-structured relations of power. Different social worlds engage in the arena, where they negotiate their commitments to action, agendas, and ongoing concerns. The Parkstadt arena engages in collective work that is highly consequential. The process has established - and seems to continually reproduce - its own urban, spatial, and architectural condition.

\subsection{Introducing the Ambivalent and Controversial Notion of Redundancy}

In this section, I introduce the notion of redundancy. Through successive stages of analysis and mappings it has been possible to follow and describe the process in the Parkstadt arena, together with its spatial, architectural, and urban consequences. There seems to be sufficiently thick evidence to propose that the process establishes a specific ambivalent quality. I have chosen the notion of redundancy to give its name to the process and the phenomena it creates, because it embodies some of the key aspects of the observed process - ambivalence, conflict, and change. However, the notion of redundancy is neither native to, nor common in architectural and urban discourse at the present moment. We encounter the term sporadically in architectural semiotics, design theory, architectural engineering, or the sociology of space, but these disparate occurrences do not constitute a theory of redundancy or a unified body of knowledge. This means, for the purpose of further terminological clarification, I connect it to established non-architectural definitions of the notion first, before I adapt the notion to our requirements of concept-building, and the situation in the Parkstadt Bogenhausen housing estate.

The term is widely used and well established in science and technology studies (STS), computer science, engineering, system theory, linguistics, communication theory, or genetics. Seminal texts include mathematician John von Neumann's "Probabilistic Logics and the Synthesis of Reliable Organisms from Unreliable Components" (Neumann 1956) and political scientist Martin Landau's "Redundancy, Rationality, and the Problem of Duplication and Overlap" (Landau 1969), who relates redundancy to large organisations, and social systems. The works of sociologist Charles Perrow and political scientist Scott Sagan relate to political and sociological problems of high risk technologies (Perrow 1984; Sagan 2004). More recently, sociologist John Downer has conceptualised redundancy in engineering as a "design paradigm" (Downer 2009, p.18) that is shared by manufacturers and public regulators, for the paradox purpose of numerically framing unquantifiable risks associated with complex technical systems (ibid.). What these texts have in common is their clearly articulated awareness of the limits of redundancy. Despite the different contexts in which we encounter the term redundancy, it is usually attributed to either one of two categories:

1. "Redundancy is the property of having more of a resource than is minimally necessary to do the job at hand. As failures happen, redundancy is exploited to mask or otherwise work around these failures, thus maintaining the desired level of functionality." (emphasis added, Koren and Krishna 2007, p.3) 
2. "[...] redundancy is said to exist whenever there is an excess or superfluity of anything. The excess may be of parts, of rules of words, ... of anything. Excess, as defined lexically, is something which is more than the normal, the required, the usual, the specified. It is useless, superfluous, needless - terms which are variously employed to define redundancy. This linguistic habit directs a negative judgment. It points to features of a situation which are of no value, which are wasteful, which are bad." (emphasis added, Landau 1969, p.346)

Redundancy in the first category is a core concept in the design of fault-tolerance and reliability in systems. Fault-tolerance defines a field of research that acknowledges the presence of faults in human productions and that seeks to conceive and implement techniques to tolerate faults while keeping the system operational and delivering an acceptable level of service (Koren and Krishna 2007, p.2). In this respect, redundancy is conceptually close to resilience. Contemporary academic discourse on urban resilience is focussed on environmental impact recovery, but if we look at other discourses and contexts, this focus widens. In disciplines such as organisational theory, economics, risk management or business continuity, resilience is seen to be more than recovering from adverse events and maintaining a given level of functioning; it is the continuing ability to anticipate and resolve new problems and to learn from past experience. Where redundancy is about performance reliability, resilience is clearly positioned in a competitive context as a strategy of growth and of economic survival (against ecological disaster, or the business adversary). Characteristically and in contrast to redundancy, there is almost no polarising controversy about the need of resilience or about the need to define limits. Proponents of the concept tend to justify their strategies with reference to sustainability, or the need to have functioning systems (cities, businesses, networks), claiming that there can hardly be too much of it.

Redundancy is different. It is controversial. Redundancy requires more of the resource than is minimally necessary to perform a task. This 'more of' defines the degree of redundancy in the system (ibid., p.3). Redundancy is a means of dealing with problems of uncertainty. "In a perfect world, were everything is certain and predictable, there would be no need for redundancy." (Streeter 1991, p.180) In this sense, redundancy could be conceived of as a narrative of anticipation - we expect something to fail or change in an undesirable way, and redundancy provides an instant fix to the problem. This implies the thinking in scenarios and the prediction of future events. The difficulty, however, is that we do not exactly know when and how problems will occur. We do not exactly know how substantial the problem will be. Hence we do not know for certain how much redundancy is needed, and we struggle to determine the adequate level of redundancy. The ensuing conflict relates problems of efficiency to problems of cost. Moreover, because of the way humans interact with systems and with each other, and for reasons of unexpected interdependencies in complex systems, increasing the number of redundant elements in a system does not necessarily improve the ability of the system to resist failure (Sagan 2004). Uncertainty combined with the need to make decisions produces further conflict. Hence, the conflictual aspects in redundancy become most clearly evident when we have to address multiple problems which require prioritisation: 
"When there exists in a system the possibility of two different types of errors, redundancy theory becomes much more complicated because of the trade-offs between the errors. It also becomes very political because of the lack of agreement about the relative importance of the errors. Classical redundancy theory as applied to hardware systems provides little help in answering these normative questions about the appropriateness of and optimal levels of redundancy." (Streeter 1991, p.179)

Hence, redundancy is invariably bound up with conflict if it is applied to situations that involve action and decisions over prioritisation. Accordingly, there are fields other than technology in which redundancy is used in ambivalent, contested, and in this sense political ways. In quality management, redundancy is the unwanted level of quality above the aimed-for quality threshold, assuming this to produce extra - and therefore unnecessary - costs. As redundancy in this context depends on where the threshold is located, it forms part of a contested zone and is subject to change. In employment law in the UK, redundancy regulates the economically motivated dismissal of employees. Employees may be 'made redundant' if the employer ceases to conduct business or if the requirements within the business change. Here, redundancy is conceived as flexible instrument for the restructuring of businesses. But this category is the opposite of the redundancy in systems that are designed for reliability. Instead of responding to uncertainty through component duplication within the system itself, it follows a strategy of partial externalisation and passes on uncertainty and the potential hardships of change to the dismissed individual.

Hence, on the one hand, redundancy represents a concept through which we may produce extra levels of functionality, reliability, adaptability, or performance - a state which is regularly defined as something that is desirable; on the other hand, redundancy connotes the useless, superfluous and excessive - a state which is regularly defined as something that is to be avoided or that needs to be externalised. The concept requires agreement about when the useless becomes functional, about when the reliable becomes a waste. But as we have seen, there is no certainty about when the desirable state of redundancy is reached. There is no predefined or pre-given threshold to which decisions could be aligned.

Both interpretations of the term are used in architecture and urbanism. In particular the technically oriented disciplines in architecture and urbanism, like structural engineering, mechanical and electrical engineering, or transportation management tend to directly connect to the above definitions. However, the situation is different in the design oriented disciplines, because criteria like 'failure' or 'excessive' cannot be easily defined from the perspective of design. Hence, in design contexts the use of the term tends to relate to the first connotation, meaning extra levels of functionality, reliability, adaptability, or performance. An early reference is by Robert Venturi, when he addresses the qualities and characteristics of residual and redundant spaces in "Complexity and Contradiction in Architecture" (Venturi (1992 [1966]). He states that "redundant enclosure, like crowded intricacies, is rare in our architecture" (ibid., p.82), and that "[...] modern architecture has tended to ignore such complex spatial ideas." (ibid.)

In a recent article on the (re-)use of buildings, Thomas Sieverts theorises about why some buildings have the capacity to change and adapt better than others, proposing that the reason for this could be in the degree of redundancy in them (Sieverts 2017). He takes the main building of ETH Zurich, which was designed by Gottfried Semper in the 
$19^{\text {th }}$ century, to exemplify how a "strong, redundant spatial structure allowed for steady, continuous adaptation without losing its basic character." (ibid., p.104) For Thomas Sieverts the "resetting [of] old buildings for new purposes" (ibid., p.99) is an important aspect when it comes to the restructuring of cities. Adaptability and the capacity of buildings to change are understood to be vital for an urbanism of change that operates predominantly within existing built environments. In many European cities a considerable amount of construction work is in this sense related to the modification, upgrading, and adaptation of existing structures. Pertaining to the design of buildings and urban structures, Sieverts concludes that "planners and architects should [...] test how much redundancy is necessary to improve and widen the reset capacities." (ibid., p.104) Hence, Sieverts' use of the term defines redundancy as a specific architectural and urban quality, as something that has the capacity to support processes of change. In doing so, he relates the term to the complex fields of preservation and design work. The 'how much' implies that there could be a 'too much' as the possible undesirable alternative. Likewise, the need for testing implies that there is no certainty as how to achieve it, or as to the precise nature of redundancy in architectural and urban contexts.

If we use the term redundancy in everyday language, the situation itself tends to implicitly clarify which of the possible meanings are associated with it in that moment. In the context of research and theory, we usually seek to eliminate ambivalence and the resulting ambiguity through definitions and demarcations. Here, the 'both/and also' tends to be explicitly substituted for the simpler 'either/or', based on the understanding that ambivalence is to be avoided in research. If defined in this way, redundant means either benefit or waste.

In the construction of the Redundant City concept I propose to follow a different approach. By explicitly emphasising its different connotations simultaneously, I intend to maintain the level of ambiguity and ambivalence inherent in the term redundancy. Similar to the dual position proposed to describe the process in the Parkstadt arena, the term is conceived as conceptual movement between two different levels in the foregrounding of conflict. It defines a position that cannot be fixed in place with certainty, and that, as a result, defies closure. By means of not eliminating its contradictions, I propose to establish an open construct that is bound up with controversy.

\subsection{Otherness and Evocative Utopian Quality}

In the following, I elaborate on the proposition that the Parkstadt Bogenhausen housing estate and its collective process have a specific ambivalent quality, or capacity, and establish further, perhaps less obvious, characteristics of the Redundant City.

We have seen that the work of and in the Parkstadt arena is spatially consequential. The effects of the work are clearly visible when we compare the housing estate with the spatial dynamics in the local area, and the transformation of other housing estates in Munich. If we look at the instrument of WEG legislation from the perspective of its effects in the Parkstadt arena, we see how it shifts the momentum of change in a specific direction. The annual meeting and all individual owners have far-reaching powers to decide on and initiate changes. However, the WEG requires that changes that involve the modification of existing property rights as layed down in the commonhold declaration ('Teilungsurkunde') need to be decided by unanimous vote. This has a 
significant impact on the process of change. It establishes a hurdle that is difficult to overcome. Practically, all modifications to the estate that add new usable building volume would fall into this category, irrespective of overall size. The experience of administrators confirms that the more voting owners belong to the commonhold-type entity, the more difficult it is to achieve consensus (Hess et al. 2015a; 2015ba, p.12). Given the number of owners in the 'Wohnungseigentümergemeinschaft' Parkstadt Bogenhausen, unanimous votes are almost impossible to achieve. Conversely, the simple majority required to adopt maintenance items is routinely established in the annual meeting. In terms of size and overall value, there is no pre-defined limit set by WEG legislation for maintenance works. This makes it possible for maintenance to develop into a comparably large project and to assume a dominant role in the collective process. Hence, physical changes that are not located within the category of the maintenance project tend to be modest in size and do not involve the modification of property rights.

Pertaining to the difficulty of accommodating change in multiple-ownership constructs, Sieverts speaks of "a conflict that has already become a serious problem." (Sieverts 2017, p.105) With a view to the scale of the city, Sieverts asserts that "the dominating habit of dividing a building into sometimes hundreds of part-ownerships makes our cities almost inflexible because it proves to be nearly impossible to achieve the necessary majorities for change decisions among the owners." (Sieverts 2017, p.105) The situation in the Parkstadt arena seems to mirror this tendency. The data obtained through interviews and participant observation suggests that the social worlds of residents, investors and administration are well aware of the difficulties imposed by the WEG decision-making model, albeit without drawing the connection between the estate and the city. Hence, further questions arise as to the possible consequences this may have for the housing estate in the long term. Pertaining to the capacity of large residential projects to change over time, John Habraken asserts that

\footnotetext{
"the balance between what will change and what will remain long term is becoming increasingly important when projects become larger and larger. A housing project of several hundred uniform units cannot just stay rigid when time goes by, but must adapt to life's variety." (Habraken 2006, p.15)
}

Hence, if John Habraken and Thomas Sieverts insist on the significance of adaptability, in particular with regard to larger structures - are constructs like the Parkstadt Bogenhausen housing estate not facing a serious dilemma? Or can we understand the ongoing process of small-scale, incremental changes to individual units as providing a sufficient level of adapting to "life's variety"?

I propose that the ambivalent and controversial notion of redundancy could be useful in raising critical questions and in this way for partially unlocking the rigidifying conceptual framework of the estate's dominant narrative of change.

In view of the observed process, could we say that in the Parkstadt arena there is an

- excessive concern with maintenance at the expense of the urban? For, if gradual upgrading, by means of adding the 'more of' convenience and comfort, is predominantly aimed at the 
- commodity aspect of housing, if the preservation of investment interests is emphasised

- at the expense of looking at other possible 'more ofs' -

- are we not looking at a process that is striving for closure rather than openness, for homogenisation rather than difference, for repetition and "dynamic conservatism" rather than real change, for "frictionless coexistence" rather than controversy?

- Are there alternatives - are there other ways of thinking, or 'doing', the Redundant City?

If one of the core capacities of cities and the urban is to generate and creatively respond to conditions of change, then the above characteristics seem to describe a situation in which the level of active participation in urban change is reduced to a minimum. However, to conceptualise the situation as mere "dead" pattern (Alexander 1979, pp.126f), or "pathological" permanence (Rossi 1982 [1966], pp.22, 59f) would be to conclude with simplifications. To avoid premature closure, the process of conceptualisation cannot end here. It is possible to further add to the list of qualities by means of identifying the less obvious characteristics of the situation. This final step in the synthesis combines the empirically grounded observations with the discursive capacity of the term redundancy.

Situations of asymmetric urban change are in a certain way indicative of some kind of 'otherness'. The Parkstadt Bogenhausen housing estate is different if compared with other housing estates in Munich, precisely because the Parkstadt arena does not seem to participate actively in the current urban discourse on possible 'more ofs'. We have seen in the comparative study that many housing estates dating from the same era are subjected to substantial urban restructurings that go far beyond energy conservation measures and floor plan adjustments. The ones that do not follow this trend, like present-day Parkstadt Bogenhausen, will diminish in numbers as the process continues.

\section{Its very limited effective capacity to generate 'otherness' on the urban level dis- tinguishes the Redundant City from other spaces in the city and makes it in this sense a space of 'otherness'.}

Hence, if we continue to develop our conceptualisation, could we conceive of the Redundant City as future "ghetto" along the lines of Manuel Castell's analysis, as a place that is detached from the faster flows of urban development, bypassed and ultimately forgotten, together with its marginalised population of 'redundant' producers? (Castells 2010a [1996], p.147; 2010b [1998], p.149) Or should we rather conceive of it as an homogeneous 'island' that follows its own trajectory of change, an island that becomes with the passage of time a romantic reminiscence of the past - of the kind criticised by Jane Jacobs in 1961?

"It may be romantic to search for the salves of society's ills in slow-moving rustic surroundings, or among innocent, unspoiled provincials, if such exist, but it is a waste of time. Does anyone suppose that, in real life, answers to any of the great questions that worry us today are going to come out of homogeneous settlements?" (Jacobs 2011 [1961], p.448) 
Or could the Redundant City, as differences grow due to further asymmetric urban change, become the object of desires and give rise to new ideas? Could the unactivated potential in the Redundant City act as catalyst and initiate public debates? Could it become the subject of discourses about the distribution of resources and access to urban qualities, engendering more spatial and programmatic diversity and the co-presence of differences? Could the Redundant City stimulate debates about higher densities, enabling more people to participate in the urban and benefit from the advantages of centrality? Could the Redundant City encourage its critics to develop alternative and better concepts for the collective production of urban space and its appropriation? Could the problematic of the commonhold-type entity inform our debates about urban commons and better forms of participation and cooperation? Clearly, the speculative and critical thinking about the Redundant City opens up future scenarios and raises many questions. Moreover, due to its ambivalent enabling and at the same time inhibiting characteristics, the Redundant City conveys the promise of a lasting catalyst for ideas and space of possibilities, because its potential is unlikely ever to be fully realised and used.

Because the urban level of the Redundant City is likely to remain inactivated, it increasingly may generate desires and 'What if?' scenarios. In this sense, there is an evocative utopian quality in the Redundant City.

At the same time, there is a degree of predictability in the Redundant City process. The arena's structural fixations and hegemonic constellations of power, combined with the integrative capacity of the maintenance project, the silencing of conflict, and the shared interest of protecting capital investment in the long term provide a backdrop of stability. The complex reality of dispersed ownership effectively removes the estate from the grasp of speculative global capital, because investment opportunities cannot be bundled for wholesale transactions. "Cataclysmic money" (Jacobs 2011 [1961], p.291) is unlikely to become effective in the housing estate. If we take the pattern of the timeline study and assume the housing estate's future process to be not much different, we have reason to believe that the housing estate will persist in its present form for a long time to come - maybe much longer than originally designed for. While some housing estates of the late modernist era are currently being demolished or partially abandoned, like Robin Hood Gardens in London, or Le Vele di Scampia in Naples (Trapp 2018; Stengel and Aquilar, in press) ${ }^{21}$, the Redundant City is unlikely to be caught up in 'urban renewal' schemes of this kind. The Redundant City is in this sense stabilised and rigidified within an otherwise rapidly changing urban environment.

Despite its limited capacity to change, the Redundant City is likely to persist for a long time. In this sense, it defines a kind of stabilised and rigidified condition in an otherwise rapidly changing urban world.

21 During winter semester 2017/18 a group of students at TUM engaged with the uncertain future of the Le Vele di Scampia - The Sails of Scampia housing estate in Naples. The design course and research project was led by Prof. Sophie Wolfrum, Heiner Stengel and Giorgia Aquilar. A publication about the project is currently in preparation. (Stengel and Aquilar, in press). 
In my earlier discussion of the concept of redundancy, I emphasised its ambivalent capacity, as well as the conflicts over prioritisations this entails. Problems become acute when there are multiple issues which need to be equally addressed (Streeter 1991, p.179). Controversies over prioritisation and the goals that are to be attained in the Parkstadt arena are of spatial and social relevance, and therefore political. Hence, the Redundant City concept has a political dimension. The Redundant City is a "matter of concern" (Latour 2005, p.39, p.47).

\section{The Redundant City has a political dimension due to its ambivalent and contro- versial qualities. The Redundant City is a "matter of concern".}

These last points in the list of characteristic qualities of the Redundant City link the present condition of the Parkstadt Bogenhausen housing estate with its possible futures. What kind of 'more ofs' will, or could, it be striving for? Which kind of redundancy will prevail? If it is true that the social worlds implicitly or explicitly align their processes with concepts like "frictionless coexistence", "stable state", "permanence", "one change at a time", "satisficing", "dynamic conservatism"; and if it is true that legislative frameworks, structural conditions and organisation of power relations rigidify the situation, what consequences will it have for the collective's ability to respond to, and generate change? Which status will it assign to the maintenance project and the preservation of investment interests in the future? In which other meaningful ways could the collective contribute to the everyday life in the housing estate? What will happen if, due to an increasing sensitivity for the situation, the social worlds in the arena begin to relate to the scale of the city and assign greater emphasis to controversy in the process? Will the collective produce, or demand, a wider arena, thus increase its radius of action as well as the number of possible alliances, encounters, and communications? Will the collective establish a new way of interacting with the urban level? Will it appropriate its resource of open spaces in different ways? Will it discover and make use of the Redundant City's utopian qualities? These and other questions may or may not be debated in the future Parkstadt arena. The new concept is meant to broaden our understanding of urban change, and expand the scope of what we can 'see' in the city. In doing so, it raises further questions. Like the urban, the Redundant City concept is an open construct, and in this sense a matter of concern.

\subsection{The Redundant City. A New Concept in Sixteen Theses}

As outlined in the methodological introduction to the case study, the goal is not to establish a coherent and finite set of causalities meant to 'explain' the Parkstadt Bogenhausen housing estate. I have argued on the basis of the project's epistemology, that a reductive approach, simplification, and closure would fail to address the specific nature of the urban condition. An explanatory model based on an alleged coherent set of causalities would also have us believe that, if we were to define the observed condition as 'a problem', there could also be 'a solution'. Despite these epistemologically and methodologically justified limitations, the new concept is meant to broaden our understanding of urban transformations - precisely because of the chosen approach.

If, for this purpose, we adopt Herbert Blumer's distinction between "[...] definitive concepts [which] provide prescriptions of what to see, [and] sensitizing concepts 
[which] merely suggest directions along which to look" (Blumer 1954, p.7), and if we reject, together with Blumer, Clarke, and others, the prescription in favour of the sensitising concept, we will have to find the adequate level of looseness and precision in the description of the new concept. In this way the synthesising stage is no different to the research process itself. This means, rather than providing a fixed, and therefore closed 'definition' of the concept, I assemble and interpret in a rather open way the empirically grounded observations made in the Parkstadt arena, the findings of my movements through the positional map, and the comparative study. Together with the ensuing discussion of possible connections, the following sixteen theses represent the main elements of the Redundant City concept. They are in this sense "[...] 'the big news' about the situation of concern" (Clarke 2005, p.111) ${ }^{22}$. Redundant City is meant to show one possible direction - among other possible directions - for looking at and engaging with the Parkstadt Bogenhausen housing estate.

\section{Redundant City is the outcome of a twofold research process, which engages with urban narratives of conflict and change and the dynamics of the Parkstadt Bogenhausen housing estate. The new concept describes a specific form of col- lectively negotiated urban change.}

I have chosen the notion of redundancy to give its name to the concept, because it embodies the key aspects of the observed process - ambivalence, conflict, and change. It is intended to make us aware of the Redundant City problematic, its simultaneously enabling and inhibiting characteristics, and the various implications this may have. By explicitly emphasising its different connotations, I seek to establish a conceptual position that is not fixed in a single place and that defies closure in the style of Latour's "matter of concern" (Latour 2005).

The term 'Redundant City' functions as a signifier both for the new concept and its socio-spatial referent, the Parkstadt Bogenhausen housing estate. The controversial notion of redundancy is an invitation to critically engage with the Redundant City concept as well as the Parkstadt Bogenhausen housing estate and to connect them to current urban debates.

\section{The Redundant City in Sixteen Theses}

1. Asymmetric Urban Change. The housing estate neither fully participates in the overall dynamics of change that prevail in Munich's metropolitan region, nor does its pattern of change correspond with the kind of changes observable in other local housing estates. Differences in transformative speed and extent of spatial change cannot be attributed to its architectural properties or to location. Rather, they are seen as being related to a specific process.

2. Rigidifying and Pre-structuring Effects in the Parkstadt Arena. The rigidity in the institutionalised framework means that core relations within the Parkstadt arena, and therefore within the estate's process, cannot be changed without changing WEG legislation and other legislative bodies at large. The predefined structure

22 Drawing on his experience as professional journalist, Robert Park used this term in the identifying of the core message of a research project. 
determines which group is authorised to participate in the collective decision making and how this has to be done.

3. Dominance and Integrative Capacity of the Maintenance Project. In the Redundant City maintenance work is a key concern. It is assigned a dominant role, which has effects on the positioning of other concerns. It serves the purpose of securing the market value of residential property, legitimising the estate administration's programme and therefore its power status, and acting as integrative device that channels and homogenises stakeholder interests. The emphasising of maintenance, rather than change, silences conflict and has a stabilising function in the decision-making process.

4. Established Assumptions on Preservation are Left Unchallenged. Substantial changes can be realised within the guiding framework of the Monument Protection Law. Questions as to how change could be accommodated in the estate beyond that which has been going on since 1984 have not been raised so far.

5. Failure to Accommodate Changes Proposed by Individual Owners. There are a growing number of issues brought directly into the arena by individual owners, of which most are related to small changes. Despite this increased level of direct involvement with the process, it does not result in increased levels of change. In this respect, we may speak of a failure in the process to accommodate the smallscale changes proposed by individual owners in an adequate way.

6. Limited Empowering Effect of Ownership. WEG legislation assigns a significant amount of control over the estate to the collective of owners. Although they have access to higher control levels than is usually the case in cities, the empowering potential does not become effective on the estate. Modifications on the estate remain limited to maintenance work and the confines of the private unit.

7. Striving for Closure and Homogenisation. The social worlds/arenas map clearly shows that not all local residents and users participate in the arena. Despite the theoretical permeability of the social worlds' boundaries, the often specialist commitments around which each social world assembles lets the Parkstadt arena appear as being fairly closed. The work of each social world is narrowly focused and is in this sense a strong delimiting and homogenising factor.

8. Loss of Interaction on the Urban Level. The more substantial changes in the estate fall into the period when it was owned and managed by the Neue Heimat group. Today, despite the factual possibility the collective has to act on the urban level, it does not participate in the restructuring, densification and diversification as other estates in Munich do, nor does it participate in discourses about Munich's housing crisis, or urban change. Spatially, the estate has ceased to change at the urban scale.

9. Institutionalised Narrative of Change Without Foregrounding of Conflict. The institutionalised and in this sense 'official' narrative of change is the combined work of all major social worlds in the arena, including the social world of the administration, investors, residents, and the subworld of the advisory board. The narrative is reproduced through the descriptions of and reflections about the collective's process. References to cohesion, consensus and compromising dominate. Discourses about basic conflicts are not made part of the narrative.

10. Containment of Change through "dynamic conservatism". The collective process bears characteristics of a "dynamic conservatism" (Schön 1971) that aims at reduc- 
ing the intensity and impact of change. Based on implicit agreements rather than an explicitly articulated strategy, its purpose is to contain the effects of change in the housing estate and (re-)establish some kind of "stable state" (ibid.).

11. The Arena's Work Does Not Include the Production of Design Knowledge. The dominance of the maintenance project, the loss of interaction on the urban level, as well as "dynamic conservatism" (ibid.) result in the collective not engaging with questions of design. The production and use of design knowledge is currently not part of the arena's work.

12. Contradictory and Ambivalent Quality of the Redundant City. The Redundant City has, on the one hand, a specific capacity to initiate and develop processes of change through the relative autonomy of a collectively exercised, ownership-based authority. On the other hand, collective self-regulation, structural and institutional frameworks, investment-driven accumulation, the silencing of conflict, and "dynamic conservatism" (Schön 1971, pp.31-60) produce conditions which allow transformations to occur on the micro level, albeit in a very regulated and limited way, while practically inhibiting changes and interactions on the urban level. In the Redundant City, spaces of individual appropriation and change are connected to spaces of stagnation. The Parkstadt Bogenhausen housing estate and its collective process have a specific ambivalent quality, or capacity.

13. Its very limited effective capacity to generate 'otherness' on the urban level distinguishes the Redundant City from other spaces in the city and makes it in this sense a space of 'otherness'. Situations of asymmetric urban change are indicative of some kind of 'otherness'. The Parkstadt Bogenhausen housing estate is different if compared with other housing estates in Munich, precisely because the Parkstadt arena does not seem to actively participate in the current urban discourse on possible 'more ofs'. We have seen in the comparative study that many housing estates dating from the same era are subjected to substantial urban restructurings that go far beyond energetic upgrading and floor plan adjustments. The ones that do not follow this trend, like present-day Parkstadt Bogenhausen, will become fewer in number as the process continues.

14. Because the urban level of the Redundant City is likely to remain unactivated, it increasingly may generate desires and 'What if?' scenarios. There is an evocative utopian quality in the Redundant City. Rather than conceiving of the Redundant City as a place that is detached from the faster flows of urban development, bypassed and ultimately forgotten, together with its marginalised population of 'redundant' producers (Castells 2010a [1996], p.147; 2010b [1998], p.149), rather than defining it as a homogeneous 'island' that with the passage of time becomes a romantic reminiscence of the past (Jacobs 2011 [1961], p.448), could we think of it as a resource of yet unknown qualities? In this scenario, the Redundant City is a space where the surplus of redundancy is of a positive kind, unfolding its hidden potentials, where the 'more ofs' are the sources of diversity, where urban change is discussed and approached in completely new ways. The 'what if?' in the Redundant City may then give rise to a new kind of cooperatively appropriated city, which enables new ways of sharing, co-designing, and collectively producing space. In this Redundant City, the sense of empowerment, which is already effective internally, increasingly embraces the outside, both conceptually and practically, and makes it in this way an urban space of lasting possibilities. Because, whatever 
the desires and ideas may be, due to its ambivalent enabling and at the same time inhibiting characteristics, the potential of the Redundant City is unlikely to be ever fully realised and used.

15. Despite its limited capacity to change, the Redundant City is likely to persist for a long time. It defines a kind of stabilised and rigidified condition in an otherwise rapidly changing urban world. There is a degree of predictability in the Redundant City process. The arena's structural fixations and hegemonic constellations of power, combined with the integrative capacity of the maintenance project, the silencing of conflict, and the shared interest of protecting capital investment in the long term provide a backdrop of stability. The complex reality of dispersed ownership effectively removes the estate from the grasp of speculative global capital, because investment opportunities cannot be bundled for wholesale transactions. We have reason to believe that the housing estate will persist in its present form for a long time to come - maybe much longer than originally designed for.

16. The Redundant City has a political dimension due to its ambivalent and controversial qualities. The Redundant City is a matter of concern. In my discussion of the concept of redundancy, I have emphasised its ambivalent capacity, as well as the conflicts over prioritisations this entails. Controversies over prioritisation and the goals that are to be attained in the Parkstadt arena are of spatial and social relevance, and therefore political. The Redundant City concept has a political dimension. The Redundant City is a "matter of concern" (Latour 2005, p.39, p.47).

Looking back, the observation of asymmetric urban change defined the point of departure for the analysis. The Redundant City concept is positioned in the contradictory field of conflict and change. The concept as well as the methodological justification for the way it was generated are meant as encouragement to approach transformative processes in the city from a different perspective. By combining architectural and urban theory with empirical research elements, I have used a research design which moves through different spaces of enquiry (multi-site research) and which draws from multiple methods. The research approach conceives of the urban as open construct, both conceptually and in terms of methodology; it is a call to challenge the linear solution-oriented approaches in urban practice with more conflict-oriented perspectives; and it is the attempt to critically examine the conceptual range of domain-specific architectural ideas about spatial transformation through confronting urban reality, as well as to widen the discourse about it. The sensitising concept is meant to broaden our understanding of urban change, and expand the scope of what we can 'see' in the city. 


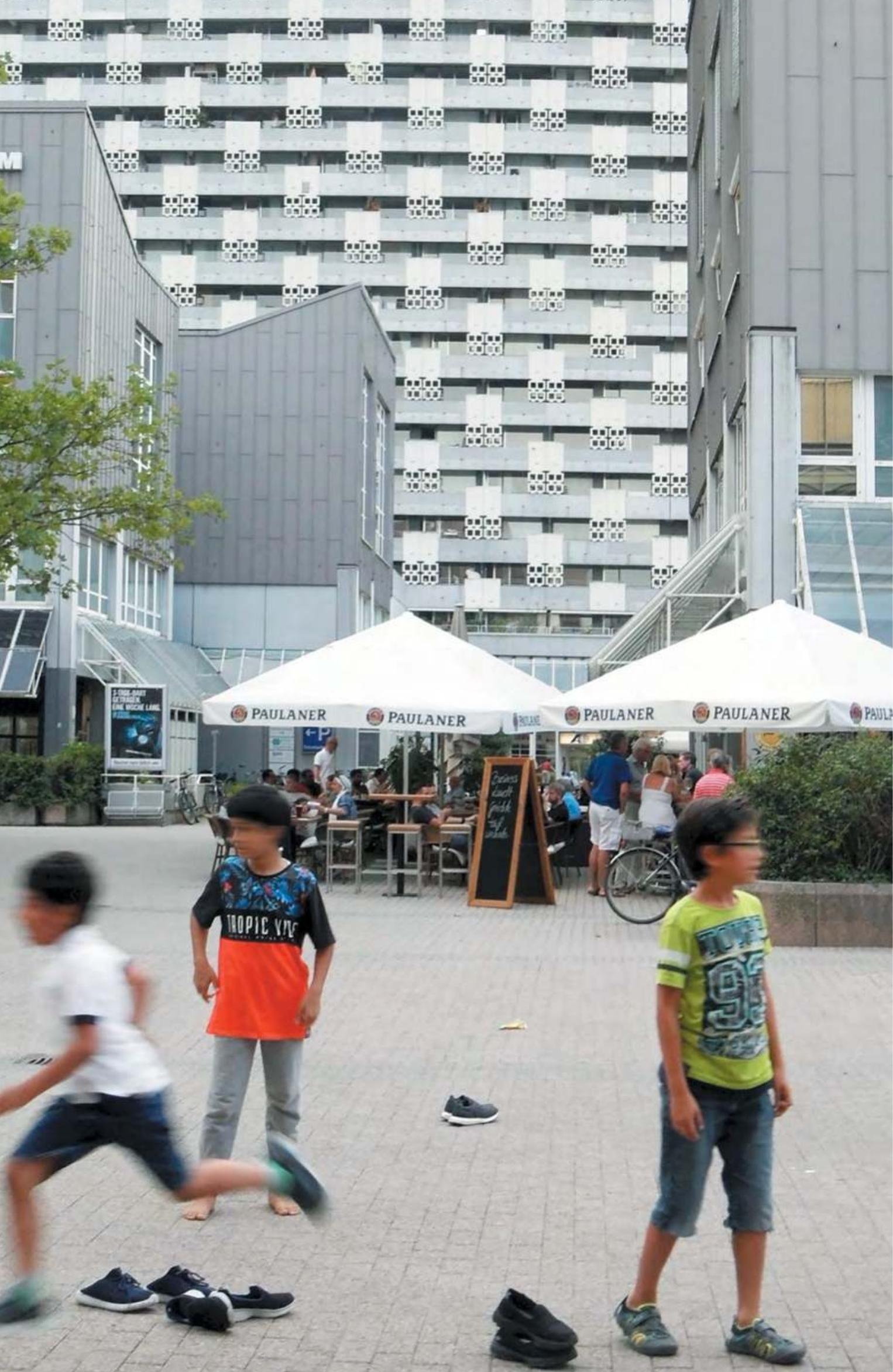


Figure 96: Arabellapark urban sub-centre, started in 1965; Rosenkavalierplatz by Stöter-Tillmann \& Kaiser, Friedrichs, Kleie 1977-1982; Arabella-Hochhaus by Toby Schmidbauer 1966-1969, Munich 2017

\section{Connecting and Releasing}

"Instead of installing themselves in their containers, instead of adapting to them and living in them 'passively', they decided that as far as possible they were going to live 'actively'. In doing so they showed what living in a house really is: an activity. They took what had been offered to them and worked it, converted it, added to it. [...] They created distinctions [...]. They introduced personal qualities." Lefebure, Henri (1972 [1969]) preface to: Boudon, Phillipe (1979) Lived-In Architecture: Le Corbusier's Pessac Revisited, Cambridge MA

"The right to the city [...] is a right to change ourselves by changing the city. It is, moreover, a common rather than an individual right since this transformation inevitably depends upon the exercise of a collective power to reshape the processes of urbanization."

Harvey, David (2008) The Right to the City, in: New Left Review, vol. 53, p.23 


\section{Making Multiple Connections}

\subsection{Multiplicity of Possible Connections in Multi-site Research}

The Redundant City concept engages with only a small part of what makes for the multiplicity and diversity in our cities. It is highly selective in its observations and depicts a specific urban condition that coexists alongside many others. Acknowledging the limits of the concept means to see it as part of, and therefore as being connected, with other urban situations.

Openness and connectedness are central to the research approach of this project, for which reason I have chosen to work with grounded theory methodology (GTM) and situational analysis (SA). The methods of theoretical sampling, anchoring, intersecting, and positioning respond to and exploit the potentiality of open field constellations. Based on the proposed adaptation of the iterative-cyclical GTM process, the research navigated through the universe of architectural and urban narratives - searching for concepts of conflict and change, as well as through the Parkstadt Bogenhausen housing estate - searching for the specifics of its transformative process. The movements followed existing connections and generated new connections. The positional map placed concepts and narratives within an analytical field, showing relations, voids and unexpected proximities. In the empirical analysis, processes of joint human action could be traced through the timeline mappings. The mappings have established connections between decision making, time and space, between human action and spatial transformation. Hence, we can say that the establishing of new connections is at the core of the research project.

In the introduction to this project, I posited that research in architecture and urbanism occupies different epistemological locations and produces knowledge that is framed in different ways. For this reason, it cannot be assumed to be a routine or pre-given process. But rather than approaching the multiple framings of knowledge as an obstacle to research, I took them as an epistemological and conceptual resource to work with, based on the understanding that urban issues cannot be grasped in isolation and from a single perspective. As part of the methodological set up, the project has established new connections between architectural and urban research, GTM and SA. These connections are not limited to the project-specific adaptation of methods. The mappings of the Parkstadt arena as well as the work with positional maps in architectural and urban theory define novel approaches that could flow back into the research perspective of SA.

The sharing of basic assumptions with social theory about how humans act in and upon the world opens up further possible connections to research questions in the social sciences. Based on the analysis of the Parkstadt Bogenhausen housing estate and the Parkstadt arena, we have argued that its collective process differs from other transformative processes. We know about the kind of decisions negotiated over time. We see the arena's effects on urban space and the spatial arrangements in the estate. We have also made assumptions about the consequences this might have for the future and on the questions this may raise. However, we have not yet undertaken an analysis of 'how' these processes develop in detail, how changes are negotiated in interpersonal interaction and between different groups; how differences in power, gender, and status are addressed in the process; and how interactions become fixated as 'facts' so that 
they appear as pre-given in a situation. Also, we do not know in detail about the relation of individual biographies, social networks, and political processes to the transformative process on the estate. Evidently, a broad range of further connections could be made in this field. They could be examined with a broad range of tools supplied by ethnography, narrative methods, ethnomethodology, as well as through the perspectives of actor network theory, or assemblage theory. Of course, we could also think of different connections with the production of design knowledge and design.

It is challenging, and maybe impossible, to fully address and exploit the possible connections opened up by a multi-site research approach. Among the many connections that may be established between the outcomes and other research, and among the many possibilities for applying and testing the outcomes in a practical way, I have selected three areas, which I discuss further below. The idea is to give a sense of the versatility of the new concept, and of the research approach that lies at its base.

\subsection{Making Research Outcomes Available for Practical Uses}

The research design of this project is not based on a 'problem identification - problem solution' approach. Offering blueprint solutions is not the intention of this research project. I have, however, suggested that the Redundant City is a matter of concern. In one way or the other, the observed conditions are part of many people's everyday lives - in and around the Parkstadt Bogenhausen housing estate and, perhaps, beyond. This justifies, and even seems to make necessary, the question as to possible practical applications of the research outcomes. For the reasons outlined above, I will, however, not be proposing a strategy, or goal-oriented set of recommendations. Rather, I point to possible ways of working with the research outcomes, showing how they could be put to practical use in different fields. The proposed way of working with the research outcomes is meant to generate an awareness for issues rather than provide solutions. In the following sections on connecting, I provide examples based on the following three areas

1. working with the new concept

2. working with the mapping tools

3. working with narratives of conflict and change in the positional map

Arenas of other housing estates, other WEG constructs, or other urban conditions of asymmetric urban change are all potential sites for working with the research outcomes. Upon outlining the research of housing schemes dating from the late modernist period, I have suggested that there is a generic quality in them as a result of the principles of universality and uniformity used in their design. Hence, despite the Parkstadt arena ranging at the far end of the spectrum in terms of its size and complexity, could we think of comparable processes being at work in other housing estates, neighbourhoods, commonhold-type properties, and condominium buildings? Many years have passed since the late modernist housing schemes and housing estates were built. They each have diversified and developed their own processes, irrespective of the similarity in their built form and common origin. The same applies to the institutionalising and rigidifying effects of WEG legislation. Although the framework regulates the process for all WEG constructs in the same way, individual forms of adapting the 
Figure 97: Balfron Tower, designed by Ernő Goldfinger in 1963, built 1965-67, grade II listed since 1996, prior to commencement of refurbishment works in 2014, Poplar, East London 2014

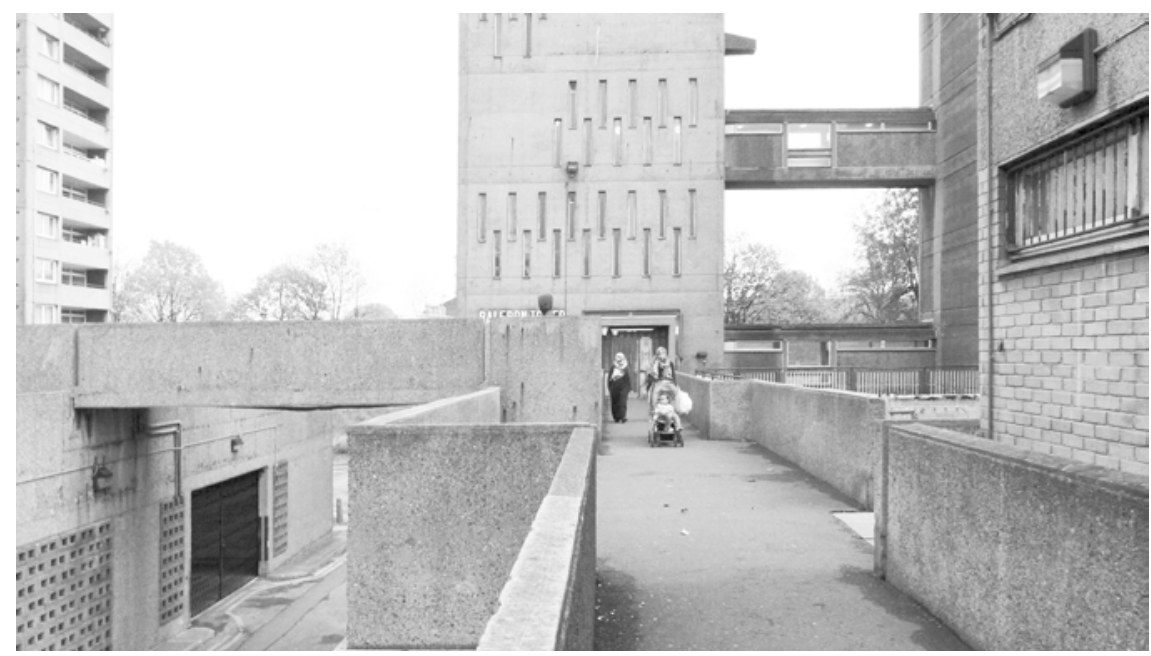

rules and working with the framework have evolved and will continue to evolve. Housing administrators, advisory boards, and protocols of annual meetings may be similar, but never identical. This produces variations for each arena in the practices and processes used. Accordingly, each situation has to be examined for its own characteristics. As I have argued at the outset of the case study, there is no such thing like 'the' housing estate.

\section{Working with the Redundant City Concept}

\subsection{Towards a Broader Understanding of Change in Housing Estates}

Research in housing is to a considerable extent commissioned and funded by organisations in the private and public housing sectors ${ }^{1}$. Due to the many different issues involved, it may include research elements on financing, housing policy and programmes, statistics, construction technology, procurement methods, management, upgrading and maintenance, or best practice. However, categories of conflict that do not lend themselves to 'solutions', such as an understanding of conflict as a creative agent in collective processes, or an understanding of conflict as basic urban condition, are typically disregarded. Where the focus is on building norms, optimisation, or added-value chains, questions relating to macro-scale issues, or different ways of 'doing' architecture typically remain unaddressed. It operates within rather narrowly defined conceptualisations and the demarcations it imposes on itself. Without questioning the usefulness of the knowledge produced in this way - due to its methodological fram-

1 In Germany, the public and private housing sectors are subsumed under the term 'Wohnungswirtschaft'. 
ing - it tends to have a limited range and tends to be focussed on conflict resolution, which is seen as a goal in itself.

A large body of research and design projects are concerned with housing estates that are in single ownership. Here, the process of change is typically negotiated between the owning entity, for example, a housing association or the municipality, and other large entities, like funding agencies or local authorities. Although residents are often consulted in the process, the ultimate responsibility and authority remains with the single owner.

However, there seems to be a growing awareness of the need to strengthen, establish, and open up arenas of conflict and change. The formerly widespread practice of managing change in housing estates as top-down process, as had been common practice in the Neue Heimat group and other large housing providers, has given way to more inclusive approaches. Innovation in the transformation and adaptation of housing today is often connected to new ways of engaging with variegated needs and diversity. Different levels of participation or co-design processes are increasingly seen as means to generate and include new qualities in housing projects.

The commonhold-type form of ownership establishes a more complex situation in estates if compared to the single owner/tenant relationship. Differences in ownership have a significant influence on how decisions are negotiated and made. Consequently, there are limits in terms of making connections between cases that are based on different ownership models. If transfer of knowledge is to be made, the differences have to be considered. The research on the transformative process in the Parkstadt Bogenhausen housing estate adds to our understanding of these differences as well as of the complexity involved. The transfer of knowledge between research in multiple and single ownership housing could work in both directions. Social worlds/arenas of housing estates in single and multiple ownership could learn from the issues to which they each have to respond.

The Redundant City concept provides a perspective that contrasts with the narratives commonly propounded by the private and public housing sectors. The understanding developed in this research project shifts the focus away from market-driven problems of optimisation and conflict resolution. It challenges the generalising and stereotyping idea of housing estates as 'mass housing' (Kling, in press), as well as the reduction of housing to its commodity aspect. In this sense, the project contributes to a shift that is already underway in both research and urban practice (Harnack 2012; 2014; Stenberg 2012; Stenberg and Fryk 2012; 2014; Benze, Gill and Hebert 2013; Stenberg et al. 2016; Kling and Ott 2019). To develop a broader understanding of change in housing estates would be a step towards enabling better change in housing estates, and in this sense towards better change in and of cities.

\subsection{Challenging the Selectivity in Munich's Densification Programme}

In 2009, the city council of Munich commissioned a study on long term development perspectives for residential uses in Munich - "Perspektive München. Langfristige Siedlungsentwicklung” (LaSie) (Landeshauptstadt München 2009). The focus in the first stage of this study was on the spatial aspects of restructuring mixed-use areas, consolidating the periphery, and planned densification. It included an analysis of urban morphology and existing spatial qualities. The studies were conduced by 
Figure 98: Initially controversial, but much beloved today. Barbican Estate by Chamberlin, Powell and Bon 1965-1976, London 2017

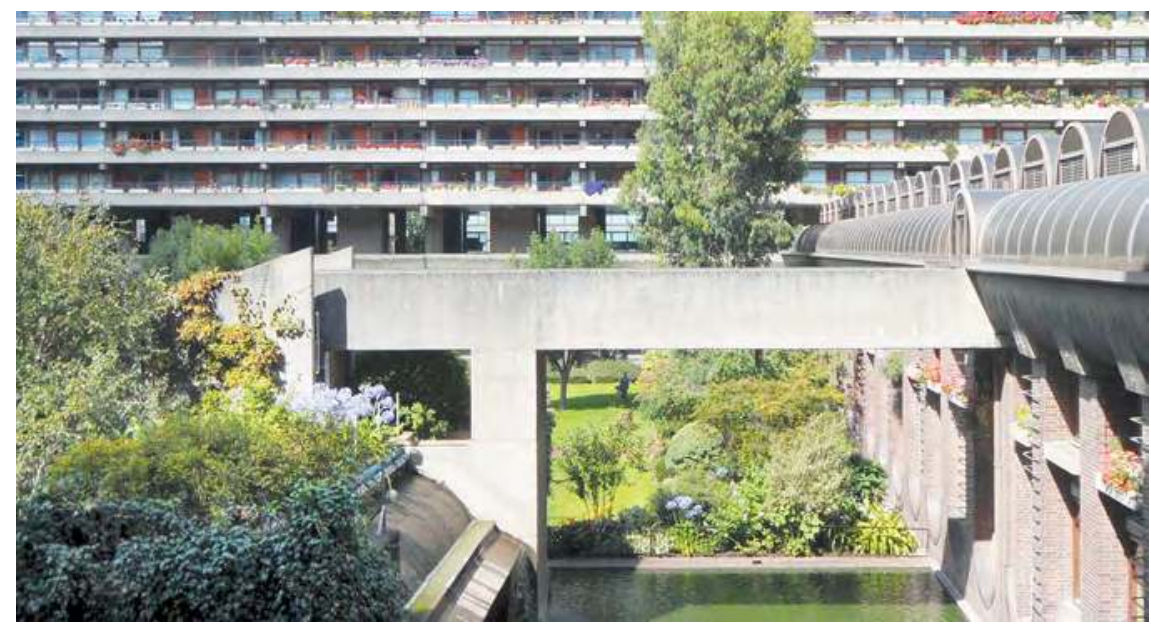

multidisciplinary groups of external experts. The results were discussed in a workshop-like setting (Landeshauptstadt München 2011). The second stage of the study resulted in a status report for the long term development of residential uses. The policy document was prepared by the Department for Urban Planning and Building Regulation ('Referat für Stadtplanung und Bauordnung') in 2015 and adopted in 2016. It covers a broad range of issues that are understood to be of relevance for the development of new housing and for the spatial transformation of the city (Landeshauptstadt München 2016a). The authors of the status report assert that the ongoing debate on densification and the long-term LaSie development perspective have raised the awareness of problems of densification among the main actors involved (ibid., p.3). They highlight that new development schemes are now based on higher densities, but also mention that a growing number of local interest groups demand protection for their low-density neighbourhoods (ibid., p.5). The awareness addressed in the report is thus divided between the adjustment of building practice on the one hand, and resistance in local neighbourhoods on the other. This seems to confirm that the question of densification in Munich continues to be a contested political issue (Geipel and Meyer 2012).

Pertaining to the situation in low-density neighbourhoods, the status report claims that the means to actively influence the process and generate revenues for the cross-funding of adequate public infrastructure or affordable housing are very limited (Landeshauptstadt München 2016a, p.6). Despite the substantial development potential identified in the 2009 study, the 2015 status report creates the impression that densification in low-density neighbourhoods is not the preferred option. The report refers to the environmental qualities that are seen to be at stake, as well as the need to protect private interests from densification projects that change the character of the low-density area (ibid., p.5). For these areas, a series of exemplary local development plans are currently being conceived. This removes them from the centre of the densification debate and confirms their privileged status. Likewise, housing estates in dispersed ownership according to the WEG, or housing estates listed under the 
Figure 99: Town hall exhibition 'Thinking Ahead. 125 Years Urban Development Planning in Munich'. The sign says: 'More people, more city', Munich 2018

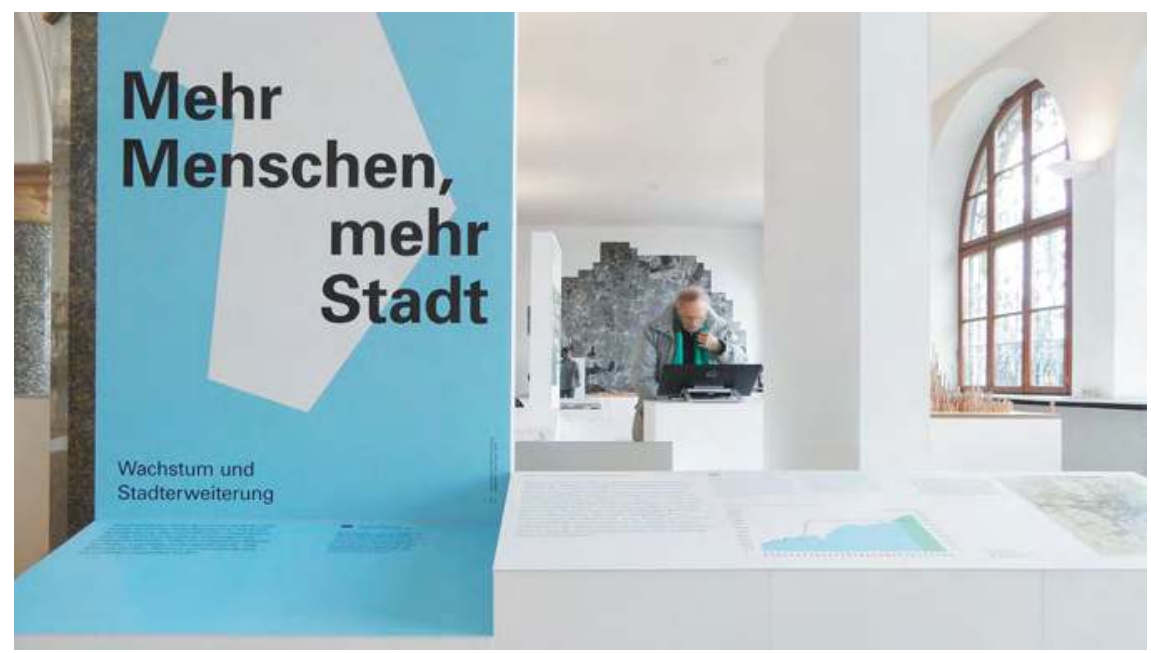

heritage protection law, are also defined as separate categories and left aside in the current debate on densification (ibid., pp.19f; Landeshauptstadt München 2016b, p.17).

Hence, Munich's current politics of densification bears the characteristics of a politics of least resistance. We currently see densification schemes being realised in housing estates that are owned and managed by housing associations, municipal housing corporations, or large housing co-operatives with centralised forms of organisation, while other housing estates are not included in the process. The Parkstadt Bogenhausen housing estate is one of them. The city administration apparently avoids interfering with organised private interests. As a result, suburban neighbourhoods and larger, privately owned housing in multiple ownership are at this stage not part of the long term Munich perspective. The current discourse on housing densification, which includes research, workshops, experimental housing schemes, and other programmes, is highly selective. The result is a process that is defined by asymmetry in terms of how debates are focussed, as well as where and how densification projects are realised. This raises questions about who in the urban population has to adapt to the consequences of densification - positive or negative, but also about the overall capacity of the city to absorb growth and respond to conflict and change.

The selective approach excludes sites of greater complexity that offer resistance. It concentrates on problems that appear sufficiently structured and clear, hoping that in this way existing instruments can be used and faster solutions provided. As argued earlier, there is a tendency in technocratic and bureaucratic processes to admit problems only if they bear the promise of a 'solution'. However, the question is if a problem which is of city-wide public concern should be approached in this way. For Munich's historic development has produced a pattern of conflict externalisation and spatial segregation that is difficult to ignore. Structures like incinerators, garbage dumps, motorways, atomic research facilities, (disused) military camps, water treatment plants, and airports are all concentrated in the north and the east of the city. Critics could claim that the current selective approach towards densification and restructur- 
ing replicates this pattern of segregation in a disguised form. Although the areas earmarked for densification are scattered over the whole city territory, they seem disproportionally to include low income neighbourhoods. The selective approach threatens to lead to the concentrating of programmes in areas that already have to cope with stigmatisation, unemployment and rising rents. A critical urban politics needs to address urban inequality in densification and restructuring schemes.

As a response to the lack of affordable housing, the city administration seeks more actively to influence the kind of housing provided. Since 2013, the city of Munich is testing a change in housing development policy, which signals a shift away from profit maximisation towards long-term commitment and higher levels of public control. While in the past public land was in most cases sold to the highest bidder, which is understood to have led to adverse effects in the development of rents, the new policy "Konzeptioneller Mietwohnungsbau" (KMB, Experimental Provision of Affordable Rental Housing) allocates land on the basis of development quality and a set of longterm goals (Landeshauptstadt München 2016b, p.86). A fixed ratio of affordable housing is to be guaranteed for up to 60 years and no conversion into commonhold-type housing according to the WEG is permitted during this period. The authorities expect the model to have alleviating effects on rents in the long term. Also, it may well be the case that the model accommodates new and alternative modes of change in the future. However, despite these promising steps towards a broader and more fundamental response to the housing crisis and resistances to change, we have seen that a degree of selectivity has already become effective in the analysis stage of the LaSie programme and is likely to persist in the near future. What consequences does the partial postponing of analysis have for decision making and the overall process? We could argue that questions of urban restructuring and densification, which are considered by the authorities as a citywide and regional task (Landeshauptstadt München 2009, p.18; 2016a, p.4) should be examined for all areas and urban situations with the same thoroughness, irrespective of the resistances this may generate. The proposed concept and the social worlds/arenas perspective contribute to a better understanding of situations in which multiple and conflicting interests are entangled with spatial issues. With the support of this knowledge, urban situations that are currently excluded from the discourse on restructuring and densification may be more easily reintegrated.

\subsection{Questioning Structural Conditions in Arenas of Change}

The prevailing phase of low interest rates in the European Union for both savings and mortgages has made residential property an attractive alternative to other forms of investment for private investors. This has led to a rising demand for residential units that are optimised towards profitability and the commodity aspect, which in turn has increased the pressure on the property markets. In Germany, metropolitan regions of larger cities like Hamburg, Munich and Berlin are particularly affected by this trend. In this situation, the construction of new commonhold-type property according to the WEG, as well as the conversion of existing property continue to thrive. In conversions, residential blocks that previously have been in single ownership are subdivided into multiple private units that can be sold separately. Subsidised affordable housing that has reached the end of the public funding period after 25-30 years is often treated 
Figure 100: Detail of model showing increase in floor area ratio (FAR) in Munich between 2012 and 2016. Note that no increase is specified for the Parkstadt Bogenhausen housing estate (", added), while the majority of neighbouring areas have grown substantially (blue). "München weiter denken. 125 Jahre Stadtentwicklung", Munich 2018

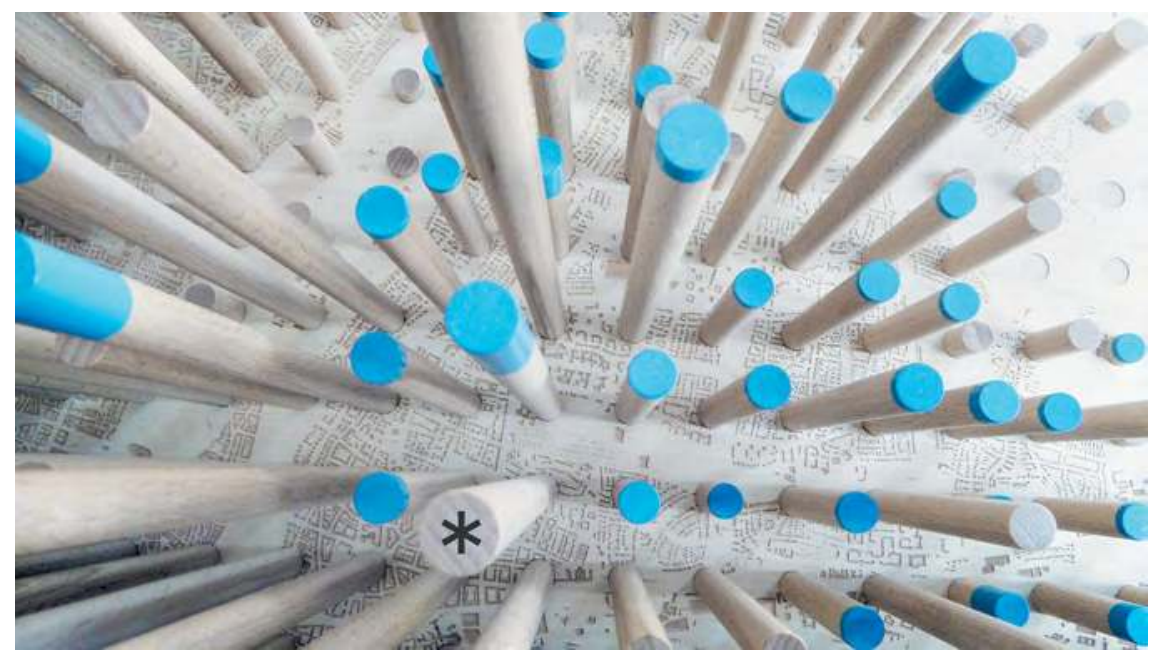

in this way. As excess rates of subdivision are understood to have adverse effects on local neighbourhoods, municipal administrations have set regulations in place that are meant to control and restrict the conversions in designated areas ('Erhaltungssatzung', respectively 'Milieuschutz') (Landeshauptstadt München 2016b, pp.30, 116ff). A better understanding of the processes that influence change in housing estates as well as in buildings that are in multiple ownership could inform the broader discourses about gentrification and change in urban areas.

If, as Thomas Sieverts suggests, the unabated conversion and construction of new commonhold-type entities according to the WEG may lead to serious problems in that they reduce a city's capacity to accommodate and adapt to change in the long term (Sieverts 2017, p.105) - in what concrete ways could we influence the process? The social worlds/arenas map provides an idea of the different collective actors and concerns involved. There seem to be multiple possible ways through which the situation could be influenced. The most obvious, and perhaps one of the most powerful means would be to revise the regulation, and in this sense inhibiting frameworks, of commonhold-type housing, including property legislation. This possibility is, perhaps, less unlikely than it may seem. The current housing crisis has brought to the fore the weaknesses and shortcomings of the established regulatory systems. This in turn has led to a new interest in questions of land ownership (Hertweck 2018a; 2018b; 2018c), as well as the (re-)politicising of the way we approach regulatory instruments. Imke Mumm, for example, suggests that "the immanent significance of societal regulatory frameworks for the physicality of our cities has to be recognized so that we do not leave their creative power (Gestaltungskraft) to chance, and instead place it in the service of positive change." (Mumm 2018, p.153) Furthermore, there is a growing interest in alternative urban practices that seek to develop the use value of urban spaces rather than their exchange value by withdrawing them from capitalist speculation (Dona 2018). 
The social agreement on private property is of such a fundamental kind that actors tend to take it for granted. In the case of Germany, a serious attempt to reform the land law ('Bodenrecht') was initiated in 1973 by SPD politician Hans-Jochen Vogel on behalf of the many who had been dissatisfied with the distribution and use of urban land, the housing situation, and market-led valorisation. The reformers demanded property owners assume their social responsibility as required by constitutional law ('Grundgesetz'), and to contribute in an appropriate way to the common good (Hertweck 2018a, p.154). Prior to holding the office of Federal Minister of Regional Planning, Building and Urban Development ('Bundesminister für Raumordnung, Bauwesen und Städtebau'), during which Vogel actively campaigned for the reform, he had been mayor of Munich during the years 1960-1972.

It is, perhaps, no coincidence that from 1956 to 1968 Vogel lived in the Parkstadt Bogenhausen housing estate (Krack 2006, p.162-164). Owned and managed by the trade union's non-profit housing association Neue Heimat Bayern, the housing scheme was by definition dedicated to the common good ('gemeinnützig'). During his long political career, Vogel also served as federal minister of justice, mayor of West-Berlin, SPD candidate for the chancellorship, and chairman of the SPD party. In 2006 he kindly assumed the patronage for the $50^{\text {th }}$ anniversary of the Parkstadt Bogenhausen housing estate (Krack 2006, p.164) and gave the ceremonial address. During Vogel's office as mayor of Munich, the city of Munich commissioned the extensive sociological study "Stadt am Stadtrand" (Town at the Edge of Town) in 1964, which covered four large housing schemes, including the Parkstadt Bogenhausen housing estate (Zapf, Heil and Rudolph 1969). In the foreword, Vogel refers to the critical questions that began to emerge with the construction of new urban quarters, giving expression to the hope that the empirical study would contribute to the public debate about the provision of affordable, high-quality housing (Vogel 1969, pp.7f). Since then, the debate has had its highs and lows, but it has never lost its relevance.

Vogel's positions have recurrently informed public debates as well as the criticisms of researchers and practitioners. A recent interview with Vogel, "Eigentum verpflichtet!", by Arno Brandlhuber and Christopher Roth is published in the Arch+ magazine's 231 volume "The Property Issue" (Brandlhuber and Roth 2018). Florian Hertweck provides an overview of Vogel's plan to reform the land law for urban areas in the same volume (Hertweck 2018b). He also refers to Vogel's reform plan in his contributions to the Porous City book and conference (Hertweck 2018a). Analysing the historical situation in 1973, Florian Hertweck suggests that for the purpose of conceptualising the reform plan, Vogel could draw on his first-hand experience with land speculation in Munich on the one hand, as well as on the affirmative 1967 court decision on the use of land by the Federal Constitutional Court on the other (ibid., p.154). Reading the court's statement today, it does not seem to have lost its relevance and urgency:

"the fact that land is both limited and indispensible means that we cannot leave its use to free market forces or to the will of individuals; our legal and social obligations, which are based on justice, mean that in this case we need to consider public interests to an extent far greater than this is required for other financial goods" (Bundesverfassungsgericht 1967, translated in ibid.). 
Figure 101: Student proposals for Neuperlach, Munich. Contribution to Munich's ongoing public debate on densification. Town hall exhibition "München weiter denken. 125 Jahre Stadtentwicklung”, Munich 2018. A major part of the Neuperlach satellite town was developed by Neue Heimat Bayern in the early 1970s, the same non-profit organisation which had developed the Parkstadt Bogenhausen housing estate 15 years earlier.

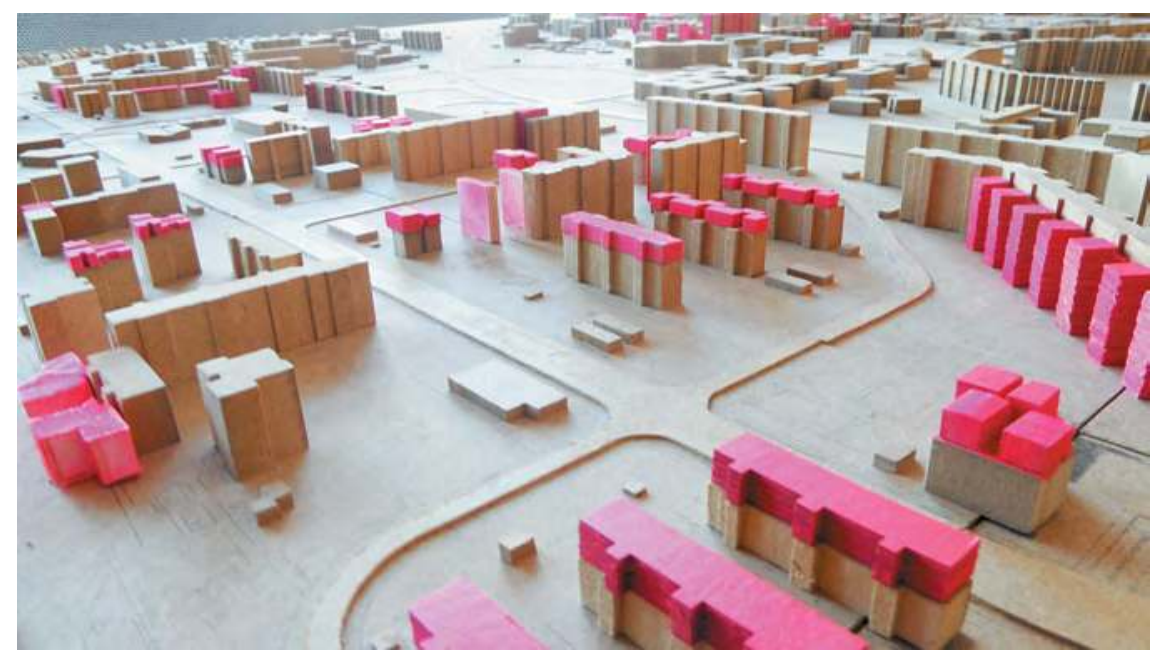

In 2018, a formal process of further reforming the German WEG was initiated. However, like in the previous reform, the focus is on problems of modernisation and efficiency. The more fundamental questions are bracketed out. Critics of the planned reform see the power of decision-making to further shift to large investors and the administration (Prantl 2020).

Problems like land speculation and the difficulty of reconciling profitability with the social obligations of property ownership are, of course, directly related to the nature of the capitalist mode of production. The social world/arenas map shows how financial interests influence the relationship of different social worlds and subworlds in the Parkstadt arena. Regulatory instruments like 'Sozialgerechte Bodennutzung' 'SoBoN', which was implemented in Munich in 1994 (Landeshauptstadt München 2016b, pp.11, 18), seek to mediate between different interests and goals by diverting a percentage of the profits to the provision of social and communal infrastructure. The provision of housing by municipal or non-profit housing associations, like the 'Gemeindebau' schemes in Vienna, or projects like Ex-Rotaprint in Berlin, where the land is withdrawn from speculation for long periods of time (Hertweck 2018c, p.14), are further examples of cooperatively or politically mediated market situations. Some initiatives go further in that they take their critique of the negative long-term effects of profit-orientated development as one of the starting points for the establishment of alternative modes of production, like the realisation of an urban commons (Stavrides 2015; 2016; Ott, Kling and Zöhrer, in press). 


\subsection{Appropriation and Redundancy in Buildings}

Can we support processes of individual and collective appropriation through more redundancy in buildings? Can we influence patterns of change through constructing and organising spaces in different ways? Based on my earlier criticism, we should be cautious not to argue from within the myth of Pruitt-Igoe. Because buildings and their spatial capacities have to be seen as being related to the multiplicity of human and non-human actors that co-constitute a situation, including the structural conditions which I have discussed in the previous section. The task, then, would be to avoid approaches that are based on an assumed 'building problem/solution' causal linearity, and rather think about the kind of contributions buildings could make in and to the situation. The case study showed that residents modify their immediate spatial environments if they have the opportunity to do so. During the $50^{\text {th }}$ anniversary of the Parkstadt Bogenhausen estate, a large cinematographic projector was installed in a private flat to make possible a free public screening, because no other means could be worked out for the technical setting-up ${ }^{2}$. The apartment was in this way converted into a temporary projection booth, and the housing estate into an open air cinema. Hundreds of guests and local residents enjoyed picnicking on the lawn, while watching films that had been made in and around the housing estate at some time in the past. If users were able more easily to add non-residential uses to the housing estate, how would it change? What other kind of changes might be possible?

Based on these and other observations we have made by studying the process in the Parkstadt Bogenhausen housing estate, a set of general practical propositions arise which relate to architectural work. For example, it would make sense to design specifically, and differently, for commonhold-type entities. The potential that is in the mix of collective and individual responsibility as well as in ownership-based authority could be coupled with concepts of adaptability to create more responsive built environments and to facilitate spatial change.

Where housing is primarily conceived as a commodity, optimisation and efficiency range as core values in the service of profitability. Any operating in the 'unknown' is considered a potential threat to this goal and therefore avoided. However, where housing is seen as being closely related to dwelling, understood as a process and creative activity, then the unknown, indeterminacy, and the 'soft' changing of space are seen as enablers, rather than threats. Pertaining to the 'soft' ways of using and changing space, Tatjana Schneider and Jeremy Till observe that "[...] soft use generally demands more space, even some redundancy, and is based on a relaxed approach to both planning and technology [...]." (Schneider and Till 2007, p.7) In this sense, the ever increasing accumulation and consumption of private residential space per capita could be converted into a productive kind of redundant space - which is available for experimentation, accommodating change, and adapting to the new. Are there further ways of providing, or designing, a positive kind of redundancy in buildings and spaces?

The concept of adaptability has gained in relevance in connection with life cycle considerations and extended time-horizons for the built environment. The limited availability of greenfield sites, a changing attitude towards our historical urban fabric, and the consistent demand for space in growing cities all increase the pressure to reuse

2 Information about this project could be obtained through the expert interviews. 
existing buildings. Many inner city sites succeeded in undergoing a rapid transition from light industrial to a post-industrial state because of their flexible building stock. Former commercial districts have been converted into thriving urban quarters, where residential use is mixed with new forms of living and working, leisure and tourism. Many of these buildings, like warehouses, $19^{\text {th }}$ century housing, or historic office buildings had not been intentionally designed as adaptable buildings, yet they were able to accommodate change. In view of the future challenges to be met in cities, Thomas Sieverts advocates "the principles of resetting existing buildings and of fostering emotional interest, responsibility and active involvement in the city" (Sieverts 2017, p.99), as well as "[...] experiments in a new relation of urban development and natural environment, which do not destroy, but enrich the realm of nature." (ibid., p.102) Sieverts observes that "growing abstraction" and "indirectness" (ibid., p.101) have contributed towards people feeling detached from problems that should be of concern (ibid.). In this sense, the move away from the technocratic, centrally managed provision of housing towards models of housing in which groups and individuals have more control of - and therefore responsibility for - the built environment and the many processes and situations to which it relates, open up new possibilities for the (re-)connecting of people with issues that are of concern. Commonhold-type constructs already enable groups and individuals to assume a degree of direct responsibility for the built environment. In view of the potentially inhibiting effects which current commonhold-type constructs have, Sieverts suggests that a different hierarchy of control levels based on structure and infill could make buildings more responsive. In the proposed arrangement "[...] heavy support structures and access systems are defined as long-term elements of urban infrastructure, whilst private living spaces are defined as short-term, modifiable 'infills' made of materials that are easily renewed and recycled, e.g. wood." (ibid., p.104) In this sense, Sievert's proposals connect to the projects and ideas of John Habraken, Otto Steidle and others, who have advocated architectures that enable groups and individuals to change the spaces they use and occupy more actively and freely. Addressing the problem of WEG entities' inhibiting influence on processes of urban adaptation, Sieverts suggests that "the conflict could perhaps be resolved by restricting part-ownerships to the 'infills', leaving the 'infrastructure' to some kind of publicly controlled body." (Sieverts 2017, p.105) However, this would require that some of the locally exercised collective authority of WEG entities be delegated to a different, perhaps less local arena. New ways of cooperation and decision making between control levels or arenas of change would have to ensure that processes do not resort to the centralised, technocratic models of the past. With reference to historic precedents, Sieverts conceives of support/infill projects as

"[...] on the one hand, abstract, open structures with general qualities, and on the other hand, strong individuals, sometime even stubborn personalities. They have a core of resistant, formal character, but also 'soft parts', which could even be taken away and substituted by new ones without destroying the basic character. In this sense they are like small models of cities." (ibid., p.104)

Actors who design, construct, modify and use spaces of this kind build on the specific "capacity" of architecture (Wolfrum and Janson 2016, pp.44f), in that on the one hand architecture may provide stabilising articulations of spaces, dense atmospheres, 
'gestalt', materiality, and on the other hand, scope for the performative and appropriation, variability in use and meaning, and openness (ibid., p.45). Sophie Wolfrum and Alban Janson have subsumed the complementary capacity of the architectural under the terms "Prägnanz" and "Spielraum" (ibid.). The perspective of an "architectural urbanism" (ibid., p.10) emphasises these and other specific qualities which the architectural can bring into cities (ibid., pp.23ff). The idea of the city as mere agglomeration of structures and buildings is rejected together with the reduction of architecture to its physical aspects and the scale of a building. Architectural urbanism stresses the relations between space and action, between process and form, between continuity and change. If the support/infill approach is conceptualised in such a way that it includes the urban rather than being limited to the scale of a building, it may connect to, and in this way make use of the capacities of an architectural urbanism.

There is a growing public interest as well as a growing market for approaches that use the support/infill approach to give users more choices for realising individualised spaces, connecting to the city, and making changes in the future. As I have mentioned in my discussion of control hierarchies and layers of change, BeL Sozietät für Architektur (Wolfrum and Brandis 2015, pp.123ff) and Praeger Richter Architekten (Praeger and Richter 2017), among others, are currently testing and experimenting with variations of the model in competitions and realised projects. In order to fully unfold their potential, propositions for new kinds of buildings should not be seen in isolation and require, among other things, a corresponding set of enabling regulatory and financing frameworks. The financing would need to be orientated towards a process, rather than commodity or product. It would have to enable the realisation of spaces over time, and accommodate mixed responsibilities according to the different levels of control involved. Using the Redundant City concept as a basis for urban intervention means seeking ways of creatively exploiting the contradiction between the stabilising and utopian capacity of redundancy, and to work with its ambivalent qualities, its otherness, its political dimension.

\section{Working with the Mapping Tools}

\subsection{Community Mapping as Means of Empowerment and Agent of Change}

The mappings presented in this book are positioned within an academic research context. They are the result of a single researcher engaging with a specific research situation. This raises the question as to what extent the mappings may be applied to the analysis of other housing estates and situations of change, and if so, could they become instruments of collective learning and of empowerment beyond academia? $?^{3}$ SA's broadly conceived methodological framework allows mapping instruments to be applied to varying data, according to the situation under study. I have added to the standard SA mapping tools a set of newly developed mappings. The mapping of

3 The Third Oikonet Conference in Manchester in September 2016 gave me the opportunity to present my work and to discuss this question in a multidisciplinary setting. I would like to thank in particular Adam Evans, Viviana Fernández Prajoux, Lasse Fryk, Leandro Madrazo, Jenny Stenberg and Iván Tosics for their comments and for sharing their ideas in the session. 
negotiated concerns in the Parkstadt arena, as well as the diagram showing the overall situational process along a timeline are key mappings in the case study. They establish a record of controversies over time, they juxtapose dominant and weaker discourses, they show how shifts in the decision-making process are linked to changes in ownership structure and other parameters that influence the process. If we think in terms of the versatility of the case-specific timeline mappings, how easily may they be reconfigured for the analysis of other situations? Housing estates are sites where a multitude of social worlds intersect with each other. The generic character frequently attributed to modernist housing should not deceive us about the uniqueness of every housing estate. Hence, mappings developed for a particular situation cannot be transferred to other situations of analysis without some modification. It seems justifiable, however, to assume that there is a common theoretical and methodological basis which could serve as a starting point for developing contextualised maps that reflect the specificity of other cases.

Individual owners in privatised commonhold-type housing estates have a statutory right to participate in the collective decision-making process and are, in this sense, already in positions of power. However, I do not distinguish between owner residents and non-owner residents, or between privatised or non-privatised housing estates in this section, for I believe there is a general need for empowerment and increased levels of participation in housing estates, irrespective of ownership form and status. The proposed empowering capacity of collective mapping could be seen as resting in both the production of knowledge, and the collective process itself. If participation is defined as participating in the making of decisions, that is, to actually make decisions (Lüttringhaus 2012; Unger 2014, pp. 40, 47; Fernández Prajoux 2014, p.4), the mappings of the Parkstadt arena engage with the very substance of participation. They represent the decision-making process and therefore the participatory process. Mappings of this kind can enable members of a specific social world in participative processes to better understand their situation in relation to other social worlds in the arena. Organised as timelines, they show transformative interactions over time. The mappings may give actors a better idea about how and in which constellations decisions are made. The mappings make visible the effects of pre-structured processes, the distribution of power, "compartmentalization" and "dynamic conservatism" (Schön 1971, pp.31-60), exclusion, or the establishing of a dominant maintenance project. Actors may in this way analyse how resistances influence participatory processes, or prevent change occurring. The knowledge thus produced could lead to the questioning of current relations between different social worlds and sub-worlds in arenas of change. It could put individuals and groups in a position from which they may more easily raise issues and engage in debates about their built environment and all aspects that intersect there. It may facilitate connecting with the macro-level, the realm of WEG legislation, urban discourses on densification, accumulation, asymmetric urban change, or urban inequality. Mappings of this kind call into question the structural conditions in arenas of change as discussed above. They could inform processes through which the power relations in the arena are renegotiated and ultimately changed.

The second empowering effect of collective mapping rests on the actual making. Similar to the self-reflexive work of community mapping (Unger 2014, pp.78ff), this could be the first step in a participatory and inclusive process which is then further developed. Groups and individuals could engage in workshop-like settings to collec- 
tively produce maps of their decision-making process and of the negotiations they engage with. They could develop timeline diagrams of the common concerns they think are of significance, for individuals, different groups, or social worlds in the arena. As part of the making, they could draw comparisons between different versions of maps. The mappings could also act as memory device, making available information about past decisions while supporting a process of collective learning. The mappings could bring to the fore possible silences that conceal positions of power, or issues that would otherwise be covered up by dominant concerns. They could help the residents of a housing estate to more critically reflect on moments of closure in the arena. This might lead towards an opening up of processes for non-owner residents, neighbours or other users of the estate.

Participatory, empowering, and collective forms of research are closely linked to questions of control. Only if participants have the right to co-determine research goals and the power to access, influence, and change the project or process can we speak of true participation (Lüttringhaus 2012; Unger 2014, pp.40, 47; Fernández Prajoux 2014, p.4). This is not without implications for the instruments used. Ideally, they can be accessed, worked with and modified by all participants. The level of control has to include the basic configuration of the instruments used. Providing tools that have user-friendly interfaces is not enough for this purpose. Even the most neutral and adaptable instrument is based on certain presumptions and moments of closure, which are beyond the control of users. Only if the collective is involved with the conceiving and actual making of instruments - as producers - will the empowering effect give full control, and make the collective gradually independent of the input of external specialists. In this sense, the tools have to be simple in terms of making, but powerful enough to probe into the complexity of situations. The maps of SA and its adaptations seem to be well-suited for this purpose. Moreover, if change is to be one of the outcomes of the empowering process, participants have to be cautious to not inscribe existing routines into their instruments and processes. Pertaining to the relationship of collective routines and spatial change, sociologist Martina Löw suggests that

"Changes emerge when routines are not merely varied, but rather old habits replaced by new routines. If this happens regularly, collectively, and with reference to relevant rules and resources, institutionalized spaces and spatial structures can be changed." (Löw 2016 [2001], p.191)

If mapping work succeeds in breaking up routines, if it supports the collective in establishing new perspectives through interpretative analysis and self-reflection, it will have the capacity to become an active agent of change. Historically, the WEG act of 1951 has to be seen as an instrument for the establishment and organisation of property rights in a situation of crisis in post-war West-Germany. The legislators' intentions were not to empower residents so that they could change the built environment, or participate in urban processes. Collective mapping could provide case-specific insights in the process and its restrictions, and in this way create an awareness of the issues involved. In view of the problem of "dynamic conservatism" in commonhold-type entities according to the WEG, empowerment through mapping could help actors to overcome some of the inhibiting effects of the WEG model. For, participants in WEG-framed arenas are currently not free to choose their modes of interaction. Here, Habraken's propo- 
sition that "[...] home owners will change their houses no matter what, even when the latter are functionally determined when bought, because ownership is empowerment [...]" (Habraken 2008, p.291) is currently limited to the confines of the single residential unit. Empowered through mapping, users, owner and non-owner residents may find new ways of extending their effective range of action to higher levels of control, and ultimately to the changing of spatial arrangements and their housing estate.

\subsection{Extending the Repertoires of Mapping in Different Fields of Representation}

Describing and analysing spatial and social relations are difficult and challenging tasks. In particular, if the representation of complex relationships is done in writing. Maps and diagrams offer complementary ways of representing spatial and social complexity. Adele Clarke sees a particular strength of mapping in the representation of connections (Clarke 2005, p.30), which includes the representation of areas where there are no connections. The capacity of maps to relate different things to each other is analytically exploited in situational analysis as well as in other mapping methodologies. Some kinds of maps are conceived to analyse a very narrowly defined field. They are often inextricably linked to a single research problem and to a specific task. Other maps are versatile and can be used more freely. This implies that maps of this category are adaptable and modifiable in some way, so that they can respond to the requirements of new research situations. However, the transfer of a specific mapping technique from one research situation to another is not self-evident and has to be backed by theoretical reflection.

The repertoire of mapping in a given discipline or research context can be extended in various ways. Existing mapping techniques can be adapted and modified. This may result in a genealogy of related mapping methods. New mapping methods can be designed and developed from scratch. This is often the case when new technologies become available, or when new problems require new tools of analysis. Another way is to transfer existing mapping methods from one discipline to another, for example from situational analysis to an architectural and urban research context. The transfer is likely to result in the modification of the mapping method. In all cases, the idea is to extend the representational and analytical range of mapping, and thus to produce new knowledge in the fields that are being mapped.

Design is a field in which mappings of different kinds are regularly used. The mappings of situational analysis proper, and the mappings I have developed on the basis of its epistemological assumptions, have no foothold in architectural or urban design at the present. This is not to say that connections between the social sciences and design are weak, for both fields can look back on a long tradition of interdisciplinary cooperation. Urban and architectural design shares with urban sociology a strong interest in the city, and with sociology of housing a strong interest in the everyday. However, research methods themselves rarely travel from the social sciences to design and vice versa. Instead, they share their respective research outcomes with each other. Design draws on data and theories generated in the social sciences. Conversely, the social sciences relate to and position their research within the (designed) built environment, but typically not by using design methods. 
As I have argued at the outset of this book, it is characteristic of architecture departments that they accommodate different framings of knowledge, "cultures of knowledge" (Biggs and Büchler 2011, pp.68f), or "knowledge landscapes" (Dunin-Woyseth and Nilsson 2011, p.80). Maps have a specific strength in the representation of connections. In this sense they could be understood as connecting devices themselves. Their connecting capacity can be exploited in the transfer of knowledge and information between different cultures and landscapes of knowledge. Geographer Michael Conzen's analytical maps are examples of mapped knowledge travelling in research practice between different framings of knowledge (Conzen 1960). His mappings of structural patterns in towns are foremost descriptive and analytical, without any intention by the researcher of making them operable in architectural and urban design (Moudon 2004, p.26). The rigorous focus on the mapping data enabled Conzen to develop new concepts, in particular about the fringe belt, burgage pattern, and plan unit (ibid., p.28). Subsequently, the versatility of the maps, and the accessibility of the knowledge embedded in the maps, allowed the information as well as the mapping method to travel fairly easily from cultural geography into other disciplines and across the boundaries of different framings of knowledge.

New mapping methods continuously enter the design disciplines and in this way expand their repertoire of analytical and interpretative instruments. The kinds of mappings developed in this research project could be among them. Transferring the mapping approach to a design context and making them useful for design work requires translation and reflective modification. To fully exploit the potential, the translation will have to ensure that the mapping approach retains its connecting capacity between the social and the material, between decision-making processes and urban space. In this way, the mappings can expand the analytical and theoretical range of design-related analysis and of design projects. Because faculties of architecture and urbanism assemble different framings and practices of knowledge, they are obvious places for the transdisciplinary transfer of information through maps.

The theory of relational space is another field in which mapping could extend the repertoire of analytical representation. Martina Löw's "The Sociology of Space" identifies ample possibilities for "(An)Ordnungen" (Löw 2015 [2001], p.158) that could be mapped and in this way interpreted. Löw's case study on "Countercultural School Spaces" reads almost as an invitation, or instruction for a mapping analysis:

"However, the analysis of spaces must not be limited to the analysis of the structuring effects of spaces that are already institutionalized [...]. In the everyday constitution of space, these arrangements are constantly subject to challenge and are shifted, temporarily suspended, and sometimes even annulled - for example by moving around or selecting one's place oneself. This resistance to institutionalized arrangements can have various causes: acting differently on reflection, feeling ill at ease, other people's manners of action, or constellations of otherness. The violation of dominant space constitutions can thus prove to be the realization of another habitus." (ibid., pp.209f)

The questions implied are, for example: What kind of (pre-)structuring powers become effective in the school spaces analysed? How are territories constituted, how are conventions violated through countercultural spatial practices? How do people move through space, use space, behave in space, when they want to be different? CHORA's 
short sequential analysis of the "Locker Girls", based on the group's "Erasure-Origination-Transformation-Migration" concept of urban change, is an example of the mapping of countercultural spaces (Bunschoten, Binet and Hoshino 2010 [2001], pp.376f). The mappings of situational analysis, including social worlds/arenas maps, as well as the timeline mapping of ongoing concerns, actions, or commitments to transformative processes, could contribute towards new kinds of conflict-orientated socio-spatial mapping analysis.

\section{Working with Concepts and Narratives of Conflict and Change}

\subsection{Challenging Dominant Modes of Space Production}

The positional map relates different and in part contradictory concepts about urban and architectural change to each other. According to the epistemological assumptions of SA, it gives marginal positions a voice, and prevents the marginal from being forced into the background by the more dominant positions (Clarke 2005, p.128, p.178). Hence, the map can be used as a conceptual device for the detecting and analysing of differences in an urban condition. If applied to a particular urban condition or site, it is, perhaps, not too difficult to identify one or more concepts in the map that dominate in the situation. Dominant concepts in architectural and urban change are concepts to which the majority and most powerful agents, institutions and stakeholders explicitly or implicitly refer in the situation. They are, in this sense, the conceptual supports for the dominant mode of space production and its discourses. However, there may be other spatial practices that leave only very faint traces in the material world.

Concepts of change that struggle to be heard in urban controversies, or that struggle to establish a different mode of space production, may be more easily detectible with the assistance of the positional map. In this sense, the positional map could provide clues as to where and how to look. Furthermore, the epistemologically justified openness of the positional map, as well as the theoretical sampling method encourage the adding of new information. Once identified in the situation under study, new positions can be added to the map. The limits of the positional map that I have presented in this research project are defined by its focus on architectural and urban narratives. This means that when using the positional map in its current form, we have to bear in mind that other, non architectural or urban concepts of conflict and change are likely to be of relevance in the situation under study, rooted, for example, in social relations, personal experiences, economic conditions, or global conflicts and climate change. Dominant concepts of urban and architectural conflict and change seek to establish stabilising spatial practices, take control of space, achieve closure. They are part of a stabilising discourse in support of the hegemonic mode of space production. Planning and planning legislation based on modernist ideas are institutionalised instruments that are directed towards this goal. However, irrespective of how dominant a concept in a given situation is, the positional map is a reminder that there is no single narrative of change. There are always alternatives - different ways of thinking and doing change. The positional map shows that conflict can be foregrounded with different intensities, that conflict is sometimes silenced, depoliticised and concealed. 
Figure 102: "Contested Porosities". Movements and sites of spatial intervention and production in Dalston, East London. A Dalston Mill, EXYZT + Agnes Denes [commissioned by Barbican Art Gallery]. B Eastern Curve Garden, muf+ J\&L Gibbons. C Barn for Curve Garden, muf + EXYZT. D Dalston Roof Park, Rob Rainbow + zectorarchitects. E Arcola Tent, Arcola Theatre. $\boldsymbol{F}$ Inflatable Roof, zectorarchitects. $\boldsymbol{G}$ The Bunker, provisional venue space. $\boldsymbol{H}$ Oto Project Space, Assemble. I 'Dalston House' by artist Leonardo Erlich [commissioned by Barbican Art Gallery] . J Bee Garden, Joy Schlageter. $\boldsymbol{K}$ Boot Yard. Bakery, brewery and other uses, Featherstone Young, zectorarchitects.

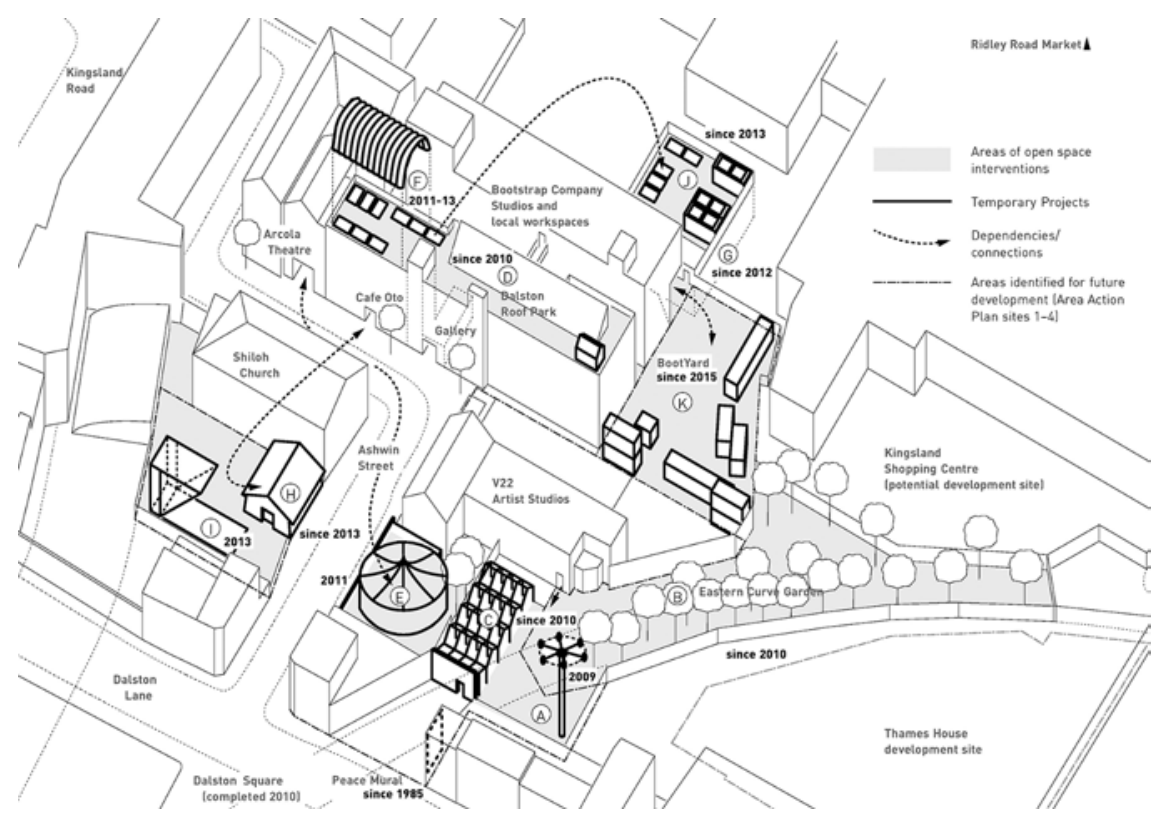

The positional map is an invitation to undertake speculative interpretative movements through the universe of architectural and urban narratives. I have done so for the construction of the dual position of the Redundant City concept.

Another opportunity arose while working on the conceptualising and analysis of a concrete urban condition in Dalston, East London, which I undertook together with Carsten Jungfer. The local area is a contested zone, in which alternative urban practices are currently challenged by institutionalised routines of space production, and vice versa. The dynamics of the area seem to be defined by a movement between appropriation and domination on the one hand, and a movement between accumulation and dispersion on the other hand (Kling and Jungfer 2018, p. 260).

Both movements exert their influence on the area in different ways, resulting in unexpected and contradictory urban situations and conditions of asymmetric urban change.

As part of the analysis, we produced a map showing all major spatial interventions in the recent past (Figure 102). Drawing on the writings of Henri Lefebvre, Neil Brenner, Martina Löw, and others, we identified 'porous' spatial qualities that support alternative spatial practices and processes of making a different city (ibid.). The positional map served as a background reference in the analysis and concept development 
Figure 103: The newly developed concept "contested porosities" added to the positional map. Relevant neighbouring concepts and alternative spatial practices in the proximity of the concept are highlighted.

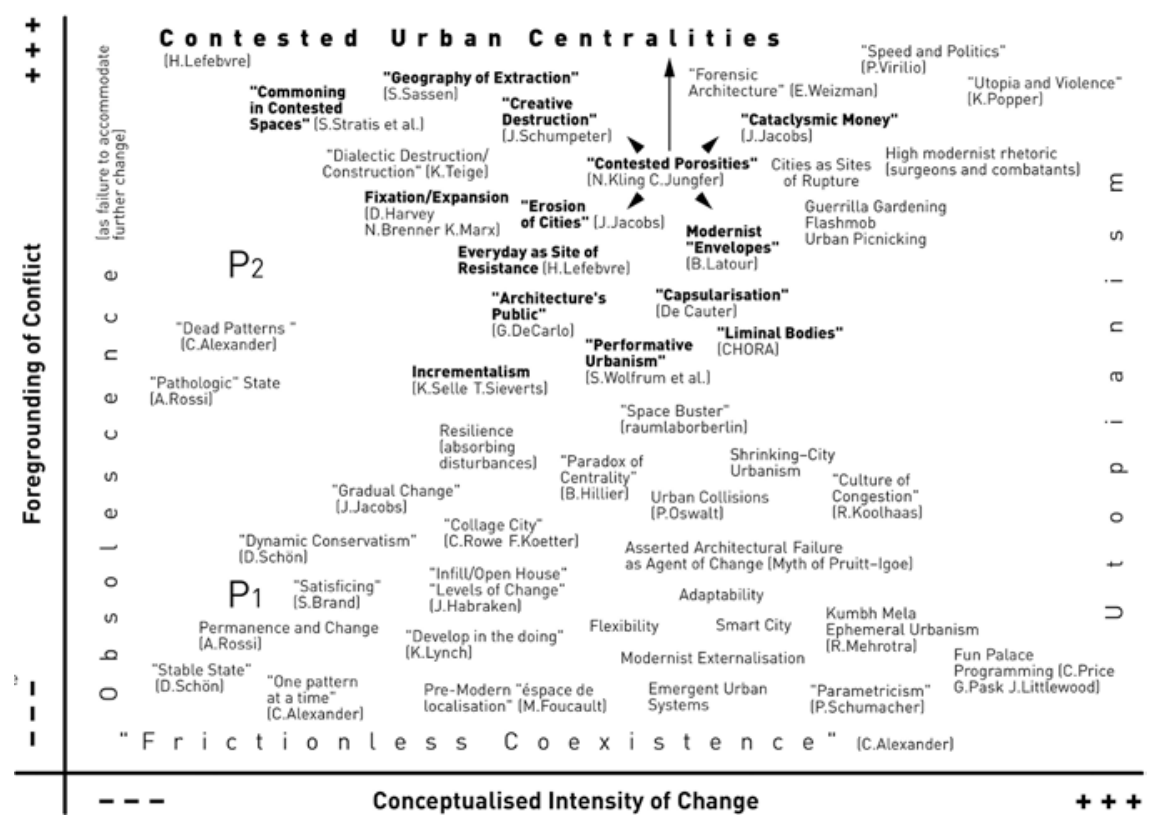

(Figure 103). We assigned a medium intensity of change to the processes observed in Dalston. To this, we added a high level in the foregrounding of conflict, reflecting the intensity of current public debates on the future development of the area. Based on these assumptions, it was then possible to place the proposed concept "Contested Porosities" in the positional map and to see how it would relate to other positions and concepts of change $e^{4}$. Adjacent concepts provided clues as to possible issues that could be of relevance in the situation. They also informed our critical discussion of the observed processes. Hence, in this mode of analysis, we used the positional map as discursive device in our theorising about urban change. The corresponding article "Contested Porosities. A Spatial Enquiry into Urban Conflicts in Dalston, East London" (Kling and Jungfer 2018) is published in the "Porous City" edited volume, which enquires into the nature and potential of porosity, and how it could become an agent of difference and change (Wolfrum et al. 2018).

The positional map holds the promise that despite the dominance of certain positions there are alternatives - and that new alternatives can be conceived and added. The positional map highlights the contingency in the universe of narratives and concepts. There could always be a different perspective on conflict and change, and therefore a different spatial practice. The map is meant to provoke controversy. In this sense, the assembling of multiple concepts of conflict and change in the positional map is in itself an act of questioning the dominant mode of space production.

4 The positional map has further evolved since then, resulting in differences between this version and the one used for the intersection. 


\subsection{Positioning Design Interventions In the Urban Field}

Architectural and urban design is in one way or the other concerned with changing a situation, or with adding something to urban reality. Design does not inevitably materialise in built form. The outcome of design can be a process, a way to organise things, a representation of an idea, an image, or a concept. As I have argued in the introduction to this book, design is a unique way of producing knowledge. "Designerly ways of knowing" (Cross 2001) have the capacity to initiate change or to contribute towards an ongoing process of change. Design can also stop a given mode of change when it introduces an alternative. Within the relational theory of space, design is discussed as a unique form of spatial acting. Through designing, relations are established between things, of which some may not yet exist in materialised form. In a design project, the existing, be it built form, ways of thinking, a process, or mode of space production, intermingles with the imaginary. The creative capacity of design enables us to conceive of new forms, new ways of thinking, other ways of doing space. The new is rarely, if at all, generated from within mental spaces that are void of preconceptions and presuppositions. The constructivist and relational perspectives both assume that once things are made by humans, they act back upon them in different ways (Berger and Luckmann 1966, p.183; Löw 2016 [2001], p.144). In this sense, we could say that modes of changing and designing, once established and communicated, recursively influence future modes of changing and designing. Designing, even if it strives for innovation and rejects the methods of the present or the past, relates to existing concepts of design, and therefore to existing narratives of change. The positional map is conceived as an open representation of past and present concepts and narratives of change in architecture and urbanism. Based on the assumption that the new always connects, in one way or the other, to that which is already there, the map can be seen as a tool for critically reflecting on the new in terms of its relatedness to the existing. In this way, it can assist designers in the conceptual positioning of their design interventions in the ever-changing urban field. If, as Jane Rendell suggests,

"[...] design is a mode of enquiry that is capable of generating new ways of knowing and understanding the world through creative processes and the production of artefacts, but also that designers are able to offer critiques of their own mode of practice, both self-reflective and politicised (Rendell 2007, p.7)

- then a critique of the productions of designers is likely to involve a critique of the overall mode of space production in which they participate. This includes critical reflection about the limits of generating new ways of knowing through design. Participants in design processes work within contradictory situations, which inevitably makes contradictions part of their ways of working. There is, on the one hand, the notorious process-inherent lack of information and the movement towards openness, which is supported by the desire to create something new. On the other hand, the more precise and concrete a design becomes, the closer it is to fixation. In David Harvey's view, "[...] to materialise space is to engage with closure (however temporary) which is an authoritarian act."(Harvey 2000, p.183) Yet, if we understand fixation not as a single and conclusive event, but rather as something that is continuously (re-)produced - for example as a competition entry, as the putting forward of ideas by interest groups, as 
the discussion of a building proposal in a council meeting, as the granting or refusal of funding, or as the exhibition produced at the end of a participatory workshop - then a strong temporal dimension is introduced to the problematic. In this way, moments of fixation are seen as being part of a temporal condition, in which the tendency towards closure is challenged by [re-]openings. The issue, then, is not to produce 'a design', as the static output of professional work, but to engage with a process, and to make designing part of the process. Competing concepts of conflict and change intersect in the city. They are related to constellations of power, which in turn are related to different ways of producing space. Working on the design and the realisation of a project means participating in the production of space. Urban and architectural projects are situated within a web of relations in the arena of urban change.

Assuming that redundancy is present in situations and spaces other than the Parkstadt Bogenhausen housing estate, what characteristics might they have? How could we engage with the ambivalent qualities of redundancy in design? As part of the development of the Redundant City concept, I have argued redundancy to convey a promise of difference. Redundant spaces are less dynamic than their surroundings due to the rigidifying frameworks and institutionalisations that keep them from engaging with the urban level. However, one of the underlying assumptions of redundancy is that changes can be initiated if action is assumed collectively. Furthermore, arenas that negotiate and produce redundant spaces have the possibility of (re-)connecting to the political and to the urban level of change. Working with redundant spaces means addressing problems of rigidity and conflict as part of a process. It also means working with the existing, not only in terms of the built environment, but more importantly with the competing desires and the web of social relations that intersect on a site. Theorising about shifts in the work of architects and the pressure of change resulting from global capitalism, conservationist Thordis Arrhenius suggests that

"Urban patterns and building programs are increasingly becoming redundant, demanding change to accommodate new functions and identities. Driven by contemporary concerns with scarcity and overflow, the building stock is constantly altered. In this situation, architects are increasingly concerned with adjusting and reprogramming what is already there. This raises an urgency or necessity for contemporary architectural culture to address the pressure of change in alternative modes." (Arrhenius 2016, p.55)

The design projects to which I refer in the following engage with three urban conditions in very different ways. What they have in common is their relatedness to redundancy in one way or the other; a temporality and connectedness to ongoing processes of change; a degree of improvisation, incompleteness and imperfection; and an openness to appropriation. In all three projects, the spaces can be reconfigured by the participants and co-producers of space, either by simply being present in the situation, or by introducing changes and engaging in different ways with the project.

I had the opportunity to contribute to these projects as a partner at zectorarchitects in various ways, together with Carsten Jungfer and many others who made them happen. 
Figure 104: Dalston Roof Park, East London, design by zectorarchitects and artist Rob Rainbow, photo 2011 @ by Mimi Mollica

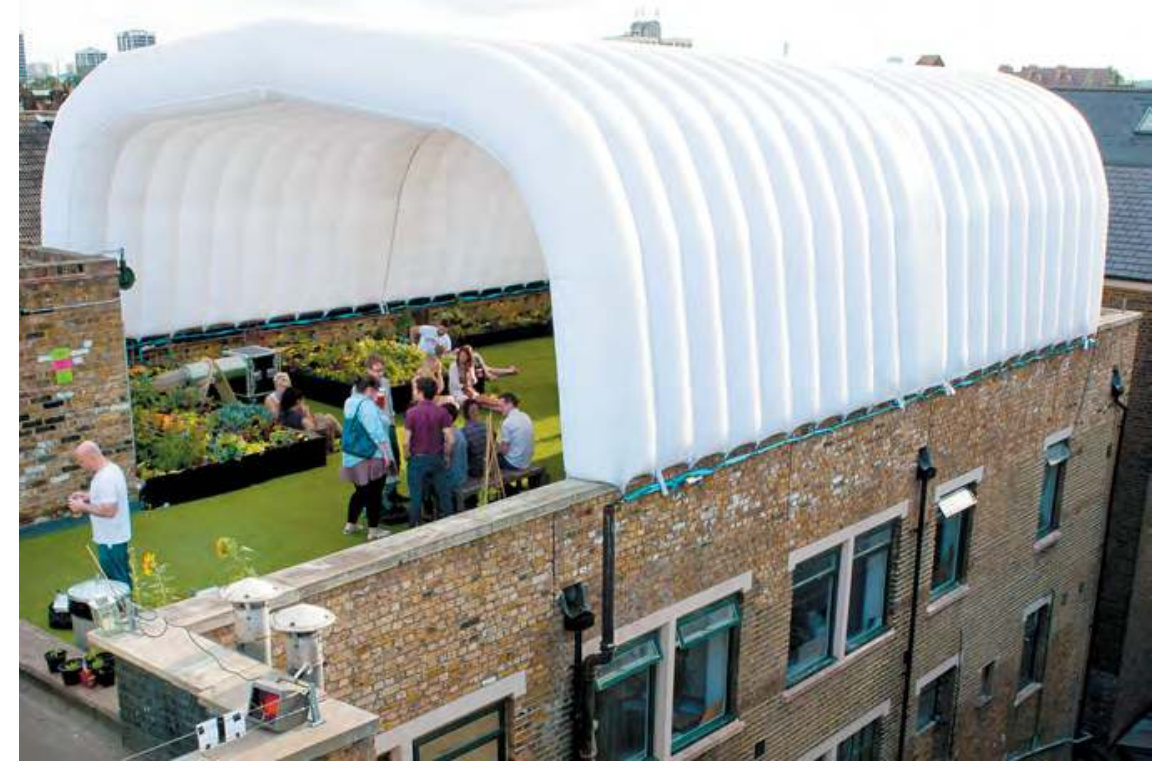

\section{Dalston Roof Park}

Dalston Roof Park is located in East London and opened in 2010. It is part of a series of local initiatives that developed in and around Ashwin Street, which gradually took over spaces that had been left by defunct light industry. Many non-profit organisations, cooperatives and charities are based in the area and provide their services to the local and wider community. Dalston Roof Park started as a gardening project and bar service on the unused flat roof of a former paint factory. The premises are managed by the Bootstrap Charity, which provides workspace and training for small social and creative enterprises. From 2011-13, a removable pneumatic canopy provided shelter so that scheduled activities on the rooftop could be hosted in less favourable weather conditions (zectorarchitects 2011). This was later replaced by a more permanent structure. Supported by many helping hands and a great number of guests and users, Dalston Roof Park evolved into a vibrant location over the years. It is a friendly and open space, offering a special atmosphere in a unique location. Dalston Roof Park and other projects attract visitors from outside Dalston and make the local cultural and community work more widely known. The project is self-funding and revenues help support local projects. The Bootstrap Charity, its tenants, neighbours, friends and the regular users of the premises are currently working on proposals for the extension and modification of the usable roof area. zectorarchitects is involved with the co-design process and the preparation of a series of workshops. Among the three projects introduced in this section, Dalston Roof Park engages with conditions of obsolescence and redundancy in the most direct way. 
Figure 105: MiPUM - Pop-Up Museum. Temporary archaeological exhibition next to London wall in Tower Hill, L-P: Archeaology, Roey Hunt and zectorarchitects, London 2015

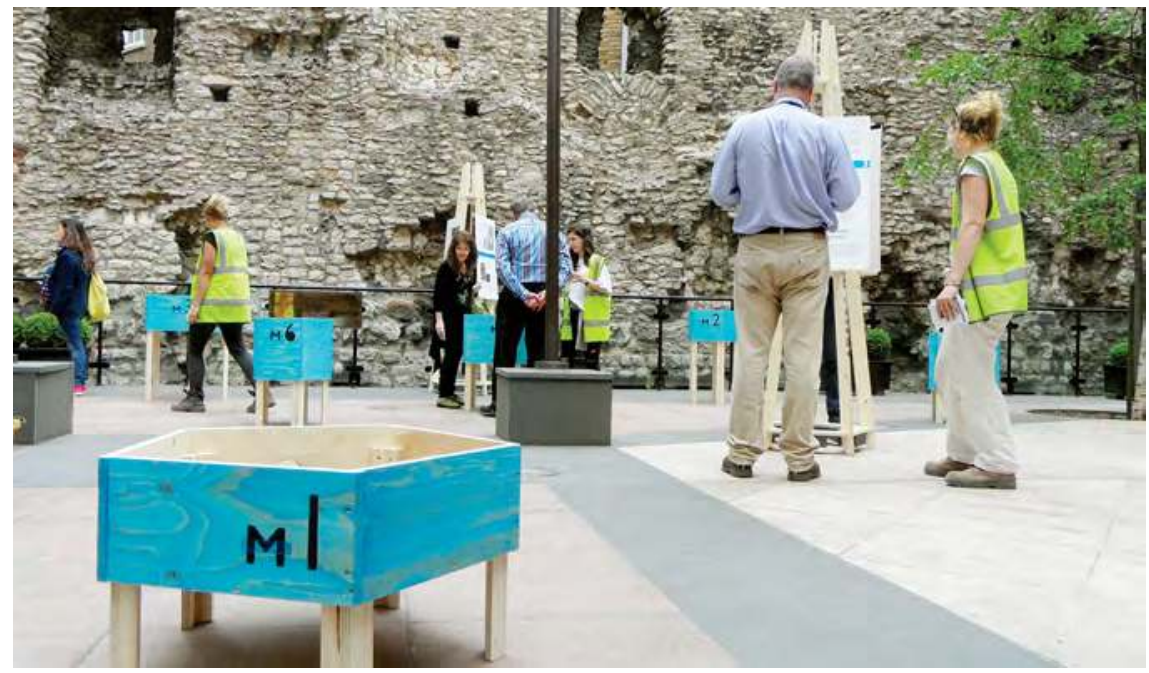

The local processes have to be seen within the broader urban situation. Since the turn of the millennium, East London has experienced substantial change through urban restructuring and investment in new public transport infrastructure. The local populations, which traditionally include minority groups, migrants and households with low incomes, are struggling with rapidly rising rents, exclusion and persistent inequality. A broader discussion of the current local situation and its specific condition of asymmetric urban change is provided in "Contested Porosities. A Spatial Enquiry into Urban Conflicts in Dalston, East London" (Kling and Jungfer 2018).

\section{MiPUM}

The 100 Minories Pop-up Museum (MiPUM) was a temporary archaeological exhibition in the City of London in 2015 (zectorarchitects 2015). The event was part of the Festival of Archaeology 2015, and realised within a close collaboration between L-P: Archaeology, zectorarchitecs and fabricator and artist Roey Hunt. The exhibition was set up in proximity to the excavation pit, off Coopers Row, directly in front of the remains of the Roman wall. The excavation covered an area that was formerly the ditch 'without' the fortification walls. Framed by the remains of the Roman wall and the open courtyard situation, the exhibition provided information about the ongoing excavation and the history of the site. Members of the archaeological team, easily recognisable by their safety vests, could be approached and engaged in conversations. A family of different display cases with a series of original artefacts invited visitors to inspect the findings closely. Information panels provided additional information for their contextualisation. The situation connects to conflict and change in various ways. Archaeological excavations usually reconstruct processes backwards in time, following the stratigraphic sequence of contexts from top to the natural bottom. The dig at 100 Minories was part of a transitional condition itself, as the excavated site was later built over by a new multi-storey building. Urban excavation sites are entangled in a complex web of conflicts that orig- 
inate from inside and outside the archaeological project. Internal conflicts are related to the destructive aspect of excavating, problems of archaeological context and interpretation, the everyday management of an excavation, or conflicts between safety and public access. External conflicts originate from the wider site constraints, from dependencies arising from funding structures, or from time schedules that do not sufficiently take into account the unforeseen. The architectural design project does not evolve in isolation from these specific conditions of conflict and change. We understand that it is only by participating in and interfering with the overall process, that the design project is able to establish adequate relations and meaningful spaces in the situation.

\section{Kavalierstraße Dessau}

The Kavalierstraße project evolved from our EUROPAN 10 competition win in 2010 (Rebois 2010, p.64; zectorarchitects 2010). During the second half of the 1990s, the city of Dessau experienced a significant decline in population, which a decade later resulted in large scale urban restructuring. Surplus housing and abandoned industrial areas were gradually dismantled, giving way to a new kind of urban landscape. The long-term spatial strategy was developed as part of the International Building Exhibition IBA, co-curated by the Bauhaus Foundation in Dessau. The urban development concept for the Dessau region "Urbane Kerne - landschaftliche Zonen" was to direct the restructuring process in such a way as to raise the quality in peripheral areas by connecting residential and lower density neighbourhoods to green spaces, while at the same time strengthening the remaining urban cores (Ministerium für Landesentwicklung und Verkehr des Landes Sachsen-Anhalt 2010, p.612). The Kavalierstraße project is one of the key initiatives within the urban core of Dessau. Our EUROPAN 10 winning entry 'roll-in' - was focussed on the activating and reinterpreting of existing potential and qualities, as well as adding new ones. The site analysis included a close-up observation of everyday spaces and local spatial arrangements. The proposal showed what kind of interventions could be possible in terms of programme, open spaces and built structures. Our initial proposal was conceived to evolve as an open process, based on high levels of public participation. The idea was to postpone any design fixations at the outset until they could emerge from a collective process in due course. In the end, the municipality chose to follow a more formal and linear route with the project, although the International Building Exhibition IBA included examples of open processes that had generated high-quality spaces for different places in the region. The revitalisation of the Stadtpark in Dessau and the local projects initiated by the Bauhaus Foundation in Dessau, for example, were based on higher levels of public participation, in the sense of establishing a collective process with stakeholders and the local community during the design phase of the projects (ibid., pp.452ff and pp.611-620). The shift fundamentally changed our initial assumptions about the process. The political difficulties related to the required relocation of traffic, the funding situation, the overall complexity, and possibly also the personal preference of the leading politicians may have contributed towards the route chosen by the local authority. 
Figure 106: Kavalierstrasse Dessau, EUROPAN 10 competition, detail of winning entry by zectorarchitects, which shows sites of possible interventions alongside a matrix organisational model conceived to hold and make available a broad set of ideas during the envisaged participative and open process. (zectorarchitects 2010)
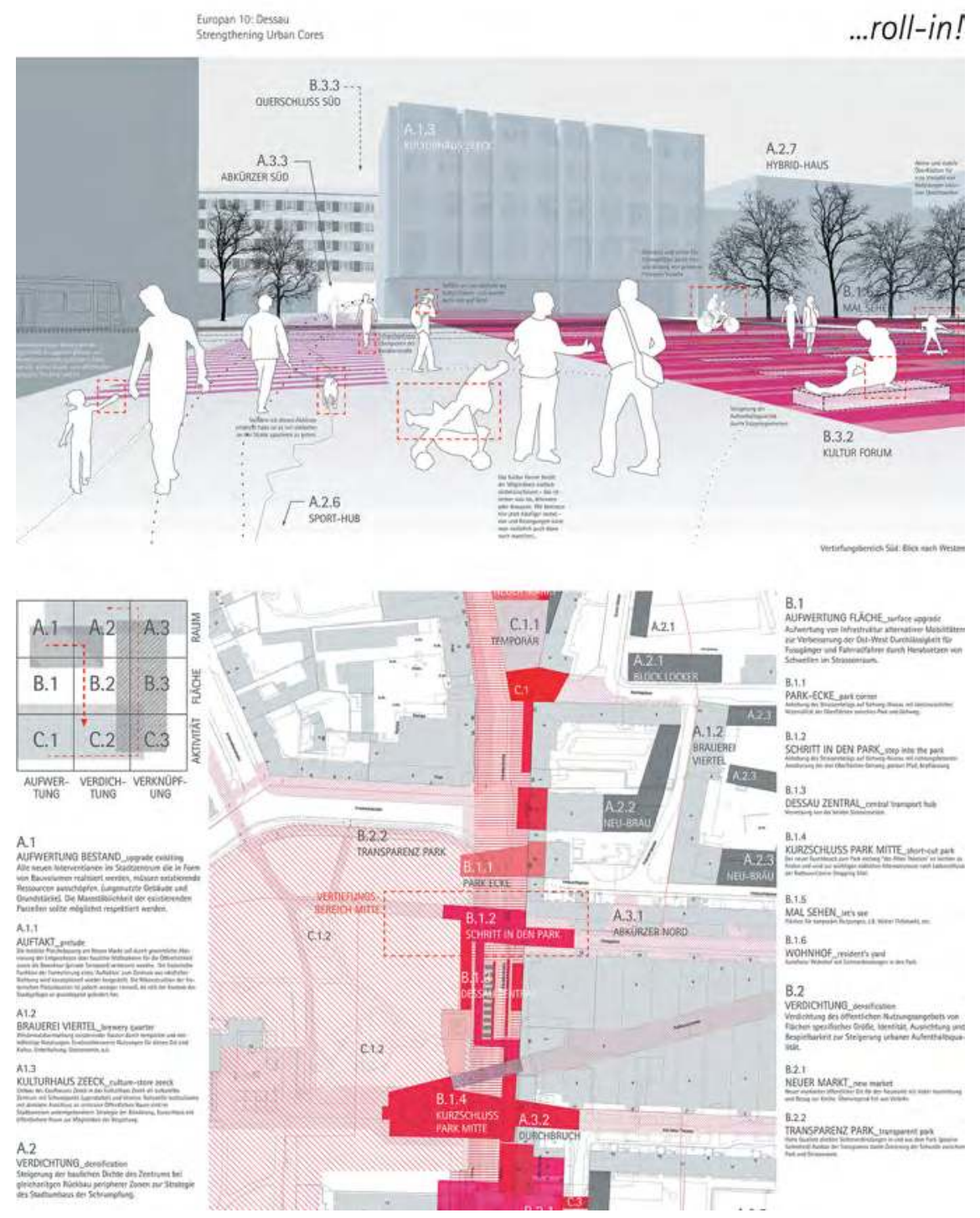

The second fundamental change occurred when it was clear that the project would concentrate exclusively on the open space of Kavalierstraße, without working in parallel on the activation of adjacent buildings and the surrounding urban area. Commissioned to develop a design proposal for the public realm of Kavalierstraße within the new parameters, zectorarchitects teamed up with landscape designer Christian Benoit and public transport consultant Stefan Besier. Our response to the new situation was to establish an alternative way of providing openness and spaces for appropriation. We 
Figure 107: Kavalierstraße Dessau, 'Aktionsfeld' with water feature and local shops, visualised by zectorarchitects in 2015

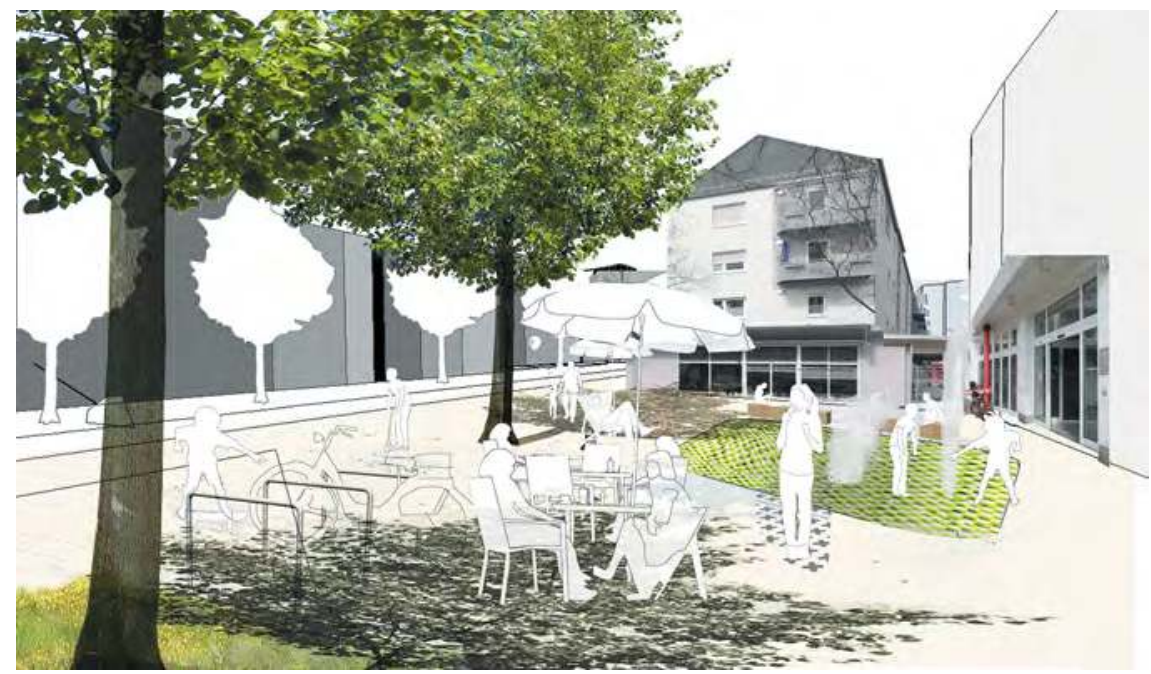

changed the idea of having an overall open design process in favour of an approach that would incorporate smaller collectively designed situations, which could then be modified and changed in the future (zectorarchitects 2013). The site is conceptualised as two superimposed organisational systems, comprising the north-south axis and a series of cross-links and small spaces that reinforce one another. The project stretches from a newly created square to the North, along the city's central public park and towards the southern main junction with the town museum. It links up with the spatial pattern defined by the heritage of socialist housing, as well as the central shopping mall built during the late 1990 .

New crossings are provided, most importantly between the historical town centre and the park. Two types of 'fields' are inserted at irregular intervals along the route, supporting different kinds of events and communicative activities. 'Flexifelder' provide an infrastructure of basic service supplies to commercial and other uses. 'Aktionsfelder' bring specific spatial qualities into public space. They contrast with the standard hard surfaces in terms of materials, use, and articulation.

The initial test-programming of the 'Aktionsfelder' was developed by the design team together with the planning department and other specialists. The public and local stakeholders were invited to comment on the overall scheme, as well as on the individual fields. A workshop held at a local school, engendered further ideas that could be developed and incorporated into the project. The intended change of material and form in the 'Aktionsfelder' produces independent elements that can be re-designed and re-configured over time. A new public transport hub is integrated to the scheme. The hub, the newly introduced crossings, reduced traffic, and the improved cycle infrastructure make the centre more accessible. The first phase of the project, comprising the central section of Kavalierstraße, was completed in November 2018. The Bauhaus Museum Dessau was constructed in a parallel process. It establishes a new cultural destination on Kavalierstraße and in the city centre. 
With this brief discussion, I hope to have provided an idea of some of the possible connections between concepts and narratives of conflict and change, and design practice. In the mutual relationship, design projects may refer to existent concepts and narratives, and conversely, new concepts and narratives may emerge in the wake of new designs. The wealth of urban and architectural concepts and narratives of conflict and change can inform design projects and the way design interventions are conceptually positioned in the urban field. Similarly, design can further add to the wealth of concepts and narratives of conflict and change. In this sense design may broaden the understanding of transformative processes as well as actively contribute towards the richness and quality of spatial practices and relations.

\section{Concluding Remarks: Architectural and Urban Work as 'Matters of Concern'}

This book explores the rich body of narrative knowledge in architecture and urbanism and confronts this knowledge with an empirically grounded situational analysis of a large housing estate. The outcome of this twofold research approach comprises a new perspective on urban narratives of conflict and change, an extension of SA mapping tools and their application to spatial issues, and the Redundant City concept, which describes a specific form of collectively negotiated urban change.

At the outset I have suggested that research in architecture and urbanism cannot be assumed to be a routine or pre-given process. In these disciplines, research occupies different epistemological locations and produces knowledge that is framed in different ways. The complex and at times contradictory nature of this knowledge needs to be addressed if naive objectivism, compartmentalised discourses and the reproduction of partial knowledge are to be avoided. Because there are valid justifications for each of these framings, and because different bodies of knowledge contribute to architectural and urban research in different ways, researchers need to define which kinds of knowledge and research perspectives they intend to relate to - for each enquiry separately and anew. I have suggested that instead of perceiving the diversity of knowledge as an obstacle to research, we could take it as a unique resource to work with, in particular if we understand urban and architectural issues as something that cannot be grasped in isolation and from a single perspective. If research and scientific work are not simply seen as the detecting of what is already 'out there', but as activities that are purposefully added to the world, then research cannot be understood as taking place within a neutral territory.

I have further suggested that conflict and change have accompanied architecture and urbanism throughout their historical development and continue to be of major relevance today. Current theory emphasises the dynamic nature of cities. Conflict and change are ever present urban conditions. Given the multitude and complexity of existing and emerging phenomena in urban environments, it seems unsurprising that architectural and urban theory struggle with constantly having to adjust and (re) invent their conceptualisations and descriptions of spatial transformations.

Cities are composed of differences and multiplicity (Wolfrum and Nerdinger 2008). They confront us with their complex physical and social reality - as an ever-changing reality, which is produced and reproduced, appropriated and inhabited in multiple 
and conflictual ways. Urban change is more than anything the product of collective human action and of the processes humans conceive to structure their lives and the world. Shifting relations of power, resistances, the contesting of urban centralities, creative destruction, and competing modes of production are sources of conflict in cities. The introduction of new ideas, desires and innovations, the imposition of new utopias upon past utopias and traditions, the introduction of new patterns of urban organisation are all associated with the emergence of conflict. Many, but not all architectural and urban narratives understand the urban condition as going hand-in-hand with the production of conflicts. Based on my discursive-interpretative analysis I have suggested that conflict embodies the concept of change. Change is understood to be both, product and driver of conflict. There is an instrumental and operational dimension to conflict. As conflict and change can be seen to be two fundamental principles of the urban condition, I have chosen to open this research project with Henri Lefebvre, who suggested that

"To think about the city is to hold and maintain its conflictual aspects: constraints and possibilities, peacefulness and violence, meetings and solitude, gatherings and separation, the trivial and the poetic, brutal functionalism and surprising improvisation." (Lefebvre 1985 [1996], p.53)

Against this background and with reference to the writings of Neil Brenner, I have proposed to conceive of the urban as open construct rather than as predefined object (Lefebvre 2003 [1970], p.174; Brenner 2014). Understanding the urban as open construct means to call into question the separation of macro and micro scales of conceptualisation, the uncritical adoption of concepts of static space, the insistence on hard disciplinary demarcations and reductionist framings of problems, the mechanisms and interests that seek to achieve closure, the privileging of specialist positions, and the enforced gap between social and material worlds. The proposed research design addresses the methodological and epistemological challenges that come with this perspective. I have established a multi-site/multiple-methods research approach in which architectural and urban theory is combined with empirically-grounded analysis. I refer to this particular form of research as 'situated and critical project'.

Taking as a methodological starting point the idea of the urban as an open construct required on the one hand that an adequate level of non-closure be maintained in the research process, while on the other hand ensuring research precision and scrutiny. For this purpose, I have adapted the iterative-cyclical research model of grounded theory methodology (GTM) together with the mapping tools provided by situational analysis (SA) (Clarke 2005; Clarke, Friese and Washburn 2018). GTM and SA conceptually move along an incremental analysis of field-related data and in this way generate theory or concepts in the course of the process. For the purpose of this study, I have developed 'anchoring' and 'intersecting' as additional analytical tools. 'Intersecting' is based on SA's positional map and acts as device for the assembling of concepts/positions in architectural and urban narratives of conflict and change, as well as heuristic 
Figure 108: "[...] the poetic, brutal functionalism and surprising improvisation." (Lefebvre 1985 [1996], p.53), Theresienwiese and Hacker-Zentrum (Ernst M. Lang, Klaus von Bleichert and Gernot E. Car 1970-1974), Munich 2017

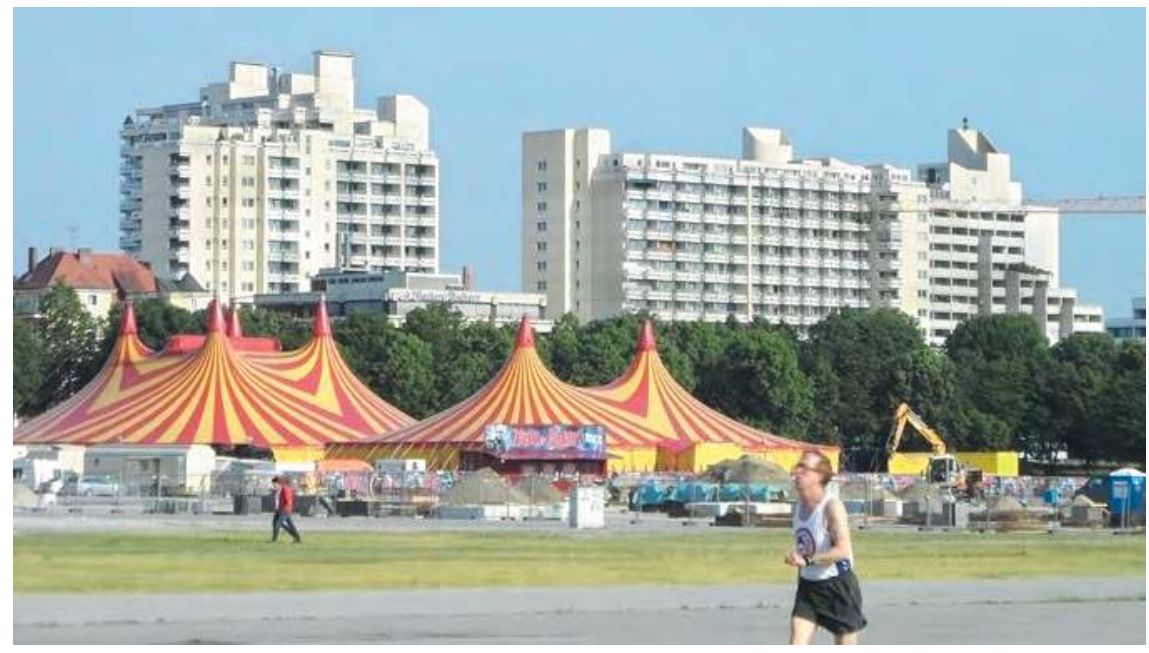

device for the development of the Redundant City concept. By means of intersecting, I have established a high-density construct with the aim of adding an additional layer of research precision and depth to the analysis.

The research project developed along two main processes. Analytical Process A concentrated on the identification and critical interpretation of domain-specific narratives that have informed, and continue to inform, our conceptualisations of and discourses on conflict and change in architecture and urbanism. I have used theoretical sampling as a theory-guided method in the selection process and as a means of reducing the possible effect of preconceptions. Each narrative was understood to hold one or more positions about conflict and change. I have assembled the positions in the shared analytical space of the positional map which relates different intensities of change and conflict with each other. The positional map showed a proportionalising tendency. Low intensities of change tended to occur in combination with a weak foregrounding of conflict in the narrative and high intensities of change with a strong foregrounding of conflict, leaving two voids in the space of the map. The first void indicated that there are no, or few, positions that combine low intensities of change with a strong foregrounding of conflict, and the second void indicated that there are no, or few, positions that combine high intensities of change with a medium foregrounding of conflict. Hence, the theorisation of conflict in architecture and urbanism seems to be strangely underdeveloped for conditions of low and high intensities of change. The positional map made visible areas, which have remained almost unexplored by architectural and urban theory in the past.

However, the growing awareness of situations of conflict, the growing significance of process-led and collectively negotiated change, seem to demand new conceptual approaches to conflict in architecture and urbanism. The Redundant City concept is a contribution towards these goals. It is an attempt to challenge the voids - if only in 
a small region - by adding a new concept that combines low intensities of change with a strong foregrounding of conflict.

With the case study of Analytical Process B, the focus of analysis shifted onto the Parkstadt Bogenhausen housing estate in Munich. The local pattern of asymmetric change which I observed over a longer period of time stood at the very beginning of this research project. In the analysis, different kinds of mapping, coding, and analysis informed a research approach that included both qualitative and quantitative perspectives. I have used the social worlds/arenas map to represent and analyse the multiple social worlds which assemble in and around the Parkstadt arena, including their relatedness. Arenas are sites in which different social worlds participate. Each social world is associated with its specific going concerns, practices, actions or commitments that contribute to the process of change in the Parkstadt Bogenhausen housing estate. The arena and its participating social worlds reconfigure themselves and are thus in a fluid state, while at the same time providing a degree of stability for the collective process.

The second kind of map, or diagram, engaged with the overall situational process and the changing structural conditions over time. The map showed connections across different scales, as well as the decision-making process in its wider context, including ownership status, formation and reformation of resident groups, decisive events, and the presence of visible and less visible actors in the situation. The third kind of map was based on the minutes of the collective's formal annual meetings (Wohnungseigentümergemeinschaft Parkstadt Bogenhausen 2016) and assembled detailed sequences of negotiated concerns. The comparative analysis of further data from the field showed that the transformation of other mid-2 $0^{\text {th }}$ century housing estates in Munich is currently under way on a grand scale. Against this background, it became apparent that the Parkstadt Bogenhausen housing estate is different. The estate does not seem to participate in the current spatial dynamics of the local area. It does not change in the same way and with the same transformative speed as other housing estates in Munich.

The comparative analysis revealed that the observed phenomenon cannot be explained with reference to differences in economic or demographic parameters, or the local urban context. It confirmed the view that the specific pattern of change in the Parkstadt Bogenhausen housing estate is not primarily the product of tight-fit functionalism and other potentially inhibiting architectural properties. Likewise, the phenomenon could not be explained by the listing of the estate as building ensemble. Rather, the empirical and comparative data suggested that the observed difference is rooted in the way the estate is owned and organised, in the conditions defined by the Parkstadt arena, and in the collective's approach to conflict and change. In the ensuing interpretative and concept-generating synthesis, I have related the findings to the concepts and positions on the positional map. The movements of discursive displacement established new interpretative links, which further informed the development of the new concept.

The Redundant City concept describes the process of change observed in the Parkstadt Bogenhausen housing estate and in this sense a situation in which urban change is strangely absent. The Redundant City has, on the one hand, a specific capacity to initiate and develop processes of change through the relative autonomy of a collectively exercised, ownership-based authority. On the other hand, collective self-regulation, structural and institutional frameworks, investment-driven accumulation, the silenc- 
ing of conflict, and "dynamic conservatism" (Schön 1971, pp.31-60) produce conditions which allow transformations to occur on the micro level, albeit in a very regulated and limited way, while practically inhibiting changes and interactions on the urban level. The ambivalence in the conceptualised situation is mirrored by the term redundancy. In the Redundant City, spaces of individual appropriation and change are connected to spaces of stagnation. Processes of change are oriented to the inside, while interactions with the city are reactive and reduced to a minimum.

The term 'Redundant City' functions as a signifier both for the sensitising concept and its socio-spatial referent, the Parkstadt Bogenhausen housing estate. Hence, the controversial notion of redundancy is an invitation to critically engage with the Redundant City concept as well as the housing estate and to connect them to current urban debates.

I have suggested that the situation cannot be changed effectively without addressing the full range of factors that are constituent of the situation: economic, legal, spatial, and social factors. WEG legislation is aimed at the single purpose of organising and managing property rights. However, as we have seen in the analysis, it has spatial implications. Through pre-structuring the arena and the decision making process, WEG legislation influences the way space is collectively and individually produced, appropriated and changed. The rules for the spatial processes do not originate from within the collective which uses the spaces. If, as David Harvey suggests, "The right to the city is far more than the individual liberty to access urban resources: it is a right to change ourselves by changing the city" (Harvey 2008, p.23) - what does it mean if the means to control change are, in effect, beyond people's control? This question, clearly, has to be a matter of common concern.

If we understand the transformative process of the Parkstadt Bogenhausen housing estate as being negotiated in the Parkstadt arena, that is, a site in which conflicting interests and agendas of multiple social worlds participate, and if we take into consideration the many structural and other rigidifying effects, we see how difficult it can be to introduce and realise change, no matter how small or modest it may be. If space is socially produced, then conditions of rigidity and resistance to change - as specific qualities of space - have to be seen as social products. An analysis of problems of architectural and urban change, therefore, has to take into consideration a broad range of different factors. Initiatives of change that are based on simplification and that define resistance to change as a predominantly architectural problem, in the sense of a critique of 'mass housing' or tight-fit functionalism, and that seek to introduce change by means of merely changing the architecture as advocated by those who maintain the myth of Pruitt-Igoe, are bound to fail in complex situations. Architecture may unfold its potentiality only if it engages with the reality of the arenas in which it participates. It seems that only if architectural agendas succeed in establishing relationships with the arena's multiple social worlds can architecture play a more active role in the process. If architecture cannot make sufficiently clear its relevance for the participating social worlds, it will continue - at least in the arena of the Redundant City - to be regarded as a mere problem of maintenance. The social worlds in the arena need to clearly know why architecture and urbanism could make a difference and why they matter.

Some of the more critical narratives analysed in this research project consider conflict as a creative force in the city, including agonistic forms of conflict that are difficult if not impossible to reconcile. If combined with urban action, they tend to strive 
for urban change and constitute what we could call an urban 'practice of conflict'. I have suggested that not to explicate conflict means to withdraw a situation from the political domain. The critical approach emphasises the gap between the actual and the possible, the contradictions within urban reality, and the contingent nature of urban processes.

From this perspective, scientific research is understood as an activity that is closely tied to the conditions in which it takes place, rather than following a linear and neutral progression of knowledge. The concept of "matters of concern" (Latour 2005) emphasises the political dimension of research and of knowledge, by means of emphasising the instrumental nature of knowledge, its connectedness to power, as well as the tendencies inherent to scientific practice. While "matters of fact" enable those who claim to be in possession of indisputable knowledge to "shut the dissenters' voice down" (ibid., p.39), "matters of concern" build upon dispute, for they acknowledge the political dimension of objects and artefacts (ibid., p.47). I have argued that, if we conceive of the researcher as critical examiner, then it is a role that cannot be confined to narrowly defined scientific domains, for she or he will be expected to justify the research in terms of how it could - or should - be of our concern. I have suggested that if orientation and directionality is required in this process, it may be sought in a double trajectory at once away from and towards - learning from our past mistakes, coupled with collectively produced ideas of and for a different future.

However, looking at our built environment, we realise that much of what we see is produced and researched as 'matters of fact', rather than 'matters of concern'. This includes the regulatory frameworks, the financing instruments, as well as the management and administration of the built environment. I have suggested that within the architectural professions there is a tendency to defining the professionals' work in terms of optimisation and 'problem solving' according to their own narrowly defined terms. This tendency is shared and reproduced by the many clients, be they individuals, corporate or public-institutional, who hire and pay for experts to solve problems, and to work on optimisation and efficiency in the service of profitability. Accordingly, current research conducted in Germany on mid- $20^{\text {th }}$ century housing tends to be focussed on restructuring, marketability, energy efficiency, optimisation of floor plans and standards of comfort. Where housing corporations, the building industry and the federal governments act as the main clients and sponsors of this research, agendas are predefined, economic questions foregrounded, and power relations and political questions excluded - or at least uncritically reproduced. This research can be classified as demand-driven research. It receives its strength through the narrow frame applied to the broad field of housing. Without questioning the merits or justification of such research, we should not expect them to go too far beyond the specific requirements and agendas of the clients. As a consequence, truly challenging and refreshing perspectives on mid- $20^{\text {th }}$ century housing seem to be the exception. There is the danger of the work of architects and urbanists being reduced to mere problem solving and the production of rigid 'matters of fact'. I have suggested that if we wish to work without pre-defined concepts and pre-defined problems, different research approaches will need to be developed.

Furthermore, I have argued that many concepts in architecture and urbanism are theorised in such a way that they do not directly relate to the social, or the political, and that disciplinary thinking and the keeping separate of material and social worlds 
makes it difficult for concepts to travel and connect. This results in the exclusion of issues and the difficulty of the disciplines in contributing their spatial and other specialist knowledge to public urban debates. Stronger levels in the foregrounding of conflict could in this sense extend the repertoire of conceptualisations in architectural and urban practice, as well as the conceptual range of analysis and theory.

Equipped with design knowledge and the experience of working with contradictions and difficult problems, architects and urbanists are in a good position to raise critical questions and engage in controversies. The disciplines could put greater emphasis on their expertise in problem detecting, identifying, spatialising. If the ways architectural and urban problems are defined were to include more of the debatable 'matters of concern', architectural and urban discourses could engage with questions from different perspectives, be more inclusive, and address issues in such a way that they can be of broader concern.

Emphasising the ambivalence and controversy associated with the notion of redundancy, the new concept is intended to contribute to ongoing controversies - not in the sense of offering solutions, but in the sense of opening up new perspectives that may be of use if we wish to think about architecture and the urban differently. The research project is conceived as an invitation to think and debate about, as well as actively engage with the specifics of the urban and of cities.

In this book, I have argued for architectural and urban research to further extend their range of enquiry, to explore more systematically the relationships between human and non-human actors, between collective action and the material world, between discursive controversy and space-generating processes. I have brought together criticisms that raise doubts as to the usefulness of constructing intellectual and institutional boundaries when engaging with urban issues. I have argued for an approaching to the urban as open construct, because of and despite the multiple mechanisms and interests that work towards its closure. With this research project, I have generated new questions by means of connecting architectural and urban theory to discursive arenas and to situations "where the action is" (Goffman 1967; Dellwing and Prus 2012, p.9) and in this way attempted to push the limits of what we can 'see' in the city. However, I have also suggested that adding to architectural and urban enquiry an analysis of process and social action is not without risk, for it raises specific methodological difficulties and has to withstand the criticisms of different disciplines. I have pointed up the issue that research conducted under the premise of openness necessarily leaves residues of unaddressed problems, and that in this sense it cannot be exhaustive or systematically complete. Nevertheless, I believe that this has been offset by the chance to develop a richer, and thicker understanding of urban and architectural reality.

I conclude this research project with the contention that architectural and urban work matter, and that, on the grounds of being entangled with all other productions humans conceive to change themselves and structure their worlds, should therefore be regarded as 'matters of concern'. 



\section{Appendix}

\section{Image References}

\section{All photography by the author, except}

Figure 24: Contested urban centrality (Dalston Roof Park), ( ) by Mimi Mollica 2011

Figure 47: Parkstadt Bogenhausen shopping centre and restaurant, (๑) by Kurt Otto 1970 (Neue Heimat Bayern 1971a, p.23)

Figures 49, 52 and 76: Maps adapted from https://geoportal.bayern.de/geoportalbayern/

Figure 55: Parkstadt Bogenhausen, aerial view, @ fkn/ archive Münchner Merkur, not dated (Gäbelein 2005)

Figure 104: Dalston Roof Park, (c) by Mimi Mollica 2011

\section{Illustration on cover:}

Conflict and change, the trivial and the poetic in the former Pfanni food production facility Werk 1, on the corner Kraftwerkgasse and Kartoffelgleis, Munich 2017

\section{References}

Adichie, Chimamanda Ngozi (2009) The danger of a single story, TED talk recorded in July $2009[\mathrm{html}]$ https://www.ted.com/talks/chimamanda_adichie_the_danger_ of_a_single_story/transcript, acc. 07.06.2018

Alexander, Christopher (1964) Notes on the Synthesis of Form, 1971 paper-back edition, Cambridge MA

Alexander, Christopher (1965) A City is Not a Tree, first published in 2 parts in Architectural Forum in 1965 (vol. 122, no. 1, April 1965, pp.58-62 (Part I), and vol. 122, no. 2, May 1965, pp.58-62 (Part II). This version based on republication in: Design no. 206, February 1966, pp.46-55

Alexander, Christopher. Ishakawa, Sara. Silverstein, Murray (1977) A Pattern Language: Towns, Buildings, Construction, New York

Alexander, Christopher (1979) The Timeless Way of Building, New York

Aquilar, Giorgia (2018) The Ideal of the Broken-down: Porous States of Disrepair, in: Wolfrum, Sophie. Stengel, Heiner. Kurbasik, Florian. Kling, Norbert. Dona, Sofia. Mumm, Imke and Zöhrer, Christian eds. (2018) Porous City. From Metaphor to Urban Agenda, Basel, pp.42-46 
Arrhenius, Thordis (2016) Monumental and Non-Monumental Strategies, in: OteroPailos, Jorge. Langdalen, Erik. Arrhenius, Thordis (2016) Experimental Preservation, Zurich, pp.41-55

Awan, Nishat. Schneider, Tatjana and Till, Jeremy (2011) Spatial Agency. Other Ways of Doing Architecture, Abingdon and New York

Bader, Markus (2004) Werkzeuge und Szenarien der Diversifizierung, in: Fezer, Jesko. Heyden, Mathias eds., Hier entsteht. Strategien partizipativer Architektur und räumlicher Aneignung, Berlin, pp.83-92

Bader, Markus (2006) Kolorado Neustadt - Aktive Diversifizierung und situative Praxis im Stadtumbau, in: Informationen zu Raumentwicklung - Stadtumbau in Großsiedlungen, vol. 3/4, Bundesamt für Bauwesen und Raumordnung, Berlin

Bader, Markus. Foerster-Baldenius, Benjamin. Hofmann, Andrea. Mayer, Christof and Rick, Matthias (2010) Bye Bye Utopia. Exhibition at Kunsthaus Bregenz 18.07.-03.10.2010 [pdf] http://raumlabor.net/wp-content/uploads/2013/12/BBU_ webA4_21august2010.pdf, acc. 22.02.2015

Beer, Gillian (2008) Introduction, in: Darwin, Charles (2008) On the Origin of Species, first published in 1859,2008 edition based on the $18602^{\text {nd }}$ edition, Oxford, pp.vii-xvv

Benevolo, Leonardo (1993) Fixierte Unendlichkeit. Die Erfindung der Perspektive in der Architektur, Frankfurt. First published 1991 as: La cattura dell'infinito, Roma

Benze, Andrea. Gill, Julia and Hebert, Saskia (2013) Urbane Lebenswelten. Strategien zur Entwicklung großer Siedlungen. Studie und Projektrecherche für die IBA Berlin 2020, Berlin 2013 [pdf] http://www.stadtentwicklung.berlin.de/staedte bau/baukultur/iba/download/studien/IBA-Studie_Urbane_Lebenswelten.pdf, acc. 17.06.2017

Berking, Helmuth. Frank, Sybille. Frers, Lars. Löw, Martina. Meier, Lars. Steets, Silke and Stoetzer, Sergej eds. (2006) Negotiating Urban Conflicts. Interaction, Space and Control, Bielefeld

Berking, Helmuth and Löw, Martina eds. (2008) Die Eigenlogik der Städte, Frankfurt a.M.

Bernst, Karin (2006) Von der Planung zur Fertigstellung der ,Parkwohnanage' Bogenhausen, in: Krack, Roland ed. (2006) Die Parkstadt Bogenhausen in München, Munich, pp.42-36

Berger, Peter and Luckmann, Thomas (1966) The Social Construction of Reality. A Treatise In the Sociology of Knowledge. 1967 reprinted edition, New York

Beyme, Klaus von (1999) Wohnen und Politik, in: Flagge, Ingeborg ed. (1999) Geschichte des Wohnens - von 1945 bis heute. Aufbau, Neubau und Umbau, Ludwigsburg, pp. $81-152$

Biggs, Michael and Büchler, Daniela (2011) Transdisciplinarity and New Paradigm Research, in: Doucet, Isabelle and Janssens, Nel eds. (2011) Transdisciplinary Knowledge Production in Architecture and Urbanism. Towards Hybrid Modes of Inquiry, pp.63-78

Blumer, Herbert (1954) What is wrong with social theory?, in: Amercian Sociological Review, vol. 19/ 2, 1954, pp.3-10

Borden, Ian and Rendell, Jane (2000) Intersections. Architectural Histories and Critical Theories, London

Brand, Stewart (1994) How buildings learn. What happens after they're built, New York 
Brandlhuber, Arno and Roth, Christopher (2018) Eigentum verpflichtet! Hans-Jochen Vogel im Gespräch mit Arno Brandlhuber und Christopher Roth, in: Arch+, vol. 231, The Property Issue, pp.54-59

Braum, Michael and Welzbacher, Christian eds. (2009) Nachkriegsmoderne in Deutschland. Eine Epoche weiterdenken, Basel

Brenner, Neil (2012) What is Critical Urban Theory?, in: Brenner, Neil. Marcuse, Peter and Mayer, Margit (2012) Cities for People, Not for Profit. Critical Urban Theory and the Right to the City, New York, pp.11-23

Brenner, Neil (2013) Theses on Urbanization, in: Public Culture, vol. 25.1, pp.85-114

Brenner, Neil (2014) Introduction. Urban Theory Without an Outside, in: Brenner, Neil ed. (2014) Implosions/Explosions. Towards a Study of Planetary Urbanization, Berlin, pp.14-29

Brenner, Neil. Madden, David and Wachsmuth, David (2011) Assemblage urbanism and the challenges of critical urban theory, in: City, vol. 15/2, pp.225-240

Brenner, Neil. Marcuse, Peter. Mayer, Margit eds. (2012) Cities for People, Not for Profit. Critical Urban Theory and the Right to the City, New York

Bristol, Katharine (1991) The Pruitt-Igoe Myth, in: Journal of Architectural Education vol.44/3, pp.163-171

Bunschoten, Raoul. Binet, Hélène and Hoshino, Takuro (2010 [2001]) Urban Flotsam. Stirring the City, Rotterdam

Burdett, Ricky and Sudjic, Deyan (2007) The Endless City, London

Carpi, Paolo. Lupi, Silvia. Pizzigoni, Vittorio. Summa, Giacomo. Tamburelli, Pier Paolo and Zanderigo, Andrea (2014) Die Architektur der Stadt. Das nicht gehaltene Versprechen, in: Arch+, vol. 214, pp.14-27, authors' publishing synonym: »baukuh«

Castells. Manuel (2002) Urban Sociology in the Twenty-First Century, in: Cidades- Comunidades e Territórios, vol. Dec. 2002, no.5, pp.9-19

Castells, Manuel (2010a) The Information Age. Economy, Society and Culture Volume 1. The Rise of the Network Society, $2^{\text {nd }}$ ed., first published in 1996, Chichester

Castells, Manuel (2010b) The Information Age. Economy, Society and Culture Volume 3. End of Millennium, $2^{\text {nd }}$ ed., first published in 1998, Chichester

Charmaz, Kathy (2005) Grounded Theory in the 21st Century. Applications for Advancing Social Justice Studies, in: Denzin, Norman and Lincoln, Yvonna eds. (2005) The Sage Handbook of Qualitative Research, Thousand Oaks, pp.507-536

CIAM (1928) La Sarraz Declaration, in: Conrads, Ulrich ed. (1970) Programs and Manifestoes on 2oth-Century Architecture, transl. by Michael Bullock, Cambridge MA, pp.109-113

Clarke, Adele (2005) Situational Analysis. Grounded Theory after the Postmodern Turn, Thousand Oaks CA

Clarke, Adele and Charmaz, Kathy eds. (2014) Grounded Theory and Situational Analysis. Situational Analysis. Essentials and Exemplars. Sage Benchmarks in Social Research Methods, vol. 4, Los Angeles

Clarke, Adele. Friese, Carrie and Washburn, Rachel eds. (2015) Situational Analysis in Practice. Mapping Research with Grounded Theory, Abingdon and New York

Clarke, Adele. Friese, Carrie and Washburn, Rachel (2018) Situational Analysis. Grounded Theory After the Interpretive Turn, Thousand Oaks CA, $2^{\text {nd }}$ edition of (Clarke 2005) 
Clarke, Adele and Keller, Reiner (2014) Engaging Complexities: Working Against Simplification as an Agenda for Qualitative Research Today. Adele Clarke in Conversation With Reiner Keller (137 paragraphs), in: Forum Qualitative Sozialforschung/ Forum: Qualitative Social Research, vol. 15, no. 2, art. 1 [pdf] doi: 10.17169/fqs15.2.2186, acc. 01.08.2020

Colletti, Marjan (2011) Turbulences Ahead. Patrik Schumacher's Book: The Autopoiesis of Architecture, in: Archithese. Zeitschrift und Schriftenreihe für Architektur, vol. 4.2011 (Architekturkritik), pp.72-77

Colquhoun, Alan (1971) The Superblock, in: Colquhoun, Alan (1981) Essays in Architectural Criticism. Modern Architecture and Historical Change, Cambridge MA, foreword by Kenneth Frampton, pp.83-103, essay first published in 1971

Commonhold and Leasehold Reform Act (2002), London [pdf] http://www.legislation. gov.uk/ukpga/2002/15/pdfs/ukpga_20020015_en.pdf, acc. 07.04.2016

Conrads, Ulrich and Neitzke, Peter eds. (2003) Die Städte Himmeloffen. Bauwelt Fundamente, vol. 125, Basel

Conzen, Michael (1960) Alnwick, Northumberland. A Study in Town Plan Analysis, The Institute of British Geographers, Publication no. 27, London

Cross, Nigel (2001) Designerly Ways of Knowing. Design Discipline versus Design Science, in: Design Issues, vol. 17 no. 3, pp.49-55

Cullen, Gordon (2010 [1961]) The Concise Townscape, New York

Dahrendorf, Ralf (1986 [1967]) Pfade aus Utopia. Zur Theorie und Methode der Soziologie, Munich

Dahrendorf, Ralf (2008 [1988]) The Modern Social Conflict. The Politics of Liberty, 2nd ed., New Brunswick

Darwin, Charles (2008) On the Origin of Species, first published in 1859, 2008 edition based on the 1860 2nd edition, Oxford

De Carlo, Giancarlo (1971) Architecture's Public, in: Blundell-Jones, Peter. Petrescu, Donia and Till, Jeremy eds. (2005) Architecture and Participation, London and New York, pp.3-22

De Cauter, Lieven (1998) The Capsular Civilization. The City in the Age of Transcendental Capitalism, in: De Cauter, Lieven (2005) The Capsular Civilization. On the City in the Age of Fear, Reflect, vol. 3, Rotterdam, pp.40-53

De Cauter, Lieven (2001) The Capsule and the Network. Preliminary Notes for a General Theory, in: OASE vol. 54, Re: Generic City, Nijmegen [pdf] https://www.oasejour nal.nl/en/Issues/54/TheCapsuleAndTheNetwork, acc. 13.08.2018

Delitz, Heike (2009) Architektursoziologie, Bielefeld

Dell, Christopher (2013) Ware: Wohnen! Politik. Ökonomie. Städtebau, Berlin

Dell, Christopher (2014) Das Urbane. Wohnen, Leben, Produzieren, Berlin

Dellwing, Michael and Prus, Robert (2012) Einführung in die interaktionistische Ethnografie. Soziologie im Außendienst, Wiesbaden

Denkmalliste Bayern (2017a) Parkstadt Bogenhausen. E-1-62-000-69 [html] https://geoportal.bayern.de/denkmalatlas/searchResult.html?objtyp=ensem ble\&koid=147409, acc. 01.08.2020

Denkmalliste Bayern (2017b) Buschingstrasse 2, 4 and 6. D-1-62-000-7843 [html] https://geoportal.bayern.de/denkmalatlas/searchResult.html?koid=30060\&obj typ=bau\&top=1, acc. 01.08.2020 
Denkmalliste Bayern (2017c) Bogenhausen. E-1-62-000-7 [html] https:/geoportal.bay ern.de/denkmalatlas/searchResult.html?koid=147331\&objtyp=ensemble\&top=1, acc. 01.08 .2020

Denkmalliste Bayern (2017d) Scheinerstraße 11. D-1-62-000-6133 [html] https://geopor tal.bayern.de/denkmalatlas/searchResult.html?koid=25101\&objtyp=bau\&top=1, acc. 01.08 .2020

Denzin, Norman (1992) Symbolic Interactionism and Cultural Studies. The Politics of Interpretation, Oxford

Denzin, Norman (2000) The practices and politics of interpretation, in: Denzin, Norman and Lincoln, Yvonna eds. (2000) The Sage Handbook of Qualitative Research, London, pp.897-922

Diefendorf, Jeffry M. (1993) In the Wake of the War. The Reconstruction of German Cities after World War II, Oxford

Dona, Sofia (2018) Cities in Suspension, in: Wolfrum, Sophie. Stengel, Heiner. Kurbasik, Florian. Kling, Norbert. Dona, Sofia. Mumm, Imke and Zöhrer, Christian eds. (2018) Porous City. From Metaphor to Urban Agenda, Basel, pp.166-169

Downer, John (2009) When Failure is an Option. Redundancy, Reliability and Regulation in Complex Technical Systems, London [pdf] http://eprints.lse.ac.uk/36537/1/ Disspaper53.pdf, acc. 01.08.2020

Droste, Magdalena (1991) Bauhaus 1919-1933, Cologne

Dunin-Woyseth, Halina (2005) The 'Thinkable' and the 'Unthinkable' Doctorates. Three Perspectives on Doctoral Scholarship in Architecture, Paper published in: Belderbos, Marc. Verbeke, Johan eds. (2005) The Unthinkable Doctorate. Proceedings of the Colloquium 'The Unthinkable Doctorate' 14-16.04.2005, Jointly published by Network for Theory, History and Criticism of Architecture and Hogeschool voor Wetenschap \& Kunst - School of Architecture Sint-Lucas, Brussels

Dunin-Woyseth, Halina and Nilsson, Fredrik (2011) Building (Trans)Disciplinary Architectural Research. Introducing Mode 1 and Mode 2 to Design Practitioners, in: Doucet, Isabelle and Janssens, Nel eds. (2011) Transdisciplinary Knowledge Production in Architecture and Urbanism. Towards Hybrid Modes of Inquiry, pp.79-96

Durth, Werner (1999) Vom Überleben. Zwischen Totalem Krieg und Währungsreform, in: Flagge, Ingeborg ed. (1999) Geschichte des Wohnens - von 1945 bis heute. Aufbau, Neubau und Umbau, Ludwigsburg, pp.17-79

Fachbereich 15 TU Darmstadt (2009) Architektur als Wissenschaft, Report of the Fachbereich 15 Architektur at TU Darmstadt, reprinted as excerpt in: Editorial (2010) Architecture as Science, in: Generalist. Research, vol. 02, issued 02/2010, Darmstadt, pp.4-5

Farias, Ignacio (2013) Virtual attractors, actual assemblages. How Luhmann's theory of communication complements actor-network theory, in: European Journal of Social Theory 1-18 [pdf], doi: 10.1177/1368431013484003, acc. 13.06.2016

Fernandez, John (2006) Material Architecture, Oxford

Fernández Prajoux, Viviana (2014) Community Participation on public space, Oikonet Conference Barcelona, [pdf] http://arc.salleurl.edu/oikonet-platform//public/up load/source/20141105120454_OIKONETBarcelonaconferenceFernandez3.pdf, acc. 01.08 .2020

Fezer, Jesko and Heyden, Mathias eds. (2004) Hier entsteht. Strategien partizipativer Architektur und räumlicher Aneignung, Berlin 
Fezer, Jesko (2007) Planungsmethodik gestern, in: Brandlhuber, Arno. Ebersbach, Bruno and Reinfeld, Philipp eds., Disko 6, Nuremberg

Fezer, Jesko (2010) Design for a Post-Neoliberal City, in:e-flux journal, vol. 17 [pdf] https:// www.e-flux.com/journal/17/67367/design-for-a-post-neoliberal-city/, acc. 22.11.2013

Fezer, Jesko (2011) Deprofessionalisierungstendenzen, in: Brandlhuber, Arno. Linden, Silvan eds., Disko 24, Nuremberg

Fezer, Jesko and Institut für Angewandte Urbanistik (2011) ifau und Jesko Fezer. 12 Arbeitsthesen, in: Brandlhuber, Arno. Linden, Silvan eds., Disko 25, Nuremberg

Fezer, Jesko (2018) Parteiisches Design, in: Förster, Marius. Hebert, Saskia. Hofmann, Mona. Jonas, Wolfgang eds. (2018) Un/Certain Futures. Rollen des Designs in gesellschaftlichen Transformationsprozessen, Bielefeld, pp.162-173

Fischer-Lichte, Erika (2015) Performativity and Space, in: Wolfrum, Sophie. Brandis, Nikolai Frhr. von eds. (2015) Performative Urbanism. Generating and Designing Urban Space, Berlin, pp.31-38

Flick, Uwe (2011) Triangulation. Eine Einführung, $3^{\text {rd }}$ edition, Wiesbaden

Foucault, Michel (1972 [1969]) The Archaeology of Knowledge, New York; first published as 'L'archéologie du savoir' in Paris in 1969, transl. 1972, 2010 edition

Foucault, Michel (1980) Power/Knowledge. Selected Interviews and Other Writings 1972-1977, edited by Gordon, Colin, transl. by Colin Gordon et al., New York

Foucault, Michel (1981 [1970]) The Order of Discourse, inaugural lecture given at the Collège de France, Paris, 2nd December 1970, first published as 'Lordre du discours' in Paris in 1972, transl. in: Young, Robert ed. (1981) Untying the Text. A Post-Structuralist Reader, Boston, pp.48-78

Foucault, Michel (1984 [1967]) Of Other Spaces, Heterotopias, in: Architecture, Mouvement, Continuité, vol. 5, 1984, pp.46-49, lecture 'Des Espace Autres' held by Foucault in March 1967, transl. by Jay Miskowiec

Frampton, Kenneth (2000) The Mutual Limits of Architecture and Science, in: Galison, Peter and Thompson, Emily eds. (2000) The Architecture of Science, Cambridge MA, pp.353-373

Frampton, Kenneth (2007 [1980]) Modern Architecture. A Critical History, $4^{\text {th }}$ edition, reprinted 2012, New York

Franck, Georg (2004) Die Stadt als dynamisches System, in: Polis, vol. 16, no. 2, June 2004, pp.42-45

Franck, Georg (2010) The Nature of Urban Space. On Space Syntax and Urban Dynamics. Paper presented at the European November Conference on Public Spaces and the Challenges of Urban Transformation in Europe: Politics and culture, Vienna 2010 [pdf] http://www.iemar.tuwien.ac.at/publications/Franck\%202010e.pdf, acc. 20.04.2015

Freidrichs, Chad (2011) The Pruitt-Igoe Myth. An Urban History, directed by Chad Freidrichs, produced by Paul Fehler, Chad Freidrichs, Jaime Freidrichs, and Brian Woodman, released 11th February, 2011 at the Oxford Film Festival

Friedmann, John (1999) The City of Everyday Life. Knowledge/Power and the Problem of Representation, in: disP - The Planning Review, ETH Zurich, vol. 35, no. 136/137, pp.4-11

Führ, Eduard (1996) Einige Anmerkungen zur 'Praktischen Aesthetik' in der Architektur, in: Wolkenkuckucksheim. International Journal of Architectural Theory. Architecture in the Realm between Art and Everyday Life, vol. 1, no. 1, 1996, published 
10/1996, edited by Eduard Führ [pdf] http://www.cloud-cuckoo.net/openarchive/ wolke/deu/Themen/961/fuehri/Fuehr_t.html, acc. 16.09.2013

Fuhrich, Manfred. Lau, Ingrid. Neusüß, Christel. Petzinger, Renate. Rindlaub, Beata and Schubert, Dirk (1983) Neue Heimat. Gewerkschaften und Wohnungspolitik, Hamburg

Gäbelein, Katja (2005) Das revolutionäre Preußen-Ghetto, in: Münchner Merkur, issue 10.11.2005, Munich, p.16b-f

Garcia, Mark ed. (2010) The Diagrams of Architecture, Chichester UK

Geertz, Clifford (1973) Thick Description. Toward an Interpretive Theory of Culture, in: Geertz, Clifford ed. (1973) The Interpretation of Cultures. Selected Essays, New York, pp.3-30

Gehl, Jan (2011 [1987]) Life Between Buildings, Washington DC. first published in Danish in 1971

Geipel, Kaye and Meyer, Friederike (2012) In Zeiten der knappen Wohnung, editorial, in: StadtBauwelt 195, Muss München dichter werden?, Berlin, pp.16f

Gieryn, Thomas F. (2006) City as Truth-Spot. Laboratories and Field-Sites in Urban Studies, London, Thousand Oaks CA, New Delhi

Glaser, Barney (1978) Theoretical Sensitivity. Advances in the Methodology of Grounded Theory, Mill Valley CA

Glaser, Barney and Strauss, Anselm (1967) The Discovery of Grounded Theory. Strategies for Qualitative Research, Chicago

Goffman, Erving (1967) Where the action is, in: Goffman, Erving ed. (1967) Interaction Ritual, New York, pp.149-270

Goonewardena, Kanishka. Kipfer, Stefan. Milgrom, Richard and Schmid, Christian eds. (2008) Space, Difference, Everyday Life. Reading Henri Lefebvre, New York

Goonewardena, Kanishka (2008) Marxism and everyday life. On Henri Lefebvre, Guy Debord, and some others, in: Goonewardena, Kanishka. Kipfer, Stefan. Milgrom, Richard. Schmid, Christian eds. (2008) Space, Difference, Everyday Life. Reading Henri Lefebvre, New York, pp.117-133

Gropius, Walter (1926) Principles of Bauhaus production, Dessau, in: Conrads, Ulrich ed. (1970) Programs and Manifestoes on 2oth-Century Architecture, transl. by Michael Bullock, Cambridge MA, pp.95-97

GWG München (2016) Ein ökologisches Modellprojekt in Holzbauweise, in: GWG München ed. (2016) Gut zu wohnen. Bauprojekte der GWG München 2003-2016 [pdf] http://www.gwg-muenchen.de/wp-content/uploads/2017/o1/GWG-Bauen_ Buchprojekt_2016.pdf, pp.68-71, acc. 23.08.2017

Haferkamp, Hans and Smelser, Neil eds. (1992) Social Change and Modernity, Berkeley Habraken, John (1987a) The Control of Complexity, in: Places Journal, vol. 4, no. 2, Cambridge MA., p.3-15

Habraken, John (1987b) Control Hierarchies in Complex Artifacts, original paper published in: Proceedings of the 1987 Conference on Planning and Design in Architecture at the International Congress on Planning and Design theory in Boston, MA [pdf] http://www.habraken.com/html/downloads/control_hierarchies.pdf

Habraken, John (1988) Type as a Social Agreement [pdf] Paper presented at the Asian Congress of Architects in Seoul [pdf] http://ftp.habraken.com/html/downloads/ type_as_a_social_agreement.pdf, acc. 08.04.2018

Habraken, John (2000) The Structure of the Ordinary, Cambridge MA 
Habraken, John (2002 [1988]) The Uses of Levels, in: Open House International vol. 27, no. 2 [pdf] http://www.habraken.com/html/downloads/the_uses_of_levels.pdf, acc. 06.05.2018

Habraken, John (2005), Palladio's Children, Abingdon

Habraken, John (2006), Questions that will not Go Away: Some Remarks on Long-Term Trends in Architecture and their Impact on Architectural Education, in: Open House International, vol. 31, no. 2, June 2006 [pdf] http://www.habraken.com/ html/downloads/questions_that_wont_go_away.pdf, acc. 11.01.2018

Habraken, John (2008), Design for Flexibility. Towards a Research Agenda, Review of the book: Schneider, Tatjana. Till, Jeremy (2010) Flexible Housing, in: Building Research and Information, vol. 36.3, p.290-296

Hacking, Ian (2012) Introductory Essay, in: Kuhn, Thomas (2012 [1962]) The Structure of Scientific Revolutions, first published 1962, $4^{\text {th }}$ edition, Chicago and London, pp.vii-xxxvii

Haid, Christian (2013) Contentious Informalities. The Narratives of Picnicking at Berlin's Thai Park, in: dérive - Magazin für Stadtforschung, vol. 51, pp.43-48

Harlander, Tilman (1999) Wohnen und Stadtentwicklung in der Bundesrepublik, in: Flagge, Ingeborg ed. (1999) Geschichte des Wohnens - von 1945 bis heute. Aufbau, Neubau und Umbau, Ludwigsburg pp.233-417

Harnack, Maren (2012) Rückkehr der Wohnmaschinen. Sozialer Wohnungsbau und Gentrifizierung in London, Bielefeld

Harnack, Maren (2014) Großsiedlungen, in: Europan Deutschland eds. (2014) Europan 12 - Adaptable City, Berlin

Harnack, Maren and Stollmann, Jörg (2017) Identifikationsräume. Potenziale und Qualitäten großer Wohnsiedlungen, Berlin

Harvey, David (1975) The Geography of Capitalist Accumulation: A Reconstruction of the Marxian Theory, in: Harvey, David (2001) Spaces of Capital. Towards a Critical Geography, New York, pp.237-266, first published in Antipode

Harvey, David (1982) The Limits to Capital, Oxford

Harvey, David (2000) Reinventing Geography. An interview with the editors of New Left Review, in: Harvey, David (2001) Spaces of Capital. Towards a Critical Geography, New York, pp.3-24

Harvey, David (2001) Spaces of Capital. Towards a Critical Geography, New York

Harvey, David (2009 [1973]) Social Justice and the City. Revised Edition, Athens Georgia

Harvey, David (2008) The Right to the City, in: New Left Review vol. 53, pp.23-53

Hassenpflug, Dieter. Giersig, Nico and Stratmann, Bernhard eds. (2011) Reading the City. Developing Urban Hermeneutics, Weimar

Hebert, Saskia (2012) Gebaute Welt. Gelebter Raum, Berlin

Hegemann, Werner (1963 [1930]) Das steinerne Berlin: Geschichte der größten Mietskasernenstadt der Welt, Bauwelt Fundamente vol. 3, Berlin

Heiler, Jörg (2013) Gelebter Raum Stadtlandschaft. Taktiken für Interventionen an suburbanen Orten, Bielefeld

Heilmayer, Florian (2010) muf architecture / art. profile and interview with Liza Fior, Alison Crawshaw and Caitlin Elster [pdf] http://www.baunetz.de/talk/crystal/pdf/ en/talk27.pdf, acc. 23.05.2014 
Heinemann, Christoph and Schmidt, Christoph (2004) Kooperieren ohne Regeln, in: Fezer, Jesko. Heyden, Mathias eds. (2004) Hier entsteht. Strategien partizipativer Architektur und räumlicher Aneignung, Berlin, pp.73-82

Heinemann, Christoph (2018) Negotiating Porosity, in: Wolfrum, Sophie. Stengel, Heiner. Kurbasik, Florian. Kling, Norbert. Dona, Sofia. Mumm, Imke and Zöhrer, Christian eds. (2018) Porous City. From Metaphor to Urban Agenda, Basel, pp.64-69 Hertweck, Florian (2018a) Towards a New Land Reform, in: Wolfrum, Sophie. Stengel, Heiner. Kurbasik, Florian. Kling, Norbert. Dona, Sofia. Mumm, Imke and Zöhrer, Christian eds. (2018) Porous City. From Metaphor to Urban Agenda, Basel, pp.154157

Hertweck, Florian (2018b) Hans-Jochen Vogels Projekt eines neuen Eigentumsrechts des städtischen Bodens. Ein Protokoll in 20 Punkten, in: Arch+, vol. 231, The Property Issue, pp.46-53

Hertweck, Florian (2018c) Architecture of the Common Ground. Eine Architekturgeschichte der Bodenfrage, in: Arch+ features, no. 75, Arch+, vol. 231, The Property Issue, pp.1-16

Hertzberger, Herman (1991) Lessons for Students in Architecture, Rotterdam

Hess, Markus. Brombacher, Simon. Mayer, Amelie-Theres and Haase, Stefan (2015a) Kommunikation und Konfliktmanagement im Stockwerkeigentum. Themenbericht Tool 1. KTI-Projekt Langzeitstrategien im Stockwerkeigentum [pdf] https://www. hslu.ch/-/media/campus/common/files/dokumente/ta/gebaeude\%20als\%20system/ cctp/stwe/luzerner\%20toolbox\%20themenbericht\%206\%20kommunikation\%20 und\%20konfliktmanagement\%20im\%20stwe.pdf?la=de-ch, acc. 27.01.2017

Hess, Markus. Brombacher, Simon. Mayer, Amelie-Theres and Haase, Stefan (2015b) Kommunikation und Konfliktmanagement im Stockwerkeigentum. Themenbericht Tool 6. KTI-Projekt Langzeitstrategien im Stockwerkeigentum [pdf] https://www. hslu.ch/-/media/campus/common/files/dokumente/ta/gebaeude\%20als\%20system/ cctp/stwe/luzerner\%20toolbox\%20themenbericht\%206\%20kommunikation\%20 und\%20konfliktmanagement\%20im\%2ostwe.pdf?la=de-ch, acc. 27.01.2017

Hesse, Markus (2006) The Compact City. A Model for Eastern German Cities? in: Overmeyer, Klaus ed. (2006) Shrinking Cities, vol. 2: Interventions, p.180ff

Hesse, Markus (2018) In Grund und Boden. Wie die Finanzialisierung von Bodenmärkten und Flächennutzung Städte unter Druck setzt, in: Arch+, vol. 231, The Property Issue, pp.78-83

Hiller, Christian. Nehmer, Alexandra. Ngo, Anh-Linh and Oswalt, Philipp (2017) Architekturen der Globalisierung. Kontroversen zum Universalismus. Editorial. Arch+, vol. 230 [pdf] http://www.archplus.net/download/artikel/4841/, pp.1-3, acc. 07.07.2018

Hillier, Bill (2007) Space is the Machine. A configurational theory of architecture. first published in 1996 at Cambridge, electronic edition by Space Syntax, London [pdf] http://spaceisthemachine.com/, acc. 24.02.2015

Hirsch Hadorn Gertrude and Pohl, Christian (2008) Methodological challenges of transdisciplinary research, in: Natures Sciences Sociétés (2008) vol. 16, no. 2, pp.111-121 [pdf] doi: 10.1051/nss:2008035, acc. 13.04.2017

Holl, Christian (2007) Der dritte Turm [html] https://www.german-architects.com/fa/ architecture-news/reviews/der-dritte-turm, acc. 13.05.2016 
Hupe, Rainer (1990) Neue Heimat. Ende mit Schrecken. Trotz massiver Proteste verkaufen die Gewerkschaften die bayerische Wohnungsgesellschaft, in: Die Zeit, vol. 20, 11.05.1990, p.28 [pdf] http://www.zeit.de/1990/20/ende-mit-schrecken, acc. 16.11 .2016

Huse, Norbert (2008) Geschichte der Architektur im 20. Jahrhundert, Munich Jacobs, Jane (2011 [1961]) The Death and Life of Great American Cities, 50 ${ }^{\text {th }}$ aniv. edition, New York

Janson, Alban and Tigges, Florian (2014) Fundamental Concepts of Architecture. The Vocabulary of Spatial Situations, Basel

Jencks, Charles (2010) Architectural Evolution. The Pulsations of Time, in: Garcia, Mark ed. (2010) The Diagrams of Architecture, Chichester UK, pp.288-309

Jencks, Charles (2011) The Story of Post-Modernism. Five Decades of the Ironic, Iconic and Critical in Architecture, London

Jocher, Thomas. Loch, Sigrid (2010) Raumpilot. vol. 1: Grundlagen, Ludwigsburg

Jöchner, Cornelia (2001) Architektur als politische Praxis. Die Räume der Stadt und ihre Grenzen, in: Wolkenkuckucksheim. International Journal of Architectural Theory. Architecture as aesthetic practice, vol. 6, no. 1, published 9/2001, edited by Eduard Führ [html] http://www.cloud-cuckoo.net/openarchive/wolke/deu/The men/o11/Joechner/joechner.htm, acc. 14.05.2013

Jungfer, Carsten and Masuyama, Emu (2013) Liminal States. Documentation of student projects by Unit A; undergraduate design studio at Oxford Brookes University, School of Architecture. co-editors F. Yang, B. Ellis and K. Kleine [html] http:// ob23ua.blogspot.de/, acc. 02.01.2018

Katz, Bruce. Altman, Andy and Wagner, Julie (2007) An Agenda for the Urban Age, in: Burdett, Ricky and Sudjic, Deyan (2007) The Endless City, London, pp.474-483

Keller, Reiner (2007) Diskurse und Dispositive analysieren. Die Wissenssoziologische Diskursanalyse als Beitrag zu einer wissensanalytischen Profilierung der Diskursforschung, in: Forum Qualitative Sozialforschung FQS, vol. 8, no.2, art. 19 [pdf] doi: 10.17169/fqs-8.2.243, acc. 17.11.2015

Keller, Reiner (2011a) Wissenssoziologische Diskursanalyse. Grundlegung eines Forschungsprogramms. $3^{\text {rd }}$ edition, Wiesbaden

Keller, Reiner (2011b) Diskursforschung. Eine Einführung für SozialwissenschaftlerInnen, 4th edition, Wiesbaden

Kling, Norbert (2016) Understanding Change. Tracing Transformative Interactions in a Large Commonhold-Type Housing Estate, in: Hadjri, Karim and Durosaiye, Isaiah eds. (2016) Proceedings of the Third Oikonet International Conference 'Global Dwelling: Sustainability. Design. Participation', 23.09.2016, Manchester, pp.175-182

Kling, Norbert (2019) Redundant City. A Sensitising Urban Concept at the Intersection of Conflict and Change. Dissertation submitted to the Faculty of Architecture at TUM on 24.10.2018, Munich

Kling, Norbert (in press) Beyond the Single Story. Leaving Behind the Stereotyping of Housing Estates, in: Stengel, Heiner and Aquilar, Giorgia (in press) Le Vele di Scampia [title to be confirmed], Munich

Kling, Norbert and Jungfer, Carsten (2018) Contested Porosities. A Spatial Enquiry into Urban Conflicts in Dalston, East London, in: Wolfrum, Sophie. Stengel, Heiner. Kurbasik, Florian. Kling, Norbert. Dona, Sofia. Mumm, Imke and Zöhrer, Christian eds. (2018) Porous City. From Metaphor to Urban Agenda, Basel, pp.260-265 
Kling, Norbert and Kurbasik, Florian (2018) Hanging Around in the Urban Field, in: Wolfrum, Sophie. Stengel, Heiner. Kurbasik, Florian. Kling, Norbert. Dona, Sofia. Mumm, Imke and Zöhrer, Christian eds. (2018) Porous City. From Metaphor to Urban Agenda, Basel, pp.283f

Kling, Norbert and Ott, Max (2019) Veränderung Verhandeln. Neue Heimat und danach, in: Lepik, Andres and Strobl, Hilde eds. (2019) Die Neue Heimat (1950-1982). Eine Sozialdemokratische Utopie und ihre Bauten, pp.94-99, Munich

Knoll, Richard. Praeger, Henri, Zillich, Julia. Kling, Norbert and Tümmers, Michael (2008) The Cottbus Experiment, in: Generalist. On Designing, vol. ○, Darmstadt, pp.74-79

Knoll, Richard. Praeger, Henri. Zillich, Julia. Kling, Norbert and Tümmers, Michael (2011) Entwurfslehre im Bachelor Architektur. Das Cottbus Experiment, Berlin

Kofman, Eleonore and Lebas, Elizabeth (1996) Lost in Transposition. Time, Space and the City, in: Kofman, Eleonore and Lebas, Elizabeth transl./eds. (1996) Henri Lefebvre. Writings on Cities. Introduction, 2006 edition, Malden MA, pp.3-60

Koolhaas, Rem (1994a [1978]) Delirious New York. A Retroactive Manifesto for Manhattan, New York

Koolhaas, Rem (1994b) The Generic City, in: Koolhaas, Rem and Mau, Bruce (1995) S,M,L,XL. $2^{\text {nd }}$ edition, New York, pp.1239-1264

Koren, Israel and Krishna, Mani (2007) Fault-Tolerant Systems, San Francisco

Krack, Roland ed. (2006) Die Parkstadt Bogenhausen in München, Munich

Krau, Ingrid (2010) Städtebau als Prozess. Kontinuität durch Transformation, Berlin

Kuhn, Thomas (2012 [1962]) The Structure of Scientific Revolutions, first published in $1962,4^{\text {th }}$ edition, Chicago and London

Lakatos, Imre (1978) The Methodology of Scientific Research Programmes. Philosophical Papers vol. 1, edited by John Worrall and Gregory Currie, Cambridge

Lampugnani, Vittorio Magnago (2013) Kritische Gedanken zur Stadtplanung. Zwischen Programm und Offenheit, Neue Zürcher Zeitung, issue 27.4.2013 [pdf] http:// www.nzz.ch/zwischen-programm-und-offenheit-1.18071788, acc. 06.10.2015

Lampugnani, Vittorio Magnago (2014) Stadt als Entwurf. Unzeitgemäße Gedanken über eine zeitgemäße Stadt. Lecture at Oskar von Miller Forum TUM Munich 05.06.2014 [webcast] http://www.oskarvonmillerforum.de/videoarchiv/ovmfvlampugnani.html, acc. 14.10.2015

Landeshauptstadt München (2007) Innenstadtkonzept Muenchen, Referat für Stadtplanung und Bauordnung, Munich [pdf] https:/www.muenchen.de/rathaus/ dam/jcr:eda2858a-fe68-4c44-b47e-85fdf250b174/inko_broschuere_2008.pdf, acc. 19.09.2018

Landeshauptstadt München (2008) Entwicklungsplanung Olympiapark 2018. Materialsammlung und Grundlagenworkshop. Referat für Stadtplanung und Bauordnung [pdf] https://www.muenchen.de/rathaus/dam/jcr:6dib3512-de13-4353-b4dod8ebc9b113ae/Denkmal_Broschuere.pdf, acc. 19.09.2018

Landeshauptstadt München (2009) Perspektive München - Langfristige Siedlungsentwicklung, Grundsatzbeschluss, Referat für Stadtplanung und Bauordnung, Munich [pdf] https://www.ris-muenchen.de/RII/RII/DOK/SITZUNGSVORLAGE/1749334.pdf, acc. 05.06.2017

Landeshauptstadt München (2011) Langfristige Siedlungsentwicklung. Congress Version, Referat für Stadtplanung und Bauordnung, Munich [pdf] https://www. 
muenchen.de/rathaus/dam/jcr:1505d79a-63ba-496f-91f7-78799809c06b/lasie_ gutachten_wwwkl.pdf, acc. 19.09.2018

Landeshauptstadt München (2015a) Demografiebericht München - Teil 1. Analyse und Bevölkerungsprognose 2013 bis 2030, Referat für Stadtplanung und Bauordnung, Munich [pdf] https://www.muenchen.de/rathaus/dam/jcr:ab228d2f-542c-4919856f-f9df230ff3b7/DemografieberichtTeil1_20132030.pdf, acc. 17.01.2017

Landeshauptstadt München (2015b) Demografiebericht München - Teil 2. Kleinräumige Bevölkerungsprognose 2013 bis 2030 für die Stadtbezirke, Referat für Stadtplanung und Bauordnung, Munich [pdf] https://www.muenchen.de/rathaus/dam/ jcr:e68b3cfa-5d78-44d3-ae85-f5790514341a/2015-05-28_Demografiebericht2_On lineversion_optimiert.pdf, acc. 17.01.2017

Landeshauptstadt München (2016a) Langfristige Siedlungsentwicklung. Statusbericht 2015, Referat für Stadtplanung und Bauordnung, Munich [pdf] https://www. ris-muenchen.de/RII/RII/DOK/SITZUNGSVORLAGE/4111034.pdf, acc. 03.03.2018

Landeshauptstadt München (2016b) Bericht zur Wohnungssituation in München 2014-2015, Referat für Stadtplanung und Bauordnung, Munich [pdf] https://www. muenchen.de/rathaus/dam/jcr:f3293bdc-oe6f-4a71-abdf-d680128de37b/LHM_ Wohnungsbausituation_Web.pdf, acc. 17.01.2017

Landeshauptstadt München (2016c) Stadtplan zum Mietspiegel für München 2017. Ausgabe 1/2016 im Maßstab 1:20000, Referat für Stadtplanung und Bauordnung, [pdf] https://www.muenchen.de/rathaus/dam/jcr:14b97db8-79ff-4d4b-9455-22f8b89406b7/ Mietspiegel\%202017\%20Wohnlagenkarten\%20gesamt.pdf, acc. 27.05.2017

Landeshauptstadt München (2017) Integriertes Handlungskonzept 2017. Sanierungsgebiet Innsbrucker Ring Baumkirchner Straße, Büro für Soziale Stadtentwicklung [pdf] https://www.muenchen.de/rathaus/dam/jcr:cc961fb7-28c0-460c-ae e1-02e40c6068ef/Integriertes\%20Handlungskonzept\%20RaBaL\%202017.pdf, acc. 23.08.2017

Landau, Martin (1969) Redundancy, Rationality, and the Problem of Duplication and Overlap, in: Public Administration Review, vol. 29, no. 4, pp.346-358, doi: 10.2307/973247

Latour, Bruno (2004) Why Has Critique Run Out of Steam? From Matters of Fact to Matters of Concern, Special issue on the 'Future of Critique', in: Critical Inquiry, pp.225-248 [pdf] http://www.bruno-latour.fr/sites/default/files/89-CRITICAL-INQUIRY-GB.pdf, acc. 19.11.2015

Latour, Bruno (2005) What Is The Style Of Matters Of Concern?, in: The Department of Philosophy of the University of Amsterdam (2008) Van Gorcum. Spinoza Lectures by Bruno Latour in April and May 2005, Amsterdam [pdf] http://www.bruno-la tour.fr/sites/default/files/97-SPINOZA-GB.pdf, acc. 16.07.2017

Latour, Bruno (2008) A Cautious Prometheus? A Few Steps Toward a Philosophy of Design (with Special Attention to Peter Sloterdijk), Keynote lecture for the Networks of Design meeting of the Design History Society Falmouth, Cornwall, 03.09.2008 [pdf] http://www.bruno-latour.fr/sites/default/files/112-DESIGN-CORNWALL-GB. pdf, acc. 07.09.2016

Latour, Bruno (2010) Networks, Societies, Spheres. Reflections of an Actor-network Theorist, Keynote speech for the 'International Seminar On Network Theory. Network Multidimensionality In The Digital Age', 19.02.2010 [pdf] http://www.brunolatour.fr/sites/default/files/121-CASTELLS-GB.pdf, acc. 02.10.2019 
Le Corbusier and Jeanneret, Pierre (1929) Analysis of the Fundamental Elements of the Problem of 'The Minimum House'. Report for the 2nd CIAM Congress at Frankfurt-am-Main, September 1929, reproduced in: Le Corbusier (1933) The Radiant City. Elements of a Doctrine of Urbanism to be Used as the Basis of our Machine-Age Civilization, transl. by Pamela Knight, Eleanor Levieux and Derek Coltman, New York, pp.29-33

Lefebvre, Henri (1972 [1969]) preface to: Boudon, Phillipe (1972) Lived-In Architecture. Le Corbusier's Pessac Revisited, transl. by Gerald Onn, Cambridge MA, first published in French in 1969 as "Pessac de le Corbusier", Paris

Lefebvre, Henri (1985) Qu'est-que penser?, Paris, p.110, transl. in: Kofman, Eleonore and Lebas, Elizabeth transl./eds. (1996) Henri Lefebvre. Writings on Cities, 2006 edition, Malden MA, p.53

Lefebvre, Henri (1991 [1947]) Critique of Everyday Life. vol. 1. Introduction, London and New York, first published in 1947 as "Critique the la vie quotidienne I: Introduction", Paris

Lefebvre, Henri (1991 [1974]) The Production of Space. Malden MA; first published in 1974 as "La Production de l'Espace", Paris

Lefebvre, Henri (1996 [1968]) The Right to the City; first published in 1968 as "Le droit à la ville"; in: Kofman, Eleonore and Lebas, Elizabeth transl./eds. (1996) Writings on cities, Malden MA, pp.61-181

Lefebvre, Henri (2002 [1961]) Critique of everyday life. vol. 2. Foundations for a Sociology of the everyday, London and New York, first published in 1961 as "Critique de la vie quotidienne II. Fondements d'une sociologie de la quotidienneté”, Paris

Lefebvre, Henri (2003 [1970]) The Urban Revolution. Minneapolis, first published in 1970 as "La révolution urbaine", Paris

Lefebvre, Henri (2008 [1981]) Critique of Everyday Life. vol. 3. From Modernity to Modernism (Towards a Metaphilosophy of Daily Life), London and New York, first published in 1981 as "De la modernité au modernisme (pour une metaphilosophie du quotidien)", Paris

Lefebvre, Henri (2013 [1992]) Rhythmanalysis. Space, Time and Everyday Life, collection of essays translated by Stuart Elden and Gerald Moore. Main chapter "Elements of Rhythmanalysis: An Introduction to the Understanding of Rhythms", pp.11-79, first published in 1992 as "Eléments de rhythmanalyse: Introduction à la connaissance des rythmes", Paris

Lehnerer, Alex (2009) Grand Urban Rules, 2013 edition, Rotterdam

Léonwohlhage Gesellschaft von Architekten mbH (2009) Wohnen am Mittleren Ring München [pdf] http://www.leonwohlhage.de/files/pdf/Projekte/LW_RSS_de.pdf, acc. 29.06.2017

Lepik, Andres. della Giustina, Marcelo and Ursini, Chiara eds. (2017) Does Permanence Matter? Ephemeral Urbanism, Augsburg

Lepik, Andres and Strobl, Hilde eds. (2019) Die Neue Heimat (1950-1982). Eine Sozialdemokratische Utopie und ihre Bauten, pp.94-99, Munich

Löw, Martina (2008) Die Soziologie der Städte, Frankfurt a.M.

Löw, Martina (2015 [2001]) Raumsoziologie, $8^{\text {th }}$ edition, Frankfurt a.M.

Löw, Martina (2016 [2001]) The Sociology of Space. Materiality, Social Structures, and Action, transl. by Donald Goodwin, New York, originally published in 2001 as "Raumsoziologie", Frankfurt a.M. 
Lüttringhaus, Maria (2012) Voraussetzungen für Aktivierung und Partizipation, in: Lüttringhaus, Maria and Richers, Hille eds. (2012) Handbuch aktivierende Befragung. Konzepte, Erfahrungen, Tipps für die Praxis, $3^{\text {rd }}$ edition, Bonn, pp.66-72

Luhmann, Niklas (1995 [1984]) Social Systems, Stanford CA, first published in German in 1984 as: Soziale Systeme. Grundriss einer allgemeinen Theorie, Frankfurt a.M.

Lynch, Kevin (1960) The Image of the City, Cambridge MA

Lynch, Kevin (1972) What Time is this Place?, Cambridge MA

Lynch, Kevin (1983) A Theory of Good City Form, Cambridge MA

Maldonado, Tomás (1972) Umwelt und Revolte. Zur Dialektik des Entwerfens im Spätkapitalismus, Reinbeck bei Hamburg, transl. of the 1970 Italian original by Gui Bonsiepe

Mathews, Stanley (2005) The Fun Palace. Cedric Price's experiment in architecture and technology, in: Technoetic Arts. A Journal of Speculative Research, vol. 3, no. 2, pp.73-91

May, Ernst (1930) Die Wohnung fuer das Existenzminimum, in: Internationale Kongresse für neues Bauen und Städtisches Hochbauamt Frankfurt Main eds. (1930) Die Wohnung für das Existenzminimum, Frankfurt, publication following the CIAM II Congress held in Frankfurt

Ministerium für Landesentwicklung und Verkehr des Landes Sachsen-Anhalt ed. (2010) Internationale Bauausstellung Stadtumbau Sachsen-Anhalt 2010. Weniger ist Zukunft. 19 Städte - 19 Themen, catalogue to the IBA exhibition at the Bauhaus Foundation in Dessau

Mitscherlich, Alexander (1965) Die Unwirtlichkeit unserer Städte. Anstiftung zum Unfrieden, Frankfurt a.M.

Moholy-Nagy, Lazlo (2001 [1929]) von material zu architektur, Berlin, facsimile of the 1929 original

Monument Protection Law (2009 [1973]) Bavarian Law for the Protection and Preservation of Monuments (Monument Protection Law), first adopted in 1973, official english translation [pdf] http://www.blfd.bayern.de/medien/dsg_eng_2009.pdf, acc. 07.12.2017

Morse, Janice. Stern, Phyllis. Corbin, Juliet. Bowers, Barbara. Charmaz, Kathy and Clarke, Adele (2009) Developing Grounded Theory. The Second Generation, Walnut Creek CA

Moudon, Anne Vernez (1986) Built for Change, Cambridge MA

Moudon, Anne Vernez (2004) Getting to Know the Built Landscape. Typomorphology, in: van den Burg, Leo ed. (2004) Urban Analysis Guidebook. Typomorphology, Delft, pp.17-46

Mouffe, Chantal (2013) Agonistics. Thinking the World Politically, London

Mumford, Lewis (1961) The City in History. Its Origins, Its Transformations, and Its Prospects, New York

Mumm, Imke (2018) About Legal Frameworks, Basic Politics, and Tactics, in: Wolfrum, Sophie. Stengel, Heiner. Kurbasik, Florian. Kling, Norbert. Dona, Sofia. Mumm, Imke and Zöhrer, Christian eds. (2018) Porous City. From Metaphor to Urban Agenda, Basel, pp.152f

Neue Heimat Bayern ed. (1971a) 15 Jahre Wohnungs- und Städtebau der ,Neue Heimat Bayern', Munich 
Neue Heimat Bayern ed. (1971b) 15 Years of Housing Construction and Town Planning by the ,Neue Heimat Bayern'-Non-profit-making Building Society Limited, Munich, 1955-1970, English and French supplement to: Neue Heimat Bayern ed. (1971a) 15 Jahre Wohnungs- und Städtebau der ,Neue Heimat Bayern', Munich

Neue Heimat Bayern ed. (1981) 25 Jahre Parkstadt Bogenhausen 1956 -1981, Munich

Neumann, John von (1956) Probabilistic Logics and the Synthesis of Reliable Organisms from Unreliable Components, in: Shannon, Claude and McCarthy, J. eds. (1956) Automata Studies, Princeton, pp.43-98

Nicolin, Paola (2008) Beyond the Failure. Notes on the XIVth Triennale, in: Log, vol.13/14, pp.86-100

Oswalt, Philipp (2000) Berlin. Stadt ohne Form. Strategien einer anderen Architektur, Munich

Otero-Pailos, Jorge (2016) Experimental Preservation. The Potential of Not-Me Creations, in: Otero-Pailos, Jorge. Langdalen, Erik and Arrhenius, Thordis (2016) Experimental Preservation, Zurich, pp.11-40

Ott, Max (2018) When Commons Become Common, in: Wolfrum, Sophie. Stengel, Heiner. Kurbasik, Florian. Kling, Norbert. Dona, Sofia. Mumm, Imke and Zöhrer, Christian eds. (2018) Porous City. From Metaphor to Urban Agenda, Basel, pp.248253

Ott, Max. Kling, Norbert and Zöhrer, Christian (in press) City of the Many, in: The Urban Transcripts Journal, vol. 3, no. 3, October 2020 (issue 'Land') [html] http:// journal.urbantranscripts.org/

Palais Mai (2015) Housing Project Braystrasse in Munich [html] http://www.palaismai. de/projekte/braystrasse/, acc. 16.11.2017

Park, Robert and Burgess, Ernest (1921) Introduction to the Science of Sociology, Chicago

Perrow, Charles (1984) Normal Accidents. Living With High Risk Technologies, 1999 revised edition, Princeton, $\mathrm{NJ}$

Plato [ ] Cratylus, Paragraph 401d, respectively 402a, in: Burnet, John (1900) Plato. Platonis Opera, Oxford, 1903 edition

Popper, Karl (1947) Utopia and Violence, in: Popper, Karl (2002a [1963]) Conjectures and Refutations. The Growth of Scientific Knowledge, $7^{\text {th }}$ edition, Abingdon and New York, pp.477-488

Popper, Karl (1948) Towards a Rational Theory of Tradition, in: Popper, Karl (2002a [1963]) Conjectures and Refutations. The Growth of Scientific Knowledge, $7^{\text {th }}$ edition, Abingdon and New York, pp.161-182

Popper, Karl (1953) Science: Conjectures and Refutations, in: Popper, Karl (2002a [1963]) Conjectures and Refutations. The Growth of Scientific Knowledge, $7^{\text {th }}$ edition, Abingdon and New York, pp.43-86

Popper, Karl (1958) Back to the Presocratics, in: Popper, Karl (2002a [1963]) Conjectures and Refutations. The Growth of Scientific Knowledge, $7^{\text {th }}$ edition, Abingdon and New York, pp.183-223

Popper, Karl (1960) On the Sources of Knowledge and Ingorance, in: Popper, Karl (2002a [1963]) Conjectures and Refutations. The Growth of Scientific Knowledge, $7^{\text {th }}$ edition, Abingdon and New York, pp.3-42

Popper, Karl (2002a [1963]) Conjectures and Refutations. The Growth of Scientific Knowledge, $7^{\text {th }}$ edition, Abingdon and New York 
Popper, Karl (2002b [1934]) The Logic of Scientific Discovery, first published in German in 1934 as: Logik der Forschung, translated to English in 1959, London and New York

Popper, Karl (2013 [1945]) The Open Society and Its Enemies, first published in two volumes in 1945, Princeton

Praeger, Henri and Richter, Jana (2017) Wohnraum individuell Ausbauen, in: Bahner, Olaf and Böttcher, Matthias eds. (2017) Neue Standards. Zehn Thesen zum Wohnen, Berlin, pp.65-76, p.171

Prantl, Heribert (2020) Mitsprache nicht erwünscht, Süddeutsche Zeitung, issue 07.6.2020 [html] https://www.sueddeutsche.de/politik/gesetz-entmachtet-wohnungseigentuemer-1.4927977?print=true, acc. 30.07 .2020

Price, Cedric (2003) Re:CP, edited by Hans Ulrich Olbricht with contributions by Arato Isozaki, Patrick Keiller and Rem Koolhaas, London

raumlaborberlin (2018) Mobile Activators [html] http://raumlabor.net/mobile-activa tor/, acc. 02.01.2018

raumlaborberlin, Förster-Baldenius, Benjamin. Zahn, Sabine, Chen, Yü and Dry, Camille (2018) St.Louis 1875-2025. A Report of 150 Years Urban Practice, in: Wolfrum, Sophie. Stengel, Heiner. Kurbasik, Florian. Kling, Norbert. Dona, Sofia. Mumm, Imke and Zöhrer, Christian eds. (2018) Porous City. From Metaphor to Urban Agenda, Basel, pp.254-259

raumlaborberlin. Maier, Julia and Heidelberger Kunstverein eds. (2008) Acting in Public, Berlin

Rakatansky, Mark (1991) Spatial Narratives, in: Whiteman, John. Kipnis, Jeffrey and Burdett, Richard eds. (1991) Strategies in Architectural Thinking, Chicago and Cambridge MA, pp.198-221

Rebois, Didier ed. (2010) Europan 10 Results. Reinventing Urbanity, Paris

Reichow, Hans-Bernhard (1959) Die autogerechte Stadt. Ein Weg aus dem Chaos, Ravensburg

Rendell, Jane (2007) Introduction. Critical Architecture. Between Criticism and Design, in: Critical Architecture, edited by Rendell, Jane, Hill, Jonathan, Fraser, Murray and Dorrian, Mark eds. (2007) London and New York, pp.1-9

Rieniets, Tim. Sigler, Jennifer and Christiaanse, Kees eds. (2009) Open City. Designing Coexistence, Amsterdam

Riessman, Catherine Kohler (2008) Narrative Methods for the Human Sciences, London

Ronneberger, Klaus (2008) Henri Lefebvre and Urban Everyday Life. In Search for the Possible, in: Goonewardena, Kanishka. Kipfer, Stefan. Milgrom, Richard and Schmid, Christian eds. (2008) Space, Difference, Everyday Life. Reading Henri Lefebvre, New York, pp.134-146

Rosenthal, Gabriele (2014) Interpretative Sozialforschung. Eine Einführung, 4th edition, Weinheim

Rossi, Aldo (1982 [1966]) The Architecture of the City. Cambridge MA, first published in 1966 as "L'architettura della città", Milan

Rowe, Colin and Koetter, Fred (1978) Collage City, Cambridge MA

Sack, Manfred (1968) Triennale-Tod auf italienisch. Nach der Eröffnung von Studenten und Künstlern okkupiert, in: Die Zeit, 7.6.1968 vol. 23 [html] http://www.zeit. de/1968/23/triennale-tod-auf-italienisch, acc. 08.01.2015 
Sagan, Scott (2004) The Problem of Redundancy Problem. Why More Nuclear Security Forces May Produce Less Nuclear Security, in: Risk Analysis, vol. 24, no. 4, pp.935946

Sassen, Saskia (2014) Expulsions. Brutality and Complexity in the Global Economy, Cambridge MA and London

Schmid, Christian (2010) Stadt, Raum und Gesellschaft. Henri Lefebvre und die Theorie der Produktion des Raumes, $2^{\text {nd }}$ edition, first published in 2005 , Zurich

Schneider, Tatjana and Till, Jeremy (2007) Flexible Housing, Oxford

Schön, Donald (1967) Technology and Change. The New Heraclitus, New York

Schön, Donald (1971) Beyond the Stable State. Public and Private Learning in a Changing Society, London

Schön, Donald (1987) Educating the Reflective Practitioner, San Francisco

Schumacher, Patrik (2010) The Autopoiesis of Architecture. Volume 1: A New Framework for Architecture, Chichester

Schumacher, Patrik (2012) The Autopoiesis of Architecture. Volume 2: A New Agenda for Architecture, Chichester

Schumpeter, Joseph (2003 [1943]) Capitalism, Socialism and Democracy, London

Seidel, Florian (2008) Ernst May. Städtebau und Architektur in den Jahren 1954-1970, Munich, phd TUM [pdf] http://mediatum2.ub.tum.de/doc/635614/635614.pdf, acc. 08.03.2016

Selle, Klaus (1994) Was ist bloß mit der Planung los? Erkundungen auf dem Weg zum kooperativen Handeln. Ein Werkbuch. Dortmunder Beiträge zur Raumplanung, vol. 69, Dortmund

Sennett, Richard (2007) The Open City, in: Burdett, Ricky and Sudjic, Deyan (2007) The Endless City, based on a talk given at the London School of Economics LSE in November 2006, London, pp.290-297

Sennett, Richard [n.d.) The Open City [pdf] https:/www.richardsennett.com/site/ senn/UploadedResources/The\%20Open\%20City.pdf, acc. 10.06.2016

Shaffir, William. Dietz, Mary and Stebbins, Robert (1994) Field Research as a Social Experience. Learning to Do Ethnography, in: Dietz, Mary. Prus. Robert and Shaffir, William eds. (1994) Doing Everyday Life. Ethnography as Human Lived Experience, pp.30-54, Toronto

Siebel, Walter (1994) Was macht eine Stadt urban? Zur Stadtkultur und Stadtentwicklung. Oldenburger Universitätsreden, no. 61, Oldenburg [pdf] http://oops.uni-old enburg.de/1232/1/ur61.pdf, acc. 05.07.2017

Sieverts, Thomas (2000) Die verstädterte Landschaft - die verlandschaftete Stadt, in: Wolkenkuckucksheim. International Journal of Architectural Theory. A New Cultural Landscape. Working and Living Environments for the Future, vol. 4, no. 2, 1999, published 2/2000, edited by Eduard Führ [html] http://www.cloud-cuckoo. net/openarchive/wolke/deu/Themen/992/Sieverts/sieverts.html, acc. 09.05.2013

Sieverts, Thomas (2003 [1997]) Cities without Cities. An Interpretation of the Zwischenstadt, London, first published in German as: Sieverts, Thomas (1997) Zwischenstadt, Basel

Sieverts, Thomas (2017) The Principle of Heritage. Preservation and its Generalisation in the Anthropocene, in: disP. The Planning Review, vol. 53, no. 1, pp.99-105 
Simmel, Georg (1904) The Sociology of Conflict I, transl. by A. W. Small in: American Journal of Sociology, vol. 9, pp.490-525

Simmel, Georg (1950 [1903]) The Metropolis and Mental Life, transl. in: Wolff, Kurt ed. (1950) The Sociology of Georg Simmel, pp.409-426

Simmel, Georg (1995a [1903]) Soziologie des Raumes, in: Georg Simmel Gesamtausgabe. vol. 7, edited by Rüdiger Kramme, Angela Rammstedt and Otthein Rammstedt (1995) Frankfurt a.M., pp.132-183

Simmel, Georg (1995b [1903]) Über räumliche Projektionen sozialer Formen, in: Georg Simmel Gesamtausgabe. vol. 7, edited by Rüdiger Kramme, Angela Rammstedt and Otthein Rammstedt (1995) Frankfurt a.M., pp.201-220

Simmel, Georg (1994 [1909]) Bridge and Door, transl. by Mark Ritter in: Theory, Culture \& Society, vol. 11, pp.5-10, London, Thousand Oaks and New Delhi

Slater, Terry (1981) The Analysis of Burgage Patterns in Medieval Towns, in: Area, vol. 13, no. 3, pp.211-216

Smith, Laurajane (2006) Uses of Heritage, London and New York, p.29

Soja, Edward (2000 [1996]) Thirdspace. Journeys to Los Angeles and Other Real-andImagined Places, Malden MA

Spuybroek, Lars (2008) The Architecture of Continuity. Essays and Conversations, Rotterdam

Stavrides, Stavros (2010) Towards the City of Thresholds [pdf] http://www.profession aldreamers.net/_prowp/wp-content/uploads/978-88-904295-3-8.pdf, acc. 26.10.2017

Stavrides, Stavros (2015) Common Space as Threshold Space. Urban Commoning in Struggles to Re-appropriate Public Space, Footprint, vol. 9, no. 1, pp.9-19 [pdf] https://journals.open.tudelft.nl/index.php/footprint/article/download/896/1061/, acc. 22.12.2019

Stavrides, Stravros (2016) Common Space. The City as Commons, Chicago

Stavrides, Stavros (2018) Urban Porosity and the Right to a Shared City, in: Wolfrum, Sophie. Stengel, Heiner. Kurbasik, Florian. Kling, Norbert. Dona, Sofia. Mumm, Imke and Zöhrer, Christian eds. (2018) Porous City. From Metaphor to Urban Agenda, Basel, pp.32-37

Stenberg, Jenny (2012) The Strength of Codesign. Citizens as Community Builders, in: Ooms, Tomas and Verbeke, Johan (2012) Design, Participation, Sustainability, ICT. Sustainable Public Open Spaces and Participation through Interaction and ICT, Ghent, pp.78-93 [pdf] http://publications.lib.chalmers.se/records/fulltext/lo cal_166381.pdf, acc. 23.12.2018

Stenberg, Jenny and Fryk, Lasse (2012) Urban empowerment through community outreach in teaching and design, in: Procedia. Social and Behavioral Sciences, vol. 46, pp.3284-3289

Stenberg, Jenny and Fryk, Lasse (2014) Interspace thinking, capacity-building and codesign, in: Hadjiri, Karim (2014) Readings on contemporary housing research [pdf] https://oikonet.wordpress.com/2014/12/17/reader1, pp.14-20, acc. 15.09.2016

Stenberg, Jenny. Thuvander, Liane. Kain, Jaan-Henrik and Adelfio, Marco (2016) Citizen Codesign Leads to a Vision of Social Intensification. Applying the Compact City Concept to a Swedish Large-scale Housing Area by Integrating Research, Education and Community Outreach, in: Hadjri, Karim and Durosaiye, Isaiah eds. (2016) Proceedings of the Third Oikonet International Conference 'Global Dwelling: Sustainability. Design. Participation', 23.09.2016, Manchester, pp.141-148 
Stengel, Heiner and Aquilar, Giorgia eds. (in press) Le Vele di Scampia (title to be confirmed), Munich

Statistisches Bundesamt ed. (2000) 50 Jahre Wohnen in Deutschland. Ergebnisse aus Gebäude- und Wohnungszählungen, -stichproben, Mikrozensus-Ergänzungserhebungen und Bautätigkeitsstatistiken, Stuttgart

Stracke, Ferdinand (2011) WohnOrt München. Stadtentwicklung im 20. Jahrhundert, Munich

Strauss, Anselm (1978a) Negotiations. Varieties, Contexts, Processes, and Social Order, San Francisco

Strauss, Anselm (1978b) A Social World Perspective, in: Strauss, Anselm (1991) Creating Sociological Awareness. Collective Images and Symbolic Representations, New Brunswick and London, pp.233-244

Strauss, Anselm (1979) Social Worlds and Spatial Processes. An Analytic Perspective, San Francisco, unpublished paper by Anselm Strauss, posthumously made available by Adele Clarke [pdf] http://dne2.ucsf.edu/public/anselmstrauss/pdf/worksocworlds_spatial.pdf, acc. 03.05.2016

Strauss, Anselm (1987) Qualitative Analysis for Social Scientists, Cambridge and New York

Stratis, Socrates ed. (2016) Guide to Common Urban Imaginaries in Contested Spaces. The 'Hands-on Famagusta' Project, Berlin

Streeter, Calvin (1991) Redundancy in Social Systems. Implications for Warning and Evacuation Planning, in: International Journal of Mass Emergencies and Disasters, no. 2, vol. 9, pp.167-182

Strübing, Jörg (2013) Qualitative Sozialforschung, München

Sturm, Ulrike (2013) Städtebau als kulturelle Praxis. Reformkonzepte in Deutschland 1910-1930, Berlin

Tafuri, Manfredo (1970 [1968]) Teorie e storie dell'architettura, $2^{\text {nd }}$ edition, Bari

Trapp, Harald (2018) Kapital Heim, in: Arch+, vol. 231, The Property Issue, pp.32-39

Unger, Hella von (2014) Partizipative Forschung, Wiesbaden

Venturi, Robert (1992 [1966]) Complexity and Contradiction in Architecture, New York

Venturi, Robert. Scott Brown, Denise and Izenour, Steven (1977 [1972]) Learning from Las Vegas, revised 1977 edition, Cambridge MA

Venturini, Tommaso. Jensen, Pablo and Latour, Bruno (2015) Fill in the Gap. A New Alliance for Social and Natural Sciences, in: Journal of Artificial Societies and Social Simulation, vol. 18, no. 2(1), doi: 10.18564/jasss.2729, acc. 01.10.2019

Verbeke, Johan and Jakimowicz, Adam (2009) Designing into Research (and vice versa). Introduction to the Proceedings of the Colloquium 'Communicating (by) Design' 15-17.04.2009, Jointly published by Hogeschool voor Wetenschap \& Kunst - Department of Architecture Sint-Lucas, Brussels and Chalmers University of Technology, Göteborg Sweden, pp.19-35

Viehöver, Willy (2011) Diskurse als Narrationen, in: Keller, Reiner. Hirseland, Andreas. Scheider, Werner and Viehöver, Willy eds. (2011) Handbuch Sozialwissenschaftliche Diskursanalyse. Band 1: Theorien und Methoden, Wiesbaden, $3^{\text {rd }}$ edition, pp.193-224

Vidler, Anthony (2008) Histories of the Immediate Present. Inventing Architectural Modernism, Cambridge MA 
Virilio, Paul (2006 [1986]) Speed and Politics. New York, first published in French in 1977

Vogel, Hans-Jochen [1969] Vorwort, in: Zapf, Katrin. Heil, Karolus and Rudoph, Justus [1969] Stadt am Stadtrand. Eine vergleichende Untersuchung in vier Münchner Neubausiedlungen, Frankfurt, pp.7f

Vogel, Hans-Jochen (2019) Mehr Gerechtigkeit! Wir brauchen eine neue Bodenordnung - nur dann wird auch Wohnen wieder bezahlbar, Freiburg

Weizman, Eyal (2007) Against Networking, in: Vlay, Bernd ed. (2007) Uropean Urbanity, Vienna

Weizman, Eyal (2012a) Forensic Architecture. The thick surface of the earth, in: Chipperfield, David (2012) Common Ground. A Critical Reader. Venice Biennale of Architecture 2012, Venice

Weizman, Eyal (2012b) Forensic Architecture. Notes from Fields and Forums, 100 Notes - 100 Thoughts, dOCUMENTA (13) 09.06.- 16.09.2012, Ostfildern

Whyte, William (1980) The Social Life of Small Urban Spaces, Washington D.C.

Whitehand, Jeremy (2001) British Urban Morphology. The Conzenian Tradition, paper presented to the Eighth International Seminar on Urban Form held in Cincinnati, Ohio, 06.09-09.09.2001

Wittemer, Werner. Krack, Roland. Bernst, Karin and Grossarth, Jan (2006) Parkstadt heute, in: Krack, Roland ed. (2006) Die Parkstadt Bogenhausen in München, Munich, pp.134-145

Wittemer, Werner (2006) Parkstadt Bogenhausen [html] www.Parkstadt-Bogenhausen.de, acc. 07.06.2013

Wohnungseigentumsgesetz (2014 [1951]) Wohnungseigentumsgesetz WoEigG respectively WEG [html] http://bundesrecht.juris.de/woeigg/BJNRoo1750951.html, acc. 24.03.2016

Wohnungseigentümergemeinschaft Parkstadt Bogenhausen (2016) Annual Meeting Minutes (AMM) 1984-2016. Archive of the Wohnungseigentümergemeinschaft at the estate administration, Munich

Wolfrum, Sophie and Nerdinger, Winfried eds., Schaubeck, Susanne coed. (2008) Multiple City, Berlin

Wolfrum, Sophie ed., Lanz, Markus. Block, Alexandra. Lanz, Markus and Schiermeier, Franz coeds. (2012) Theodor Fischer Atlas. Städtebauliche Planungen München, Munich

Wolfrum, Sophie (2015) Performative Urbanism. Generating and Designing Urban Space, in: Wolfrum, Sophie. Brandis, Nikolai Frhr. von eds. (2015) Performative Urbanism. Generating and Designing Urban Space, Berlin, pp.11-16

Wolfrum, Sophie and Brandis, Nikolai Frhr. von eds. (2015) Performative Urbanism. Generating and Designing Urban Space, Berlin

Wolfrum, Sophie and Janson, Alban (2016) Architektur der Stadt, Stuttgart

Wolfrum, Sophie. Stengel, Heiner. Kurbasik, Florian. Kling, Norbert. Dona, Sofia. Mumm, Imke and Zöhrer, Christian eds. (2018) Porous City. From Metaphor to Urban Agenda, Basel

Yaneva, Albena (2012) Mapping Controversies in Architecture, Farnham

Yaneva, Albena (2016) Mapping Controversies as a Teaching Philosophy in Architecture, in: Stratis, Socrates ed. (2016) Guide to Common Urban Imaginaries in Contested Spaces. The 'Hands-on Famagusta' Project, Berlin, pp.147-161 
Zapf, Katrin. Heil, Karolus and Rudolph, Justus (1969) Stadt am Stadtrand. Eine vergleichende Untersuchung in vier Münchner Neubausiedlungen, Frankfurt a.M. zectorarchitects (2010) ...roll-in!, EUROPAN 10, Dessau-Roßlau, $1^{\text {st }}$ prize in the EUROPAN competition, Carsten Jungfer and Norbert Kling [html] http://www.zectorar chitects.net/index.php?/urbanism/roll-in--europan1o/, acc. 01.08.2020

zectorarchitects (2011) Dalston Roofpark, London, project initiated in 2010, pneumatic structure 2011-2015, Carsten Jungfer and Norbert Kling [html] http://www.zec torarchitects.net/index.php?/architecture/dalston-roof-park/, acc. 01.08.2020 zectorarchitects (2013) Kavalierstraße Dessau, Dessau-Roßlau, public realm project, design framework developed by Carsten Jungfer and Norbert Kling in cooperation with Christian Benoit of cpb Landschaftsarchitektur and Stephan Besier of StadtBahnGestaltung in 2013, advisory role during project realisation 2010-2018 [html] http://www.zectorarchitects.net/index.php?/urbanism/kavalierstrasse-dessau/, acc. 01.08 .2020

zectorarchitects (2015) MIPUM -100 Minories Pop-up Museum, cooperation between LP Archaeology, zectorarchitecs and Roey Hunt, Tower Hill, London [html] http://www. zectorarchitects.net/index.php?/objects/mipum--pop-up-museum/, acc. 01.08.2020 


\section{Social Sciences}

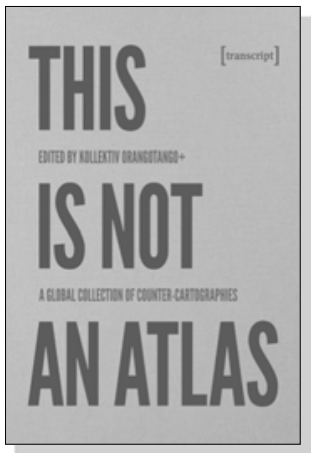

kollektiv orangotango+ (ed.)

This Is Not an Atlas

A Global Collection of Counter-Cartographies

2018, 352 p., hardcover, col. ill.

$34,99 €(D E), 978-3-8376-4519-4$

E-Book: free available, ISBN 978-3-8394-4519-8

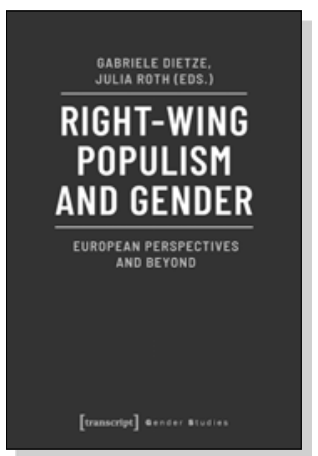

Gabriele Dietze, Julia Roth (eds.)

Right-Wing Populism and Gender

European Perspectives and Beyond

April 2020, 286 p., pb., ill.

$35,00 €(D E), 978-3-8376-4980-2$

E-Book: 34,99€ (DE), ISBN 978-3-8394-4980-6

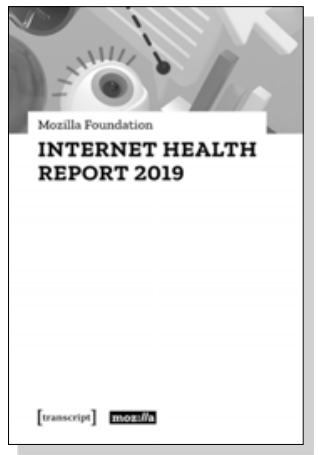

Mozilla Foundation

Internet Health Report 2019

2019, 118 p., pb., ill.

$19,99 €$ (DE), $978-3-8376-4946-8$

E-Book: free available, ISBN 978-3-8394-4946-2

All print, e-book and open access versions of the titles in our list are available in our online shop www.transcript-verlag.de/en! 


\section{Social Sciences}

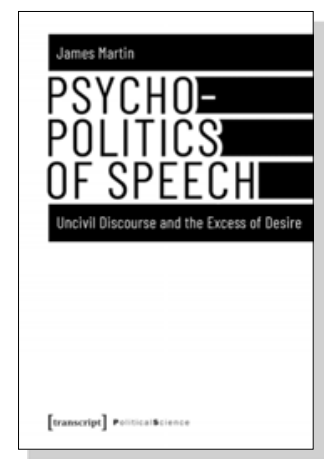

James Martin

\section{Psychopolitics of Speech}

Uncivil Discourse and the Excess of Desire

2019, 186 p., hardcover

79,99€ (DE), 978-3-8376-3919-3

E-Book: 79,99€ (DE), ISBN 978-3-8394-3919-7

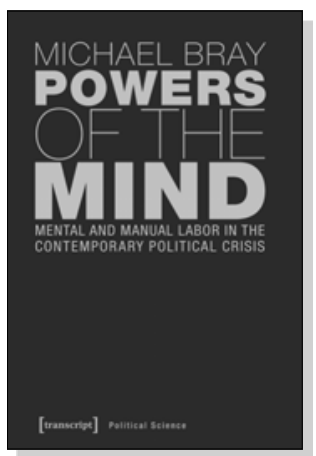

Michael Bray

Powers of the Mind

Mental and Manual Labor

in the Contemporary Political Crisis

2019, 208 p., hardcover

99,99€ (DE), 978-3-8376-4147-9

E-Book: 99,99 € (DE), ISBN 978-3-8394-4147-3

lain MacKenzie

Resistance and the Politics of Truth

Foucault, Deleuze, Badiou

2018, 148 p., pb.

29,99€ (DE), 978-3-8376-3907-0

E-Book: 26,99 € (DE), ISBN 978-3-8394-3907-4

EPUB: $26,99 €$ (DE), ISBN 978-3-7328-3907-0

All print, e-book and open access versions of the titles in our list are available in our online shop www.transcript-verlag.de/en! 
